Bulletin of

Selence and

Practice

Scientific Journal

2020, Volume 6, Issue 2 
Издательский центр «Наука и практика».

Е. С. Овечкина.

БЮЛЛЕТЕНЬ НАУКИ И ПРАКТИКИ

Научный журнал.

Издается с декабря 2015 г.

Выходит один раз в месяц.

$16+$

Главный редактор Е. С. Овечкина

Редакционная коллегия: 3. Г. Алиев, К. Анант, А. А. Афонин, Р. Б. Баймахан, Р. К. Верма, В. А. Горшков-
Кантакузен,
Е. В. Зиновьев,
С. Ш. Казданян,
С. В. Коваленко, Д. Б. Косолапов,
Н. Г. Косолапова,

Р. А. Кравченко, Н. В. Кузина, К. И. Курпаяниди, Р. А. Махесар, Ф. Ю. Овечкин (отв. ред.), Р. Ю. Очеретина, Т. Н. Патрахина, И. В. Попова, А. В. Родионов, С. К. Салаев, П. Н. Саньков, Е. А. Сибирякова, С. Н. Соколов, С. Ю. Солдатова, Л. Ю. Уразаева, А. М. Яковлева.

Адрес редакции:

628605, Нижневартовск, ул. Ханты-Мансийская, 17

Тел. +7(3466)437769

https://www.bulletennauki.com

E-mail: bulletennaura@inbox.ru, bulletennaura@gmail.com

Свидетельство о регистрации ЭЛ №ФС 77-66110 от 20.06.2016

Журнал «Бюллетень науки и практики» включен в Crossref, Ulrich's Periodicals Directory, AGRIS, GeoRef, Chemical Abstracts Service (CAS), фонды Всероссийского института научной и технической информации (ВИНИТИ РAН), eLIBRARY.RU (РИНЦ), ЭБС IPRbooks, ЭБС «Лань», ЭБС Znanium.com, информационную матрицу аналитики журналов (MIAR), ACADEMIA, Google Scholar, ZENODO, AcademicKeys (межуниверситетская библиотечная система), Polish Scholarly Bibliography (PBN), индексируется в РИНЦ, Index Copernicus Search Articles, Open Academic Journals Index (OAJI), BASE (Bielefeld Academic Search Engine), Internet Archive, Dimensions.

Импакт-факторы журнала: РИНЦ-0,291; MIAR - 3,1; Open Academic Journals Index (OAJI) - 0,350, Index Copernicus Journals (ICI) Master List database for 2018 (ICV) - 100,00.

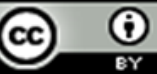

Тип лицензии СС поддерживаемый журналом: Attribution 4.ktyf0 International (CC BY 4.0).

В журнале рассматриваются вопросы развития мировой и региональной науки и практики. Для ученых, преподавателей, аспирантов, студентов.

Бюллетень науки и практики. 2020. Т. 6. №2. https://doi.org/10.33619/2414-2948/51

СИздательский центр «Наука и практика»

Нижневартовск, Россия

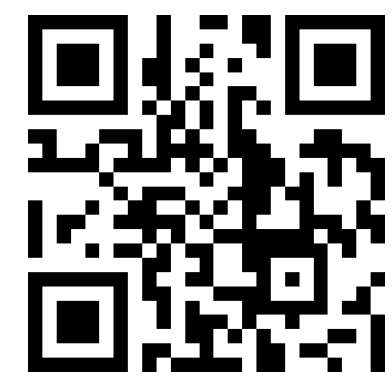


Publishing center Science and Practice.

E. Ovechkina.

Volume 6, Issue 2.

BULLETIN OF SCIENCE AND PRACTICE

Scientific Journal.

February 2020.

Published since December 2015.

Schedule: monthly.

$16+$

\section{Editor-in-chief E. Ovechkina}

Editorial Board: Z. Aliev, Ch. Ananth, A. Afonin, R. Baimakhan, V. Gorshkov-Cantacuzène, S. Kazdanyan, S. Kovalenko, D. Kosolapov, N. Kosolapova, R. Kravchenko, N. Kuzina, K. Kurpayanidi, R. A. Mahesar, R. Ocheretina, F. Ovechkin (executive editor), T. Patrakhina, I. Popova, S. Salaev, P. Sankov, E. Sibiryakova, S. Sokolov, S. Soldatova, A. Rodionov, L. Urazaeva, R. Verma, A. Yakovleva, E. Zinoviev.

Address of the editorial office:

628605, Nizhnevartovsk, Khanty-Mansiyskaya str., 17.

Phone $+7(3466) 437769$

https://www.bulletennauki.com

E-mail: bulletennaura@inbox.ru, bulletennaura@gmail.com

The certificate of registration EL no. FS 77-66110 of 20.6.2016.

The Bulletin of Science and Practice Journal is Crossref, Ulrich's Periodicals Directory, AGRIS, GeoRef, Chemical Abstracts Service (CAS), included ALL-Russian Institute of Scientific and Technical Information (VINITI), RINTs, the Electronic and library system IPRbooks, the Electronic and library system Lanbook, MIAR, ZENODO, ACADEMIA, Google Scholar, AcademicKeys (interuniversity library system, Polish Scholarly Bibliography (PBN), the Electronic and library system Znanium.com, Open Academic Journals Index (OAJI), BASE (Bielefeld Academic Search Engine), Internet Archive, Scholarsteer, Dimensions.

Impact-factor RINTs-0.291; MIAR - 3.1; Open Academic Journals Index (OAJI) - 0.350, Index Copernicus Journals (ICI) Master List database for 2018 (ICV) - 100.00.

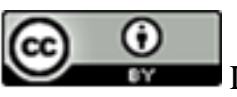

License type supported CC: Attribution 4.0 International (CC BY 4.0).

The Journal addresses issues of global and regional Science and Practice. For scientists, teachers, graduate students, students.

(2020). Bulletin of Science and Practice, 6(2). https://doi.org/10.33619/2414-2948/51

CPublishing center Science and Practice

Nizhnevartovsk, Russia

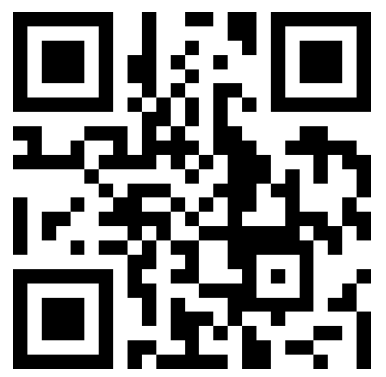




\section{СОДЕРЖАНИЕ}

1. Крыленко М. В., Крыленко В. В.

\section{Науки о Земле}

Особенности выполнения высокоточной съемки рельефа абразионного берега с помощью БПЛА

2. Мамедова Ш. И.

Экогеографические проблемы загрязнения атмосферы крупных городов

Азербайджана

3. Мамедова М. В.

Роль экологических факторов в формировании структур почвенного покрова

бассейна р. Зеям

4. Петренко Е. В.

\section{Биологические науки}

Представления о развитии человека в вузах

5. Сарыева Г. Р.

Сравнительная характеристика флор Ганых-Айричайской долины и Илисуйского природного заповедника (Азербайджан)

6. Шидаков Ю. Х.-М., Шарова Е. В., Абдумаликова И. А., Машанло Т. Р., Абдулбакиев А. A.

Влияние рациона кормления крыс на биохимический профиль крови и морфологию печени

7. Романчук П. И.

\section{Медицинские науки}

Возраст и микробиота: эпигенетическая и диетическая защита, эндотелиальная и сосудистая реабилитация, новая управляемая здоровая биомикробиота

8. Абдурахманов Ш. Т., Чынгышева Ж. А., Мусалиев Б. Ж., Тилеков Э. А.

Результаты контролируемого клинического испытания аппаратной

интраоперационной реинфузии крови, собранной из брюшной полости в условиях медленного и быстрого режимов

9. Лабзина М. В., Лабзина Л. Я., Нечайкин А. С., Вахляева В. С., Кожурин Т. Ю., Еремкина E. C.

Анализ результатов кольпоскопии в диагностике неоплазий шейки матки

10. Тилеков Э. А., Ибраимова Д. Д., Болбачан О. А., Садамкулова К. И.

Пути улучшения онкологической помощи

11. Койчубеков А. А., Сабыралиев М. К., Сулайманов Ж. Д.

Передний корпородез поясничного отдела позвоночника с пористым никелидом титана

12. Байрамов Л. А.

\section{Сельскохозяйственные науки}

Изучение зон распространения и агробиологических особенностей айвы, возделываемой в Шахбузском районе Нахичеванской Автономной Республики

13. Мамедова С. 3.

Экологический мониторинг почв Ленкоранчайского бассейна по районам

14. Аллахвердиев Э. Р.

Влияние органических и минеральных удобрений на накопление азота, фосфора и

калия в надземной части люцерны при покрытом посеве

15. Бабаев В. A.

Научно-практические аспекты ведения органического производства томатов в

Азербайджане

16. Ботирова Х. Э.

Факторы и сущность коренных структурных изменений в аграрном секторе южных областей Узбекистана 
17. Беркетова Л. В., Игинова Р. В.

\section{Технические науки}

Питание на воздушных суднах: анализ меню (Часть 1)

18. Абдуллаев А. М., Курпаяниди К. И., Тешабаев А. Э., Солиева Д. А.

Исследование систем управления предприятием: сущность, методы и проблемы .......

19. Жумаев А. Статистический анализ туризма в Узбекистане: эмпирический тест модели А-B-C (Т-АВС)

20. Давлетов И. Х., Маманазаров О. Ш.

Вопросы управления, сохранения и модернизации многоквартирного жилищного фонда

21. Ерлыгина Е. Г., Филимонова В. Д.

Управление взаимоотношениями с клиентами

22. Аманалиева М. O.

Развитие цифровой экономики в регионах Кыргызстана

23. Прокопенкова А. С., Смирнов В. Н.

Разработка концепции продвижения проекта Sony на площадке Babyblog

24. Ротенберг С. В., Смирнов В. Н.

Разработка стратегии продвижения предприятия малого бизнеса в социальных сетях на примере ООО «Бьюти Клиник»

25. Филимонова В. Д.

CRM-системы как инструмент повышения эффективности бизнеса

26. Аманалиев У. О.

\section{Юридические науки}

Актуальные проблемы в избирательной системе Киргизской Республики

27. Василенко А. В.

Особенности правового регулирования аренды предприятий

28. Танская В. В., Савватеева В. В.

Идеологическая функция права в теории государства и права

29. Савватеева В. В.

Духовная свобода и зависимость в современном мире

30. Попова С. А., Чернов Ю. И.

Соотношение конституционно-правового и административно-правового

регулирования статуса мигрантов

31. Ломакина Е. Н., Петров А. Д., Глинщикова Т. В.

Принцип наиболее тесной связи в международном частном праве

\section{Социологические науки}

32. Коровкина Н. В., Адигамова О. Ф.

Роль средств массовой коммуникации в социальном конструировании гражданской идентичности россиян (на примере полиэтничного региона)

\section{Психологические науки}

33. Адыкулов А. А.

Феномен бессознательного в психике и духовное становление подростков, юношей и девушек

34. Вахеди Н. Г.

\section{Педагогические науки}

Обучение английскому языку в гетерогенных классах

35. Вахеди Н. Г.

Особенности коммуникативного подхода при обучении иностранному языку

36. Музулманов М. У., Маматова А. А., Раимбердиев 3. С.

Внеклассное изучение образа учителя в романе Жуная Мавлянова «Ясное небо» 
37. Абдиев К. Р.

Методические особенности упражнений по переводу

38. Хидиров Х. Д.

\section{Исторические науки}

Из истории Термезской железнодорожной магистрали

39. Туропова М. T.

Экономическое положение южных городов Узбекистана в начале XX века и процессы миграции

40. Турсунов А. С.

Реформы социально-бытовой сферы в городах южных областей Узбекистана и их результаты

41. Жумашова Г. С., Арстанов С. А. Роль и место Таш-Кумырского завода полупроводниковых материалов в региональном развитии

\section{Филологические науки}

42. Акинбекова А. У.

Морфологические диалектизмы в произведении Молдо Нияза «Санат дигарасттар» ...

43. Акынбекова А. У.

Общности суффиксов, образующих от глаголов именные части речи в кыргызском и чагатайском языках

44. Бобоева С. Р.

Исторические топонимы вдоль торгового пути Термез - «Железные ворота»

45. Антипина A. C.

\section{Философские науки}

Феноменологическая социальная теория в контексте постнеклассики

46. Шарипова Э. К., Кедейбаева Ж. А., Курбанбаев К. А.

Природа и источники духовной опасности

47. Черныииов Е. М.

\section{Рецуензии}

Рецензия на монографию Плазменные технологии создания и обработки строительных материалов 


\section{TABLE OF CONTENTS}

1. Krylenko M., Krylenko V.

\section{Sciences about the Earth}

Features of Performing High-precision Survey of the Abrasion Coast Relief by UAV ........

2. Mammadova Sh.

Ecogeographical Problems of Air Pollution in the Big Cities of Azerbaijan

3. Mammadova M.

The Role of Environmental Factors in the Formation of Soil Cover Structure of the

Zeyamchay Basin

4. Petrenko E.

\section{Biological Sciences}

Universities Ideas About Human Development

5. Saryeva $G$.

Comparative Characteristics of Floras of the Ganykh-Airichai Valley and Ilisu Nature

Reserve (Azerbaijan)

6. Shidakov Yu., Sharova E., Abdumalikova I., Mashanlo T., Abdulbakiev A.

Effect of Feeding Rat on the Biochemical Profile of Blood and Liver Morphology

7. Romanchuk $P$.

\section{Medical Sciences}

Age and Microbiota: Epigenetic and Dietary Protection, Endothelial and Vascular

Rehabilitation, the New Operated Healthy Biomicrobiota

8. Abdurakhmanov Sh., Chyngysheva Zh., Musaliev B., Tilekov E.

Results of the Controlled Clinical Test of Intraoperative Blood Reinfusion Hardware, Assembled From the Abdominal Cavity in Conditions of Slow and Fast Modes

9. Labzina M., Labzina L., Nechaikin A., Vakhlyaeva V., Kozhurin T., Eremkina E. Analysis of Coloscopy Results in the Diagnosis of Cervical Neoplasia

10. Tilekov E., Ibraimova D., Bolbachan O., Sadamkulova K.

Ways to Improve Cancer Care

11. Koichubekov A., Sabyraliev M., Sulaimanov Zh.

Anterior Spondylosyndesis of the Lumbar Spine With Porous Nitinol

12. Bairamov $L$.

\section{Agricultural Sciences}

Study of Distribution Zones and Agrobiological Characteristics of the Pears in the Shahbuz

District of the Nakhchivan Autonomous Republic

13. Mamedova $S$.

Ecological Monitoring of Soils of the Lenkoranchay Basin by Region

14. Allahverdiev E.

Impact of Organic and Mineral Fertilizers on Gathering of Total Nitrogen, Phosphorus and

Potassium in Surface Mass of Lucerne in Coated Planting

15. Babaev $V$.

Scientific-Practical Aspects of the Organic Tomato Production in Azerbaijan

16. Botirova $H$.

Factors and Essence of Indigenous Structural Changes in the Agrarian Sector of the

Southern Regions of Uzbekistan

17. Berketova L., Iginova $R$.

\section{Technical Sciences}

Nutrition on Aircrafts: a Menu Analysis (Part 1)

18. Abdullaev A., Kurpayanidi K., Teshabaev A., Solieva D.

Research of Enterprise Management Systems: Essence, Methods and Problems 
19. Jumayev A.

Statistical Analyses of Tourism in Uzbekistan: An Empirical Test of Tourism A-B-C (T-

ABC) Model

20. Davletov I., Mamanazarov $O$.

Issues to Management, Preservation and Modernization of Multi-apartment Housing

21. Erlygina E., Filimonova $\mathrm{V}$.

Customer Relationship Management

22. Amanalieva $M$.

Development of Digital Economy in Regions of Kyrgyzstan

23. Prokopenkova A., Smirnov V.

Development of Promotion Concept Sony Project on Babyblog Site

24. Rotenberg S., Smirnov V.

Development of a Strategy for Promoting a Small Business in Social Networks on the

Example of Beauty Clinic LLC

25. Filimonova $V$.

CRM Systems as a Tool for Improving Business Efficiency

26. Amanaliev $U$.

\section{Juridical Sciences}

Actual Problems in the Election System of the Kyrgyz Republic

27. Vasilenko A.

Features of Legal Regulation of Enterprise Leases

28. Tanskaya V., Savvateeva $V$.

The Ideological Function of Law in the Theory of State and Law

29. Savvateeva $V$.

Spiritual Freedom and Dependence in the Contemporary World

30. Popova S., Chernov Yu.

Constitutional-Legal and Administrative-Legal Bases of the Status of Migrants

31. Lomakina E., Petrov A., Glinshchikova T.

Principle of the Closest Relationship in Private International Law

$268-272$

32. Korovkina $N$., Adigamova $O$.

\section{Sociological Sciences}

The Role of Media in Social Construction of Civil Identity of the Russians (on the Example of a Multiethnic Region)

33. Adykulov A.

\section{Psychological Sciences}

The Phenomenon of Unconscious in the Psyche and the Spiritual Formation of an

Adolescent Boys and Girls

34. Wahedi N.

\section{Pedagogical Sciences}

Teaching English Language in Heterogeneous Classrooms

35. Wahedi $N$.

Peculiarities of Communicative Approach in Foreign Language Teaching

36. Muzulmanov M., Mamatova A., Raimberdieva $Z$.

Extracurricular Study of Teacher Image in the Novel 'Clear Sky' by Zhunai Mavlyanov ....

37. Abdiev $K$.

Methodical Features of Exercises on Translation

38. Hidirov $H$.

\section{Historical Sciences}

From the History of the Termez Railway

39. Turopova $M$.

The Economic Situation of the Southern Cities of Uzbekistan at the Beginning of the

Twentieth Century and the Migration Processes 
40. Tursunov A.

Reforms of the Social Sphere in the Cities of the Southern Regions of Uzbekistan and Their Results

41. Zhumashova G., Arstanov $S$.

Role and Place of Tash-Kumyr Semiconductor Materials Plant in Regional Development ...

42. Akynbekova A.

\section{Philological Sciences}

Morphological Dialectisms in the Work Sanat Digarasttar by Moldo Niyaz

43. Akynbekova A.

Common Suffixes That Form Nominal Parts of Speech From Verbs in the Kyrgyz and

Chagatai Languages

44. Boboeva $S$.

Historical Toponyms Along 'Termez - Iron Gate' Trading Way

45. Antipina A.

\section{Philosophical Sciences}

Phenomenological Social Theory in the Context of Post-non-classics

46. Sharipova E., Kedeybaeva Zh., Kurbanbaev K.

Nature and Sources of Spiritual Danger

$362-368$

$369-371$ 


\section{ОСОБЕННОСТИ ВЫПОЛНЕНИЯ ВЫСОКОТОЧНОЙ СЬЕМКИ РЕЛЬЕФА АБРАЗИОННОГО БЕРЕГА С ПОМОЩЬЮ БПЛА}

СКрыленко М. В., ORCID: 0000-0003-4407-0548, канд. геогр. наук, Институт океанологии им. П.П. Ширшова РАН, г. Геленджик, Россия, krylenko@mail.ru

СКрыленко В. В., ORCID: 0000-0001-8898-8479, канд. геогр. наук, Институт океанологии им. П.П. Ширшова РАН, г. Геленджик, Россия, krylenko.slava@gmail.com

\section{FEATURES OF PERFORMING HIGH-PRECISION SURVEY OF THE ABRASION COAST RELIEF BY UAV}

CKrylenko M., ORCID: 0000-0003-4407-0548, Ph.D., Shirshov Institute of Oceanology of Russian Academy of Sciences, Gelendzhik, Russia, krylenko@mail.ru

CKrylenko V., ORCID: 0000-0001-8898-8479, Ph.D., Shirshov Institute of Oceanology of Russian Academy of Sciences, Gelendzhik, Russia, krylenko.slava@gmail.com

Аннотация. В работе приведены результаты адаптации методики высокоточной съемки наземного рельефа с помощью БПЛА для условий морского берегового обрыва. Анализ полученных цифровых снимков и созданных высокодетальных цифровых моделей рельефа показал, что данный вид съемки для рассматриваемого природного объекта является оптимальным, но имеет ряд ограничений. В число достоинств метода входит низкая себестоимость и оперативность получения данных. Недостатками метода является сложность обработки и интерпретации данных при наличии плотного растительного покрова и в зоне заплеска.

Abstract. The results of adaptation of the methodology for high-precision surveying of the ground relief using UAVs for conditions of marine coastal cliff are given in this work. Analysis of the obtained digital images and created digital elevation models showed that this type of survey is optimal for the considered natural object but has a number of limitations. Low cost and speed of data acquisition are the advantages of the method. The processing complexity and interpreting data in the presence of dense vegetation cover and near coastline are disadvantages of the method.

Ключевые слова: морской абразионный берег, съемка рельефа, беспилотный летательный аппарат, дистанционные методы.

Keywords: marine abrasion coast, relief survey, unmanned aerial vehicle, remote methods.

\section{Введение}

Рельеф как базисный элемент природного комплекса в значительной степени влияет на все его компоненты. Характеристики рельефа такие, как морфометрия, морфология, современная динамика, разнообразие, происхождение и т.д. являются важной информацией при изучении функционирования природных комплексов и прогноза их развития. Исследования рельефа необходимы при проведении большинства полевых научных и инженерных исследований. Обеспечение оперативного мониторинга рельефа береговой зоны 
является одной из важнейших задач исследования берегов.

Долгое время методы изучения рельефа включали лишь прямые наземные измерения. Недостатками наземных измерений являются малый пространственный охват, трудоемкость, резко возрастающая при необходимости большей детализации, и низкая оперативность. Изучение рельефа высоких абразионных берегов такими методами было невозможно, поэтому для геодезических работ применялись дистанционные методы. Наиболее широко использовался фотограмметрический метод, включающий получение более или менее точных стереопар снимков, их оптическую и геометрическую коррекцию и последующую фотограмметрическую обработку. Однако, для условий морского берега, съемка была возможна только с моря, что препятствовало оборудованию закрепленных съемочных базисов с фиксированными координатами. Кроме того, требовалось привлечение дорогостоящих технических средств, на ряде этапов требовалась специальная, как правило, ручная обработка материалов, что снижало оперативность получения требуемых данных.

Существенный прорыв в съемках рельефа произошел после развития технологий компьютерной обработки исходных данных и разработки технологии лазерного сканирования. Лазерное сканирование, особенно воздушное, позволяет получить поле точек с недостижимой ранее плотностью для практически неограниченных площадей, в том числе труднодоступных $[1,2]$. Использование воздушного и наземного лазерного сканирования в сочетании со спутниковыми снимками и геоинформационным моделированием позволяет получать высокоточные пространственные данные о характеристиках рельефа [3, 4]. Однако, наземная лазерная съемка, как и фотограмметрическая, на морском берегу затруднена необходимостью размещения съемочной аппаратуры в море и наличием недоступных для съемки участков при сложном рельефе.

В настоящее время аэрофотосъемка с беспилотных летательных аппаратов (БПЛА) является наиболее простым способом получения малоплощадной техническоинформационной съемки, имеющей целью составление ортофотопланов местности и построение цифровых моделей рельефа (ЦМР). Цифровая аэрофотосъемка выполняется с помощью небольших беспилотных летательных аппаратов (БПЛА), оснащенных цифровыми камерами высокого разрешения, системой стабилизации и ориентации в пространстве [5-7].

В работе рассмотрены особенности методики проведения цифровой аэрофотосъемки с помощью БПЛА и построение цифровой модели рельефа для участка абразионного берега в Геленджикском районе.

\section{Особенности проведения циифровой аэрофотосъемки}

С 2017 года для изучения состояния и динамики рельефа морских берегов сотрудниками Южного отделения Института океанологии им. П. П. Ширшова РАН применялась технология аэрофотосъемки с беспилотных летательных аппаратов (БПЛА) с последующей фотограмметрической обработкой полученных высокодетальных цифровых снимков [8, 9]. Для съемки использовалась интеллектуальная камера «FC 6310», установленная на квадрокоптере «Fantom 4Pro». Это современный профессиональный БПЛА обладающий эффективной системой стабилизации, благодаря которой можно удерживать летающий аппарат в точке с погрешностью 0,5 м по высоте и 1 м по горизонтали. Квадрокоптер Fantom 4Pro способен на работу в режиме ручного управления, автономные полеты по заранее заданным координатам, с автоматическим возвратом на точку старта и автоматическую посадку в случае потери сигнала управления или в других нештатных ситуациях, что необходимо при съемке сложного рельефа с обеспечением требуемых параметров. Кроме того, имеется система защиты аппарата от опасного сближениями с препятствиями. 
Объектом исследования в представленной работе являлся берег между бухтой Рыбацкая и мысом Дооб (Рисунок 1). Берег сложен карбонатными флишевыми породами [10, 11]. На участке развиты абразионный и абразионно-оползневой типы берега. Встречаются глубокие долины временных водотоков. Высота береговых обрывов достигает 100 м. Вдоль береговой линии встречаются единичные крупные обвально-оползневые конуса, сложенные грубообломочным материалом.

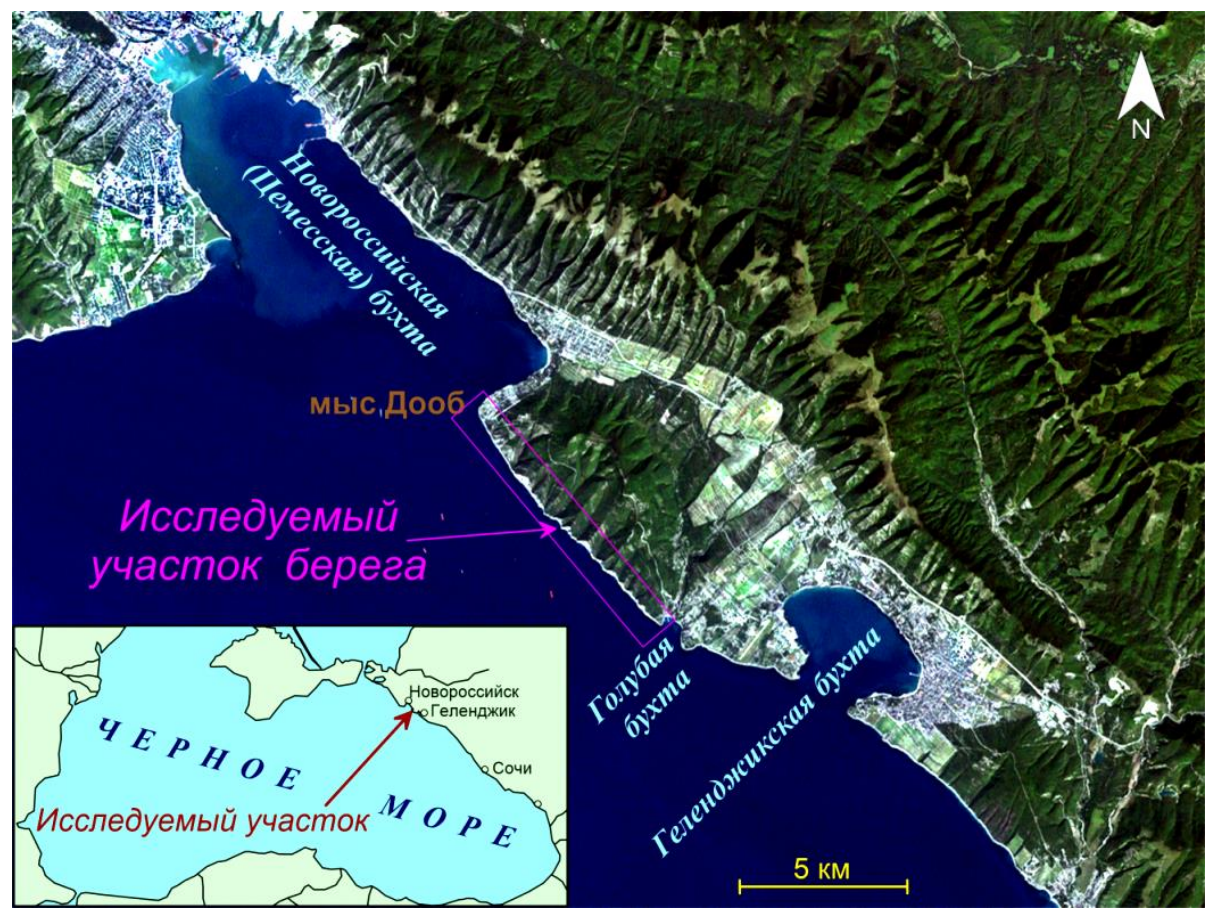

Рисунок 1. Участок проведения работ

В мае-июне 2019 г. была выполнена аэрофотосъемка морского берега с последующей фотограмметрической обработкой полученных цифровых снимков, с целью составления высокодетальных ортофотопланов и построения цифровых моделей рельефа (ЦМР). Для съемок была использована методика, ранее примененная нами при исследовании рельефа различных участков берегов Азовского и Черного морей $[8,9,12]$ с дополнительной адаптацией для участков высокими береговыми обрывами.

Для аккумулятивных участков морских берегов, как правило, выполняется плановая съемка: объектив камеры квадрокоптера направлен вертикально вниз. Для нешироких линейных природных объектов (к примеру, участок береговой линии с пляжем) съемка производится в один пролет с обеспечением продольного перекрытия между соседними фотоснимками 60\%. Если требуется провести аэрофотосъёмку большого по ширине участка, то фотографирование заданной площади производят серией параллельных маршрутов, имеющих поперечное перекрытие. При такой фотосъёмке стандартное значение перекрытия составляет 30\% [9]. При съемке абразионных морских берегов, имеющих рельеф с большими перепадами высот, в дополнение к плановой аэрофотосъемке было решено использовать перспективную аэрофотосъемку (с наклоном оптической оси), позволившую более эффективно распознавать объекты местности и анализировать их пространственное взаимное положение.

Перед началом аэрофотосъёмки для пространственной привязки было произведено размещение 30 наземных реперов, распределенных по всей площади исследуемых участков. При размещении реперов учитывались конфигурация и рельеф участков, схема планируемых 
траекторий пролетов БПЛА, наличие и состояние растительного покрова, вероятность антропогенного вмешательства. На рыхлом грунте реперы (круги красного цвета диаметром 22 см) закреплялись на уровне грунта. На скалах отметки делались на ровных участках коренных пород. Определение точных координат наземных реперов производилось с помощью оборудования спутниковой системы позиционирования фирмы Leica Geosystems $[13,14]$. В состав оборудования входили два двухчастотных приемных устройства (Leica GS 10, Leica GS 15), обрабатывающие сигналы навигационных спутников GPS и ГЛОНАСС.

Сначала аэрофотосъемка выполнялась в ручном режиме, но сложный рельеф абразионно-оползневого берега приводил к периодической потере сигнала между пультом управления и БПЛА, поэтому было принято решение перейти на автоматический режим полетов по заранее разработанным маршрутам. В этом случае при потере сигнала пульта управления БПЛА продолжает двигаться по заданному маршруту и возвращается в точку взлета после окончания съемки.

При подготовке маршрута полета учитывались следующие факторы: - протяженность полета и удаление аппарата от оператора; - прогнозное направление и сила ветра; конфигурация и ландшафт косы; - обеспечение 30 \% поперечного и 60 \% продольного перекрытия. Обеспечение точного выполнения параметров полета реализовывалось с помощью программного обеспечения (ПО) “Litchi” (Рисунок 2). Подготовленные треки проверялись на сайте производителя ПО [15].

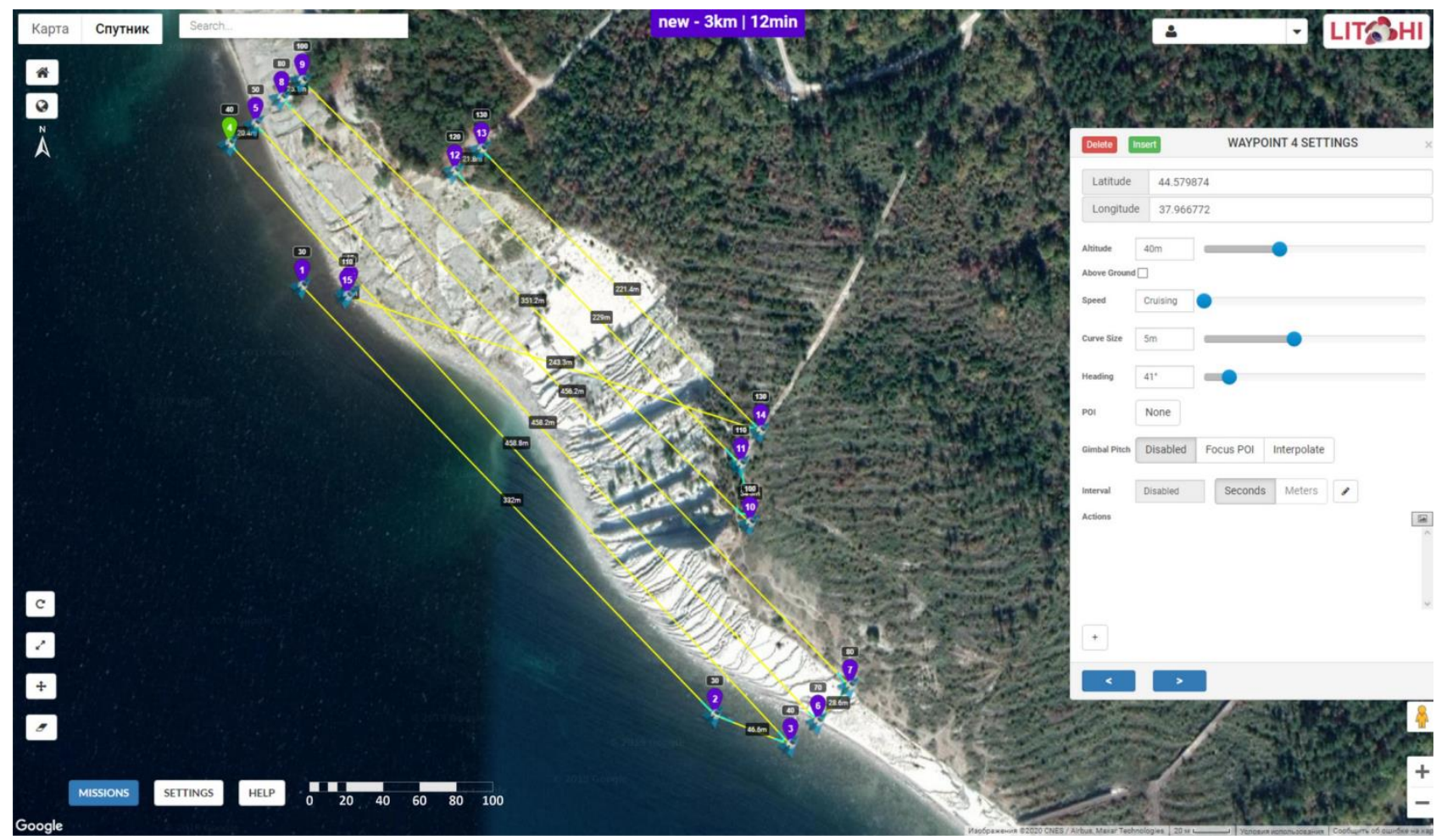

Рисунок 2. Подготовка маршрута полета

Для обеспечения сплошной съемки участков с требуемым для фотограмметрической обработки перекрытием были выполнены 4 полета общей протяженностью 11,5 км. В результате аэрофотосъемки были получены 1574 снимка, распределенных по маршрутам съемки с 30\% поперечным и $60 \%$ продольным перекрытием. Кроме того, за счет работы навигационного комплекса БПЛА были получены параметры внешнего ориентирования снимков.

Съемка проводилась с переменной высотой полета относительно точки старта БПЛА 
для сохранения одинакового расстояния от объектива камеры до поверхности береговой обрыва. При повышении абсолютной высоты элементов рельефа БПЛА также поднимался относительно высоты точки старта, сохраняя расстояние до земной поверхности. Примеры используемых параметров полетов приведены в Таблице. Для каждого участка проводилась съемка с двумя положениями оптической оси камеры относительно горизонта (вертикально вниз и 45 град.), что избежать «мертвых зон» под и за растительностью и выступающими форами рельефа. Также, изменение наклона камеры позволило избежать различного расстояния от камеры до снимаемой поверхности на одном и том же снимке. Примеры снимков одного и того же участка клифа при вертикальном и наклонном положении оптической оси камеры представлены на Рисунке 3.

Таблица.

ПРИМЕРЫ ПАРАМЕТРОВ ПОЛЕТОВ В АВТОМАТИЧЕСКОМ РЕЖИМЕ

\begin{tabular}{|c|c|c|c|c|c|c|c|}
\hline $\begin{array}{c}\text { Протяженность } \\
\text { полета, } м\end{array}$ & $\begin{array}{c}\text { Скорост } \\
\text { в полета, } \\
\text { км/час }\end{array}$ & $\begin{array}{c}\text { Время } \\
\text { полета, } \\
\text { минут }\end{array}$ & $\begin{array}{c}\text { Выссота } \\
\text { полета } \\
\mathcal{M}\end{array}$ & $\begin{array}{c}\text { Наибольшее } \\
\text { удаление } \\
\text { от точки } \\
\text { взлета, м }\end{array}$ & $\begin{array}{c}\text { Угол } \\
\text { наклона } \\
\text { камеры, } \\
\text { град }\end{array}$ & $\begin{array}{c}\text { Радиус } \\
\text { поворотов } \\
, \%\end{array}$ & $\begin{array}{c}\text { Частот } \\
\text { а съемки, } \\
c\end{array}$ \\
\hline 3000 & 20 & 12 & $30-130$ & 200 & 45 & 50 & 2 \\
\hline 2400 & 15 & 13 & $50-140$ & 200 & 90 & 50 & 2 \\
\hline
\end{tabular}

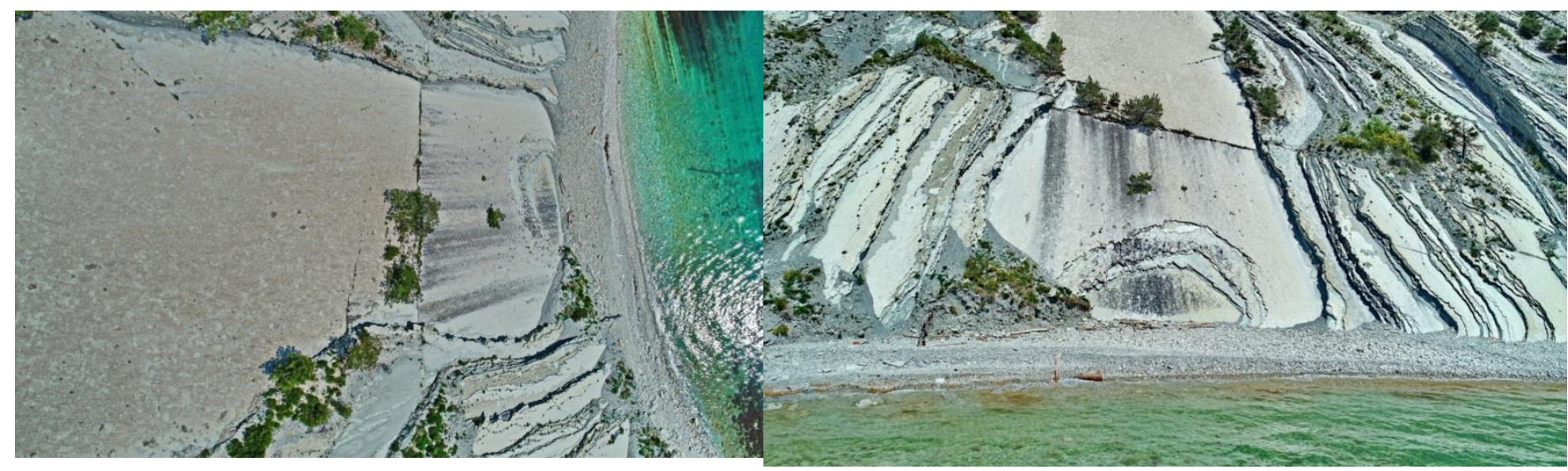

Рисунок. 3. Снимки при вертикальном (вверху) и наклонном (снизу) положении оптической оси камеры

\section{Интерпретация полученных дистанщионных данных}

Для обработки полученных аэрофотоснимков использовалось программное обеспечение Agisoft Metashape [16], позволяющее создавать высококачественные 3D модели объектов на основе цифровых фотографий методами цифровой фотограмметрии (ЦФ). На первом этапе обработки Metashape находит общие точки фотографий («связующие точки») и по ним определяет параметры камер: положение, ориентацию, внутреннюю геометрию (фокусное расстояние, параметры дисторсии и т.п.) (Рисунок 4). Далее, на основе рассчитанных положений камер по цифровым фотографиям произведено построение плотного облака точек фотограмметрической обработки (ТФО) (Рисунок 5). На основе плотного облака точек строится цифровая модель поверхности и (после выделения класса точек «земля») — цифровая модель рельефа (ЦМР). Кроме того, на базе плотного облака точек были построены полигональные модели поверхности, использованные для составления обзорных ортофотопланов исследуемых участков с пространственным разрешением 0,05 м. 


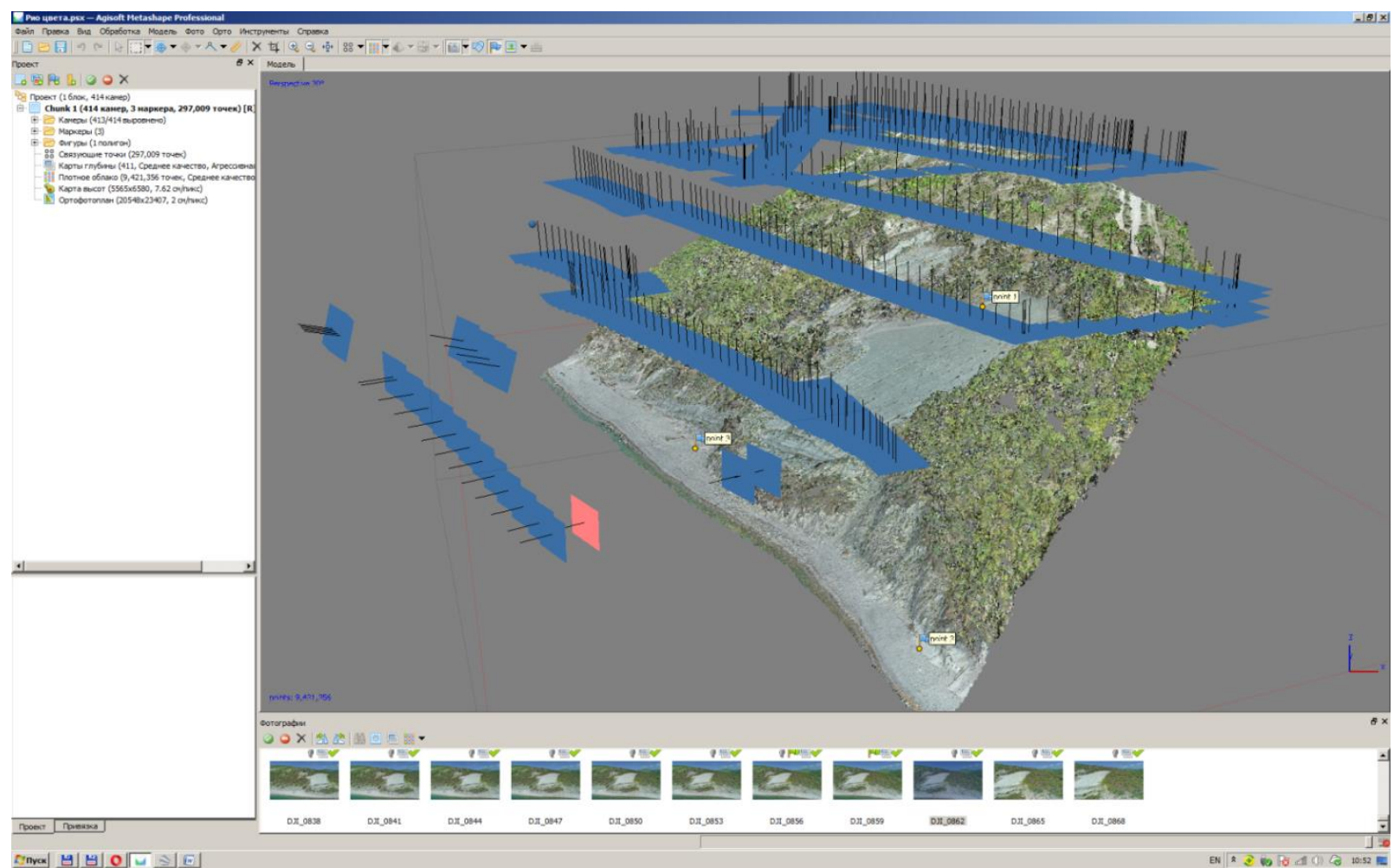

Рисунок 4. Расположение полученных фотографий для одного из участков съемки

Классификация полученного плотного поля ТФО с целью выделения класса точек «земля» производилась при помощи программного пакета TerraScan (TerraSolid, Финляндия) [17] на платформе MicroStation V8 (Bentley Systems, США) [18]. Фильтрация облака точек осуществляется в TerraScan по итерационному принципу с использованием стандартных инструментов классификации "low points", "air points", "isolated points", "below surface". Инструмент "low points” позволяет выделить обособленные точки и их группы, расположенные ниже основного облака точек и не описывающие реально существующие объекты. Инструмент “air points" позволяет выделить ТФО реальных объектов, расположенных значительно выше уровня земной поверхности и не являющихся топографическими (например, птицы). Инструмент “isolated points" позволяет выделить ложные ТФО на основании их обособленности от остального облака точек. Инструмент "below surface" используется для отбора ложных точек, находящихся ниже основной поверхности. После автоматической классификации был проведен контроль для выявления и устранения ошибок классификации. Контроль проводился методами оценки плотности покрытия классифицированными точками, профилирования облака точек, визуального анализа 3D модели, построенной по точкам земли с ручным отбором ложных отражений. Использование перечисленных инструментов позволило свести к минимуму возможность ошибок и ускорить процесс обработки данных. Наибольшую сложность при фильтрации облака точек представляли собой деревья и кустарники [19, 20], автоматически «отфильтровать» которые не представлялось возможным, поскольку необходимо было сохранить исходную конфигурацию имеющихся элементов рельефа — выступов скал, останцов, обрывов. К сожалению, большую часть этой работы пришлось выполнять в ручном режиме, методом профилирования облака точек. Точки, классифицированные как «земля», были сохранены в виде файлов данных для построения моделей GRID и дальнейшей обработки и анализа в программах SAGA и Golden Software Surfer. 


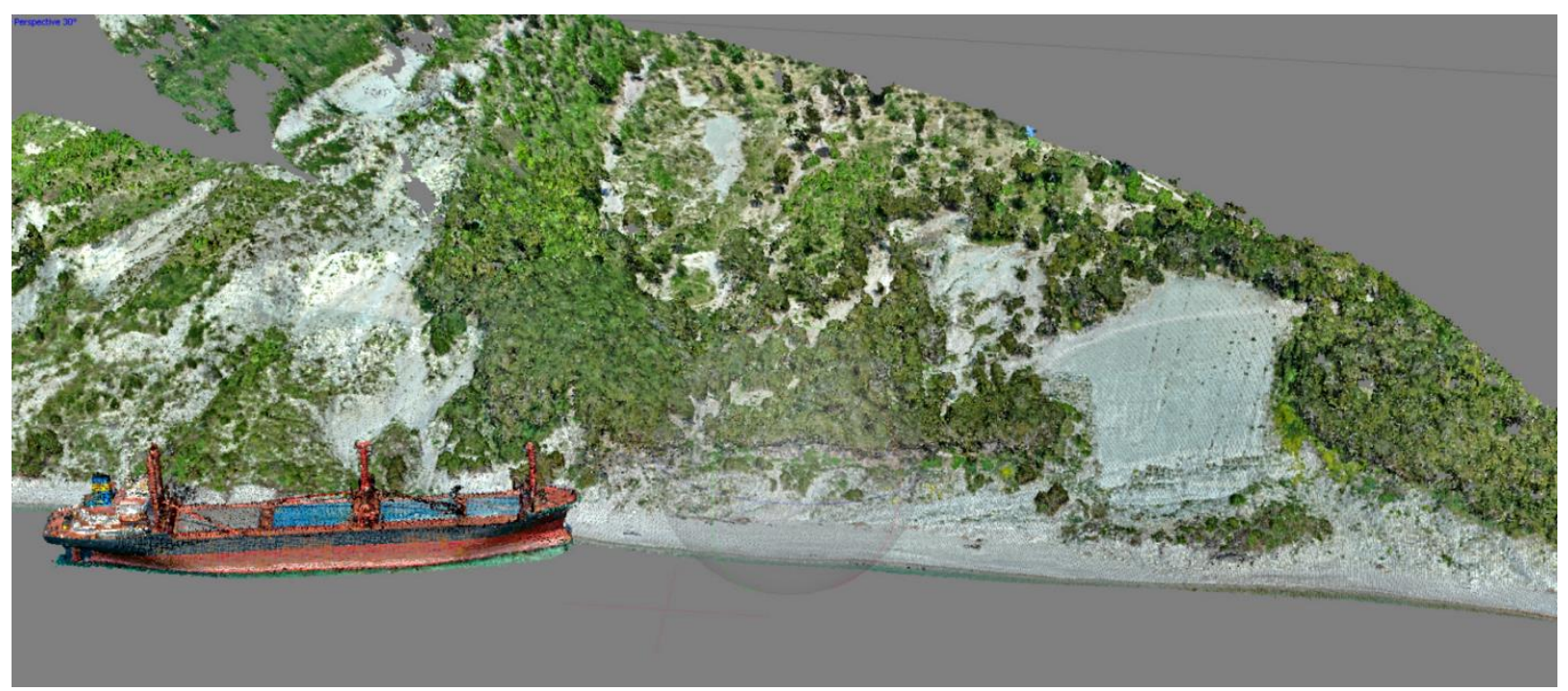

Рисунок 5. Плотное облако точек участка абразионно-оползневого берега

Надо отметить, что обработка данных в Agisoft Metashape и TerraScan на всех этапах требует введения оператором ряда параметров и их комбинаций, зависящих от типа изучаемой поверхности, качества, количества и взаимного расположения исходных снимков, конфигурации полигона, требуемой точности. Достижение оптимального варианта возможно лишь после многочисленных итераций и требует значительного времени. Имеется погрешность, связанная с наличием участков сплошного древесно-кустарникового растительного покрова, где фотограмметрическим методом получить достоверные отметки коренной поверхности невозможно. Соответственно, на участках с плотной растительностью цифровая модель строится по среднему уровню поверхности. Поскольку целью наших исследований были рельеф берегового обрыва и обвально-оползневых конусов, где древеснокустарниковая растительность присутствует фрагментарно, на точности измерений данная погрешность не сказалась.

С использованием материалов съемки, выполненной в 2019 г. с БПЛА, удалось построить высокоточные ЦМР для выбранных участков абразионного берега, с плановой и вертикальной точностью 10 см, что достаточно для исследования микроформ рельефа абразионного берега.

\section{Заключение}

Несмотря на наличие ограничений использованного метода, доступность получения цифровых фотографий береговых обрывов при помощи БПЛА имеет преимущество перед методом цифровой фотограмметрии при изучении рельефа с неплотным растительным покровом. Для повышения точности привязки аэрофотосъёмки необходимо производить определение геодезических координат наземных реперов. Аэрофотосъемку береговых обрывов рекомендуется выполнять в автоматическом режиме по подготовленным маршрутам полетов с использованием вертикального и наклонного положений оптической оси фотокамеры.

В отличие от космической и аэрофотосъемки с самолета, съемка с БПЛА дает возможность проводить мониторинг участков с высокими уклонами поверхности вплоть до отвесных, что необходимо при изучении абразионных берегов с выраженными клифами и сложным рельефом.

Работа выполнена в рамках темы Госзадания № 0149-2019-0014 и при поддержке РФФИ, грант 19-05-00716. 


\section{Список литературы:}

1. Pogorelov A. V., Boyko E. S., Rizaev I. G. The use of laser-location data for modeling and analysis of the structure and topography of mountainous areas reliefoid // Bulletin of the North Caucasus State Technical University. 2009. V. 4. №21. P. 46-52.

2. Boyko E., Krylenko V., Krylenko M. LIDAR and airphoto technology in the study of the Black Sea accumulative coasts // Third International Conference on Remote Sensing and Geoinformation of the Environment (RSCy2015). International Society for Optics and Photonics, 2015. V. 9535. P. 95351Q. https://doi.org/10.1117/12.2192577

3. Погорелов А. В., Антоненко М. В., Бойко Е. С., Федорова С. И., Елецкий Ю. Б. Исследование компонентов береговой зоны Азовского моря по данным воздушного лазерного сканирования (район Вербяной косы) // Защита окружающей среды в нефтегазовом комплексе. 2014. №11. С. 33-39.

4. Кравцова В. И., Другов М. Д. Типы динамики дюнного рельефа Анапской пересыпи: исследование по материалам воздушного лазерного сканирования // Геодезия и картография, 2019. T. 80. №2. C. 32-45. https://doi.org/10.22389/0016-7126-2019-944-2-32-45

5. Глинка В. В., Беспалова Л. А., Ивлиева О. В. Исследование типов берегов Цимлянского водохранилища с использованием беспилотных летательных аппаратов // Закономерности формирования и воздействия морских, атмосферных опасных явлений и катастроф на прибрежную зону РФ в условиях глобальных климатических и индустриальных вызовов («Опасные явления»), 2019. С. 157-158.

6. Kosolapov A. E., Skripka G. I., Bespalova L. A., Ivlieva O. V., Filatov A. A. Study of Morphological and Morphometric Characteristics of Tsimlyansk Reservoir Shores Using Unmanned Aerial Vehicles and GIS Technologies // Arid Ecosystems. 2018. V. 8. №3. P. 184-189. https://doi.org/10.1134/S2079096118030034

7. Мисиров С. А., Беспалова Л. А., Сапрыгин В. В. Исследование геоморфологических особенностей берегов Таганрогского залива с применением беспилотных летательных аппаратов и ГИС-технологий // Экология. Экономика. Информатика. Серия: Геоинформационные технологии и космический мониторинг, 2018. №3. С. 42-48.

8. Крыленко В. В., Крыленко М. В. Высокоточная съемка рельефа Бакальской косы // Экологическая безопасность прибрежной и шельфовой зон моря, 2018. №4. С. 65-72. https://doi.org/10.22449/2413-5577-2018-4-65-72

9. Крыленко В. В., Руднев В. И. Методика аэрофотосьемки Бакальской косы // Экологическая безопасность прибрежной и шельфовой зон моря. 2018. №4. С. 59-64. https://doi.org/10.22449/2413-5577-2018-4-59-64

10. Келлер Б. М. Верхнемеловые отложения Западного Кавказа // Труды ГИН АН СССР, серия геология, 1947. №48. С. 122-125.

11. Антонов Б. А. Региональная геоморфология Кавказа. М: Наука, 1979. 196 с.

12. Krylenko M. V., Krylenko V. V., Volkova T. A. Development prospects of naturalterritorial complex of the Dolgaya spit // Ocean and Coastal Management, 2018. V. 166. P. 98-102.

13. Крыленко В.В. Применение оборудования ГНCC LEICA GEOSYSTEMS в научных исследованиях // Геопрофи. Москва, 2013. Вып. 5. С. 19-23.

14. Krylenko M., Krylenko V. Active registration method of the coast changes // The XIII International MEDCOAST Congress on Coastal and Marine Sciences, Engineering, Management and Conservation. Mugla: MEDCOAST Foundation, 2017. V. 2. P. 871-880.

15. Litchi. Режим доступа: https://flylitchi.com/hub (дата обращения 12.06.2019)

16. Metashape - photogrammetric processing of digital images and 3D spatial data generation. Режим доступа: https://www.agisoft.com (дата обращения 10.09.2019) 
17. Software for Processing Point Clouds and Image. Режим доступа: http://www.terrasolid.com/products/terrascanpage.php (дата обращения 12.09.2019)

18. Bentley Systems. Режим доступа: https://www.bentley.com (дата обращения 12.09.2019).

19. Russ J. C. The Image Processing Handbook. Boca Raton: CRC Press, Taylor \& Francis Group, 2011. 838 p.

20. Ризаев И. Г., Погорелов А. В., Бойко Е. С. Пороговый метод фильтрации цифровых моделей растительного покрова в среде ГИС // Геоинформатика, 2016. №2. С. 14-18.

\section{References:}

1. Pogorelov, A. V., Boyko, E. S., \& Rizaev, I. G. (2009). The use of laser-location data for modeling and analysis of the structure and topography of mountainous areas reliefoid. Bulletin of the North Caucasus State Technical University, 4(21), 46-52.

2. Boyko, E., Krylenko, V., \& Krylenko, M. (2015, June). LIDAR and airphoto technology in the study of the Black Sea accumulative coasts. In Third International Conference on Remote Sensing and Geoinformation of the Environment (RSCy2015) 9535, 95351Q. International Society for Optics and Photonics. https://doi.org/10.1117/12.2192577

3. Pogorelov, A. V., Antonenko, M. V., Boyko, E. S., Fedorova, S. I., \& Eletsky, Yu. B. (2014). Research into the components of the coastal zone of the Sea of Azov by the airborne laser scanning data (Verbyanaya Spit area). Environmental protection in the oil and gas complex, 11, 33-39. (in Russian)

4. Kravtsova, V. I., \& Drugov, M. D. (2019). Types of dune terrain dynamics of Anapa bay bar: research based on airborne LIDAR data. Geodesy and Cartography, 80(2), 32-45. https://doi.org/10.22389/0016-7126-2019-944-2-32-45 (in Russian)

5. Glinka, V. V., Bespalova, L. A., \& Ivlieva, O. V. (2019). Study of types of shores of the Tsimlyansk water storage reservoir using unmanned aerial vehiclesю In Patterns of formation and impact of marine, atmospheric hazardous phenomena and disasters on the coastal zone of the Russian Federation in the context of global climatic and industrial challenges ("Dangerous phenomena"), 157-158. (in Russian)

6. Kosolapov, A. E., Skripka, G. I., Bespalova, L. A., Ivlieva, O. V., \& Filatov, A. A. (2018). Study of Morphological and Morphometric Characteristics of Tsimlyansk Reservoir Shores Using Unmanned Aerial Vehicles and GIS Technologies. Arid Ecosystems, 8(3), 184-189. https://doi.org/10.1134/S2079096118030034 (in Russian)

7. Misirov, S. A., Bespalova, L. A., \& Saprygin, V. V. (2018). Issledovanie geomorfologicheskikh osobennostei beregov Taganrogskogo zaliva s primeneniem bespilotnykh letatel'nykh apparatov i GIS-tekhnologii. Ekologiya. Ekonomika. Informatika. Seriya: Geoinformatsionnye tekhnologii i kosmicheskii monitoring, (3), 42-48. (in Russian)

8. Krylenko, V. V., \& Krylenko, M. V. (2018). High-precision survey of the relief of the Bakal spit. Ecological safety of the coastal and shelf zones of the sea, (4), 65-72. https://doi.org/10.22449/2413-5577-2018-4-65-72 (in Russian)

9. Krylenko, V. V., \& Rudnev, V. I. (2018). Technique of photographic Aerial Survey of the Bakalskaya Spit. Ecological safety of the coastal and shelf zones of the sea, (4), 59-64. https://doi.org/10.22449/2413-5577-2018-4-59-64 (in Russian)

10. Keller, B. M. (1947). Upper Cretaceous deposits of the Western Caucasus [Transactions of the GIN, USSR Academy of Sciences, series geology], (48), 122-125. (In Russian)

11. Antonov, B. A. (1979). Regional geomorphology of the Caucasus. Moscow, 196. (in Russian) 
12. Krylenko, M. V., Krylenko, V. V., Volkova, T. A. (2018). Development prospects of natural-territorial complex of the Dolgaya spit. Ocean and Coastal Management, 166, 98-102.

13. Krylenko, V. V. (2013). The use of GNIC LEICA GEOSYSTEMS equipment in scientific research. Geoprofi. Moscow, 5, 19-23. (in Russian)

14. Krylenko, M., \& Krylenko, V. (2017). Active registration method of the coast changes. In The XIII International MEDCOAST Congress on Coastal and Marine Sciences, Engineering, Management and Conservation. Mugla: MEDCOAST Foundation, 2, 871-880.

15. Litchi. URL: https://flylitchi.com/hub (12.06.2019)

16. Metashape - photogrammetric processing of digital images and 3D spatial data generation. URL: https://www.agisoft.com (10.09.2019)

17. Software for Processing Point Clouds and Image. URL: http://www.terrasolid.com/products/terrascanpage.php (12.09.2019)

18. Bentley Systems. URL: https://www.bentley.com (12.09.2019).

19. Russ, J. C. (2016). The image processing handbook. CRC press.

20. Rizaev I. G., Pogorelov A.V., Boyko E.S. (2016). Method of threshold filtering Canopy Height Models in the environment of GIS. Geoinformatics, 2, 14-18. (in Russian)

Работа поступила

в редакциюю 08.01.2020 г.
Принята к публикациии

11.01.2020 2.

Ссылка для циитирования:

Крыленко М. В., Крыленко В. В. Особенности выполнения высокоточной съемки рельефа абразионного берега с помощью БПЛА // Бюллетень науки и практики. 2020. Т. 6. №2. C. 10-19. https://doi.org/10.33619/2414-2948/51/01

Cite as (APA):

Krylenko, M., \& Krylenko, V. (2020). Features of Performing High-precision Survey of the Abrasion Coast Relief by UAV. Bulletin of Science and Practice, 6(2), 10-19. https://doi.org/10.33619/2414-2948/51/01 (in Russian). 


\title{
ECOGEOGRAPHICAL PROBLEMS OF AIR POLLUTION IN THE BIG CITIES OF AZERBAIJAN
}

\author{
CMammadova Sh., Ph.D., Baku State University, Baku, Azerbaijan

\section{ЭКОГЕОГРАФИЧЕСКИЕ ПРОБЛЕМЫ ЗАГРЯЗНЕНИЯ АТМОСФЕРЫ КРУПНЫХ ГОРОДОВ АЗЕРБАЙДЖАНА}

\author{
(СМамедова Ш. И., канд. геогр. наук, Бакинский государственный университет, \\ г. Баку, Азербайджан
}

Abstract. In connection with the development of urbanization, the protection of cities and the environment, issues of restoring the ecological balance become an urgent issue. The scale and intensity of product development in Azerbaijan enhance the anthropogenic impact on the nature of the regions. Such an effect is manifested in the pollution of soils with industrial, household waste, chemical fertilizers, the burning of hydrocarbons, the emission of harmful substances in the water and vehicles into the environment. Like in the whole world and in Azerbaijan, such negative processes are no exception. In this regard, the environmental problems of cities and urban agglomerations around the world are in the focus of attention of specialists and scientists. The presented article considers environmental and geographic problems that arose as a result of air emissions in 8 cities of Azerbaijan. The historical properties of studying atmospheric pollution in cities are analyzed, ecogeographic methods for studying atmospheric pollution of cities are identified, environmental pollutants of large cities and the ecogeographic properties of their influence are considered. The ecological properties of the geographical condition, meteorological climatic conditions in air pollution, aerospace research in the study of atmospheric pollution in large cities and the effect of pollution on the health of the population of large cities are studied. The transport system of cities, their geography, and the effect of emissions of harmful, poisonous substances into the atmosphere by vehicles on public health were also noted. Based on the methods for predicting atmospheric air pollution in large cities and the non-linear regression technique, a mathematical model of ecogeographic forecasting of air pollution is applied. Comprehensive indicators and the level of air pollution in unfavorable conditions for urban agglomerations are determined.

Аннотащия. В связи с развитием урбанизации, охрана городов и окружающей среды, актуальными становятся вопросы восстановления экологического равновесия. Масштабность и интенсивность развития производства в Азербайджане усиливает антропогенное воздействие на природу регионов. Такое воздействие проявляется в загрязнении почв промышленными, бытовыми отходами, химическими удобрениями, сжиганием углеводородов, выбросами в акватории вредных веществ и транспортными средствами в окружающую среду. Как и во всем мире, в Азербайджане такие негативные процессы не исключение. В связи с этим экологические проблемы городов и городских агломераций во всем мире находятся в центре внимания специалистов и ученых. В представленной статье рассмотрены экогеографические проблемы, возникшие в результате выбросов в атмосферу в 8 городах Азербайджана. Проанализированы исторические аспекты загрязнения атмосферы в 
городах, определены экогеографические методы исследования атмосферного загрязнения городов, рассмотрены факторы загрязнения атмосферного воздуха крупных городов, экогеографические свойства их влияния. Изучены экологические свойства географического условий, метеорологические климатические условия в загрязнении атмосферы, аэрокосмические исследования в изучении загрязнения атмосферы крупных городов и влияние загрязнения на здоровье населения крупных городов. Отмечены также воздействие транспортной системы городов, их география, влияние выбросов в атмосферу транспортными средствами вредных, ядовитых веществ на здоровье населения. На основе методов прогнозирования загрязнения атмосферного воздуха в крупных городах и методике нелинейной регрессии, применена математическая модель экогеографического прогнозирования загрязнения атмосферы. Определены комплексные показатели и уровень загрязнения атмосферы в неблагоприятных условиях по городским агломерациям.

Keywords: meteorological and climatic conditions, aerospace, ecological and geographical, favorable weather conditions, synoptic processes, mathematical model.

Ключевые слова: метеоролого-климатические условия, аэрокосмические, экологогеографические, благоприятные метеоусловия, синоптические процессы, математическая модель.

Several big-scale air pollution disasters were recorded in the world in the XX century. For example, the valley of Moz (Belgium) in 1930, almost became poison trap as a result of air pollutants emitted to the atmosphere by the coke ovens, steel and zinc smelting plants, glass factories and sulfuric acid plants located in the valley. The result was devastating, causing 63 deaths and 600 positioned by the industrial sulfuric oxide [1].

The first disaster caused by air pollution in the United States occurred Donora, Pennsylvania in 1948. The pollutants emitted from several industrial enterprises such as sulfuric acid plant, steel and zinc production plants settled on the land surface as a result of temperature inversion and created the fog and air mixture causing breathing difficulty. As a result, 6000 people complained about dizziness and sore throat and during the 3 days, 20 people died [2].

Among the many scientists who studied air pollution and its impact on living beings D. Anjelkovich, C. Tolby, M. Saymons (1976), I. Barnes, V. Bastian, K. Beker, Z. Tong (1990), C. Bond, A. Dahl, R. Henderson, L. Bönbaum (1987), L. Vichers, C. Nolan, D. Uinsett, D. Ledbeta, A. Kodavanti, U. Skladveyler, M. Kosta, D. Uatkinson (2004) should be mentioned.

Preparation of methods for the study of air pollution in USSR started in the $1960 \mathrm{~s}$. In this regard the scientific works of M. E. Berlyand, T. G. Berlyand (1968), E. Y. Bezuglaya, L. R.Sonkina (1971), M. T. Dmitriyeva, G. P. Sidorenko (1976) and many others can be specifically mentioned. Regarding the study of the air pollution and implementation of the prepared methodology in Azerbaijan SSR the scientific works of A. A. Gorchiyev (1969), R. M. Rafiyev (1970), R. B. Abdullayev (1993), B. H. Mammadov, B. A. Mammadov (1987), Sh. I. Mammadova (1993-1998), M. A. Jabbarov (1973) and others' can be mentioned. The scientific works of A. M. Shikhlinski (1968), A. A. Madatzada (1948,1953,1963), A. J. Ayyubov (1962, 1989), M. A. Jabbarov (1973), B. A. Mammadov (1985), B. H. Mammadov, I. A. Jafarova (1978,1980), A. A. Gorchiyev (1978, 1979, 1982), B. M. Madatzada (1987), R. Sh. Hasanov $(1992,1994)$ and others' have been devoted to the study of the role of climatic and meteorological conditions in the dispersion of air pollutants in Azerbaijan. The Russian scientists such as M. E. Berlyand, T. Q. Berlyand (1985), E. Y. Bezuglaya, L. R. Sonkina (1971), R. I. Onikul (1971), B. B. Goroshko, L. S. Gandi, V. K. Petrenko, V. I. 
Arishkova (1973), S. I. Ponomarenko (1975) played an important role in the preparation of theoretical and methodological base for the study of the role of meteorological aspects in the dispersion of air pollutants.

First of all the study of urban air pollution as a subject was reflected in the sources of ecological and geographical sciences. The studies conducted mainly covered the typological directions of the urban atmosphere [3].

Generally, the conceptual base of air pollution is the preparation of plans and programmes for the improvement of air quality management.

As being a strong and constant aspect of atmosphere air pollution has an impact on human health and the environment. This problem is especially actual in big industrial cities. Clustering of multi-profile industries, over-developed transportation systems, the existence of industrial and household waste problem in big cities results in a huge impact on all components of the environment.

The geographical studies conducted in the Azerbaijan Republic play an important role in the development of geographical science not only within boundaries of the CIS but also outside of its limits. Furthermore, most of the geographers in Azerbaijan have the opportunity to study the geographical problems both at the regional and global scale.

During the Soviet period, the scientific research activities of geographers in Azerbaijan were mainly focused on two major directions. First and the most important direction was research activities and studies focused on the geographical problems within the boundaries of Azerbaijan SSR. The second direction in the geographical research was together with scientists of Institue of Geography of USSR Academy of Sciences to contribute to the studies of scientific problems which had all union importance.

Research studies in the field of geography and geographical ecology started in the 80s of the XX century and are still ongoing. (H. A. Aliyev, B. A. Budagov, Kh. Hasanov, Sh. Y. Goychayli, M. A. Salmanov, N. K. Mikhailov, T. A. Khalilov, R. B.Abdullayev and others).

The democratization of public and social spheres in Azerbaijan as a result of the transition to the new development path had a huge impact on the transformation of science and its rapid development.

Analysing geography and ecology together might help us to clarify the following problems: firstly, the integration of geography with newly emerged political and economic sciences at the beginning of the XX century, formation of political geography; secondly, while studying natural and social processes identification of not only patterns of earth layer and social production but also direct and indirect impact of the space processes and solar system on the earth layer and social production; thirdly, right assessment of linkage and synthesis of geography with other sciences and clarify the misinterpretation of geographical ecology (geo-ecology) and etc. It should be noted that, some scientists is-assessed the idea of 'unified geography' which was the discussion topic 150-200 years ago and reappeared again in the 70s of XX century (D.N.Anuchin, Y. G.Saushkin, and others). They insist that the above-mentioned idea does not lead to the right results. However, it is not acceptable. We can already witness the results of attention paid by the scientists to the idea of 'unified geography' in the second half of the XX century even though it is late. At the end of XX century the re-activation of political geography, the emergence of geographical ecology and other sub-disciplines happened purely on the bases of the idea - 'unified geography'. The emergence of ecological geography on the bases of both physical and human geographies indicates the development of geography not only as theoretical and methodological science but also its applied fields.

All the above studies we analysed and implemented have contributed to the development of science in Azerbaijan. However, geomorphological, landscape, hydrometeorological, economical 
geography, landscape-ecology and other studies never researched the air pollution and its reasons in cities and environment. Unlike the studies mentioned above, we first time in Azerbaijan conducted research where the problems caused by the air pollution in the cities of Azerbaijan were studied in a complex way, the role of meteorological-climatic conditions in dispersion of air pollutants investigated and the sources of air pollution in the cities and its impact on human health have been studied and correlation between them have been identified. İn addition, by utilising the aerospace methods the air pollution areas in the cities have been spotted and prognosis/prediction schematics have been prepared for the big cities of Azerbaijan. Diverse natural conditions and rich natural resources create opportunities for the development of Azerbaijan Republic. The modern territorial production complexes of the Republic developed based on the local natural resources and conditions and as a result, the main sectors of urban production have emerged. The creation of sustainable social and economic base of cities depends on the efficient assessment of the ecological and geographical situation of the country and its regions.

Each of above-mentioned source has its own share in air pollution. Pollutants originating from stationary sources such as energy, machine-building, chemistry, agriculture, light industry and etc. are in the form of gas, dust and some as a liquid. Every air pollutant to some extent depending on the meteorological condition play an important role in the deterioration of the ecological situation.

\section{The assessment of the role of the meteorological conditions in the air pollution of big cities of Azerbaijan}

The natural climatic conditions have a big role in the air pollution of cities. As the main component of climatic conditions the speed and direction of the wind, synoptic conditions, temperature, humidity ratio, fog, cloudiness and etc. have been considered. The main focus of this research was synoptic processes, temperature, humidity, the speed and direction of the wind and under the aerospace analysis, it was fog and cloudiness.

One of the actual problems of ecogeographical research is the study of the air pollution of multi-functional big cities and the protection of their atmosphere. Even though there were many studies dedicated to this problem still some aspects of this problem have not been studied enough. The studies indicate that in air pollution of cities meteorological conditions also play an important role besides the anthropogenic impacts [4]. Thus, while studying the air pollution of cities and spreading of polluted particles in the air it is important to consider not only, anthropogenic aspects but also meteorological parameters of the area and the seasonal change of synoptic processes during the year which also have crucial scientific and practical importance. Since the boundaries of modern cities cover very big areas, the change of existence and share of air pollutants in the atmosphere are impacted by the mesoscale and macroscale climatic processes.

The studies found that the movement of air pollutants in the atmosphere, once they are formed, depends on weather condition and height, the shape of chimneys of the air pollutant emitting sources. It is known that maximal reach distance of air pollutants from a stationary source in the windless condition is 20 to 40 times more depending on the height of air pollution source. Supposing that the industrial enterprise chimney height is $120 \mathrm{~m}$ then based on the above-mentioned assumption maximum density on the land surface has to be within the $2.4-4.8 \mathrm{~km}$ and this distance is enough to cover industrial and residential areas around the air pollution source.

Generally, there are 10 synoptic -climatic regions in Azerbaijan: Guba-Shamakhi, AbsheronGobustan, Central-Steppe, Jeyranchol-Bozdag, Lankaran-Astara, Oguz-Ismayilli, Zagatala-Shaki, Ganca-Gazakh, HigherGarabagh, Nakhchivan. Let's review the regions were cities under the study located. 
As a result of studies, it was found that the traffic is the main reason of higher anthropogenic air pollutants such as carbon monoxide and nitrogen during the warmer periods of the year in the cities of our Republic. The share of traffic emissions in the air pollution of industrial cities of Azerbaijan is $65-70 \%$ [5-10].

The analysis of observation data indicates that except Sumgait city there were differences in the quantities of traffic emissions into the air of big industrial cities in separate years. The quantities of such pollutants in Baku in 2000 was 229,9 thousand tons but, in 2007 it was 410,7 thousand tons, in Ganja city it was respectively 20,8 and 37,2 thousand tons and in Sumgait, the city it was 14,3 and 8,2 thousand tons [20].

Table 1

FREQUENCY OF ATMOSPHERIC PROCESSES (\%)

\begin{tabular}{lccccc}
\hline \multirow{2}{*}{ Types of Atmospheric processes } & Annual frequency in \% & \multicolumn{4}{c}{ Repeat on seasons (\%) } \\
\cline { 3 - 6 } & & winter & spring & summer & autmn \\
\hline Global air circulation & 36 & 20 & 27 & 28 & 25 \\
Entrance of tropical air masses & 27 & 37 & 28 & 14 & 21 \\
Impact of continental air masses & 21 & 24 & 24 & 28 & 24 \\
Impact of southern cyclons & 16 & 31 & 27 & 23 & 19 \\
\hline
\end{tabular}

The studies indicate $[11,12]$ that unfavourable weather conditions such as light breeze, high temperature and humidity and foggy weather have more impact on the increased concentration of air pollutant particles in the atmosphere. As a result of the several occurrences of such unfavourable weather conditions in Sumgait city in last two years the air pollutants exceeded the allowable density thresholds such as dust 1,2-2,0 times, nitrogen 4-oxide 1,5-2,5 times, carbon dioxide 2,03,0 times and in Ganja city dust, nitrogen 4-oxid concentrations were higher than maximum threshold. However, in other cities of Azerbaijan, the concentration of air pollutants in the atmosphere were within the tolerances.

As a result of observations and analysis it was found that the level of air pollution in Baku city is average, in Sumgait and Ganja it is moderate and in other cities it is low. The air pollution almost was not observed in Nakhchivan city.

\section{The role of aerospace research in the study of air pollution of cities}

The results of large-scale studies of atmospheric processes utilising satellite imagery are given below-mentioned studies [13-15]. Those studies cover the investigation of earth surface weather conditions based on the aerospace data.

It can be concluded from the above mentioned assumptions that anthropogenic pollution of urban air is a pressing problem that many researchers have studied in modern times. At the same time, not all aspects of the problem have been fully studied yet. Many scientists refer either to the surface discrete surveillance data or aerospace data in their research, However, surface and aerospace surveillance data should be used to give a clearer picture of urban anthropogenic pollution [16]. Images from artificial satellites allow us to identify trends in the development of anthropogenic landscapes, identify ways to disperse atmospheric pollutants, identify areas of accumulation of pollutants and so on. However, to fully understand the state of atmospheric contamination, comprehensive use of appropriate surface and direct aerial (radiosonductivity) measurements with multi-field space shots is required. Only in this case can the maximum effect be monitored by air pollution. Such an approach is more appropriate in exploring urban anthropogenic pollution. These researches allow us to determine the general patterns of air pollution and the 
dynamics of pollution hoses in cities, as well as the relationship between pollutant concentrations and meteorological conditions.

The main problem of cities in the creation and maintenance of a favorable environment for people. Cleanliness is a necessary condition for a person's existence, but also an important factor in the well-being of his or her life, and a means to meet his spiritual and aesthetic needs. With the growth of industrial facilities and other stationary sources, conditions for anthropogenic pollution of the environment are created, which negatively affects human health.

The Absheronmegapolis area is home to large industrial centres with numerous sources of pollution, as is known from the quantitative and qualitative methods of estimating harmful gas mixtures and water vapour in the atmosphere. An infrared spectrometer (ICOs-25) was mounted on the AN-30 to study atmospheric gas mixtures in the Absheron peninsula. The purpose of the measurements is to investigate the impact of large enterprises on the composition of atmospheric gas on the basis of an integrated amount of minor gas mixtures, to predict the environmental impact of the data obtained, and to determine the absorption strips in the measurement ranges. Measurements were made at a height of $500 \mathrm{~m}$ to $6000 \mathrm{~m}$. At that time it was divided into sheets that differed $50 \mathrm{~Pa}$ by atmospheric pressure. Measurements were made at the boundaries of all layers except the last layer. Based on earlier experiments, the average temperature in the sheet was calculated based on the amount of water vapour [16].

Analysis of aerobiotic conditions revealed that the smoke cloud over the Absheron peninsula is formed at $<2 \mathrm{~m} / \mathrm{sec}$. wind speed, high relative humidity $(>90 \%)$ and strong inversion. At this point, the smoke of the mentioned cities occurs. Thus, at night time, in the steady temperature stratification and high air humidity, no harmful impurities are scattered and their accumulation occurs on the surface. At nightfall, when the surface inversion is more intense, high concentrations of harmful impurities are recorded in the air. In the morning, surface inversion collapses and height inversion forms due to the Sun's surface heating and wind speeds forming. The lower boundary of such inversion is gradually increasing, and in this connection, the volume of air is increased, which also includes harmful impurities from sources of pollution. At this time, a cloud of smoke is formed in the inversion layer at high air humidity [15-19].

It should be noted that industrial fumes usually have strip monograde in space images, while the texture is matte or fibrous. Fogs of industrial origin often form on cities. Such fumes tend to have a clearer tone and higher albedo value in space images. Such fumes are characteristic of the coastal strip of the city of Sumgait and are clearly visible in the photographs from the YSP [16, 19]. They have a clear tone in the photos and are formed by the inversion layer as well as by the high humidity (>90\%). Presence of harmful substances in the atmosphere.

In addition, the appearance deteriorates due to the conversion of $\mathrm{SO}_{2}$ into the aerosol. Thus, the rate of rotation is sometimes up to several percent per hour.This is due to the fact that sulfur dioxide is more readily soluble in fumes than in gases. This is due to the fact that there are some micronutrients that have catalyst properties, usually in fumes. Due to these micronutrients, oxidation is becoming more intense. If the fume contains metal sensors (manganese, iron, copper) or ammonia, the oxidation process is accelerated. At the same time, the weight of the harmful mixture increases, with $1 \mathrm{~g}$ of sulfuric acid produces $1.5 \mathrm{gr}$. of sulfuric acid [14, 16, 20, 21].

It is not always possible to identify smog pollution at the land based meteorological stations. However, it is possible to identify smog with the multicomponent satellite images.On the satellite image which has spectral range of 0,7-1,1 microns (Figure 3) it is possible to see that tone of image of area covered with the industrial smog is closer to the tone of water object image. Thus, it is difficult to distinguish the outlines of Baku and Sumgait cities. This is occur not only due to the temprature inversion but also as an impact of 'heat islands'. Constant temperature startification 
causes the creation of smog in the sub-inversion layer and formation of industrial smog pollution. The urban 'heat influence' increases the inversion. The upper boundry of created smog has higher temprature compared to the temprature on the land surface. Therefore, in infrared images the industrial smog is seen darker than fog in the space.

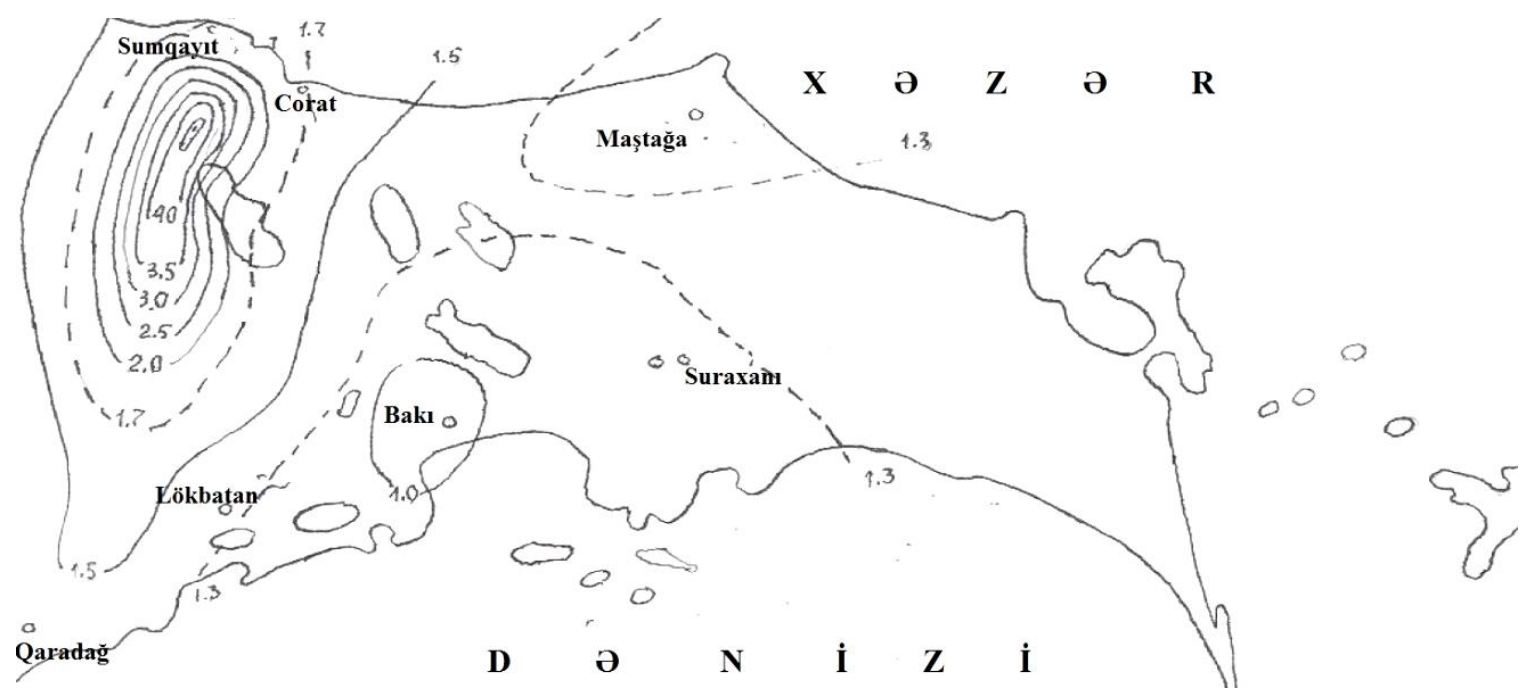

Figure 1. The distrubition area of $\mathrm{SO}_{2}$ at the highest/dangerous speed limit of northern wind

Using the satellite information creates an opportunity to study the overall tendencies of air pollution levels of cities, distribution of air pollutants in the air and to identify the correlation between the density of air pollutants and meteorological conditions. The obtained study results have practical/applied importance. These results can be used for a wide range of purposes such as the organization of monitoring of the air pollution, urban planning and development, planning of the location of the industrial and residential areas, implementation of air protection activities and etc.

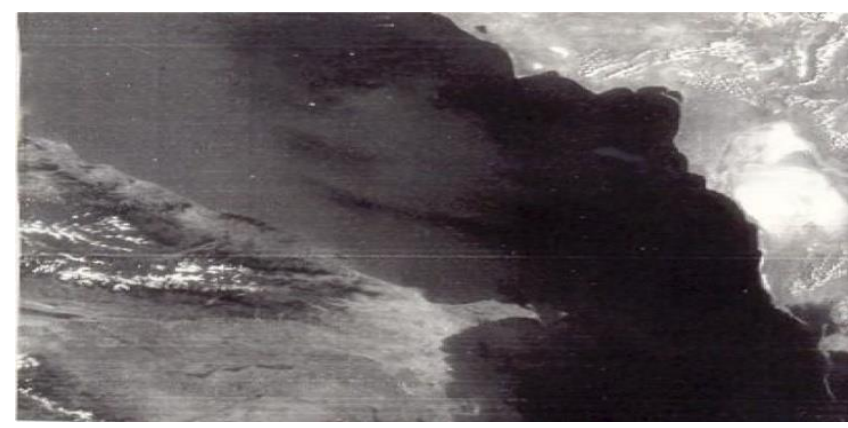

a)

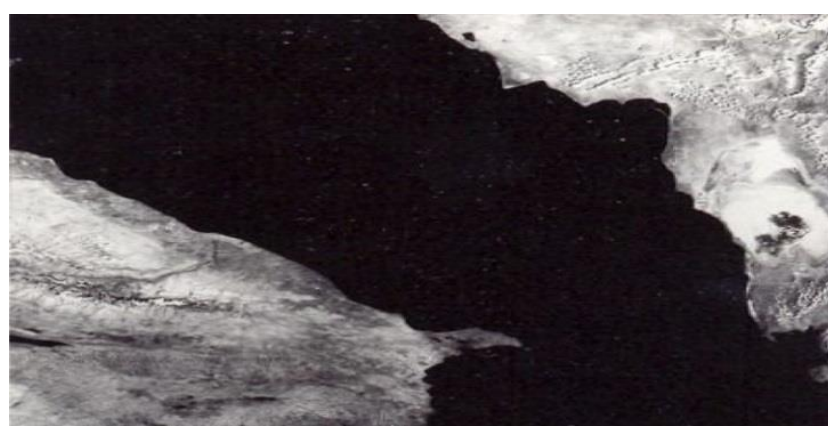

b)

Figure 2. A snapshot of satellite imagery of Absheron peninsula. Meteor a) 0,5-0,7 mkm, b) 0,7-1,1 $\mathrm{mkm}$

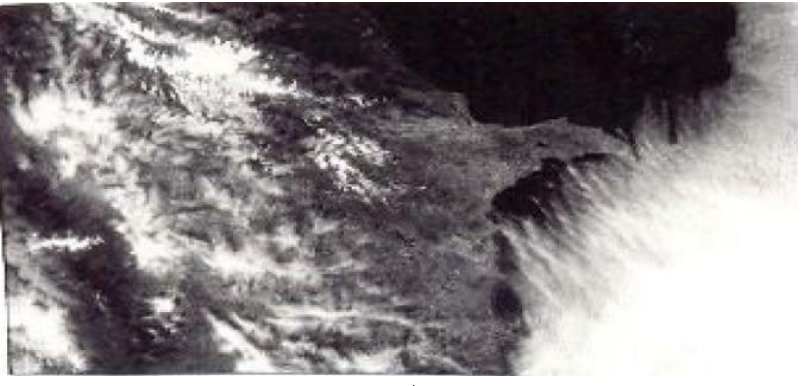

a)

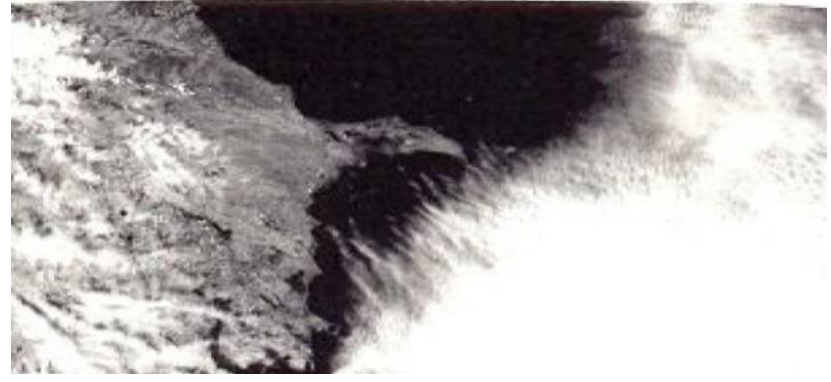

b)

Figure 3. A snapshot of satellite imagery of Absheron peninsula. Meteor 0,5-0,7 mkm, b) 0,7-1,1 mkm 
The assessment of the impact of air pollution on the human health in the big cities of Azerbaijan

It is indicated in the studies that $[14,16,21-23]$ there is a correlation between the level of air pollution and some diseases (such as damage to the upper respiratory tract, heart problems, bronchitis, asthma, pneumonia, pulmonary emphysema, eye diseases and etc.).

One of the most pressing ecogeographical problems is the air pollution of the urban environment and protection of the health of the urban population.

Year by year analysis indicate that the number of deaths among working-age population decreased 11030 person in 1990 and 12084 person in 2000. However, the rise in the mortality rates in this group again was observed in 2005 and 2006 (respectively, 13945; 14243 people) [26] (Figure 4).

a)

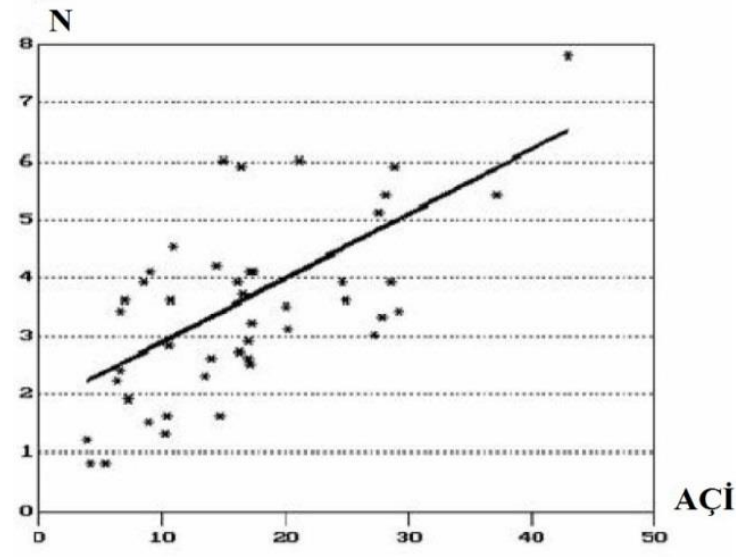

b)

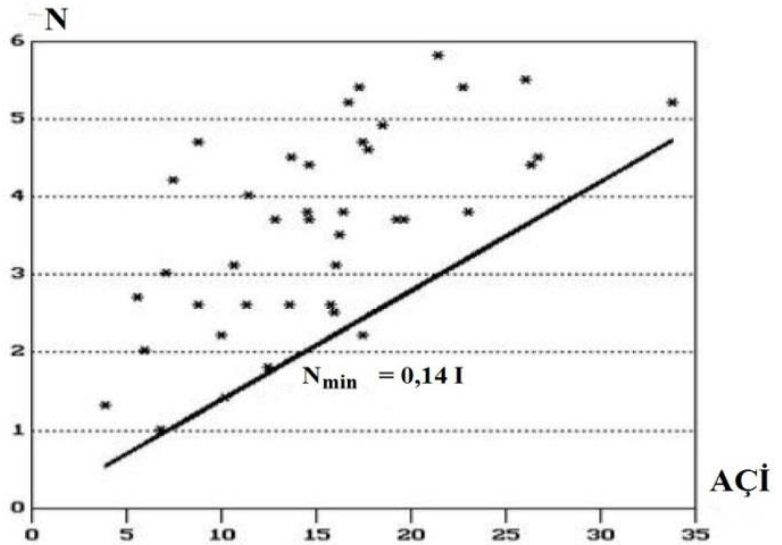

Figure 4. The dependence of the number of malignant tumor diseases on Air Pollution Index (per 1000 person) a) year - 2006; b) between years 2002-2006

Babies who are most susceptible to air pollution are almost an indicator of the quality of the environment and human health. The statistical indicators clearly confirm this fact. Infant mortality was 4193 in 1990 and 1508 in 2006. The infant mortality decreased in 2906 between 1990-2004. Unfortunately, this type of infant mortality numbers is again at the risk of increase.

The infant mortality indicators among the cities of Azerbaijan Republic was as following: Baku city - 769 in 1990, 511 in 2006, Sumgait city - 127 in 1990, 83 in 2006, Ganjacity - 61 in 1990, 38 in 2006, Shaki city - 81 in 1990, 47 in 2006, Lankaran city - 70 in 1990, 22 in 2000, Shirvan — 35 in 1990, 7 in 2006, Mingachevircity — 44 in 1990, 9 in 2006, Nakhchivan city — 18 in 1990, 6 in 2006 [26, 27].

Table 2.

THE RESULTS OF THE ANALYSIS OF CORRELATION BETWEEN AIR POLLUTION INDEX AND THE MALIGNANT TUMOR DISEASE FOR FIVE YEARS PERIOD

\begin{tabular}{lccccccc}
\hline \multicolumn{1}{c}{ Year } & $a$ & $\sigma_{a}$ & $b$ & $\sigma_{b}$ & $R$ & $r^{2}$ & $\mathrm{n}$ \\
\hline 2002 & 1,59 & 1,06 & 0,11 & 0,03 & 0,69 & 0,48 & \\
2003 & 1,47 & 1,17 & 0,13 & 0,03 & 0,58 & 0,34 & \\
2004 & 1,94 & 0,95 & 0,10 & 0,02 & 0,69 & 0,46 & \\
2005 & 1,93 & 1,25 & 0,11 & 0,04 & 0,42 & 0,18 & \\
2006 & 1,58 & 1,16 & 0,11 & 0,02 & 0,66 & 0,43 & \\
\hline For all preiods & 1,80 & 1,11 & 0,11 & 0,01 & 0.60 & 0,36 & \\
\hline Average for period & 1,67 & 1,00 & 0,12 & 0,02 & 0,62 & 0,38 & \\
\hline
\end{tabular}


In the table $a$ - free limit of regression equation; $b$ - APİ-coefficient; $r$ - correlation factor; $n$ - number of cities in the study.

It is obvious from the Table 3.15 that the correlation between air pollution index and malignant tumor diseases is high and sustainable. All statistical parametres $\left(a, \sigma_{a}, b, \sigma_{b}, R\right)$ change very little from year to year. Between years 2002 - 2006 the correlation coefficient was 0,60 $\pm 0,07$. The correlation between Air Pollution Index and malignant tumor diseases is illustrated in the fihure below.

Location of the city in the mountainous or hilly area can cause rapid diffusion of air pollutants if the natural terrain cuts the wind speed the level of air pollution might increase. That is why in the cities which are located in the valleys the air pollutants get trapped and as a result the level of air pollution increases. Even though the wind speed can decrease the air pollution near the pollution source, it causes the air pollutants to diffuse into wider areas. The sun light causes the increase in the air pollution level by causing the start of formation of photochemical smog and decomposition of moist pollutants in the air or formation of new compunds.However, the rain cleanes the air and decreases the air pollution.

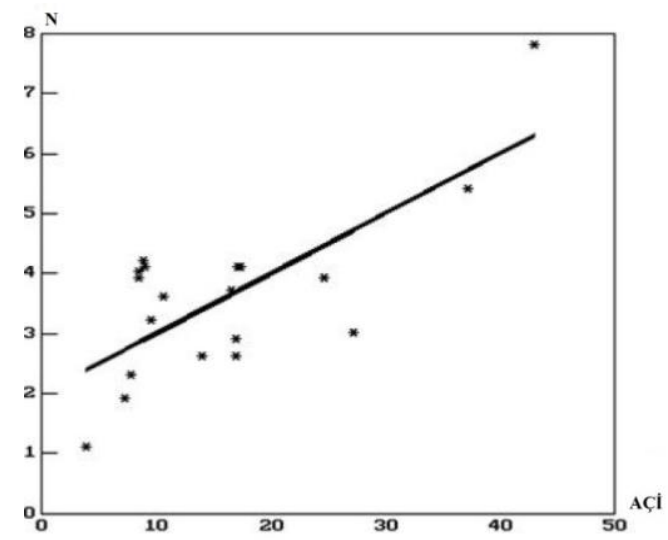

Figure. 4 The dependence of the number of malignant tumor diseases on Air Pollution Index (per 1000 person) For the big cities of Azerbaijan (Baku, Ganja,Sumgait)

Itwas found that there was decrease in the concentration of different air pollutants (nitrogen, carbon dioxide) in the years 2000-2010. However the ratio of some poluttants per person started to decrease in 2010 [24].

\section{The transport system geography of Azerbaijan and assessment of its environmental impact}

The transport system is the base of modern economic infrastructure of Azerbaijan Republic.Currently, tehre are more than 860 thousand motor vehicles in the Republic. The increasing usage of motor vehicles per year leads to the high concentrations of non-burning hydrocarbons, as well as lead, mercury compounds, sulfur, nitrogen, carbon monoxide, benzopyran and other hazardous substances. Hazardous emissions from the motor vehicles enter into the active zone of the biosphere and affect it. Lead, which is a part of the used gas emissions, is highly toxic which might affect the human body. The emissions entering into the lower layers of the atmosphere are poorly distributed when no windy weather is observed. In that case since warm air mass stongly rises in the central streets of the city, the toxic emissions are unable to spread largely. Mostly the emissions are accumulated between skyscrapers, in the lower relief areas. The pollution of air in the cities by the transport emissions also impact health of urban population.

The main emissions from the motor vehicles include toxic gases such as sulfur compounds, nitrogen oxide, carbon dioxide and carbon monoxide and mechanical gas mixtures. 
$\mathrm{CO}_{2}$ (carbon dioxide) of course is the number one pollutant and most of it emitted by the motor vehicles. The idustry emissions of carbon dioxide is 5 times less compared to the emssions of motor vehicles [2].

Since the $\mathrm{CO}$ has a toxic effect it is more dangerous to human life and it is lighter than oxygen by interacting with the hemoglobin in the blood creates stable carbohydrobulin. As a result human body has a oxygen deficiency. $\mathrm{CO}$ also causes disorders of the cardiovascular system. Carbon dioxide (CO) has lethal threat to the people who has cardiovascular disea ses [30].

\section{COMPISITION OF EXHAUST GASES EMITTED FROM AUTOMOILES MG/M³}

Table 3

\begin{tabular}{cccc}
\hline Compounds & \multicolumn{3}{c}{ The quantity of pollutants emitted to the air under different conditions } \\
\hline & When engine is idle & Low speed & High speed \\
$\mathrm{NO}_{\mathrm{x}}$ & $0-50 \mathrm{mln}^{-1}$ & $1000 \mathrm{mln}^{-1}$ & $4000 \mathrm{mln}^{-1}$ \\
$\mathrm{CO}$ & $3-10$ size, $\%$ & $3-8$ size, $\%$ & $1-5 \mathrm{size}, \%$ \\
$\mathrm{HC}$ & $300-8000 \mathrm{mln}^{-1}$ & $200-500 \mathrm{mln}^{-1}$ & $100-300 \mathrm{mln}^{-1}$ \\
$\mathrm{CO}_{2}$ & $6,5-8$ size, $\%$ & $7-11$ size, $\%$ & $12-13$ size, $\%$ \\
\hline
\end{tabular}

Nitrogen oxides are involved in phtochemical processes. There is a close connection between the level of photochemical pollution in the air and dirving mode. Huge amounts of nitrogen oxide and hydrocarbon gases emitted to the air during the mornings and evenings when the trafic intensity is specially high. These gases emitted to the air react with each other and cause photochemical contamination of air.People with chronic cardiovascular and respiratory diseases are highly sensitive to nitrogen oxides [25].

The level of overloading of streets and main roads of the city leads to the fact that, at a specified speed, the vehicleas operating time may be less than $30 \%$ of the total time-limit of traffic in the city, the length of the acceleration and braking (slowdown) areas is about $70-80 \%$ of the total distance traveled by the vehicle.Engine idle run time is $15-45 \%$; slowdown - 13-32\%; acceleration $18-37 \%$; the set speed is $12-54 \%$.

\section{Study of impact of the transport emissions on the human health}

$50 \%$ of diseases caused by environmental factors cause more serious complications in the elderly. In the atmospheric air, there are mainly organic and inorganic pollutants of anthropogenic origin. The main reason for their diffusion in the atmosphere is industrial enterprises, road transport, and most pollutants play a major role in human morbidity, including sulfur dioxide, nitrogen oxides, carbon dioxide and carbohydrates. Sulfur, phenol, styrene, hydrogen-chloride, hydrogen-fluoride, formaldehyde, ethyl-benzene, chlorine, benzapirine, metals, and others also play a role in air pollution. Respiratory, digestive, nervous, endocrine, cardiovascular, blood and gastrointestinal diseases, diabetes, allergies, malignant tumours, anomalies, complications of pregnancy and so on.

Babies who are most susceptible to air pollution are almost an indicator of the quality of the environment and human health. The statistical indicators clearly confirm this fact. Infant mortality was 4193 in 1990 and 1508 in 2006. The infant mortality decreased in 2906 between 1990-2004. Unfortunately, this type of infant mortality numbers is again at the risk of increase.

Too many vehicles in the big cities increases the degree of air pollution in those cities. The share of pollutants originating from transport emissions constitute the $40-50 \%$ of overall air pollution.

The actual studies of the traffic flow on the highways and crossroads are recommended to carry out within 20 minutes from 08:00 to 10:00 and from 17:00 to 19:00 in rush hours of the traffic movement. 
The studies indicate that there is non-linear dependence between traffic speed and density. This dependence calculated using Greenshields model and is expressed as traffic density -

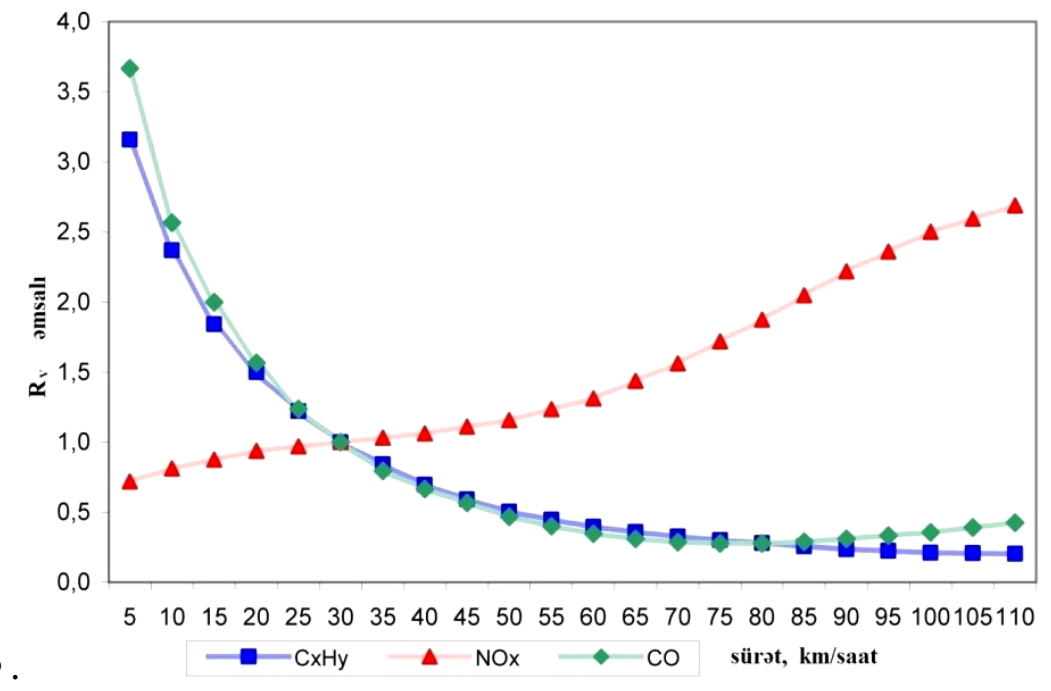

Figure 5. Dependence of $\mathrm{R}_{\mathrm{V}}$ coefficient on the traffic speed

When the traffic density - $\rho$ increases (increase in the number of vehicles on the roads), the drivers in order to ensure safe driving distance decrease the speeed - V.

When the traffic flow with mixed content is $120 \mathrm{per} v \mathrm{veh} / \mathrm{km}$, provided that the free movement velocity of the motor vehicles is $60 \mathrm{~km} /$ hour in the city, then $\mathrm{N}_{\max }$ share of the maximum intensity of the traffic flowacross one strip of the highway under urban conditions could be shown as follows (Figure 3):

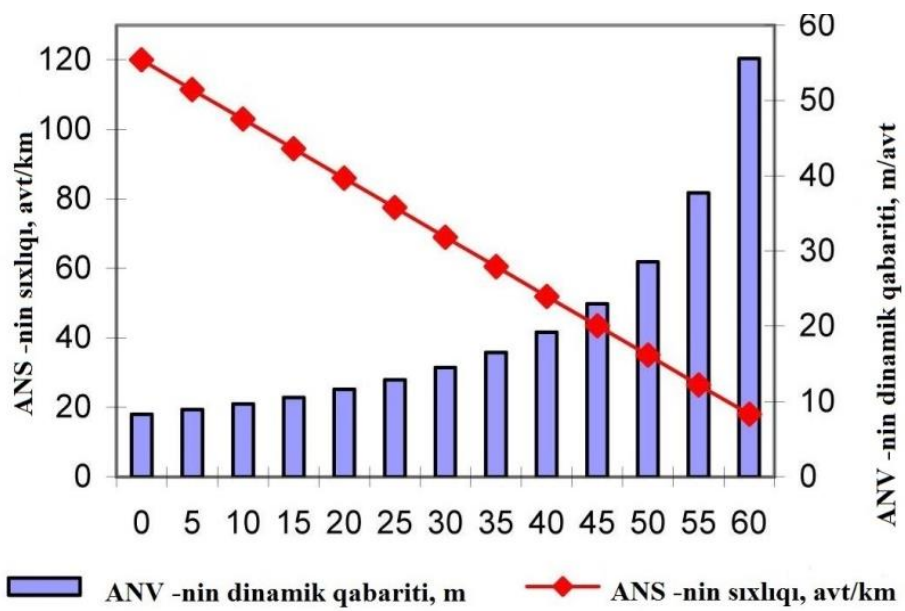

Figure 6. Dependence of traffic intensity and its overall dynamic dimensions on traffic speed

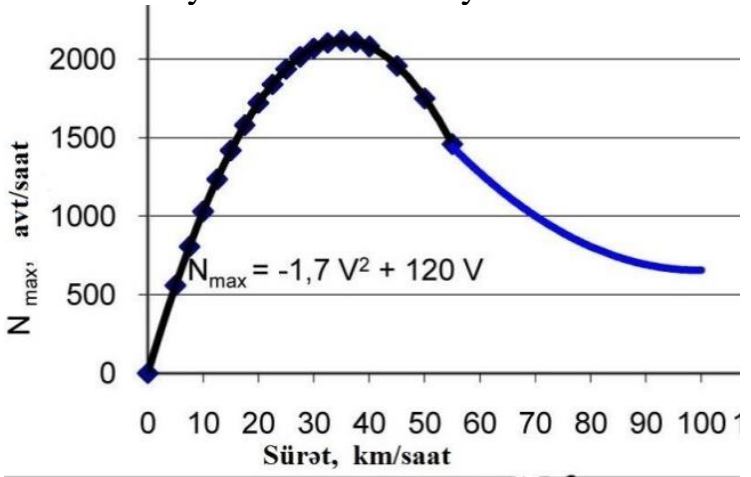

Figure 7. The dispersion of maximal traffic intensity — Nmax 
Currently, when the studies of the highways are carried out, the velocity of the motor vehicles of different types is evaluated based on the visual method, which leads to the major errors regarding the results. Therefore, it would be more reasonable to use internet based geographical information services. These systems inform the observer of the street - road network condition on an operational basis.

As experience shows, to define the queue length in front of a crossroad based on the visual method is difficult. Hence, the calculation method is recommended to use. This method is based on the maximum intensity, velocity and density values of the traffic flow. The geographical information system is recommended to be applied in operative mode together with the internetservices in the major cities with high traffic intensity of motor vehicles, which is considered more accurate and reasonable [26].

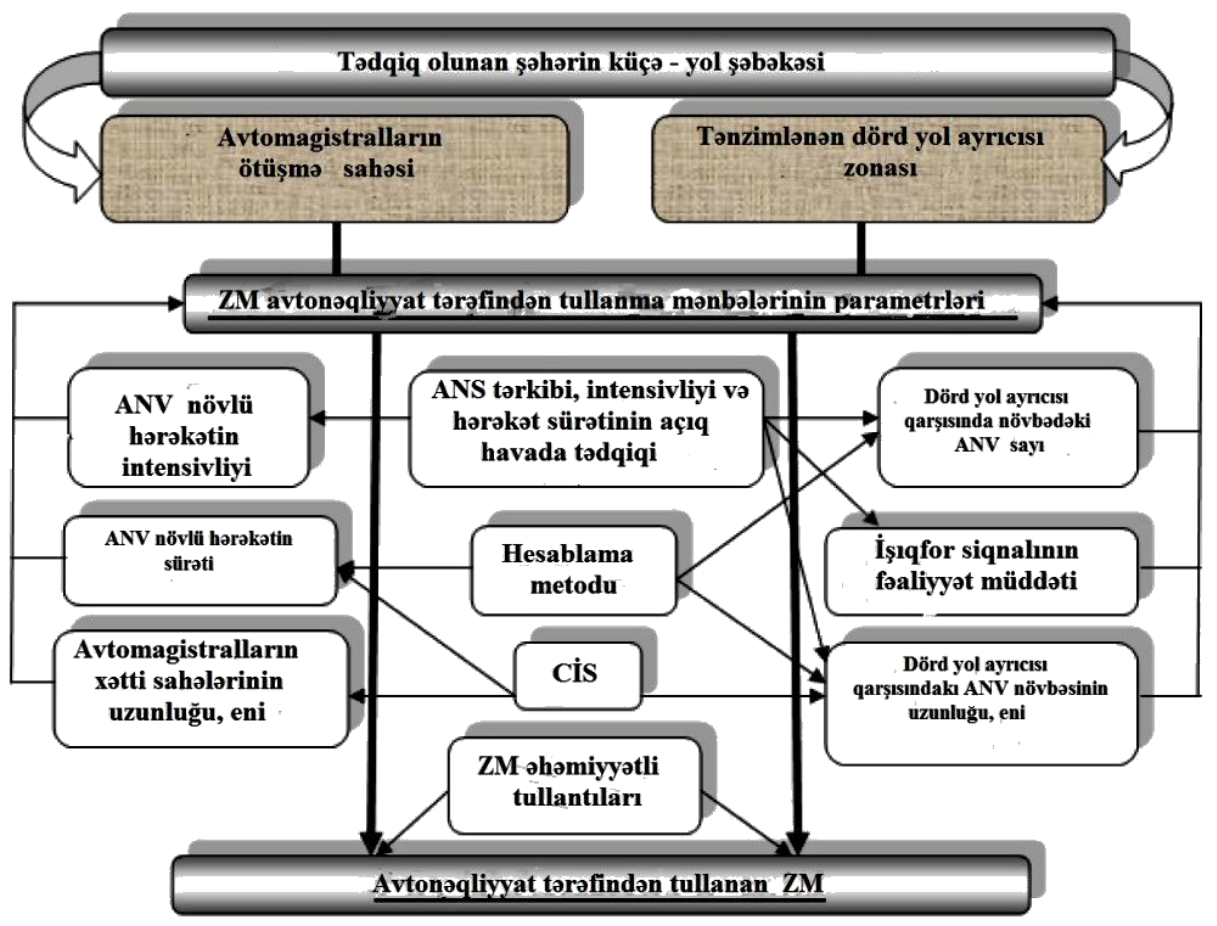

Block diagram for calculation of the maximal indicatros of transport emissions using GIS.

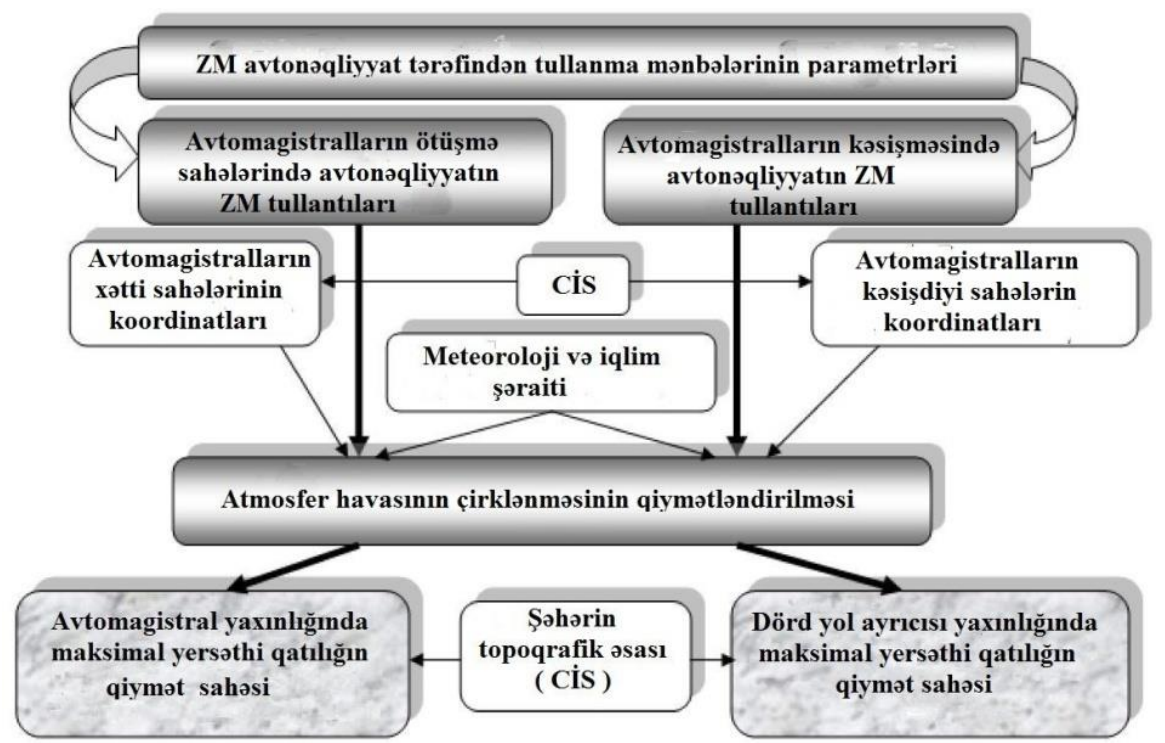

Air pollution assessment scheme on the highways and at the crossroads using GIS. 
As calculations represent, when the traffic speed is reduced at the highway crossroads, $\mathrm{CO}$ emissions increase, while $\mathrm{NO}_{2}$ emissions decrease.

When the traffic intensity increases, the maximum surface concentrations also increase. When the traffic speed is reduced from $60 \mathrm{~km} / \mathrm{h}$ to $5 \mathrm{~km} / \mathrm{h}$, the density of carbon dioxide in the linear areas of highways increases 1,5-8 times, while the density of nitrogen oxide decreases 1,1-1,6 times.

When the queue length increases (from $30 \mathrm{~m}$ to $250 \mathrm{~m}$ ) at the regulated crossroads, the level of air pollution with carbon dioxide increases 5,0-6,5 times on average and thus, exceed 1 ADL (the allowable density limit).

The method of prediction of air pollution in the big cities.

One of the methods used in environmental studies in urban areas is monitoring, which is one of the most important scientific issues of the economy and environment. The main objective of monitoring the megacities is to achieve environmental assessment, control and forecasting in an area where millions of people live and hundreds of industries operate [16].

In the large cities, the followings are the factors that are considered environmentally sound:

1. Optimal location of large industrial enterprises, thermal power plants (TPP), high-density transport arteries and concentration of pollution sources in a particular area.

2. The direction of winds that play a key role in the transport of pollutants, that is, the relative preference.

The expected concentration of pollutants at specific points should be calculated, taking into account the location and production capacity of enterprises in the city in order to establish environmental monitoring of atmospheric air when implementing application issues.

Based on the calculations, it is possible to draw up a thematic environmental map on the urban area plan that reflects the expected concentration of pollutants. The map should be designed in such a way that it can be continuously corrected and can provide additional information.

Recent measurements show that $\mathrm{NO}, \mathrm{CH}_{4}, \mathrm{CO}_{2}$ emissions can be recorded at a distance of 1$1.5 \mathrm{~km}$, while the concentration of gases at a temperature of $30^{\circ} \mathrm{C}$ is $10 \mathrm{ppm}$. Currently, a number of foreign firms (Bruner, Vicolet) produce Furye spectrometers that work on various applications.It allows quantitative and qualitative estimation of a number of gas mixtures by means of devices, and also allows determining the temperature of gas mixtures.

It has been established that the temperature in the water spectrum corresponds to the temperature determined by the carbon dioxide (CO) spectrum. The accuracy of setting the temperature varies depending on the source temperature. When the source temperature is $1000^{\circ} \mathrm{K}$, the measurement accuracy is not less than $20^{\circ} \mathrm{K}$. To determine the atmospheric concentration of $\mathrm{CO}, \mathrm{NO}_{2}, \mathrm{CH}_{4}$ gases, a special noise reduction program is applied at the system entrance. The minimum concentration of gases varies for different gases: For example, $0.07 \mathrm{ppm}$ for CO; $0.5 \mathrm{ppm}$ for $\mathrm{NO} ; 0.1 \mathrm{ppm}$ for $\mathrm{CH}_{4}[14,16]$.

\section{Ecogeographic prediction of air pollution using non-linear regression method}

Development of methods for forecasting air pollution is one of the key issues that arise in the context of air protection problems. Predictions and warnings of high air pollution are considered as the basis for the regulation of wastes during the meteorological conditions and for mitigation measures.

Regression analysis examines the relationship between one dependent variable and several independent variables. This relationship is expressed by the mathematical model, that is, the equation that connects the dependent variable to the independent variables. In the context of regression analysis, this model is expressed as follows:

The effectiveness of the developed prediction scheme (used to establish regression equations) and independent (not involved in the regression equation) is monitored. 
The work done is aimed at improving the quality of pollution assessment using a new forecast method.The model can be proposed for operational use in industrial cities, as well as for warning of the dangerous level of air pollution.
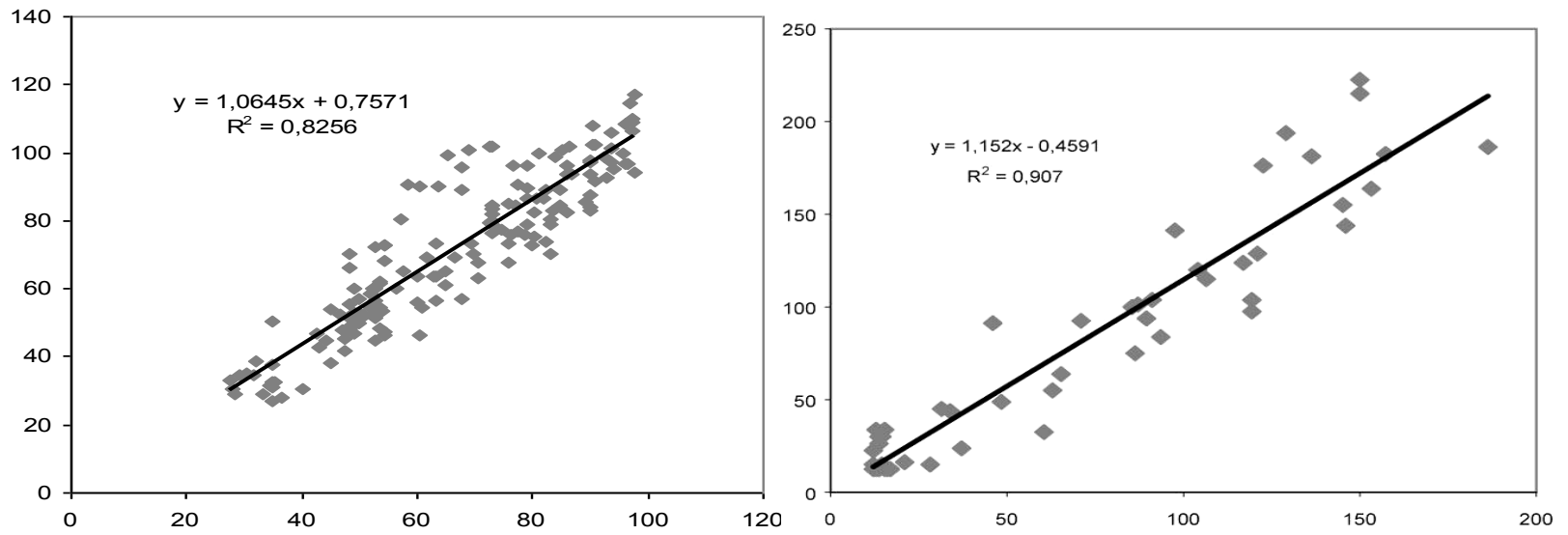

Figure 8. Correlation graph of the maximum daily nitrogen oxide measured and predicted daily concentrations (in Baku city).
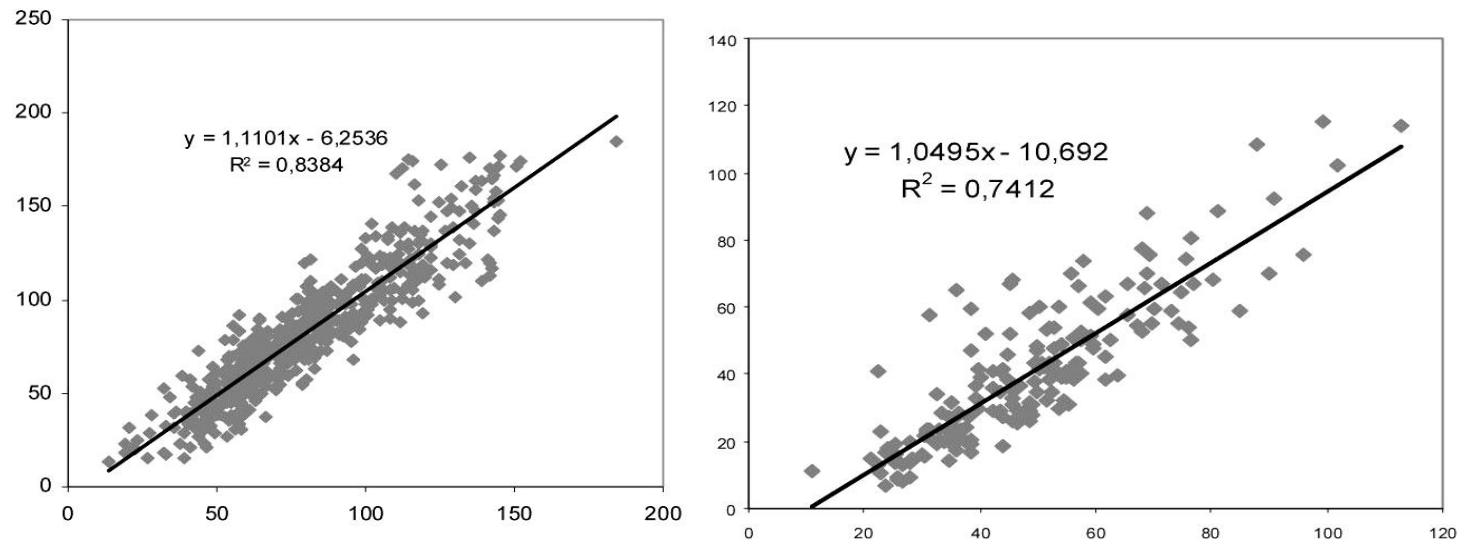

Figure 9. Correlation graph of the maximum daily nitrogen oxide measured and predicted daily concentrations (in Sumgait city)

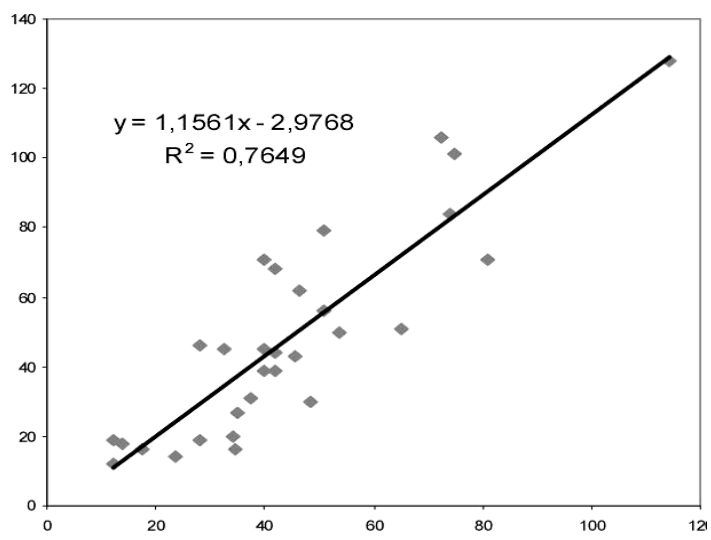

Figure 10. Correlation graph of the maximum daily nitrogen oxide measured and predicted daily concentrations (in Minghachevir city)

The main goal of implemented study is to improve the quality of air pollution assessment using a new prognosis method. The model can be offered for operational use in the industrial city, as well as for warning of the dangerous level of air pollution. 


\section{Mathematical model of prognosis of air pollution in industrial cities}

As a key criterion for assessing atmospheric air pollution, the permissible mix of the hazardous mixture is taken into account Concentration allowable limit (CAC). The total mass of the mixture is used as a key indicator of air pollution risk.However, this is true for dust and aerosols, as for gases.

From the foregoing it can be said that the wind is the one that most influences the speed of dissolution in the air, or rather its velocity. So, when there are $V \leq 3-5 \mathrm{~m} / \mathrm{san}$ persistent events in the atmosphere, there are unfavorable conditions for scattering of impurities.Subsequently, precipitation has the necessary effect on the change in the concentration of atmospheric pollutants.For example: mixtures that are soluble in fog are almost completely absorbed by water droplets. The formation of acids occurs. Thus, sulfur dioxide is converted to sulfuric acid under mist.At the same time, when $\succ 0,05 \mathrm{~mm}$ the amount of rainfall is around the clock, pollutants are washed away, which leads to their purification. In addition, it has been established that the presence of pollutants in the atmosphere changes $T \succ 0$ and $T \prec 0$ attaches itself.

\section{Determination of complex indicators and levels of air pollution in unfavorable meteorological conditions}

Many researchs address complex indicators of atmospheric pollution. Such indicators are used to determine the relationship between the pollution of the population with atmospheric pollution, the determination of comprehensive standards for atmospheric cleanliness, the prioritization of settlements and so on. The study addresses complex indicators for the short-term regulation of industrial waste emissions [23, 28-31].

Three working modes are proposed in unfavorable weather conditions (UWC). Under the first production regime, emissions are reduced through organizational measures.In the second production mode, the capacity of auxiliary production is reduced.At the end, they move to the third production mode, reducing the main production.

There are many approaches to the determination of atmospheric pollution levels [32-34]. Here are two problems: what pollution will be determined by atmospheric pollution and how many levels and levels of pollution should be determined. For example, in the USA [33] there are four levels of high atmospheric pollution: reserve, excitement, danger, and extreme danger.

Atmospheric contamination is characterized by pollutants contained in it. The greater the content of the contaminant, the stronger the pollution. So, because there are different substances in the atmosphere, the same value of their presence does not mean that they are the same. As we know, the harm of a substance is characterized by its CAC.To compare risk or collect different pollutants, it is necessary to look at their ratio to CAC.Based on this, the following sequence of atmospheric pollution assessment is proposed, taking into account the disadvantages and weaknesses of the methods discussed above.

Initial data for the determination of atmospheric pollution are taken into consideration at the $p$ -point of the $I$ - ingredient at the p-point, which is done three times a day, for example at $7^{00}, 13^{00}$, $19^{00}$. In cities, it can be measured from the $N$ station. The normalized ratio of each ingredient is as following:

$$
C_{p l}=q_{p l} / Y V Q H_{l}
$$

here $q_{p l}$ — the intensity measured at any moment of observation; $Y V Q H_{l}$ — one-time maximum YVQH. 
We can record the average value of the normalized $l$ - component for all points:

$$
C_{l}=\frac{1}{N_{l}} \sum_{n=1}^{N_{l}} C_{p l_{i}}
$$

Here $N_{l^{-}} \mathrm{i}$ - is the number of stations with measured concentrations of the ingredient.

When estimating the level of contamination, it should be noted that during the average atmospheric pollution, $C_{p}, C^{p}, S$ will be equal to one unit. Then, high atmospheric pollution will characterize the change in these indicators from one unit to the maximum.

According to the research, the most harmful ingredient for Baku city is soot and dust, formaldehyde for the Ganja city, and dust, soot and hydrogen sulfide for Sumgait city.

\section{Results and recommendations}

1. Generally, the concept of air pollution reflects the certain events and processes which lead to the worsening of the actual and natural quality of atmospehre.In a narrow sense, according to the agreed conception of the Comecon states, the air pollution is defined as emission of pollutants into the air in the solid, liquid and gas form.

The protection of atmosphere can not be succsessful only by the one sided or half implemented activities that directed to the specific pollution source. In this regard, the better results can be achieved only by objective and multifaceted approach to the identification of each pollution source and mitigation of their impacts.

2. Even though many studies have been conducted up to now, generally accepted model of dispersion of pollutant compounds in the air is not existing yet. The difficulty and difference of these processes linked with the subjective aspects. For $10 \mathrm{~km}$ distance $10 \mathrm{~km}$ Pasquill-Gifford model is used and this is working model of International Atomic Energy Agency.Among other models used for identification of air pollutants' dispersion the model perpared by the Experimental Meteorological Institue can be mentioned. This model is used for $100 \mathrm{~km}$ distance. The scientific foundation of model and its comparison with Pasquill-Gifford model is given.

3. Air temprature, wind direction and speed and also average monthly and annual indicators for the carbon monoxide in the atmosphere of Bakus city based on the data gathered in recent years (1990-2012) observations was calculated.As curves indicating the dynamics of change of average monthly density of the carbon monoxid in the air of Baku city for last five years depending on the temprature and wind speed, it is seen that even though the air temprature was higher in August, the concentration of carbon dioxide was higher in June and July when the wind speed is relatively lower.In general, it was found that there is high correlation between courses of curves (correlation coefficients change from 0,73 to 0,88 ).

4. Studies indicate that since the chemical composition of rains changes over the seasons the density of compounds calculated based on average annual indicator fo the current year. According to the results of the observations and stduies the average annual composition of rain in Baku city is as following: $19,5 \%$ sulphate, $9,5 \%$ nitrate, $1,0 \%$ ammonium, 11,0\% chloride, 20,5 hydrocarbon, $0,02 \%$ phosphate, $8,73 \%$ calciumand 3,75\% magnesium ions. More than half of the identified air pollutants are transport emissions. Specifically, higher intensity of traffic in Baku considerably differs it from other cities of Republic in terms of share of toxic substances in the rain.

5. Studies found that the main reason of higher concentration of harmfull ingredients of anthropogenic origin such as carbon monoxide, nitrogen compounds in the air of cities of Republic during the warmer periods of the year is motor vehicles' emissions. The share of motor vehicles in the overall ingredients of the air pollutants in industrial cities of Azerbaijan is between $65-70 \%$.

First time in Azerbaijan we observed that, except Sumgait city there were differences in the quantities of traffic emissions into the air of big industrial cities in seperate years. The quantity of 
such pollutants in Baku in 2000 was 229,9 thousand tons but, in 2007 it was 410,7 thousand tons, in Ganja city it was respectively 20,8 and 37,2 thousand tons and in Sumgait city it was 14,3 and 8,2 thousand tons.

6. Babies who are most susceptible to air pollution are almost an indicator of the quality of the environment and human health. The statistical indicators clearly confirm this fact. Infant mortality was 4193 in 1990 and 1508 in 2006. The infant mortality decreased 2906 between 1990-2004. Unfortunately, this type of infant mortality numbers is again at the risk of increase.

First time in Azerbaijan the study was conducted and the infant mortality indicators among the cities of Republic were identified as following: Baku city - 769 in 1990, 511 in 2006, Sumgait city - 127 in 1990, 83 in 2006, Ganja city - 61 in 1990, 38 in 2006, Shaki city - 81 in 1990, 47 in 2006, Lankaran city - 70 in 1990, 22 in 2000, Shirvan - 35 in 1990, 7 in 2006, Mingachevircity - 44 in 1990, 9 in 2006, Nakhchevan city — 18 in 1990, 6 in 2006.

7. As a result of studies we found that existence of harmfull pollutants in the air increases the diseases of population 30-40\%.Moreover, the correlation analysis between air pollution index and malignant tumor diseases have been carried out and the correlation percentage of $36-38 \%$ was found.

8. It was found that, in some cities of Republic (Baku, Ganja, Mingachevir, Sumgait) the correlation coefficient between air pollution index and respiratory diseases is low. It should be mentioned that, when air pollution index increases or decreases then its indicator changes also in the density of sulfur dioxide. İt is found that when air pollution index changes, the number of respiratory diseases are increases. For example, the change in the air pollution index just for two units, corresponds to the $100 \mathrm{mkq} / \mathrm{m}^{3}$ change in the density of sulfur dioxide. Such an increase in air pollution causes $12 \%$ increase in overall disease numbers. This is closer to the indicators of other researchers.

9. First time in Azerbaijan with the aid of multi-zone satellite images the clouds of smoke were observed over the Sumgait city area, to the south from it and west of Absheron peninsula and it was identified that the main mass of the air pollutants concentrated up to the $60 \mathrm{~m}$ height. Furthermore smog was recorded over the Baku city based on the analysis of satellite images and according to the tone of the images the smog was lighter than the one observed over Sumgait indsutrial area. The comparison of imgae of smoke clouds and the dispersion areas of the density of $\mathrm{SO}_{2}$ gas indicates that the density of $\mathrm{SO}_{2}$ in Baku area has smaller indicator (up to 2 allowable density limit) than in the industrial areas of Sumgait under the strong/dangerous wind condition $\left(U_{m}\right.$ $=1,7 \mathrm{~m} / \mathrm{sec}$ ).

10. The remote optical method is more efficient method of studying the area of atmosphericaerosol. This method creates the opportunity to get operative, precise and reliable information about the dispersion areas of brightness of the background aerosol in the atmosphere. In this regard, the method of study of the angular structure of the birghtness of the aerosol pollutin in the atmosphere over the Baku city was consdiered.

11. It was found that when the traffic speed is reduced at the highway crossroads, $\mathrm{CO}$ emissions increase, while $\mathrm{NO}_{2}$ emissions decrease. When the traffic intensity increases, the maximum surface concentrations also increase. When the traffic speed is reduced from $60 \mathrm{~km} / \mathrm{h}$ to 5 $\mathrm{km} / \mathrm{h}$, the density of carbon dioxide in the linear areas of highways increases 1,5-8 times, while the density of nitrogen oxide decreases 1,1-1,6 times. When the queue length increases (from $30 \mathrm{~m}$ to $250 \mathrm{~m}$ ) at the regulated crossroads, the level of air pollution with carbon dioxide increases 5,0-6,5 times on average and thus, exceed 1 ADL (the allowable density limit).

12. According to the analysis which were carried out first time in Azerbaijan, the highest level of air pollution with the basic and specific compounds in the Republic are observed in Sumgait, 
Baku and Shirvan cities. The highest average anuual density of air pollutant ingredients was observed in Sumgait city and the concentration of chlorine was 2.7 times; hydrogen fluoride 2.0 times; nitrogen 4-oxide 2.2 times above the allowable density lmit.

13. The observations of air pollution in Baku city are carried out at 9 observation stations located at the Sabail, Nizami, Narimanov, Binagadi, Khatai, Yasamal and Sabunchu districts of the city and observations covered dust, sulfur dioxide, dissolved sulfates, carbon dioxide, nitrogen 4oxide, nitrogen 2-oxide, hydrogen sulfide, smokeblack, solid fluorides, hydrogen fluoride, chlorine, ammonia, sulfuric acid, formaldehyde, furfurol concentrations in the air.

14. The meterological capacity of atmosphere was determined by us on the sample of Ganja city first time in Azerbaijan. Annauly, there are 90.74 days with the wind speed of $0-1 \mathrm{~m} / \mathrm{sec}$. in Ganja. The repetition of the such winds occur between September and December (8.15-9.89 days). During other months such windy days cosntitue 6.06-7.44 days. The average annual recurrence of days with the wind speed of $6 \mathrm{~m} / \mathrm{sec}$. is 9.77 . these days are observed in III, IV, VII and VIII months (5.21-5.55 ). It varies between 2.07-3.04 in October, November, December and January.

15. The correlation graph reflecting the difference between actual and prognosed density of pollutants was used in order to ensure efficency of prepared prgonosis/prediction schematic and first time in Azerbaijan the efficiency of the prognosis/prediction schematic for several cities of Republic was provided.Main purpose of utilising the prognosis method was to increase the quality of air pollution asssessment level. The end result model might be proposed for operative use in industrial cities for the warning of dangerous level of air pollution in them.

\section{References:}

1. Eminov, F. A. (2005). Vliyanie neftyanoi promyshlennosti na okruzhayushchuyu sredu i neftyanye dokhody. Baku. 128. (in Azerbaijani)

2. Konstruktivnaya geografiya Azerbaidzhanskoi Respubliki (1996). Geograficheskaya nauka za 50 let. Baku. 265. (in Azerbaijani)

3. Aliev, G. A. (2001). Transport i ekonomika Azerbaidzhana. Baku. 244. (in Azerbaijani)

4. Gezalov, A. A. (1999). Metody prognozirovaniya v sotsial'nykh i glabal'nykh ekologicheskikh sistemakh. Baku. 113. (in Azerbaijani)

5. Gasanov, T. G. (2007). Uroven' razvitie infrastrukturnykh otraslei Azerbaidzhana i analiz territorial'noi organizatsii. Baku. 44. (in Azerbaijani)

6. Kazymly, X. G., Panaliev, A. V., \& Kazimova, A. Kh. (2009). Otsenka transportnykh sredstv. Baku. 129-133. (in Azerbaijani)

7. Mekhtiev, A. Sh. (1998). Aerokosmicheskie issledovaniya v Azerbaidzhane. Azerbaidzhan v preddverii XXI veka. Baku. 343-346. (in Azerbaijani)

8. Mamedova, Sh. I. (2011). Otsenka roli fizicheskikh i ekonomicheskikh faktorov v razvitii gorodov Azerbaidzhana. In Optimizatsiya, ratsional'naya organizatsiya sovremennye problemy ustoichivogo razvitiya landshaftov v Azerbaidzhane, 16. 331-333. (in Azerbaijani)

9. Mamedova, Sh. I. (2013). Ekologo geograficheskii analiz sostoyaniya zagryazneniya atmosfery v gorodakh Azerbaidzhana. Otsenka potentsial'nykh resursov geosistem i ratsional'noe ikh ispol'zovanie v usloviyakh global'nykh izmenenii. Trudy GOA, 18. 406-415. (in Azerbaijani)

10. Businger, Dzh. A., Tennekes, Kh., \& Vingaard, Dzh. K. (1985). Atmosfernaya turbulentnost' i modelirovanie rasprostraneniya primesei. Gidrometeoizdat. 351. (in Russian).

11. Geokchaily, Sh. Ya. (2009). Mesto i problemy geografii i geograficheskoi ekologii v sisteme nauk. In Materialy mezhdunarodnoi nauchnoi konferentsii posv. 90-letiyu BGU, seriya prirodovedeniya, Baku. 529-531. (in Azerbaijani)

12. Geokchaily, Sh. Ya. (2010). Osnovy geograficheskoi ekologii. Baku. 400. (in Azerbaijani) 
13. Gasanov, A. M., \& Azizov, B. M. (2005). Monitoring okruzhayushchei sredy. Baku. 233. (in Azerbaijani)

14. Mamedova, Sh. I. (2014). Sovremennoe sostoyanie Bakinskoi gorodskoi aglomeratsii i transporta. Vesti $B G U, 141-152$. (in Azerbaijani)

15. Pashaev, A. M., Guliev, G., \& Safarov, S. G. (2007). Fizicheskie osnovy atmosfernykh protsessov. Baku. 415. (in Azerbaijani)

16. Efendiev, V. A., \& Nagiev, S. G. (2005). Geografiya naseleniya. Baku. 380. (in Azerbaijani)

17. Abduddaev, R. B., \& Mamedova, Sh. I. (1998). Sostoyanie okruzhayushchei sredy na Absheronskom poluostrove i ikh estestvenno-geograficheskie aspekty. In Materialy VII s"ezda GOA. Baku. (in Azerbaijani)

18. Abduddaev, R. B., \& Mamedova, Sh. I. (2000). Ekologicheskaya otsenka antropogennogo vozdeistviya na atmosferu. Obshchestvennoe obrazovaniya AR, (1). 107-110. (in Azerbaijani)

19. Grigor'ev, A. A., \& Lipatov, B. B. (1978). Dymovoe zagryaznenie atmosfery po nablyudeniyam iz kosmosa. Leningrad, Gidrometeoizdat. 34. (in Russian).

20. Efendiev, V. A., \& Mamedova, Sh. I. (2013). Matempticheskie modeli prognozirovaniya atmosfernogo zagryazneniya $\mathrm{v}$ promyshlennykh gorodakh Azerbaidzhana. Trudy IPA Pochvovedenie i Agrokhimiya, 21(1). 144-153. (in Azerbaijani)

21. Mamedova, Sh. I. (2009). Issledovanie zagryazneniya atmosfery $\mathrm{v}$ gorodakh Azerbaidzhana. Trudy IPA Pochvovedenie i Agrokhimiya, 14. 462-466. (in Azerbaijani)

22. Mamedov, Z. S. (2002). Transportnyi faktor ekonomicheskogo razvitiya XXI veka. Baku. 432. (in Azerbaijani)

23. Afifi, A., \& Eizen, S. (1982). Statisticheskii analiz: Podkhod s ispol'zovaniem EVM. Moscow, Mir. 488. (in Russian).

24. Keller, A. A., \& Kuvakin, V. I. (1999). Meditsinskaya ekologiya. St. Petersburg. 255. (in Russian).

25. Sotsial'no-ekonomicheskoe razvitie regionov Azerbaidzhanskoi Respubliki v 2009-2013 gg. In Itogi ispolneniya gosudarstvennoi programmy (in Azerbaijani)

26. Vel'chishcheva, N. F. (1973). Ispol'zovanie dannykh o mezomasshtabnykhosobennostyakh oblachnosti v analize pogody. Leningrad, Gidrometeoizdat. 150. (in Russian).

27. Abdullaev, R. B., \& Mamedova, Sh. I. (1998). Problemy ekologii Baku v period perekhoda k rynochnoi ekonomiki. Baku. (in Azerbaijani)

28. Mamedova, Sh. I. (2014). Bakinskaya gorodskaya aglomeratsiya i sovremennoe sostoyanie transporta. Vesti BGU, 142-152. (in Azerbaijani)

29. Gabdullin, V. M., \& Semakina, A. V. (2010). Modelirovanie zagryazneniya atmosfery nad territoriei Privolzhskogo federal'nogo okruga. Vestnik Udmurtskogo universiteta. Seriya Biologiya. Nauki o Zemle, (2). (in Russian).

30. Gasanov, A. A. (2003). Problemy ekologii gorodov Azerbaidzhana. Baku: Elm. 339.

31. Metodicheskie ukazaniya po prognozu zagryazneniya vozdukha (1979). Leningrad, Gidrometeoizdat. 145. (in Russian).

32. Kushelev, V. P. (1979). Okhrana prirody ot zagryaznenii promyshlennymi vybrosami. Moscow, Khimiya. 240. (in Russian).

33. Gorchiev, A. A., \& Rafiev, R. M. (1979). Issledovanie polei kontsentratsii vrednykh primesei metodom razlozheniya po estestvennym ortogonal'nym funktsiyam. Izvestiya ANAzSSSR, (3). 101-109. (in Russian). 
34. Mamedova, Sh. I. (2002). Ekologicheskie svoistva atmosfery srednikh i krupnykh gorodov Azerbaidzhana. In Materialy konferentsii instuta.geografii, posv. 95-letiyu akad. G. A. Alieva, Baku. 146-148. (in Azerbaijani)

35. Mamedova, Sh. I. (2013). Ispol'zovanie ne lineinoi regressii v zagryaznenii atmosfery krupnykh gorodov Azerbaidzhana. Izvestiya BGU, (1). 159-166. (in Azerbaijani)

36. Mamedova, Sh. I. (2014). Proekty regulirovaniya infrastruktury transporta Bakinskoi gorodskoi aglomeratsii. In Aktual'nye problemy nauk ekologii i pochvovedeniya $v$ XXI veke: Materialy Respublikanskoi konferentsii. Baku. 285-287. (in Azerbaijani)

37. Bell, R. Dzh. (1975). Vvedenie v fur'e-spektroskopiyu. Moscow. Mir, 382. (in Russian).

38. Ismailov, T. A. (2007). Ekologicheskie problemy Azerbaidzhana. Baku. 205. (in Russian).

39. Rafiev, R. M. (1981). Fiziko-statisticheskii analiz i prognoz stepeni zagryazneniya vozdushnogo basseina krupnykh promyshlennykh gorodov Azerbaidzhana: dis. ... kand. fiz.-mat. nauk. Baku. 167. (in Russian).

\section{Список литературы:}

1. Эминов Ф. А. Влияние нефтяной промышленности на окружающую среду и нефтяные доходы. Баку. 2005. 128 с.

2. Конструктивная география Азербайджанской Республики. Географическая наука за 50 лет. Баку. 1996. 265 с.

3. Алиев Г. А. Транспорт и экономика Азербайджана. Баку. 2001. 244 с.

4. Гезалов А. А. Методы прогнозирования в социальных и глабальных экологических системах. Баку. 1999. 113 с.

5. Гасанов Т. Г. Уровень развитие инфраструктурных отраслей Азербайджана и анализ территориальной организации. Баку. 2007. 44 с.

6. Казымлы Х. Г., Паналиев А. В., Казимова А. Х. Оценка транспортных средств. Баку. 2009. C. 129-133.

7. Мехтиев А. Ш. Аэрокосмические исследования в Азербайджане // Азербайджан в преддверии XXI века. Баку. 1998. С. 343-346.

8. Мамедова Ш. И. Оценка роли физических и экономических факторов в развитии городов Азербайджана // Оптимизация, рациональная организация современные проблемы устойчивого развития ландшафтов в Азербайджане. 2011. T. XVI. С. 331-333.

9. Мамедова Ш. И. Эколого географический анализ состояния загрязнения атмосферы в городах Азербайджана. Оценка потенциальных ресурсов геосистем и рациональное их использование в условиях глобальных изменений // Труды ГОА. 2013. T. XVIII. C. 406-415.

10. Бусингер Дж. А., Теннекес Х., Вингаард Дж. К. и др. Атмосферная турбулентность и моделирование распространения примесей. Л. Гидрометеоиздат 1985. $351 \mathrm{c.}$

11. Геокчайлы Ш. Я. Место и проблемы географии и географической экологии в системе наук // Материалы международной научной конференции посв. 90-летию БГУ, серия природоведения. Баку. 2009. С. 529-531.

12. Геокчайлы Ш. Я. Основы географической экологии. Баку. 2010. 400 с.

13. Гасанов А. М., Азизов Б. М. Мониторинг окружающей среды. Баку. 2005. 233 с.

14. Мамедова Ш. И. Современное состояние Бакинской городской агломерации и транспорта // Вести БГУ. 2014. С. 141-152.

15. Пашаев А. М., Гулиев Г., Сафаров С. Г. Физические основы атмосферных процессов. Баку. 2007. 415 с.

16. Эфендиев В. А., Нагиев С. Г. География населения. Баку. 2005. 380 с. 
17. Абдуддаев Р. Б., Мамедова Ш. И. Состояние окружающей среды на Абшеронском полуострове и их естественно-географические аспекты // Материалы VII съезда ГОА. Баку. 1998.

18. Абдуддаев Р. Б., Мамедова Ш. И. Экологическая оценка антропогенного воздействия на атмосферу // Общественное образования АР. 2000. №1. С. 107-110.

19. Григорьев А. А., Липатов Б. Б. Дымовое загрязнение атмосферы по наблюдениям из космоса. Л.: Гидрометеоиздат. 1978. 34 с.

20. Эфендиев В. А., Мамедова Ш. И. Матемптические модели прогнозирования атмосферного загрязнения в промышленных городах Азербайджана // Труды ИПА Почвоведение и Агрохимия. 2013. Т. 21. №1. С. 144-153.

21. Мамедова Ш. И. Исследование загрязнения атмосферы в городах Азербайджана // Труды ИПА Почвоведение и Агрохимия. 2009. Т. XIV. C. 462-466.

22. Мамедов 3. С. Транспортный фактор экономического развития XXI века. Баку. 2002. $432 \mathrm{c}$.

23. Афифи А., Эйзен С. Статистический анализ: Подход с использованием ЭВМ. М.: Мир. 1982, 488 с.

24. Келлер А. А., Кувакин В. И. Медицинская экология. СПб. 1999. 255 с.

25. Социально-экономическое развитие регионов Азербайджанской Республики в 20092013 гг. // Итоги исполнения государственной программы.

26. Вельчищева Н. Ф. Использование данных о мезо-масштабныхособенностях облачности в анализе погоды. Л.: Гидрометеоиздат. 1973. 150 с.

27. Абдуллаев Р. Б., Мамедова Ш. И. Проблемы экологии Баку в период перехода к рыночной экономики. Баку. 1998.

28. Мамедова Ш. И. Бакинская городская агломерация и современное состояние транспорта // Вести БГУ. 2014. С. 142-152.

29. Габдуллин В. М., Семакина А. В. Моделирование загрязнения атмосферы над территорией Приволжского федерального округа // Вестник Удмуртского университета. Серия «Биология. Науки о Земле». 2010. №2.

30. Гасанов А. А. Проблемы экологии городов Азербайджана. Баку: Элм. 2003. 339 с.

31. Методические указания по прогнозу загрязнения воздуха. Л.: Гидрометеоиздат. 1979. $145 \mathrm{c}$.

32. Кушелев В. П. Охрана природы от загрязнений промышленными выбросами. М.: Химия. 1979. 240 с.

33. Горчиев А. А., Рафиев Р. М. Исследование полей концентрации вредных примесей методом разложения по естественным ортогональным функциям // Известия АНАзСССР. 1979. №3. С. 101-109.

34. Мамедова Ш. И. Экологические свойства атмосферы средних и крупных городов Азербайджана // Материалы конференции инстута.географии, посв. 95-летию акад. Г. А. Алиева. Баку. 2002. С. 146-148.

35. Мамедова Ш. И. Использование не линейной регрессии в загрязнении атмосферы крупных городов Азербайджана // Известия БГУ. 2013. №1. С. 159-166.

36. Мамедова Ш. И. Проекты регулирования инфраструктуры транспорта Бакинской городской агломерации // Актуальные проблемы наук экологии и почвоведения в XXI веке: Материалы Республиканской конференции. Баку. 2014. С. 285-287.

37. Белл Р. Дж. Введение в фурье-спектроскопию. М.: Мир. 1975. 382 с. 
38. Исмаилов Т. А. Экологические проблемы Азербайджана. Баку. 2007. 205 с.

39. Рафиев Р. М. Физико-статистический анализ и прогноз степени загрязнения воздушного бассейна крупных промышленных городов Азербайджана: дис. ... канд. физ.-мат. наук. Баку. 1981. 167 с.

Работа поступила

Принята к публикациии

в редакцию 14.01.2020 2.

19.01.2020 2.

Ссылка для ичитирования:

Mammadova Sh. Ecogeographical Problems of Air Pollution in the Big Cities of Azerbaijan // Бюллетень науки и практики. 2020. Т. 6. №2. С. 20-41. https://doi.org/10.33619/2414$2948 / 51 / 02$

Cite as (APA):

Mammadova, Sh. (2020). Ecogeographical Problems of Air Pollution in the Big Cities of Azerbaijan. Bulletin of Science and Practice, 6(2), 20-41. https://doi.org/10.33619/2414-2948/51/02 


\section{РОЛЬ ЭКОЛОГИЧЕСКИХ ФАКТОРОВ В ФОРМИРОВАНИИ СТРУКТУР ПОЧВЕННОГО ПОКРОВА БАССЕЙНА Р. ЗЕЯМ}

СМамедова М. В., Азербайджанский университет архитектуры и строительства Баку, Азербайджан,

\section{THE ROLE OF ENVIRONMENTAL FACTORS IN THE FORMATION OF SOIL COVER STRUCTURE OF THE ZEYAMCHAY BASIN}

\section{(CMammadova M., Architecture and Construction University of Azerbaijan, Baku, Azerbaijan}

Аннотация. Бассейн реки Зеям выделяется разнообразием комплексного строения рельефа, климатических условий, биоразнообразием, разновидностями почвенных типов и почвообразующих пород. Разнообразие почвообразовательных факторов в рамках бассейна способствовало образованию различных форм структуры почвенного покрова. Поэтому изучение структуры почвенного покрова, его детальное картирование, оценка и оптимизация путей использования приобретает особую научно-теоретическую и практическую значимость. Объектом исследования является бассейн р. Зеям, расположенный на северозападном склоне Малого Кавказа, общей площадью 94200 га, охватывающей Товузский, Шамкирский и Гедабекский административные районы. За время исследований использованы эмпирические картографические, аэропространственные, ландшафтные и геоморфологические методы.

Abstract. The Zayamchay basin is selected by its complex structure, various climatic conditions, rich vegetation and soil-rich rocks. This variation of soil-forming factors has led to the formation of various forms of soil cover structure within the basin. Therefore, the study of land and its space manifestation - the soil cover structure, detail mapping, evaluation and optimization both scientifically-theoretical and practical. The Zeyamchay basin, which is located on the northwestern slope of the Lesser Caucasus, is the object of the research. The Zeyamchay basin is selected by its complex relief structure, various climatic conditions, rich vegetation and soil-rich rocks. The area of the basin is 94200 hectares. The basin covers part of Tovuz, Shamkir and Gadabay districts from the administrative point of view. These kind of soil-forming factors have led to the formation of different forms of soil cover structure within the basin. During the research, empirical information is collected from cartographic, soil research, aerospace, landscape and geomorphological methods and so on was used.

Ключевые слова: бассейн р. Зеям, тип почвы, структура почвенного покрова.

Keywords: Zayamchay basin, soil type, soil cover structures.

\section{Введение}

Изучение в 70-80 гг закономерностей расположения почвенных контуров в пространстве послужило созданию учения о структуре почвенного покрова (СПП). В Азербайджане этому направлению всегда уделялось внимание и в результате были 
исследованы СПП различных регионов. При составлении карт структуры почвенного покрова использовались карты пластики рельефа [1-5].

В конце 90-х годов исследователи помимо изучения СПП, уделяли внимание агроэкологической оценки почв.

Бассейн р. Зеям выделяется своим сложным рельефом, разнообразием климатических условий, растительным миром и почвообразующими породами.

Разнообразие почвообразовательных факторов привело к формрованию различных форм СПП в рамках бассейна. Изучение СПП, его детальное картирование, оценка и оптимизация путей использования преобретает особую научно-теоретическую и практическую значимость.

\section{Объект и методика исследований}

Объектом исследования выделены формы СПП, сформированные под влиянием географических (экологических) факторов в черте бассейна p. Зеям. По получении эмпирических информаций были использованы картографические, почвенные аэрокосмические, ландшафтные и геоморфологические методы.

При оппределении форм и оценки воспользовались методикой И. Н. Степанова [6] и Г. Ш. Мамедова [7].

\section{Анализ и результаты}

На первых этапах классического почвоведения и составления почвенных карт, понятие о «структуре почвенного покрова» просто не было. При этом специалистам данной области было хорошо известно, что, как и другие системы, почвенный покров также по своей внутренней структуре и пространственным формам достаточно сложна. Именно поэтому при составлении почвенных карт отражение структуры почвенного покрова, считается неотложным вопросом требующего решения данного научно-теоретического вопроса. Учение о структуре почвенного покрова является одной из фундаментальных направлений почвоведения. Но при этом хотелось бы отметить, что изучение СПП сохранила свою актуальность локально в понятии территории.

На современном этапе организация рационального использования земельными ресурсами, требует научно-обоснованного требования внедрения в жизнь правильного планирования, агротехнических, мелиоративных и агротехнических мероприятий, которое требует учет созданных форм СПП в пространстве. Изучение СПП и созданые в географическом пространстве его форм пребретает особую актуальность.

СПП как формы почвенного покрова, формируются под непосредственным влиянием ряда экологических факторов.

\section{Роль географического расположения, геологического строения и геоморфологических факторов в формировании СПП}

В научных разработках прфессора И. Н. Степанова [6] основным фактором формирования СПП примались географическое расположение местности, геологическое строение и геоморфологические факторы, автором за основные факторы фломирования принимается рельеф земной поверхности и геологическое строение (почвообразующие породы).

На примере исследований бассейна р. Зеям, в формироапнии форм СПП, основными факторами принимаются подчененные закономерности вертиуальной зональности, расположение на северном склоне Малого Кавказа уклон рельефа, климатические условия и 
почвенно-растительный покров. Среднее и верхнее течение рек бассейна р. Зеям относится к области Малого Кавказа, а нижнее течение - к Кура-Аразской депрессии.

Бассейн р. Зеям имеет достаточно сложное геологическое и геоморфологическое строение $[8,9]$. Бассейн граничит справа - с Чингильдаг, а слево - с Шекербейли хребтами.

Водороздел в верховье хребта покрыт отложениями среднего и верхнего эоцена. Для данного пояса характерен интенсивно расчлененная гористно-синклинопная форма в высокогорье и средне расчлененный складчатый рельеф среднегорья, что в свою очередь отразилось на сложных формах СПП местности [10].

Ближе к истоку р. Зеям наблюдаются каньены и V-образные ущелья, а также расчлененные средне и частично высокогорья сложенные из осадочных пород, послужило созданию типа вариации СПП. В данной зоне нередко можно встретить карствовавые формы рельефа. В среднегорье (транзитная зона) отложения среднего и верхнего эоцена заменяются отложениями нижне Юрского периода Мезозоя. На фоне этих отложений, отложения средне Юрского периода проявлены локально, в виде пятен.

Климатические факторы бассейна р. Зеям в процессе и дифференцации ССП выступают доминирущим фактором, формирование которого непосредственно связано со сложностью рельефа [10].

Обеспеченность солнечной радиацией изменяется в зависимости от гипсометрического уровня. Годовая сумма солнечных часов составляет 2000-2400 час, и в зависимости от высоты подразделяется на 4 пояса: высокогорье - 2000-2200 час; среднегорье - < 2000; низкогорье - 2000-2200 и равнинный — 2200-2400 час. Максимальные значения солнечного сияния приходятся на летние, а минимальные - на январь месяц.

Сумма активных температур $\left(\sum>10^{\circ}\right)<800-4500^{\circ} \mathrm{C}$, которое также изменяется с повышением уровня от земной поверхности: водораздел $<800^{\circ}$, высокогорье и среднегорье800-2000; средне и низкогорье 2000-3700; предгорье и равнинный пояс 3800-4500.

Годовое количество солнечной радиации в зависимости от гипсометрического уровня

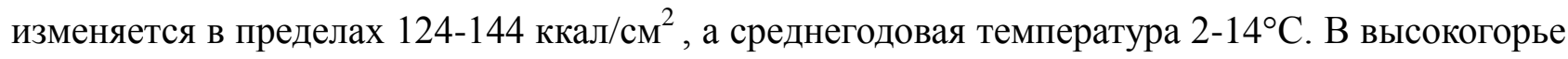
данные показатели варьируют $-2-6^{\circ} \mathrm{C}$, в среднегорье - 6-10 ${ }^{\circ} \mathrm{C}$, в предгорье и на равнине $10-14^{\circ} \mathrm{C}$.

Бассейн р. Зеям достаточно обеспечен атмосферными осадками и в зависимости от уровня от земной поверхности изменяется от 3000 мм до 1000 мм. В высокогорье - 8001000 мм, в среднегорье - 600-800 мм, в низкогорье - 400-500 мм и на равнине - 300-400 MM.

В зависимости от количества атмосферных осадков существенно изменяется и коэффициент увлажнения Мd. Выделяются 6 зон увлажнения:

$>0,60-0,45$ (высокогорная зона);

0,35-0,45 (среднегорная зона);

0,25-0,35 (низкогорная зона);

0,15-0,25 (предгорная зона);

0,10-0,15 (равнинная зона).

Основные типы климата: холодный климат с сухой зимой; умеренно-теплый климат с сухой зимой; климат полупустынь и сухостепей с сухим жарким летом.

Климатические факторы в комбинациях СПП формируются под влиянием мезо и микроформ рельефа, т.к. на увлажненных и слабо обеспеченных солнечной энергии северных склонах с малым уклоном, контуры СПП мало подвержены к расчленению, нежели на южных склонах с высоким уклоном. 
Под действием экологических факторов в рамках бассейна р. Зеям сформированы следующие формы СПП: комплексы - формы СПП образованные под влиянием микрорельефа; между почвами распространенных в различных элементах рельефа в это время происходит обмен веществ и генетиченская связь и почвы преобретают резкую контрастность; такие формы в бассейне р. Зеям сформированы под действием элементов рельефа; пятнистые - являясь формой СПП, сформированные под действием микрорельефа и растительного покрова в высокогорьях, обладают относительно низкой контрастностью; мозаичные - выявляются в случае распожения рядом почв, сформированных на почвообразовательных породах различного минералогического состава.

Данная форма СПП также характерна для высокогорного пояса.

\section{Bblводbl}

Роль экологических факторов географического положения, рельефа и географического строения, растительного покрова и гидрографической сети, в формировании СПП является определяющей.

Расположение бассейна p. Зеям на северо-западной части Малого Кавказа, горный рельеф (гипсометрический уровень и уклон), климатические показатели (атмосферные осадки, температура и др.), растительный покров играют решающую роль в формировании комбинаций СПП.

\section{Список литературы:}

1. Искендеров Ш. И. Структура почвенного покрова Юго-восточного склона Большого Кавказа и их агрономическая оценка: автореф. ... дисс. канд. с.-х. наук. Баку. 1992. 21 с.

2. Гасымов Л. Дж. Характерные особенности структуры почвенного покрова Ленкоранской низменности // Сборник трудов ОП. 2010. Т. XI. Ч. I. С. 244-248.

3. Гасымов Л. Дж. Значение пластики рельефа в формировании структуры почв рельефа Ленкоранской низменности. Баку. 2011. Т. ХХ. №1. С. 285-288.

4. Манафова Ф. А. Экологическая оценка структуры почвенного покрова Апшерона: Автореф. ... дисс. канд. с.-х. наук. Баку. 2006. 19 с.

5. Gasanov V. G. Environmental genetic features and diagnosis of alluvial marsh marled soils in the dry-steppe subtropical zone of the Kura floodplain // Russian Agricultural Sciences. 2017. V. 43. №3. P. 249-254. https://doi.org/10.3103/S1068367417030077

6. Степанов И. Н., Лошакова Н. А. О трех типах контурности на почвенных картах // Почвоведение. 1998. №3. С. 359.

7. Мамедов Г. Ш. Состав и структура почвенного покрова Азербайджана и его сельскохозяйственное значение // Международный симпозиум почвенного покрова. Москва. 1993. С. 188-191.

8. Бабаев М. П., Гасанов В. Г., Джафарова Ч. М. Современная классификация и теоретические основы номенклатуры почв Азербайджана. Баку. 2006. 300 с.

9. Мамедов Э. Э. Морфогенетическая диагностика ксерофильных горно-лесных почв Малого Кавказа и их антропогенное изменение: автореф. ... дисс. канд. с.-х. наук. Баку. 2010. $20 \mathrm{c}$.

10. Национальный почвенный атлас Азербайджана. Баку. 2015. 300 с.

11. Алиев Б. Г., Алиев И. Н. Проблемы эрозии в Азербайджане и пути ее решения. Баку. 2000. 122 c. 


\section{References:}

1. Iskenderov, Sh. I. (1992). Struktura pochvennogo pokrova Yugo-vostochnogo sklona Bol'shogo Kavkaza i ikh agronomicheskaya otsenka: avtoref. ... diss. kand. s.-kh. nauk. Baku. 21. (in Russian).

2. Gasymov L. Dzh. 2010. Kharakternye osobennosti struktury pochvennogo pokrova Lenkoranskoi nizmennosti. Sbornik trudov OP, 11(1). 244-248. (in Azerbaijani)

3. Gasymov, L. Dzh. (2011). Znachenie plastiki rel'efa v formirovanii struktury pochv rel'efa Lenkoranskoi nizmennosti. Baku. (1). 285-288. (in Russian).

4. Manafova, F. A. (2006). Ekologicheskaya otsenka struktury pochvennogo pokrova Apsherona: Avtoref. ... diss. kand. s.-kh. nauk. Baku. 19.

5. Gasanov, V. G. (2017). Environmental genetic features and diagnosis of alluvial marsh marled soils in the dry-steppe subtropical zone of the Kura floodplain. Russian Agricultural Sciences, 43(3), 249-254. https://doi.org/10.3103/S1068367417030077

6. Stepanov, I. N., \& Loshakova, N. A. (1998). O trekh tipakh konturnosti na pochvennykh kartakh. Pochvovedenie, (3), 359. (in Russian).

7. Mamedov, G. Sh. (1993). Sostav i struktura pochvennogo pokrova Azerbaidzhana i ego sel'skokhozyaistvennoe znachenie. Mezhdunarodnyi simpozium pochvennogo pokrova. Moscow. 188-191. (in Russian).

8. Babaev, M. P., Gasanov, V. G., \& Dzhafarova, Ch. M. (2006). Sovremennaya klassifikatsiya i teoreticheskie osnovy nomenklatury pochv Azerbaidzhana. Baku. 300. (in Russian).

9. Mamedov, E. E. (2010). Morfogeneticheskaya diagnostika kserofil'nykh gorno-lesnykh pochv Malogo Kavkaza i ikh antropogennoe izmenenie: avtoref. ... diss. kand. s.-kh. nauk. Baku. 20. (in Azerbaijani)

10. Natsional'nyi pochvennyi atlas Azerbaidzhana (2015). Baku. 300. (in Russian).

11. Aliev, B. G., \& Aliev, I. N. (2000). Problemy erozii v Azerbaidzhane i puti ee resheniya. Baku. 122. (in Russian).

Работа поступила

в редакичию 08.01.2020 г.
Принята к публикациии

19.01.2020 2.

Ссылка для циитирования:

Мамедова М. В. Роль экологических факторов в формировании структур почвенного покрова бассейна р. Зеям // Бюллетень науки и практики. 2020. Т. 6. №2. С. 42-46. https://doi.org/10.33619/2414-2948/51/03

Cite as (APA):

Mammadova, M. (2020). The Role of Environmental Factors in the Formation of Soil Cover Structure of the Zeyamchay Basin. Bulletin of Science and Practice, 6(2), 42-46. https://doi.org/10.33619/2414-2948/51/03 (in Russian). 


\title{
ПРЕДСТАВЛЕНИЯ О РАЗВИТИИ ЧЕЛОВЕКА В ВУЗАХ
}

(Сетренко Е. В., канд. мед. наук, Наџиональный государственный университет физической культуры, спорта и здоровья им. П.Ф. Лесгафта, 2. Санкт-Петербург, Россия, deptanatomy@hotmail.com

\section{UNIVERSITIES IDEAS ABOUT HUMAN DEVELOPMENT}

\author{
CPetrenko E., M.D., The Lesgaft National State University of Physical Education, Sports and \\ Health, St.Petersburg, Russia,deptanatomy@hotmail.com
}

Аннотация. В статье обсуждаются основные положения книги, в которой ее автор описал развитие человека с определенными отличиями от представлений, существующих в вузах по этой проблеме, возникшими в результате его многолетних исследований, анализа собственных и литературных данных. Развитие человека на разных этапах, до и после рождения автор изучал на основе учета тесной взаимосвязи всех частей тела индивида, всех его органов, таких важных особенностей его развития, как неравномерный по темпам и направлениям рост органов и асинхронное на протяжении онтогенеза развитие разных формирующихся систем органов. Наибольшая новизна такого представления в обсуждаемой книге касается пищеварительной, венозной и лимфатической систем, развитие которых автор исследовал в наибольшей мере, хотя им были проведены и другие исследования.

Abstract. The article discusses the main provisions of the book, in which its author described the development of man with certain differences from the ideas existing in universities on this problem, which arose as a result of his many years of research, analysis of his own and literary data. Human development at different stages, before and after birth, the author studied on the basis of taking into account the close relationship of all parts of the body of the individual, all his organs, such important features of his development as uneven growth rates and directions of organs and asynchronous during ontogenesis development of different emerging organ systems. The greatest novelty of such a representation in the book under discussion concerns the digestive, venous and lymphatic systems, the development of which the author has investigated to the greatest extent, although he has conducted other studies.

Ключевые слова: представления, развитие человека, анатомия, вуз.

Keywords: ideas, human development, anatomy, university.

\section{Введение}

В 2015 г. В. М. Петренко опубликовал книгу, которую посвятил очень важной проблеме - развитию человека [1]. Вопросы развития составляют важный и весьма сложный раздел анатомии человека. На их рассмотрение отводится очень мало времени на кафедре анатомии человека, причем главным образом в рамках лекционного курса. Для облегчения усвоения студентами обширного и насыщенного материала по данному разделу В. М. Петренко были написаны и изданы учебные пособия «Основы эмбриологии. Вопросы развития в анатомии 
человека» (2004) [2], «Эмбриология человека» (2005) [3], «Вопросы развития в анатомии человека. Контрольно-обучающие тестовые задания» (2005) [4], «Анатомия детского возраста. Вопросы развития человека» (2005) [5]. Материалы базового учебного пособия «Основы эмбриологии...» были учтены им также при написании учебного пособия «Анатомия человека (тезисы лекций)» (2005) [6]. Таким образом, был сформирован полный цикл из учебных пособий трех типов, облегчающих самостоятельное освоение студентами программного материала по вопросам развития человека и самоконтроль приобретенных знаний. На основе пособий этой серии В. М. Петренко составил новое учебное пособие «Развитие человека» [1].

В дополнение к материалам о развитии человека до и после рождения в книге представлены контрольно-обучающие тестовые задания, которые охватывают ключевые вопросы развития человека и его органов. Они сгруппированы по темам основных лекций по анатомии человека и составлены в виде незавершенного предложения. Тестовые задания могут быть использованы как для обучения студентов, так и для контроля (самоконтроля) их знаний, текущего и итогового (экзаменационного). Современная анатомия развивается сразу в нескольких направлениях. Студенты медицинских вузов осваивают системную и топографическую (хирургическую) анатомию с элементами сравнительной и возрастной анатомии. Возрастная анатомия изучает строение человека в возрастном аспекте, на протяжении его индивидуального развития. Из возрастной анатомии выделились две самостоятельные науки - эмбриология и геронтология (наука о старости, которая исследует особенности строения и жизнедеятельности пожилых и старых людей). Для педиатров важное значение имеет анатомия детского возраста, которая стала складываться в конце XIX столетия. Но гораздо большее развитие получила эмбриология - наука о зародыше, о «зачаточном организме». Она изучает строение организма в связи с его функциями от момента его зачатия до того этапа, когда зародыш приобретает внешний вид, сходный со взрослым организмом, и способность к обитанию в видоспецифической среде. Эмбриология позволяет установить сроки и механизмы возникновения индивидуальных вариантов нормального строения и аномалий развития человека и животных. Сегодня эмбриология это обширная область научных знаний, в которой однако остается еще немало загадочного, необъяснимого, неизвестного. Читателю предлагается краткое изложение основных сведений о развитии человека, главным образом до рождения и анатомического плана. Они необходимы для понимания целого ряда особенностей строения и положения органов, сосудов и нервов у взрослого человека, а, следовательно — и структурных основ его жизнедеятельности. Поскольку вопросы развития органов рассматриваются главным образом на лекциях по анатомии человека, то учебное пособие [1] было составлено в виде сборника кратких очерков по вопросам развития человека в рамках системной анатомии. Данное учебное пособие, как надеется автор, восполнит недостающую в учебниках информацию и поможет студенту освоить вопросы развития в анатомии, подтолкнет его к чтению специальной литературы для углубленного изучения таких вопросов. Автор книги [1] находится в поисках подобного рода со студенческой скамьи. Он надеется, что, быть может, эта книга окажется полезной для начинающих коллег в качестве введения в мир фундаментальных трудов о развитии человека.

Основные положения книги, их отличия от представлений о развитии человека в вузах Обсуждаемая книга начинается с описания сущности возрастной анатомии и ее основных разделов, их связи со сравнительной анатомией, краткого очерка истории развития этой проблемы. В. М. Петренко кратко изложил сведения о начальных этапах онтогенеза 
человека и критических периодах в его онтогенезе. Наряду с обычно описываемыми стадиями и фазами развития человека, он сообщил об установлении типов роста в развитии человека и животных (общий рост; мозговой, лимфоидный и генитальный типы роста), указал на неравномерность роста тела человека, конечностей и туловища, что влияет на пропорции тела на разных этапах онтогенеза. Текст главы В. М. Петренко сопроводил иллюстрациями. В следующей главе книги он описал возрастные особенности анатомии детей, в т.ч. первый и второй ростовые сдвиги в конце первого периода детства и в подростковом периоде, появление вторичных половых признаков у мальчиков и девочек. Текст главы В. М. Петренко сопроводил иллюстрациями.

Следующую главу он посвятил развитию скелета, костей и их соединений, подробно описал особенности строения черепа новорожденного. Текст этой главы В. М. Петренко также сопроводил иллюстрациями. Сходным образом он построил главу о развитии скелетных мышц. А вот следующий раздел книги, посвященный развитию внутренних органов, представлен гораздо более подробно. Вначале было рассмотрено развитие пищеварительной системы человека из первичной кишки, которая постепенно отделяется от желточного мешка. В процессе неравномерного роста и дифференциации первичной кишки формируются первичная кишечная петля и физиологическая пупочная грыжа, печень, поджелудочная железа и другие органы. Особое место в работе занимает описание многоэтапного поворота кишечной трубки против часовой стрелки, вокруг верхней брыжеечной артерии, причем в 4 этапа, а не в три, как это обычно трактуется в других книгах [7-10]. В них не выделяется первый этап: нисходящее (верхнее) колено первичной кишечной петли опускается справа от восходящего (нижнего) колена, в связи с формированием физиологической пупочной грыжи. Нарушения поворота кишечной трубки, например, задержка на одном из его этапов, приводят к возникновению аномалий ее развития. В. М. Петренко описыаает также становление физиологической непроходимости производных первичной кишки: в течение эмбриогенеза человека, преимущественно на 2-м мес, происходит временное и частичное (локальное) нарушение проходимости формирующегося алиментарного (пищеварительного) канала. В окружении плотной мезенхимы интенсивно пролиферирующий эпителий заполняет полость первичной кишки, дифференцирующейся на закладки дефинитивных органов. Это приводит к резкому сужению (физиологический стеноз) или полному перерыву (физиологическая атрезия) просвета разделяющегося тракта. Постоянные эпителиальные «пробки» определяются на протяжении пищевода (5-6 нед) и двенадцатиперстной кишки (6-8 нед), а также в дыхательных путях. Позднее проходимость пищеварительного и дыхательного трактов восстанавливается в связи с расширением их просвета и физиологической гибелью части эпителиоцитов. Нарушение последующего процесса реканализации органов (избыточная гибель эпителиоцитов, прорастание соединительной ткани в просвет) приводит к переходу физиологической непроходимости органов в патологическую (пороки развития). Наиболее подробно данный вопрос В. М. Петренко изучил на примере двенадцатиперстной кишки. Кроме того, он описывает развитие ротовой полости, бранхиогенных образований головы и шеи, происхождение отделов пищеварительной системы (резюме), аномалии развития пищеварительной системы. Отдельно рассматривается развитие брюшины. Он обратил внимание на то, что головная и хвостовая кишка изначально лишены брыжеек. Поэтому глотка и нижняя часть прямой кишки (анальный канал) не имеют серозной оболочки. Подобным образом В.М.Петренко объяснил особенности покрытия серозной оболочкой других органов пищеварительной и дыхательной систем, что обусловлено неравномерным ростом органов. На этой же основе у зародышей 8,5-9,5 нед происходит вправление физиологической пупочной грыжи в 
брюшную полость. Это приводит к резкому увеличению плотности ее заполнения, образованию плотных контактов между задней брюшной стенкой, внутренними органами и брыжейками. В результате возникают вторичные сращения брюшины - качественно новые морфологические взаимосвязи между органами брюшной полости, влияющие на их дефинитивные анатомо-топографические взаимоотношения. У плодов 3-5 мес появляются прямые плотные соединения, например, правой почки с двенадцатиперстной и восходящей ободочной кишкой, поперечной ободочной кишки с желудком, поджелудочной железой и селезенкой. Это стабилизирует форму и положение внутренних органов брюшной полости, препятствует сдавлению и перекруту кишечной трубки при прямохождении, возникновению кишечной непроходимости наружного типа. Далее В. М. Петренко описал особенности развития пищеварительной системы и брюшины в детском возрасте. Подобным образом, но гораздо более кратко он описал нормальное развитие, аномалии развития и особенности развития в детском возрасте дыхательной системы. После описания развития мочевых органов В. М. Петренко сделал следующее резюме: почка и мочеточник развиваются из промежуточной мезодермы, экскреторная часть почки - из дивертикула мезонефрического протока, секреторная часть (нефроны) - из метанефрогенной бластемы, мочевой пузырь из энтодермы хвостовой кишки (основные источники развития органов). Затем были представлены аномалии развития и особенности развития мочевых органов в детском возрасте, что имеет, безусловно, важное практическое значение, в т.ч. для хирургов [11].

Далее В. М. Петренко довольно подробно описал нормальное развитие половых органов и его аномалии у человека, которое повторяет основные этапы ее филогенеза. Как своеобразную форму бесполого размножения В. М. Петренко предлагает рассматривать развитие однояйцевых близнецов путем расщепления морулы или более раннего организма. Затем появляются первичные половые клетки, причем до образования зародышевых листков, еще позднее - половые органы. Вначале половые органы проходят индифферентную стадию развития. Хотя пол зародыша определяется уже на стадии образования зиготы комбинацией половых хромосом, однако первые 1,5 мес эмбриогенеза морфологически пол зародыша не проявляется. Морфологическая дифференциация главных половых желез начинается у эмбрионов 7-8 нед, причем более крупные яички определяются раньше яичников. Среди особенностей развития в детском возрасте отмечены завершение опущения главных половых желез, т.е. обретение ими дефинитивного полового положения после рождения. Яичники в первые месяцы жизни опускаются в полость малого таза, но окончательное положение приобретают к 4-7 годам. Молочная железа приобретает половые различия в пубертатный период развития. Текст этого обширного раздела книги В. М. Петренко сопроводил адекватными множественными иллюстрациями. Следующий большой раздел книги [1] посвящен развитию сердечно-сосудистой системы человека, его подразделы - «Основные этапы развития сосудистой системы», «Развитие сердца», «Развитие артерий», «Развитие вен», «Кровообращение плода», «Развитие лимфатической системы» и «Развитие лимфоидной системы», после чего автор книги представил многочисленные иллюстрации по рассмотренным вопросам.

В. М. Петренко обращает внимание на то, что дефинитивная сердечно-сосудистая система у человека включает кровеносные и лимфатические сосуды, а также лимфоидные образования разной сложности строения, которые развиваются и фукционируют в тесной взаимосвязи с утробного периода жизни. Подробно описаны развитие сердца и артерий до и после рождения, аномалии их развития, изменения кровообращения после рождения. Сходно автор книги поступил и с освещением развития вен, причем в связи с органогенезом, но в этом подразделе представил собственные, оригинальные данные и представления по этой 
проблеме. Они касаются, прежде всего, систем воротной вены печени и нижней полой вены. Воротная вена, ее корни и ветви, по данным В. М. Петренко, возникают у эмбрионов 4-6 нед на базе подпеченочной системы желточно-брыжеечных вен. Неравномерный рост желудка, двенадцатиперстной кишки и зачатков поджелудочной железы сопровождается перерывом среднего сегмента левой желточно-брыжеечной вены и нижнего анастомоза. Средний сегмент правой желточно-брыжеечной вены и средний анастомоз образуют ствол воротной вены, средний анастомоз и нижний сегмент левой желточно-брыжеечной вены - верхнюю брыжеечную вену, нижний сегмент правой желточно-брыжеечной вены - нижнюю брыжеечную вену, верхние сегменты обеих желточно-брыжеечных вен и верхний анатомоз - ветви воротной вены. Селезеночная вена дифференцируется на 6-й нед в связи с ростом селезенки и впадает в общий ствол брыжеечных вен. Общий угол слияния брыжеечных и селезеночной вен обнаруживается в начале 7-й нед позади закладки головки поджелудочной железы. Дефинитивный вариант формирования воротной вены определяется в процессе вторичных сращений брюшины, формирования двенадцатиперстно-тощекишечного изгиба. Нижняя полая вена формируется, по данным В. М. Петренко, у эмбрионов 4-7 нед в процессе перестройки системы посткардинальных вен. Замена первичных почек вторичными сопровождается редукцией брюшной части задних кардинальных вен. Их грудные отрезки сохраняются, но удаляются от сердца, уменьшаются в относительных размерах, превращаются в непарную и полунепарные вены. Они впадают в гораздо более крупные у эмбрионов 5-6 нед передние кардинальные вены. Притоки задних кардинальных вен объединяются продольными анастомозами: передние притоки - субкардинальными венами (около половых желез и корня дорсальной брыжейки), задние притоки супракардинальными венами (около формирующихся позвонков). Вторичные кардинальные вены расширяются и получают значительное развитие в брюшной полости, где замещают задние кардинальные вены. Закладка хвостатой доли печени (4 нед) сопровождается образованием дивертикула правого желточнопупочного ствола - это примитивная полая вена. Она объединяет печеночные синусоиды на дорсальной поверхности печени. Синусоиды образуют печеночные вены. На 6-й нед примитивная полая вена достигает закладки правого надпочечника и вовлекает в свой состав правую верхнюю субкардинальную вену около надпочечника. Она служит продольным анастомозом передних, брыжеечных притоков посткардинальной вены. При этом расширяется верхний интерсубкардинальный анастомоз. Он объединяет верхние (надпочечниковые) субкардинальные вены. В начале 7-й нед сближаются быстрорастущие закладки почек и надпочечников. Расположенный между ними верхний интерсубкардинальный анастомоз принимает нижние (гонадные) субкардинальные вены и резко расширяется в субкардинальный синус. В него впадают нижние мезокардинальные вены - это продольные анастомозы вен, огибающих почки с медиальной стороны и соединяющих нижние субкардинальные и супракардинальные вены. Ствол нижней полой вены дополняют правая часть субкардинального синуса, правая нижняя мезокардинальная вена и правая часть сакрокардинального анастомоза (соединение сакрокардинальных вен тазовых концов посткардинальных вен, а также их медиальных коллатералей — каудальных вен). Субкардинальный синус разделяется на почечный отрезок нижнеей полой вены и левую почечную вену (центральная часть синуса), а также забрюшинный лимфатический мешок. Сакрокардинальный анастомоз дифференцируется соответственно на начальный отрезок нижней полой вены и левую общую подвздошную вену, а также субаортальный лимфатический мешок. Супракардинальные вены на задней брюшной стенке превращаются в восходящие поясничные вены. Они непосредственно продолжаются в непраную и 
полунепарную вены на задней грудной стенке, которые осуществляют коллатеральный отток крови из поясничной области относительно новой магистрали - нижней полой вены.

При описании особенностей кровообращения плода В. М. Петренко обращает внимание читателей на влияние региональных особенностей кровообращения плода на особенности роста разных частей его тела: худшим питанием можно объяснить отставание в развитии органов нижней части тела у плода человека, за исключением печени, которая получает артериальную кровь из пупочной вены.. Оригинальные данные и свои представления В. М. Петренко представил при описании развития лимфатической системы. В частности, он подчеркивает, что часть первичных вен зародыша в процессе неравномерного роста органов и сосудов обособляется от венозного русла и образует презумптивную лимфатическую систему. Лимфатическая система в пренатальном онтогенезе человека проходит 3 стадии развития:

1) синусную (5-7 нед);

2) мешков и первичных сосудов - первичная система (6-10 нед);

3) сосудов и узлов - вторичная система, формируется с 3-го мес.

Главными лимфатическими коллекторами в эмбриогенезе являются лимфатические мешки. Они образуются в результате слияния обособленных венозных карманов крупных первичных вен или, иначе говоря, лимфатических щелей. В процессе обособления венозных карманов из кровотока выключается часть вен, притоков таких карманов. Так возникают закладки грудных протоков, поясничных и кишечных стволов. Первые клапаны в грудном протоке обнаруживаются на 8-й нед эмбриогенеза, наибольшее их число определяется у плодов 5 мес, а затем немного уменьшается в связи с развитием мышечных манжеток лимфангионов (межклапанных сегментов). После рождения расширяются цистерны, увеличиваются размеры и количество миоцитов в стенках лимфатических сосудов и капсулах лимфатических узлов. В лимфоидных узелках лимфоузлов появляются герминативные центры.

При описании развития лимфоидной системы, еще одного автономного отдела сердечно-сосудистой системы человека. В. М. Петренко замечает, что лимфоидная (иммунная) система имеет ряд особенностей развития - единый источник происхождения лимфоцитов (стволовая клетка красного костного мозга); закладка в эмбриогенезе первичных органов и селезенки; раннее созревание (к моменту рождения или в первые недели после него); ранняя инволюция (начиная с подросткового возраста), но полностью иммунные органы не исчезают до конца жизни.

Развитие нервной системы в книге изложено более кратко, но основательно. Описаны известные этапы начального генеза нервной системы - нервной пластинки, нервного желобка, нервной трубки, а затем формирование 3 и 5 мозговых пузырей, дальнейший неравномерный рост головного мозга и его отделов; особенности развития спинного мозга, его неравномерного роста в связи с позвоночным столбом и основанием черепа; развитие оболочек головного и спинного мозга, нервных узлов; особенности строения нервной системы у новорожденного и позднее; аномалии и пороки развития нервной системы [1].

Отдельно рассматривается развитие органов чувств (зрения, слуха и равновесия, обонятельного и вкусового, общего чувства), описаны их аномалии, периферическая нервная система после рождения.

Представлены необходимые иллюстрации по освещенной проблеме. Заключительная глава книги посвящена развитию эндокринных желез человека, в т.ч. плаценты, которая заменяет эндокриноциты половых желез и аденогипофиз, обеспечивая стабильность системы (мать-плод) [1]. Затем автор разместил в книге два важных приложении: 
1) краткий эмбриологический словарь;

2) контрольно-обучающие тесты по всем разделам книги и анатомии детского возраста в виде незавершенного предложения с ответами в квадратных скобках. В завершение книги В. М. Петренко представил список дополнительной литературы и список собственных публикаций автора, базовых для издания книги [1].

\section{Заключение}

В этой статье я изложила основные положения книги [1], в которой ее автор, В. М. Петренко, описал развитие человека с определенными отличиями от представлений, существующих в вузах по этой проблеме, отличиями, возникшими в результате его многолетних исследований, анализа собственных и литературных данных. Развитие человека на разных этапах онтогенеза, до и после рождения В. М. Петренко изучал на основе учета тесной взаимосвязи всех частей тела индивида, всех его органов, таких важных особенностей его развития, как неравномерный по темпам и направлениям рост органов и асинхронное на протяжении онтогенеза развитие разных формирующихся систем органов.

Наибольшая новизна такого представления в обсуждаемой книге касается пищеварительной, венозной и лимфатической систем, развитие которых В. М. Петренко исследовал в наибольшей мере, хотя им были проведены и другие исследования $[12,13]$.

\section{Список литературы:}

1. Петренко В. М. Развитие человека: вопросы развития в анатомии человека. М.Берлин: Директ-Медиа, 2015. 165 с.

2. Петренко В. М. Основы эмбриологии. Вопросы развития в анатомии человека. СПб: ДЕАН, 2004. $400 \mathrm{c}$.

3. Петренко В. М. Эмбриология человека. СПб: ДЕАН, 2005. 128 с.

4. Петренко В. М. Вопросы развития в анатомии человека. Контрольно-обучающие тестовые задания. СПб: СПбГМА. 2005. 31 с.

5. Петренко В. М. Анатомия детского возраста. Вопросы развития человека. СПб: СПбГМА. 2007. 40 с.

6. Петренко В. М. Анатомия человека. СПб: СПбГМА. 2005. 72 с

7. Волкова О. В., Пекарский М. И. Эмбриогенез и возрастная гистология внутренних органов человека. М.: Медицина. 1976. 416 с.

8. Карлсон Б. Основы эмбриологии по Пэттену. М.: Мир, 1983. Т. 2. С. 352.

9. Пэттен Б. М. Эмбриология человека. М. 1959. 768 с.

10. Станек И. Эмбриология человека. Братислава: Веда. 1977. 440 с.

11. Маргорин Е. М. Оперативная хирургия детского возраста. Л.: Медгиз. 1959. 476 с.

12. Петренко В. М. Как устроена жизнь? Анатомия поиска. М.-Берлин: Директ-Медиа, 2018.113 c.

13. Петренко В. М. Морфогенез в эволюции: элементы сравнительной анатомии: сборник научных статей. М.-Берлин: Директ-Медиа, 2019. 228 с.

\section{References:}

1. Petrenko, V. M. (2015). Razvitie cheloveka: voprosy razvitiya v anatomii cheloveka. Moscow-Berlin: Direkt-Media, 165. (in Russian).

2. Petrenko, V. M. (2004). Osnovy embriologii. Voprosy razvitiya v anatomii cheloveka. St. Petersburg, DEAN, 400. (in Russian).

3. Petrenko, V. M. (2005). Embriologiya cheloveka. St. Petersburg, DEAN, 128. (in Russian). 
4. Petrenko, V. M. (2005). Voprosy razvitiya v anatomii cheloveka. Kontrol'noobuchayushchie testovye zadaniya. St. Petersburg, SPbGMA. 31. (in Russian).

5. Petrenko, V. M. (2007). Anatomiya detskogo vozrasta. Voprosy razvitiya cheloveka. St. Petersburg, SPbGMA. 40. (in Russian).

6. Petrenko, V. M. (2005). Anatomiya cheloveka. St. Petersburg, SPbGMA. 72. (in Russian).

7. Volkova, O. V., \& Pekarskii, M. I. (1976). Embriogenez i vozrastnaya gistologiya vnutrennikh organov cheloveka. Moscow, Meditsina. 416. (in Russian).

8. Karlson, B. (1983). Osnovy embriologii po Pettenu. Moscow, Mir, (2). 352. (in Russian).

9. Petten, B. M. (1959). Embriologiya cheloveka. Moscow. 768. (in Russian).

10. Stanek, I. (1977). Embriologiya cheloveka. Bratislava: Veda. 440. (in Russian).

11. Margorin, E. M. (1959). Operativnaya khirurgiya detskogo vozrasta. Leningrad, Medgiz. 476. (in Russian).

12. Petrenko, V. M. (2018). Kak ustroena zhizn'? Anatomiya poiska. Moscow-Berlin: DirektMedia, 113. (in Russian).

13. Petrenko, V. M. (2019). Morfogenez v evolyutsii: elementy sravnitel'noi anatomii: sbornik nauchnykh statei. Moscow-Berlin: Direkt-Media, 228. (in Russian).

Работа поступила

в редакциюю 07.01.2020 г.
Принята к публикациии

11.01.2020 2.

Ссылка для циитирования:

Петренко Е. В. Представления о развитии человека в вузах // Бюллетень науки и практики. 2020. Т. 6. №2. С. 47-54. https://doi.org/10.33619/2414-2948/51/04

Cite as (APA):

Petrenko, E. (2020). Universities Ideas About Human Development. Bulletin of Science and Practice, 6(2), 47-54. https://doi.org/10.33619/2414-2948/51/04 (in Russian). 


\title{
СРАВНИТЕЛЬНАЯ ХАРАКТЕРИСТИКА ФЛОР ГАНЫХ-АЙРИЧАЙСКОЙ ДОЛИНЫ И ИЛИСУЙСКОГО ПРИРОДНОГО ЗАПОВЕДНИКА (АЗЕРБАЙДЖАН)
}

\author{
ССарыева Г. Р., Бакинский государственный университет, г. Баку, Азербайджан
}

\section{COMPARATIVE CHARACTERISTICS OF FLORAS OF THE GANYKH-AIRICHAI VALLEY AND ILISU NATURE RESERVE (AZERBAIJAN)}

\author{
CSaryeva G., Baku State University, Baku, Azerbaijan
}

Аннотащия. В данной статье даны результаты сравнительного анализа флор ГаныхАйричайской долины и Илисуйского природного заповедника. Количество таксонов формирующих современную флору долины и заповедника составляет соответственно 959 и 857. Коэффициент флористической общности двух территорий для родов составляет $31,7 \%$, для видов $16,6 \%$.

Abstract. This article contains the results of a comparative analysis of floras of the GanykhAirichai valley and Ilisu nature reserve. The number of taxa forming the modern flora of the valley and the reserve are 959 and 857, respectively. The coefficient of floristic similarity of the two territories for genera is $31.7 \%$, for species $16.6 \%$.

Ключевые слова: флора, Ганых-Айричайская долина, Илисуйский природный заповедник, индекс сходства Жаккара.

Keywords: flora, Ganykh-Airichai valley, Ilisu Nature Reserve, Jaccard similarity coefficient.

\section{Введение}

История изучения растительного покрова долины началась с 1930 годов. Судя по опубликованным данным, проведенные флористические исследования $[1,2,3,4]$ не полностью охватили территорию исследования, поэтому возникла потребность более подробного изучения и обновления имеющихся данных. С этой же целью Флора Ганых -Айричайской долины впервые была детально изучена Г.Р.Сарыевой в 2013-2017 гг.

Задачи исследования - Получить результаты сравнительной характеристики для выбранных региональных флор и вычислить коэффициенты флористической общности для двух территорий.

\section{Методика исследований}

Территория Ганых-Айричайской долины совпадает с территорией АлазаньАйричайской ботанико-географического района в пределах Азербайджанской Республики [5]. Для определения видов растений и проведения флористического; фитогеографического анализа флоры долины были использованы различные методы и источники [6-9].

Поскольку флоры государственных природных заповедников Гах, Загатала и Исмайыллы до сих пор не были исследованы, для сравнения флоры долины в качестве ближайшего района был выбран природный паповедник Илису. 
Сходства родов и видов во флорах Ганых-Айричайской долины и Илисуйского заповедника вычислены индексом сходства Жаккара:

$$
\mathrm{k}=\mathrm{cx} 100 /(\mathrm{a}+\mathrm{b})-\mathrm{c},
$$

где $\mathrm{a}$ - число видов растений на первом ключевом участке; $\mathrm{b}$ - число видов растений на втором ключевом участке; с — число видов, общих для обоих участков [10].

Ганых-Айричайская долина расположена на северо-западной части Азербайджана. Рельеф долины расположен между высотами 159-800 м н.у.м.

Биотопы долины - полупустынные территории, аридно-ксерофитные кустарники, водно-болотные местности, конусы выноса рек, полузасушливые низинные леса и частично мезофитные горные леса. Господствующий тип климата на территории долины - умеренный с засушливым зимним периодом.

Биотопы Илисуйского заповедника - в основном горные мезофитные леса и горные луга, расположенные на высоте 700-2100 м н.у.м. Типы климата Илисуйского заповедника умеренный и холодный с засушливым зимним периодом.

\section{Результаты и обсуждения}

В результате проведенных исследований во флоре Ганых-Агричайской долины было зарегистрировано 505 видов, 28 подвидов, 2 вариации сосудистых растений, которые сгруппированы в 92 семейства и 330 рода [10-12].

По опубликованным данным в 1996 году Т. А. Абдуллаевой [13] во флоре Илисуйского заповедника было выявлено 500 видов растений, 290 родов, 76 семейств. Результаты сравнения флор дух территорий на основе результатов Г. Р. Сарыевой и Т. А. Абдуллаевой представлены в Таблице.

Результаты фитогеографического анализа территорий исследования позволили выявить ареальные типы, которые представлены многочисленными видами.

На территории долины древне средиземноморский ареальный тип представлен 204 видами, бореальный - 187 видами.

В Илисуйском природном заповеднике бореальный тип ареала представлен 164 видами, древнесредиземноморский (ксерофитный) - 120 видами.

Количество общих родов и видов для обеих сравниваемых территорий соответственно 147 и 143.

Коэффициент флористической общности двух территорий для родовсоставляет $31,07 \%$, для видов $16,6 \%$.

Сравнительно низкое значение видового сходства обусловлено разностью физикогеографических условий и биотопов, что определяет экологические характеристики видов растений в двух сравниваемых территориях. Например, на территории долины наиболее широко представлен род Осока (Carex): 11 видов и 1 подвид.

Виды, относящиеся к вышеуказанному роду на исследуемой территории были зарегистрированы в различных биотопах: в избыточно увлажненных территориях, в мезофитных низинных лесах, в ксерофитных кустарниках расположенных в конусах выноса рек южного склона Большого Кавказа.

По данным Т. А. Абдуллаевой во флоре Илисуйского заповедника наибольшими видами представлен род Колокольчик (Campanula): 7 видов. Представители данного рода характерны для горных лесов и горных лугов.

В связи с вышеперечисленными факторами, экологические характеристики представителей флор двух территорий четко различаются, а коэффициент флористической общности низкий. 
СРАВНЕНИЕ ФЛОРЫ ГАНЫХ-АЙРИЧАЙСКОЙ ДОЛИНЫ

Таблица. И ИЛИСУЙСКОГО ПРИРОДНОГО ЗАПОВЕДНИКА

\begin{tabular}{|c|c|c|c|c|c|}
\hline \multicolumn{3}{|c|}{$\begin{array}{c}\text { Ганых-Айричайская долина } S=3473,11 \text { км² }^{2} \\
\text { (Сарыева, 2017) }\end{array}$} & \multicolumn{3}{|c|}{$\begin{array}{c}\text { Илисуйский заповедник } S=96,54 \text { км² } \\
(\text { Абдуллаева, 1996) }\end{array}$} \\
\hline $\begin{array}{l}\text { Bulcшие } \\
\text { cпоровые }\end{array}$ & Голосеменные & Покрытосеменные & $\begin{array}{l}\text { Bblcuиe } \\
\text { cnopoвble }\end{array}$ & Голосеменные & Покрытосеменные \\
\hline \multirow{2}{*}{10 видов } & \multirow{2}{*}{8 видов } & однодольные: 115 & \multirow{2}{*}{9 видов } & \multirow{2}{*}{5 видов } & однодольные: 71 \\
\hline & & двудольные: 403 & & & однодольные: 415 \\
\hline & & Итого: 518 & & & Итого: 486 \\
\hline $\begin{array}{c}\text { Кол-во } \\
\text { семейств }\end{array}$ & Кол-во родов & Кол-во видов & $\begin{array}{c}\text { Кол-во } \\
\text { семейств }\end{array}$ & Кол-во родов & Кол-во видов \\
\hline 92 & 332 & $\begin{array}{c}505 \text { видов, } \\
28 \text { подвидов, } \\
2 \text { вариаций }\end{array}$ & 76 & 290 & 500 \\
\hline
\end{tabular}

Первые 10 доминантные семейства

\begin{tabular}{l} 
Poaceae - 65 видов \\
Leguminosae -44 вида, 3 подви \\
Compositae -40 видов, 3 подви \\
Cyperaceae -24 вида, 2 подвида \\
Lamiaceae -21 вид \\
Rosaceae -16 видов, 1подвид \\
Boraginaceae -16 видов \\
Brassicaceae -15 видов \\
Ranunculaceae -13 видов \\
Caryophyllaceae -13 видов \\
\\
Carex - 11 видов, 1 подвид \\
Trifolium - 11 видов, 1 подвид \\
Medicago - 8 видов \\
Geranium - 7 видов \\
Vicia - 7 видов \\
Ranunculus - 7 видов \\
Galium -7 видов \\
Euphorbia - 7 видов \\
\hline
\end{tabular}

Leguminosae - 44 вида, 3 подвида

Rosaceae - 16 видов, 1подвид

Boraginaceae - 16 видов

Brassicaceae - 15 видов

Ranunculaceae - 13 видов

Caryophyllaceae - 13 видов
Asteraceae - 75 видов
Rosaceae - 35 видов
Lamiaceae - 30 видов
Арiaceae - 29 видов
Роасеае - 29 видов
Scrophulariaceae -21 вид
Fabaceae - 20 видов
Ranunculaceae - 19 видов
Liliaceae - 16 видов
Caryophyllaceae - 16 видов

Доминантные роды

Campanula -7 видов
Festuca -6 видов
Orchis -6 видов
Silene -6 видов
Ranunculus -6 видов
Acer -6 видов
Trifolium -6 видов
Alchemilla -6 видов

\section{Bblвodbl}

Количество таксонов формирующих современную флору Ганых-Айричайской долины и Илисуйского природного заповедника составляет соответственно 959 и 857.

Коэффициент флористической общности двух территорий для родов составляет $31,7 \%$, для видов $16,6 \%$.

Сравнительно низкое значение видового сходства обусловлено разностью физикогеографических условий и особенностями биотопов сравниваемых территорий.

\section{Список литературь:}

1. Гейдеман Т. С. Краткий очерк растительности Закатало-Белоканской низменности // Труды Ботанического института АзФАН СССР. 1940. Т. IX. С. 179-240.

2. Дмитриева С. И. Сорная растительность северо-западной части Алазань-Авторанской долины (в пределах Азербайджана) и меры борьбы с нею: Автореф. дисс. ... канд. биол. наук. Баку. 1966. 25 с. 
3. Прилипко Л. И. Краткий геоботанический очерк южных склонов Большого Кавказа (в пределах Азербайджана) // Труды Ботанического Института. АН Азерб ССР. 1950. T. XV. C. 118-145.

4. Прилипко Л. И. Лесная растительность Азербайджана. Баку: Изд-во Акад. наук АзССР, 1954. $488 \mathrm{c}$.

5. Флора Азербайджана. Баку: Изд-во Акад. наук АзССР. 1950-1961: T. I., 370 с.; T. II., 317 c.; T. III, 407 c.; T. IV, 400 c.; T. V, 580 c.; T. VI, 540 c.; T. VII, 648 c.; T. VIII, 676 c.

6. Гроссгейм А. А. Флора Кавказа. М.: Изд-во АН СССР. 1939-1967. Т. I-VII.

7. Миркин Б. М., Наумова Л. Г. Введение в современную науку о растительности, М.: 2017. 278 c.

8. Портениер Н. Н. Система географических элементов Флоры Кавказа // Ботанический журнал. 2000. №9. Т. 85. С. 94-98.

9. Юрцев Б. А., Камелин Р. В. Основные понятия и термины флористики. Пермь 1991. $80 \mathrm{c}$.

10. Сарыева Г. Р. Анализ флоры Ганых-Агричайской долины (В пределах Азербайджанской Республики) // Международный журнал прикладных и фундаментальных исследований. 2018. №1. С. 115-120.

11. Сарыева Г. Р. Полупустынный тип растительности, распространенный в ГаныхАгричайской долине // Актуальные проблемы экологии и почвоведения в XXI веке: труды VI республиканской научной конференции, посвященной 94-летию со дня рождения общенационального лидера Гейдара Алиева (4-5 мая, 2017). Баку. С. 182-183.

12. Сарыева Г. Р., Гурбанов Е. М. Фитоценологическая структура аридно-ксерофитных редколесий и кустарниковых ландшафтов, образованных в Ганых-Агричайской долине // Известия Бакинского университета. 2016. №2. С. 44-51.

13. Абдуллаева Т. А. Флора Илисуйского заповедника и ее флористический анализ: Автореф. дисс. ... канд. биол. наук. Баку. 1996. 24 с.

\section{References:}

1. Geideman, T. S. (1940). Kratkii ocherk rastitel'nosti Zakatalo-Belokanskoi nizmennosti. Trudy Botanicheskogo instituta AzFAN SSSR, 9. 179-240. (in Russian).

2. Dmitrieva, S. I. (1966). Sornaya rastitel'nost' severo-zapadnoi chasti Alazan'-Avtoranskoi doliny (v predelakh Azerbaidzhana) i mery bor'by s neyu: Avtoref. diss. ... kand. biol. nauk. Baku. 25. (in Russian).

3. Prilipko, L. I. (1950). Kratkii geobotanicheskii ocherk yuzhnykh sklonov Bol'shogo Kavkaza (v predelakh Azerbaidzhana). Trudy Botanicheskogo Instituta. AN Azerb SSR. 15. 118145. (in Russian).

4. Prilipko, L. I. (1954). Lesnaya rastitel'nost' Azerbaidzhana. Baku: Izd-vo Akad. nauk AzSSR, 488. (in Russian).

5. Flora Azerbaidzhana (1950-1961): Baku: Izd-vo Akad. nauk AzSSR. V. I., 370.; V. II., 317; V. III, 407.; V. IV, 400; V. V, 580; V. VI, 540; V. VII, 648; V. VIII, 676. (in Russian).

6. Grossgeim, A. A. (1939-1967). Flora Kavkaza. Moscow, Izd-vo AN SSSR. V. I-VII.

7. Mirkin, B. M., \& Naumova, L. G. (2017). Vvedenie v sovremennuyu nauku o rastitel'nosti. Moscow. 278. (in Russian).

8. Portenier, N. N. (2000). Sistema geograficheskikh elementov Flory Kavkaza. Botanicheskii zhurnal, 85(9). 94-98. (in Russian).

9. Yurtsev, B. A., \& Kamelin, R. V. (1991). Osnovnye ponyatiya i terminy floristiki. Perm' 80. (in Russian). 
10. Saryeva, G. R. (2018). Analiz flory Ganykh-Agrichaiskoi doliny (V predelakh Azerbaidzhanskoi Respubliki). Mezhdunarodnyi zhurnal prikladnykh $i$ fundamental'nykh issledovanii, (1). 115-120. (in Russian)

11. Saryeva, G. R. (2017). Polupustynnyi tip rastitel'nosti, rasprostranennyi v GanykhAgrichaiskoi doline. In Aktual'nye problemy ekologii $i$ pochvovedeniya $v$ XXI veke: trudy VI respublikanskoi nauchnoi konferentsii, posvyashchennoi 94-letiyu so dnya rozhdeniya obshchenatsional'nogo lidera Geidara Alieva (4-5 maya, 2017). Baku. 182-183. (in Azerbaijani)

12. Saryeva, G. R., \& Gurbanov, E. M. (2016). Fitotsenologicheskaya struktura aridnokserofitnykh redkolesii i kustarnikovykh landshaftov, obrazovannykh v Ganykh-Agrichaiskoi doline. Izvestiya Bakinskogo universiteta, (2), 44-51. (in Azerbaijani)

13. Abdullaeva, T. A. (1996). Flora Ilisuiskogo zapovednika i ee floristicheskii analiz: Avtoref. diss. ... kand. biol. nauk. Baku. 24. (in Azerbaijani)

Работа поступила

в редакциию 12.01.2020 2.
Принята к публикации 19.01.2020 2.

Ссылка для цчитирования:

Сарыева Г. Р. Сравнительная характеристика флор Ганых-Айричайской долины и Илисуйского природного заповедника (Азербайджан) // Бюллетень науки и практики. 2020. Т. 6. №2. C. 55-59. https://doi.org/10.33619/2414-2948/51/05

Cite as (APA):

Saryeva, G. (2020). Comparative Characteristics of Floras of the Ganykh-Airichai Valley and Ilisu Nature Reserve (Azerbaijan). Bulletin of Science and Practice, 6(2), 55-59. https://doi.org/10.33619/2414-2948/51/05 (in Russian). 


\section{ВЛИЯНИЕ РАЦИОНА КОРМЛЕНИЯ КРЫС НА БИОХИМИЧЕСКИЙ ПРОФИЛЬ КРОВИ И МОРФОЛОГИЮ ПЕЧЕНИ}

СШидаков Ю. Х.-М., SPIN-код: 9677-9338, акад. Международной академии традиционной и экспериментальной медицины при Минздраве Киргизской Республики, канд. мед. наук, Киргизско-российский славянский университет, г. Бишкек, Кыргызстан, ychidakov@mail.ru CШарова E. В., SPIN-код: 3711-2020, ORCID: 0000-0003-4302-0055, канд. биол. наук, Киргизско-российский славянский университет, г. Бишкек, Кыргызстан, shevkg@таil.ru

(САбдумаликова И. А., SPIN-код:8262-6197, канд. мед. наук, Киргизско-российский славянский университет, г. Бишкек, Кыргызстан, speleolog53@ mail.ru

(омашанло Т. Р., Киргизско-российский славянский университет, г. Бишкек, Кыргызстан, seriiserg@gmail.com

(САбдулбакиев А. А., Киргизско-российский славянский университет, г. Бишкек, Кыргызстан,_Ablikim_66@mail.ru

\section{EFFECT OF FEEDING RAT ON THE BIOCHEMICAL PROFILE OF BLOOD AND LIVER MORPHOLOGY}

CShidakov Yu., SPIN-code: 9677-9338, Academician International Academy of Traditional and Experimental Medicine at the Ministry of Health of the Kyrgyz Republic, M.D., Kyrgyz-Russian Slavic University, Bishkek, Kyrgyzstan,ychidakov@mail.ru

CSharova E., SPIN-code: 3711-2020, ORCID: 0000-0003-4302-0055, Ph.D., Kyrgyz-Russian Slavic University, Bishkek, Kyrgyzstan, shevkg@mail.ru

(CAbdumalikova I., SPIN-code: 8262-6197, M.D., Kyrgyz-Russian Slavic University, Bishkek, Kyrgyzstan, speleolog53@mail.ru

CMashanlo T., Kyrgyz-Russian Slavic University, Bishkek, Kyrgyzstan, seriiserg@gmail.com

CAbdulbakiev A., Kyrgyz-Russian Slavic University, Bishkek, Kyrgyzstan, Ablikim_66@mail.ru

Аннотация. Характер питания модифицирует метаболизм веществ и обеспечивает либо нормальную жизнедеятельность, либо способствует нарушению обмена веществ и развитию патологий. Проведено исследование влияния разного рациона кормления (липидного, углеводного и белкового) на биохимический профиль крови взрослых половозрелых крыс. Работа выполнена на 28 белых лабораторных крысах-самцах, весом 180-250 г, которые составили 4 группы: первую (1) группу (n=7) кормили исключительно липидами (курдючным салом), вторую (2, n=7) - углеводами (сахаром), третью (3, n=7) - белками, а четвертую (4, $\mathrm{n}=7)$ - стандартным кормом. Определены уровни глюкозы, холестерина, общего белка и альбумина колориметрическим методом. Выявлено, что при приеме липидного корма в крови повысились уровни холестерина, глюкозы, общего белка и альбумина; при употреблении углеводного корма - содержание глюкозы и липидов; при потреблении белкового рациона - общего белка, альбумина и липидов. Концентрация холестерина выросла при употреблении всех видов рациона, особенно значительно при липидном. Концентрация глюкозы повысилась при углеводном и липидном рационах; общего белка при белковом; глюкозы в равной степени при липидном и углеводном. Наиболее высокая концентрация альбумина отмечена при липидном рационе, наиболее низкая - при углеводном. Изменения биохимических показателей метаболизма веществ, сопрягаются с ремоделированием печени. Кормление крыс в течение 15 дней курдючным салом привело к нарушению баланса между скоростью синтеза и распада жиров в гепатоцитах. К липидозу присоединяются 
диспротеиноз и углеводная дистрофия печени. Кормление крыс сахаром вызвало углеводную дистрофию печени, к которой присоединяются очаги диспротеиноза и липидоза, вакуольной дистрофии и фиброза.

Abstract. The nature of nutrition modifies the metabolism of substances and ensures either normal functioning, or contributes to metabolic disorders and the development of pathologies. A study was made of the effect of different feeding diets (lipid, carbohydrate and protein) on the blood biochemical profile of adult sexually mature rats. The work was performed on 28 white laboratory male rats weighing 180-250 g, which were 4 groups: the first (1) group ( $n=7)$ was fed exclusively with lipids (fat tail fat), the second $(2, n=7)$ - carbohydrates (sugar), the third $(3, n=7)$ - proteins, and the fourth $(4, n=7)$ - standard food. The levels of glucose, cholesterol, total protein and albumin were determined by the colorimetric method. It was revealed that when taking lipid food in the blood, levels of cholesterol, glucose, total protein and albumin increased; when consuming carbohydrate feed - the content of glucose and lipids; when consuming a protein diet — total protein, albumin and lipids. The concentration of cholesterol increased with the use of all types of diet, especially significantly with lipid. Thus, glucose concentration increased with carbohydrate and lipid diets; total protein — with protein; glucose equally — with lipid and carbohydrate. The highest concentration of albumin is observed with a lipid diet, the lowest — with a carbohydrate.

Ключевые слова: липиды, белки, углеводы, холестерин, глюкоза, общий белок, альбумин, диспротеиноз, липидоз

Keywords: lipids, proteins, carbohydrates, blood, cholesterol, glucose, total protein, albumin, dysproteinosis, lipidosis

\section{Актуальность}

Проблема рационального сбалансированного питания является одним из приоритетных в мировом масштабе. Существуют большое количество диет и гипотез питания, противоречащих друг другу. Согласно исследованиям, опубликованным в медицинском журнале «The lancet», диета является важным фактором способным предотвратить риск неинфекционных заболеваний [1].

Сбалансированное питание обеспечивает нормальный рост и развитие организма, обеспечивает оптимальный метаболизм веществ, нормальные биохимические и физиологические процессы [2-4]. Резкое изменение питания трансформирует обмен веществ, приводит к нарушению метаболизма, структурной организации, расстройству функциональной специализации органов и систем организма, развитию заболеваний [5-7]. Об этом, в частности, свидетельствуют проведенные исследования влияния современных прохладительных напитков на биохимические показатели и функциональное состояние печени и почек крыс [8].

Целью настоящего сообщения является изложение результатов изучения глюкозы, холестерина, общего белка и альбумина в крови и структурно-функциональных изменений печени белых лабораторных крыс при употреблении разных рационов кормления.

\section{Материаль и методы исследования}

Работа выполнена на 28 белых лабораторных крысах-самцах, весом 180 г, которые составили 4 группы: первую (1) группу (n=7) кормили исключительно липидами (курдючным 
салом), вторую (2, n=7) - углеводами (сахаром), третью $(3, \mathrm{n}=7)$ - белками, а четвертую (4, $\mathrm{n}=7)$ - стандартным кормом.

Через 15 дней методом декапитации собрали кровь и отделили сыворотку. В сыворотке крови определили уровень холестерина, глюкозы, общего белка и альбумина энзиматическим колорометрическим методом с использованием тест-систем "Vital" (Россия).

Полученные результаты обработали в программе SPSS 16.0, достоверность различий определяли по критерию Стьюдента, при $\mathrm{P}<0,05$.

Кусочки печени фиксировались в 10\% нейтральном формалине с последующим обезвоживанием в спиртах возрастающей концентрации, заливались парафином. Готовые препараты, окрашенные гематоксилин-эозином изучались под микроскопом Olympus Bx40 (Япония).

Содержание и использование лабораторных животных при проведении исследования соответствовало международным, национальным правилам по этическому обращению с животными.

\section{Результаты и их обсуждение}

Сыворотка крови у крыс, содержащихся на липидном рационе имела хилезный вид, что свидетельствует о патологически высокой концентрации хиломикронов и триглицеридов в крови и нарушении метаболизма веществ.

Концентрация холестерина повысилась во всех трех опытных группах крыс по сравнению с контрольной (Рисунок 1). Наиболее высокий уровень холестерина отмечен у

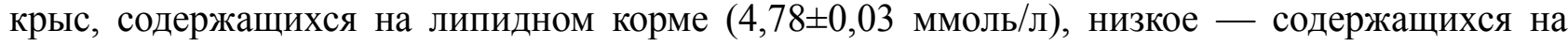
белковом рационе $(2,06 \pm 0,12$ ммоль/л), промежуточный - во 2 группе крыс, находящихся на углеводном рационе $(3,45 \pm 0,20$ ммоль/л).

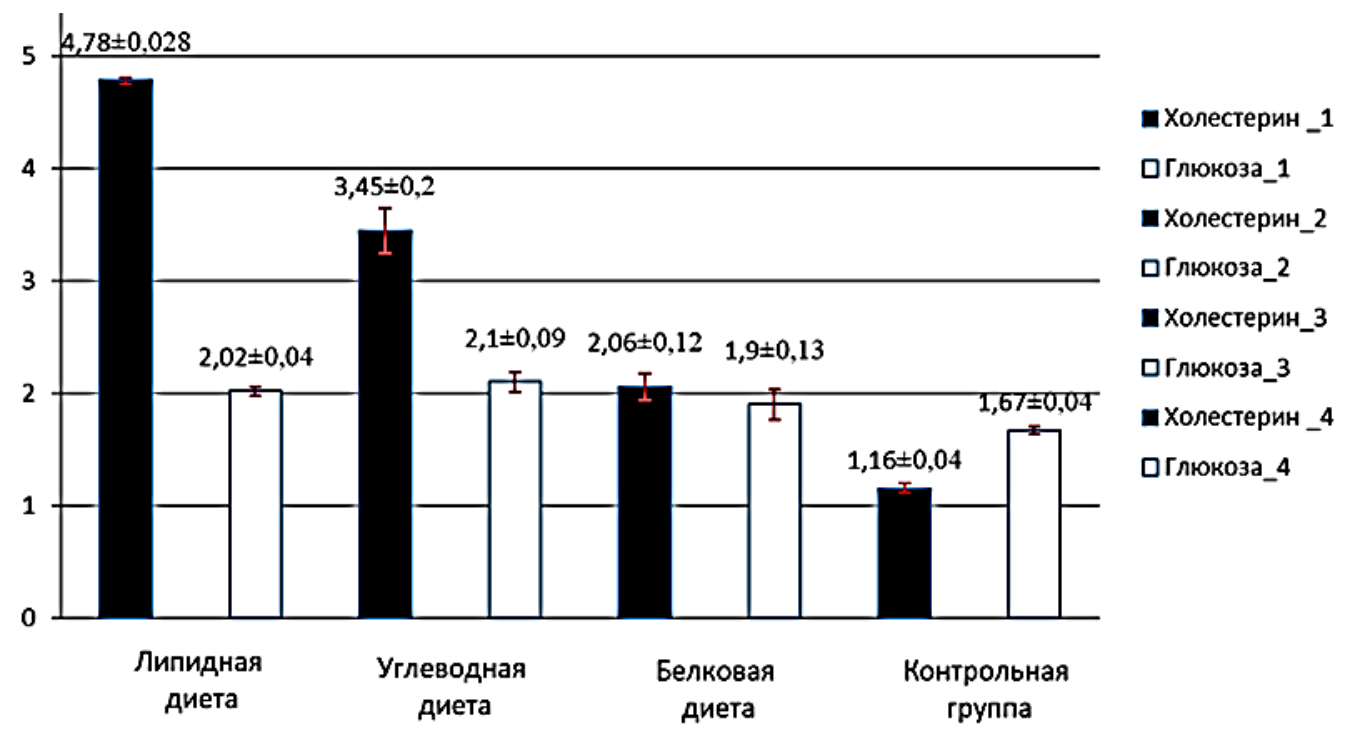

Рисунок 1. Показатели концентрации глюкозы и холестерина у крыс с разными рационами питания: 1 - крысы, находящиеся на липидном рационе; 2 - крысы, находящиеся на углеводном рационе; 3 - крысы, находящиеся на белковом рационе; 4 - крысы, находящиеся на стандартном рационе

Липидный рацион вызвал достоверное увеличение концентрации холестерина по сравнению с данными крыс, принимавших углеводный и белковый рацион на 38,5\% $(\mathrm{P}<0,001)$ и $132 \%(\mathrm{P}<0,001)$ соответственно. Усиление процесса липогенеза от углеводных и белковых источников происходит через ацетил-Ко-А, образующихся в процессе метаболизма веществ. Результаты исследования подтверждают тезис, что на синтез холестерина 
используются как молекулы ацетилКоА, полученные в результате метаболизма углеводов, так и липидов, при этом в этот процесс активнее вовлекаются липидные молекулы.

Наиболее высокие показатели глюкозы отмечены в крови крыс, содержащихся на углеводном рационе $(2,10 \pm 0,09$ ммоль/л, рис.1), низкие - у крыс, принимавших белковый корм $(1,9 \pm 0,13$ ммоль/л), различия статистически достоверные $(\mathrm{P}<0,05)$. Между данными, полученными у крыс, содержащихся на липидной (1) и белковой (3) диетами достоверных статистических различий нет ( $>0,05)$. При этом обращает на себя внимание незначительное отличие концентрации глюкозы между данными, полученными у крыс, получавших различный рацион кормления. Это, возможно, указывает на универсальность регуляции константы уровня глюкозы в организме.

Наиболее высокий уровень общего белка отмечен у крыс, принимавших белковую диету $-103 \pm 12,9$ г/л (Рисунок 2).

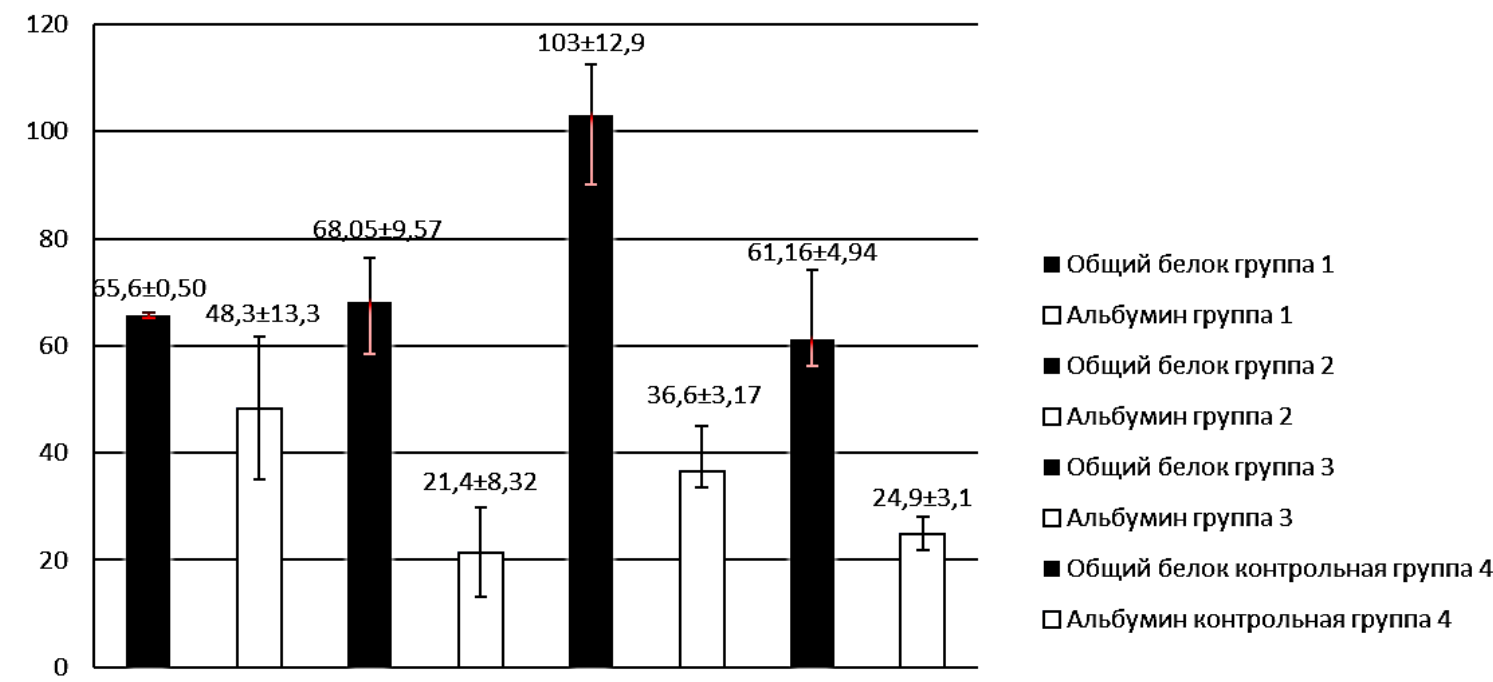

$$
\begin{array}{cccc}
\text { Липидная } & \text { Углеводная } & \text { Белковая } & \text { Контрольная } \\
\text { диета } & \text { диета } & \text { диета } & \text { группа }
\end{array}
$$

Рисунок 2. Концентрация общего белка и альбумина в крови у крыс при различном рационе кормления: 1 - крысы, находящиеся на липидном рационе: 2 - крысы, находящиеся на углеводном рационе: 3 - крысы, находящиеся на белковом рационе; 4 - крысы, находящиеся на стандартном рационе

У крыс, содержащихся на липидном и углеводном рационе кормления показатели общего белка одного уровня — $65,6 \pm 0,50,68,5 \pm 9,57$ г/л, что в 1,57 и 1,5 раз ниже по сравнению с данными 3 группы. При этом минимальная концентрация белка наблюдается у крыс, содержащихся на углеводном корме, а максимальная - у крыс на белковой.

Другая картина наблюдается в отношении содержания альбумина. Наиболее высокая концентрация альбумина зарегистрирована у крыс, находящихся на липидном корме $(48,3 \pm 13,3 \Gamma / л$, Рисунок 2). Вероятно, это частично связано с выполнением альбумином функции абсорбции и транспорта гидрофобных соединений. Наиболее низкий уровень

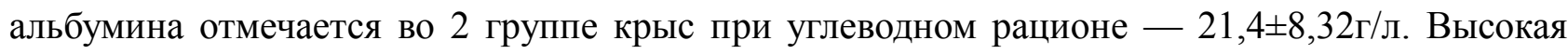
концентрация глюкозы в крови приводит к росту осмотического давления крови. Следует отметить высокую вариативность показателей альбумина во всех опытных группах крыс.

Ремоделирование метаболизма веществ сопрягаются с морфологическими изменениями печени. Так, в печени отмечается мутное набухание или зернистая дистрофия гепатоцитов на 15 день кормления крыс курдючным салом (Рисунок 3). Увеличенные в размерах гепатоциты 
сдавливают синусоиды, что прекращает по ним кровоток, нарушается микроциркуляция. Это ведет к кислородной недостаточности и нарушению окислительного фосфорилирования. Нарушается синтез и выработка АТФ с последующим нарушением осмотического и онкотического баланса. Таким образом, на 15 день эксперимента проявляются картины липидоза и диспротеиноза.

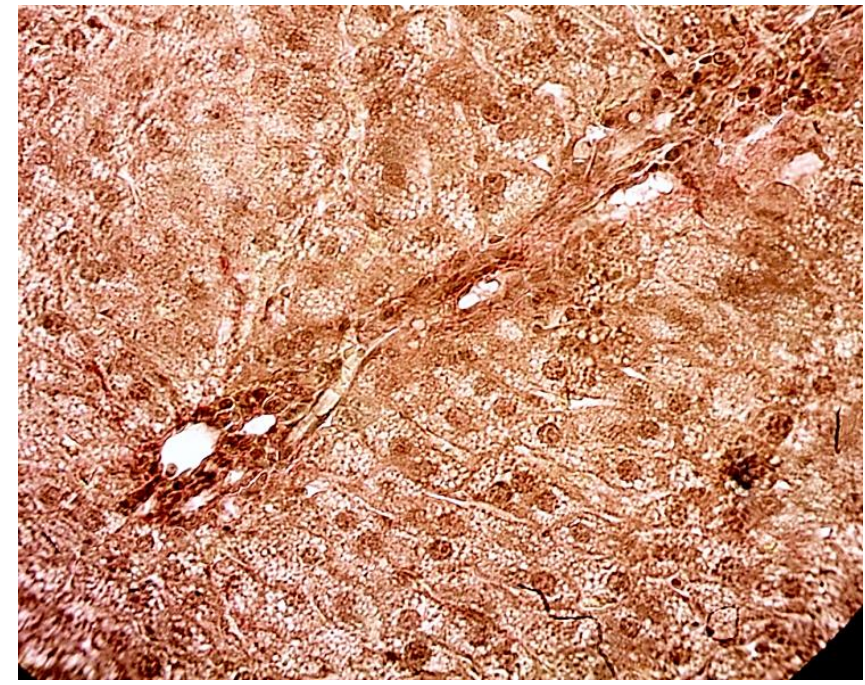

Рисунок 3. Протальная область печени крысы, содержащейся на жировом рационе кормления. Заливка в парафин х 400

В группе с углеводной диетой наблюдается исчезновение границ между печеночными и портальными дольками, а также ацинусов Раппопорта (Рисунок 4). В печеночных дольках нарушается радиарное расположение печеночных балок, состоящих из тяжей гепатоцитов. Из-за набухания гепатоцитов синусоиды печени сдавливаются и не обнаруживаются под микроскопом. В результате создается картина хаотичного распределения гепатоцитов, находящихся на разных стадиях повреждения.

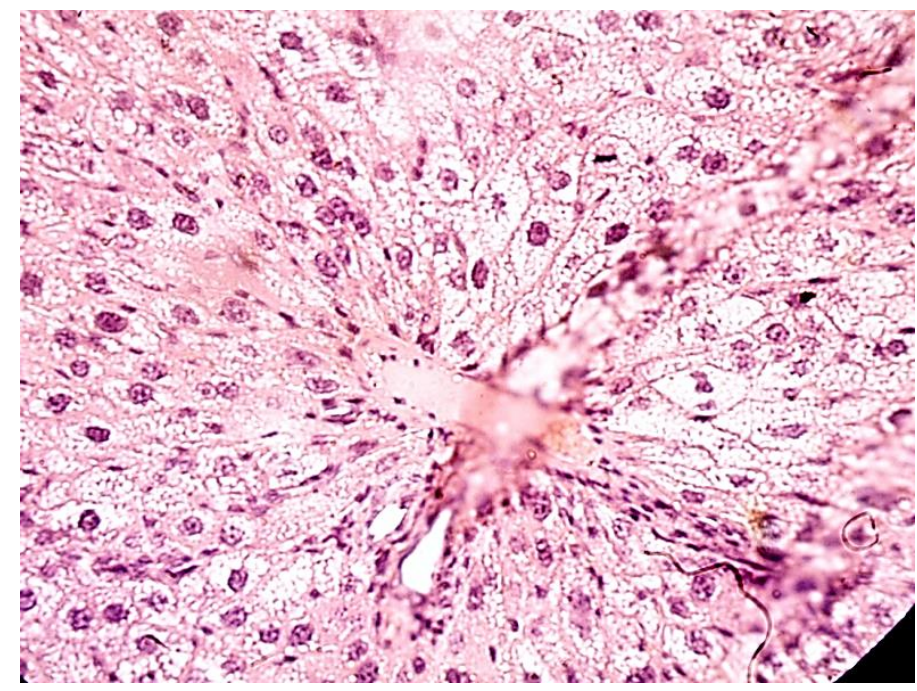

Рисунок 4. Протальная область печени крысы содержащейся на углеводном рационе кормления. Заливка в парафин х 400

Большинство гепатоцитов находятся в состоянии углеводной дистрофии, наряду с которыми обнаруживаются очаги диспротеиноза и липидоза. Гепатоциты характеризуются просветлением цитоплазмы и ядра с разной степенью повреждения. Многие печеночные 
клетки превращаются в вакуоли, заполненные прозрачной жидкостью. Развивается вакуольная дистрофия, перемежающаяся с зернистой дистрофией.

\section{Bblвodbl}

1. Концентрация холестерина в крови повышается при углеводном, белковом и жировом рационах кормления крыс, особенно - при липидном.

2. Концентрация глюкозы в крови выросла при содержании животных на углеводном и липидном рационе.

3. Содержание общего белка увеличилось в группах с белковым питанием, в группах с липидным и углеводным кормом количество глюкозы было равнозначным. Отмечена наиболее высокая концентрация альбумина в группе с липидной диетой и наиболее низкая с углеводной.

4. Кормление крыс в течение 15 дней курдючным салом приводит к нарушению баланса между скоростью синтеза и распада жиров в гепатоцитах. К липидозу присоединяются диспротеиноз и углеводная дистрофия печени.

5. Кормление крыс сахаром вызывает углеводную дистрофию печени. Наряду с углеводной обнаруживаются очаги диспротеиноза и липидоза, развивается вакуольная дистрофия и формируется фиброз.

\section{Список литературы:}

1. Воздействие диетических рисков на здоровье в 195 странах, 1990-2017 гг: систематический анализ для Глобального исследования бремени болезней 2017 г. // Ланцет. 2019. T. 393. №10184. C. 1958-1972. https://doi.org/10.1016/S0140-6736(19)30041-8

2. Тутельян В. А., Самсонов М. А. Справочник по диетологии. М: Медицина. 2002. 50 c.

3. Тутельян В. А. Наука о питании: прошлое, настоящее, будущее: к 75-летию Института питания РАМН // Вопросы питания. 2005. Т. 74. №6. С. 3-10.

4. Богданов А. Р., Дербенева С. А., Залетова Т. С., Найденова М. А., Никитюк Д. Б., Каганов Б. С. Оценка эффективности стандартных диет в лечении больных ожирением с хронической сердечной недостаточностью // Вопросы диетологии. 2018. №8(1). С. 5-10.

5. Барановский А. Ю. Болезни обмена веществ. СПб.: СпецЛит. 2002. 235 с.

6. Кабков М. В., Полянина А. Ю., Шнайдер Д. Д., Неганова А. Ю., Дрангой М. Г., Яшкина Е. В. Справочник диетолога. Л.: Научная книга. 2017. 544 с.

7. Барановский А. Ю. Диетология. СПб: Питер. 2012. 1024 с.

8. Шарова Е. В., Горборукова Л. П., Айтматов М. К., Ибраева И. Г. Влияние прохладительных напитков на биохимические показатели крови опытных животных // Современные тенденции развития науки и технологий. 2017. Т. 4. №2. С. 104-107.

\section{References:}

1. Vozdeistvie dieticheskikh riskov na zdorov'e v 195 stranakh, 1990-2017 gg: sistematicheskii analiz dlya Global'nogo issledovaniya bremeni boleznei 2017 g. (2019). Lantset, 393(10184). 1958-1972. https://doi.org/10.1016/S0140-6736(19)30041-8 (in Russian).

2. Tutel'yan, V. A., \& Samsonov, M. A. (2002). Spravochnik po dietologii. Moscow, Meditsina. 50. (in Russian).

3. Tutel'yan, V. A. (2005). Nauka o pitanii: proshloe, nastoyashchee, budushchee: $\mathrm{k}$ 75-letiyu Instituta pitaniya RAMN. Voprosy pitaniya, 74(6). 3-10. (in Russian). 
4. Bogdanov, A. R., Derbeneva, S. A., Zaletova, T. S., Naidenova, M. A., Nikityuk, D. B., \& Kaganov, B. S. (2018). Otsenka effektivnosti standartnykh diet v lechenii bol'nykh ozhireniem s khronicheskoi serdechnoi nedostatochnost'yu. Voprosy dietologii, 8(1). 5-10. (in Russian).

5. Baranovskii, A. Yu. 2002. Bolezni obmena veshchestv. St. Petersburg, SpetsLit. 235. (in Russian).

6. Kabkov, M. V., Polyanina, A. Yu., Shnaider, D. D., Neganova, A. Yu., Drangoi, M. G., \& Yashkina, E. V. (2017). Spravochnik dietologa. Leningrad. Nauchnaya kniga. 544. (in Russian).

7. Baranovskii, A. Yu. (2012). Dietologiya. St. Petersburg, Piter. 1024. (in Russian).

8. Sharova, E. V., Gorborukova, L. P., Aitmatov, M. K., \& Ibraeva, I. G. (2017). Vliyanie prokhladitel'nykh napitkov na biokhimicheskie pokazateli krovi opytnykh zhivotnykh. Sovremennye tendentsii razvitiya nauki i tekhnologii, 4(2). 104-107. (in Russian).

Работа поступила

в редакциию 05.01.2020 г.
Принята к публикащии

10.01.2020 2.

Ссылка для цчитирования:

Шидаков Ю. Х.-М., Шарова Е. В., Абдумаликова И. А., Машанло Т. Р., Абдулбакиев А. А. Влияние рациона кормления крыс на биохимический профиль крови и морфологию печени // Бюллетень науки и практики. 2020. Т. 6. №2. С. 60-66. https://doi.org/10.33619/2414$2948 / 51 / 06$

Cite as (APA):

Shidakov, Yu., Sharova, E., Abdumalikova, I., Mashanlo, T., \& Abdulbakiev, A. (2020). Effect of Feeding Rat on the Biochemical Profile of Blood and Liver Morphology. Bulletin of Science and Practice, 6(2), 60-66. https://doi.org/10.33619/2414-2948/51/06 (in Russian). 


\section{ВОЗРАСТ И МИКРОБИОТА: ЭПИГЕНЕТИЧЕСКАЯ И ДИЕТИЧЕСКАЯ ЗАЩИТА, ЭНДОТЕЛИАЛЬНАЯ И СОСУДИСТАЯ РЕАБИЛИТАЦИЯ, НОВАЯ УПРАВЛЯЕМАЯ ЗДОРОВАЯ БИОМИКРОБИОТА}

СРоманчук П. И., ORCID: 0000-0002-0603-1014, SPIN-код: 2546-9211, акад. PAMTH, Гериатрический Центр, г. Самара, Россия, Romanchukpi@yandex.ru

\section{AGE AND MICROBIOTA: EPIGENETIC AND DIETARY PROTECTION, ENDOTHELIAL AND VASCULAR REHABILITATION, THE NEW OPERATED HEALTHY BIOMICROBIOTA}

\section{CRomanchuk P., ORCID: 0000-0002-0603-1014, SPIN-code: 2546-9211, Academician RAMTN,} Geriatric Center, Samara, Russia, Romanchukpi@yandex.ru

Аннотация. Исследованы основные современные инструменты и методики эпигенетической, диетической и биомикробиотической защиты здорового старения. Искусственный интеллект, нейросети «мозг-микробиота» позволяют управлять взаимодействием генетических и эпигенетических программ старения и здорового долголетия. Новая управляемая здоровая биомикробиота и персонализированное функциональное и сбалансированное питание «мозга и микробиоты» - это долговременная медицинская программа пациента, которая позволяет комбинированному применению питательной эпигенетики и фармэпигенетики, а главное проведению профилактики полипрагмазии. Мультимодальные инструменты, биочипирование, нейронные и мозговые чипы, технологии секвенирования следующего (нового) поколения создают биомаркеры для управления структурой здоровой биомикробиоты и функционального питания, в зависимости от достигаемых целевых показателей. Функциональный продукт питания с помощью биомаркеров и технологий искусственного интеллекта является целевой питательной средой как для организма в целом, так и для биомикробиоты в частности. Хрономедицинские технологии - это математические модели и искусственный интеллект, которые предсказывают биологический возраст человека с помощью данных метилирования ДНК, модификации гистонов, ремоделирование нуклеосом и микроРНК, и являются наиболее точными биомаркерами процесса старения. Эпигенетические механизмы (метилирование ДНК, модификации гистонов, нкРНК) взаимосвязаны и образуют «эпигенетическую сеть». Факторы образа жизни и воздействия окружающей среды оставляют эпигенетические следы на нашей ДНК, которые влияют на экспрессию генов, некоторые из них оказывают защитное действие, а другие - вредное. Генетические и эпигенетические факторы обеспечивающие долголетие и сверхдолголетие, требуют от человека разумного нового взаимодействия с природой и обществом, и ответственности за будущие здоровые поколения.

Abstract. The main modern tools and techniques of epigenetic, dietary and biomicrobiotic protection of healthy ageing have been studied. Artificial intelligence, brain-microbiota neural networks allow to control interaction of genetic and epigenetic programs of ageing and healthy longevity. The new managed healthy biomicrobiota and personalized functional and balanced nutrition of 'brain and microbiota' is a long-term medical program of the patient, which allows the combined application of nutritional epigenetics and pharmacepigenetics, and the main thing to carry 
out prevention of polypragmasia. Multimodal tools, biochyping, neural and brain chips, nextgeneration (new) sequencing technologies create biomarkers to manage the structure of healthy biomicrobiota and functional nutrition, depending on the targets achieved. A functional food product using biomarkers and artificial intelligence technologies is a target breeding ground for both the body in general and biomicrobiota in particular. Chronomedical technologies are mathematical models and artificial intelligence that predict human biological age using DNA methylation data, histone modifications, nucleosome remodeling, and microRNA, and are the most accurate biomarkers of the aging process. Epigenetic mechanisms (DNA methylation, histone modifications, ncRNAs) are interconnected and form an 'epigenetic network'. Lifestyle factors and environmental exposures leave epigenetic marks on our DNA that impact gene expression; some have protective effects while others are harmful. Genetic and epigenetic factors that ensure longevity and super-longevity require a reasonable new human interaction with nature and society, and responsibility for future healthy generations.

Ключевые слова: новая эпигенетика, новая управляемая здоровая биомикробиота, возрастные заболевания, воспаление, биомаркеры, эпигенетические часы, эпигенетическая и диетическая защита, долголетие.

Keywords: new epigenetics, new manageable healthy biomicrobiota, age-related diseases, inflammaging, biomarkers, epigenetic clocks, epigenetic and dietary protection, longevity.

Целью исследования является установить основные современные инструменты и методики эпигенетической, диетической и биомикробиотической защиты здорового старения и долголетия человека разумного.

В настоящем исследовании были рассмотрены следующие эпигенетические, микробиотические и диетические проблемы:

Геронтологические и гериатрические мультимодальные методики и инструменты защитного сопровождения долголетия Homo Sapiens.

Искусственный интеллект и нейросети «мозг-микробиота» являются ли инструментом эпигенетического регулирования функционального макробиотического питания «мозга-тела (организма)-микробиоты».

Современная эпигенетическая, микробиотическая и диетическая защита Нomo sapiens и мозг Homo sapiens, с помощью создания (культивирования) новой персонифицированной здоровой биомикробиоты.

Современное и своевременное внедрение эпигенетических постулатов питания от «Здоровое питание матери - лучшее начало жизни» до «Здоровое питание человека обеспеченное здоровое старение» позволит эффективной реализации программ долголетия и сверхдолголетия Ноmo sapiens и мозга Homo sapiens.

Эпигенетика предполагает более широкое представление о развитии организма и функционировании генома и рассматривает гены и окружающую среду комплексно, как две неразрывно функционирующие системы, и объясняет такие биологические явления, как пластичность развития и образование множества фенотипов на основе одного генотипа.

Эпигенетические механизмы задействованы от внутриутробного развития ребенка до старения в более позднем возрасте. Функциональные продукты питания и их целевые пищевые компоненты могут вызывать защитные эпигенетические модификации на протяжении всей жизни, причем питание на ранних этапах жизни особенно важно. Помимо генетики, общее состояние здоровья индивидуума можно рассматривать как интеграцию 
многих экологических сигналов, начинающихся в период беременности и действующих на протяжении жизнедеятельности через эпигенетические модификации.

Микро- и макронутриенты функциональных продуктов питания в сочетании с фруктами и овощами могут оказывать сходное воздействие на ДНК с эпигенетическими препаратами. Более глубокое понимание эпигенетических эффектов и сигнальных путей, активируемых функциональными пищевыми компонентами, оказывает потенциальную пользу питательных веществ, для нашего здоровья и снижения восприимчивости к возрастассоциированным заболеваниям. Питательная (функционально-сбалансированная) эпигенетика может сочетаться с лекарственными средствами для синергического воздействия в целях лечения или профилактики и быть адаптирована для беременных женщин с целью снижения бремени хронических заболеваний у потомства посредством «эпигенетически здоровой» диеты. Как в развитых, так и в развивающихся странах оптимизация рациона питания матерей является сложной проблемой общественного здравоохранения. Будущая работа в области питания и эпигенетики может принести значительную пользу общественному здравоохранению, а персонализированное питание может стать частью медицинской программы пациента.

Модификации метаболической экспрессии генов включают краткосрочное метилирование гистонов, ацетилирование, фосфорилирование, убиквитинирование и более долгосрочный сайленсинг ДНК как результат метилирования ДНК.

Современная эпигенетическая защита мозга Ноmo sapiens позволяет с помощью генетических и эпигенетических программ старения управлять здоровым долголетием, посредством мультимодальных инструментов:

-комбинированного и гибридного информационного кластера в диагностике, лечении, профилактике и реабилитации когнитивных нарушений и когнитивных расстройств;

-регуляции эпигенетических часов под контролем искусственного интеллекта для ранней диагностики, лечения и профилактики здорового старения Homo sapiens;

-эпигенетического регулирования сердечно-сосудистого старения для замедления развития сосудистой деменции и болезни Альцгеймера;

-профилактики полипрагмазии через комбинированное применение питательной эпигенетики и фармэпигенетики;

-нутригенетики и нутригеномики - персонализированного функционального питания «мозга и микробиоты» - медицинской программы пациента;

-биочипирования, нейронных и мозговых чипов, технологий секвенирования следующего (нового) поколения для создания информативных биомаркеров;

-new EPIGENETICS Homo sapiens и мозг Homo sapiens [1, 19].

Количество видов бактерий пищеварительного тракта человека достигает от 10 тыс штаммов - до 50 тыс. Количественное содержание этих бактерий находится в пределах сотен триллионов, а с вирусами - превышает квадриллион. Количество генов в хромосомах человека достигает 25000; микрогеном включает до 5-10 милн генов. Восстановление (замена) всех эукариотических клеток у человека требует не менее 20-25 лет, за это время все симбиотические микроорганизмы меняются не менее пяти-шести раз, что свидетельствует о высокой адаптационной способности человеческого надорганизма. Более $80 \%$ энергии человека синтезируется в митохондриях, 20\% энергетического обеспечения человека приходится на микроорганизмы кишечника. Установлено, что 90\% энергии для клеток пищеварительного тракта производится кишечными бактериями. Именно микроорганизмы являются ключевым звеном, стартерами возникновения, а затем эволюции и разнообразия биологической жизни, включая человека, на нашей планете. Молекулярными, клеточными и средовыми основами 
здоровья и долголетия являются метагеном и эпигеном человека и полноценность их реализации в конкретных условиях его жизнедеятельности [34, 44-46].

Нейродегенеративные и возраст - ассоциированные хронические заболевания, при которых имеют место такие патофизиологические проявления как нестабильность генома и эпигенома, окислительный стресс, хроническое воспаление, укорочение теломер, утрата протеостазиса, митохондриальные дисфункции, клеточное старение, истощение стволовых клеток и нарушение межклеточной коммуникации преимущественно инициируются несбалансированным питанием и дисбалансом симбиотической кишечной микробиоты.

С возрастом эффективность работы системы активные радикалы/антиоксидантная защита снижается, что приводит к нарушению работы дыхательной цепи переноса электронов и уменьшению образования АТФ. Увеличение образования активных радикалов кислорода и липидов в митохондриях сопровождается повреждением функций последних и приводит к преждевременной гибели клеточных структур и клеток. Долголетию способствует повышенная активность ряда белков, связанных с антиоксидантной защитой (Mn-SOD; $\mathrm{Cu} / \mathrm{Zn}, \mathrm{SOD}$; митохондриальная каталаза). Активные радикалы усиливают пролиферативные процессы и выживаемость клеток в ответ на физиологические стрессы и сигналы, активируя компенсаторные гомеостатические ответы [35, 38, 42, 48, 52].

В результате пищеварительной деятельности кишечной микробиоты образуется огромное количество разнообразных низкомолекулярных соединений, в том числе и обладающих нейро-гормональной активностью $[36,38,49,52,53]$.

Понимание механизмов функционирования генома, эпигенома, их взаимоотношений с факторами среды повышает точность диагностики заболеваний, позволяет разрабатывать персонифицированные диеты и выявлять среди известных или вновь созданных лекарственных средств те, которые имеют эпигеномную направленность [50, 62].

Основное внимание для реализации этого подхода уделяется созданию персонифицированных пищевых рационов для родителей (прежде всего женщин в детородном возрасте) и детей во все периоды их жизни после рождения, а также сохранению и восстановлению кишечной микробной экологии будущих матерей, беременных и кормящих женщин. Большое значение имеет поддержание на нужном уровне всех этапов становления и сукцессии микробиоты кишечника будущего человека. Более широкое применение для оптимизации пищевых рационов населения находят функциональные продукты питания, позволяющие целенаправленно конструировать пищевые рационы с учетом этнической принадлежности потребителей, их возраста, профессии, экологических и географических особенностей регионов их проживания [55, 61].

Такие продукты, предназначены для систематического (регулярного) употребления в составе обычных пищевых рационов всеми группами здорового населения, сохраняющие и улучшающие состояние их здоровья и снижающие риск алиментарных заболеваний, благодаря наличию в составе подобных продуктов функциональных нутриентов, способных оказывать благоприятный эффект на физиологические функции, метаболические и/или поведенческие реакции организма человека [55, 61].

В категорию функциональных продуктов относят продукты, естественно содержащие требуемые количества функционального ингредиента или группы их; натуральные продукты, дополнительно обогащенные каким-либо функциональным ингредиентом или группой их; натуральные продукты, из которых удален компонент, препятствующий проявлению физиологической активности присутствующих в них функциональных ингредиентов; натуральные продукты, в которых исходные потенциальные функциональные ингредиенты модифицированы таким образом, что они начинают проявлять свою биологически активную физиологическую 
активность или эта активность усиливается; натуральные пищевые продукты, в которых в результате тех или иных модификаций биоусвояемость входящих в них функциональных ингредиентов увеличивается; натуральные или искусственные продукты, которые в результате применения комбинации вышеуказанных технологических приемов, приобретают способность сохранять и улучшать физическое и психическое здоровье человека и/или снижать риск возникновения заболеваний $[37,54,60]$.

Кишечная микробиота играет жизненно важную роль в различных аспектах здоровья человека. Многочисленные исследования связали изменения в микробиоте кишечника с развитием различных заболеваний. Среди огромного бактериального сообщества кишечника бифидобактерии- это род, который доминирует в кишечнике здоровых грудных детей, тогда как в зрелом возрасте уровни ниже, но относительно стабильны. Наличие различных видов бифидобактерий изменяется с возрастом, от детства до глубокой старости (Рисунок 1). Bifidobacterium longum, B. breve и В. bifidum как правило, доминируют у новорожденных, тогда как В. catenulatum, В. adolescentis и, а также В. longum они более распространены у взрослых [39].

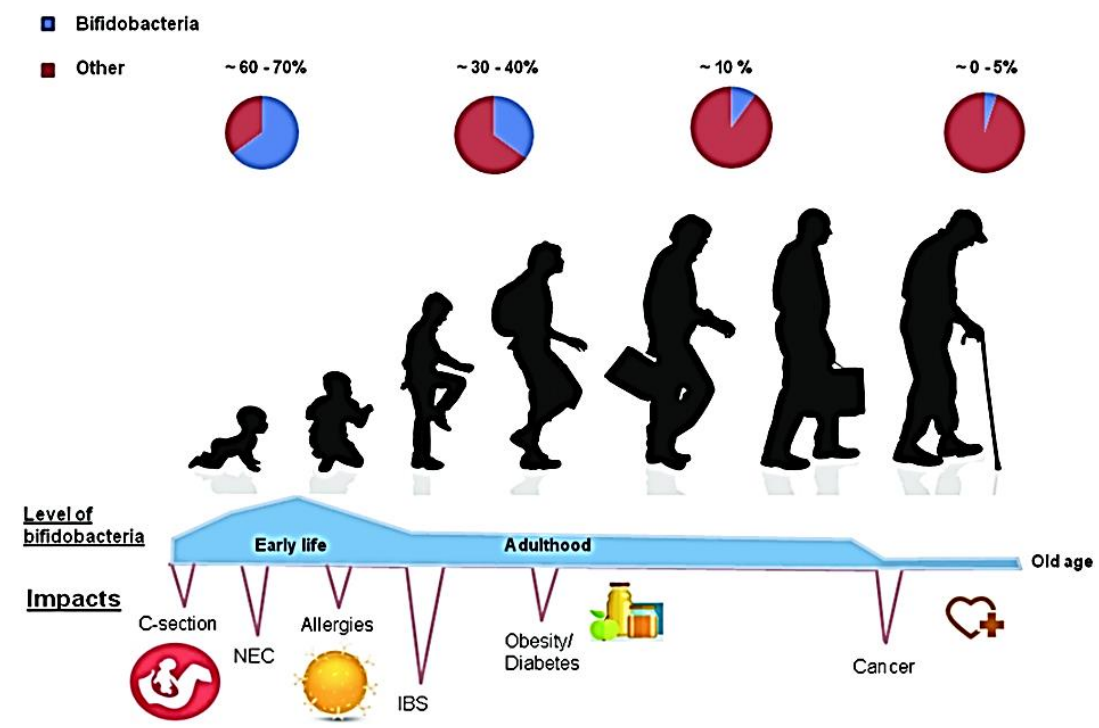

Рисунок 1. При рождении уровень бифидобактерий находится на самом высоком уровне. В случаях естественного деторождения это число наиболее велико при рождении [39]

Убедительные доказательства указывают на наличие окна возможностей в ранней жизни, во время которого изменения в кишечной микробной колонизации могут привести к иммунной дисрегуляции, которая предрасполагает восприимчивых хозяев к заболеванию. Хотя экологические закономерности микробной сукцессии в первый год жизни были частично определены в конкретных человеческих группах, таксономические и функциональные особенности, а также пороги разнообразия, характеризующие эти микробные изменения, по большей части неизвестны. Установлены, наиболее важные связи между временной мозаикой микробной колонизации кишечника и зависящими от возраста иммунными функциями, которые зависят от них. Взаимодействие между сложной экосистемой и иммунной системой хозяина ведет к пониманию важности темпорально структурированных структур разнообразия, ключевых групп и межцарственных микробных взаимодействий для экосистемных функций имеет большой потенциал для разработки биологически обоснованных мероприятий, направленных на поддержание и/или улучшение развития иммунной системы и предупреждение заболеваний. 
В конечном счете, выявление критических событий и факторов, влияющих на устойчивость и функционирование микробиома, позволит разработать эффективные мероприятия, направленные на поддержание и/или улучшение развития иммунной системы и профилактику заболеваний. Выполнен огромный объем работы, чтобы понять зависимость иммунной системы от микробиома кишечника ребенка, многое еще предстоит выяснить о конкретных механизмах, ответственных за эту подготовку (Рисунок 2). Улучшение нашего понимания будет происходить в результате продолжения междисциплинарных совместных усилий иммунологов, микробиологов, клиницистов, биоинформатиков и экологов [25].

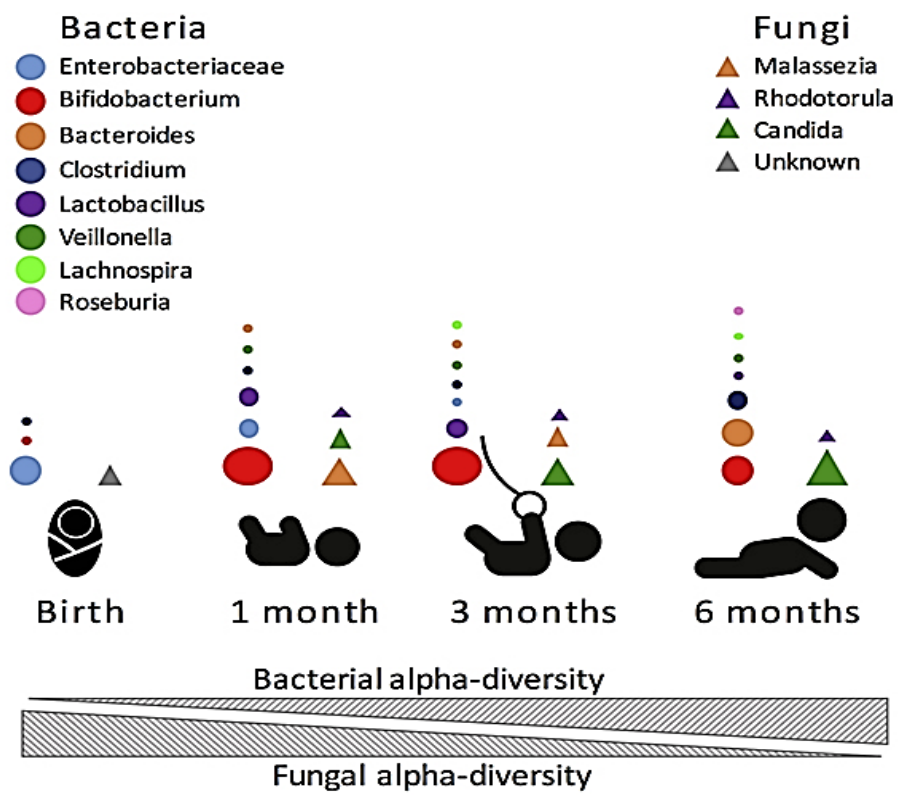

Рисунок 2. Наиболее распространены бактериальные (круги) и грибковые (треугольники) таксоны в течение первых 6 месяцев жизни человека. Размер круга пропорционален относительному обилию бактериальных таксонов [25]

Кишечная микробиота - это динамичная система, которая ежедневно перестраивается в соответствии с пищевым рационом.

Микробиота младенцев и взрослых имеет важное значение для физиологических метаболических процессов (пищеварения) и должна быть способна снабжать хозяина метаболическими предшественниками, биологически активными молекулами, которые не присутствуют в основном в рационе и не производятся самим хозяином (Рисунок 3 ). Поглощение питательных веществ происходит на уровне кишечного барьера, обширной поверхности эпителия около $400 \mathrm{~m}^{2}$ поддерживается за счет плотного соединения между ячейками. Здоровая микробиота кишечника может модулировать метаболизм хозяина эпигенетической регулировкой. Следовательно, измененный состав микробиоты будет подавать аберрантный сигнал клеткам-хозяевам, что приведет к нарушению обмена веществ [20]. В настоящее время, мало что известно об отдаленном влиянии этих бактерий на эукариотическую эпигенетическую регуляцию. В последнее время дифференциальное метилирование ДНК и ковалентная модификация гистонов, регулирующих транскрипцию генов, были связаны с питанием. Было показано, что как недостаточное, так и избыточное питание во время беременности и/или лактации индуцируют устойчивые модификации потомства через программирования генетического наследования. Связь между микробиотой и эпигенетическими модификациями должна быть дополнительно исследована. Эпигенетика проявляет унаследованные характеристики (так называемое «эпигенетическое программирование»), именно клеточное микроокружение (бактериальные поверхностные 
антигены и секретируемые белки, низкомолекулярные соединения из бактерий и биологически активные молекулы, поступающие через диету и обрабатываемые кишечной микробиотой) остается неизменным от одного поколения к другому [20].

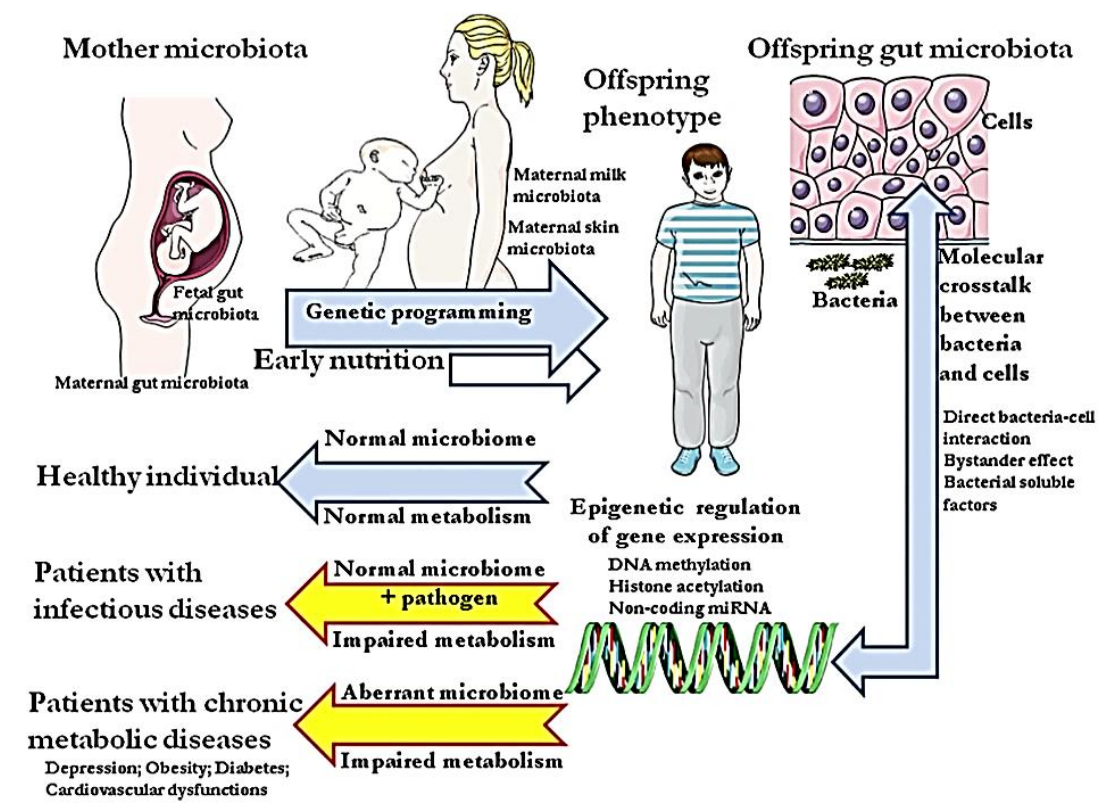

Рисунок 3. Схематическое представление о колонизации кишечника симбионтными бактериями начиная с эмбриональной среды в утробе матери вплоть до раннего периода жизни и от младенцев до взрослых особей [20]

«Микробиологическая память» будет доставлять прямые и случайные сигналы в целевую ячейку (левая панель) (Рисунок 4). После поверхностного взаимодействия клеток (например, растворимое бактериальное соединение, взаимодействующее с рецепторным комплексом клеточной поверхности) внутриклеточные пути активации сигнала будут модулироваться (например, фосфорилирование цитоплазматических белков киназами, ядерная транслокация факторов транскрипции), тем самым влияя на баланс между активацией и генетическим блокированием транскрипции метилированием ДНК и нкРНК. Нуклеосомы состоят из гистонов и двухцепочечной ДНК. Когда динуклеотиды CpG неэтилируются в области промотора гена, РНК-полимераза (РНКпол) может связывать и активировать транскрипцию (справа). Метилирование $\mathrm{CpG}$-динуклеотидов (красные символы) метилтрансферазами ДНК рекрутирует гистондиацетилазу (HDAC) / гистоновый комплекс метилтрансферазы (НMT), который в свою очередь удалит ацетильные группы из гистонов и метилирует специфические остатки, общий эффект которых заключается в подавлении транскрипции. Показана также транскрипционная и/или трансляционная интерференция некодирующей РНК (нкРНК) [20].

Исследовано [20], что передача биологической информации от одного поколения к другому основана на ДНК, то наиболее наследуемые фенотипические признаки, такие как хронические метаболические заболевания, не связаны с генетической вариабельностью последовательностей ДНК. Негенетическая наследуемость может иметь несколько причин, включая эпигенетический, родительский эффект, адаптивное социальное обучение и влияние экологической среды. Различение этих причин имеет решающее значение для разрешения основных фенотипических загадок. 


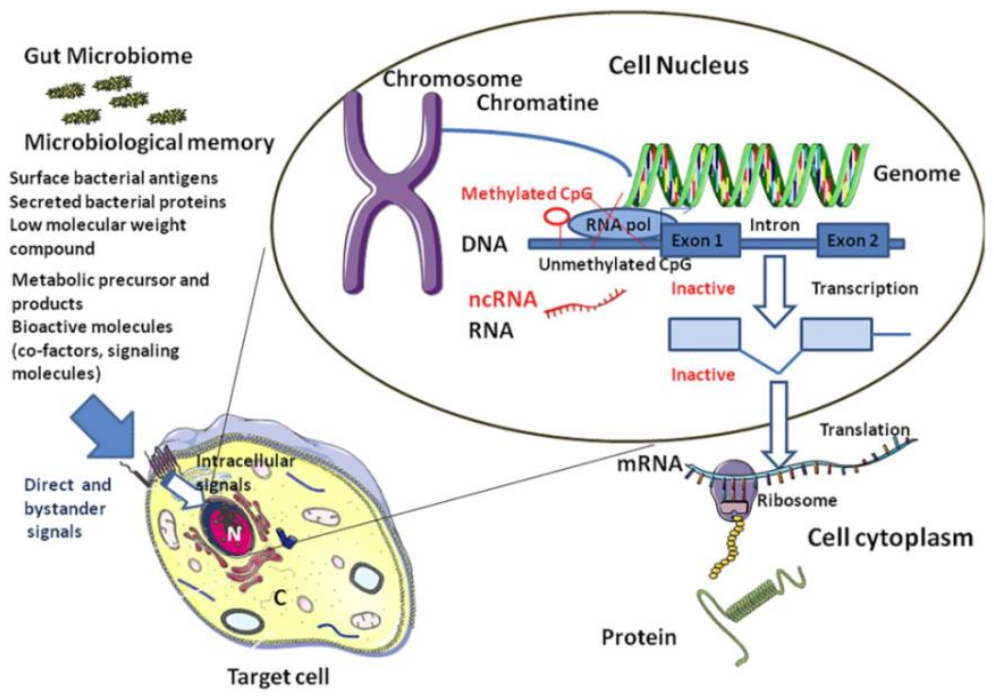

Рисунок 4. Связь между микробиотой и эпигенетическими модификациями [20]

Убедительные доказательства указывают на то, что изменения в экспрессии ДНК через различные эпигенетические механизмы, могут быть связаны, со сходством между родителями и потомством с точки зрения чувствительности к метаболическим заболеваниям. Среди негенетических наследуемых признаков функциональное питание объясняет долгосрочное программирование экспрессии генов, ответственных за метаболические заболевания во взрослом возрасте. Питание может формировать неадекватную микробиоту кишечника (дисбиоз), вызывая эпигенетическое дерегулирование транскрипции, которое может наблюдаться при хронических заболеваниях обмена веществ. Дисбиоз может быть основной причиной наследуемых эпигенетических паттернов, обнаруженных в связи с метаболическими заболеваниями. Последние достижения в области микробиома кишечника, подтверждают гипотезу о том, что микробиота кишечника может способствовать молекулярному перекрестному столкновению между бактериями и окружающими клеткамихозяевами, которое контролирует патологическую эпигенетическую сигнатуру.

Микробиологическая память - это основной регулятор эпигенетических сигнатур, тем самым указывая, что различные причины негенетической наследуемости могут взаимодействовать в сложных путях для получения наследования (Рисунок 5, 6).

Последствия дисрегуляции иммунного ответа

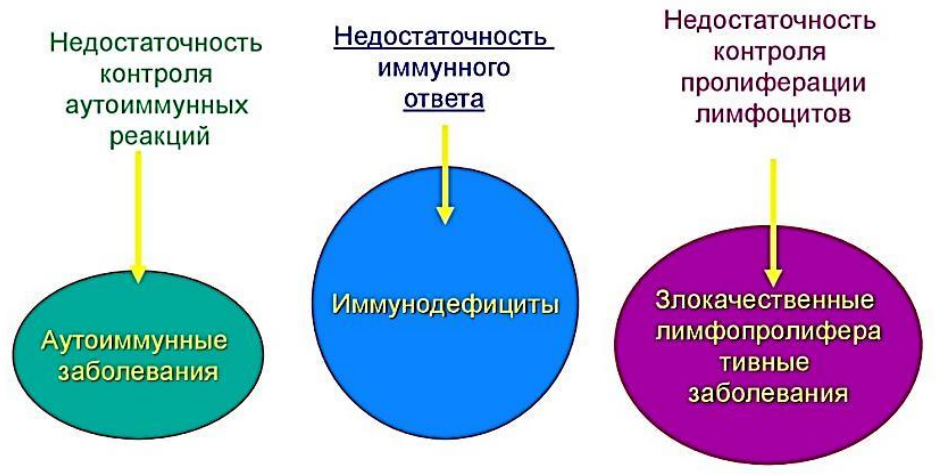

Рисунок 5. Последствия дисрегуляции иммунного ответа 


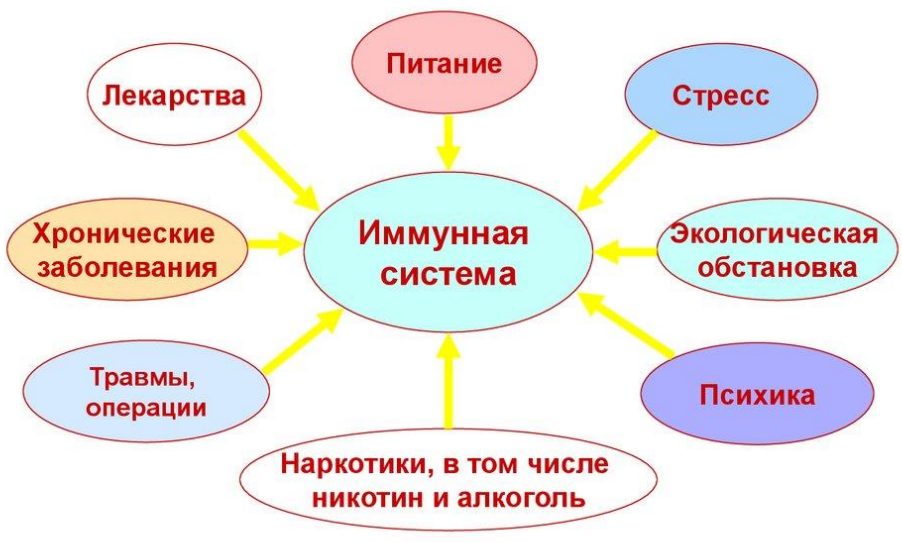

Рисунок 6. Основные факторы, оказывающие влияние на иммунную систему

Комбинированное основное действие различных эпигенетических факторов на человека из различных источников, присутствующих в окружающей среде. Хотя некоторые из них могут быть полезны для здоровья и поведения, другие могут быть вредными и мешать телу и головному мозгу, создавая дисбаланс, который может проявляться как болезнь или психологическое расстройство. Некоторые из перечисленных благотворных влияний включают физические упражнения, микробиом (полезные кишечные бактерии) и альтернативную медицину, в то время как вредные влияния включают воздействие токсичных химических веществ и наркотиков злоупотребления. Такие факторы, как диета, сезонные изменения, финансовое положение, психологическое состояние, социальные взаимодействия, терапевтические препараты и воздействие болезни, могут оказывать благотворное или вредное воздействие в зависимости от конкретного характера воздействия. Таким образом, окружающая среда дополняет и формирует здоровье человека.

Микробиологическая память будет оставаться стабильной, когда рацион питания и микробиота остаются почти неизменными. Согласно этой модели, в настоящее время известно как эпигенетическое программирование, вероятно, является не более чем негенетической наследуемой сигнатурой, возникающей в результате молекулярного скрещивания между прокариотами кишечника (метаболитом микробиоты) и эукариотическими клетками. Эта перекрестная помеха вызвала бы непрерывную перестройку клеточных генов через активацию сигнальных путей в клетках-хозяевах, тем самым контролируя эпигенетическую сигнатуру. Эпигенетика может быть исследована более или менее простым способом, изучая сигнатуру заболеваний, влияние микробиологической памяти гораздо труднее расшифровать из-за вовлечения многих переменных. Исследования очень необходимы для того, чтобы различать, что является причинным и что является совместным явлением в триаде «диете-микробиоте-эпигенетике» [20].

Оба хозяина клетки и микробы взаимодействуют друг с другом через множество молекул и механизмов (Рисунок 7), которые зависят от способности обоих типов ячеек адаптироваться к (1) данной среде, то есть кишечнику хозяина; (2) а при лечении, т.е. специальном рационе питания; или (3) при воспалении кишечника. Эти механизмы являются гибкими (4), (5), поскольку бактерии, особенно патобиоты, используют свой спящий арсенал вирулентности в зависимости от патофизиологического статуса хозяина [21]. 


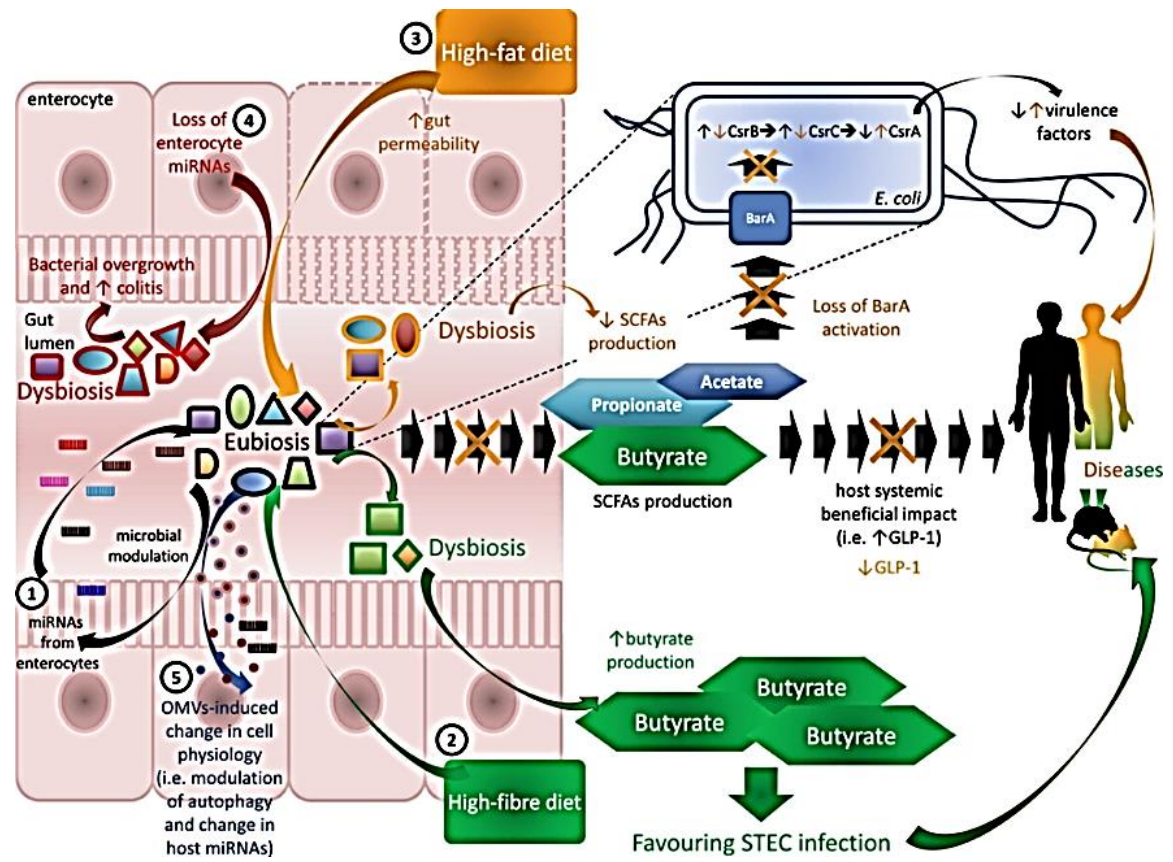

Рисунок 7. Основные особенности молекулярного диалога между хозяином и кишечником для индукции заболеваний и инфекций [21]

В исследовании [14], установлена сильная связь между микробиотой кишечника и многими заболеваниями человека, и понимание динамических перекрестных связей взаимодействия хозяина и микроба в кишечнике стало необходимым для обнаружения, профилактики или терапии заболеваний. Диета, питательные вещества, фармакологические факторы и многие другие стимулы играют доминирующую роль в модуляции микробных композиций кишечника. Факторы, связанные с эпителием, включая врожденные иммунные сенсоры, антимикробные пептиды, слизистый барьер, секреторные IgAs, эпителиальные микроворсинки, эпителиальные плотные соединения, метаболизм эпителия, кислородный барьер и даже микроРНК участвуют в формировании микробиоты. Указанные факторы, клеточного кишечного эпителия селективно «выбирают» микробы и влияют на микробный состав. Полученные результаты, предоставляют возможность для более эффективного контроля многих заболеваний и прогнозирования клинического успеха трансплантации фекальной микробиоты [14].

Важным фактором является понимание того, что соизмеримые микроорганизмы, которые составляют человеческую микробиоту, являются не просто пассажирами в хозяине, но могут фактически управлять определенными функциями [40]. Микробиота и ее микробиома, как установлено, имеют не только ассоциацию, но и ключевую модулирующую роль. Благодаря лучшему пониманию механизмов и вклада микробиоты в эти заболевания, будут разработаны новые терапевтические средства и стратегии для модулирования микробиоты для лечения или профилактики заболеваний. Кроме того, в некоторых случаях это может быть возможность использования микробиомы для выявления заболеваний, связанных с кишечником, до проведения обычной диагностики. В будущем будет проводится стратификация пациентов более точно для более эффективного лечения (Рисунок 8). Заболевания печени и микробиота кишечника. Печень получает $70 \%$ своего кровоснабжения из кишечника через портальную вену, таким образом, она постоянно подвергается воздействию кишечных факторов, включая бактериальные компоненты. В настоящее время установлено, что микробиота кишечника и хронические заболевания печени тесно связаны между собой. Дисбиоз кишечника, целостность кишечного барьера и механизмы иммунного 
ответа печени на гуморальные факторы, полученные из кишечника, свидетельствуют о потенциальной актуальности разработки новых методов лечения хронических заболеваний печени [40].

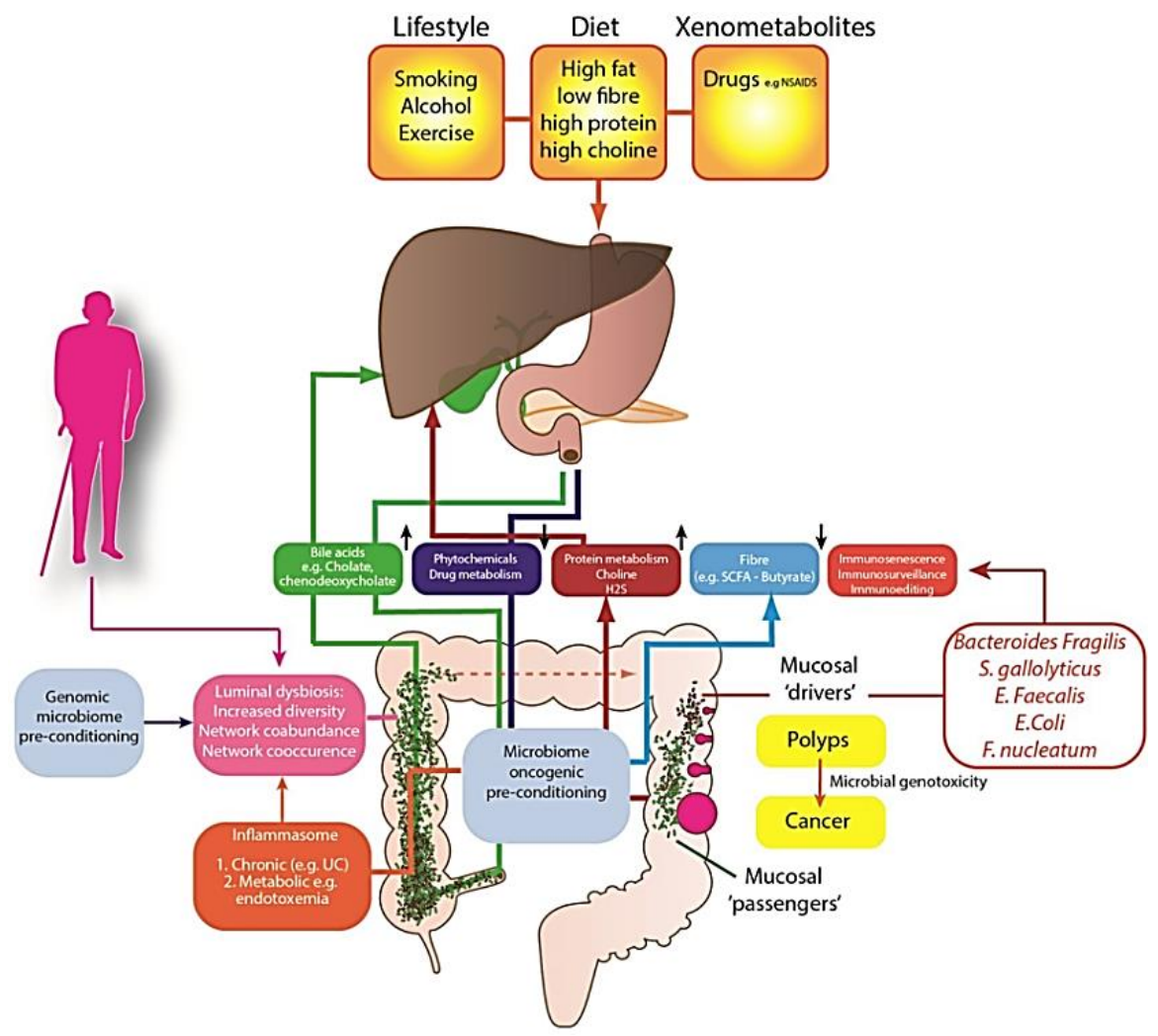

Рисунок 8. Роль кишечной микробиоты в этиологии рака толстой кишки [40]

Научные данные, касающиеся микробиоты кишечника, позволяют объяснить связь между питательными веществами и чертами человека. Микробиота кишечника не только непосредственно взаимодействует с соматическими клетками своего хозяина, влияя на особенности человека, как в случае тренировки иммунологических сетей, но и вырабатывает различные химические вещества, которые могут непосредственно модифицировать биохимические пути человека (Рисунок 9, 10).

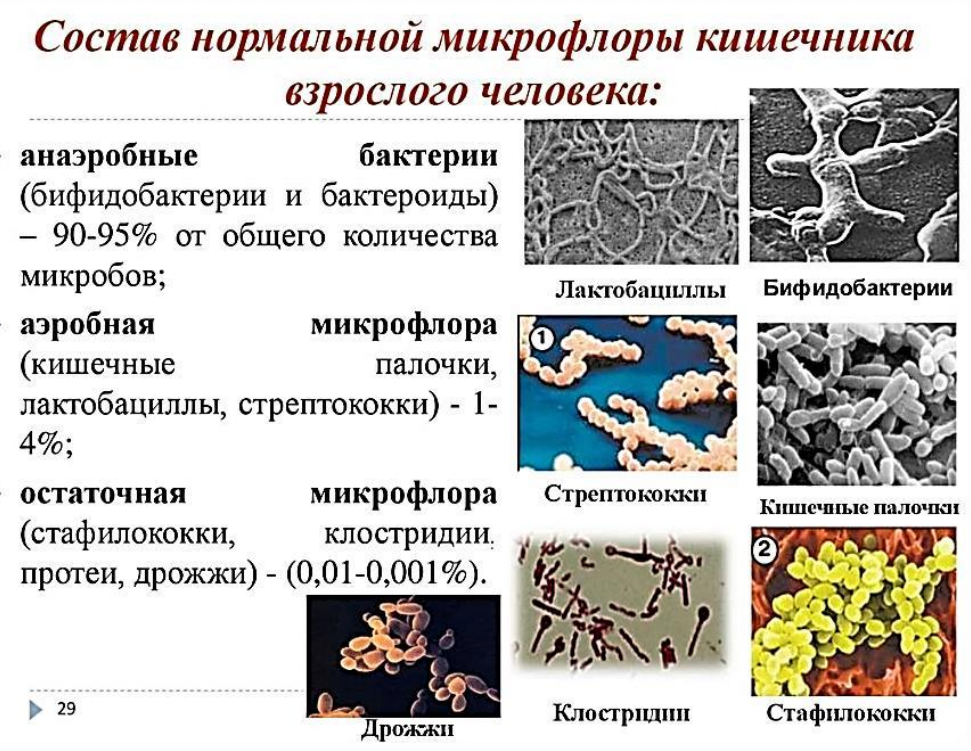

Рисунок 9. Состав нормальной микрофлоры кишечника взрослого человека [40] 


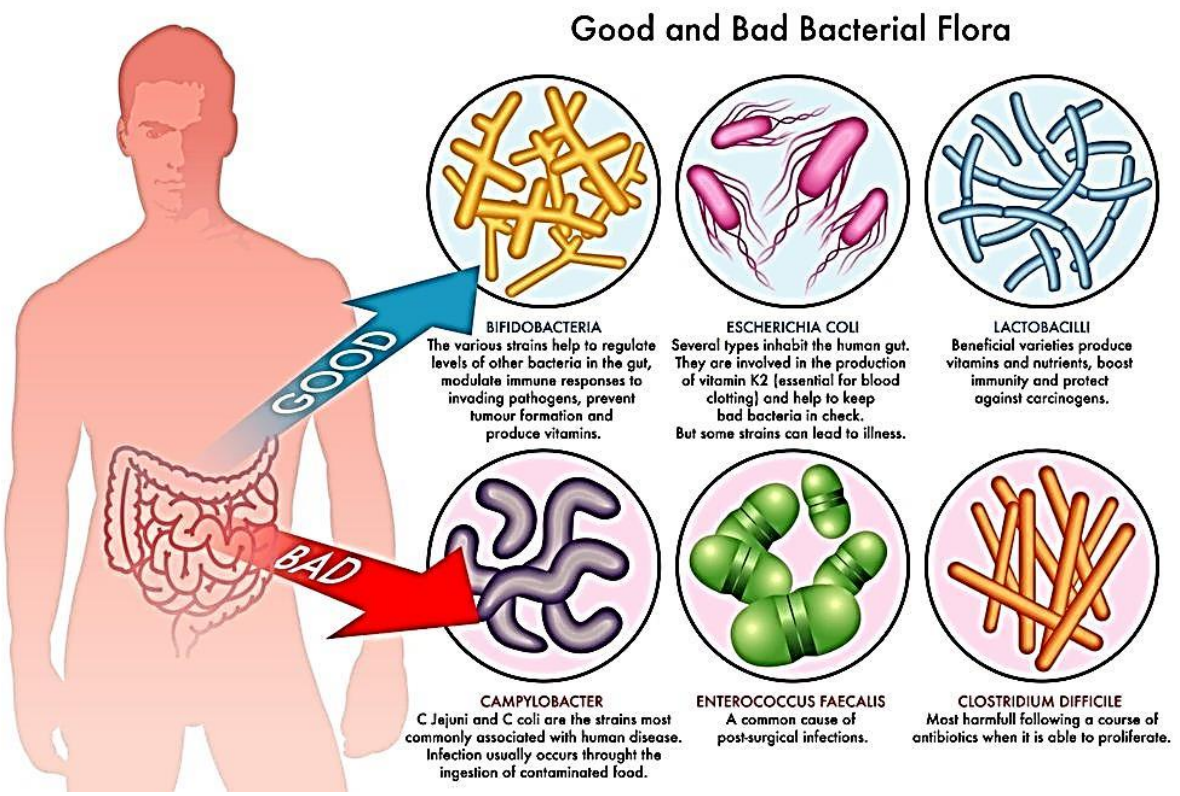

Рисунок 10. Нормальная и патологическая флора кишечника [26]

Состав микробиоты кишечника колеблется в зависимости от поглощения питательных веществ его хозяином, и состав микробиоты кишечника влияет на различные человеческие черты так же сильно, как и наши гены (Рисунок 11). Поэтому вполне разумно предположить, что воздействие питательных веществ на человеческие черты будет представлять собой комбинированные результаты как микробиоты кишечника, модифицированной поглощением питательных веществ, так и самих питательных веществ. Исследовано, что микробиота кишечника является недостающим звеном между питательными веществами и модификациями человеческих черт [22].

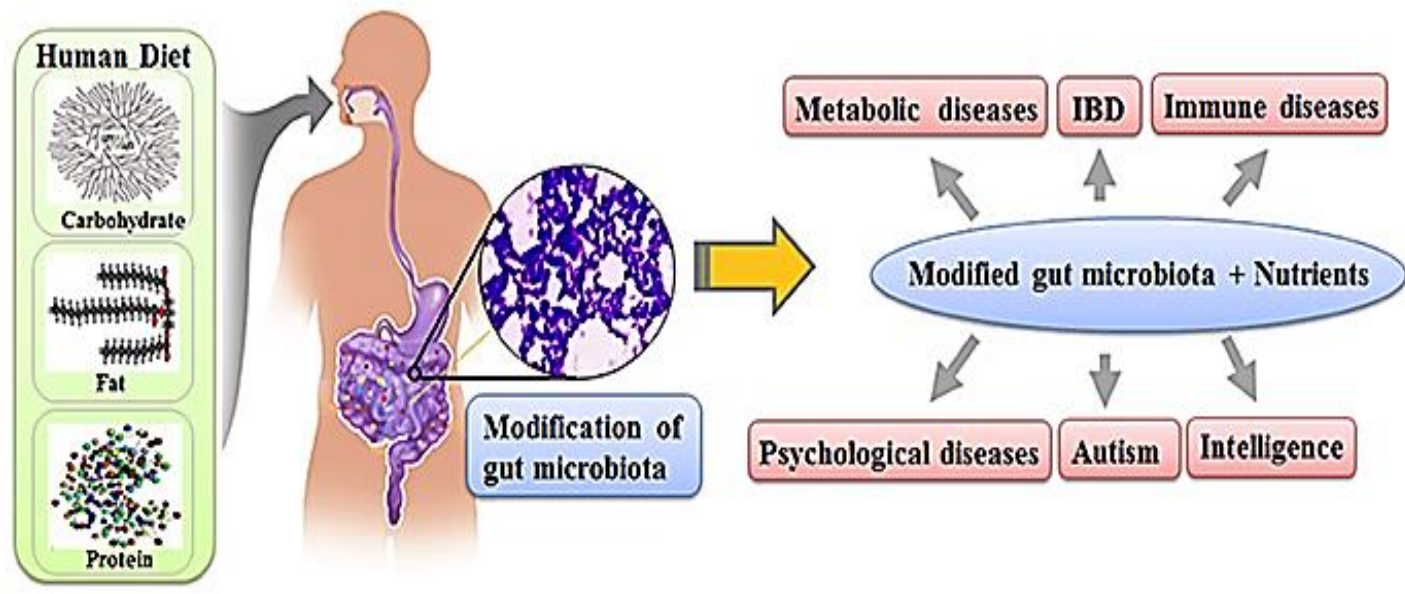

Рисунок 11. Принципиальная схема о том, как питательные вещества влияют на человеческие черты через кишечную микробиоту [22]

Влияние микробиоты кишечника на фенотипы человека стало бурно развивающейся областью исследований и представляет собой новую парадигму возможностей для применения в медицине и пищевой промышленности [22].

Многочисленные современные исследования, установили следующие функции кишечной микробиоты [1, 3, 9, 52-56, 58-62]:

1. Защитная функция (колонизационная резистентность) заключается в предотвращении колонизации желудочно-кишечного тракта условно-патогенными и 
патогенными микроорганизмами. Микробный антагонизм реализуется посредством конкуренции за питательные вещества и рецепторы адгезии, а также за счет выработки органических кислот, перекиси водорода, антибиотикоподобных веществ - бактерицинов, препятствующих росту патогенных микроорганизмов.

2. Пищеварительная функция реализуется за счет, как регуляции функций кишечника, так и непосредственной утилизации питательных субстратов. Облигатная микрофлора толстой кишки в норме обеспечивает конечный гидролиз белков, омыление жиров, сбраживание высокомолекулярных углеводов, которые не абсорбировались в тонкой кишке. Протеолитические микроорганизмы (бактероиды, нормальная кишечная палочка) ферментируют протеины. Некоторые поступающие с пищей вещества могут метаболизироваться только кишечной микрофлорой. Так, сахаролитическая микрофлора расщепляет целлюлозу и гемицеллюлозу до короткоцепочечных жирных кислот.

3. Детоксикационная и антиканцерогенная функция. Нормальная микрофлора способна нейтрализовать многие токсические субстраты и метаболиты (нитраты, ксенобиотики, гистамин, мутагенные стероиды), предохраняя энтероциты и отдаленные органы от воздействия повреждающих факторов и канцерогенов.

4. Синтетическая функция. Нормальная микрофлора обеспечивает синтез многих макро- и микронутриентов: витаминов группы В, С, К, фолиевой, никотиновой кислоты. Только кишечная палочка синтезирует 9 витаминов. Синтез гормонов и биологически активных веществ лежит в основе регуляторного действия микрофлоры на функции внутренних органов и ЦНС.

5. Иммунная функция. Как известно, слизистая оболочка кишечника обладает собственной лимфоидной тканью, известной как GALT (gut-associated lymphoid tissue), которая является одним из значимых компонентов иммунной системы макроорганизма. В слизистой оболочке кишечника локализовано около $80 \%$ иммунокомпетентных клеток, 25\% слизистой оболочки кишечника состоит из иммунологически активной ткани. Таким образом, кишечник можно рассматривать как самый большой иммунный орган человека. Микрофлора участвует в формировании как местного (активация продукции IgA, фагоцитарной активности), так и системного иммунитета. Само наличие бактерий оказывает постоянное антигенное тренирующее действие.

6. Генетическая функция. Микробиота является своего рода «генетическим банком», обмениваясь генетическим материалом с клетками человека путем фагоцитоза. В результате этого микробиота приобретает рецепторы и другие антигены, присущие хозяину и делающие ее «своей» для иммунной системы. Эпителиальные ткани в результате такого обмена приобретают бактериальные антигены. Известно также, что микроорганизмы влияют на экспрессию генов макроорганизма.

7. «Суперорганизменная». Кишечная микрофлора - сложнейший «суперорганизм», не уступающий любому другому жизненно важному органу.

Технология производства функциональных продуктов питания. Функционально макробиотические продукты из мытого, цельного зерна (пшеницы, риса, гречки, овса, ржи, кукурузы, сои, проса, пшена), термообработанного с использованием технологии взрыва (паром), и содержат натуральные не подвергнутые термической обработке растительные добавки: расторопши, льна, амаранта, топинамбура, тыквы, шиповника, кедра, ламинарии, стевии, спирулина, виноградной косточки. Инновационность цикла приготовления готового лечебного продукта питания заключается в использовании современных нанотехнологий с применением импульсного теплового воздействия длительностью 10 сек. Импульс обеспечивает разрыхление зернового продукта из внутри клетки 7-10 сек и измельчение 
пектиновых связей в растительном сырье, тем самым улучшается биологическая доступность растительной клетки [55].

В исследовании $[50,56,59,60]$, под наблюдением находились 41 пациент с различной патологией желудочно-кишечного тракта: хроническим панкреатитом - 14, эрозивным гастритом - 7, гастроэзофагеальной рефлюксной болезнью - 5, хроническим гастродуоденитом - 3, постхолецистэктомическим синдромом - 6, синдромом раздраженного кишечника с преобладанием запоров - 4, язвенной болезнью

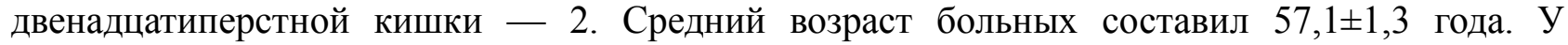
большинства пациентов имело место сочетание 2-х или 3-х гастроэнтерологических заболеваний. Стеатогепатоз имел место у 5, стеатогепатит - у 3, гипомоторная дискинезия толстой кишки - у 7 пациентов.

Больные были разделены на 2 группы: 31 пациент составил основную группу, 10 контрольную. Пациенты основной группы получали ФПП «Самарский здоровяк» с фитокомпопентами, по 60 г 2 раза в день (утром и вечером). 31 пациент получал питание «Самарский здоровяк» с фитокомпонентами на фоне комплексной медикаментозной и физиобальнеотерапии. Контрольная группа (10 пациентов) принимали ФПП «Самарский здоровяк» без какой-либо терапии.

При поступлении в реабилитационный комплекс больные предъявляли жалобы на боли в эпигастрии $(46,3 \%)$ и в правом подреберье $(26,8 \%)$, изжогу $(44 \%)$, дискомфорт в эпигастрии $(32 \%)$ и в правом подреберье (20\%), вздутие и урчание живота $(39 \%)$, горечь во рту $(19,5 \%)$, отрыжку (54\%), тошноту (10\%), запоры (56\%), диарею (12,2\%).

При оценке синдрома цитолиза учитывали уровни АЛТ и АСТ в крови. Синдром холестаза оценивали по уровню билирубина, щелочной фосфотазы и ГГТП в крови, липидный обмен - по уровню холестерина, холестерина ЛПНП, холестерина ЛПОНП, холестерина ЛПВП и триглицеридов.

Исследование биоценоза кишечника у 41 больного выявило нарушение нормального состава микрофлоры толстой кишки до лечения (у 85,3\% пациентов).

У обследованных больных выявлены общие закономерности в характеристике эубиотического состояния толстой кишки: изменено общее количество микроорганизмов с одновременным снижением содержания бифидобактерий, лактобактерий и кишечной палочки; отмечены качественные изменения микрофлоры толстой кишки; выявлен высокий процент высевания условно-патогенных энтеробактерий: гемолитических и лактозонегативных штаммов кишечных палочек, клостридий, грибов рода Кандида.

У 95,0\% находившихся под наблюдением больных установлено положительное восстановление биоценоза кишечника (Рисунок 12) [50].

Получены однозначные доказательства роли кишечной микробиоты в развитии атеросклероза, ожирения, сахарного диабета, артериальной гипертонии, а также аллергических, аутоиммунных и многих других заболеваний. В последнее время активно обсуждается роль кишечной микрофлоры в развитии заболеваний печени. Показано, что длительно существующий дисбиоз кишечника, в особенности синдром избыточного бактериального роста, приводит к развитию неалкогольного стеатоза и стеатогепатита, внутрипеченочного интралобулярного холестаза, а также функциональных нарушений внепеченочных желчных путей [50, 54].

Разработан и внедрен [2] комбинированный и гибридный кластер в диагностике, лечении, профилактике и реабилитации когнитивных нарушений и когнитивных расстройств. 


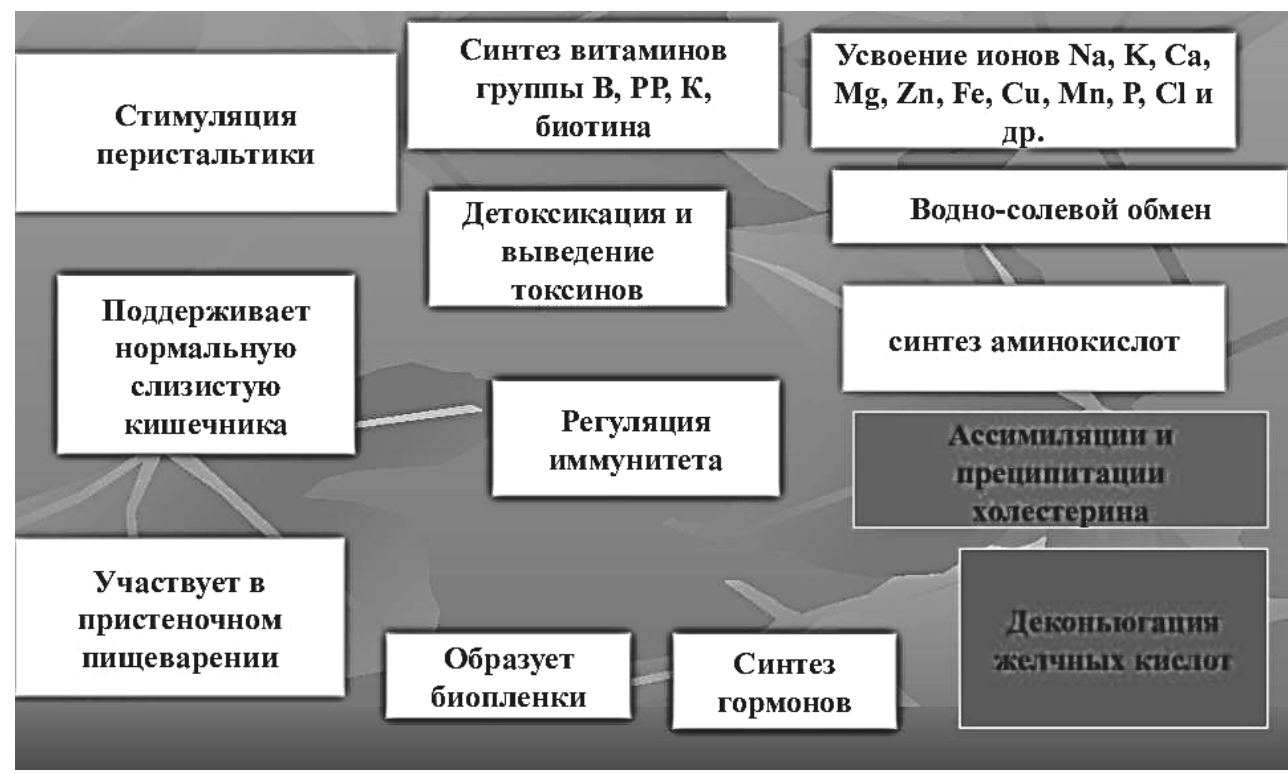

Рисунок 12. Функции нормальной микрофлоры [2]

Человеческий мозг - главный инструмент и самый ценный ресурс на нашей планете. Новая ЭПИГЕНЕТИКА Ноmo sapiens и мозг Ноmo sapiens управляет взаимодействием генетических и эпигенетических программ старения и здорового долголетия [2].

Генетические и эпигенетические факторы, ограничивающие продолжительность жизни человека, безусловно, являются правомерными аспектами биогеронтологических исследований, особенно с точки зрения медицинской экономики. Продолжительность жизни не может быть приравнена к длительному периоду здоровья и здорового старения [1].

Эпигенетические часы - это математические модели и искусственный интеллект, которые предсказывают биологический возраст человека с помощью данных метилирования ДНК и являются наиболее точными биомаркерами процесса старения. Генетические и эпигенетические факторы, ограничивающие продолжительность жизни человека, являются актуальными в биогеронтологических, биофизических, нейрофизиологических и нейроиммунологических исследованиях (Рисунок 13) [1].

Комбинированный и гибридный кластер в диагностике, лечении, профилактике и реабилитации когнитивных нарушений и когнитивных расстройств позволяет установить, ограничивают ли возрастные изменения кровотока или перенос питательных веществ из крови в мозг функцию тканей в сильно локализованных областях мозга и прямо или косвенно приводят к нарушению структуры и функции [2].

Конструкция «когнитивного мозга» представляет собой набор переменных, включая интеллект, образование и умственную стимуляцию, которая предположительно позволяет мозгу адаптироваться к основным патологиям, поддерживая когнитивную функцию, несмотря на лежащие в основе нейронные изменения. Мозг Нomo sapiens также указывает на устойчивость к нейропатологическим повреждениям и может быть определен как способность оптимизировать или максимизировать производительность за счет эффективного набора нейронных сетей и/или альтернативных когнитивных стратегий. Познание в детском возрасте, уровень образования и занятия для взрослых - все это независимо друг от друга способствует формированию когнитивного резерва [2, 25].

Исследование «Ранняя диагностика когнитивных нарушений» посвящено актуальной задаче современной медицины - раннему распознаванию когнитивных нарушений [47]. Рассматриваются подходы к диагностике, обсуждаются вопросы патогенеза и систематики 
когнитивных нарушений, психометрические и патопсихологические методики оценки когнитивных расстройств, подходы к комплексному психофармакологическому лечению и профилактике когнитивных расстройств. Результаты ориентируют врача на использование мультидисциплинарного подхода К пониманию проблемы нейродегенераций и формированию научно-обоснованных алгоритмов ведения таких пациентов [6].
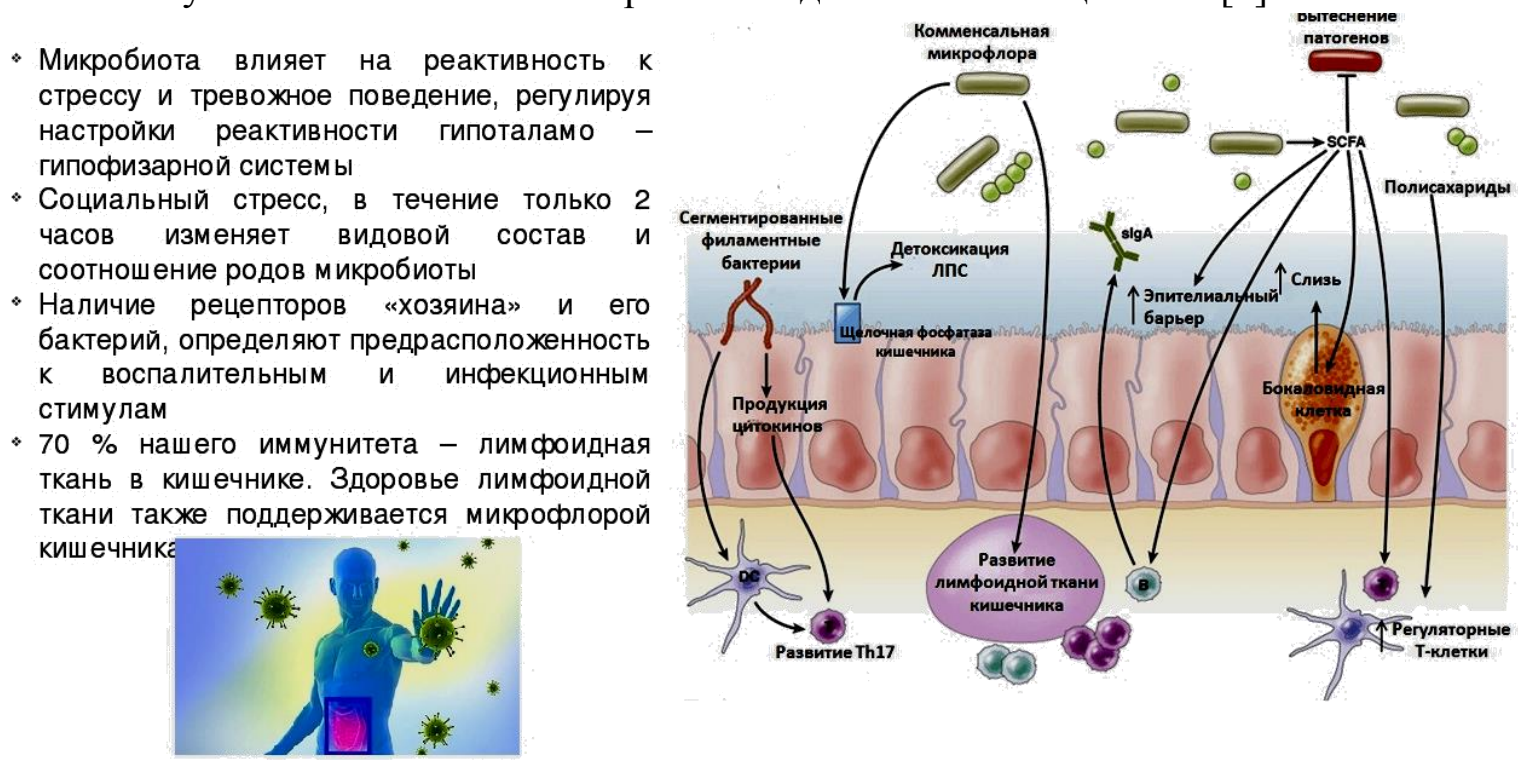

Рисунок 13. Стабильность иммунитета зависит от здоровой микробиоты кишечника [1]

Когнитивное снижение является отличительной чертой старения нервной системы, характеризуется увеличением потери памяти и ухудшением умственных способностей, что в свою очередь создает благоприятный фон для развития нейродегенеративных заболеваний $[4$, $12,13]$.

Рассмотрены способы [5, 27, 28, 29] сохранения эффективной нейропластичности, с помощью использования принципов своевременной профилактики хронической ишемии головного мозга человека, влияния циркадианной биофизики и хрономедицины, применения новых аспектов метаболомики и сбалансированного функционального питания, с целью клинического применения комбинированных активных методов повышения качества функционирования головного мозга человека. Современная многоуровневая и полифункциональная информационная и электромагнитная «перегрузка» приводит к перестройке нейронной сети. Эта перестройка не должна искажать результатов предыдущего воздействия (возбуждения, обучения и т.д.), т. е. не должна затрагивать образованных нейрональных компартментов вторичных нейронных сетей.

Мозг стареет, мы склонны испытывать когнитивное снижение и подвержены большему риску нейродегенеративных заболеваний и деменции. Симптомы хронических нервнопсихических заболеваний также обостряются в процессе старения. Однако процесс старения не оказывает на людей единообразного воздействия; и, по сути, процесс старения не представляется единообразным даже внутри отдельного человека. Современные нейровизуализационные исследования старения мозга и использования информативных биомаркеров старения организма, включая длину теломер, эпигенетические часы и силу захвата и т.д., устанавливают прогноз хронологического возраста у здоровых людей. В настоящее время они применяются к группам неврологических и психиатрических заболеваний, чтобы дать представление о том, как эти заболевания взаимодействуют с процессом старения, и дать индивидуальные прогнозы о будущем здоровье мозга и тела. 
Исследуется интеграции различных видов биологических измерений, как из мозга, так и тела, чтобы построить более полные модели процесса биологического старения $[6,9,30]$.

Одним из наиболее пагубных изменений, происходящих на молекулярном уровне в головном мозге во время старения, является модификация эпигенетических механизмов, контролирующих экспрессию генов. В результате этих эпигенетических изменений в транскриптоме большинство функций мозга, включая синаптическую пластичность, обучение и память, с возрастом снижаются. Эпигенетические механизмы, изменяющиеся в процессе старения, включают метилирование ДНК, модификации гистонов, ремоделирование нуклеосом и микроРНК-опосредованную регуляцию генов [10].

Экспрессия генов в стареющем мозге зависит от транскрипционных сигналов, генерируемых возрастной физиологией, взаимодействующей с генетическими и эпигенетическими программами. В свою очередь, факторы окружающей среды влияют на эпигенетические механизмы, такие как эпигенетическая связь с окружающей средой может способствовать накоплению клеточного повреждения, восприимчивости или устойчивости к стрессорам, а также вариабельности траектории возрастного когнитивного снижения. Эпигенетические механизмы, метилирование ДНК и модификации гистонов, изменение структуры хроматина и доступность ДНК. Кроме того, малые некодирующие РНК, называемые микроРНК (миРНК), связываются с мессенджерной РНК (мРНК) для регулирования трансляции. Главные современные проблемные вопросы, касающиеся эпигенетических механизмов регуляции экспрессии генов, связанных со старением головного мозга и возрастным когнитивным снижением [1, 50, 62].

Эпигенетика старения и долголетия обеспечивает углубленный анализ эпигенетической природы старения и роли эпигенетических факторов в опосредовании связи между ранним жизненным опытом, здоровьем и старением на протяжении всей жизни. В главах ведущих международных авторов исследуется влияние неблагоприятных условий в раннем возрасте, которые могут приводить к нарушению эпигенетических путей, а также потенциал коррекции этих нарушенных путей с помощью целенаправленных терапевтических вмешательств. Эпигенетические часы - это математические модели, которые предсказывают биологический возраст человека с помощью данных метилирования ДНК и являются наиболее точными биомаркерами процесса старения. Современная проблема состоит в познании молекулярных механизмов, управляющих скоростью таких часов [3].

Генная регуляция является важнейшим узлом в этой сети. Эпигенетические метки и факторы транскрипции играют ключевую роль почти для каждого клеточного процесса, а возрастные изменения в регуляции генов, в свою очередь, могут вызвать появление других признаков старения в результате эффекта снежного кома. Другим ключевым моментом в роли эпигеномных изменений с возрастом является то, насколько пластичны и устойчивы эпигеномные сети. Понимание того, как экологические стимулы могут модулировать эти сети, не только повысит наше понимание старения, но и может привести к открытию новых (или перепрофилированнию) соединений, которые могут замедлить или даже обратить вспять прогрессирование старения.

На клеточном и молекулярном уровнях - детерминанты старения для контроля начала и прогрессирования старения, включают потерю полезных компонентов и накопление вредных факторов. Эпигенетический прогресс в области выявление различных факторов, влияющих на процесс старения и долголетия, делают акцент, как эти детерминанты влияют на продолжительность жизни Homo Sapiens, являются современным медико-социальным инструментом, а также мультимодальным ключом междисциплинарного и межведомственного взаимодействия [1-3]. 
Когнитивное снижение является отличительной чертой старения нервной системы, характеризуется увеличением потери памяти и ухудшением умственных способностей, что в свою очередь создает благоприятный фон для развития нейродегенеративных заболеваний. Одним из наиболее пагубных изменений, происходящих на молекулярном уровне в головном мозге во время старения, является модификация эпигенетических механизмов, контролирующих экспрессию генов. В результате этих эпигенетических изменений в транскриптоме большинство функций мозга, включая синаптическую пластичность, обучение и память, с возрастом снижаются. Эпигенетические механизмы, изменяющиеся в процессе старения, включают метилирование ДНК, модификации гистонов, ремоделирование нуклеосом и микроРНК-опосредованную регуляцию генов.

Современные данные, касающиеся изменений эпигенетических модификаций вместе с молекулярными механизмами, лежат в основе нарушения транскрипции нейрональных генов в процессе старения [29].

Старение связано со снижением нескольких когнитивных процессы: эпизодическая память, внимание и исполнительные функции, которые зависят от гиппокампа и префронтальной коры. Тем не менее, не все люди стареют с одинаковой скоростью. Вариабельность траектории когнитивного старения связана с генетическими и экологическими факторами, которые влияют на накопление клеточного повреждения и восприимчивость или устойчивость к стрессорам старения. Эта изменчивость в когнитивное старение фенотипов подчеркивает, что хронологический возраст является плохим предиктором функционального упадка. Скорее, функциональный или физиологический возраст, определяемый биомаркерами (т. е., биологический возраст), обеспечивает лучшую оценку траектории успешного или патологического старения. Микрочип и технология секвенирования следующего поколения позволяет исследовать экспрессию тысяч генов, которые могут быть использованы в качестве биомаркеров физиологического и/(или) функционального возраста и указать на механизмы, лежащие в основе изменчивости старения [2, 12, 13, 28, 29].

Оптимизация нейробиологических и хрономедицинских процессов, возможна при циркадианной выработке мелатонина и обеспечении его длительной концентрации в организме человека, посредством работы трех составляющих:

-употребления функционального и сбалансированного питание, содержащее в большом количестве растительные белки [55].

-воздействия света определенной длины светового спектра [58],

-активации проприоцептивной сенсорной системы при физической нагрузке [58].

Длительный, более 15 мин, яркий свет стимулирует нейроны СХЯ гипоталамуса и тормозит выработку мелатонина эпифизом. В исследованиях Н. П. [3, 55, 58] разработана методика воздействие на циркадианные биологические ритмы человека, устройства (очков) состоящего из источника питания, светодиодных излучателей, регуляторов режимов подачи светового потока, выполненного в виде очков, излучателей светового потока, генерирующих пиковую длину волны в области от $480 \pm 5$ нм до $490 \pm 10$ нм и смонтированных в виде концентрических кругов, эллипсов или линий на светопрозрачной основе, а в электрическую цепь блока излучателей включено реле-прерыватель светового потока с постоянным временем 400 мс, автоматически управляемое от блока регуляции яркости светового потока. Используемые светодиоды смонтированы в виде горизонтальных, вертикальных или круговых линий, между которыми имеется светопрозрачные промежутки, необходимые для осуществления зрительной функции. Светодиоды имеют диапазон длин волн в синей части видимого спектра величиной от $480 \pm 5$ нм до $490 \pm 10$ нм. Источник питания светодиодов 
смонтирован в оправе очков. После включения питания кнопками управления задаются режим светового потока по показателям яркости частоты пауз светового потока по субъективному предпочтению человека.

Функциональные продукты питания различные по составу, с системным воздействием как на гуморальные и гормональные циркадианные колебания, так и на персонифицированное состояние здоровья, и его полиморбидность. Включение в комбинированную схему функционального продукта питания обусловлено его сбалансированностью по содержанию микро- и макроэлементов, витаминов и минералов, клетчатки и др., необходимых мужскому и женскому организму человека как для профилактики гормональных нарушений в репродуктивной системе, так и для диетического, профилактического и функционального питания при диссомнии, десинхронозе [55].

Концентрация мелатонина в желудочно-кишечных тканях превосходит уровень крови в 10-100 раз, а в желудочно-кишечном тракте по крайней мере в 400 раз больше мелатонина, чем в шишковидной железе [3]. Организм человека представляет собой симбиотическое сообщество многочисленных эукариотических, прокариотических клеток, вирусов и архебактерий. Общее число соматических и зародышевых клеток достигает 1 трлн, а микробных клеток - свыше 100 трлн. В системно-интегративной деятельности головного мозга человека насчитывается огромное количество - примерно 10 млрд. связанных между собой и постоянно взаимодействующих клеток [4].

В исследованиях Н. П.Романчук $[55,56]$ установлено, что системно-локальное и индивидуальное сочетанное (медикаментозное и немедикаментозное) вмешательство в циркадианную ось «микробиота-кишечник-мозг» с помощью ежедневного употребления функциональных продуктов питания, положительно влияет на когнитивное и психическое здоровье человека. Висцеральный и когнитивный мозг регулируя уровни мелатонина изменяют флору кишечника и улучшают антимикробные действия. Функциональное и сбалансированное питание обеспечивают циркадианное функционирование нейрооси «мозг-кишечник» с одновременным питанием «мозга» и «микробиоты». Новая концепция, рассматривающая микрофлору кишечника как ключевой регулятор поведения и функционирования головного мозга, представляет собой смену парадигмы в нейронауке и клинической гериатрии.

Внедрение изобретения [55] позволило получить пищевой продукт для подавления свободно-радикальной активности, инвазивной детоксикации организма человека, оптимизации нейрогенной регуляции сосудистого тонуса и восстановления репродуктивных функций у лиц мужского и женского пола.

Помимо влияния диетических привычек на эпигенетическую регуляцию метаболизма существует еще несколько социальных факторов, таких как режим сна, время приема пищи и рабочие смены, которые вызывают циркадное рассогласование. Даже одна ночь недосыпания приводит к гиперметилированию различных тканеспецифических часовых генов, что приводит к повышению инсулинорезистентности и нарушению толерантности к глюкозе. Кроме того, метаболиты являются субстратами, используемыми для формирования модификаций хроматина и играют фундаментальную роль в деятельности всех биохимических путей. Было показано, что метаболиты, вытекающих из различных пищевых источников могут служить субстратами для транскрипционных факторов и гистонов модификации ферментов, которые потом влияют на уплотнение хроматина. С другой стороны, существует несколько линий доказательств того, что эпигенетика, в свою очередь, может влиять на метаболизм и болезни. 
Питание и энергетический обмен являются одними из наиболее важных функций, необходимых для поддержания физической формы и выживания организма, и поэтому являются мощными движущими силами эволюции.

Диетическая модуляция эпигенома. Хорошо известна важная роль эпигенетических механизмов в развитии и функционировании мозга. Однако прогресс в этой области на пути к пониманию механизмов вызванных диетой изменений ограничен в первую очередь из-за недоступности мозга от живых субъектов человека в сочетании со сложностью эпигенетических сигнатур различных типов клеток в головном мозге.

Все больше данных свидетельствует о том, что различные эпигенетические механизмы (метилирование ДНК, модификации гистонов, нкРНК) взаимосвязаны и образуют «эпигенетическую сеть». Наблюдаемый фенотип - включая глобальное здоровье и возрастные процессы - является конечным результатом ряда интегральных сигналов. Факторы образа жизни и воздействия окружающей среды оставляют эпигенетические следы на нашей ДНК, которые влияют на экспрессию генов; некоторые из них оказывают защитное действие, а другие - вредны. Богатые фруктами и овощами диеты могут оказывать сходное воздействие на ДНК с эпигенетическими препаратами. Более глубокое понимание эпигенетических эффектов и сигнальных путей, активируемых биологически активными пищевыми компонентами, помогло бы оценить роль и потенциальную пользу питательных веществ для нашего здоровья (Рисунок 14) [18, 19].

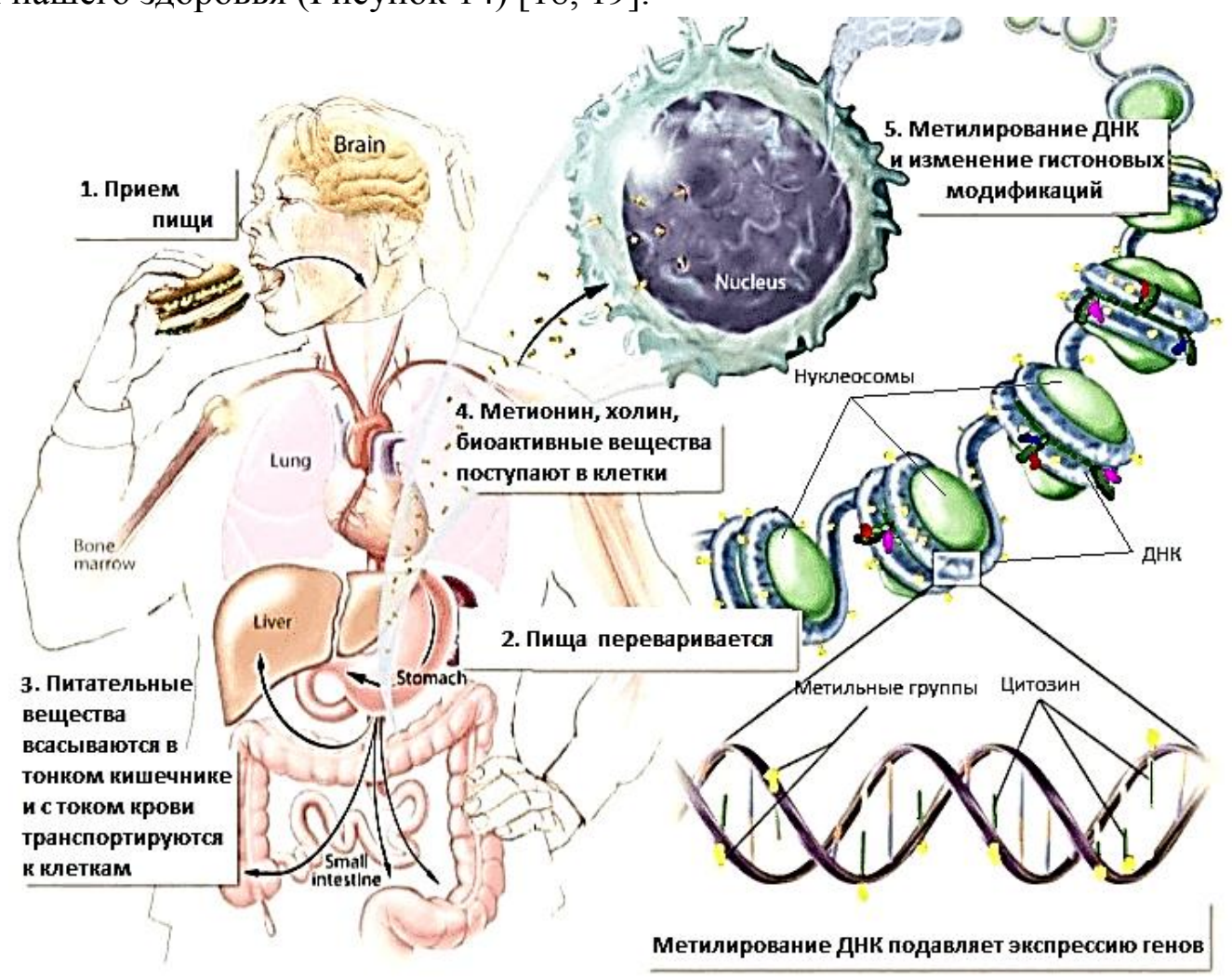

Рисунок 14. Механизм влияния пищи на эпигенетические модификации $[18,19]$

Питательная эпигенетика может сочетаться с лекарственными средствами для синергического воздействия в целях лечения или профилактики или быть адаптирована для беременных женщин с целью снижения бремени хронических заболеваний у потомства посредством эпигенетически здоровой диеты. Дальнейшие исследования в области питания и эпигенетики может принести значительную пользу общественному здравоохранению, а персонализированное питание может стать частью медицинской программы пациента. 
Мозг регулирует кишечник и его микробиоту посредством нейроанатомических, иммунологических и нейроэндокринных нейросетевых путей, сообщающихся с помощью нейромедиаторов, нейропептидов или продуктов микробного происхождения, влияющих на микробиоту кишечника. Соответственно, микробиота кишечника влияет на мозг. Эти два способа формируют двунаправленную связь и взаимодействие между кишечником и мозгом (Рисунок 15) [24, 41].

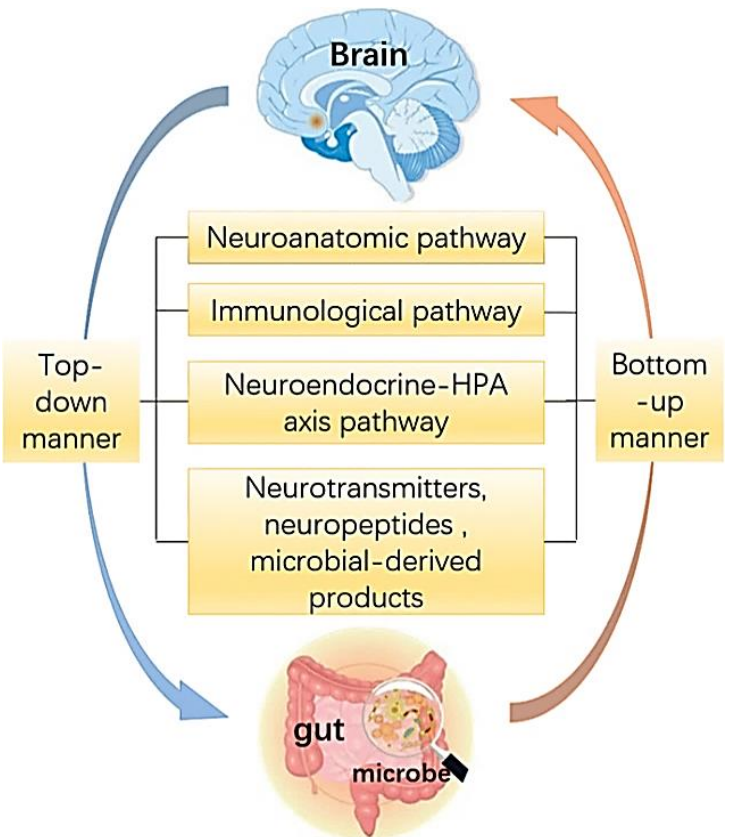

Рисунок 15. Взаимодействие мозга и микробиоты. Общая концепция двунаправленной оси: кишечник-мозг-микробиота [23, 41]

Дисбактериоз кишечника может быть вызван различными факторами окружающей среды, в том числе такими как диета, стресс, воздействие антибиотиков, токсинов, лекарств и патогенов (Рисунок 16).

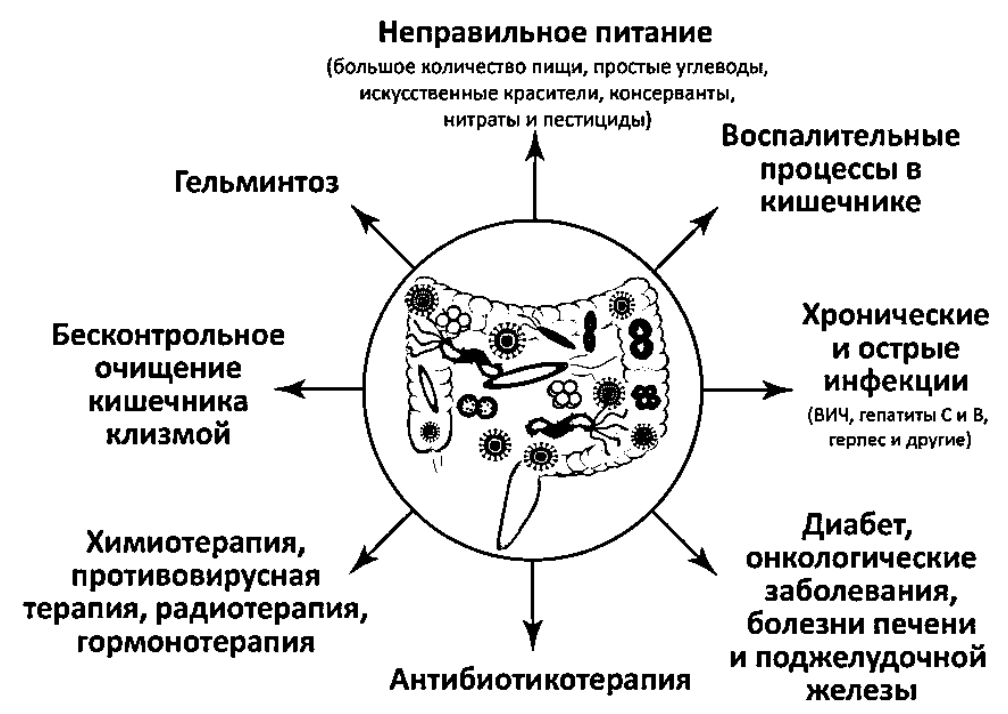

Рисунок 16. Причины дисбактериоза [23, 41]

Перспективными являются продолжающиеся наши стратегические исследования в области генетики и эпигенетики сердечно-сосудистых заболеваний

В исследовании, разработан и внедрен [57] способ оценки возрастных изменений сердечно-сосудистой системы организма человека, заключающийся в определении 
биофизических и биохимических показателей организма человека, при котором дополнительно проводят ЭКГ и ЭхоКГ сердца, и по отклонениям указанных показателей и показаний измерений ЭКГ и ЭхоКГ сердца судят о структурно-функциональных и метаболических изменениях в локальных кровеносных сосудах, региональных сосудистых бассейнах, отличающийся тем, что осуществляют одновременное измерение системного артериального давления на левом и правом плече, левой и правой лодыжке для определения значений лодыжечноплечевого индекса в левой и правой половине туловища и скорости распространения пульсовой волны в левой и правой половинах туловища, а возрастные изменения сердечно-сосудистой системы организма человека оценивают по величине лодыжечноплечевого индекса и указанным показателям измерений в момент регистрации этого импульса, а также по показателям состояния центральной и периферической гемодинамики, изменению геометрии сердца, работе сердечно-сосудистой системы, темпу возрастных изменений и их взаимосвязи [57].

Старение связано с прогрессирующим снижением структуры и функции сердечнососудистой системы. Накопление доказательств связывает сердечно-сосудистое старение с эпигенетическими изменениями, включающими сложное взаимодействие метилирования ДНК, посттрансляционных модификаций гистонов и динамической занятости нуклеосом, регулируемой многочисленными эпигенетическими факторами. Достижения в области геномной технологии привели к глубокому пониманию реорганизации хроматина как при сердечно-сосудистом старении, так и при заболеваниях. Обобщены последние открытия в области эпигенетических механизмов, участвующих в сердечно-сосудистом старении и заболеваниях, и обсуждаются потенциальные терапевтические стратегии для замедления сердечно-сосудистого старения и борьбы с сопутствующими заболеваниями путем омоложения эпигенетических сигнатур до молодого состояния.

Старение сердца - это сложный процесс, характеризующийся снижением функций сердца и ремоделированием желудочков и предсердий. Этот процесс включает утолщение стенки левого желудочка вследствие гипертрофии кардиомиоцитов, увеличение размеров левого предсердия, утолщение и уплотнение интимы сосудов вследствие отложения коллагена и кальция. Среди четко определенных признаков старения, включая геномную нестабильность, укорочения теломер, эпигенетические изменения, потерю протеостаза, нарушение регуляции восприятия питательных веществ, митохондриальную дисфункцию, старение клеток, истощение стволовых клеток и изменение межклеточной связи, многие особенности часто наблюдаются и при сердечно-сосудистых заболеваниях. Например, укорочение теломер связано с сердечно-сосудистыми заболеваниями. Укорочение теломер отражает кумулятивную нагрузку воспалительного, окислительного, возрастающего с возрастом прогрессирующего фиброза сердца, так как профибротические сигналы усиливаются при старении.

Найдены патофизиологические аспекты функционирования системы нейрорефлекторной регуляции артериальных сосудов. Найдена биофизическая причина развития первичной артериальной гипертонии, как нарушение кардиосинхронизированного механизма антифлаттерной стабилизации сосудистой системы. На основе авторской концепции функционирования системы нейрорефлекторной регуляции артериальных сосудов показана особая важность дозированного снижения артериального давления антигипертензивными лекарственными препаратами до порога возрастной нормы под контролем лодыжечно-плечевого индекса. Применение новых биофизических, электрокардиологических и клинических маркёров оценки эффективности лечения и прогноза осложнений у пациентов с первичной артериальной гипертонией позволили 
внедрить восстановительно-реабилитационный системокомплекс мероприятий. Системный алгоритм инноваций восстановительной медицины для решения проблемы первичной артериальной гипертонией и увеличения профессионального долголетия составляется индивидуально с позиции доказательной медицины, данных генетического паспорта, биологического возраста, профессиональной деятельности, верифицированной полиморбидности [59].

Оценка старения организма человека в существующих способах проводится по величине отклонения индивидуального биологического возраста человека от его календарного возраста, при этом определяется повышенный риск раннего развития возрастной патологии, который влияет на качество и продолжительность жизни.

Определение биологического возраста и индивидуальной скорости старения особо актуально для оценки и прогнозирования риска развития наиболее распространенных хронических заболеваний современного человека, сцепленных с онтогенетическим развитием и процессами старения человека: артериальная гипертония, ишемическая болезнь сердца, ожирение, сахарный диабет 2 типа, атеросклероз и др.

Настоящее изобретение направлено на достижение технического результата, заключающегося в повышении достоверности и объективности оценки возрастных изменений сердечно-сосудистой системы организма человека за счет учета показателя лодыжечно-плечевого индекса, как биомаркера в кровеносных сосудах и региональных сосудистых бассейнах, в совокупности с морфологическими (структурными) и функциональными (динамическими) показателями скорости старения сердечно-сосудистой системы.

Новым в заявленном способе является то, что применяется системный подход с изучением пятидесяти показателей (маркеров) - коэффициентов скорости старения сердечно-сосудистой системы и биологического возраста, которые основаны на оценке возрастных изменений показателей в различных возрастных группах, т.е. в любом возрасте.

На основании полученных данных (50 маркеров) проводят диагностику поражения органов-мишеней у больных с артериальной гипертензией, судят об атеросклеротических и других изменениях кровеносного сосуда, состоянии центральной и периферической гемодинамики, изменении геометрии сердца, работе всей сердечно-сосудистой системы в целом и при нарушении делают вывод о степени возрастных изменениях сердечнососудистой системы.

Указанные признаки являются существенными и взаимосвязаны с образованием устойчивой совокупности существенных признаков, достаточной для получения требуемого технического результата.

Кроме того, очень важным в заявленном способе является возможность разрабатывать алгоритмы терапии и оценивать эффективность проводимого медикаментозного и немедикаментозного лечения во времени с заданным интервалом и под контролем 50 биопоказателей (биомаркеров).

Полученные при клинических исследованиях значения измеряемых показателей и их взаимосвязь позволяют одновременно проводить раннюю диагностику поражения органовмишеней у больных с артериальной гипертензией, атеросклеротические и другие изменения кровеносного сосуда, состояние центральной и периферической гемодинамики, изменение геометрии сердца, работы всей сердечно-сосудистой системы в целом.

В настоящее время предлагаемый способ оценки возрастных изменений сердечнососудистой системы организма человека имеет достаточно оснований для клинического применения в практическом здравоохранении, широкого внедрения в алгоритмы 
профилактических обследований, профосмотров и обследований пациентов медицинских учреждений для системной оценки возрастных изменений сердечно-сосудистой системы человека - как надежных, воспроизводимых показателей, позволяющих на доклинической стадии выявить пациентов с гемодинамически значимой патологией артерий нижних конечностей, повышенным риском наличия атеросклеротических поражений в каротидном и коронарном артериальных бассейнах, а также уточнить риски развития сердечно-сосудистых осложнений.

Старение сердца - гетерогенный процесс, характеризующийся повышенным уровнем активных форм кислорода, повреждением геномной ДНК, эпигенетическими модификациями и укорочением теломер. Последствия старения в соответствии с этими вредными изменениями включают дефектный белковый гомеостаз, прогрессирующую потерю процессов контроля качества и накопление дисфункциональных органелл, которые непосредственно влияют на популяции кардиомиоцитов, фибробластов и стволовых клеток. Такие стохастические нарушения, инициируемые как внешними, так и внутренними стимулами, в конечном итоге приводят к нарушению сократительной функции, снижению показателей гемодинамики, а также к нарушению регенеративных реакций на травмы и стресс-стимулы.

Старение человеческого мозга - это сложное, многомерное явление. Для правильного решения не только медицинских, но и социальных, психологических и правовых вопросов, связанных с этим явлением, необходимо знать и учитывать многочисленные аспекты здорового, ускоренного и патологического старения. В ближайшие десятилетия необходимо будет найти решения по управлению прогрессирующим старением населения с тем, чтобы увеличить число лиц, достигающих успешного здорового старения.

Хроническая ишемия головного мозга человека сосудистого, токсического, метаболического и смешанного генеза имеет место у огромного числа больных, находящихся в многопрофильных стационарах и обращающихся за оказанием медицинской помощи в амбулаторно-поликлинические учреждения.

В современной медицине, и в частности в неврологии и нейрофизиологии, применяются следующие принципы лечения хронической ишемии головного мозга человека:

1. воздействие на сосудистые факторы (коррекция артериального давления, профилактика острых нарушений мозгового кровообращения);

2. восстановление мозгового кровотока, улучшение церебрального метаболизма;

3. улучшение и стабилизация когнитивных функций;

4. коррекция других клинических проявлений заболевания.

Одним из наиболее современных перспективных подходов в медикаментозном лечении дисциркуляторной энцефалопатии является применение вазоактивной, нейрометаболической и нейропротективной терапии с помощью назначения комбинированных лекарственных медикаментозных препаратов, обладающих полимодальным действием (антигипоксическое, метаболическое (ноотропное) и сосудорасширяющее).

Однако вышеперечисленные современные комбинированные лекарственные препараты в лечении хронической ишемии головного мозга человека относятся к медикаментозным средствам, преимущественно применяются в амбулаторно-поликлинических, стационарных и санаторно-курортных учреждениях для курсовой терапии основного и сопутствующего заболевания, приведшего к ишемии мозга, и не содержат комбинированных немедикаментозных средств. 
В продолжающемся другом исследовании, изобретение относится к области медицины, а именно к неврологии и нейрофизиологии, и касается диетического, профилактического и функционального питания при хронической ишемии головного мозга человека [56].

Настоящее изобретение направлено на достижение технического результата, заключающегося в повышении диетического, функционального и профилактического воздействия функциональных продуктов питания на организм человека при хронической ишемии головного мозга за счет введения в рацион функциональных продуктов питания, сбалансированных по содержанию необходимых макро- и микронутриентов, витаминов и минералов, клетчатки, необходимых для диетического и функционального питания при хронической ишемии головного мозга человека, a также для профилактической ревитализации вазоактивной, нейрометаболической и нейропротективной функции головного мозга человека.

Указанный технический результат достигается тем, что в продукте функционального, диетического и профилактического питания для больных с хронической ишемией головного мозга, представляющем собой заливаемую при употреблении жидкостью смесь, изготовленную из экологического цельнозернового натурального сырья, произведенного в РФ и не содержащего генно-модифицированных организмов, содержащего высушенное зерно твердой пшеницы, термообработанное методом взрыва, арбузные семена, семена льна, расторопшу, дополнительно введены высушенные зерна ржи, термообработанные методом взрыва, растолченные частицы чечевицы, грецких и кедровых орехов, соя (в виде окары), пчелиная перга, порошок топинамбура, спирулины, ламинарии, женьшеня и каменного масла.

Компоненты находятся в следующем соотношении, г/100 г готового сухого продукта:

1) зерно твердой пшеницы 19,5-20,5,

2) зерно ржи 19,5-20,5,

3) соя 19,5-20,5,

4) чечевица $10,5-11,0$,

5) семена льна 5,0-5,5,

6) расторопша 5,0-5,5,

7) порошок топинамбура 2,5-2,75,

8) арбузные семена 2,5-2,75,

9) грецкие орехи 2,5-2,75,

10) кедровые орехи $2,5-2,75$,

11) перга пчелиная 2,5-2,75,

12) порошок спирулины 2,5-2,75,

13) порошок ламинарии 2,5-2,75,

14) порошок женьшеня $0,5-0,75$,

15) порошок каменного масла 0,5-0,75.

Указанный продукт сбалансирован по содержанию микро- и макроэлементов, витаминов и минералов, клетчатки и др., необходимых организму человека для сохранения интеллектуальных, творческих, производственных способностей и повышения качества жизни, а также для профилактики хронической ишемии головного мозга, с помощью систематического употребления диетического, профилактического и функционального питания заявленного состава.

Указанные признаки являются существенными и взаимосвязаны с образованием устойчивой совокупности существенных признаков, достаточной для получения требуемого технического результата. 
Установлено с позиции доказательной медицины, во-первых, что более 33\% граждан, страдающих психическими расстройствами личности (депрессия, тревога, немотивированные страхи), испытывают дефицит витаминов «В» в рационе повседневного питания. Во-вторых, быстрая производственная и творческая утомляемость, а также снижение интеллектуальных способностей, свидетельство дефицита железа и недостаточное содержание витаминов В3, В6, В9 (фолиевая кислота) в организме. Фолиевая кислота способствует сохранению и частичному восстановлению краткосрочной и долгосрочной памяти, устойчивости запоминания.

В-третьих, аминокислоты (в т.ч. и незаменимые) и витамины (B3, В6, В9, В12, С и др.), а также ведущие микро- и макроэлементы (магний, цинк, селен и др.) для головного мозга в организме человека не синтезируются, а поступают только с пищей и являются профилактическим базисом по поддержанию функционирования нейрометаболических и интегративных процессов высшей нервной деятельности человека посредством гармонизации биофизических, биохимических и гормональных взаимодействий в циклической системе «хронобиология - хрономедицина».

В настоящем изобретении используются способ получения функционального продукта питания с использованием инновационных технологий (патент PФ RU 2423873 C1 «Способ производства зернового компонента для пищевого продукта быстрого приготовления и способ производства функционального пищевого продукта быстрого приготовления», приоритет от 05,04.2010) [55].

В рамках настоящего изобретения рассматривается новый следующий состав функционального продукта питания для профилактического и диетического питания, содержащий:

- во-первых, рожь 19,5-20,5\% в 100 г готового сухого продукта - как базовый ФПП, необходимый для восполнения недостающих полезных веществ, так и цельнозерновой продукт - «платформа» для биосинтеза витаминов и биохимических реакций в организме женщины (эндокринной и др. систем);

- во-вторых, чечевица 10,5-11,0\% в 100 г готового сухого продукта - важный источник железа и фолиевой кислоты. Она способна обеспечить до 90\% суточной нормы этих веществ, необходимых человеку. Чечевица содержит большое количество сложных углеводов и аминокислот, необходимых для быстрого протекания биохимических нейрометаболических процессов в клетках мозга;

- в-третьих, впервые введена цельнозерновая экологическая без ГМО соя 19,5-20,5\% в 100 г готового сухого продукта со среднего Поволжья с функциональными характеристиками, решающими поставленную техническую задачу;

- в-четвертых, введен порошок топинамбура, который содержит до $20 \%$ сухих веществ, среди которых до 80\% содержится полимерного гомолога фруктозы - инулина. Топинамбур аккумулирует кремний из почвы и относится к «кремнефильным» растениям, содержание этого элемента составляет до $8 \%$ в расчете на сухое вещество. Кроме того, содержит 8 аминокислот, которые синтезируются только растениями и не синтезируются в организме человека: аргинин, валин, гистидин, изолейцин, лейцин, лизин, метионин, триптофан, фенилаланин;

- в-пятых, добавлен порошок спирулины, имеющий в своем составе полноценный белок, углеводы, жиры, микро- и макроэлементы, витамины, фикоцианин, бета-каротин, линолевую кислоту и другие биологически активные компоненты. Как мощный антиоксидант спирулина предотвращает преждевременное старение в результате окислительных процессов в организме; 
- в-шестых, введена ламинария, которая обладает противоопухолевой активностью, антимикробным, антибактериальным и противовирусным действием. Антимутагенным и радиопротекторным действием, а также противовоспалительной и иммуномодулирующей активностью. В ламинарии концентрация магния превышает таковую в морской воде в 9-10 раз, серы - в 17 раз, брома - в 13 раз. В 1 кг ламинарии содержится столько йода, сколько его растворено в 100000 л морской воды. Содержание полисахаридов фукоидана и ламинарина способствует профилактике и лечению сердечно-сосудистых и цереброваскулярных заболеваний. Эти заболевания во многом зависят от баланса липидов, нарушение которого приводит к повышенной склонности к образованию атеросклеротических бляшек в сосудах. Ламинарин также оказывает гипотензивный эффект и проявляет антикоагулянтную активность, которая составляет 30\% от активности гепарина;

- в-седьмых, натуральное экологическое специально переработанное (для лучшей усвояемости) каменное масло, необходимое для организма человека, вместе с другими компонентами, входящими в данный состав, для достижения профилактического базиса по поддержанию функционирования нейрометаболических и интегративных процессов высшей нервной деятельности человека, посредством гармонизации биофизических, биохимических и гормональных взаимодействий в циклической системе «хронобиология - хрономедицина».

Клинические испытания проводились в Федеральном государственном учреждении «Российский научный центр Восстановительной медицины и курортологии (ФГУ «РНЦ ВМ и К») Минздравсоцразвития РФ в период с 20.10.2009 г. по 19.03.2010 г. по договору № 1389/09 от 20.10.2009.

Установлены следующие клинические эффекты при употреблении функциональных продуктов питания в рекомендуемых дозах и режимах:

1) геропротекторный,

2) дезинтоксикационный,

3) пребиотический,

4) гепатопротекторный,

5) пробиотический,

6) антиоксидантное действие

7) постоянный синтез ферментов и гормонов.

Результаты клинического исследования эффективности функциональных продуктов питания с фитокомпонентами в предложенных дозах эффективно применяются в качестве диетического, пребиотического и функционального питания при ишемии головного мозга.

Данный функциональных продуктов питания содержит антиоксиданты, витамины, минералы, фитопродукты, пищевые волокна, микро- и макроэлементы без наличия ГМО, консервантов и пищевых химических добавок, необходимые для достижения указанного результата.

Здоровое старение человека связано с управлением социальной, экономической, «метаболической», поведенческой и психической деятельности. Профилактика является наилучшим способом избежать когнитивных нарушений и когнитивных расстройств, особенно учитывая болезнь Альцгеймера — как проблему общественного здравоохранения [31].

Болезнь Альцгеймера - это разрушительное нейродегенеративное заболевание, связанное со старением. Прямая причина болезни Альцгеймера остается неясной, но появляются эпидемиологические данные, связывающие данную нейродегенерацию с циркулирующими концентрациями гомоцистеина и витаминов группы В. Эпигенетический анализ показал, что ткани головного мозга при болезни Альцгеймера и альцгеймероподобных 
заболеваниях имеют повышенный уровень ацетилирования гистонов по сравнению с неврологически нормальным мозгом. Предполагается, что вызванные диетой эпимутации в раннем возрасте повышают риск развития различных хронических заболеваний в более поздние сроки жизни и могут даже передаваться будущим поколениям по аналогии с мутациями последовательности ДНК. Однако доказать причинно-следственную связь эпигенетических изменений у человека достаточно сложно $[7,8]$.

Таким образом, вызванные диетой изменения в эпигенетической регуляции могут быть внутренним адаптивным механизмом, посредством которого диета может модифицировать экспрессию генов, регулирующих метаболизм, чтобы приспособиться к долгосрочным изменениям в питании. Наследование таких изменений может быть логической адаптацией в популяции, и дальнейшее изучение этой темы будет поддерживать парадигму, в которой семейное наследование риска заболевания передается не только генами, но и эпигенетической информацией, накопленной за предыдущие поколения [31].

В исследовании [51, 56, 57] реализовано профилактическое воздействие на организм человека за счет введения жизненно важных пищевых веществ в функциональный пищевой продукт для подавления свободнорадикальной активности, инвазивной детоксикации организма человека, оптимизации нейрогенной регуляции сосудистого тонуса при артериальной гипертонии и восстановления репродуктивных функций у лиц мужского и женского пола путем оптимизации качественной структуры компонентов продукта.

Благотворное влияние на циркадианную синхронизацию, качества сна, настроение и когнитивные показатели - зависят от времени, интенсивности и спектрального состава светового воздействия. Мультидисциплинарное и мультимодальное взаимодействие в триаде «мозг-глаза-сосуды» позволяет выявить ранние биомаркеры как общего ускоренного и патологического старения, так и своевременно диагностировать нейродегенерацию, и провести эффективную нейрореабилитацию когнитивных нарушений [33].

С позиции доказательной медицины знание генетической предрасположенности к развитию тех или иных функциональных нарушений и заболеваний позволяет в персонифицированной медицине провести эффективные био- и ревитализационные мероприятия [32].

Взаимосвязь данных мониторинга биологического возраста человека с биологической средой (нерациональное питание, и дисбаланс питательных компонентов, потребление алкоголя и некачественной питьевой воды, нерегулярный сон и нарушение циркадианных биоритмов, различные инфекции, длительный гормональный дисбаланс, токсикомания, сигаретный дым, выхлопные газы, загрязнение атмосферы), а также с психологической (климат в семье, на работе, наличие/отсутствие друзей и т.д.) и с электромагнитной (компьютер, мобильный телефон, СВЧ-печь, телевизор и другая бытовая техника, проходящая рядом с домом высоковольтная линия электропередачи и т.д.) позволяют с помощью программ «Активное долголетие» и «Генетика и эпигенетика» управлять здоровым старением мозга Homo sapiens [1, 50].

В связи с этим оценка продолжительности жизни человека на основе медикосоциального и биофизико-математического подхода во взаимосвязи с генетической, математической и биофизической оценками (биопоказатели и биомаркеры) влияния фактора случайного мутагенеза как на геном человека в процессе жизнедеятельности, так и на популяцию в целом, позволяет прогнозировать уровень отклонения частоты аллеля от нормы, который свидетельствует о медико-демографической стабильности в регионе $[1,50]$.

Для восстановления циркадианной нейропластичности мозга предлагается мультимодальная схема: циркадианные очки, функциональное питание и физическая 
активность. Разработан и внедрен [2] комбинированный и гибридный кластер в диагностике, лечении, профилактике и реабилитации когнитивных нарушений и когнитивных расстройств.

Комбинированный и гибридный кластер в диагностике, лечении, профилактике и реабилитации когнитивных нарушений и когнитивных расстройств, включает в себя [2]:

1. Искусственный интеллект, П4 Медицину и цифровое здравоохранение.

2. Искусственный интеллект - инструмент объемной оценки жизни пациента, семейного анамнеза, физикального обследования, батареи нейропсихологических тестов, лабораторных показателей (биомаркеров), биофизических показателей (биомаркеров) сосудистого старения сердечно-сосудистой системы, нейрофизиологических исследований, нейровизуализации, секвенирования нового поколения и др.

3. Генетику (геномные исследования) и эпигенетику (эпигеном и старение, фенотипические исследования и др.).

4. Нейропсихологическое тестирование (MOCA, MMSE, Mini-Cog, FAB, TMT, GDS и др.).

5. Комбинированную и гибридную нейровизуализацию с секвенированием нового поколения.

6. Метаболомику, метагеномику, микробиоту: сбалансированное, функциональное и безопасное питание.

7. Искусственный интеллект и искусственные нейронные сети.

8. Биочипирование, нейронные и мозговые чипы.

9. Комбинированную и гибридную реабилитацию.

10. Персонифицированное управление биовозрастом.

11. Медико-социальное и экономическое сопровождение при болезни Альцгеймера, в т.ч. с помощью бытовых роботов и медицинских биороботов.

Человека: с его информационной «перегрузкой» (интернет, сотовая связь, и др.) и электромагнитной совместимостью: природа, быт, циркадианные гаджеты и «экогаджеты».

Контроль и лечение сосудистых факторов риска и эндокринных нарушений позволяет снизить распространенность длительной нетрудоспособности среди пожилого населения. Комбинированные и гибридные методы нейровизуализации в содружестве с технологиями искусственного интеллекта, позволяют понять и диагностировать неврологические расстройства и найти новые методы нейрореабилитации и медико-социального сопровождения, которые приведут к улучшению психического здоровья $[7,8]$.

Будущая реализация парадигм системной биологии и системной нейрофизиологии, основанных на комплексном анализе больших и глубоких гетерогенных источников данных, будет иметь решающее значение для достижения более глубокого понимания патофизиологии болезни Альцгеймера, с использованием современных технологий интерфейс «мозг-компьютер» и «искусственный интеллект», для того чтобы увеличить информацию которую можно извлечь от доклинических и клинических показателей. Интеграция различных источников информации позволит исследователям получить новую целостную картину патофизиологического процесса заболевания, которая будет охватывать от молекулярных изменений до когнитивных проявлений [1-9].

В дополнение к нейропсихологическим тестам, комбинированным и гибридным технологиям нейровизуализации, сочетанному использованию современных технологий интерфейс «мозг-компьютер» и «искусственный интеллект» позволит более качественному исследованию молекулярных и клеточных событий, которые управляют развитием болезни Альцгеймера, прежде чем проявятся когнитивные симптомы [30, 31$]$. 
Болезнь Альцгеймера и искусственный интеллект, П4 Медицина и цифровое здравоохранение - это современный комбинированный и гибридный информационный кластер в диагностике, лечении, профилактике и реабилитации когнитивных нарушений и когнитивных расстройств, для расширения ресурсов brain Homo Sapiens. Искусственный интеллект - инструмент объемной оценки жизни пациента, семейного анамнеза, физикального обследования, батареи нейропсихологических тестов, лабораторных показателей (биомаркеров), нейрофизиологических исследований, нейровизуализации, секвенирования нового поколения и др. Искусственный интеллект - стратегический путь повышения качества и продолжительности жизни больных с болезнью Альцгеймера [5].

Ядерное перепрограммирование изображается как многослойный процесс. Многоуровневый характер ядерного перепрограммирования отражает ограничение в потенциале развития и старения, которое имеет место при переходе от яйцеклетки к взрослому возрасту, когда каждое ограничение перепрограммируется, чтобы вновь обрести потенциал, которым оно когда-то обладало [23].

Будущие исследования будут определять, можно ли так омолодить другие признаки, тем самым поставив возрастное перепрограммирование на основу, независимую и экспериментально отделимую от перепрограммирования развития. Кроме того, большой интерес будет представлять изучение того, можно ли перепрограммировать возрастные признаки старения независимо друг от друга.

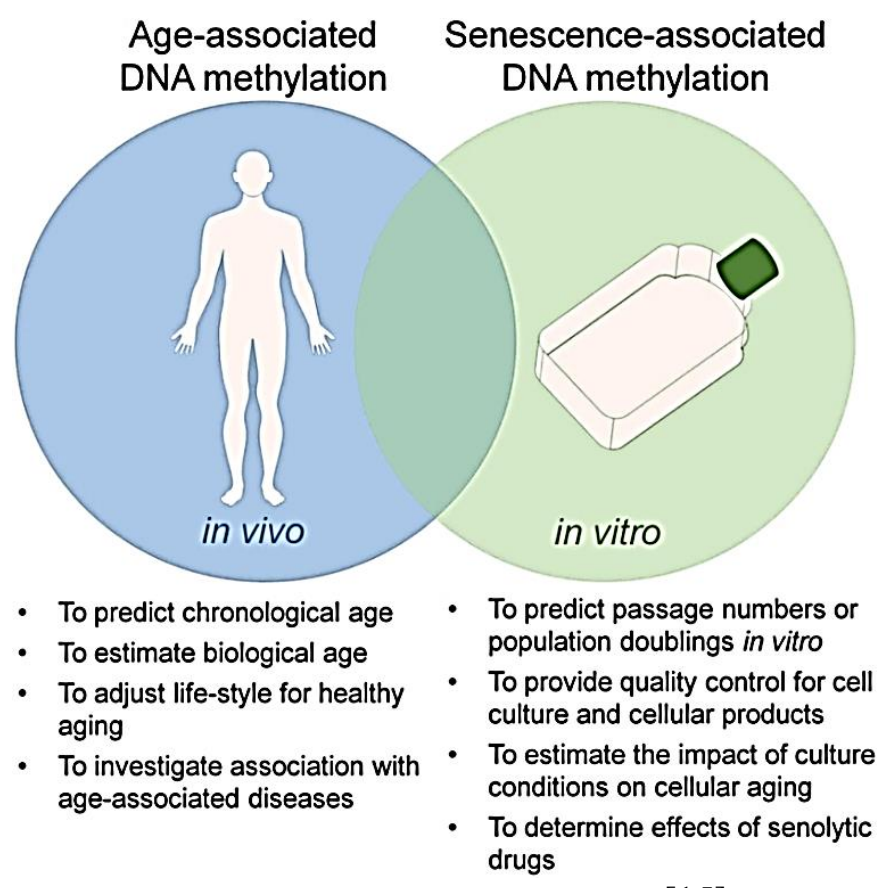

Рисунок 17. Полезность эпигенетических часов для старения [15]

Эпигенетические изменения в процессе старения характеризуются множественными эпигенетическими часами, которые позволяют прогнозировать хронологический возраст на основе статуса метилирования. Несмотря на их точность и полезность, биомаркеры эпигенетического возраста оставляют без ответа многие вопросы об эпигенетическом старении. В частности, они не позволяют объективно охарактеризовать нелинейные эпигенетические тенденции старения на протяжении всего жизненного цикла, что является критическим вопросом, лежащим в основе этой области исследований. Здесь мы предлагаем комплексную основу для решения этого вопроса. Наша модель, вдохновленная эволюционными моделями, способна учитывать ускорение/замедление эпигенетических 
изменений, приспосабливая модельный возраст индивида, эпигенетический возраст, который связан с хронологическим возрастом нелинейным образом. Применение этой модели к данным метилирования ДНК, измеренным в широких возрастных диапазонах, от рождения до старости, и от двух типов тканей, позволяет предположить, что универсальный логарифмический тренд характеризует эпигенетическое старение на протяжении всей жизни [15].

Старение и реплицирующее старение отражаются как высоко воспроизводимыми изменениями метилирования ДНК (DNAm), так и значительным перекрытием между этими эпигенетическими модификациями. С другой стороны, эти два процесса могут быть отслежены независимо с помощью эпигенетических сигнатур, которые могут быть использованы для различных приложений.

Реплицирующее старение клеток in vitro часто рассматривается как аналог старения организма in vivo. На самом деле оба процесса связаны с функциональным распадом и подобными молекулярными модификациями. На эпигенетическом уровне реплицирующее старение и старение вызывают характерные изменения в паттерне метилирования ДНК, но в разных участках генома. Различные эпигенетические сигнатуры, которые часто называют эпигенетическими часами, обеспечивают полезные биомаркеры: связанные со старением эпигенетические модификации могут использоваться для контроля качества клеточных препаратов или для выяснения влияния условий культивирования на состояние клеточного старения. Возраст-ассоциированные эпигенетические модификации возлагают большие надежды на определение хронологического возраста в судебной медицине или на выявление параметров, влияющих на биологическое старение. Несмотря на эти различия, есть некоторые поразительные сходства между старением и возрастом, связанным с метилированием ДНК, такими как полное омоложение во время перепрограммирования в индуцированные плюрипотентные стволовые клетки. В настоящее время неясно, что заставляет эпигенетические часы работать, полученные доказательства свидетельствуют, что основные механизмы обоих процессов связаны с аналогичными модификациями в коде гистона или хроматине более высокого порядка. Реплицирующее старение представляется подходящей модельной системой для лучшего понимания того, как старение организмов может управляться эпигенетически [16].

Исследовано, что клетки зародышевой линии сохраняют потенциал к регенерации вида неопределенно долго, клетки в ходе дифференцировки претерпевают прогрессивные модификации, которые ограничивают либо их способность к неограниченной репликации (например, происходит в момент или около потери плюрипотентности (переход плюрипотентности), либо на последующих этапах, которые ограничивают их потенциал к регенерации и росту. Современные молекулярные подходы к регенеративной медицине, такие как перепрограммирование клеток на плюрипотентность или частичное перепрограммирование для индуцирования регенерации тканей, эффективно обращают вспять большинство маркеров старения и имеют значительный потенциал для клинического применения при старении [17].

В исследовании [11], установлено, что микробиом играет ключевую роль в сохранении здоровья и профилактике заболеваний, и существует значительный интерес к терапевтическому таргетированию микробиома, а также к разработке этого богатого ресурса в усилиях по открытию лекарств. Однако все больше данных свидетельствует о том, что микробиота кишечника сама может влиять на действие целого ряда ксенобиотиков, как благотворно, так и потенциально вредно. Традиционно клинические исследования, оценивающие фармакокинетику новых лекарственных средств, в основном игнорируют 
важное прямое и косвенное влияние микробиома кишечника на метаболизм и эффективность лекарственных средств.

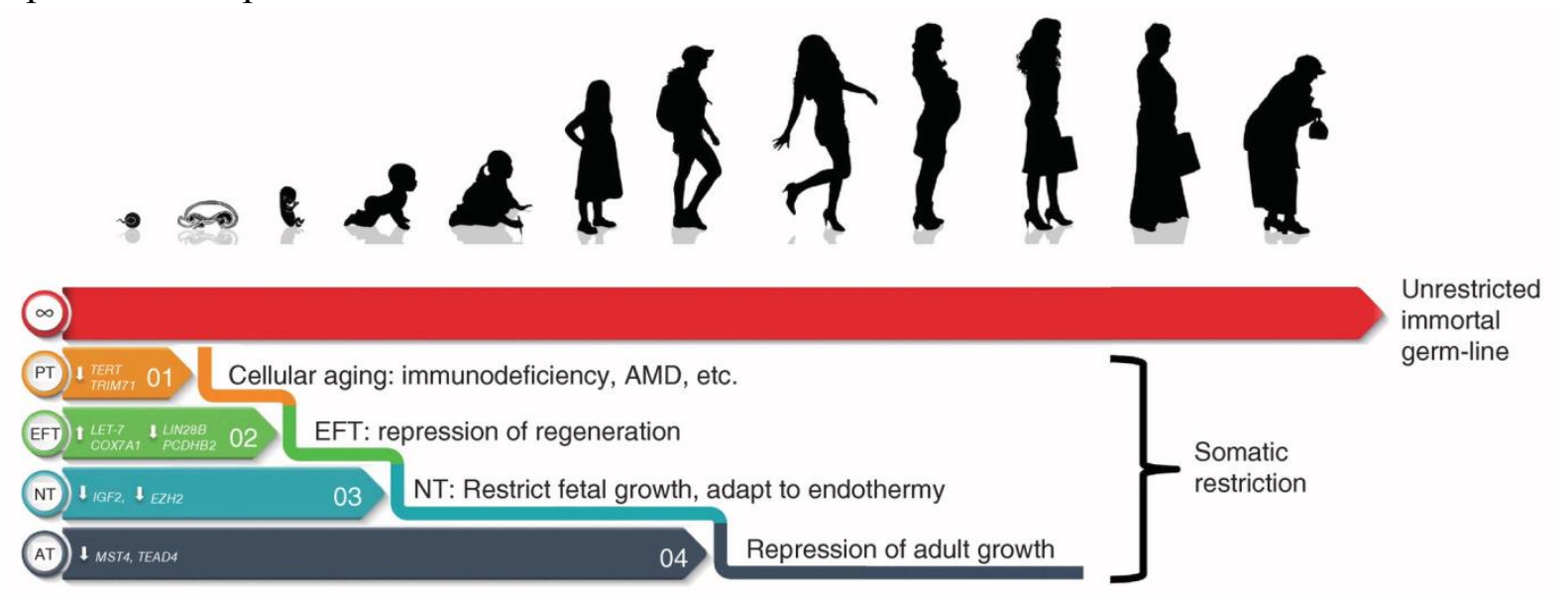

Рисунок 18. Этапы соматической рестрикции [17]. ВМД: возрастная макулярная дегенерация; АТ: переход у взрослых; ЭФТ: эмбрионально-фетальный переход; НТ: неонатальный переход; ПТ: Плюрипотентный переход

Несмотря на некоторые важные наблюдения за метаболизмом ксенобиотиков в целом, существует лишь неполное представление о масштабах влияния микробиома конкретно на метаболизм и абсорбцию лекарственных средств, а также о том, как это может влиять на системные концентрации исходных соединений и токсичных метаболитов. Значение как микробного метаболизма ксенобиотиков, так и влияния микробиома кишечника на ферментные системы печени хозяина, тем не менее, набирает обороты и представляет собой дополнительную проблему в усилиях по открытию лекарственных средств, имеющих последствия для улучшения результатов лечения или противодействия неблагоприятным лекарственным реакциям. В настоящее время микробные факторы должны учитываться при определении фармакокинетики лекарственных средств и влияния, которое эволюционирующий и динамичный микробиом может оказывать в этом отношении. Интегрировав вклад микробиома кишечника в сохранение здоровья и патогенез болезней к метаболизму ксенобиотиков, сосредоточив внимание на терапевтических вмешательствах, фармакологическом действии лекарственных средств и химических биотрансформациях, которые в совокупности являются стратегическими в доказательной медицине (Рисунок 19).

А) метаболические ниши в микробиоме кишечника. Локализация и пространственная организация кишечной микробиоты неоднородны по всему желудочно-кишечному тракту. Эта динамическая экосистема кишечника состоит из многих уникальных особенностей, таких как микрониши, градиенты рН и динамические микробно-тканевые взаимодействия, имеющие отношение к микробной биотрансформации. Самая высокая плотность бактерий присутствует в толстой кишке, причем последние оценки $10^{13}$ бактериальных клеток в толстой кишке связаны с микробными генами, кодирующими широкий спектр ферментов, необходимых для биотрансформации ксенобиотиков.Эти бактерии, вероятно, наиболее важны для фармакомикробиомики и обитают в реакционной камере со средним рН 6,4-7 и более низким окислительно-восстановительным потенциалом, чем другие желудочнокишечные ниши. Парциальное давление кислорода по желудочно-кишечному тракту также вносит свой вклад в эти метаболические ниши.

В) факторы, влияющие на состав и функционирование метаболической ниши толстой кишки. На композиционные характеристики микробиома кишечника оказывает влияние целый ряд факторов, при этом начальный посев и траектория движения к здоровому 
подобию взрослому разнообразию и стабильности определяются способом доставки (естественный или кесарево сечение) и ранними схемами кормления (грудное вскармливание против искусственного вскармливания). Генетика хозяина также играет определенную роль, как и географическое положение, в то время как стресс на протяжении всей жизни может рассматриваться как угроза для разнообразия микробиома кишечника. Считается также, что «западная» диета нарушает целостность микробиома кишечника, в то время как повышенное потребление клетчатки связано с повышенным разнообразием. Физические упражнения могут также способствовать стабильности микробиома здоровья, хотя процесс старения связан с сужением разнообразия, как и многие болезненные состояния и чрезмерное/ нецелесообразное использование антибиотиков (Рисунок 19).
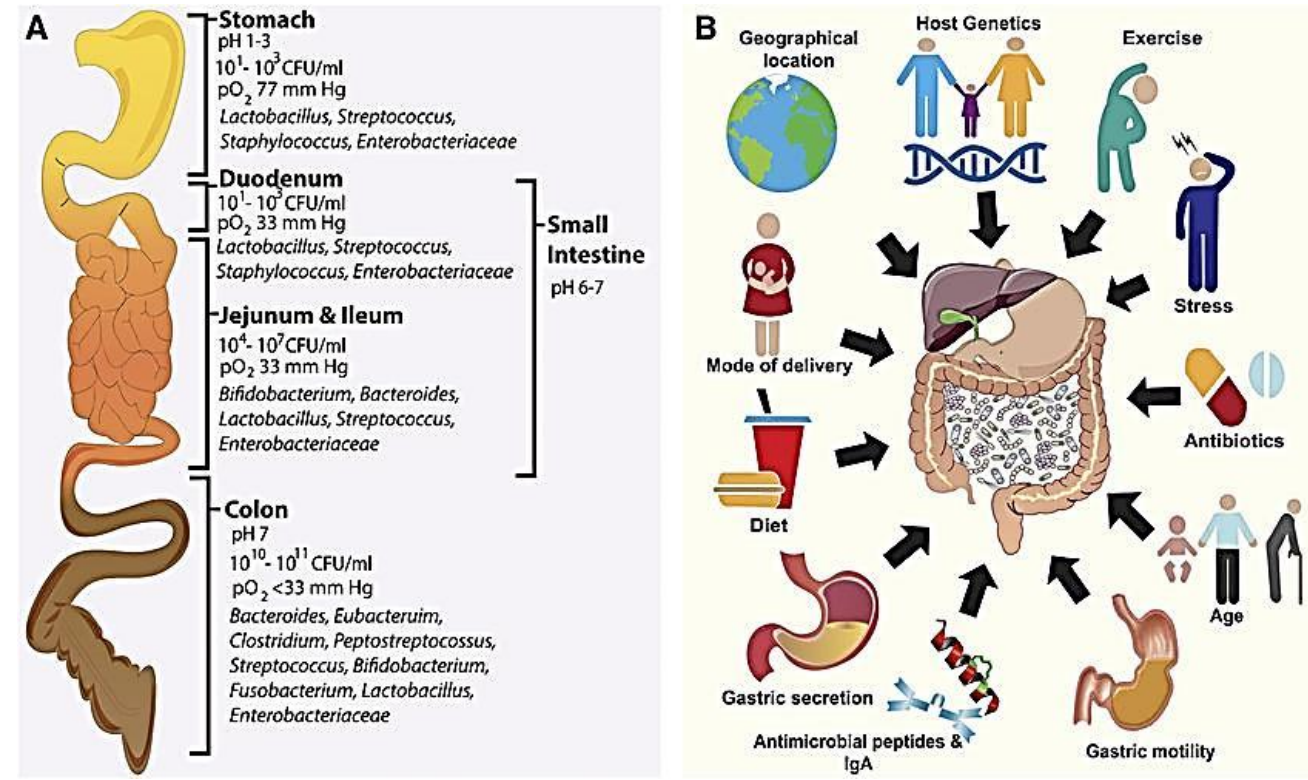

Рисунок 19. Метаболические ниши в микробиоме пищеварительного тракта, их локализация и пространственная организация [11]

Исследованы [11] микробные биотрансформации, свидетельствуют, что комплексные различия могут не обязательно приравниваться к функциональным изменениям, индивидуально-специфический генетический состав генома хозяина объясняет некоторые различия в характеристиках микробиома кишечника и может влиять на метаболические результаты. Например, микробные ферменты, такие как $\beta$ - глюкуронидазы, могут отличаться по селективности субстрата и активности, в зависимости от бактерий, из которых они возникают. Другие известные факторы, влияющие на состав микробиома кишечника, такие как возраст, гормональный статус и пол, также перекрываются с переменной фармакокинетикой препарата и влияют на относительное содержание генов, кодирующих ферменты метаболизма ксенобиотиков. Метаболизм ксенобиотиков хозяина также зависит от циркадианных ритмов, и это может также быть истинно микробной ферментативной деятельности потому что структура сообщества микробиоты кишечника и метаболически деятельность также отличают биологическими ритмами. Также пока не ясно, сколько переменных, связанных с изменением состава и стабильности микробиома кишечника, в том числе диеты и географии, оставляют свой след на способности к ксенобиотическому метаболизму. Одним из примером модифицируемой природы микробиома кишечника в контексте диеты и географии является передача бактериальных генов, кодирующих порфираназы, агаразы и связанные с ними белки от морских красных водорослей к 
бактериям, обитающим в желудочно-кишечном тракте японских индивидуумов в результате их потребления морскими водорослями (Рисунок 20).

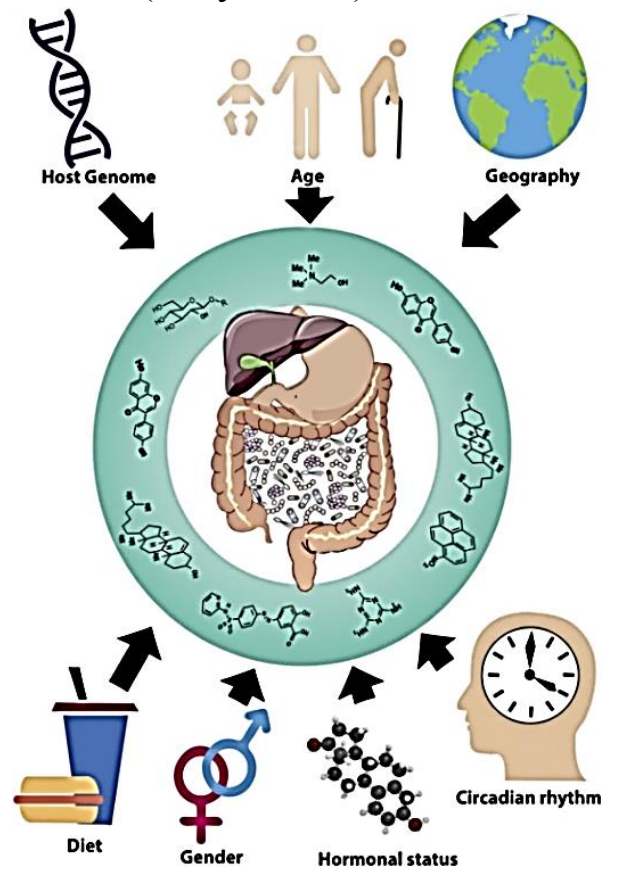

Рисунок 20. Факторы, влияющие на метаболизм ксенобиотиков микробиома кишечника [11]

Многие ксенобиотики также влияют на характеристики микробиома кишечника (Рисунок 21). Это включает в себя фармацевтические соединения, такие как метформин и метотрексат, и психотропные агенты, такие как Оланзапин. Другие рецептурные препараты связаны с изменениями в разнообразии микробиома кишечника, включая ингибиторы протонной помпы, опиоиды и нестероидные противовоспалительные препараты. Пищевые соединения также оказывают значительное влияние на микробиом кишечника, включая полифенольные фитохимические вещества (ресвератрол, флавоноиды), полиненасыщенные жирные кислоты и сложный эфир растительного стерола. Кроме того, экологические и промышленные химикаты, включая эндокринные разрушающие химикаты, тяжелые металлы, пестициды и загрязнители, оказывают влияние на структуру, состав и функцию микробиома кишечника [11].

Микробиота кишечника экспрессирует более 3,3 миллиона бактериальных генов, в то время как геном человека экспрессирует только 20 тысяч генов. Ген-продукты микроба оказывают решающее влияние на регуляцию переваривания пищи и развитие иммунной системы. Исследования подтверждают [43], что манипуляции с непатогенными бактериальными штаммами в организме хозяина могут стимулировать восстановление иммунного ответа на патогенные бактерии, вызывающие заболевания. Различные подходы, включая использование нутрицевтиков (пребиотиков и пробиотиков), а также фагов, сконструированных с помощью систем CRISPR/Cas, были разработаны в качестве новых методов лечения дисбиоза (изменений в микробном сообществе) и распространенных заболеваний (например, диабета, ожирения и др.).

В исследовании [43], был сделан прогноз на действия и молекулярные подходы, направленные на защиту окружающей среды и микробных экосистем человека. Измерения экологических, филометагеномных и микробных метаболических изменений в микробиомах требуют специализированного и сложного набора знаний. Сотрудничество между университетами, исследовательскими учреждениями, неправительственными организациями и специалистами фармацевтической промышленности имеют ключевое значение для оценки 
как биологического, так и фармацевтического воздействия на экосистемы и выяснения механизма действия новых соединений в организме хозяина и его микробиомах. Полезность метагеномной функциональной реконструкции для прямой ассоциации функций сообщества с фенотипом среды обитания и хозяина будет иметь решающее значение для надлежащего изучения конструкций и производства более экологичных фармацевтических продуктов для будущей персонализированной медицины.

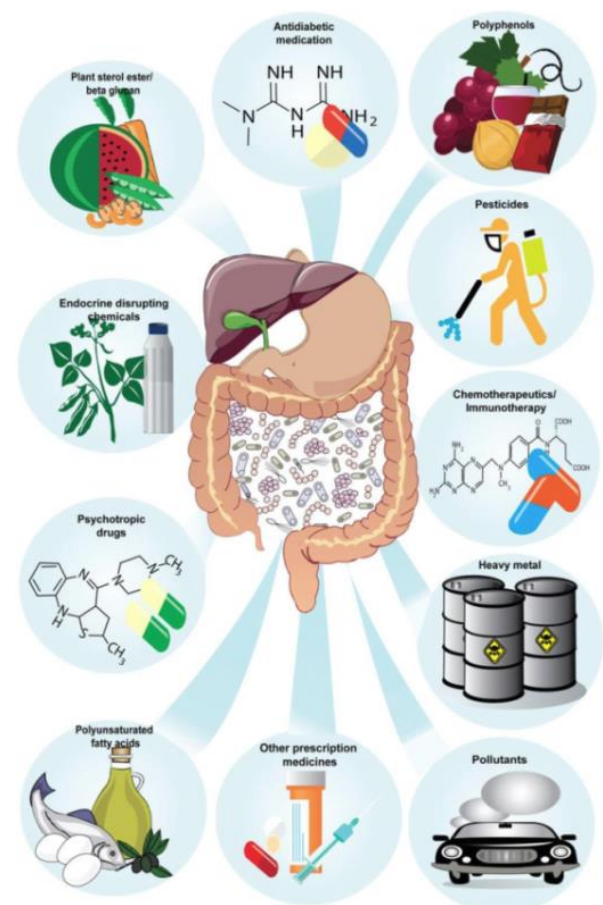

Рисунок 21. Ксенобиотики, которые изменяют микробиом кишечника [11]

Таким образом, понимание механизмов функционирования генома, эпигенома, их взаимоотношений с факторами окружающей среды повышает точность диагностики заболеваний, позволяет разрабатывать персонифицированные функциональные диеты и выявлять среди известных или вновь созданных лекарственных средств те, которые имеют эпигеномную направленность.

Нейроось «микробиота-кишечник-мозг» представляет собой динамическую матрицу тканей и органов, включая желудочно-кишечную микробиоту, иммунные клетки, ткани кишечника, железы, вегетативную нервную систему и головной мозг, которые взаимодействуют сложным разнонаправленным образом через ряд анатомически и физиологически различных систем. Долгосрочные возмущения этой гомеостатической среды могут способствовать прогрессированию ряда нарушений путем изменения физиологических процессов, включая активацию гипоталамо-гипофизарно-надпочечниковой оси, нейромедиаторных систем, иммунной функции и воспалительной реакции.

Продолжаются исследования того, что триллионы микробов, населяющих наш кишечник, являются существенным фактором, способствующим психическому здоровью и, в равной степени, прогрессированию нервно-психических расстройств. Экстраординарная сложность экосистемы кишечника и ее взаимодействие с кишечным эпителием для проявления физиологических изменений в головном мозге, влияющих на настроение и поведение. Homo sapiens имеет уникальное сообщество микробиоты и здоровой биомикробиоты, которая меняется под воздействием ряда факторов, включая диету, физические упражнения, стресс, состояние здоровья, генетику, «свою полипрагмазию» и т.д. 
Современные инструменты и методики эпигенетической, диетической и биомикробиотической защиты здорового старения - это междисциплинарные, межвузовские и межведомственные направления, которые фокусируются на изучении нервной системы и влияния мозга на поведение и мыслительную способность людей $[1,2,30,31]$.

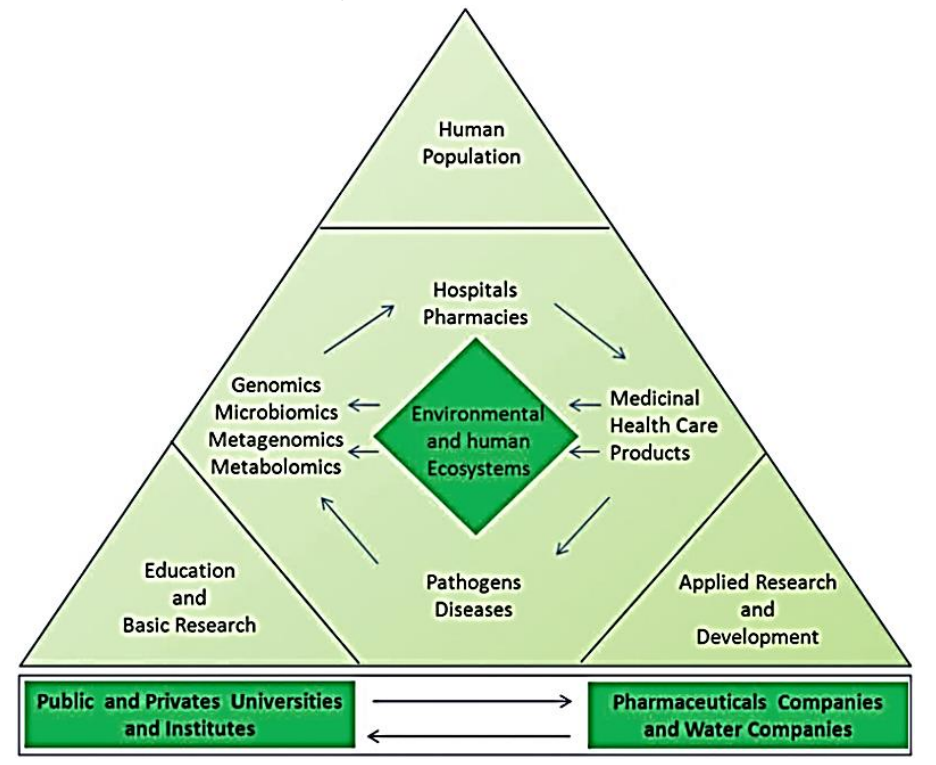

Рисунок 22. Эпигенетическая защита микробиома: мультимодальное, междисциплинарное и межведомственное взаимодействие [43]

Новая ЭПИГЕНЕТИКА Нomo sapiens управляет взаимодействием эпигенетических механизмов старения и долголетия с биологией, биофизикой, физиологией и факторами окружающей среды в регуляции транскрипции. Старение - это структурно-функциональная перестройка (перепрограммирование) и постепенное снижение физиологических функций организма, которые приводят к возрастной потере профессиональной пригодности, болезням, и к смерти. Понимание причин здорового старения составляет одно из самых проблемных междисциплинарных направлений.

Генетический и эпигенетический вклад в старение и долголетие человека огромен. В то время как факторы окружающей среды и образа жизни важны в более молодом возрасте, вклад генетики проявляется более доминантно в достижении долголетия и здоровой старости. Эпигеномные изменения во время старения глубоко влияют на клеточную функцию и стрессоустойчивость. Дисрегуляция транскрипционных и хроматиновых сетей, вероятно, является важнейшим компонентом старения. В ближайшем будущем искусственный интеллект и крупномасштабная биоинформационная система анализа сможет выявить вовлеченность многочисленных сетей взаимодействия.

\section{Bblводbl:}

Продолжительность жизни человека в значительной степени определяется эпигенетически.

Эпигенетическая информация - обратима, наши исследования дают возможность терапевтического вмешательства при здоровом старении и связанных с возрастом заболеваниях.

Микробиологическая память будет оставаться стабильной, когда рацион функционального (здорового) диетического питания и здоровая биомикробиота остаются почти неизменными. 
Искусственный интеллект, нейросети «мозг-микробиота» позволяют управлять взаимодействием генетических и эпигенетических программ старения и здорового долголетия.

Новая управляемая здоровая биомикробиота и персонализированное функциональное и сбалансированное питание «мозга и микробиоты» - это долговременные медицинские программы пациента, которые позволяет проведению профилактики полипрагмазии.

Мультимодальные инструменты, биочипирование, нейронные и мозговые чипы, технологии секвенирования следующего (нового) поколения создают биомаркеры для управления структурой здоровой биомикробиоты и функционального питания, в зависимости от целевых показателей.

Функциональный продукт питания $\mathrm{c}$ помощью биомаркеров и технологий искусственного интеллекта является целевой питательной средой как для организма в целом, так и для биомикробиоты в частности.

Хрономедицинские технологии - это математические модели и искусственный интеллект, которые предсказывают биологический возраст человека с помощью данных метилирования ДНК, модификации гистонов, ремоделирование нуклеосом и микроРНК, и являются наиболее точными биомаркерами процесса старения.

Факторы образа жизни и воздействия окружающей среды оставляют эпигенетические следы на нашей ДНК, которые влияют на экспрессию генов, некоторые из них оказывают защитное действие, а другие - вредное.

Генетические и эпигенетические факторы: обеспечивающие здоровое старение, долголетие и сверхдолголетие, требуют от человека разумного нового взаимодействия с природой и обществом, и ответственности за будущие здоровые поколения.

\section{Список литературь:}

1. Романчук П. И., Волобуев А. Н. Современные инструменты и методики эпигенетической защиты здорового старения и долголетия Нomo sapiens // Бюллетень науки и практики. 2020. Т. 6. №1. С. 43-70. https://doi.org/10.33619/2414-2948/50/06

2. Романчук Н. П., Романчук П. И. Нейрофизиология и нейрореабилитация когнитивных нарушений и расстройств // Бюллетень науки и практики. 2019. Т. 5. №11. С. 176-196. https://doi.org/10.33619/2414-2948/48/19

3. Романчук Н. П., Пятин В. Ф. Мелатонин: нейрофизиологические и нейроэндокринные аспекты // Бюллетень науки и практики. 2019. Т. 5. №7. С. 71-85. https://doi.org/10.33619/2414-2948/44/08

4. Волобуев А. Н., Романчук П. И., Романчук Н. П., Давыдкин И. Л., Булгакова С. В. Нарушение памяти при болезни Альцгеймера // ВРАЧ. 2019. Т. 30. №6. С. 10-13. https://doi.org/10.29296/25877305-2019-06-02

5. Булгакова С. В., Романчук П. И., Романчук Н. П., Пятин В. Ф., Романов Д. В., Волобуев А. Н. Болезнь Альцгеймера и искусственный интеллект: долговременная персонифицированная реабилитация и медико-социальное сопровождение // Бюллетень науки и практики. 2019. Т. 5. №11. С.136-175. https://doi.org/10.33619/2414-2948/48/18

6. Булгакова С. В., Романчук П. И., Волобуев А. Н. Нейросети: нейроэндокринология и болезнь Альцгеймера // Бюллетень науки и практики. 2019. Т. 5. №6. С. 112-128. https://doi.org/10.33619/2414-2948/43/16

7. Булгакова С. В., Романчук П. И., Волобуев А. Н. Клинико-биофизические принципы лечения сосудистой деменции и болезни Альцгеймера // Бюллетень науки и практики. 2019. T. 5. №5. C. 57-72. https://doi.org/10.33619/2414-2948/42/08 
8. Волобуев А. Н., Романчук П. И. Биофизика кровообращения при сосудистой деменции и болезни Альцгеймера // Бюллетень науки и практики. 2019. Т. 5. №4. С.76-102. https://doi.org/10.33619/2414-2948/41/08

9. Волобуев А. Н., Романчук П. И., Булгакова С.В. Нейросеть «мозг-микробиота»: регуляция «висцерального» мозга и накопление когнитивной памяти // Бюллетень науки и практики. 2019. Т. 5. №2. С. 33-52. https://doi.org/10.33619/2414-2948/39/05

10. Тренева Е. В., Булгакова С. В., Романчук П. И., Захарова Н. О., Сиротко И. И. Мозг и микробиота: нейроэндокринные и гериатрические аспекты // Бюллетень науки и практики. 2019. T. 5. №9. C. 26-52. https://doi.org/10.33619/2414-2948/46/03

11. Clarke G., Sandhu K. V., Griffin B. T., Dinan T. G., Cryan J. F., Hyland N. P. Gut reactions: breaking down xenobiotic-microbiome interactions // Pharmacological reviews. 2019. V. 71. №2. P. 198-224. https://doi.org/10.1124/pr.118.015768

12. Волобуев А. Н., Давыдкин И. Л., Пятин В. Ф., Романчук Н. П. Проблема «Информационного голода» в пери- и постперинатальном периоде // ВРАЧ. 2018. Т. 29. №8. C. 35-36. https://doi.org/10.29296/25877305-2018-08-08

13. Волобуев А. Н., Пятин В. Ф., Романчук Н. П., Булгакова С. В.. Давыдкин И. Л. Когнитивная дисфункция при перевозбуждении структур головного мозга // ВРАЧ. 2018. Т. 29. №9. C. 17-20. https://doi.org/10.29296/25877305-2018-09-04

14. Chang C. S., Kao C. Y. Current understanding of the gut microbiota shaping mechanisms // Journal of biomedical science. 2019. V. 26. №1. P. 59. https://doi.org/10.1186/s12929-019-0554-5

15. Snir S., Farrell C., Pellegrini M. Human epigenetic ageing is logarithmic with time across the entire lifespan // Epigenetics. 2019. V. 14. №9. P. 912-926. doi.org/10.1080/15592294.2019.1623634

16. Wagner W. The link between epigenetic clocks for aging and senescence // Frontiers in genetics. 2019. V. 10. https://doi.org/10.3389/fgene.2019.00303

17. West M. D., Sternberg H., Labat I., Janus J., Chapman K. B., Malik N. N., ... Larocca D. Toward a unified theory of aging and regeneration // Regenerative medicine. 2019. V. 14. №9. https://doi.org/10.2217/rme-2019-0062

18. Ideraabdullah F. Y., Zeisel S. H. Dietary modulation of the epigenome // Physiological reviews. 2018. V. 98. №2. 3. 667-695. https://doi.org/10.1152/physrev.00010.2017

19. Tiffon $\mathrm{C}$. The impact of nutrition and environmental epigenetics on human health and disease // International journal of molecular sciences. 2018. V. 19. №11. P. 3425. https://doi.org/10.3390/ijms 19113425

20. Devaux C. A., Raoult D. The microbiological memory, an epigenetic regulator governing the balance between good health and metabolic disorders // Frontiers in microbiology. 2018. V. 9. P. 1379. https://doi.org/10.3389/fmicb.2018.01379

21. Serino M. Molecular paths linking metabolic diseases, gut microbiota dysbiosis and enterobacteria infections // Journal of molecular biology. 2018. V. 430. №5. P. 581-590. doi: 10.1016/j.jmb.2018.01.010

22. Chung H. J., Nguyen T. T., Kim H. J., Hong S. T. Gut Microbiota as a missing link between nutrients and traits of human // Frontiers in microbiology. 2018. V. 9. P. 1510. https://doi.org/10.3389/fmicb.2018.01510

23. Singh P. B., Newman A. G. Age reprogramming and epigenetic rejuvenation // Epigenetics \& chromatin. 2018. V. 11. №1. P. 1-7. https://doi.org/10.1186/s13072-018-0244-7

24. Giau V. V., Wu S. Y., Jamerlan A., An S. S. A., Kim S., Hulme J. Gut microbiota and their neuroinflammatory implications in Alzheimer's disease // Nutrients. 2018. V. 10. №11. P. 1765. https://doi.org/10.3390/nu10111765 
25. Laforest-Lapointe I., Arrieta M. C. Patterns of early-life gut microbial colonization during human immune development: an ecological perspective // Frontiers in immunology. 2017. V. 8. P. 788. https://doi.org/10.3389/fimmu.2017.00788

26. Романчук Н. П., Пятин В. Ф., Волобуев А. Н. Нейрофизиологические и биофизические принципы нейропластичности // Здоровье и образование в XXI веке. 2017. Т. 19. №2. С.97-101.

27. Пятин В. Ф., Романчук Н. П. Геронтологические и гериатрические аспекты нейропластичности головного мозга человека // Клинические и фундаментальные аспекты геронтологии. Самара. 2017. С. 371-385.

28. Пятин В. Ф., Романчук Н. П., Волобуев А. Н. Нейровизуализация и нейропластичность: инновации в диагностике и лечении // Бюллетень науки и практики. 2017. №9(22). C.51-61.

29. Романчук Н. П., Пятин В. Ф., Волобуев А. Н. От электроэнцефалографии до позитронно-эмиссионной томографии: гибридные и комбинированные методы управления когнитивным мозгом // Здоровье и образование в XXI веке. 2017. Т. 19. №28. С. 2-8. http://dx.doi.org/10.26787/nydha-2226-7417-2017-19-8-2-8

30. Романчук Н. П., Пятин В. Ф., Волобуев А. Н. Нейропластичность: современные методы управления // Здоровье и образование в XXI веке. 2016. Т. 18, №9. С. 92-94.

31. Волобуев А. Н., Захарова Н. О., Романчук Н. П., Романов Д. В., Романчук П. И., Адыширин-Заде К. А. Современные принципы гериатрического анализа в медицине // Успехи геронтологии. 2016. №29(3). С. 461-470.

32. Волобуев А. Н., Романчук Н. П., Пятин В. Ф. Циркадианная биофизика и нейропластичность // Здоровье и образование в XXI веке. 2016. Т. 18. № 8. С. 79-83.

33. Mika A., Fleshner M. Early-life exercise may promote lasting brain and metabolic health through gut bacterial metabolites // Immunology and cell biology. 2016. V. 94. №2. P. 151-157. https://doi.org/10.1038/icb.2015.113

34. Rea I. M., Dellet M., Mills K. I. Living long and ageing well: is epigenomics the missing link between nature and nurture? // Biogerontology. 2016. V. 17. №1. P. 33-54. https://doi.org/10.1007/s10522-015-9589-5

35. El Aidy S. et al. Microbiome to brain: unravelling the multidirectional axes of communication // Microbial endocrinology: Interkingdom signaling in infectious disease and health. Springer, Cham, 2016. P. 301-336. https://doi.org/10.1007/978-3-319-20215-0_15

36. Шендеров Б. А. Микроэкологическая эпигенетика стресса, заболеваний, здоровья и долголетия // Вестник восстановительной медицины 2016. №1 . С. 21-28.

37. Олескин А. В., Эль-Регистан Г. И., Шендеров Б. А. Межмикробные химические взаимодействия и диалог микробиота-хозяин: роль нейромедиаторов // Микробиология. 2016. Т. 85. №1. C. 1-24. https://doi.org/10.7868/S0026365616010080

38. Arboleya S. et al. Gut bifidobacteria populations in human health and aging // Frontiers in microbiology. 2016. V. 7. P. 1204. https://doi.org/10.3389/fmicb.2016.01204

39. Marchesi J. R., Adams D. H., Fava F., Hermes G. D., Hirschfield G. M., Hold G., ... Thomas L. V. The gut microbiota and host health: a new clinical frontier // Gut. 2016. V. 65. №2. P. 330-339. http://dx.doi.org/10.1136/gutjnl-2015-309990

40. Wang H. X., Wang Y. P. Gut microbiota-brain axis // Chinese medical journal. 2016. V. 129. №19. P. 2373.

41. Paul B. et al. Influences of diet and the gut microbiome on epigenetic modulation in cancer and other diseases // Clinical epigenetics. 2015. V. 7. №1. P. 112. https://doi.org/10.1186/s13148-0150144-7 
42. Belizário J. E., Napolitano M. Human microbiomes and their roles in dysbiosis, common diseases, and novel therapeutic approaches // Frontiers in microbiology. 2015. V. 6. P. 1050. https://doi.org/10.3389/fmicb.2015.01050

43. Clarke G. et al. Minireview: gut microbiota: the neglected endocrine organ // Molecular endocrinology. 2014. V. 28. №8. P. 1221-1238. https://doi.org/10.1210/me.2014-1108

44. Galland L. The gut microbiome and the brain // Journal of medicinal food. 2014. V. 17. №12. P. 1261-1272. https://doi.org/10.1089/jmf.2014.7000

45. Sharkey K. A., Savidge T. C. Role of enteric neurotransmission in host defense and protection of the gastrointestinal tract // Autonomic Neuroscience. 2014. V. 181. P. 94-106. https://doi.org/10.1016/j.autneu.2013.12.006

46. Романов Д. В., Романчук Н. П. Ранняя диагностика когнитивных нарушений. Самара. 2014. $34 \mathrm{c}$.

47. Bengmark S. Gut microbiota, immune development and function // Pharmacological Research. 2013. V. 69. №1. P. 87-113. https://doi.org/10.1016/j.phrs.2012.09.002

48. Lyte M. Microbial endocrinology and nutrition: a perspective on new mechanisms by which diet can influence gut-to-brain communication // PharmaNutrition. 2013. V. 1. №1. P. 35-39. https://doi.org/10.1016/j.phanu.2012.11.002

49. Романчук П. И., Волобуев А. Н., и др. Активное долголетие: биофизика генома, нутригеномика, нутригенетика, ревитализация. 2013. 416 с.

50. Волобуев А. Н., Петров Е. С., Кондурцев В. А., Романчук П. И. Некоторые принципы подбора лекарственных препаратов при комбинированной лекарственной терапии первичной артериальной гипертонии // ВРАЧ. 2013. №3. С. 49-51.

51. Москалев А. А. Генетика и эпигенетика старения и долголетия // Экологическая генетика. 2013. Т. 11. №1. С. 3-11.

52. Шендеров Б. А. Роль питания и кишечной микрофлоры в программировании и реализации эпигенома здоровых и больных людей // Вестник восстановительной медицины 2013. Специальный выпуск. С. 102.

53. Малышев В. К., Романчук П. И. Функциональные продукты питания: инновации в диетологии и кардиологии. М.-Самара. 2012. 248 с.

54. Романчук Н. П. Способ производства зернового компонента для пищевого продукта быстрого приготовления и способ производства функционального пищевого продукта быстрого приготовления. Патент РФ на изобретение №2423873.

55. Романчук Н. П., Романчук П. И., Малышев В. К. Продукт диетического, профилактического и функционального питания при хронической ишемии головного мозга. Патент РФ на изобретение № 2489038.

56. Романчук П. И., Романчук Н. П. Способ оценки возрастных изменений сердечнососудистой системы. Патент РФ на изобретение 2485886.

57. Пятин В. Ф., Романчук Н. П., Романчук П. И., и др. Способ нормализации циркадианных ритмов человека. Патент РФ на изобретение 2533965.

58. Романчук П. И. и др. Роль новых механизмов регуляции артериальных сосудов при первичной артериальной гипертонии // Вестник восстановительной медицины. 2010. №3(37). C. 34-37.

59. Разумов А. Н., Романчук П. И. и др. Активное долголетие и артериальная гипертония: роль новых медико-генетических механизмов и инноваций восстановительной медицины // Вестник восстановительной медицины. 2010. №5(39). С. 2-7. 
References:

1. Romanchuk, P., \& Volobuev, A. (2019). Modern Tools and Methods of Epigenetic Protection of Healthy Aging and Longevity of the Homo sapiens. Bulletin of Science and Practice, 6(1), 43-70. https://doi.org/10.33619/2414-2948/50/06 (in Russian).

2. Romanchuk, N. P., \& Romanchuk, P. I. (2019). Neurophysiology and neurorehabilitation of cognitive disorders and disorders. Bulletin of Science and Practice. 5(11). 176-196. https://doi.org/10.33619/2414-2948/48/19 (in Russian)

3. Romanchuk, N., \& Pyatin, V. (2019). Melatonin: neurophysiological and neuroendocrine aspects. Bulletin of Science and Practice, 5(7), 71-85. https://doi.org/10.33619/2414-2948/44/08 (in Russian)

4. Volobuev, A. N., Romanchuk, P. I., Romanchuk, N. P., Davydkin, I. L., \& Bulgakova, S.V. (2019). Memory impairment in Alzheimer's disease. Vrach, (6) 10-13. https://doi.org/10.29296/25877305-2019-06-02 (in Russian)

5. Bulgakova, S. V., Romanchuk, P. I., Romanchuk, N. P., Pyatin, V. F., Romanov, D. V., \& Volobuev, A. N. (2019). Alzheimer's Disease and artificial intelligence: long-term personalized rehabilitation and medical and social support. Bulletin of Science and Practice. 5(11). 136-175. https://doi.org/10.33619/2414-2948/48/18 (in Russian).

6. Bulgakova, S., Romanchuk, P., \& Volobuev, A. (2019). Neural Networks: Neuroendocrinology and Alzheimer's Disease. Bulletin of science and practice, 5(6). 112-128. https://doi.org/10.33619/2414-2948/43/16 (in Russian).

7. Bulgakova, S., Romanchuk, P., \& Volobuev, A. (2019). Clinical and Biophysical Principles of Vascular Dementia and Alzheimer's Disease Treatment. Bulletin of Science and Practice, 5(5), 57-72. https://doi.org/10.33619/2414-2948/42/08. (in Russian)

8. Volobuev, A. N., \& Romanchuk, P. I. (2019). Biophysics of blood circulation in vascular dementia and Alzheimer's disease. Bulletin of science and practice, 5(4). 76-102. https://doi.org/10.33619/2414-2948/41/08 (in Russian)

9. Volobuev, A. N., Romanchuk, P. I., \& Bulgakova, S. V. (2019). Neural Network "brainmicrobiota": regulation of "visceral" brain and accumulation of cognitive memory. Bulletin of science and practice, 5(2). 33-52. https://doi.org/10.33619/2414-2948/39/05.

10. Treneva, E., Bulgakova, S., Romanchuk, P., Zakharova, N., \& Sirotko, I. (2019). The Brain and Microbiota: Neuroendocrine and Geriatric Aspects. Bulletin of Science and Practice, 5(9), 26-52. https://doi.org/10.33619/2414-2948/46/03 (in Russian)

11. Clarke, G., Sandhu, K. V., Griffin, B. T., Dinan, T. G., Cryan, J. F., \& Hyland, N. P. (2019). Gut reactions: breaking down xenobiotic-microbiome interactions. Pharmacological reviews, 71(2), 198-224. https://doi.org/10.1124/pr.118.015768

12. Volobuev, A. N., Davydkin, I. L., Pyatin, V. F., \& Romanchuk, N. P. (2018). The problem of "Information hunger" in peri-and postperinatal period. Vrach, (8), 35-36. https://doi.org/10.29296/25877305-2018-08-08 (in Russian)

13. Volobuev, A. N., Pyatin, V. F., Romanchuk, N. P. Bulgakova, S. V. \& Davydkin, I. L. (2018). Cognitive dysfunction in the over-stimulation of the brain structures.Vrach, (9) 17-20. doi:10.29296/25877305-2018-09-04 (in Russian)

14. Chang, C., Kao, C. (2019) Current understanding of the gut microbiota shaping mechanisms. J Biomed Sci 26, 59. https://doi.org/10.1186/s12929-019-0554-5

15. Snir, S., Farrell, C., \& Pellegrini, M. (2019). Human epigenetic ageing is logarithmic with time across the entire lifespan. Epigenetics, 14(9), 912-926. https://doi.org/10.1080/15592294.2019.1623634 
16. Wagner, W. (2019). The link between epigenetic clocks for aging and senescence. Frontiers in genetics, 10. https://doi.org/10.3389/fgene.2019.00303

17. West, M. D., Sternberg, H., Labat, I., Janus, J., Chapman, K. B., Malik, N. N., ... \& Larocca, D. (2019). Toward a unified theory of aging and regeneration. Regenerative medicine, 14(9), 867-886. https://doi.org/10.2217/rme-2019-0062

18. Ideraabdullah, F. Y., \& Zeisel, S. H. (2018). Dietary modulation of the epigenome. Physiological reviews, 98(2), 667-695. https://doi.org/10.1152/physrev.00010.2017

19. Tiffon, C. (2018). The impact of nutrition and environmental epigenetics on human health and disease. International journal of molecular sciences, 19(11), 3425. https://doi.org/10.3390/ijms19113425

20. Devaux, C. A., \& Raoult, D. (2018). The microbiological memory, an epigenetic regulator governing the balance between good health and metabolic disorders. Frontiers in microbiology, 9 , 1379. https://doi.org/10.3389/fmicb.2018.01379

21. Serino, M. (2018). Molecular paths linking metabolic diseases, gut microbiota dysbiosis and enterobacteria infections. Journal of molecular biology, 430(5), 581-590. https://doi.org/10.1016/j.jmb.2018.01.010

22. Chung, H. J., Nguyen, T. T., Kim, H. J., \& Hong, S. T. (2018). Gut Microbiota as a missing link between nutrients and traits of human. Frontiers in microbiology, 9, 1510. https://doi.org/10.3389/fmicb.2018.01510

23. Singh, P. B., \& Newman, A. G. (2018). Age reprogramming and epigenetic rejuvenation. Epigenetics \& chromatin, 11(1), 1-7. https://doi.org/10.1186/s13072-018-0244-7

24. Giau, V. V., Wu, S. Y., Jamerlan, A., An, S. S. A., Kim, S., \& Hulme, J. (2018). Gut microbiota and their neuroinflammatory implications in Alzheimer's disease. Nutrients, 10(11), 1765. https://doi.org/10.3390/nu10111765

25. Laforest-Lapointe, I., \& Arrieta, M. C. (2017). Patterns of early-life gut microbial colonization during human immune development: an ecological perspective. Frontiers in immunology, 8, 788. https://doi.org/10.3389/fimmu.2017.00788

26. Romanchuk, N. P. Pyatin, V. F., \& Volobuev, A. N. (2017). Neurophysiological and biophysical principles of neuroplasticity // Health \& education in the XXI century, 19(2). 97-101. (in Russian).

27. Pyatin, V. F., \& Romanchuk, N. P. (2017). Gerontological and geriatric aspects of neuroplasticity of the human brain. Clinical and fundamental aspects of gerontology. Samara. 371385.

28. Pyatin, V., Romanchuk, N., \& Volobuev, A. (2017). Neurovisualization and neuroplasticity: innovations in diagnosis and treatment. Bulletin of Science and Practice, (9), 51-61. (in Russian)

29. Romanchuk, N. P., Pyatin, V. F., Volobuev, A. N. (2017). From electroencephalography to positron emission tomography: hybrid and combined methods of cognitive brain control. Health and education in the XXI century, 19(28). 2-8. http://dx.doi.org/10.26787/nydha-2226-7417-201719-8-2-8 (in Russian)

30. Romanchuk, N. P. Pyatin, V. F., \& Volobuev, A. N. (2016). Neuroplasticity: modern methods of management. Health \& education in the XXI century, 18(9). 92-94. (in Russian).

31. Volobuev, A. N., Zakharova, N.O., Romanchuk, N. P., Romanov, D. V., Romanchuk, P. I., \& Adyshirin-Zade K. A. (2016). Modern principles in analysis of geriatric medicine. Advances in gerontology, 29(3). 461-470. (in Russian)

32. Volobuev, A. N., Romanchuk, N. P., \& Pyatin, V. F. (2016). Circadian Biophysics and neuroplasticity. Health \& education in the XXI century, 18(8). 79-83. (in Russian). 
33. Mika, A., \& Fleshner, M. (2016). Early-life exercise may promote lasting brain and metabolic health through gut bacterial metabolites. Immunology and cell biology, 94(2), 151-157. https://doi.org/10.1038/icb.2015.113

34. Rea, I. M., Dellet, M., \& Mills, K. I. (2016). Living long and ageing well: is epigenomics the missing link between nature and nurture?. Biogerontology, 17(1), 33-54. https://doi.org/10.1007/s10522-015-9589-5

35. El Aidy, S., Stilling, R., Dinan, T. G., \& Cryan, J. F. (2016). Microbiome to brain: unravelling the multidirectional axes of communication. In Microbial endocrinology: Interkingdom signaling in infectious disease and health (301-336). Springer, Cham. https://doi.org/10.1007/9783-319-20215-0_15

36. Shenderov, B A. (2016). Microecological epigenetics of stress, disease, health and longevity. Journal of Restorative Medicine, 1. 21-28.

37. Oleskin, A B, El-Registran G I, Shenderov B A. (2016). Role of neuromediators in the functioning of the human microbiota: "Business talks" among microorganisms and the microbiotahost dialogue. Microbiology, 85(1). 1-24. https://doi.org/10.7868/S0026365616010080

38. Arboleya, S., Watkins, C., Stanton, C., \& Ross, R. P. (2016). Gut bifidobacteria populations in human health and aging. Frontiers in microbiology, 7, 1204. https://doi.org/10.3389/fmicb.2016.01204

39. Marchesi, J. R., Adams, D. H., Fava, F., Hermes, G. D., Hirschfield, G. M., Hold, G., ... \& Thomas, L. V. (2016). The gut microbiota and host health: a new clinical frontier. Gut, 65(2), 330339. http://dx.doi.org/10.1136/gutjnl-2015-309990

40. Wang, H. X., \& Wang, Y. P. (2016). Gut microbiota-brain axis. Chinese medical journal, 129(19), 2373. Wang, H. X., \& Wang, Y. P. (2016). Gut Microbiota-brain Axis. Chinese medical journal, 129(19), https://doi.org/10.4103/0366-6999.190667

41. Paul, B., Barnes, S., Demark-Wahnefried, W., Morrow, C., Salvador, C., Skibola, C., \& Tollefsbol, T. O. (2015). Influences of diet and the gut microbiome on epigenetic modulation in cancer and other diseases. Clinical epigenetics, 7(1), 112. https://doi.org/10.1186/s13148-015-01447

42. Belizário, J. E., \& Napolitano, M. (2015). Human microbiomes and their roles in dysbiosis, common diseases, and novel therapeutic approaches. Frontiers in microbiology, 6, 1050. https://doi.org/10.3389/fmicb.2015.01050

43. Clarke, G., Stilling, R. M., Kennedy, P. J., Stanton, C., Cryan, J. F., \& Dinan, T. G. (2014). Minireview: gut microbiota: the neglected endocrine organ. Molecular endocrinology, 28(8), 12211238. https://doi.org/10.1210/me.2014-1108

44. Galland, L. (2014). The gut microbiome and the brain. Journal of medicinal food, 17(12), 1261-1272. https://doi.org/10.1089/jmf.2014.7000

45. Sharkey, K. A., \& Savidge, T. C. (2014). Role of enteric neurotransmission in host defense and protection of the gastrointestinal tract. Autonomic Neuroscience, 181, 94-106. https://doi.org/10.1016/j.autneu.2013.12.006

46. Romanov, D. V., \& Romanchuk, N. P. (2014). Rannyaya diagnostika kognitivnykh narushenii. Samara. 34. (in Russian).

47. Bengmark, S. (2013). Gut microbiota, immune development and function. Pharmacological Research, 69(1), 87-113. https://doi.org/10.1016/j.phrs.2012.09.002

48. Lyte, M. (2013). Microbial endocrinology and nutrition: a perspective on new mechanisms by which diet can influence gut-to-brain communication. PharmaNutrition, 1(1), 3539. https://doi.org/10.1016/j.phanu.2012.11.002 
49. Romanchuk, P. I., \& Volobuev, A. N. (2013). Active longevity: biophysics of the genome, nutrigenomics, nutrigenetics, revitalization. 416. (in Russian)

50. Volobuev, A. N., Petrov, E. S., Kondurtsev, V. A., \& Romanchuk, P. I. (2013). Some principles of selection of drugs in combination drug therapy of primary arterial hypertension. Vrach, (3). 49-51. (in Russian)

51. Moskalyov, A. A. (2013). Genetics and epigenetics of aging and longevity. Ecological genetics, 11(1). 3-11.

52. Shenderov, B. A. (2013). The role of nutrition and intestinal microflora in programming and implementing the epigenoma of healthy and sick people. Journal of Restorative Medicine; Special release, 102.

53. Malyshev, V. K., \& Romanchuk, P. I. (2012) Functional food products: innovations in dietology and cardiology. Moscow-Samara. 248.

54. Romanchuk, N. P. Sposob proizvodstva zernovogo komponenta dlya pishchevogo produkta bystrogo prigotovleniya i sposob proizvodstva funktsional'nogo pishchevogo produkta bystrogo prigotovleniya. Patent RF na izobretenie №2423873. (in Russian).

55. Romanchuk, N. P. Romanchuk, P. I., \& Malyshev, V. K. Product diet, preventive and functional nutrition for chronic cerebral ischemia. Patent 2489038. (in Russian)

56. Romanchuk, P. I., \& Romanchuk, N. P. Method of assessment of age-related changes in cardiovascular system. Patent 2485886. (in Russian).

57. Pyatin, V. F., Romanchuk, N. P., \& Romanchuk, P. I., Sposob normalizatsii tsirkadiannykh ritmov cheloveka. Patent RF na izobretenie 2533965. (in Russian).

58. Romanchuk P.I. et al. (2010). Role of new mechanisms of arterial vascular regulation in primary arterial hypertension. Bulletin of restorative medicine. 3(37). 34-37.

59. Razumov A. N., \& Romanchuk P. I. (2010). Active longevity and arterial hypertension: the role of new medical and genetic mechanisms and innovations in restorative medicine. Bulletin of restorative medicine, 5(39). 2-7.

Работа поступила

в редакиию 08.01.2020 г.
Принята к публикациии

14.01.2020 2.

Ссылка для циитирования:

Романчук П. И. Возраст и микробиота: эпигенетическая и диетическая защита, эндотелиальная и сосудистая реабилитация, новая управляемая здоровая биомикробиота // Бюллетень науки и практики. 2020. Т. 6. №2. С. 67-110. https://doi.org/10.33619/2414$2948 / 51 / 07$

Cite as (APA):

Romanchuk, P. (2020). Age and Microbiota: Epigenetic and Dietary Protection, Endothelial and Vascular Rehabilitation, the New Operated Healthy Biomicrobiota. Bulletin of Science and Practice, 6(2), 67-110. https://doi.org/10.33619/2414-2948/51/07 (in Russian). 
УДК 616.83/.85:616.89+573.7.017.6+612.67/.68+575 https://doi.org/10.33619/2414-2948/51/08

\title{
РЕЗУЛЬТАТЫ КОНТРОЛИРУЕМОГО КЛИНИЧЕСКОГО ИСПЫТАНИЯ АППАРАТНОЙ ИНТРАОПЕРАЦИОННОЙ РЕИНФУЗИИ КРОВИ, СОБРАННОЙ ИЗ БРЮШНОЙ ПОЛОСТИ В УСЛОВИЯХ МЕДЛЕННОГО И БЫСТРОГО РЕЖИМОВ
}

(САбдурахманов Ш. Т., канд. мед. наук, Ошский государственный университет, 2. Ou, Кыргызстан, Osh_2017_b@mail.ru

(СЧынгышева Ж. А., канд. мед. наук, Киргизская государственная медииинская академия им. И.К. Ахунбаева, г. Бишкек, Кыргызстан

СМусалиев Б. Ж., канд. мед. наук, Национальный хирургический цеентр,

г. Бишкек, Кыргызстан

(стилеков Э. А., д-р мед. наук, Национальный центр онкологии и гематологии Министерства здравоохранения Киргизской Республики, г. Бишкек, Кыргызстан

\section{RESULTS OF THE CONTROLLED CLINICAL TEST OF INTRAOPERATIVE BLOOD REINFUSION HARDWARE, ASSEMBLED FROM THE ABDOMINAL CAVITY IN CONDITIONS OF SLOW AND FAST MODES}

\author{
(CAbdurakhmanovSh., M.D., Osh State University, Osh, Kyrgyzstan,Osh_2017_b@mail.ru \\ CChyngysheva Zh., M.D., I.K. Akhunbaev Kyrgyz State Medical Academy, Bishkek, Kyrgyzstan \\ CMusaliev B., M.D., National Surgical Center, Bishkek, Kyrgyzstan \\ (C)Tilekov E., Dr. habil., National Center for Oncology and Hematology of the Ministry of Health of \\ the Kyrgyz Republic, Bishkek, Kyrgyzstan
}

Аннотация. Проведение параллельного клинического и экспериментального контроля на базе контролируемых клинических испытаний было обусловлено необходимостью, в целом, более тщательной оценки эффективности аппаратной интраоперационной реинфузии крови с установлением возможности «переноса» экспериментальных данных по моделированию полостной кровопотери на клиническую платформу. Цель paботьл: сравнительная характеристика результатов следующих исследований, выполненных в ракурсе контролируемых клинических испытаний: 1) экспериментального контроля исследования крови, собранной из плевральной и брюшной полостей до и после аппаратной интраоперационной реинфузии крови в условиях моделирования у животных ранения живота и груди с образованием, соответственно, гемоторакса и гемоперитонеума; 2) клинического контроля - исследование крови, собранной из брюшной и грудной полостей до и после аппаратной интраоперационной реинфузии крови у пострадавших с травмами и ранениями груди и живота с соответствующим образованием гемоторакса и гемоперитонеума.

Abstract. Conducting parallel clinical and experimental control on the basis of controlled clinical trials was necessitated by, on the whole, a more thorough assessment of the effectiveness of intraoperative blood reinfusion hardware with the establishment of the possibility of 'transfer' of experimental data on modeling cavity blood loss to a clinical platform. Objective: a comparative description of the results of the following studies performed in the context of controlled clinical trials: 1) experimental control - a study of blood collected from the pleural and abdominal cavities before and after intraoperative blood reinfusion hardware under simulation conditions in animal injuries of the abdomen and chest with the formation, respectively, of hemothorax and 
hemoperitoneum; 2) clinical control - a study of blood collected from the abdominal and thoracic cavities before and after intraoperative blood reinfusion hardware in patients with injuries and injuries of the chest and abdomen with the corresponding formation of hemothorax and hemoperitoneum.

Ключевые слова: клинический контроль, эксперимент, кровопотеря, биохимия крови, реинфузия.

Keywords: clinical control, experiment, blood loss, blood biochemistry, reinfusion.

В Таблице 1. показана динамика морфологии крови, собранной из брюшной полости при медленном (1 группа) и быстром (2 группа) режимах ее аспирации. Как видно из Таблицы 1, в обеих группах, как клинического иконтроля (КК), так и экспериментального контроля (ЭК) при проведении аппаратной интраоперационной реинфузии крови (ИО РИК), количество Эр. синхронно уменьшается. Однако, во 2-й группе с опережающим темпом. Если достоверность такой динамики характерно лишь для Нb и Нt в ЭК, то в КК имеет место более заметное снижение Эр., Нb и $\mathrm{Ht}$, но достоверность такой динамики характерно лишь для Эр.иНt.

Таблица 1.

ПАРАЛЛЕЛИ КК И ЭК ГЕМОГРАФИЧЕСКИХ ПОКАЗАТЕЛЕЙ ПРИ РАЗЛИЧНЫХ СКОРОСТЯХ АСПИРАЦИИ КРОВИ ДЛЯ ИО РИК

\begin{tabular}{ccccc}
\hline Контроль & Показатели & Исходный & 1 -я группа & 2 -я группа \\
\hline КК & Эр. & $3,3 \pm 0,8$ & $3,0 \pm 0,5 *$ & $2,5 \pm 0,2 *, * *$ \\
& ЦП & $0,7 \pm 0,02$ & $0,65 \pm 0,02$ & $0,60 \pm 0,04 *$ \\
$\mathrm{Hb}$ & $66,2 \pm 5,5$ & $60,2 \pm 4,2 *$ & $78,6 \pm 4,5 *$ \\
$\mathrm{Ht}$ & $32,2 \pm 2,2$ & $30,2 \pm 3,9 *$ & $32,6 \pm 1,8 *, * *$ \\
& Лейк. & $4,8 \pm 0,2$ & $5,0 \pm 0,2 *$ & $4,4 \pm 0,4 *$ \\
\hline ЭК & Эр. & $3,7 \pm 0,2$ & $3,1 \pm 0,2 *$ & $2,6 \pm 0,4 *, * *$ \\
& ЦП & $0,90 \pm 0,04$ & $0,80 \pm 0,04$ & $0,68 \pm 0,05 *$ \\
$\mathrm{Hb}$ & $106,2 \pm 8,4$ & $85,8 \pm 2,4 *$ & $71,1 \pm 3,2 *, * *$ \\
& $\mathrm{Ht}$ & $33,2 \pm 1,1$ & $25,0 \pm 2,2 *$ & $20,1 \pm 2,1 *, * *$ \\
& Лейк. & $4,9 \pm 0,5$ & $4,4 \pm 0,3 *$ & $3,1 \pm 0,2 *, * *$ \\
\hline
\end{tabular}

Примечание: * - достоверно в сравнении с исходным уровнем; **-достоверно в сравнении с 1-й группой

Следует отметить, что синхронность изменения показателей отмечается и в отношении количества лейкоцитов, а также таких показателей, как ЦП, Hb и $\mathrm{Ht}$ [1]. Причем, в обоих исследованиях (КК, ЭК). Что касается степени разрушаемости таких форменных элементов крови, как Эр.и лейкоциты во 2 группе достоверно выше, чем в 1 группе. Причем, как в КК, так и в ЭК.

По нашим данным, во 2 группе этот показатель превышает 35\% в ЭК и КК. В целом, данные КК и ЭК по тенденции и динамике снижения исследуемых гемографических показателей совпадают. Однако, в КК снижение показателей более выражены, чем в ЭК.

В Таблице 2 приведена физколлоидная характеристика крови, собранная из брюшной полости в зависимости от скорости (медленный и быстрый режимы) аппаратной ее эксфузии. 
Как видно из Таблицы 2, на фоне снижения количества Эр.в обеих группах наблюдения осмотическая резистентность снижается в 3 раза. В КК и ЭК снижение аналогичное. Между тем, на фоне снижения осмотической резистентности Эр. удельный вес свободного Нb плазмы достоверно и резко возрастает, что в особенности заметно во 2 группе $(\mathrm{P}<0,05)$.

Таблица 2.

ПАРАЛЛЕЛИ КК И ЭК ФИЗКОЛОИДНЫХ ПОКАЗАТЕЛЕЙ ПРИ РАЗЛИЧНЫХ СКОРОСТЯХ АСПИРАЦИИ КРОВИ ДЛЯ ИО РИК

\begin{tabular}{llccc}
\hline Контроль & Показатели & Исходный & 1-я группа & 2 2-я группа \\
\hline КК & Осм. резист.Эр. (\%) & $0,8 \pm 0,01$ & $0,3 \pm 0,001 *$ & $0,2 \pm 0,001 *$ \\
& Гемолиз, \% к общ. Нb & $3,1 \pm 0,4$ & $6,8 \pm 0,3 *$ & $14,1 \pm 0,5 *, * *$ \\
& Своб.Нb плазмы, мг\% & $1,0 \pm 0,01$ & $8,2 \pm 0,6 *$ & $18,5 \pm 0,8 *, * *$ \\
\hline \multirow{2}{*}{$Э К$} & Осм. резист.Эр. (\%) & $0,6 \pm 0,002$ & $0,2 \pm 0,001 *$ & $0,2 \pm 0,001 *$ \\
& Гемолиз, \% к общ. Нb & $3,3 \pm 0,2$ & $5,9 \pm 0,5 *$ & $11,6 \pm 0,3 *, * *$ \\
& Своб.Нь плазмы, мг\% & $1,2 \pm 0,02$ & $6,8 \pm 1,3 *$ & $28,4 \pm 1,4 *, * *$ \\
\hline
\end{tabular}

Примечание: * - достоверно в сравнении с исходным уровнем; $* *$ - достоверно в сравнении с 1-й группой

Вышеуказанный факт свидетельствует о возрастании уровня гемолиза крови [2]. Так, в ЭКпри малом режиме эксфузиигемолиз крови возрастает до $5,9 \pm 0,5 \%$, а при быстром - до $11,6 \pm 0,3 \%$. Нужно заметить, что величина снижения вышеуказанного показателя в КК более

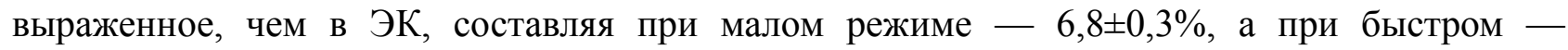
$14,1 \pm 0,5 \%$.

Таким образом, гемолиз крови, рассчитанный в отношении всего количества $\mathrm{Hb}$, при быстрой аппаратной эксфузии составляет $>28 \%$ в ЭК и $>32 \%$ в КК, что следует учитывать при выполнении ИО РИК.

В целом, возникает вопрос о применимости высокого режима эксфузии крови, так как при этом режиме удельный вес разрушенных Эр.достигает $28 \%$, а степень гемолиза - $32 \%$.

В Таблице 3. показана динамика содержания белка и ее фракций в крови, собранной для ИО РИК в условиях малого (1 группа) и скоростного (2 группа) режима. Как видно из Таблицы 3, концентрация общего белка снижается. Причем, в КК этот процесс более выражен, чем в ЭК.

Таблица 3.

ПАРАЛЛЕЛИ КК И ЭК ПРОТЕИНОГРАММНЫХ ПОКАЗАТЕЛЕЙ ПРИ РАЗЛИЧНЫХ СКОРОСТЯХ АСПИРАЦИИ КРОВИ ДЛЯ ИО РИК

\begin{tabular}{lllll}
\hline Контроль & \multicolumn{1}{c}{ Показатели } & \multicolumn{1}{c}{ Исходный } & \multicolumn{1}{c}{2 -я группп } \\
\hline КК & Белок & $54,2 \pm 6,6$ & $45,5 \pm 1,9 *$ & $42,5 \pm 2,5 *, * *$ \\
& Альбумин & $30,2 \pm 6,2$ & $44,3 \pm 2,0 *$ & $44,0 \pm 3,8$ \\
& Глобулин & $42,5 \pm 2,2$ & $53,6 \pm 4,1 *$ & $34,6 \pm 3,7 *, * *$ \\
& Коэф. А/Г & $1,0 \pm 0,05$ & $0,4 \pm 0,02 *$ & $1,5 \pm 0,02 *, * *$ \\
\hline ЭК & Белок & $62,1 \pm 5,2$ & $56,1 \pm 2,5 *$ & $49,2 \pm 2,2 *, * *$ \\
& Альбумин & $65,2 \pm 4,4$ & $49,8 \pm 2,7 *$ & $68,2 \pm 4,5$ \\
& Глобулин & $48,3 \pm 4,6$ & $52,4 \pm 2,9 *$ & $31,2 \pm 3,1 *, * *$ \\
& Коэф. А/Г & $1,1 \pm 0,03$ & $0,7 \pm 0,01 *$ & $2,2 \pm 0,02 *, * *$ \\
\hline
\end{tabular}

Примечание: * - достоверно в сравнении с контролем; **- достоверно в сравнении с 1-й группой 
По данным КК и ЭК, чем быстрее выполнена аппаратная эксфузия, тем значительнее снижение содержания белка [3]. На этом фоне относительно возрастает альбуминовая фракция, которая, как известно, играет существенную роль в поддержании нормальной осмотической резистентности форменных элементов крови [4]. В ЭК это более заметно.

Характерным является изменение соотношения альбуминовой и глобулиновой фракций. Если судить по коэффициенту А/Г, то заметно, что при медленном режиме эксфузии крови в ЭК этот показатель составляет - 0,7, тогда как при быстром - 2,2. В КК указанный показатель составляет, соответственно, 0,4 и 1,5.

В Таблице 4. показана динамика ряда биохимических показателей крови, собранной из брюшной полости в условиях медленного (1 группа) и быстрого (2 группа) сбора крови.

Таблица 4.

ПАРАЛЛЕЛИ КК И ЭК БИОХИМИЧЕСКИХ ПОКАЗАТЕЛЕЙ ПРИ РАЗЛИЧНЫХ СКОРОСТЯХ АСПИРАЦИИ КРОВИ ДЛЯ ИО РИК

\begin{tabular}{llccc}
\hline \multicolumn{1}{c}{ Контроль } & \multicolumn{1}{c}{ Показатели } & Исходный & 1 -я группа & $2-я$ группа \\
\hline КК & Билирубин & $15,3 \pm 2,4$ & $12,3 \pm 1,6$ & $14,6 \pm 1,8$ \\
& Остат. N & $19,3 \pm 1,01$ & $31,2 \pm 2,8 *$ & $35,1 \pm 4,4 *, * *$ \\
& Мочевина & $4,8 \pm 0,4$ & $12,5 \pm 2,7 *$ & $8,1 \pm 1,1 *, * *$ \\
& Na++ & $140,2 \pm 5,5$ & $132 \pm 2,5$ & $145 \pm 8,8$ \\
& К+ & $4,1 \pm 0,2$ & $4,3 \pm 0,4 *$ & $4,6 \pm 0,4 *$ \\
\hline ЭК & Билирубин & $6,9 \pm 0,3$ & $6,1 \pm 0,2$ & $5,1 \pm 0,1$ \\
& Остат. N & $25,3 \pm 2,03$ & $29,9 \pm 2,6 *$ & $32,4 \pm 5,1 *, * *$ \\
& Мочевина & $9,3 \pm 1,0$ & $13,2 \pm 2,1 *$ & $22,2 \pm 3,0 *, * *$ \\
& Nа++ & $144 \pm 6,6$ & $135 \pm 2,3$ & $141 \pm 4,4$ \\
& К+ & $4,9 \pm 0,4$ & $5,2 \pm 0,2 *$ & $5,8 \pm 0,2 *, * *$ \\
\hline
\end{tabular}

Примечание: * - достоверно в сравнении с контролем; ** - достоверно в сравнении с 1-й группой

Из Таблицы 4 видно, что в ЭК концентрация билирубина также имеет тенденцию к снижению с увеличением скорости аппаратной эксфузии крови. Между тем, в КК особой динамики общего билирубина не наблюдается. А вот, что касается остаточного N, то ее концентрация в КК заметно увеличивается. Этого касается и концентрации мочевины.

Впрочем, и в ЭК концентрация мочевины, а также К+, остаточного $\mathrm{N}$ имеет тенденцию к достоверному увеличению. В КК концентрация $\mathrm{Na}++$ при медленном режиме аспирации снижается, а при быстром, наоборот, повышается. То же самое наблюдается и в ЭК [5].

Таким образом, в собранной из брюшной полости крови, как в ЭК, так и в КК, отмечается более высокая концентрация К+, остаточного $\mathrm{N}$ и мочевины, что обязательно следует учесть при применении аппаратной ИО РИК.

В Таблице приведена расширенная гемостазиограмма крови, собранной из брюшной полости в зависимости от скорости аппаратной эксфузии крови в ЭК (медленном и быстром режимах аспирации).

Как видно из Таблицы, в ЭК отмечается снижение свертываемости крови, о чем свидетельствует укорочение времени свертываемости по Ли-Уайту в силиконированной и в не силиконированной пробирках. Зафиксировано снижение количества тромбоцитов, особенно при использовании быстрого режима сбора крови (до $172 \pm 12,1$ мин против исходного значения $288 \pm 11,6$ мин). 
На таком фоне процесс агрегации тромбоцитов достоверно замедляется, причем при быстром режиме сбора крови - в 2 раза в сравнении с медленным режимом аспирации крови $(\mathrm{P}<0,05)$.

Установлено, что время рекальцификации плазмы достоверно уменьшается на 40\% при использовании высокоскоростного режима сбора крови в сравнении с контрольными показателями, что почти в 3 раза выше, чем при применении медленной аспирации крови $(\mathrm{P}<0,05$ и $\mathrm{P}<0,05)$.

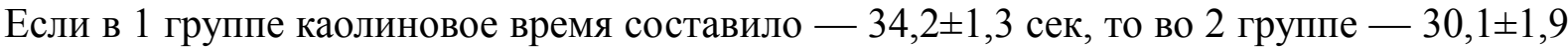
сек. Такая же динамика отмечается и для каолин-кефалинового времени свертывания плазмы,

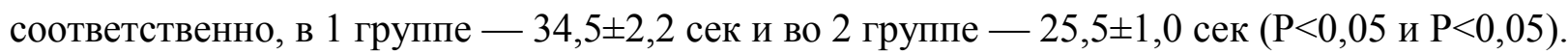

В ЭК выявлено синхронная динамика тромбинового и протромбинового времени. В

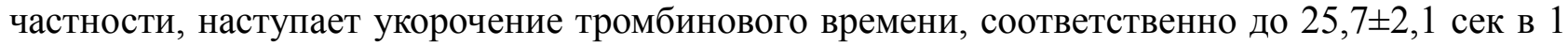
группе против исходного $37,7 \pm 2,4$ сек $(\mathrm{P}<0,05)$ и до $20,0 \pm 1,6$ сек во 2 группе $(\mathrm{P}<0,05)$.

В 1 группе протромбиновое время укорачивалось до 22,2士2,3 сек, тогда как во 2 группе - до $15,9 \pm 1,8$ сек $(\mathrm{P}<0,05)$. Между тем, содержание фибриногена постепенно возрастает в

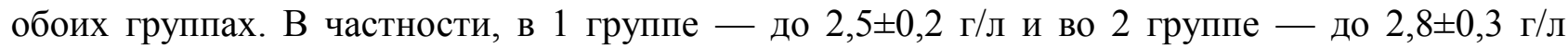
против контрольного значения - 1,9 $\pm 0,2$ г/л $(\mathrm{P}<0,05$ и $\mathrm{P}<0,05)$. Следует отметить, что АКТ во все сроки реакции (6,8 и 10 мин) синхронно укорачиваются. Причем, во 2 группе более значительно, чем в 1 группе.

В Таблице приведены данные КК по расширенной гемостазиограмме крови, собранной из брюшной полости в зависимости от скорости аппаратной эксфузии крови, соответственно, медленном (1 группа) и быстром (2 группа) режимах аспирации.

Как видно из Таблицы, в КК установлено, что каолиновое время составило в 1 группе

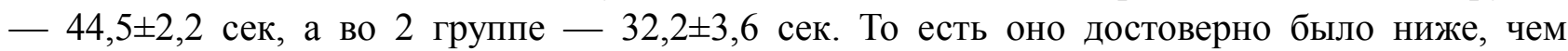
исходный уровень, а также при сравнении 2-1 группы больных с 1 группой $(\mathrm{P}<0,05$ и 0,05). Кстати, такая динамика отмечается и в ЭК.

Более того, такая динамика была характерно и в отношении каолин-кефалинового времени свертывания плазмы [6]. Если в ЭК этот показатель был равен в 1 и 2 группах, соответственно, $34,5 \pm 2,2$ сек и $25,5 \pm 1,0$ сек $(\mathrm{P}<0,05$ и $\mathrm{P}<0,05)$, то в КК, соответственно, $35,2 \pm 2,8$ сек и $28,2 \pm 1,5$ сек $(\mathrm{P}<0,05$ и $\mathrm{P}<0,05)$.

Нужно заметить, что и в КК, и в ЭК динамика тромбинового и протромбинового времени также однотипны и синхронны. В частности, в КК наступает укорочение тромбинового времени, соответственно до 28,2 $\pm 2,3$ сек в 1 группе против исходного значения

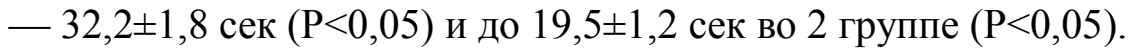

Что касается протромбинового времени, то оно укорачивалось в 1 группе до 20,8 $\pm 2,1$

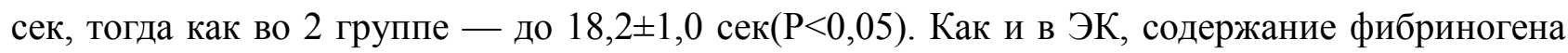

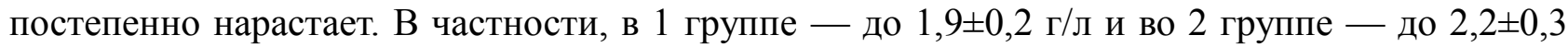
г/л против контрольного значения $-1,3 \pm 0,1$ г/л $(\mathrm{P}<0,05$ и $\mathrm{P}<0,05)$.

В КК, как, впрочем, и в ЭК, во все сроки реакции (6, 8 и 10 мин) АКТ синхронно укорачиваются. Причем, во 2 группе более значительно, чем в 1 группе. То же самое можно сказать и о показателях свертываемости крови. Как и в ЭК имеет место снижение свертываемости крови по Ли-Уайту [7].

Об этом можно судить также и по снижению количества тромбоцитов [8-10]. При использовании быстрого режима сбора крови (до $288 \pm 18,5 \times 109 /$ л против исходной величины $-302 \pm 16,8 \times 109 /$ л).

Четко замедляется и процесс агрегации тромбоцитов: в 1,7 раза при быстром режиме сбора крови; почти в 2 раза при медленном режиме аспирации крови $(\mathrm{P}<0,05)$. 


\section{Список литературь:}

1. Чынгышова Ж. А., Чапыев М. Б. Контролируемое клиническое испытание и определение релевантности клинического и экспериментального контроля гемографических и физколлоидных показателей состояния полостной крови для интраоперационной реинфузии // Международный журнал прикладных и фундаментальных исследований. 2019. №5. С. 77-82.

2. Бащинский С. Е. Разработка клинических практических руководств с позиций доказательной медицины. М.: Медиа Сфера. 2014. 164 с.

3. Власов В. В. Введение в доказательную медицину. М.: Медиа Сфера. 2011. 221 с.

4. Воробьев А. И., Городецкий В. М., Шулутко Е. М., Васильев С. А. Острая массивная кровопотеря. М. 2014. 176 с.

5. Давидян А. Э. Обеспечение анестезиологической безопасности при интраоперационной аутогемотрансфузии в хирургии ИБС у больных с критической степенью операционного риска: автореф. дис. ... канд. мед. наук. М. 2018. 22 с.

6. Котельников Г. П., Захарова Н. О., Чеснокова И. Г. Особенности гемостаза у пожилых с хирургической патологией. Самара. 2012160 с.

7. Морган Дж.Э., Михаил М.С. Клиническая анестезиология. М. 2011. 366 с.

8. Морган Дж. Э., Михаил М. С. Клиническая оценка результатов лабораторных исследований. М.: Медицина, 2010. С. 15-16.

9. Точенов А. В. Трансфузионная терапия острой кровопотери: коррекция постгеморрагических нарушений системы гемостаза // Новое в трансфузиологии. 2013. №34. C. 23-29.

10. Суфианова Г. 3., Иванова Н. Е., Суфианов А. А., Гаибов С. С. Применение эритропоэтина как способ кровосбережения удетей снесиндромальными краниосиностозами // Педиатрическая фармакология. 2017. Т. 12. №6-2015. С. 686-691.

\section{References:}

1. Chyngyshova, Zh. A., \& Chapyev, M. B. (2019). Kontroliruemoe klinicheskoe ispytanie i opredelenie relevantnosti klinicheskogo i eksperimental'nogo kontrolya gemograficheskikh i fizkolloidnykh pokazatelei sostoyaniya polostnoi krovi dlya intraoperatsionnoi reinfuzii. Mezhdunarodnyi zhurnal prikladnykh i fundamental'nykh issledovanii, (5). 77-82. (in Russian).

2. Bashchinskii, S. E. (2014). Razrabotka klinicheskikh prakticheskikh rukovodstv s pozitsii dokazatel'noi meditsiny. Moscow. Media Sfera. 164. (in Russian).

3. Vlasov, V. V. (2011). Vvedenie v dokazatel'nuyu meditsinu. Moscow.: Media Sfera. 221. (in Russian).

4. Vorob'ev, A. I., Gorodetskii, V. M., Shulutko, E. M., \& Vasil'ev, S. A. (2014). Ostraya massivnaya krovopoterya. Moscow. 176. (in Russian).

5. Davidyan, A. E. (2018). Obespechenie anesteziologicheskoi bezopasnosti pri intraoperatsionnoi autogemotransfuzii $\mathrm{v}$ khirurgii IBS u bol'nykh $\mathrm{s}$ kriticheskoi stepen'yu operatsionnogo riska: avtoref. dis. ... kand. med. nauk. Moscow. 22. (in Russian).

6. Kotel'nikov, G. P., Zakharova, N. O., \& Chesnokova, I. G. (2012). Osobennosti gemostaza u pozhilykh s khirurgicheskoi patologiei. Samara. 160. (in Russian).

7. Morgan, Dzh.E., \& Mikhail, M. S. (2011). Klinicheskaya anesteziologiya. Moscow. 366. (in Russian).

8. Morgan Dzh. E., \& Mikhail M. S. (2010). Klinicheskaya otsenka rezul'tatov laboratornykh issledovanii. Moscow Meditsina, 15-16. (in Russian). 
9. Tochenov, A. B. (2013). Transfuzionnaya terapiya ostroi krovopoteri: korrektsiya postgemorragicheskikh narushenii sistemy gemostaza. Novoe v transfuziologii, (34). 23-29. (in Russian).

10. Sufianova, G. Z., Ivanova, N. E., Sufianov, A. A., \& Gaibov, S. S. Kh. (2017). Primenenie eritropoetina kak sposob krovosberezheniya udetei snesindromal'nymi kraniosinostozami. Pediatricheskaya farmakologiya, 12(6-2015), 686-691. (in Russian).

Работа поступила

в редакциюю 15.01.2020 2.
Принята к публикации

19.01.2020 2.

Ссылка для циитирования:

Абдурахманов Ш. Т., Чынгышева Ж. А., Мусалиев Б. Ж., Тилеков Э. А. Результаты контролируемого клинического испытания аппаратной интраоперационной реинфузии крови, собранной из брюшной полости в условиях медленного и быстрого режимов // Бюллетень науки и практики. 2020. Т. 6. №2. С. 111-117. https://doi.org/10.33619/2414-2948/51/08

Cite as (APA):

Abdurakhmanov, Sh., Chyngysheva, Zh., Musaliev, B., \& Tilekov, E. (2020). Results of the Controlled Clinical Test of Intraoperative Blood Reinfusion Hardware, Assembled From the Abdominal Cavity in Conditions of Slow and Fast Modes. Bulletin of Science and Practice, 6(2), 111-117. https://doi.org/10.33619/2414-2948/51/08 (in Russian). 


\section{АНАЛИЗ РЕЗУЛЬТАТОВ КОЛЬПОСКОПИИ В ДИАГНОСТИКЕ НЕОПЛАЗИЙ ШЕЙКИ МАТКИ}

(СЛабзина М. В., SPIN-код: 5015-6082, канд. мед. наук, Национальный исследовательский Мордовский государственный университет им. Н.П. Огарева, г. Саранск, Россия

СЛабзина Л. Я., SPIN-код: 9511-0764, канд. биол. наук, Национальный исследовательский Мордовский государственный университет им. Н.П. Огарева,

2. Саранск, Россия, LudmilaMedin@yandex.ru

(CНечайкин A. C., SPIN-код: 8031-4536, канд. мед.наук, Национальный исследовательский Мордовский государственный университет им. Н.П. Огарева,

2. Саранск, Россия, nechaykinas@ rambler.ru

СВахляева В. С., Национальный исследовательский Мордовский государственный университет им. Н.П. Огарева, г.Саранск, Россия, nika555355@yandex.ru

СКожсурин Т. Ю., Наџиональный исследовательский Мордовский государственный университет им. Н.П. Огарева, г. Саранск, Россия, kozhurin97@bk.ru

СЕремкина E. С., Национальный исследовательский Мордовский государственный университет им. Н.П. Огарева, г. Саранск, Россия, k.eryomkina2012@yandex.ru

\section{ANALYSIS OF COLOSCOPY RESULTS IN THE DIAGNOSIS OF CERVICAL NEOPLASIA}

CLabzina M., SPIN-code: 5015-6082, M.D., Ogarev Mordovia State University, Saransk, Russia CLabzina L., SPIN-code: 9511-0764, M.D., Ogarev Mordovia State University,

Saransk, Russia, LudmilaMedin@yandex.ru

CNechaikin A., SPIN-code: 8031-4536, M.D., Ogarev Mordovia State University,

Saransk, Russia,nechaykinas@rambler.ru

CVakhlyaeva V., Ogarev Mordovia State University, Saransk, Russia,nika555355@yandex.ru

CKozhurin T., Ogarev Mordovia State University, Saransk, Russia, kozhurin97@bk.ru

CEremkina E., Ogarev Mordovia State University, Saransk, Russia, k.eryomkina2012@yandex.ru

Аннотация. Работа посвящена актуальной проблеме медицины - цервикальным интраэпителиальным неоплазиям. Авторами установлено, что группа женщин с цервикальными интраэпителиальными неоплазиями, это пациентки трудоспособного возраста, и раннее обнаружение цервикальных интраэпителиальных неоплазий может предотвратить развитие инвазивного рака, рассматриваемого как одну из основных причин инвалидизации и смертности женского населения. В гинекологической практике наиболее доступным и информативным методом диагностики цервикальных интраэпителиальных неоплазий является кольпоскопия.

Abstract. The work is devoted to the actual problem of medicine - cervical intraepithelial neoplasia. The authors found that a group of women with cervical intraepithelial neoplasia is a patient of working age, and early detection of cervical intraepithelial neoplasia can prevent the development of invasive cancer, considered as one of the main causes of disability and female mortality. In gynecological practice, the most accessible and informative method for cervical intraepithelial neoplasia diagnosing is colposcopy.

Ключевые слова: цервикальная интраэпителиальная неоплазия, кольпоскопия, дисплазия шейки матки. 
Keywords: cervical intraepithelial neoplasia, colposcopy, cervical dysplasia.

\section{Введение}

В настоящее время отмечается значительное увеличение заболеваемости злокачественными новообразованиями шейки матки [4].

Развитию рака шейки матки, предшествуют цервикальные интраэпителиальные неоплазии (CIN) легкой (CIN I), средней (CIN II) и тяжелой (CIN III) степени тяжести, при этом в 10-30\% случаев наблюдается прогрессирование до CIN III и карциномы in situ, в 1,5\% - развивается инвазивный рак [1].

Своевременная диагностика CIN позволяет выявлять заболевания на ранних стадиях, проводить мониторинг в группах риска, выработать оптимальные схемы диагностики и лечения предопухолевых процессов [2].

Целью исследования стало изучение распространенности цервикальных интраэпителиальных неоплазий у женщин, которым проводилась кольпоскопия.

\section{Материал и методы исследования}

В работе представлены результаты обследования 40 женщин, проведенного в период с сентября 2018 г по сентябрь 2019 г на базе ГБУЗ РМ «Родильный дом» Женская консультация №1.

У 22 пациенток по данным гистологической картины был выставлен диагноз CIN (основная группа), и у 18 женщин - без патологии шейки матки (группа сравнения). Средний возраст всех женщин с CIN составил 34 года.

Материалами исследования явились: сбор анамнеза; результаты кольпоскопической картины.

При обследовании женщин были использованы следующие данные: возраст женщин; возраст начала половой жизни; данные акушерско-гинекологического и соматического анамнеза; данные диагностики ВПЧ.

По данным кольпоскопической картины оценивалась: характеристика кольпоскопической картины разных степеней CIN [5].

Результаты исследования обрабатывались программой для обработки статистических данных — VSTAT 2.01

\section{Результаты и обсуждение}

При изучении акушерского-гинекологического анамнеза одним из факторов риска развития диспластических процессов выступало курение. Интенсивное курение увеличивает риск развития CIN и является из факторов риска развития данной патологии. В ходе исследования обнаружено, что количество курящих пациенток в основной группе составляет 7 человек (31,8\%), и 5 пациенток $(27,7 \%)$ в группе сравнения. Таким образом, в основной группе количество курящих пациенток достоверно преобладает над группой сравнения.

Травмы шейки матки, вследствие родов и искусственного прерывания беременности, также являются предрасполагающем фактором в развитии цервикальных интраэпителиальных неоплазий. В основной группе было выявлено, что искусственное прерывание беременности с CIN имело место у 10 пациенток(45,5\%), по сравнению с 8 женщинами $(44,4 \%)$ из второй группы.

В первой группе у 16 женщин (72,7\% случаев) в анамнезе отмечены одни роды через естественные родовые пути, из них у 5 пациенток двое и более, при этом у $4(18,1 \%)$ пациенток в анамнезе малые (до 2 см) разрывы шейки матки. 
Также проведен анализ возраста начала половой жизни обследуемых групп женщин. Число женщин с возрастом начала половой жизни с 17 лет составило 31,8\% случаев (7 пациенток), с 18 лет 31,5\% (7), 22,7\% (5 пациенток) с 19 лет и 13,6\% женщин (3 пациентки) с 20 лет. Таким образом, ранее начало половой жизни является одним из основных предрасполагающим фактором риска развития дисплазии шейки матки разной степени тяжести.

Проведен анализ заболеваний женской половой системы обследуемых групп женщин. При анализе гинекологических заболеваний выяснилось, что большинство женщин с CIN имеют в анамнезе перенесенные заболевания женской половой сферы. Выяснилось, что в структуре гинекологических заболеваний пациенток преобладают синдром поликистозных яичников (СПКЯ) 8 (36,4\%), хронический аднексит 5 (22,7\%), миома матки 6 (27,2\%), эндометриоз яичников $3(13,6 \%)$.

Вероятность развития CIN возрастает, при наличии ВПЧ - инфекции, при этом вероятность развития CIN тяжелой степени (при наличии 16, 18 типов) значительно возрастает.

Одним из ведущих высокоинформативных и общедоступных методов для диагностики патологии шейки матки является кольпоскопия. Основная цель, которой состоит в оценке состояния экзоцервикса, вульвы и влагалища, выявлении очагов и границ поражения, дифференцировки доброкачественных изменений от злокачественных для осуществления прицельной биопсии и взятия цитологических мазков [3].

При оценке кольпоскопической картины у 65,2\% пациенток из группы исследования выявлялся ацетобелый эпителий, что является самым встречаемым и одним из основных диагностических признаков дисплазии эпителия шейки матки. Также, в структуре кольпоскопической картины особого внимание заслуживает обнаружение йоднегативной зоны (пробы Шиллера, проба с 3\% уксусной кислотой) у 43,4\% женщин в основной группе.

По данным кольпоскопической картины диагноз CIN разной степени тяжести был поставлен у 21 женщины.

\section{Заключение}

Анализируя полученные данные показано, что:

Группа женщин трудоспособного возраста - это пациентки с CIN. Обнаружение CIN может предотвратить развитие инвазивного рака, рассматриваемого как одну из основных причин инвалидизации и смертности женского населения.

При оценке акушерского-гинекологического анамнеза выявлено, что у пациенток с дисплазий шейки матки в анамнезе чаще отмечается наличие ВПЧ-инфекции (16, 18 типов).

К группе факторов риска необходимо отнести также дисгормональные нарушения, заболевания приводящих к дисфункции яичников, курение, раннее начало половой жизни.

В гинекологической практике наиболее доступным и достаточно информативным методом диагностики CIN является кольпоскопия.

В практических целях необходимо шире использовать кольпоскопический метод исследования с целью мониторинга и скрининга женского населения с целью выявления CIN и рака на ранних стадиях развития, применять активное диспансерное наблюдение женщин с $\mathrm{CIN}$ до достижения стабильно положительной кольпоскопической картины на протяжении 2х лет и более. 


\section{Список литературь:}

1. Сухих Г. Т., Прилепская В. Н. Профилактика рака шейки матки. М: МЕД-прессинформ. 2012. $190 \mathrm{c.}$

2. Роговская С. И., Бебнева Т. Н., Некрасов П. И. Эффективность терапии заболеваний гениталий при сочетании папилломавирусной и герпесвирусной инфекции // Акушерство и гинекология. 2014. №9. С. 90-97.

3. Роговская С. И. Практическая кольпоскопия. М: ГЭОТАР-Медиа. 2016. 256 с.

4. Сафронникова Н. Р. Превентивная онкогинекология. СПб: КОСТА. 2007. 208 с.

5. Бауэр Г. Цветной атлас по кольпоскопии. М.: ГЭОТАР-Медиа. 2002. 288 с.

\section{References:}

1. Sukhikh, G. T., \& Prilepskaya, V. N. (2012). Profilaktika raka sheiki matki. Moscow. MEDpress-inform. 190. (in Russian).

2. Rogovskaya, S. I., Bebneva, T. N., \& Nekrasov, P. I. (2014). Effektivnost' terapii zabolevanii genitalii pri sochetanii papillomavirusnoi i gerpesvirusnoi infektsii. Akusherstvo $i$ ginekologiya, (9). 90-97. (in Russian).

3. Rogovskaya, S. I. (2016). Prakticheskaya kol'poskopiya. Moscow. GEOTAR-Media. 256. (in Russian).

4. Safronnikova, N. R. (2007). Preventivnaya onkoginekologiya. St. Petersburg. KOSTA. 208. (in Russian).

5. Bauer, G. (2002). Tsvetnoi atlas po kol'poskopii. Moscow. GEOTAR-Media. 288. (in Russian).

Работа поступила

в редакиию 10.01.2020 г.
Принята к публикации 17.01.2020 2.

Ссылка для цุитирования:

Лабзина М. В., Лабзина Л. Я., Нечайкин А. С., Вахляева В. С., Кожурин Т. Ю., Еремкина Е. С. Анализ результатов кольпоскопии в диагностике неоплазий шейки матки // Бюллетень науки и практики. 2020. Т. 6. №2. С. 118-121. https://doi.org/10.33619/24142948/51/09

Cite as (APA):

Labzina, M., Labzina, L., Nechaikin, A., Vakhlyaeva, V., Kozhurin, T., \& Eremkina, E. (2020). Analysis of Coloscopy Results in the Diagnosis of Cervical Neoplasia. Bulletin of Science and Practice, 6(2), 118-121. https://doi.org/10.33619/2414-2948/51/09 (in Russian). 


\section{ПУТИ УЛУЧШЕНИЯ ОНКОЛОГИЧЕСКОЙ ПОМОЩИ}

(СТилеков Э. А., д-р мед. наук, Национальный изентр онкологии и гематологии Министерства здравоохранения Киргизской Республики, г. Бишкек, Кыргызстан, tilekovernis@mail.ru

СИбраимова Д. Д., Киргизско-российский славянский университет,

г. Бишкек, Кыргызстан, ibraimova_70@ mail.ru

СБолбачан О. А., Киргизско-российский славянский университет,

г. Бишкек, Кыргызстан, ozizk@mail.ru

(ССадмкулова К. И., Киргизская государственная медицинская академия им. И.К. Ахунбаева, г. Бишкек, Кыргызстан, sad.k@таil.ru

\section{WAYS TO IMPROVE CANCER CARE}

(CTilekov E., Dr. habil., National Center for Oncology and Hematology

Ministry of Health of the Kyrgyz Republic, Bishkek, Kyrgyzstan, tilekovernis@mail.ru

CIbraimova D., Kyrgyz-Russian Slavic University,

Bishkek, Kyrgyzstan, ibraimova_70@mail.ru

CBolbachan O., Kyrgyz-Russian Slavic University, Bishkek, Kyrgyzstan,ozizk@mail.ru

CSadamkulova K., I.K. Akhunbayev Kyrgyz State Medical Academy, Bishkek, Kyrgyzstan,sad.k@mail.ru

Аннотаџия. Эпидемиологическая ситуация по онкологическим заболеваниям остается неблагоприятной во всем мире в связи с устойчивой тенденцией роста. По прогнозам Международного агентства по изучению рака, к 2030 году число новых ежегодно выявляемых злокачественных новообразований достигнет 26,4 млн в год, а число летальных исходов - 17 млн. Причины этого сложны, они отражают как старение и рост численности населения, так и изменения в распространенности и распределении основных факторов риска развития рака, часть из которых связаны с социально-экономическим развитием. В Киргизской Республике смертность от злокачественных новообразований находится на втором и на четвертом месте, как причина инвалидизации населения. Снижение смертности от злокачественных новообразований может быть достигнуто в результате выполнения комплексной научно-обоснованной целевой программы, включающей усиление роли первичного звена здравоохранения, активизацию работы смотровых кабинетов и восстановление отделений профилактики на первичном уровне, повышение квалификации медицинских работников онкологической службы, разработку методов ранней диагностики, новых подходов к лечению злокачественных новообразований, совершенствование ракового регистра больных и проведение массовых скринингов населения. Качественная организация системы смотровых кабинетов, подкрепленной действующей цитологической службой, непрерывный мониторинг при оказании специализированной онкологической помощи с целью выявления слабых мест, пробелов в маршрутизации онкологических больных, коррекции мероприятий по раннему выявлению, возможности рационального использования ресурсов способствует решению проблем раннего выявления злокачественных новообразований. Восстановление профилактических осмотров, а также более совершенная организация повышения квалификации врачей общей лечебной сети по онкологии, проведение для терапевтов, хирургов тематических семинаров по диагностике злокачественных опухолей, выявлению ранних стадий, а также внедрение телемедицинских 
технологий в первичные онкологические кабинеты позволят повысить качество и доступность медицинской помощи больным со злокачественными новообразованиями.

Abstract. The epidemiological situation for cancer remains unfavourable worldwide due to a steady growth trend. According to the International Agency for Cancer Research, by 2030, the number of new annually detected malignant neoplasms will reach 26.4 million per year and the number of deaths -17 million. The reasons for this are complex, reflecting both ageing and population growth and changes in the prevalence and distribution of major cancer risk factors, some of which are linked to socio-economic development. In the Kyrgyz Republic, mortality from malignant neoplasms is in the second and fourth place, as a cause of disability of the population. The reduction of mortality from malignant neoplasms can be achieved as a result of the implementation of a comprehensive science-based targeted programme, which includes strengthening the role of the primary health care unit, activating the work of observation rooms and restoring prevention departments at the primary level, improving the skills of oncological health workers, developing early diagnosis methods, new approaches to the treatment of malignant neoplasms, improving the cancer register of patients and conducting mass screening of the population. Qualitative organization of the system of observation rooms, supported by the current cytological service, continuous monitoring of specialized oncological care in order to identify weaknesses, gaps in the routing of oncological patients, correction of early detection measures, possibility of rational use of resources contributes to solving problems of early detection of malignant neoplasms. Restoration of preventive examinations, as well as improved organization of advanced training of doctors of the general medical network on oncology, holding thematic seminars for therapists, surgeons on diagnosis of malignant tumors, detection of early stages, as well as introduction of telemedicine technologies in primary oncological offices will improve the quality and availability of medical care for patients with malignant neoplasms.

Ключевые слова: заболеваемость, злокачественные новообразования, канцер-регистр, онкологическая помощь, профилактика, ранняя диагностика, репродуктивные органы, скрининг, смертность.

Keywords: morbidity, malignant neoplasms, chancellor-register, cancer care, prevention, early diagnosis, reproductive organs, screening, mortality.

Проанализированы литературные источники по онкологической помощи, оказываемой населению.

В настоящее время эпидемиологическая ситуация по онкологическим заболеваниям остаётся неблагоприятной во всём мире. Регистрируется устойчивая тенденция роста заболеваемости злокачественными новообразованиями [1, с. 44, 2, с. 4; 3, 4, с. 629].

В 2008 г в мире было зарегистрировано 12,4 млн. новых случаев злокачественных новообразований и 7,6 млн. случаев смертельных исходов, связанных с онкологическими заболеваниями, а общее количество людей с диагностированным злокачественным новообразованием составило 28 млн. человек [5, с. 338, 6, с. 476].

Заболеваемость и смертность от злокачественных новообразований значительно различаются по странам, по соседним регионам и даже в одном регионе. В 2008 г в африканском регионе было зарегистрировано 667000 новых случаев злокачественных новообразований, в Америке — 2617000 случаев, в Юго-восточной Азии — 1589000 
случаев, в Европе - 3422000 случаев (население указанных регионов в 2008 г составляло соответственно 812, 831, 1768 и 891 млн. человек).

Заболеваемость злокачественными новообразованиями колеблется от 384 случаев на 100000 человек в Европе до 82 случаев на 100000 человек в Африке, составляя в среднем 185 случаев на 100 тыс. [7, с. 4].

По данным Международного агентства по изучению рака (МАИР) ожидается 18,1 млн. новых случаев и 9,6 млн. смертей от злокачественных новообразований $[8$, с. 10, 9, с. 395, $10]$.

Отмечается быстрый рост абсолютных показателей заболеваемости и смертности злокачественными новообразованиями в мире (в 2012 г они составляли 14,1 и 8,2 млн., соответственно [11, с. 360].

Причины этого сложны, они отражают как старение и рост численности населения, так и изменения в распространенности и распределении основных факторов риска развития рака, часть из которых связаны с социально-экономическим развитием. Во всем мире общее число людей, живущих в течение 5 лет после постановки онкологического диагноза, оценивается в 43,8 млн. человек.

С учетом кумулятивных рисков в мире для обоих полов развития рака $21,4 \%$ и смерти от злокачественного заболевания 17,7\% до достижения 75 лет, при условии отсутствия других причин смерти, один из 5 мужчин и одна из 6 женщин заболеет, а один из 8 мужчин и одна из 10 женщин умрет от онкологического заболевания [12].

В последние десятилетия отмечается увеличение показателя заболеваемости всеми злокачественными новообразованиями, особенно это характерно для опухолей женской репродуктивной системы [1, с. 47]. Факт существенного увеличения гормонозависимых злокачественных новообразований органов репродуктивной системы стал одним из самых заметных в последние десятилетия. Это в значительной степени обусловлено тем, что выявление злокачественных новообразований шейки матки отмечается в возрастном диапазоне от 20 до 70 лет и старше.

Большое внимание в решении вопроса улучшения ранней диагностики отводится установлению факторов риска с помощью эпидемиологических исследований по изучению причин возникновения злокачественных новообразований для формирования групп высокого онкологического риска [3].

В Кыргызской Республике смертность от злокачественных новообразований находится на втором и на четвертом месте, как причина инвалидизации населения [13].

Нет сомнения, что высокий уровень заболеваемости и смертности от злокачественных новообразований обусловлен, в первую очередь, состоянием окружающей среды и образом жизни людей, доступностью и качеством медицинской помощи онкологическим больным $[14$, c. 185$]$.

По прогнозам Международного агентства по изучению рака, к 2030 г число новых ежегодно выявляемых злокачественных новообразований достигнет 26,4 млн. в год, а число летальных исходов - 17 млн. [15, с. 221].

Одной из важных причин увеличения распространённости злокачественных новообразований является увеличение средней продолжительности жизни, регистрируемое во многих регионах мира. Так, в Китае средняя продолжительность жизни увеличилась с 40,8 года в 1955 г до 71,5 года в 2005 г, а в Индии — с 32 лет в 1947 г до 62 лет в 1997 г.

Поскольку в развивающихся странах средняя продолжительность жизни увеличивается быстрее, чем в развитых странах, предполагается, что в будущем именно развивающиеся страны будут вносить больший вклад в онкологическую заболеваемость в мире. 
В 2008 г на развивающиеся страны приходилось около 56\% новых случаев злокачественных новообразований и $64 \%$ летальных исходов, что в значительной степени отличается от данных, полученных в середине XX века [15, с. 222, 16, с. 100].

Международная онкологическая общественность уделяет большое внимание профилактике. В 2015 г. в Милане состоялась третья сессия Мирового онкологического форума (World Cancer Forum), посвященная профилактике и проходившей под лозунгом "Prevent-Preventable". Участники Форума подчеркнули примат профилактики в противораковой борьбе и рекомендовали пересмотреть приоритеты в области онкологических научных исследований и онкологической практики. Приоритету профилактики посвящены конференция Американской ассоциации онкологических исследований "Shaping the future of Cancer prevention" (2016) и международная конференция в Мумбаи "Challenging Dogmas" (2016). На этих конференциях рассматривалась необходимость переосмысления тактики и стратегии противораковой борьбы с учетом научных данных в области эпидемиологии и достижений первичной профилактики. Первичная профилактика является наиболее эффективным направлением противораковой борьбы. Снижение смертности от злокачественных новообразований может быть достигнуто лишь в результате выполнения комплексной научно обоснованной целевой программы, включающей в себя первичную профилактику, скрининг и лечение [17, с. 213].

Для эффективного выполнения мероприятий по ранней диагностике и профилактике злокачественных новообразований необходима координация действий между различными службами практического здравоохранения, в первую очередь онкологической и первичного звена системы здравоохранения.

Для решения задач вторичной профилактики злокачественных новообразований необходима четкая организация раннего выявления заболеваний силами медицинских работников общей лечебной сети с внедрением единых стандартов диагностической и диспансерной работы в отношении злокачественных опухолей. Необходимо дальнейшее развитие целевой программы по онкологии с реализацией следующих задач: усиление роли первичного звена здравоохранения, активизация работы смотровых кабинетов и восстановление отделений профилактики на первичном уровне; повышение квалификации медицинских работников онкологической службы; разработка методов ранней диагностики, новых подходов к лечению злокачественных новообразований; совершенствование ракового регистра больных, проведение массовых скринингов населения [18, с. 19].

Без качественно организованной работы системы смотровых кабинетов, подкрепленной на местном уровне действующей цитологической службой, решить проблемы раннего выявления злокачественных новообразований не представляется возможным. Успех организации борьбы против рака на современном этапе, а также снижение смертности от онкологических причин зависят от профилактики, ранней диагностики и, как следствие, своевременного лечения больных со злокачественными опухолями и предопухолевыми заболеваниями [19, с. 40].

Необходим непрерывный мониторинг при оказании специализированной онкологической помощи с целью выявления слабых мест, пробелов в маршрутизации онкологических больных, коррекции мероприятий по раннему выявлению и специализированному лечению больных, возможности рационального использования ресурсов [20, с. 122].

Некоторые ученые предлагают с целью своевременной диагностики злокачественных новообразований восстановить проводившиеся в предыдущие десятилетия и доказавшие свою эффективность стандартные схемы профилактических осмотров, а также более 
совершенную организацию повышения квалификации врачей общей лечебной сети по онкологии, проведение для терапевтов, хирургов тематических семинаров по диагностике злокачественных опухолей, выявлению ранних стадий [18, с. 20, 21, с. 44].

Внедрение телемедицинских технологий в первичные онкологические кабинеты и обучение врачей основам телемедицины позволяет повысить качество и доступность медицинской помощи больным со злокачественными новообразованиями [22, с. 21].

Социологические исследования позволяют достоверным методом получить объективную информацию об изучаемых явлениях. Так, в исследовании Казанцевой М.В. (2014) выявлена, что более 30\% врачей недостаточно осведомлены о распространенности онкологических заболеваний, смертности от данной патологии, более $40 \%$ респондентов недостаточно эрудированны по вопросам этиологии злокачественных новообразований, возрастным особенностям онкологической заболеваемости, более $20 \%$ респондентов не имеют четких представлений о наиболее эффективных методах лечения злокачественных новообразований и подавляющее большинство респондентов считает, что существующая система профилактики онкологических заболеваний не соответствует современным требованиям [19, с. 5].

По мнению авторов, активная санитарно-просветительская работа, повышение информированности женщин об онкологических заболеваниях, пропаганда здорового образа жизни, разработка и внедрение скрининговых программ, а также выявление факторов риска с формированием групп риска позволят своевременно диагностировать заболевания и провести их адекватное лечение, что будет способствовать изменению эпидемиологической ситуации в сторону снижения заболеваемости и смертности женщин от злокачественных опухолей органов репродуктивной системы [23, с. 26].

На фоне стабилизации общей заболеваемости рака шейки матки прослеживается тенденция к росту заболеваемости у женщин более молодого возраста (40-49 лет) и к снижению заболеваемости в возрасте 60-69 лет и старше. Это свидетельствует об “омоложении” рака шейки матки, и такая тенденция специфична для всех основных форм генитальных опухолей - рака шейки матки, рака тела матки и рака яичников. Выявленные особенности заболеваемости исследуемой патологии, сопровождающиеся нарастанием ее интенсивности в молодых группах женщин, необходимо учитывать при разработке скрининговых программ по раннему выявлению предраковых состояний и профилактике рака шейки матки [24, с. 39, 25, с. 63].

По мнению Сухарева Е.А. и соавт. (2017) только тесное взаимодействие мероприятий первичной и вторичной профилактики приведет к повышению выявляемости рака молочной железы и снижению смертности от данной патологии [26, с. 98].

Начиная с 2012 г. пройден большой путь по воплощению в жизнь положений политики «Здоровье 2020», однако и сейчас сохраняются большие различия в социальном положении людей в разных странах Европейского региона ВОЗ. Согласно новому докладу ВОЗ получены новые данные о факторах, порождающих разрывы по показателям здоровья и вклад каждого из этих факторов в общее бремя различий, связанных с несправедливостью. Одним и факторов, порождающих разрывы по показателям здоровья в Европейском регионе ВО3, является доступность и качество медико-санитарной помощи. Так, неспособность систем здравоохранения обеспечить всеобщий доступ к качественным услугам и высокий уровень платежей из собственных средств граждан за услуги здравоохранения являются причиной $10 \%$ неравенств в отношении здоровья. Платежи из собственных средств зачастую вынуждают людей делать выбор между приобретением жизненно важных услуг здравоохранения и удовлетворением других базовых потребностей [27, с. 12]. 
Следует отметить, что и злокачественные новообразования молочной железы и шейки матки являются визуальными локализациями. Показатели выявления злокачественных новообразований визуальных локализаций в сравнении с аналогичными показателями свидетельствуют о недостаточном внимании гинекологической службы к выявлению злокачественных новообразований репродуктивных органов и молочных желез в республике [3].

Результаты канцер-регистра, внедренного в Чуйском районе Кыргызской Республики, показавшего проблемы качества регистрации, доступности диагностики и лечения злокачественных новообразований, диктуют необходимость внедрения профилактических программ, имеющих высокую степень доказательности (вакцинация, ранняя диагностика, скрининг) с обязательным мониторингом всех проводимых мероприятий и подсчетом экономической эффективности [28, с. 15].

\section{Список литературы:}

1. Каприн А. Д., Старинский В. В., Петрова Г. В. Злокачественные новообразования женских половых органов в России: ситуация и проблемы // Архив акушерства и гинекологии им. В. Ф. Снегирева. 2014. №1(2). С. 44-47.

2. Каприн А. Д., Старинский В. В., Петрова Г. В. Злокачественные новообразования в России в 2017 году (заболеваемость и смертность). М. 2018. 250 с.

3. Гатагажева 3. М., Зеленова О. В., Узденова 3. Х. Заболеваемость и смертность от злокачественных заболеваний женских репродуктивных органов в Республике Ингушетия // Социальные аспекты здоровья населения. 2019. № 4 (68).

4. Boyle P. The globalisation of cancer // Lancet (London, England). 2006. V. 368. №9536. P. 629. https://doi.org/10.1016/S0140-6736(06)69225-8

5. Иванилов А. К. Заболеваемость злокачественными новообразованиями в мире, РФ и отдельных её регионах (обзор литературы) // Молодой ученый. 2014. №2. С. 337-339.

6. Borras J. M., Albreht T., Audisio R., Briers E., Casali P., Esperou H., ... Knox S. Policy statement on multidisciplinary cancer care // European Journal of Cancer. 2014. V. 50. №3. P. 475480. https://doi.org/10.1016/j.ejca.2013.11.012

7. Boyle P., Levin B. World cancer report 2008. IARC Press, International Agency for Research on Cancer, 2008.

8. Давыдов М. И., Аксель Е. М. Статистика злокачественных новообразований в России и странах СНГ в 2012 г. // Вестник Российского онкологического научного центра им. Н. Н. Блохина РАМН. 2014. 226 с.

9. Bray F. et al. Global cancer statistics 2018: GLOBOCAN estimates of incidence and mortality worldwide for 36 cancers in 185 countries // CA: a cancer journal for clinicians. 2018. V. 68. №6. P. 394-424. https://doi.org/10.3322/caac.21492

10. Krasowska D., Iraci N., Santi C., Drabowicz J., Cieslak M., Kaźmierczak-Barańska J., ... Sancineto L. Diselenides and Benzisoselenazolones as Antiproliferative Agents and Glutathione-STransferase Inhibitors // Molecules. 2019. V. 24. №16. P. 2914. https://doi.org/10.3390/molecules24162914

11. Ferlay J., Soerjomataram I., Dikshit R., Eser S., Mathers C., Rebelo M., ... Bray F. Cancer incidence and mortality worldwide: sources, methods and major patterns in GLOBOCAN 2012 // International journal of cancer. 2015. V. 136. №5. P. E359-E386. https://doi.org/10.1002/ijc.29210

12. International Agency for Research on Cancer et al. Global cancer observatory // World Health Organization. http://gco. iarc. fr. Accessed. 2018. V. 8. 
13. Здоровье населения и деятельность организаций здравоохранения Кыргызской Республики в 2018 году // Центр электронного здравоохранения МЗ КР. 2019. Режим доступа: cez.med.kg/здоровье-населения-и-деятельность-оз/.

14. Мерабишкили В. М. Приоритетные задачи совершенствования онкологической статистики в России // Биосфера. 2018. Т. 10, №2. С. 176-186.

15. Are C., Rajaram S., Are M., Raj H., Anderson B. O., Chaluvarya Swamy R., ... Cazap E. L.A review of global cancer burden: trends, challenges, strategies, and a role for surgeons // Journal of surgical oncology. 2013. V. 107. №2. P. 221-226. https://doi.org/10.1002/jso.23248

16. Are C., Colburn L., Rajaram S., Vijayakumar M. Disparities in cancer care between the United States of America and India and opportunities for surgeons to lead // Journal of surgical oncology. 2010. V. 102. №1. P. 100-105. https://doi.org/10.1002/jso.21579

17. Заридзе Д. Г. Профилактика - наиболее эффективное направление противораковой борьбы // Практическая онкология. 2016. Т. 17, № 4. С. 213-227.

18. Шаров С. В. Обоснование организационных мероприятий по совершенствованию онкологической помощи населению: автореф. ...канд. мед. наук. СПб, 2010. 22 с.

19. Казанцева М. В. Научное обоснование направлений совершенствования организации онкологической помощи на региональном уровне: автореф. ... д-ра мед. наук. М. 2014. $48 \mathrm{c}$.

20. Гнатюк А. П., Самсонов Ю. В. Современное состояние оказания онкологической помощи в городе Москве // Исследования и практика в медицине. 2015. №2(3). С. 118-123.

21. Бутрина В. И. Медико-организационные технологии своевременного выявления онкологических заболеваний трудоспособного населения мегаполиса: автореф. ...дис. д-ра мед. наук: ФГУП «Всероссийский научно-исследовательский институте железнодорожной гигиены Роспотребнадзора». М. 2014. 49 с.

22. Леванов В. М., Камаев И. А., Железин О. В. Предпосылки создания онкологического сегмента региональной телемедицинской сети // Медицинский альманах. 2018. №6. С. 21-25.

23. Умарова С. Г., Зикиряходжаев А. Д., Каримова Ф. Н. [и др.]. Эпидемиология злокачественных новообразований органов репродуктивной системы в Республике Таджикистан // Опухоли женской репродуктивной системы. 2012. №1. С. 24-27.

24. Шихнабиева Н. Д. Возрастные особенности заболеваемости генитальным раком у женщин Республики Дагестан // Современные проблемы науки и образования. 2014. №1. С. 34-40.

25. Макимбетов Э. К., Султангазиева Б. Б., Букуев Н. М. Возрастные особенности при заболеваемости женщин раком шейки матки в Кыргызстане // Вестник КРСУ. 2017. Т. 17. №10. С. 61-63.

26. Сухарева Е. А., Егорова А. Г., Сомов А. Н. Характеристика онкоэпидемиологических факторов риска заболеваний молочных желез // Медицинский альманах. 2017. №6. С. 94-98.

27. Здоровая и благополучная жизнь для всех: Доклад о ситуации с обеспечением справедливости в отношении здоровья в Европейском регионе ВОЗ // Европейское региональное бюро ВОЗ. 2019. 129 с.

28. Тен Е. Е., Намазбекова А. М., Рыжов А. Ю. Отчет популяционного регистра онкологических больных Кыргызской Республики (канцер-регистра). Данные по Чуйской области, за 2015-2017 гг. // Канцер-регистр Кыргызской Республики (2015-2017). Бишкек: Алтын Тамга. 2019. 31 с. 


\section{References:}

1. Kaprin, A. D., Starinskii, V. V., \& Petrova, G. V. (2014). Zlokachestvennye novoobrazovaniya zhenskikh polovykh organov v Rossii: situatsiya i problem. Arkhiv akusherstva $i$ ginekologii im, F. Snegireva. 1(2). 44-47. (in Russian).

2. Kaprin, A. D., Starinskii, V. V., \& Petrova, G. V. (2018). Zlokachestvennye novoobrazovaniya v Rossii v 2017 godu (zabolevaemost' i smertnost'). Moscow. 250. (in Russian).

3. Gatagazheva, Z. M., Zelenova, O. V., \& Uzdenova, Z. Kh. (2019). Zabolevaemost' i smertnost' ot zlokachestvennykh zabolevanii zhenskikh reproduktivnykh organov $\mathrm{v}$ Respublike Ingushetiya. Sotsial'nye aspekty zdorov'ya naseleniya, 4(68). (in Russian).

4. Boyle, P. (2006). The globalisation of cancer. Lancet (London, England), 368(9536), 629. https://doi.org/10.1016/S0140-6736(06)69225-8

5. Ivanilov, A. K. (2014). Zabolevaemost' zlokachestvennymi novoobrazovaniyami v mire, RF i otdel'nykh ee regionakh (obzor literatury). Molodoi uchenyi, (2). 337-339. (in Russian).

6. Borras, J. M., Albreht, T., Audisio, R., Briers, E., Casali, P., Esperou, H., ... \& Knox, S. (2014). Policy statement on multidisciplinary cancer care. European Journal of Cancer, 50(3), 475480. https://doi.org/10.1016/j.ejca.2013.11.012

7. Boyle, P., \& Levin, B. (2008). World cancer report 2008. IARC Press, International Agency for Research on Cancer.

8. Davydov, M. I., \& Aksel', E. M. (2014). Statistika zlokachestvennykh novoobrazovanii v Rossii i stranakh SNG v 2012 g. Vestnik Rossiiskogo onkologicheskogo nauchnogo tsentra im. N. N. Blokhina RAMN, 226. (in Russian).

9. Bray, F., Ferlay, J., Soerjomataram, I., Siegel, R. L., Torre, L. A., \& Jemal, A. (2018). Global cancer statistics 2018: GLOBOCAN estimates of incidence and mortality worldwide for 36 cancers in 185 countries. CA: a cancer journal for clinicians, 68(6), 394-424. https://doi.org/10.3322/caac.21492

10. Krasowska, D., Iraci, N., Santi, C., Drabowicz, J., Cieslak, M., Kaźmierczak-Barańska, J., ... \& Sancineto, L. (2019). Diselenides and Benzisoselenazolones as Antiproliferative Agents and $\begin{array}{llll}\text { Glutathione-S-Transferase } & \text { Inhibitors. } & \text { Molecules, } & 24(16),\end{array}$ https://doi.org/10.3390/molecules24162914

11. Ferlay, J., Soerjomataram, I., Dikshit, R., Eser, S., Mathers, C., Rebelo, M., ... \& Bray, F. (2015). Cancer incidence and mortality worldwide: sources, methods and major patterns in GLOBOCAN 2012. International journal of cancer, 136(5), E359-E386. https://doi.org/10.1002/ijc. 29210

12. International Agency for Research on Cancer. (2018). Global cancer observatory. World Health Organization. http://gco. iarc. fr. Accessed, 8.

13. Zdorov'e naseleniya i deyatel'nost' organizatsii zdravookhraneniya Kyrgyzskoi Respubliki v 2018 godu (2019). Tsentr elektronnogo zdravookhraneniya MZ KR. Rezhim dostupa: cez.med.kg/zdorov'e-naseleniya-i-deyatel'nost'-oz/.

14. Merabishkili, V. M. (2018). Prioritetnye zadachi sovershenstvovaniya onkologicheskoi statistiki v Rossii. Biosfera, 10(2). 176-186. (in Russian).

15. Are, C., Rajaram, S., Are, M., Raj, H., Anderson, B. O., Chaluvarya Swamy, R., ... \& Cazap, E. L. (2013). A review of global cancer burden: trends, challenges, strategies, and a role for surgeons. Journal of surgical oncology, 107(2), 221-226. https://doi.org/10.1002/jso.23248 
16. Are, C., Colburn, L., Rajaram, S., \& Vijayakumar, M. (2010). Disparities in cancer care between the United States of America and India and opportunities for surgeons to lead. Journal of surgical oncology, 102(1), 100-105. https://doi.org/10.1002/jso.21579

17. Zaridze, D. G. 2016. Profilaktika - naibolee effektivnoe napravlenie protivorakovoi bor'by. Prakticheskaya onkologiya, 17(4). 213-227. (in Russian).

18. Sharov, S. V. (2010). Obosnovanie organizatsionnykh meropriyatii po sovershenstvovaniyu onkologicheskoi pomoshchi naseleniyu: avtoref. ...kand. med. nauk. SPb, 22. (in Russian).

19. Kazantseva, M. V. (2014). Nauchnoe obosnovanie napravlenii sovershenstvovaniya organizatsii onkologicheskoi pomoshchi na regional'nom urovne: avtoref. ... d-ra med. nauk. Moscow. 48. (in Russian).

20. Gnatyuk, A. P., \& Samsonov, Yu. V. (2015). Sovremennoe sostoyanie okazaniya onkologicheskoi pomoshchi v gorode Moskve. Issledovaniya i praktika v meditsine, 2(3). 118-123. (in Russian).

21. Butrina, V. I. (2014). Mediko-organizatsionnye tekhnologii svoevremennogo vyyavleniya onkologicheskikh zabolevanii trudosposobnogo naseleniya megapolisa: avtoref. ...dis. d-ra med. nauk: FGUP "Vserossiiskii nauchno-issledovatel'skii institute zheleznodorozhnoi gigieny Rospotrebnadzora". Moscow. 49. (in Russian).

22. Levanov, V. M., Kamaev, I. A., \& Zhelezin, O. V. (2018). Predposylki sozdaniya onkologicheskogo segmenta regional'noi telemeditsinskoi seti. Meditsinskii al'manakh, (6). 21-25. (in Russian).

23. Umarova, S. G., Zikiryakhodzhaev, A. D., \& Karimova, F. N. (2012). Epidemiologiya zlokachestvennykh novoobrazovanii organov reproduktivnoi sistemy v Respublike Tadzhikistan. Opukholi zhenskoi reproduktivnoi sistemy, (1). 24-27. (in Russian).

24. Shikhnabieva, N. D. (2014). Vozrastnye osobennosti zabolevaemosti genital'nym rakom u zhenshchin Respubliki Dagestan. Sovremennye problemy nauki i obrazovaniya, (1). 34-40. (in Russian).

25. Makimbetov, E. K., Sultangazieva, B. B., \& Bukuev, N. M. (2017). Vozrastnye osobennosti pri zabolevaemosti zhenshchin rakom sheiki matki v Kyrgyzstane. Vestnik KRSU, 17(10). 61-63. (in Russian).

26. Sukhareva, E. A., Egorova, A. G., \& Somov, A. N. (2017). Kharakteristika onkoepidemiologicheskikh faktorov riska zabolevanii molochnykh zhelez. Meditsinskii al'manakh, (6). 94-98. (in Russian).

27. Zdorovaya i blagopoluchnaya zhizn' dlya vsekh: Doklad o situatsii s obespecheniem spravedlivosti v otnoshenii zdorov'ya v Evropeiskom regione VOZ (2019). Evropeiskoe regional'noe byuro VOZ. 129. (in Russian). 
28. Ten, E. E., Namazbekova, A. M., \& Ryzhov, A. Yu. (2019). Otchet populyatsionnogo registra onkologicheskikh bol'nykh Kyrgyzskoi Respubliki (kantser-registra). Dannye po Chuiskoi oblasti, za 2015-2017 gg. Kantser-registr Kyrgyzskoi Respubliki (2015-2017). Bishkek: Altyn Tamga. 31. (in Russian).

Работа поступила

в редакциюю 16.01.2020 2.
Принята к публикаџии

21.01.2020 2.

Ссылка для циитирования:

Тилеков Э. А., Ибраимова Д. Д., Болбачан О. А., Садамкулова К. И. Пути улучшения онкологической помощи // Бюллетень науки и практики. 2020. Т. 6. №2. С. 122-131. https://doi.org/10.33619/2414-2948/51/10

Cite as (APA):

Tilekov, E., Ibraimova, D., Bolbachan, O., \& Sadamkulova, K. (2020). Ways to Improve Cancer Care. Bulletin of Science and Practice, 6(2), 122-131. https://doi.org/10.33619/24142948/51/10 (in Russian). 


\section{ПЕРЕДНИЙ КОРПОРОДЕЗ ПОЯСНИЧНОГО ОТДЕЛА ПОЗВОНОЧНИКА С ПОРИСТЫМ НИКЕЛИДОМ ТИТАНА}

(СКойчубеков А. А., канд. мед. наук, Киргизский научно-исследовательский институт курортологии и восстановительного лечения,

c. Таши-Добо, Кыргызстан, Koichubekov@mail.ru

ССабыралиев М. К., канд. мед. наук, Бишкекский научно-исследовательский центр травматологии и ортопедии, г. Бишкек, Кыргызстан

(ССулайманов Ж. Д., д-р мед. наук, Бишкекский научно-исследовательский иентр травматологии и ортопедии, г. Бишкек, Кыргызстан

\section{ANTERIOR SPONDYLOSYNDESIS OF THE LUMBAR SPINE WITH POROUS NITINOL}

CKoichubekov A., M.D., Kyrgyz Research Institute of Balneology and Restorative treatment, Tash-Dobo, Kyrgyzstan, Koichubekov@mail.ru

CSabyraliev M., M.D., Bishkek Research Center for Traumatology and Orthopedics, Bishkek, Kyrgyzstan

CSulaimanov Zh., Dr. habil., Bishkek Research Center for Traumatology and Orthopedics, Bishkek, Kyrgyzstan

Аннотация. Патология позвоночника занимает одно из ведущих мест среди заболеваний опорно-двигательного аппарата. Болью в спине в возрасте 20-50 лет страдают до 98\% населения. Одна из основных причин ее возникновения - дегенеративные изменения межпозвоночных дисков. Дегенеративные заболевания позвоночника занимают первое место (46,7\%) среди причин первичной инвалидности. В 25 случаях боли в нижних конечностях полностью исчезли в первые дни после операции, а в 18 - значительно уменьшились (в среднем с 6,2 до 1,5 балла по ВАШ). Через два-три года после операции клинические результаты лечения у 41 (79\%) пациентов расценены как хорошие, у 11 (21\%) как удовлетворительные. Неудовлетворительных результатов не было.

Abstract. Spinal pathology is one of the leading places among diseases of the motor system. Back pain between the ages of 20 and 50 affects up to $98 \%$ of the population. One of the main causes for its occurrence is degenerative changes in the herniated discs. Degenerative disorders of the spine occupy the first place (46.7\%) among the causes of primary disability. In 25 cases, pain in the lower extremities completely disappeared in the first days after the operation, and in 18 they significantly decreased (on average from 6.2 to 1.5 on VAS score). Two to three years after surgery, the clinical results of treatment in $41(79 \%)$ patients were rated as good, in $11(21 \%)$ - as satisfactory. There were no unsatisfactory results.

Ключевые слова: патология позвоночника, остеохондроз, передний корпородез.

Keywords: spinal pathology, osteochondrosis, anterior spondylosyndesis.

Проблема лечения и реабилитации вертеброгенной патологии является актуальной, так как согласно статистическим данным, только на долю неврологических синдромов, обусловленных изменениями в позвоночнике, приходится 75-85\% всех заболеваний периферической нервной системы. Пик заболеваемости приходится на наиболее активный период трудовой деятельности (20-55 лет). По данным эпидемиологических исследований, в 
указанной возрастной группе при патологии позвоночника страдают 24\% мужчин и $32 \%$ женщин [2, 3].

Множество существующих и появляющихся методов хирургического лечения поясничного остеохондроза требуют глубокого понимания и дифференцированного подхода к выбору правильной тактики. Несмотря на множество существующих оперативных способов лечения остеохондроза позвоночника по данным различных авторов частота неудовлетворительных результатов колеблется от $20 \%$ до $40 \%$ случаев $[1,4-6]$.

\section{Материал и методы}

В ретроспективное исследование включены 52 пациента, оперированных в отделении нейроортопедии и реабилитационной ортопедии КНИИКиВЛ с применением пористого никелид титана с 2010 по 2016 гг. по поводу остеохондроза позвоночника. Среди пациентов было 30 женщин и 22 мужчин в возрасте от 22 до 67 лет $(\mathrm{M}=42,6)$. Средняя продолжительность стационарного лечения составило 10 суток.

Самыми первыми жалобами пациентов, ведущих на прием к ортопеду являются боли в спине. При обращении в стационар у всех больных отмечались боль в области поясницы иррадиирущие в ноги. Боли могут отличаться по интенсивности, и часто связаны с физической нагрузкой или травмой. Причем нагрузка эта может быть, как динамическая, так и статическая. Длительность болевого синдрома составляло от 1мес до 9мес. 2 больных обращались первично. 50 больных ранее получали консервативное лечение в разных клиниках республики и обращались к нам из-за неэффективности консервативного лечения.

Клинические симптомы при обращении отражены в Таблице 1.

ЧАСТОТА НЕВРОЛОГИЧЕСКИХ СИМПТОМОВ

Таблица 1.

\begin{tabular}{|c|c|c|}
\hline \multirow[t]{2}{*}{ Ортопедические симптомы } & \multicolumn{2}{|c|}{ Частота проявления симптомов } \\
\hline & $n$ & $\%$ \\
\hline \multicolumn{3}{|l|}{ Люмбалгия: } \\
\hline -в покое & 41 & 78.8 \\
\hline - при динамической нагрузке & 52 & 100 \\
\hline \multicolumn{3}{|l|}{ Нарушения чувствительности: } \\
\hline -гиперстезия & 2 & 3.8 \\
\hline -гипестезия & 42 & 80.1 \\
\hline -анестезия & 2 & 3.8 \\
\hline \multicolumn{3}{|l|}{ Симптом Ласега: } \\
\hline -больше $60^{0}$ & 21 & 40.4 \\
\hline$-40-60^{\circ}$ & 20 & 38.5 \\
\hline -меньше $40^{\circ}$ & 11 & 21.2 \\
\hline Признак «плоской спины» & 25 & 48.1 \\
\hline \multicolumn{3}{|l|}{ Нарушения рефлексов: } \\
\hline -коленных & 38 & 70.1 \\
\hline -ахиловых & 12 & 23.1 \\
\hline -подошвенных & 9 & 17.3 \\
\hline \multicolumn{3}{|l|}{ Двигательные расстройства: } \\
\hline -гипотрофия мышц нижних конечностей & 31 & 60 \\
\hline -снижение силы в мышцах бедра, голени & 16 & 30.8 \\
\hline Изменение походки & 31 & 60 \\
\hline Вынужденная позовая установка & 24 & 46.2 \\
\hline Гипертонус паравертебральных мышц & 47 & 90.4 \\
\hline Ограничение движений в поясничном отделе позвоночника & 48 & 92.3 \\
\hline
\end{tabular}


Предоперационный диагностический комплекс включал общеклиническое, неврологическое, рентгенологическое обследования, КТ, МРТ.

\section{Техника операцчии}

После предоперационной обработки операционного поля под общей анестезией производится левосторонний внебрюшной доступ. Доступ осуществляется строго избирательно над очагом дегенеративного поражения. Послойно не рассекая, а раздвигая между мышечными волокнами, обнажается межпозвоночный диск. После выполнения хирургического доступа выполняется рентгенограмма или снимок с помощью электроннооптического преобразователя (ЭОП) для уточнения расположения оперируемого сегмента относительно плоскости операционного стола. Зона вмешательства полностью освобождается от мягких тканей, перевязываются и пересекаются мелкие сосуды. Затем «П» образно рассекается фиброзное кольцо. Край легируется и разводится в сторону ограничивая тем самым зону оперативного действия от магистральных сосудов. После удаляются фрагменты межпозвонкового диска, остатки пульпозного ядра, грыжи диска. Костной ложкой очищается гиалиновая оболочка. Подготовка имплантата - осуществляется выбор типоразмера соответствующего диаметра. Имплантат из пористого никелид титана который устанавливается в межпозвоночное пространство. Производится контрольный снимок. Далее устанавливается дренаж, накладывается послойные швы на рану и асептическая повязка. Постельный режим сохраняется 3-7 дней.

После вмешательств на поясничном отделе позвоночника используются полужёсткий корсет в течение 3-6 месяцев.

В послеоперационном периоде производится рентгенологический снимок или КТконтроль через 6 и 12 месяцев после вмешательства.

Результаты хирургического лечения в сроки от одного года до трех лет изучены у всех больных. При этом оценивали неврологический статус, динамику болевого синдрома по десятибалльной визуально-аналоговой шкале (ВАШ) и нарушения активности (дееспособности) по индексу Освестри.

\section{Результаты и их обсуждение}

Клинически при поступлении у 52 (100\%) больных отмечали боли в спине, усиливающиеся при физической нагрузке, длительной ходьбе, а иногда и при длительном нахождении в положении сидя.

Изменение интенсивности болевого синдрома по 10 бальной шкале ВАШ в послеоперационном периоде показано в Таблице 2.

Таблица 2

ДИНАМИКА ИНТЕНСИВНОСТИ БОЛЕВОГО СИНДРОМА ПО ВАШ ДО И ПОСЛЕ ЛЕЧЕНИЯ ДЕГЕНЕРАТИВНЫХ ЗАБОЛЕВАНИЙ ПОЯСНИЧНОГО ОТДЕЛА ПОЗВОНОЧНИКА (N=52)

\begin{tabular}{lcccc}
\hline & N до лечения & $\%$ & $N$ после лечения & $\%$ \\
\hline Значительно выраженный & 14 & 26,9 & & $0 * *$ \\
Умеренно выраженный & 19 & 36.6 & 11 & 21.1 \\
Менее выраженный & 18 & 34.6 & 16 & 30.8 \\
Нет болей & 1 & 1.9 & 25 & $48.1 * *$ \\
\hline Всего & 52 & $100 \%$ & 52 & $100 \%$ \\
\hline
\end{tabular}

Примечание: * - достоверность разницы показателей * - $\mathrm{p}<0,05$ ** - $\mathrm{p}<0,01$ 
В 25 случаях боли в нижних конечностях полностью исчезли в первые дни после операции, а в 18 - значительно уменьшились (в среднем с 6,2 до 1,5 балла по ВАШ).

Функциональные результаты лечения в сроки от двух до трех лет после операции оценивали с учетом степени восстановления физической и социальной активности пациентов.

Отдаленные результаты оценивались по классической трехбалльной системе:

- хороший результат - исчезновение болевого синдрома, полный регресс неврологических симптомов, полное возвращение к прежнему уровню социальной и физической активности;

- удовлетворительный результат - болевой синдром при физической нагрузке, частичный регресс неврологической симптоматики, бытовая и социальная активность восстановлена не полностью;

- неудовлетворительный результат - отсутствие эффекта от операции или ухудшение.

Через два-три года после операции клинические результаты лечения у 41 (79\%) пациентов расценены как хорошие, у 11 (21\%) — как удовлетворительные. Неудовлетворительных результатов не было.

Рентгенологические и КТ-исследования, проведенные в сроки от 6 мес. до 3 лет, ни в одном из наблюдений не выявили миграции имплантантов, внедрения их в тела позвонков.

\section{Заключение}

Выполнение переднего корпородеза поясничного отдела позвоночника с пористым никелид титаном является эффективным и патогенетически обоснованным способом хирургического лечения при дегенеративных заболеваниях поясничного отдела позвоночника, а также плотности исключить возможность возникновения послеоперационной нестабильности, миграции и лизиса установленных имплантатов.

\section{Список литературы:}

1. Ветрилэ С. Т., Швец В. В., Крупаткин А. И. Показания и особенности выбора тактики хирургического лечения поясничного остеохондроза с использованием транспедикулярных фиксаторов // Хирургия позвоночника. 2004. №4. С. 40-46.

2. Вербицкая Г. Д., Дышловой В. Н., Зинченко В. Г. Хирургические аспекты вертебральной патологии // Бюл. Укр. ассоц. нейрохирургов. 1998. №6. С. 156.

3. Воронович И. Р. Дулуб О. И., Николаев В. Н. Компьютерная томография при повреждениях позвоночника // Ортопед. травматол. 1990. №8. С. 1-10.

4. Раткин И. К., Луцик А. А., Дорофеев Ю. И., Бондаренко Г. Ю. Применение армированных имплантатов из пористого никелида титана для формирования переднего опорного спондилодеза у больных, перенесших позвоночно-спинномозговую травму // Хирургия позвоночника. 2004. №3. С. 26-32.

5. Сампиев М. Т., Доценко В. В., Васильев Ф. В. Метод оперативного лечения сегментарного дегенеративного стеноза поясничного отдела позвоночника // Науч.-практ. конф. SICOT: Тез. докл. СПб., 2002. С. 135.

6. Schiffman M., Brau S. A., Henderson R., Gimmestad G. Bilateral implantation of lowprofile interbody fusion cages: subsidence, lordosis, and fusion analysis // The Spine Journal. 2003. V. 3. №5. P. 377-387. https://doi.org/10.1016/S1529-9430(03)00145-1 


\section{References:}

1. Vetrile, S. T., Shvets, V. V., \& Krupatkin, A. I. (2004). Pokazaniya i osobennosti vybora taktiki khirurgicheskogo lecheniya poyasnichnogo osteokhondroza $\mathrm{s}$ ispol'zovaniem transpedikulyarnykh fiksatorov. Khirurgiya pozvonochnika, (4). 40-46. (in Russian).

2. Verbitskaya, G. D., Dyshlovoi, V. N., \& Zinchenko, V. G. (1998). Khirurgicheskie aspekty vertebral'noi patologii. Byul. Ukr. assots. neirokhirurgov, (6), 156. (in Russian).

3. Voronovich, I. R., Dulub, O. I., \& Nikolaev, V. N. (1990). Komp'yuternaya tomografiya pri povrezhdeniyakh pozvonochnika. Ortoped. travmatol, (8), 1-10. (in Russian).

4. Ratkin, I. K., Lutsik, A. A., Dorofeev, Yu. I., \& Bondarenko, G. Yu. (2004). Primenenie armirovannykh implantatov iz poristogo nikelida titana dlya formirovaniya perednego opornogo spondilodeza u bol'nykh, perenesshikh pozvonochno-spinnomozgovuyu travmu. Khirurgiya pozvonochnika, (3). 26-32. (in Russian).

5. Sampiev, M. T., Dotsenko, V. V., \& Vasil'ev, F. V. (2002). Metod operativnogo lecheniya segmentarnogo degenerativnogo stenoza poyasnichnogo otdela pozvonochnika. In Nauch.-prakt. konf. SICOT: Tez. dokl. SPb. 135. (in Russian).

6. Schiffman, M., Brau, S. A., Henderson, R., \& Gimmestad, G. (2003). Bilateral implantation of low-profile interbody fusion cages: subsidence, lordosis, and fusion analysis. The Spine Journal, 3(5), 377-387. https://doi.org/10.1016/S1529-9430(03)00145-1

Работа поступила

в редакичию 04.01.2020 г.
Принята к публикации

15.01.2020 2.

Ссылка для цчитирования:

Койчубеков А. А., Сабыралиев М. К., Сулайманов Ж. Д. Передний корпородез поясничного отдела позвоночника с пористым никелидом титана // Бюллетень науки и практики. 2020. Т. 6. №2. С. 132-136. https://doi.org/10.33619/2414-2948/51/11

Cite as (APA):

Koichubekov, A., Sabyraliev, M., \& Sulaimanov, Zh. (2020). Anterior Spondylosyndesis of the Lumbar Spine With Porous Nitinol. Bulletin of Science and Practice, 6(2), 132-136. https://doi.org/10.33619/2414-2948/51/11 (in Russian). 


\title{
ИЗУЧЕНИЕ ЗОН РАСПРОСТРАНЕНИЯ И АГРОБИОЛОГИЧЕСКИХ ОСОБЕННОСТЕЙ АЙВЫ, ВОЗДЕЛЫВАЕМОЙ В ШАХБУЗСКОМ РАЙОНЕ НАХИЧЕВАНСКОЙ АВТОНОМНОЙ РЕСПУБЛИКИ
}

СБайрамов Л. А., канд. с.-х. наук, Нахичеванское отделение НАН Азербайджана, г. Нахичевань, Азербайджан, bayramov-logman @mail.ru

\section{STUDY OF DISTRIBUTION ZONES AND AGROBIOLOGICAL CHARACTERISTICS OF THE PEARS IN THE SHAHBUZ DISTRICT OF THE NAKHCHIVAN AUTONOMOUS REPUBLIC}

\author{
CBairamov L., Ph.D., Nakhichivan branch of Azerbaijan NAS, \\ Nakhchivan, Azerbaijan, bayramov-logman @mail.ru
}

Аннотация. Определены зоны распространения сортов и форм айвы, возделываемых на территории Шахбузского района, уточнены их названия, синонимы и сортотипная принадлежность. Проведены фенологические наблюдения на выявленных сортах и формах, отобран материал и путем прививок размножены перспективные сорта и формы на территориях местообитания и в ботаническом саду. Также определена урожайность нововыявленных сортов и форм, которые предложены для насаждения в фермерских и подсобных хозяйствах.

Abstract. Zones for the distribution of varieties and forms of quince cultivated on the territory of the Shahbuz district of the autonomous republic are defined, their names and synonyms and their type-specific affiliation are specified. Conducted phenological observations on the identified varieties and forms, selected varieties and forms of promising varieties and forms in habitat areas and in the Botanical Gardens. Pomological descriptions of the first-discovered forms of Badamli Zavod-1, Bichenek-2, and Güney Gyshlag-2 are given. Also determined the yield of newly identified varieties and forms, and they are proposed for planting farms and subsidiary farms.

Ключевые слова: фенологические наблюдения, селекция, помология, коллекция, агробиологическая характеристика, Бадамлы, Гюней, Биченек.

Keywords: phenological observations, selection, pomology, collection, agrobiological characteristic, Badamli, Güney, Bichenek.

Нахчыванская земля богата растительностью. Почвенно-климатические условия региона благоприятно влияют на рост, развитие и урожайность многих плодовых культур. На территории Нахчыванской Автономной Республики плодоводство с древних времён занимало особое место среди отраслей сельского хозяйства и имело промышленное значение. Среди всех возделываемых на всех зонах плодовых культур по обилию преобладают семечковые плодовые деревья. В семечковых садовых насаждениях по 
занимаемой площади деревья айвы занимают третье место или составляют 25-17\% [1, с. 141147].

В разные годы И. М. Ахундзаде, Г. З. Бабаев, А. С. Реджебли, Т. Г. Талыбов, Т. М. Тагиев, Ф. Р. Худавердиев, А. А. Гуламов, Л. А. Байрамов и др. занимались изучением Нахчыванского садоводства. Однако, в проведенных исследованиях не были отражены сведения о генетических ресурсах айвы и возможностях их использования [2, с. 133-139; 4, с. 4-6].

Растение айва относится к роду Айва (Cydoniya L.) подсемейства Яблоко (Pomoideae) семейства Розовые (Rosaceae). Растение с монофилетическим происхождением. Единственный представитель рода. Все культурные сорта айвы произошли от этого вида. Дерево среднего роста (5-6 м) или кустарникового типа с широкой кроной. Ствол покрыт коричнево-черноватой корой, с возрастом она, лупясь, опадает. Почки и ростки войлочно опушены. Листья широко яйцевидной формой, снизу опушены. Цветки большие, в основном одиночные, светло розового цвета. Они образуются на ростках. Плоды крупные (200-450 г, редко 650-700 г), шарообразной или грушевидной формы. Кожура зеленого, зеленолимонного или буро-желтого цвета, волосистая. Мякоть светло белая, мягкая, или жёсткая у некоторых сортов с многочисленными каменистыми клетками. Плоды по морфологическим признакам разделяются на несколько разновидности [3, с. 30].

Плоды айвы обладают высокими вкусовыми качествами. Употребляются они больше в свежем виде. Также готовят из плодов айвы компот, джем и фруктовый сок. Плоды айвы обладают также лечебным действием. Населением они используются при лечении болезней сердца, почек и кишечника. Содержание многих сахаров, кислот, минеральных солей, солей калия, каротина в составе плодов позволяет лечить ими ряд других заболеваний. Существуют 2 сорта и формы айвы: скороспелые и позднеспелые. Растения айвы долгоживущие и живут примерно 60-80 лет. Урожайность одного дерева 70-85 кг. Айва возделывается на всех зонах автономной республики.

В течение 2018 г в подсобных хозяйствах и фруктовых садах Шахбузского района Нахчыванской AP обнаружено распространение 8 сортов и 3 форм рода айвы (Сydonia L.). Из них 4 сорта - Сары айва, Турш айва, Пампыгы и Сулу айва аборигенные и созданы путём народной селекции. Гара айва, Армудвари айва, Гусейни и Даш айва привезены извне в территорию автономной республики в 50-60 годах прошлого столетия. Последние сорта созревают в середине сентября и в начале ноября, что их делает ценными с точки зрения селекционных работ.

Изучение сортов айвы на территории Шахбузского района Нахчыванской АР, которая считается одной из основных областей плодоводства в Азербайджанской Республике, собрание в «Генофондно-селекционном саду» сортов и форм с превосходящими качествами и исследование их агробиологических особенностей явились основной целью данной работы.

Впервые на территории района выявлено 8 сортов и 3 формы айвы, отличающихся помологическими особенностями. Проведены прививки перспективных сортов и форм на местах обитания, и они в будущем будут перенесены в Генофондный сад.

Считаем целесообразным собрание соответствующих к почвенно-климатическим условиям автономной республики высокоурожайных, устойчивых к болезням и вредителям, морозам сортов и форм айвы в «Генофондно-селекционном саду» и использование их в будущем как исходный материал в насаждении новых плодовых садов и в селекционных работ. Задача - отобрать местные и ввезенные, адаптированные к местным почвенно- 
климатическим условиям высокоурожайные, качественные и устойчивые сорта и рекомендовать их фермерским хозяйствам.

\section{Материал и методика работьл}

При выполнении исследовательской работы использованы: методика ВНИИС имени И. В. Мичурина [5, с. 93-124]; 3. М. Гасанов «Плодоводство: лабораторный практикум»; И. Н. Бейдемана «Методика изучения фенологии растений и растительных сообществ» [6, с. 2140]; «Программа и методика интродукции и сортоизучения плодовых культур» [7, с. 60-62] и др. рекомендации и методические указания.

\section{Результаты и обсуждения}

В ходе экспедиции на территории Шахбузского района выявлены 8 сортов и 3 формы айвы. С первых дней марта проведены фенологические наблюдения над местными и интродуцированными сортами айвы начиная с набуханий почек до созревания плодов. Изучены их хозяйственные и агробиологические особенности, взяты материалы от перспективных сорт и форм и проведены прививки.

Следует отметить, что в течение 1988-2000 гг частые засухи, массовый выруб деревьев в зимние месяцы в автономной республике создали угрозу исчезновения и генетическим ресурсам сортов и форм айвы. Несмотря на наличие на территории более 15 сортов и форм айвы, некоторые из них, к сожалению, находятся на грани исчезновения. По этой причине уточнение зон распространения сортов и форм айвы, составляющих генофонл айвы в Шахбузском районе и в будущем вовлечение их в селекционные работы для нас является одной их актуальных задач, предстоящей перед нами. Поэтому и те сорта, и формы айвы вместе с широко распространенными посажены в «Генофондно-селекционном саду», ведутся работы по их восстановлению. Возделываемые нами сорта айвы высоко продуктивны и устойчивы к разным болезням и вредителям.

Из них 3 сорта и одна форма (Новрест, Джыр айва, Сулу айва (Еппек айва) и Бадамлы завод-1) скороспелые, созревают в конце сентября в начале октября, а 5 сортов и 2 формы (Сары айва, Турш айва, Гусейни, Армудвари, Махмуду и Гюней Гышлаг-2, Биченек-2) позднеспелые, созревают в конце октября и в начале ноября.

Установлено, что на территории Шазбузского района, в зависимости от зон распространения у сортов и форм айвы цветение происходит с конца марта по второй декады мая, а созревание плодов продолжается от начала октября до конца ноября. Несмотря на проведенные многосторонние исследования, точный список сортов и форм айвы, распространенных на территории Шахбузского района, никем не установлен и не изучен.

Впервые в исследуемом году на территории Шахбузского района выявлены основные зоны распространения сортов и форм айвы, обнаружены 8 видов и 3 формы. Из них 3 сорта и одна форма распространены на горной зоне - в селениях Саласуз, Бадамлы, Кенд Шахбуз, Махмудоба и Карабаба, а 5 сортов и 2 формы - на высокогорной зоне (они в основным возделываются в подсобных хозяйствах). Наблюдения проведены над этими сортами с начала марта до конца ноября, до сбора урожая. Выявлены перспективные сорта и формы, предусматриваются их размножение в будущем.

Агробиологические и помологические особенности некоторых из вышеупомянутых видов и форм приведены ниже. Следовательно, определены высота, диаметр деревьев, вес, цвет, запах, вкус плодов, вес и цвет семечек, длина черешка и дегустационная оценка (в 5 
баллах). Нарисованы рисунки плодов, листьев и ростков этих сортов, выявлены помологические показатели.

Бадамль Завод - 1: Впервые обнаружен в частном дворе в селе Бадамлы Завод Шахбузского района. Условно названо именем местообитания. Низкорослое дерево с пирамидальной короной. Плоды овальной формы, вершина их с выемкой. Средний вес каждого плода составляет 180-220 граммов. Форма Бадамлы Zavod-1 похожа на сорт Армудвари, но отличается от него размером плода, вкусом и плотностью, длиной и формой. Окраска желтая, на кожуре очень маленькие белые точки. Мякоть светлая, умеренно сладкая, хрупкая и мягкая. Семенные камеры меньше, но жирноваты, чем у других сортов. В каждой семенной камере по 3 коричневых семечек. Черешки плодов присоединяются к веткам. Созревает в конце октября. Полное потребительское созревание наступает в третьей декаде ноября. Это незаменимое сырье для айвового сока. Транспортабелен, устойчив к болезням и вредителям.

Биченек - 2: Форма обнаружена недавно. Она найдена во дворе в селе Бичанек Шахбузского района. Условно названа по месту нахождения. Эта форма напоминает сортотип Турш айвы, но резко отличается от него толщиной черешка, объёмом семенной камеры, плотностью мякоти и толщиной кожуры. Дерево средней высоты (3-3,5 м), корона широкая, слегка растопыренная, а стебель светло-коричневого цвета. Плоды круглые и овальные, их вершина слегка выемчато-гладкие. Средняя масса плодов составляет 250-300 граммов, в отличие от сортотипа Турш айвы. Окраска плодов светло-желтая и на кожуре имеются мало заметные точки. Мякоть желтая, сочная, сладкая, приятным ароматом и кислотность мала. Семенные камеры большие, семечки темно-коричневые, покрыты густым соком. Плодовые черешки плотно прикреплены к ветке. Созревает в конце октября. Плоды переносят перевозку. Эта форма стойка к болезням и вредителям. При хранении у плодов аромат усиливается.

Гюней Гылилаг - 2: Форма впервые обнаружена нами в селе Гюней Гишлаг Шахбузского района. Она условно названа по месту обитания. Форма напоминает сортотип Сары айва, но резко отличается от него размерами плодов, толщиной кожуры, плотностью мякоти и длиной черешок. У кустарникового дерева высота 3-3,5 м, корона обратно пирамидальная, огибается вокруг. Годичные ростки темно-коричневые. Их длина 15-17 см. Листья имеют яйцевидную форму яйца, листовой черешок короток. В зависимости от зоны распространения, она процветает в начале мая, овальные плоды бороздками разделены на 5 долей, снизу выемчатые. Плоды сильно войлочно-опушенные, с заметными пятнами. Окраска желтая, солнечная сторона слегка затемнена. Мякоть мягкая, желтовато-белая, умеренна сочная, камеры маленькие, каменистая часть заметно большая и хрупкая. Плоды большие, вес каждого плода 200-230 г. Это очень продуктивная форма, дающая 35-40 кг урожая на дерево. Длина черешков плодов 20-25 мм, а толщина 1,5-2 мм. Прикрепление к веткам зрелых, слабо опушенных плодов сильное. Плоды в ветке иногда располагаются один за другим. Плоды ценны для варенья и компота. Урожай собирают в конце октября и начале ноября. Подходит для транспортировки, устойчив к болезням и вредителям. 
Реформы, проводимые в аграрном секторе республики предполагает эффективное использование почв и сохранение плодородия почв в качестве важной проблемы современности. Решение этой проблемы, наряду с многими задачами, позволяет иметь высокую и качественную урожайность из плодовых садов со сортами, соответствующими почвенно-климатическим условиям для каждого региона.

Таким образом, можно обобщать следующие результаты:

Целесообразно использовать рекомендуемые сорта фермерскими хозяйствами для обеспечения эффективного использования существующих земельных участков;

Рекомендуемые сорта айвы устойчивы к болезням и вредителям, и отвечают требованиям рыночной экономики в отношении урожайности и качества продукции;

Результаты научных исследований показывают, что каштановые, светло-каштановые, горно-коричневые и коричневые почвы Шахбузского района позволяют выращивать здесь рекомендуемые сорта айвы в продолжительное время;

В айвовых садах должны проводиться комплексные агротехнические услуги для сохранения плодородия почв в соответствии с биологическими характеристиками сортов.

\section{Список литература:}

1. Байрамов Л. А. Исследования сортов и форм айвы (Cydoniya L.), возделываемых на территории Шарурского и Садаракского районов и изучение их агробиологических особенностей // Известия Нахчыванского Отделения НАН Азербайджана. Серия естественных и технических наук. 2017. Т. 13. №2. С. 141-147.

2. Байрамов Л. А., Садигов А. Н. Помологические особенности сортов и форм айвы (Cydoniya L.) возделываемых на территории Шарурского и Садаракского районов // Известия Нахчыванского Отделения НАН Азербайджана. Серия естественных и технических наук, 2017. T. 13. №4. С. 133-139.

3. Гасанов 3. М. Плодоводство (Лабораторный практикум). Баку: Билик. 1977. 151 с.

4. Худавердиев Ф. П. Семечковые плодовые сорта Нахчыванской АССР и рекомендации по их выращиванию. Баку. 1984. 14 с.

5. Методика ВНИИС им. И.В. Мичурина. 1973. 493 с.

6. Бейдеман И. Н. Методика изучения фенологии растений и растительных сообшеств. Новосибирск: Наука. 1974. 156 с.

7. Программа и методика интродукчии и сортоизучения плодовых культур. Кишинев: Штиинча. 1972. 608 с.

\section{References:}

1. Bairamov, L. A. (2017). Issledovaniya sortov i form aivy (Cydoniya L.), vozdelyvaemykh na territorii Sharurskogo i Sadarakskogo raionov i izuchenie ikh agrobiologicheskikh osobennostei. Izvestiya Nakhchyvanskogo Otdeleniya NAN Azerbaidzhana. Seriya estestvennykh i tekhnicheskikh nauk, 13(2). 141-147. (in Russian).

2. Bairamov, L. A., \& Sadigov, A. N. (2017). Pomologicheskie osobennosti sortov i form aivy (Cydoniya L.) vozdelyvaemykh na territorii Sharurskogo i Sadarakskogo raionov. Izvestiya Nakhchyvanskogo Otdeleniya NAN Azerbaidzhana. Seriya estestvennykh $i$ tekhnicheskikh nauk, 13(4). 133-139. (in Russian).

3. Gasanov, Z. M. (1977). Plodovodstvo (Laboratornyi praktikum). Baku: Bilik. 151. (in Russian). 
4. Khudaverdiev, F. P. (1984). Semechkovye plodovye sorta Nakhchyvanskoi ASSR i rekomendatsii po ikh vyrashchivaniyu. Baku. 14. (in Russian).

5. Metodika VNIIS im. I.V. Michurina. (1973). 493. (in Russian).

6. Beideman, I. N. (1974). Metodika izucheniya fenologii rastenii i rastitel'nykh soobshestv. Novosibirsk, Nauka. 156. (in Russian).

7. Programma i metodika introdukchii i sortoizucheniya plodovykh kul'tur. (1972). Kishinev: Shtiincha. 608. (in Russian).

Работа поступила

в редакцию 11.01.2020 г.
Принята к публикации

19.01.2020 2.

Ссылка для цุитирования:

Байрамов Л. А. Изучение зон распространения и агробиологических особенностей айвы, возделываемой в Шахбузском районе Нахичеванской Автономной Республики // Бюллетень науки и практики. 2020. Т. 6. №2. С. 137-142. https://doi.org/10.33619/2414$2948 / 51 / 12$

Cite as (APA):

Bairamov, L. (2020). Study of Distribution Zones and Agrobiological Characteristics of the Pears in the Shahbuz District of the Nakhchivan Autonomous Republic. Bulletin of Science and Practice, 6(2), 137-142. https://doi.org/10.33619/2414-2948/51/12 (in Russian). 
AGRIS F01

\title{
ЭКОЛОГИЧЕСКИЙ МОНИТОРИНГ ПОЧВ ЛЕНКОРАНЧАЙСКОГО БАССЕЙНА ПО РАЙОНАМ
}

\author{
СМамедова С. 3., д-р биол. наук, Институт почвоведения и агрохимии НАН Азербайджана, \\ г. Баку, Азербайджан
}

\section{ECOLOGICAL MONITORING OF SOILS OF THE LENKORANCHAY BASIN BY REGION}

\author{
CMamedova S., Dr. habil., Institute of Soil Science and Agrochemistry Azerbaijan NAS, \\ Baku, Azerbaijan
}

Аннотащия. Экологический мониторинг плодородия почв Ленкоранчайского бассейна показывает, что фактор плодородия идет на снижение, как на водораздельных и транзитных, так и на аккумулятивных почвах экологического района. Однако показатели плодородия почв этого экологического района были меньше, чем у предыдущих. Это связано с тем, что скрубберные материалы, доставляемые через Ленкоранчай, частично собираются на почвах аккумулятивного экологического района.

Abstract. Ecological monitoring of soil fertility in the Lenkoranchay basin shows that the fertility factor is decreasing both on watershed and transit soils, and on accumulative soils of the ecological region. However, soil fertility indicators in this ecological region were lower than in previous ones. This is due to the fact that scrubber materials delivered through Lenkoranchay are partially collected on the soils of an accumulative ecological region.

Ключевые слова: Ленкоранчайский бассейн, экологический мониторинг, аккумулятивный район, транзитный район, водораздельный район, плодородие почв.

Keywords: Lenkoranchay basin, environmental monitoring, accumulative region, transit region, watershed region, soil fertility.

\section{Введение}

Защита окружающей среды, включая почвенный покров, стала важной глобальной проблемой, выходящей за пределы границ отдельных государств. Неприемлемые антропогенные эффекты и нарушение естественного экологического баланса привели к деградации почв сельскохозяйственных и природных биогеоценозов, включая минерализацию гумуса, повышенную кислотность или щелочность, накопление солей вдоль профиля и другие негативные воздействия [1]. Все это привело к ухудшению состава почв и, в некоторых случаях, к их непригодности. Азербайджан, также не является исключением, на территории странынаблюдаются случаи деградации земель. Так, недавние исследования в различных регионах, в том числе в Ленкоранской зоне, показывают, что если 35-40 лет назад площадь горно-коричневых почв в зоне составляла 357 т/га, то этот показатель снизился на $26 \%$ до 260 т/га.

Почвенный покров был и будет фактором, определяющим жизнеспособность нации и общества. Почва - великое национальное богатство [2, 3]. Прогнозирование и 
предотвращение экологических и хозяйственно-экономических изменений является важной общегосударственной задачей. Задержка комплексного мониторинга почв может привести неприятным последствиям $[2,5]$.

Служба мониторинга почв может обеспечить не только научно обоснованную защиту, но и способствовать экономическому развитию уже в первые годы своего создания. На основе полученной информации оптимальные и критические, физические и химические показатели могут позволить решить важные проблемы, связанные с производством сельскохозяйственных культур в различных типах почв. Системные наблюдения показывают критическое состояние показателей, подлежащих мониторингу, и на их основе, возможно, предпринимать шаги для устранения негативных процессов. Если наблюдаемые показатели не достигают критических уровней, но в динамике наблюдается направление негативных процессов, то служба мониторинга почв может поставить перед директивными органами вопросы для решения этих процессов [3].

Влияние природных и антропогенных факторов на почвенный покров и, следовательно, постоянное ухудшение параметров плодородия почвы (физические, физико-химические и химические свойства), а также снижение ее плодородия, его восстановление и улучшение имеют большое теоретическое и практическое значение [6, 7].

\section{Методика исследования}

На основе анализа природных условий и характеристик Ленкоранчайского бассейна, выбранного в качестве объекта исследования, в бассейне были определены три экологических района:

1. Водораздельный экологический район

2. Транзитный экологический район

3. Аккумулятивный экологический район

Был проведен сравнительный анализ природных условий и показателей плодородия почв экологических районов в пределах Ленкоранчайского бассейна. Впервые были созданы экологические модели, основанные на исторических показателях плодородия и сопоставленные с современным состоянием Ленкоранчайского бассейна.

Ленкоранчайский Результаты и обсуждения сельскохозяйственных районов Азербайджана с древних времен. В последние 40-50 лет развитие чайных и других хозяйств, а также быстрый рост населения привели к резким изменениям в природе Ленкоранчайского бассейна и, как следствие, произошли кардинальные изменения в почвенном покрове.

Проведение экологического мониторинга показателей плодородия почв, прежде всего, требует правильного выбора этих показателей для наблюдений. Показатели плодородия являются факторами, влияющими на продуктивность окружающей среды, в том числе отдельные сельскохозяйственные и природные биоценозы почвы [8].

Изменчивость основных показателей плодородия, влияющих на развитие растительности в бассейне, представлена в следующих блоках по выделенным экологическим районам: блок агроэкологии, блок агрофизики, блок состава и свойств почвы, блок агрохимических свойств $[1,4]$.

Площадь водораздельного экологического района составляет 20258 га, или 19,5\% от общей площади бассейна. В зависимости от рельефа, растительности, климатических 
условий и почвообразующих пород, в этом регионе в основном распространены следующие типы почв.

Таблица 1

БЛОК АГРОФИЗИКИ ПОЧВ ВОДОРАЗДЕЛЬНОГО ЭКОЛОГИЧЕСКОГО РАЙОНА

\begin{tabular}{|c|c|c|c|c|c|c|}
\hline Почвbl & \multicolumn{3}{|c|}{ Горно-луговые степные } & \multicolumn{3}{|c|}{ Горные светло-каштановые } \\
\hline & старая & новая & & старая & новая & \\
\hline Показатели плодородия & $\begin{array}{c}\text { модель } \\
1985-1990\end{array}$ & $\begin{array}{c}\text { модель } \\
\text { 2014-2019 }\end{array}$ & разница & $\begin{array}{c}\text { модель } \\
1985-1990\end{array}$ & $\begin{array}{c}\text { модель } \\
\text { 2014-2019 }\end{array}$ & разница \\
\hline 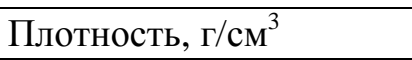 & 1,05 & 1,12 & $+0,07$ & 1,21 & 1,31 & $+0,10$ \\
\hline Пористость, \% & 54,15 & 50,12 & $-4,03$ & 49,57 & 46,25 & $-3,32$ \\
\hline $\begin{array}{l}\text { Водопрочные агрегаты } \\
\text { (>0,25 мм), \% }\end{array}$ & 65,53 & 58,41 & $-7,12$ & 60,50 & 54,20 & $-6,30$ \\
\hline $\begin{array}{l}\text { Физическая глина } \\
(<0,01 \text { мм), \% }\end{array}$ & 40,94 & 39,01 & $-1,93$ & 32,40 & 30,89 & $-1,51$ \\
\hline Шлам (<0,001 мм), \% & 19,66 & 16,25 & $-3,41$ & 14,47 & 11,95 & $-2,52$ \\
\hline Общая влагоемкость, \% & 51,48 & 47,35 & $-4,13$ & 38,41 & 35,20 & $-3,21$ \\
\hline $\begin{array}{l}\text { Водопроницаемость, } \\
\text { мм/мин }\end{array}$ & 3,7 & 3,3 & $-0,4$ & 5,8 & 5,6 & $-0,2$ \\
\hline
\end{tabular}

Таблица 2

БЛОК СТРУКТУРЫ И СВОЙСТВА ПОЧВ ВОДОРАЗДЕЛЬНОГО ЭКОЛОГИЧЕСКОГО РАЙОНА

\begin{tabular}{|c|c|c|c|c|c|c|}
\hline \multirow{2}{*}{$\begin{array}{c}\text { Почвы } \\
\text { Показатели } \\
\text { плодородия }\end{array}$} & \multicolumn{3}{|c|}{ Горно-луговые степные } & \multicolumn{3}{|c|}{ Горные светло-каштановые } \\
\hline & $\begin{array}{c}\text { старая } \\
\text { модель } \\
1985-1990\end{array}$ & $\begin{array}{c}\text { новая } \\
\text { модель } \\
2014-2019\end{array}$ & разница & $\begin{array}{c}\text { старая } \\
\text { модель } \\
1985-1990\end{array}$ & $\begin{array}{c}\text { новая } \\
\text { модель } \\
2014-2019\end{array}$ & разниияа \\
\hline $\begin{array}{l}\text { Количество } \\
\text { гумуса, \% }\end{array}$ & 2,9 & 1,5 & $-1,4$ & 2,0 & 1,2 & $-0,8$ \\
\hline $\begin{array}{l}\text { Запас гумуса, т/га } \\
0-20 \text { см } \\
0-50 \text { см } \\
0-100 \text { см }\end{array}$ & $\begin{array}{l}104,1 \\
176,8 \\
231,3\end{array}$ & $\begin{array}{c}36,5 \\
78,0 \\
153,6\end{array}$ & $\begin{array}{l}-67,6 \\
-72,8 \\
-77,7\end{array}$ & $\begin{array}{c}75,0 \\
126,0 \\
174,2\end{array}$ & $\begin{array}{c}38,7 \\
75,6 \\
134,0\end{array}$ & $\begin{array}{l}-36,3 \\
-50,4 \\
-40,2\end{array}$ \\
\hline Общий азот, \% & 0,31 & 0,25 & $-0,06$ & 0,15 & 0,08 & $-0,07$ \\
\hline Общий фосфор, \% & 0,08 & 0,05 & $-0,03$ & 0,09 & 0,07 & $-0,02$ \\
\hline Общий калий, \% & 1,91 & 1,75 & $-0,16$ & 2,81 & 2,70 & $-0,11$ \\
\hline $\begin{array}{l}\text { Сумма } \\
\text { поглощенных } \\
\text { оснований, в } 100 \text { г } \\
\text { почве мг.экв. }\end{array}$ & 49,36 & 41,64 & $-7,72$ & 27,67 & 23,50 & $-4,17$ \\
\hline $\mathrm{Ca}+\mathrm{Mg}, \%$ & 98,16 & 96,39 & $-1,77$ & 98,00 & 95,08 & $-2,92$ \\
\hline $\begin{array}{l}\mathrm{pH}, \text { в водном } \\
\text { растворе }\end{array}$ & 7,1 & 7,4 & $+0,3$ & 7,7 & 8,1 & $+0,4$ \\
\hline
\end{tabular}

Количество показателей плодородия почв в водораздельном экологическом районе значительно снизилось по сравнению с предыдущим периодом. Основной причиной снижения плодородия стал выпас скота в этом районе. Таким образом, растительность в этом районе не вносит значительного вклада в накопление гумуса в почве и не играет важной роли в предотвращении эрозии на склонах.

Следует отметить, что большинство процессов эрозии почвы в бассейне, которые оказывают наибольшее влияние на снижение плодородия почв, были исследованы многими учеными. На основании этих исследований, можно прийти к выводу, что если раньше эрозия составляла 25,70\% территории, то теперь эта цифра увеличилась на 11,61\%, 37,31\%. 
В пределах Ленкоранчайского бассейна площадь транзитного экологического района составляет 70976 га, 68,2\% от общей площади. В зависимости от климатических условий, рельефа, растительного покрова и почвообразующих пород, почвенный покров здесь разный. В транзитном экологическом районе распространены следующие типы почв: горно-лесная коричневые, горно-лесные желтые и псевдоподзольные желтые [9].

Таблица 3

БЛОК АГРОФИЗИКИ ПОЧВ ТРАНЗИТНОГО ЭКОЛОГИЧЕСКОГО РАЙОНА

\begin{tabular}{|c|c|c|c|c|c|c|c|c|c|}
\hline \multirow{2}{*}{$\begin{array}{c}\text { Почвы } \\
\\
\text { Показатели } \\
\text { плодородия }\end{array}$} & \multicolumn{3}{|c|}{ Горно-лесные коричневые } & \multicolumn{3}{|c|}{ Горно-лесные желтые } & \multicolumn{3}{|c|}{$\begin{array}{c}\text { Псевдоподзольные } \\
\text { желтые }\end{array}$} \\
\hline & 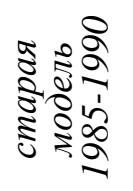 & 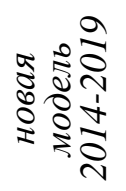 & 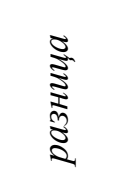 & 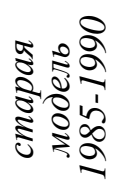 & 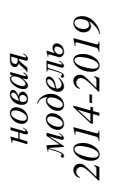 & 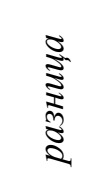 & 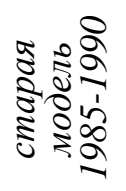 & 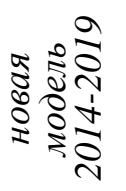 & 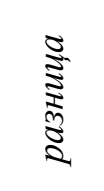 \\
\hline 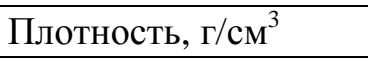 & 1,12 & 1,20 & $+0,08$ & 1,23 & 1,27 & $+0,04$ & 1,29 & 1,34 & $+0,05$ \\
\hline Пористость, \% & 56,50 & 52,37 & $-4,13$ & 56,13 & 53,44 & $-2,69$ & 54,20 & 50,22 & $-3,98$ \\
\hline $\begin{array}{l}\text { Водопрочные } \\
\text { агрегаты (>0,25 мм), } \\
\%\end{array}$ & 58,32 & 60,68 & $-7,64$ & 61,45 & 54,77 & $-6,68$ & 59,88 & 53,56 & $-6,32$ \\
\hline $\begin{array}{l}\text { Физическая глина } \\
(<0,01 \text { мм), \% }\end{array}$ & 59,18 & 58,77 & $-0,41$ & 58,72 & 58,01 & $-0,71$ & 57,28 & 57,12 & $-0,16$ \\
\hline $\begin{array}{l}\text { Шлам }(<0,001 \text { мм), } \\
\%\end{array}$ & 38,66 & 37,10 & $-1,56$ & 30,48 & 29,12 & $-1,36$ & 26,36 & 25,12 & $-1,24$ \\
\hline $\begin{array}{l}\text { Общая } \\
\text { влагоемкость, \% }\end{array}$ & 34,27 & 30,22 & $-4,05$ & 37,59 & 33,76 & $-3,83$ & 35,33 & 32,23 & $-3,10$ \\
\hline $\begin{array}{l}\text { Водопроницаемость, } \\
\text { мм/мин }\end{array}$ & 6,70 & 6,10 & $-0,60$ & 2,30 & 1,80 & $-0,50$ & 1,40 & 0,60 & $-0,80$ \\
\hline
\end{tabular}

Таблица 4

БЛОК СТРУКТУРЫ И СВОЙСТВА ПОЧВ ТРАНЗИТНОГО ЭКОЛОГИЧЕСКОГО РАЙОНА

\begin{tabular}{|c|c|c|c|c|c|c|c|c|c|}
\hline \multirow{2}{*}{$\begin{array}{c}\text { Почвы } \\
\\
\text { Показатели } \\
\text { плодородия }\end{array}$} & \multicolumn{3}{|c|}{ Горно-лесные коричневые } & \multicolumn{3}{|c|}{ Горно-лесные желтые } & \multicolumn{3}{|c|}{$\begin{array}{c}\text { Псевдоподзольные } \\
\text { желтые }\end{array}$} \\
\hline & 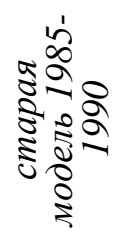 & 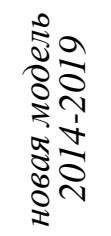 & 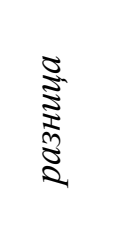 & 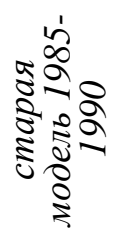 & 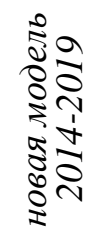 & 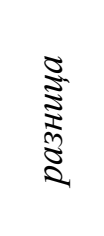 & 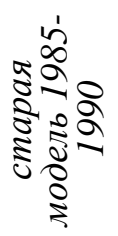 & 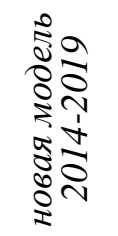 & 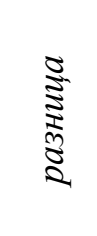 \\
\hline $\begin{array}{l}\text { Количество } \\
\text { гумуса, \% }\end{array}$ & 2,7 & 2,0 & $-0,7$ & 3,1 & 2,5 & $-0,6$ & 2,4 & 1,9 & $-0,5$ \\
\hline \multicolumn{10}{|l|}{$\begin{array}{l}\text { Запас гумуса, } \\
\text { т/га }\end{array}$} \\
\hline $0-20$ см & 100,6 & 66,3 & $-34,3$ & 130,4 & 101,7 & $-28,7$ & 105,8 & 79,4 & $-26,4$ \\
\hline $0-50 \mathrm{~cm}$ & 145,6 & 112,0 & $-33,6$ & 199,9 & 161,2 & $-38,7$ & 154,8 & 132,1 & $-22,7$ \\
\hline $0-100 \mathrm{~cm}$ & 181,5 & 157,3 & $-24,2$ & 236,3 & 200,1 & $-36,2$ & 211,3 & 196,6 & $-14,7$ \\
\hline $\begin{array}{l}\text { Общий азот, } \\
\%\end{array}$ & 0,15 & 0,13 & $-0,02$ & 0,19 & 0,14 & $-0,05$ & 0,17 & 0,13 & $-0,04$ \\
\hline $\begin{array}{l}\text { Общий } \\
\text { фосфор, \% }\end{array}$ & 0,16 & 0,14 & $-0,02$ & 0,20 & 0,17 & $-0,03$ & 0,16 & 0,13 & $-0,03$ \\
\hline $\begin{array}{l}\text { Общий } \\
\text { калий, \% }\end{array}$ & 2,60 & 2,47 & $-0,13$ & 3,62 & 3,48 & $-0,14$ & 2,55 & 2,42 & $-0,13$ \\
\hline
\end{tabular}




\begin{tabular}{|c|c|c|c|c|c|c|c|c|c|}
\hline \multirow{2}{*}{$\begin{array}{c}\text { Почвы } \\
\\
\text { Показатели } \\
\text { плодородия }\end{array}$} & \multicolumn{3}{|c|}{ Горно-лесные коричневые } & \multicolumn{3}{|c|}{ Горно-лесные желтые } & \multicolumn{3}{|c|}{$\begin{array}{c}\text { Псевдоподзольные } \\
\text { желтые }\end{array}$} \\
\hline & 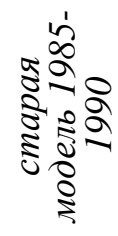 & 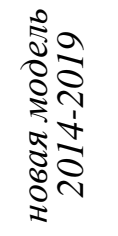 & 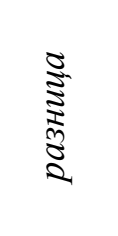 & 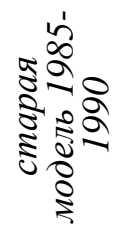 & 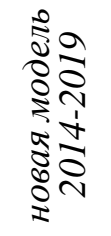 & 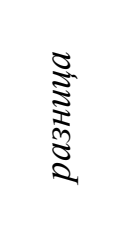 & 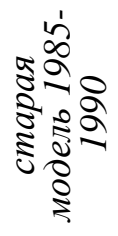 & 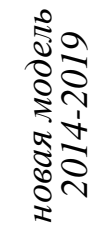 & 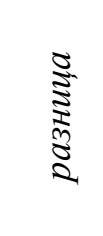 \\
\hline $\begin{array}{l}\text { Сумма } \\
\text { поглощенных } \\
\text { оснований, в } \\
100 \text { г почве } \\
\text { мг.экв. }\end{array}$ & 28,72 & 22,56 & $-6,16$ & 31,44 & 27,70 & $-3,74$ & 26,62 & 23,10 & $-3,62$ \\
\hline $\mathrm{Ca}+\mathrm{Mg}, \%$ & 96,70 & 94,60 & $-2,10$ & 97,28 & 94,47 & $-2,81$ & 95,80 & 92,65 & $-3,15$ \\
\hline $\mathrm{Na}, \%$ & 2,50 & 4,20 & $+1,70$ & - & - & - & - & - & - \\
\hline $\mathrm{Al}, \%$ & - & - & - & 0,68 & 0,93 & $+0,25$ & 0,75 & 1,03 & $+0,28$ \\
\hline $\begin{array}{l}\mathrm{pH}, \text { в водном } \\
\text { растворе }\end{array}$ & 6,7 & 7,3 & $+0,6$ & 6,0 & 5,3 & $-0,7$ & 5,9 & 5,1 & $-0,8$ \\
\hline $\begin{array}{l}\mathrm{pH}, \text { в солевом } \\
\text { растворе }\end{array}$ & 5,7 & 6,2 & $+0,5$ & 4,9 & 4,4 & $-0,5$ & 4,8 & 4,2 & $-0,6$ \\
\hline
\end{tabular}

Таким образом, сравнительный характер показателей плодородия почв транзитного экологического района показывает, что произошло некоторое изменение плодородия почв этого экологического района. Есть много факторов, которые влияют на это изменение. Так как, почвы транзитного экологического района ранее были в значительной степени покрыты лесами (59000 га). Впоследствии леса оставались для снабжения дровами и для развития новых областей сельского хозяйства, которое было сокращено на $30 \%$ до 41300 га. В площадях очищенных от лесов были развиты кустарники и травы, а другие части использовались под сельскохозяйственные культуры. В отличие от лесов, это имело менее почвозащитное свойство. Климат, растительный покров, агротехнические мероприятия и другие факторы повлияли на плодородие почв транзитного экологического района. В то же время возделывание почв под сельскохозяйственные культуры без соблюдения противоэрозионных мер привело к снижению плодородия этих земель.

Таблица 5

БЛОК АГРОФИЗИКИ ПОЧВ АККУМУЛЯТИВНОГО ЭКОЛОГИЧЕСКОГО РАЙОНА

\begin{tabular}{|c|c|c|c|c|c|c|}
\hline Почвы & \multicolumn{3}{|c|}{$\begin{array}{c}\text { Oромаемые псевдоподзольные } \\
\text { глеевые желтые }\end{array}$} & \multicolumn{3}{|c|}{ Окультуренные лугово-болотные } \\
\hline & старая & новая & & старая & новая & \\
\hline Показатели плодородия & $\begin{array}{c}\text { модель } \\
1985-1990\end{array}$ & $\begin{array}{c}\text { модель } \\
2014-2019\end{array}$ & разницุа & $\begin{array}{c}\text { модель } \\
1985-1990\end{array}$ & $\begin{array}{c}\text { модель } \\
2014-2019\end{array}$ & разница \\
\hline Плотность, г/см ${ }^{3}$ & 1,30 & 1,34 & $+0,04$ & 1,13 & 1,15 & $+0,02$ \\
\hline Пористость, \% & 55,23 & 53,44 & $-1,79$ & 57,55 & 56,10 & $-1,45$ \\
\hline $\begin{array}{l}\text { Водопрочные агрегаты } \\
\text { (>0,25 мм), \% }\end{array}$ & 52,12 & 49,10 & $-3,02$ & 67,95 & 69,65 & $+1,70$ \\
\hline $\begin{array}{l}\text { Физическая глина } \\
\text { (<0,01 мм), \% }\end{array}$ & 53,01 & 53,47 & $+0,46$ & 46,15 & 46,86 & $+0,71$ \\
\hline Шлам (<0,001 мм), \% & 27,71 & 29,01 & $+1,30$ & 27,87 & 29,37 & $+1,50$ \\
\hline Общая влагоемкость, \% & 30,23 & 27,65 & $-2,58$ & 38,92 & 37,30 & $-1,62$ \\
\hline $\begin{array}{l}\text { Водопроницаемость, } \\
\text { мм/мин }\end{array}$ & 1,3 & 0,6 & $-0,7$ & 0,3 & 0,8 & $+0,5$ \\
\hline
\end{tabular}


Площадь аккумулятивного экологического района составляет 12766 га, 12,3\% от общей площади бассейна. В зависимости от климатических условий, рельефа, растительности и почв, а также многолетней хозяйственной деятельности региона распространены следующие типы почв: орошаемые псевдоподзольные-глеевые-желтые, окультуренные лугово-болотные.

Таблица 6 БЛОК СТРУКТУРЫ И СВОЙСТВА ПОЧВ АККУМУЛЯТИВНОГО ЭКОЛОГИЧЕСКОГО РАЙОНА

\begin{tabular}{|c|c|c|c|c|c|c|}
\hline \multirow{2}{*}{$\begin{array}{c}\text { Почвы } \\
\begin{array}{l}\text { Показатели } \\
\text { плодородия }\end{array}\end{array}$} & \multicolumn{3}{|c|}{$\begin{array}{c}\text { Орошаемые псевдоподзольные глеевые } \\
\text { желтые }\end{array}$} & \multicolumn{3}{|c|}{ Окультуренные лугово-болотные } \\
\hline & $\begin{array}{c}\text { старая } \\
\text { модель } \\
1985-1990\end{array}$ & $\begin{array}{c}\text { новая } \\
\text { модель } \\
2014-2019\end{array}$ & разница & $\begin{array}{c}\text { старая } \\
\text { модель } \\
1985-1990\end{array}$ & $\begin{array}{c}\text { новая } \\
\text { модель } \\
2014-2019\end{array}$ & разница \\
\hline $\begin{array}{l}\text { Количество } \\
\text { гумуса, \% }\end{array}$ & 2,3 & 1,9 & $-0,4$ & 3,8 & 3,5 & $-0,3$ \\
\hline $\begin{array}{l}\text { Запас гумуса, т/га } \\
0-20 \text { см } \\
0-50 \text { см } \\
0-100 \text { см }\end{array}$ & $\begin{array}{c}89,9 \\
150,4 \\
203,8\end{array}$ & $\begin{array}{c}72,8 \\
132,1 \\
177,5 \\
\end{array}$ & $\begin{array}{l}-17,1 \\
-18,3 \\
-26,3\end{array}$ & $\begin{array}{l}112,9 \\
220,4 \\
315,8\end{array}$ & $\begin{array}{c}96,4 \\
203,0 \\
291,6\end{array}$ & $\begin{array}{l}-16,5 \\
-17,4 \\
-24,2\end{array}$ \\
\hline Общий азот, \% & 0,15 & 0,12 & $-0,03$ & 0,20 & 0,17 & $-0,03$ \\
\hline Общий фосфор, \% & 0,18 & 0,15 & $-0,03$ & 0,21 & 0,19 & $-0,02$ \\
\hline Общий калий, \% & 2,58 & 2,47 & $-0,11$ & 2,90 & 2,81 & $-0,09$ \\
\hline $\begin{array}{l}\text { Сумма } \\
\text { поглощенных } \\
\text { оснований, в } 100 \text { г } \\
\text { почве мг.экв. }\end{array}$ & 27,81 & 23,68 & $-4,13$ & 28,49 & 25,11 & $-3,38$ \\
\hline $\mathrm{Ca}+\mathrm{Mg}, \%$ & 96,22 & 92,85 & $-3,37$ & 98,67 & 97,58 & $-1,09$ \\
\hline $\mathrm{Al}, \%$ & 0,73 & 1,03 & $+0,30$ & 0,25 & 0,36 & $+0,11$ \\
\hline $\begin{array}{l}\mathrm{pH}, \text { в водном } \\
\text { растворе }\end{array}$ & 5,7 & 5,3 & $-0,4$ & 6,5 & 6,3 & $-0,2$ \\
\hline $\begin{array}{l}\mathrm{pH}, \text { в солевом } \\
\text { растворе }\end{array}$ & 4,8 & 4,4 & $-0,4$ & 5,6 & 5,4 & $-0,2$ \\
\hline
\end{tabular}

Сравнительная характеристика показателей плодородия почв аккумулятивного экологического района показывает, что, как и на водораздельных и транзитных почвах экологических районов, наблюдается снижение плодородия. Однако территория аккумулятивного экологического района пострадала меньше, чем в предыдущий период.

\section{Заключение}

В горных и предгорных районах Ленкоранчайского бассейна из-за сокращения лесного покрова в реке происходит больше наводнений, что способствует эрозии почв бассейна. За последние годы загрязнение воды в Ленкоранчае показывает, что как водораздельные, так и транзитные экологические районы бассейна были подвержены эрозии, и плодородие почвы значительно снизилось по сравнению с почвами аккумулятивного экологического района [10].

Таким образом, на основании современных исследований можно показать, что в результате природных факторов и деятельности человека, исследуемые почвы претерпели глубокие изменения. В условиях влажного субтропического климата во время хозяйственной деятельности человека произошли более резкие изменения в почвах. Эти изменения произошли в основном в районах, где развито сельское хозяйство и животноводство. В некоторых случаях агротехнические мероприятия привели к ускорению физических, физико- 
химических процессов в почве и изменениям показателей плодородия за 40-50 лет. Эти изменения проявились главным образом в количестве и в запасе гумуса, который является основным показателем плодородия почвы.

\section{Список литературь:}

1. Мамедова С. 3., Шабанов Дж. А., Кулиев М. Б. Экологический мониторинг почв Ленкоранчайского бассейна. Баку. 2005. 167 с.

2. Мамедов Г. Ш. Агроэкологические особенности и бонитировки почв Азербайджана. Баку. 1990. 170 с.

3. Мамедов Г. Ш. Экологическая оценка почв сельскохозяйственных и лесных угодий Азербайджана: Автореф. .. дисс. д-ра биол. наук. Днепропетровск. 1991. 23 с.

4. Мамедова С. 3. Почвы Ленкоранской области и их экологическая оценка // Сохраним Планету Земля: международный экологический форум. СПб. 2004. С. 173-176.

5. Джафаров А. Б., Раджабова С. Б., Гасанова А. Ф., Шабанов Д. А., Юсифова М. М. Разработка моделей высокого плодородия антропогенных почв Азербайджана // Проблемы антропогенного почвообразования: международная конференция. М. 1997. С. 73-75.

6. Алиев Ф. Ш. Почвы реликтовых лесов Ленкоранской субтропической области и их охрана: Автореф... дисс. канд. с.-х. наук. Баку. 1994. 23 с.

7. Абдинов М. М., Байрамов Г. Г., Керимов Н. Б. Комплексная мелиорация переувлажненных почв Ленкоранской зоны Азербайджанской ССР. Баку. 1986. 7 с.

8. Залова Р. Б. Экологическая характеристика и оценка почв высокогорной части бассейнов рек Гарачай и Вельвеличай // Известия высших учебных заведений. СевероКавказский регион. Естественные науки. 2012. №3. С. 68-70.

9. Абдуллаева Г. М. Экологическая оценка и мониторинг почв бассейнов ГусарчайГудиалчай : автореф. дис. ... канд. биол. наук. Баку, 2009. 20 с.

10. Shabanov J. A. The Ecological Control over Productivity Parameters of Some River Basins of Azerbaijan // Agricultural and Biological Sciences Journal. 2015. V. 1. №3. P. 110-112.

\section{References:}

1. Mamedova, S. Z., Shabanov, Dzh. A., \& Kuliev, M. B. (2005). Ekologicheskii monitoring pochv Lenkoranchaiskogo basseina. Baku. 167. (in Russian).

2. Mamedov, G. Sh. (1990). Agroekologicheskie osobennosti i bonitirovki pochv Azerbaidzhana. Baku. 170. (in Russian).

3. Mamedov, G. Sh. (1991). Ekologicheskaya otsenka pochv sel'skokhozyaistvennykh i lesnykh ugodii Azerbaidzhana: Avtoref. .. diss. d-ra biol. nauk. Dnepropetrovsk. 23. (in Russian).

4. Mamedova, S. Z. (2004). Pochvy Lenkoranskoi oblasti i ikh ekologicheskaya otsenka. In Sokhranim Planetu Zemlya: mezhdunarodnyi ekologicheskii forum. St. Petersburg. 173-176. (in Russian).

5. Dzhafarov, A. B., Radzhabova, S. B., Gasanova, A. F., Shabanov, D. A., \& Yusifova, M. M. (1997). Razrabotka modelei vysokogo plodorodiya antropogennykh pochv Azerbaidzhana. In Problemy antropogennogo pochvoobrazovaniya: mezhdunarodnaya konferentsiya, Moscow. 73-75. (in Russian).

6. Aliev, F. Sh. (1994). Pochvy reliktovykh lesov Lenkoranskoi subtropicheskoi oblasti i ikh okhrana: Avtoref... diss. kand. s.-kh. nauk. Baku. 23. (in Russian).

7. Abdinov, M. M., Bairamov, G. G., \& Kerimov, N. B. (1986). Kompleksnaya melioratsiya pereuvlazhnennykh pochv Lenkoranskoi zony Azerbaidzhanskoi SSR. Baku. 7. (in Russian). 
8. Zalova, R. B. (2012). Ekologicheskaya kharakteristika i otsenka pochv vysokogornoi chasti basseinov rek Garachai i Vel'velichai. Izvestiya vysshikh uchebnykh zavedenii. Severo-Kavkazskii region. Estestvennye nauki, (3). 68-70.

9. Abdullaeva, G. M. (2009). Ekologicheskaya otsenka i monitoring pochv basseinov Gusarchai-Gudialchai : avtoref. dis. ... kand. biol. nauk. Baku, 20. (in Russian).

10. Shabanov, J. A. (2015). The Ecological Control over Productivity Parameters of Some River Basins of Azerbaijan. Agricultural and Biological Sciences Journal, 1(3). 110-112.

Работа поступила

в редакцию 15.01.2020 г.
Принята к публикации 20.01.2020 2.

Ссылка для циттирования:

Мамедова С. 3. Экологический мониторинг почв Ленкоранчайского бассейна по районам // Бюллетень науки и практики. 2020. Т. $6 . \quad$ №2. С. 143-150. https://doi.org/10.33619/2414-2948/51/13

Cite as (APA):

Mamedova, S. (2020). Ecological Monitoring of Soils of the Lenkoranchay Basin by Region. Bulletin of Science and Practice, 6(2), 143-150. https://doi.org/10.33619/2414-2948/51/13 (in Russian). 


\title{
ВЛИЯНИЕ ОРГАНИЧЕСКИХ И МИНЕРАЛЬНЫХ УДОБРЕНИЙ НА НАКОПЛЕНИЕ АЗОТА, ФОСФОРА И КАЛИЯ В НАДЗЕМНОЙ ЧАСТИ ЛЮЦЕРНЫ ПРИ ПОКРЫТОМ ПОСЕВЕ
}

(САллахвердиев Э. Р., канд. с.-х. наук, Государственный аграрный университет, г. Гянджа, Азербайджан

\section{IMPACT OF ORGANIC AND MINERAL FERTILIZERS ON GATHERING OF TOTAL NITROGEN, PHOSPHORUS AND POTASSIUM IN SURFACE MASS OF LUCERNE IN COATED PLANTING}

\author{
CAllahverdiev E., Ph.D., Azerbaijan State Agrarian University, \\ Ganja Azerbaijan
}

Аннотация. В статье рассмотрены вопросы влияния органических и минеральных удобрений на накопления общего азота, фосфора и калия в надземной фитомассе в покрытых полях, на слабо обеспеченных питательными веществами давно орошаемых сероземнолуговых почвах Карабахской области. Обеспеченность питательными веществами растений за вегетационный период, непосредственно зависит от продуктивности, качества урожая и запасов усвояемых форм питательных веществ. С целью получения высоких и устойчивых урожаев необходимо ежегодное внесение в почву органических и минеральных удобрений на основе почвенных картограмм и соблюдение правил агротехники. Благоприятный питательный режим для люцерны зависит от оптимизации норм удобрений при различных нормах и видах полива. Наибольшие значения общего NPK приходятся на первый укос и снижаются в последующих. При каждом укосе в надземной массе растений наличие азота, фосфора и калия пониженное. Наблюдались высокие показатели NPK по укосам люцерны на 2 и 3-й годы, что связано азотофиксирующей способностью люцерны и способностью повышения плодородия почв. Оно также влияет регулированию питательных веществ по укосам в надземной массе люцерны.

Abstract. The problems of impact of organic and mineral fertilizers on gathering of total nitrogen, phosphorus and potassium in the lucerne surface mass in coating planting of the greymeadow soils which are weakly provided with the nutrient under the condition of Karabakh region were commented. Provision of plants with the main nutrient during the vegetation, productivity, crop quality depends on supply of the nutrient which is easily assimilated. In order to get high yields from agricultural plants, the organic and mineral fertilizers must be applied to a norm which was fixed on the basis of soil cartograms, the cultivation agrotechnics must be correctly fulfilled every year. The good food regime for the lucerne depends on optimization of fertilizer norms in different irrigation. The highest quantity of total NPK was observed in the first mowing, but it reduced in the next mowing's. Nitrogen and potassium is high in each of the mowing's, but phosphorus is little on the surface mass. This is due to increase of the nutrient quantity of lucerne and soil fertility. This positively influences on nutrient regulation on the surface mass over the mowing's in lucerne plant. 
Ключевые слова: люцерна, органические удобрения, минеральные удобрения, надземная масса, покрытый посев, экологический урожай, качественные показатели.

Keywords: lucerne, organic fertilizers, mineral fertilizers, surface mass, coating planting, ecological product, quality indicators.

\section{Введение}

Поглотительная способность питательных веществ растительностью зависит от биолгических свойств растений, водно-физических свойств почв, потенциального уровня плодородия почв, соединений органических и минеральных элементов с органическими веществами в почве, гранулометрического состава почв, водно-температурного и влажностного режимов почв, реакции среды, освященности и других естественных факторов. Использование растениями калием, кальцием и фосфором в ночное время уменьшается 1,5-3 раз. В связи, с чем следует анализировать потребности растений к удобрениям и учитывать физиологические, биохимические механизмы поглотительной способности растений и их зависимость от почвенно-климатических условий.

Обеспеченность питательными веществами растений за вегетационный период, зависит от плодородия и запасов легко освояемых форм питательных веществ. С целью получения высоких и устойчивых урожаев сельскохозяйственных культур, необходимо на основе соответствующих картограмм внесение органических и минеральных удобрений и соблюдение агротехники.

Итак, внесение минеральных и органических удобрений способствуют увеличению количества азота, фосфора, калия, кальция, магния и других веществ в растениях, что в свою очередь отражается на урожайности [1].

\section{Анализ и результатьл}

Основными элементами в питании растений являются азот, фосфор и калий. При нехватки азота листья приобретают светло зеленую окраску и в результаты развитие растения приостанавливается. Азот содержится в составе белковых веществ. По мнению Энгельса нельзя представить белок без азота и жизнь без белка. По литературным источникам 16-18\% веса белка составляет азот. Проникая в состав хлорофиллов, аминокислот и ферментов, азот составляет основу протоплазмы. Он также существует в составе нуклеиновых кислот, играющих существенную роль в обмене веществ в организме.

Основным источником питания азотом растений, являются нитраты и аммиачные соли. Наряду с этим растения поглощают из почвы также аминокислоты и амиды. Поглощенные растением азот, при участии органических кислот создает аминокислоты, что в свою очередь используется в синтезе белка.

Одной из важных элементов в жизнедеятельности растений является также фосфор, без которого не возможно существование не только высших, но и простейших растений. Обмен большинства синтетических веществ происходит с участием фосфора. Часть поступивщего в растения фосфора — в виде органических, а другая — в виде минеральных соединений.

Калий, как следующий питательный элемент играет существенную роль в нормальном протекании процессе фотосинтеза и оказывает влияние синтезу сахарозы, образованию крахмала, твердости стебля, морозоустойчивости и усилению азото потреблению растением [2].

С развитием животновоства пропорционально увеличивается потребность в кормовой базе. Всвязи с чем бобвые культуры, как основной источник белка имеет огромное значение. 
Нехватка протеина в кормах отражается на снижении продуктивности и нерациональному использованию кормов. В сухой массе люцерны содержится примерно $22 \%$ протеина. Помимо этого в составе люцерны имеются каротин, витамин В, аскорбиновая кислота, макро и микроэлементы, что свидетельствует на важность люцерны, как питательной кормовой культуры.

Проведенные в Гянджа-Газахской зоне исследования подтверждают уменьшение в составе люцерны NPK по укосам, т.к. в варианте контроль б/у в первом году развития люцерны NPK соответственно составил $2,49 \% ; 0,68 \%$ и $2,10 \%$, во втором укосе - 2,33\%; $0,65 \% ; 1,76 \%$, в третьем укосе - $2,12 \% ; 0,58 \%$ и $1,66 \%$, что свидетельствует о увеличении с внесением в почвы минеральных удобрений.

Наибольшие нзачения NPK приходится в вариант 10 т/га+ $\mathrm{P}_{65}$, где по отношению к контролю в первом укосе наличие общего азота составила $0,30 \%$, общего фосфора $0,07 \%$ и калия $0,04 \%$. Во втором и третьем укосах данные показатели соответственно составили 0,22 $0,28 \% ; 0,07-0,10 \% ; 0,05-0,08 \%$ [3].

Внесение минеральных удобрений наряду с увеличиваем наличия питательных веществ в корнях и зеленой массе растений, высокие дозы фосфора и калия способствуют нейтрализации высоких и лишних соединений азота в растениях [4 ].

Накопление в растениях питательных элементов зависит от наличия их в почве и состава и доз внесенных минеральных удобрений. При отсутствии фосфора и калия, или их содержания в незначительном количестве увеличение доз азотных удобрений, способствует уменьшених калия, фосфора, кальция и магния в растении наоборот увеличению натрия. [5, $6]$.

Данные Г. А. Аслонова также утверждают, что наибольшая величина фосфора в люцерне наблюдается при первом укосе и уменьшается в последующих укосах [8].

Возделывание люцерны улучшает физические, биологические и агрохимические свойства почв, снижая затраты на приобретение азотных удобрений. Внесение минеральных удобрений в дозе $(\mathrm{NPK})_{30}$ увеличивает количество азота и фосфора в зеленой массе. Так, в варианте контроль содержание азота 2,6\%, фосфора 0,68-0,76\%, а при внесении минеральных удобрений их содержание возросло, составляя 2,81-2,90\%, и 0,86-0,97\% [9-11].

Проведенные исследования в Карабахской области на слабо обеспеченных питательными элементами сероземно-луговых почвах, после жатвы зерновых и применением поливов, проводились опыты с посевами люцерны. Изучена динамика накопления питательных веществ в растении и почве.

Результаты подтвердили, что внесение органических и минеральных удобрений, увеличили их количество в растении по укосам (Рисунок 1,2 ).

Так, на контроле с 4 поливами в первом укосе, в надземной фитомассе содержание общего $\mathrm{N}-2,32 \%, \mathrm{P}_{2} \mathrm{O}_{2}-0,60 \%, \mathrm{~K}_{2} \mathrm{O}-1,84 \%$, во II укосе - соответственно $2,38 \%$; $0,64 \% ; 1,97 \%$, в III укосе: $2,42 \% ; 0,66 \% ; 2,10 \%$, в IV укосе: $2,25 \%: 0,59 \%: 1,78 \%$.

В варианте с применением минеральных удобрений в дозе $\mathrm{N}_{30} \mathrm{P}_{90} \mathrm{~K}_{60}$ содержание $\mathrm{NPK}$ по укосам составила:

I укос: $\mathrm{N}-2,49 \%, \mathrm{P}_{2} \mathrm{O}_{2}-0,62 \%, \mathrm{~K}_{2} \mathrm{O}-1,89 \%$,

II укос: $2,46 \% ; 0,65 \% ; 2,11 \%$,

III укос: $2,47 \% ; 0,68 \% ; 2,21 \%$,

IV укос: $2,00 \% ; 0,67 \% ; 2,10 \%$.

При дозе минеральных удобрений $\mathrm{N}_{45} \mathrm{P}_{120} \mathrm{~K}_{90}$ в растении $\mathrm{N} ; \mathrm{P}_{2} \mathrm{O}_{5} ; \mathrm{K}_{2} \mathrm{O}$ возрасло соответственно составляя:

І укос: 2,55\%; 0,70\%; 1,94\%, 
II укос: $2,48 \% ; 0,66 \% ; 2,07 \%$,

III укос: $2,47 \% ; 0,69 \% ; 2,05 \%$,

IV укос: $2,49 \%$ : $0,69 \% ; 2,54 \%$.

В варианте с внесением новоза 10 т/га показатели соостветственно составили:

I укос: $2,47 \% ; 0,61 \% ; 1,87 \%$,

II укос: $2,44 \% ; 0,63 \% ; 2,00 \%$,

III укос: $2,43 \% ; 0,64 \% ; 2,10 \%$,

IV укос: $2,41 \%$ : $0,65 \% ; 2,00 \%$.

При совместном внесении органических и минеральных удобрений в соотношении новоз $10 \mathrm{~T} / г \mathrm{a}+\mathrm{N}_{15} \mathrm{P}_{65} \mathrm{~K}_{30}$ показатели накоплпения а растении составили:

I укос: $2,51 \% ; 0,66 \% ; 1,91 \%$,

II укос: $2,50 \% ; 0,68 \% ; 2,09 \%$,

III укос: $2,49 \% ; 0,67 \% ; 2,14 \%$,

IV укос: $2,47 \%$ : 0,66\%; 2,09\%.

За период вегетации люцерны проводилаось 5 поливов и получены следующие результаты: в контроле б.у. содержание в надземной фитомассе люцерны общего NPK,

в I укосе: $2,41 \%, 0,63 \%, 1,96 \%$,

в II укосе $2,49 \% ; 0,66 \% ; 2,05 \%$,

в III укосе $2,51 \% ; 0,67 \% ; 2,04 \%$,

в IV укосе 2,41\%: 0,64\%: 1,82\%;

в варианте с применением минеральных удобрений $\mathrm{N}_{30} \mathrm{P}_{90} \mathrm{~K}_{60}$ соответственно порядковой очередности

I укос: $\mathrm{N}-2,54 \%, \mathrm{P}_{2} \mathrm{O}_{2}-0,66 \%, \mathrm{~K}_{2} \mathrm{O}-2,10 \%$,

II укос: $2,53 \% ; 0,68 \% ; 2,19 \%$,

III укос: $2,56 \% ; 0,69 \% ; 2,21 \%$,

IV укос: $2,53 \% ; 0,67 \% ; 1,84 \%$;

при дозе удобрений $\mathrm{N}_{45} \mathrm{P}_{120} \mathrm{~K}_{90}$ :

I укос: 2,79\%; 0,76\%; 2,21\%,

II укос: $2,77 \% ; 0,75 \% ; 2,25 \%$,

III укос: $2,76 \% ; 0,73 \% ; 2,25 \%$,

IV укос: $2,71 \% ; 0,74 \% ; 2,24 \%$.

В данном фоне поливовов в варианте с органическим и минеральными удобрениями новоз 10 т/га содержание питательных элементов в растении составили:

І укос: $2,52 \% ; 0,63 \% ; 2,05 \%$,

II укос: $2,49 \% ; 0,66 \% ; 2,11 \%$,

III укос: $2,47 \% ; 0,67 \% ; 2,09 \%$,

IV укос: $2,48 \%$ : $0,66 \% ; 1,84 \%$;

в варианте новоз 10 т/га $+\mathrm{N}_{15} \mathrm{P}_{65} \mathrm{~K}_{30}$ :

І укос: $2,54 \% ; 0,68 \% ; 2,12 \%$,

II укос: $2,59 \% ; 0,67 \% ; 2,18 \%$,

III укос: $2,57 \% ; 0,68 \% ; 2,19 \%$,

IV укос: $2,54 \%$ : $0,67 \% ; 1,85 \%$.

Из представленных графиков следует, что для люцерны благоприятный питательный режим, при различных режимах полива , является оптимизация норм удобрений (Рисунок 1, 2). 


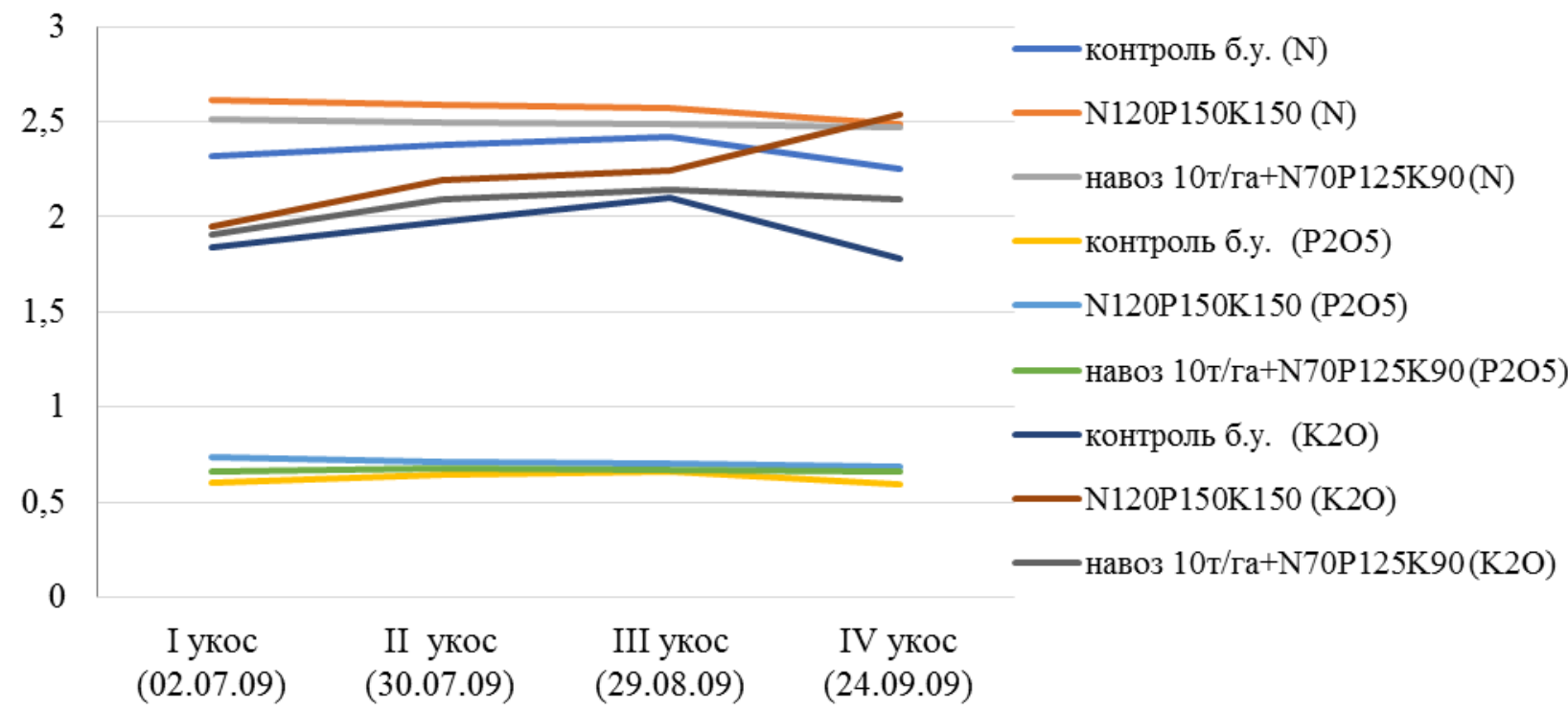

Рисунок 1. Влияние норм поливов и удобрений на накопление питательных элементов в надземной массе ячменя и люцерны (воздушно-сухая масса в \%), при 4 поливах

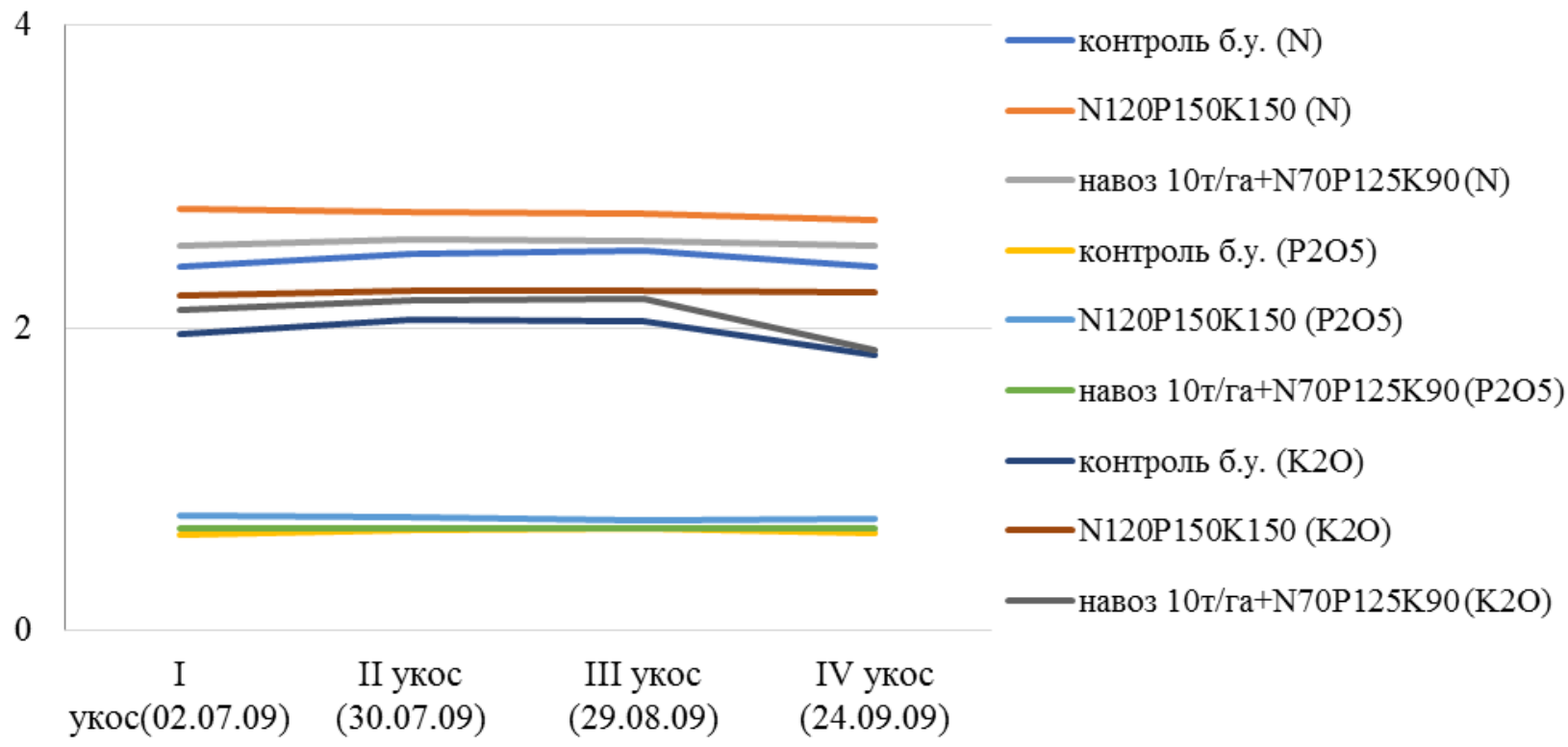

Рисунок 2. Влияние норм поливов и удобрений на накопление питательных элементов в надземной массе ячменя и люцерны (воздушно-сухая масса в \%) при 5 поливах

\section{Bblвod}

В заключении следует отметить, что наибольшое содержание общего NPK в растении по годам выявлено в первом укосе, с последующим их уменьшением.

В надземной фитомассе содержание азота и калия превосходят содержание фосфора.

Наличие общего NPK во 2-3 годах превысило их содержанию по сравнении с первым годом, что связано с возрастанием плодородия почв.

\section{Список литературы:}

1. Аллахвердиев Э. Р. Значение покрытых насаждений // Материалы научнопрактической конференции АГГУ. Гянджа. 2009. С. 34-36.

2. Аллахвердиев Э. Р. Рациональное использование почвы. Гянджа. 2019. 58 с. 
3. Мамедова К. Ю. Влияние удобрений на урожайность люцерны и плодородие малопродуктивных почв Гянджа-Казахской зоны: дисс....канд. с-х. наук. Баку. 2007. 19 с.

4. Гусейнов М. С. Оптимизация азотного питания сахарной свеклы как кормовой культуры на орошаемой светло каштановой почве: дисс....канд. с-х. наук. Гянджа. 1990. 140 c.

5. Бородоев В. В., Костякова А. Н., Пимоков К. И. Агрохимическая оценка применения минеральных удобрений и биоперепаратов при воздельваний нута в Ростовский области // Плодородие. 2018. №1(100). С. 34-37.

6. Корзун О. С., Исаев С. В. Биохимический состав зеленой массы проса и просовидных культур в зависимости от доз минеральных удобрений // Кормопроизводство: технологии, экономика, почвосбережение: сборник материалов. Минск. 2009. С. 220.

7. Гусейнов М. С. Оптимизация азотного питания сахарной свеклы как кормовой культуры на орошаемой светло каштановой почве: дисс. ... канд. с.-х. наук. Гянджа. 1990. 140 c.

8. Осипов М. А Совершенствование системы удобрения люцерны, возделываемой на черноземе выщелоченном Западного Предкавказья: автореферат дис. ... канд. с.-х. наук. Краснодар. 2009. 23 с.

9. Асланов Г. А. Влияние природного цеолита совместно с минеральными удобрениями на орошаемых каштановых почвах по укосам надземной массы люцерны на количество питательных элементов // Вестник регионального научного центра. 2006. №21. С. 61-65.

10. Кулиев В. Ф. Эффективность применения минеральных удобрений под люцерну в условиях Ширванской степи: Автореф: дисс....канд. с-х. наук. Баку. 1985. 24 с.

11. Мамедов Е. Н. Эффективность различных доз и соотношений минеральных удобрений на урожай и качество кормовых культур (кукуруза и люцерна) на эродированных орошаемых сероземах Нахичеванской Автономной Республики: Автореф. дисс....канд. с-х. наук. Баку. 1994. 25 с.

\section{References:}

1. Allakhverdiev, E. R. (2009). Znachenie pokrytykh nasazhdenii. In Materialy nauchnoprakticheskoi konferentsii AGGU. Gyandzha. 34-36. (in Russian).

2. Allakhverdiev, E. R. (2019). Ratsional'noe ispol'zovanie pochvy. Gyandzha. 58.

3. Mamedova, K. Yu. (2007). Vliyanie udobrenii na urozhainost' lyutserny i plodorodie maloproduktivnykh pochv Gyandzha-Kazakhskoi zony: diss....kand. s-kh. nauk. Baku. 19.

4. Guseinov, M. S. (1990). Optimizatsiya azotnogo pitaniya sakharnoi svekly kak kormovoi kul'tury na oroshaemoi svetlo kashtanovoi pochve: diss....kand. s-kh. nauk. Gyandzha. 140. (in Russian).

5. Borodoev, V. V., Kostyakova, A. N., \& Pimokov, K. I. (2018). Agrokhimicheskaya otsenka primeneniya mineral'nykh udobrenii i biopereparatov pri vozdel'vanii nuta $\mathrm{v}$ Rostovskii oblasti. Plodorodie, 1(100). 34-37. (in Russian).

6. Korzun, O. S., \& Isaev, S. V. (2009). Biokhimicheskii sostav zelenoi massy prosa i prosovidnykh kul'tur $\mathrm{v}$ zavisimosti ot doz mineral'nykh udobrenii. In Kormoproizvodstvo: tekhnologii, ekonomika, pochvosberezhenie: sbornik materialov. Minsk. 220. (in Russian).

7. Guseinov, M. S. (1990). Optimizatsiya azotnogo pitaniya sakharnoi svekly kak kormovoi kul'tury na oroshaemoi svetlo kashtanovoi pochve: diss. ... kand. s.-kh. nauk. Gyandzha. 140. (in Russian). 
8. Osipov, M. A (2009). Sovershenstvovanie sistemy udobreniya lyutserny, vozdelyvaemoi na chernozeme vyshchelochennom Zapadnogo Predkavkaz'ya: avtoreferat dis. ... kand. s.-kh. nauk. Krasnodar. 23. (in Russian).

9. Aslanov, G. A. (2006). Vliyanie prirodnogo tseolita sovmestno s mineral'nymi udobreniyami na oroshaemykh kashtanovykh pochvakh po ukosam nadzemnoi massy lyutserny na kolichestvo pitatel'nykh elementov. Vestnik regional'nogo nauchnogo tsentra, (21). 61-65. (in Russian).

10. Kuliev, V. F. (1985). Effektivnost' primeneniya mineral'nykh udobrenii pod lyutsernu v usloviyakh Shirvanskoi stepi: Avtoref: diss....kand. s-kh. nauk. Baku. 24.

11. Mamedov, E. N. (1994). Effektivnost' razlichnykh doz i sootnoshenii mineral'nykh udobrenii na urozhai i kachestvo kormovykh kul'tur (kukuruza i lyutserna) na erodirovannykh oroshaemykh serozemakh Nakhichevanskoi Avtonomnoi Respubliki: Avtoref. diss....kand. s-kh. nauk. Baku. 25. (in Russian).

Работа поступила

в редакцию 08.01.2020 2.
Принята к публикации

19.01.2020 2.

Ссылка для ичитирования:

Аллахвердиев Э. Р. Влияние органических и минеральных удобрений на накопление азота, фосфора и калия в надземной части люцерны при покрытом посеве // Бюллетень науки и практики. 2020. Т. 6. №2. С. 151-157. https://doi.org/10.33619/2414-2948/51/14

Cite as (APA):

Allahverdiev, E. (2020). Impact of Organic and Mineral Fertilizers on Gathering of Total Nitrogen, Phosphorus and Potassium in Surface Mass of Lucerne in Coated Planting. Bulletin of Science and Practice, 6(2), 151-157. https://doi.org/10.33619/2414-2948/51/14 (in Russian). 


\title{
НАУЧНО-ПРАКТИЧЕСКИЕ АСПЕКТЫ ВЕДЕНИЯ ОРГАНИЧЕСКОГО ПРОИЗВОДСТВА ТОМАТОВ В АЗЕРБАЙДЖАНЕ
}

\author{
(СБабаев В. А., канд. с.-х. наук, Институт почвоведения и агрохимии НАН Азербайджана,
} г. Баку, Азербайджан,

\section{SCIENTIFIC-PRACTICAL ASPECTS OF THE ORGANIC TOMATO PRODUCTION IN AZERBAIJAN}

\author{
CBabaev V., Ph.D., Institute of Soil Science and Agrochemistry of Azerbaijan NAS, \\ Baku, Azerbaijan
}

Аннотащия. За последние 50-60 лет удельный вес овощных культур в рационе людей увеличивался, а увеличение спроса привело к росту производства. Так, на долю Китая приходится 31\% из 170 млн тонн томатов, производимых в мире, 11,2\% в Индии, 8,8\% в США и 6,9\% в Турции. В Азербайджане этот показатель составляет 465 тысяч тонн. Широкое использование и применение удобрений и других ядохимикатов в овощеводстве создает серьезную угрозу для здоровья человека и окружающей среды. В среднем в мире 200000 человек умирают каждый год от воздействия этих ядов на организм человека. Таким образом, рост смертельных заболеваний и загрязнения окружающей среды привел к увеличению числа стран, которые в настоящее время занимаются экологически чистым (органическим) производством (181 страна). Природные условия Азербайджана предоставляют большие возможности для расширения производства овощей в стране. Однако, учитывая жизнеспособность и историческую важность перехода к органическому овощеводству в стране, решение этой проблемы зависит от государственного подхода.

Abstract. Over the past 50-60 years, the proportion of vegetable crops in the diet of people has increased, and an increase in demand has led to an increase in production. Thus, China accounts for $31 \%$ of the 170 million tons of tomatoes produced in the world, $11.2 \%$ in India, $8.8 \%$ in the USA and $6.9 \%$ in Turkey. In Azerbaijan, this figure is 465 thousand tons. The widespread use and use of fertilizers and other pesticides in vegetable production poses a serious threat to human health and the environment. Research shows that the quality indicators of vegetable products often do not meet international standards and medical norms. One of the main reasons for this is the excess of nitrates in the product. Overusing of nitrogen fertilizers, as well as pollution of ground and surface water sources, atmospheric nitrogen compounds, also accumulates large amounts of nitrate in fruit and vegetable and feed crops (and therefore dairy products). Nitrate $\left(\mathrm{NO}_{3}\right)$ is one of the most common compounds in nitrogen in nature. They are always present in the soil and play an important role in plant nutrition. Part of the nitrogen and other fertilizers supplied to the soil is washed with rain and irrigation water and accumulated in ponds and water sources, mixed with river salts and poured into the sea. On average, 200,000 people die each year from the effects of these poisons on the human body. Thus, the growth of fatal diseases and environmental pollution has led to an increase in the number of countries that are currently engaged in environmentally friendly (organic) production (181 countries). The natural conditions of Azerbaijan provide great opportunities for expanding the production of vegetables in the country. However, given 
the viability and historical importance of the transition to organic vegetable growing in the country, the solution to this problem depends on the state approach.

Ключевые слова: органический продукт, нитраты, нитриты, ТЕТI, сорт Лейла, фитонциды, полынь горькая, биогумус.

Keywords: organic product, nitrates, nitrites, TETI, Leila cultivar, volatile production, bitter wormwood, biohumus.

На современном этапе население мире предпочитает потребление органических сельскохозяйственных продуктов. Глобальные экологические проблемы, загрязнение окружающей среды, значительное возрастание заболеваний, способствовало активизации действий приеприятий, занимающихся органическим сельским хозяйством. Для улучшения качества с-х продуктов и предотвращения деградации почв, згачительно расширилось производство органических продуктов во многих странах мира. Так, уже в 181 странах осуществляется производства продуктов органического сельского хозяйства [1-5].

\section{Анализ и результатьл}

Органические продукты являются в среднем на 40-80\% дороже по сравнению с другими продуктами. Всвязи с чем увеличиваются объемы производства и отраслей, управляемых органическими приемами. Если в 1999 г. в странах мира производство органических продуктов занимала 11,0 млн. га, то в 2015 г. данный показатель составил 50,9 млн. га, а в 85 странах принят Закон по производству органических удобрений.

По статистическим данным в Азербайджане 37,630 га сертифицированы как органические. Иностранные сертифицирующие подразделения: 305 производителей, 50 обрабатывающих предприятий и 50 импортеров.

Площадь сельскохозяйственных земель, занятых под производство овощей в Азербайджане в 2003 г. составляла 73,2 тыс. га, в 2018 г. - 69,5 тыс. га.

В открытом грунте данные показатели соответственно составляют - 72,7 и 66,4 тыс.га.

В 2018 г. площади посевов, занятых под огурцы составили 10,6 тыс.га, помидоры 17,3 тыс. га, чеснока - 4,6 тыс. га, баклажаны - 4,6 тыс. га, перца - 2,6 тыс. га, горького перца - 1,3 тыс. га.

В закрытом грунте площади, занятые под выращивание огурцов составили 0,7 тыс.га, а под помидоры - 2,3 тыс.га.

В 2018 г. в открытых условиях было произведено 1521,9 тыс. т. овощей, в том числе 182,8 тыс т. огурцов, 327,9 тыс. т. помидор, 44,9 тыс. т чеснока, 79,7 тыс. т. баклажан, 36,1 тыс. т. сладкого и 13,5 тыс. т. горького перца. В том же году в закрытом грунте производство огурцов составла 41,0 тыс. т., а помидор - 281,3 тыс. т.

В 2018 г. урожайность огурцов на га составила - 154 ц, помидоров - 175 ц, чеснока - 97 ц, баклажан - 168 ц, сладкого перца - 137 ц и горького - 104 ц.

Анализы показали, что во многих случаях, качественные показатели произведенных продуктов овощей не отвечают международным стандартам и медицинским нормам. Основной причиной этого являнтся чрезмерное количество нитратов в плодах.

Пр неправильном применении азотных удобрений просходит загрязнение как наземных, так и грунтовых вод, а также увеличенное накопление их в кормовых культурах. Нитаты $\left(\mathrm{NO}_{3}\right)$ являются наиболее распространной формой азота в природе и играют значительную роль в питании растений. Некоторая часть внесенных в почву азотистих и 
других удобрений подвергается вымыванию атмосферными осадками и оросительными водами и накоплению в водоемах [6-10].

Повышенное наличие азота в почве оказывает отрицательное влияние на развитие растений и снижает производительность. Количество накопленного в почве азота как и других элементов, должна соответствовать их наличию в растениях. Превышение нитратов ПДК в растениях способствует существенному снижению качества урожая и создает потенциальную угрозу здоровью человека и животных.

Часть из поступивших в организм человека нитратов под действием некоторых микроорганизмов и ферментов в кишечно-желудочной системе превращаются в более токсичное вещство - нитриты, влияние которых в 10-20 раз превышает нитраты.

Нитраты и нитриты оказывают действие на организм сильное, поверхностное и хроническое влияние. Поступление за один раз в высоком количестве нитратов в организм человекома или животного, происходит развитие процесса мезомоглобинемии. Поступление нитратов в организм даже в малом количестве, но постоянно, происходит отравление организма. В результате чего в печени и почках, в сердце и легких происходят отрицательные изменения.

В отличии от зрелого организма нитраты и нитриты более сильно влияют на организм детей. Это связано с тем, что в организме зрелых существует особая система ферментов, которая способствует распаду мезомоглобилина и увеличению количества гемоглобина. Отсутствие у детей такой системы способствует отравлению организма нитратами и нитритами. В связи с этим в некоторых зарубежных странах ведется особый контроль за питанием и употребляются продукты с пониженным содержанием в плодах нитратов и нитритов [10].

На основе договора о взаимном сотрудничестве, подписанной между НАНА и Министерством сельского хозяйства АР, НИИ овощеводства и региональным центром экологически чистого сельского хозяйства, для реализации намеченной программы и проведению соответствущих опытов, представлены 10 сортов помидор, 3 сорта баклажан, 1 сорт перца.

Целью данных опытов является выявление свойств соответствия данных сортов овощей природным условиям Шеки-Закатальской зоны, изучение производиельности в различных условиях режима питания, борьба с вредителеми с применением различных органических микроорганизмов. Для сравнения представленных сортов НИИ овощеводства, были поставлены опыты дополнительно еще с 2 местными сортами помидор.

На первом этапе на ключевых участках «Центра» в парниковых условиях для получения саженцев были посажены семена помидор сорта «Лейла», баклажан, перца и местных сортов 21 марта 2019 г.

Наблюдения показали, что саженцы сорта «Лейла» выращенные в условиях «Центра» оказались более здоровыми по сравнению с представленными саженцами, отличающимися биологически полноценным видом и признаками урожайности.

На всех участках посевов помидор обработка почв, нормы и сроки поливов проводились одинакво.

Согласно принципам экологически чистого сельского хозяйства, на всех участках вспашка почв не применялась.

Проводилась боронование глубиною 7-12 см. После чего при поступлении заморозков на участки подавалась вода в объеме 500-700 м³/га. Данный полив играет значительную роль в брьбе с вредителями, создает запас влаги в почве и, соответственно, - получение высоких и устойчивых урожаев. 
С целью обеспечения питательного баланса опытного участка, внесение органических удобрений (навоз, компост, биогумус, биомакс и др.) проводилась в 2 вариантах.

Подкормка в норме 2/3 вносилась до боронования, а $1 / 3$ часть - в течении вегетационного периода растений.

Пересадка рассады на открытые участки - рассада была перенесена на открытые учвстки 24 мая по рядам размером 70х35 см. После 4-5 дней посадки рассады, проведена проверка растений и невсхожие рассады были заменены новыми.

Подкормка - внесена в норме 3 т/га биогумус 23 мая и 24 мая в почву в узкие борозды. Первая подкормка проведена 7 июня, а вторая - 31 августа.

1 кетменование: 2 недели после посадки, 7 июня, последующее - спустя еще 2 недели, 21 июня.

Мотыжение проводилось 2 раза между рядами растений. Агротехнические мероприятия проводились систематически.

На 2 участке, где были посажены сорта «Хазар», «Азербайджан-94», «Перспектива», «Элм» и «Шекер», в растениях наблюдались гниение, фитофтора и хлопковая совка, в борьбе с которыми 3 раза проводилось опрыскивание. После применения препаратов против вредителей получены следующие результаты, представленные в Таблице 1.

Таблица 1

РЕЗУЛЬТАТЫ ПО БОРЬБЕ С ВРЕДИТЕЛЯМИ И ЗАБОЛЕВАЕМОСТЬЮ РАСТВОРОМ ИЗГОТОВЛЕННЫХ ИЗ ФИТОЦИДНОЙ РАСТИТЕЛЬНОСТЬЮ

\begin{tabular}{|c|c|c|c|c|c|c|c|c|c|}
\hline \multirow[t]{3}{*}{ Фитонцидный раствор } & \multirow[t]{3}{*}{$\begin{array}{c}\text { Расходная } \\
\text { норма, } \\
\text { л:\% }\end{array}$} & \multirow{2}{*}{\multicolumn{4}{|c|}{$\begin{array}{c}\text { Развитие } \\
\text { заболеваемости после } \\
\text { проведенных } \\
\text { мероприятий, \% } \\
\text { По дням }\end{array}$}} & \multicolumn{4}{|c|}{$\begin{array}{c}\text { Биологическая } \\
\text { эффективность } \\
\text { фитонцидов, \% }\end{array}$} \\
\hline & & & & & & \multicolumn{4}{|c|}{ По дням } \\
\hline & & 5 & 10 & 15 & 20 & 5 & 10 & 15 & 20 \\
\hline \multicolumn{10}{|c|}{ Хлопковая совка } \\
\hline Табак, кора лука, смятый чеснок & $0,6: 10$ & 7,0 & 11,0 & 14,0 & 17,0 & 48,2 & 40,2 & 37,0 & 26,2 \\
\hline \multirow[t]{2}{*}{ I вариант } & $1: 10$ & 5,0 & 8,0 & 9,0 & 11,0 & 64,3 & 56,6 & 54,1 & 47,3 \\
\hline & $1,5: 10$ & 3,0 & 4,0 & 5,0 & 7,0 & 81,0 & 77,5 & 73,2 & 67,4 \\
\hline Ноготки & $0,2: 10$ & 5,0 & 8,0 & 11,0 & 13,0 & 52,5 & 41,2 & 38,0 & 31,4 \\
\hline \multirow[t]{2}{*}{ II вариант } & $0,5: 10$ & 3,0 & 6,0 & 9,0 & 11,0 & 69,3 & 61,3 & 57,2 & 52,0 \\
\hline & $1,0: 10$ & 2,0 & 3,0 & 5,0 & 7,0 & 88,2 & 81,4 & 73,4 & 71,2 \\
\hline \multicolumn{10}{|c|}{ Фитофлора } \\
\hline Горький полынь & $0,5: 10$ & 6,0 & 8,0 & 11,0 & 12,0 & 51,2 & 45,0 & 39,2 & 34,1 \\
\hline \multirow[t]{2}{*}{ I вариант } & $1,0: 10$ & 3,0 & 5,0 & 7,0 & 10,0 & 71,5 & 62,3 & 58,7 & 48,4 \\
\hline & $1,5: 10$ & 1,0 & 3,0 & 4,0 & 5,0 & 91,2 & 86,4 & 69,3 & 61,2 \\
\hline огневица & $0,5: 10$ & 8,0 & 10,0 & 12,0 & 15,0 & 38,0 & 32,1 & 29,2 & 20,8 \\
\hline \multirow[t]{2}{*}{ II вариант } & $1,0: 10$ & 4,0 & 6,0 & 9,0 & 11,0 & 64,0 & 56,7 & 48,5 & 43,4 \\
\hline & $1,5: 10$ & 2,0 & 3,0 & 5,0 & 8,0 & 83,0 & 74,3 & 68,4 & 57,3 \\
\hline \multicolumn{10}{|c|}{ Гниение верхней части } \\
\hline \multirow[t]{3}{*}{ Конский щавель } & $0,3: 10$ & 7,0 & 9,0 & 10,0 & 13,0 & 36,0 & 30,4 & 28,5 & 19,2 \\
\hline & $0,5: 10$ & 4,0 & 7,0 & 8,0 & 10,0 & 62,0 & 52,5 & 45,2 & 41,7 \\
\hline & $1: 10$ & 2,0 & 4,0 & 6,0 & 7,0 & 79,0 & 72,4 & 64,3 & 55,8 \\
\hline Табак, кора лука, смятый чеснок & $0,5: 10$ & 5,0 & 8,0 & 11,0 & 12,0 & 53,4 & 48,2 & 37,2 & 32,6 \\
\hline \multirow[t]{2}{*}{ II вариант } & $1: 10$ & 3,0 & 5,0 & 7,0 & 9,0 & 72,3 & 66,4 & 58,5 & 47,4 \\
\hline & $1,5: 10$ & 2,0 & 3,0 & 5,0 & 6,0 & 92,1 & 87,1 & 74,3 & 68,2 \\
\hline
\end{tabular}


В 1 варианте после применения препаратов в соотношении 0.6:10; 1:10; 1.5:10, на 5 день после выявления заболеваемости, наилучшая биологическая эффективность $81 \%$ составила в соотношении 1.5:10.

Раствор, изготовленный из ноготков в дозе против хлопковой совки 0.2:10; 0.5:10; 1.0:10 — наилучшая биологическая эффективность $88,2 \%$ составила в соотношении 1.0:10. В обоих вариантах биологическая эффективность раствора оказалась достаточно высокой.

На втором опытном участке примененные растворы, изготовленные из горькой полыни и огневицы, против заболеваемости фитотрофа были получены следующие результаты:

В 1 варианте с горькой полынью в 3 дозах $(0.5: 10 ; 1.0: 10 ; 1.5: 10)$ на 5 день после выявления заболеваемости, наилучшая биологическая эффективность $(92,2 \%)$ приходится в соотношении 1.5:10.

Во 2 варианте с раствором огневицы, примененной в 3 дозах $(0.5: 10 ; 1.0: 10 ; 1.5: 10)$ наилучшая биологическая эффективность $(83,0 \%)$ приходится на соотношение 1.5:10 на 5 день выявления заболеваемости. В каждом варианте при 3 опрыскиваниях наиболее эффективным оказался раствор изготовленной из горькой полыни.

С применением под томаты растворов из табака,коры лука и смятого чеснока получены следующие результаты:

В 1 варианте из конского щавеля, растворы применялись в 3 дозах $(0.3: 10 ; 0.5: 10 ; 1: 10)$ и наилучшая биологическая эффективность (79,0\%) приходится в соотношении 1.0:10 на 5 день выявления заболеваемости. А во 2 варианте - наилучшая биологическая эффективность $(92,1 \%)$ наблюдалась на 5 день выявления заболеваемости и в каждом варианте при 4 опрыскиваниях были получены высокие результаты.

27 июня 2019 г. на 5 участке в варианте - фон, применялось 3 опрыскивания. 1 и 2 биологичеаским препаратом Nostalgist BL (10 л вода/100 мг), 3 2\% раствором Bordo, результаты которых представлены в Таблице 2. При опрыскивании раствором Nostalgist BL против заболеваемости, наилучший результат в 93,1\%, получен после 5 дня.

Таблица 2

РЕЗУЛЬТАТЫ ПРИМЕНЕНИЯ БИОПРЕПАРАТОВ ПРОТИВ ВРЕДИТЕЛЕЙ НА 5 УЧАСТКЕ

\begin{tabular}{|c|c|c|c|c|c|c|c|c|c|}
\hline \multirow{3}{*}{$\begin{array}{c}\text { Биологический } \\
\text { раствор }\end{array}$} & \multirow{3}{*}{$\begin{array}{l}\text { Норма } \\
\text { расхода } \\
\text { л:\% }\end{array}$} & \multirow{2}{*}{\multicolumn{4}{|c|}{$\begin{array}{c}\text { Степень развития } \\
\text { заболеваемости после } \\
\text { проведенных мероприятий, \% } \\
\text { По дням }\end{array}$}} & \multicolumn{4}{|c|}{$\begin{array}{c}\text { Биологическая эффективность } \\
\text { фитонцидов, \% }\end{array}$} \\
\hline & & & & & & \multicolumn{4}{|c|}{ По дням } \\
\hline & & 5 & 10 & 15 & 20 & 5 & 10 & 15 & 20 \\
\hline \multicolumn{10}{|c|}{ Заболевание вирусом } \\
\hline \multirow{3}{*}{ Nostalgist BL } & $1: 10$ & 6,0 & 9,0 & 12,0 & 14,0 & 56,3 & 47,2 & 41,5 & 36,8 \\
\hline & $1: 10$ & 2,0 & 6,0 & 8,0 & 11,0 & 76,2 & 68,4 & 59,3 & 47,1 \\
\hline & $1: 10$ & 1,0 & 4,0 & 5,0 & 6,0 & 93,1 & 89,3 & 71,6 & 63,4 \\
\hline \multirow{3}{*}{$\begin{array}{l}2 \% \text { раствор } \\
\text { Бордо }\end{array}$} & $2: 10$ & 5,0 & 8,0 & 11,0 & 12,0 & 53,4 & 48,2 & 37,2 & 32,6 \\
\hline & $2: 10$ & 3,0 & 5,0 & 7,0 & 9,0 & 72,3 & 66,4 & 58,5 & 47,4 \\
\hline & $2: 10$ & 2,0 & 3,0 & 5,0 & 6,0 & 92,1 & 87,1 & 74,3 & 68,2 \\
\hline
\end{tabular}

Из представленных семян сортов баклажан «Биллур» и «Захра» была полученна рассада, которая в последующем была перенесена на участки. В течение вегетационного периода на участке был обнаружен колорадский жук и проведены соответствующие меры по защите посадок. 
Выявлено, что среди сортов баклажан, наиболее адаптированными к заболеваниям и к почвенно-климатическим условиям шеки-закатальской зоны, оказалася сорт «Захра», урожайность данного сорта составила 60,0 т, а урожайность сорта «Биллур» — 55,6 т (Таблица 3).

Таблица 3

ИТОГОВЫЕ ПОКАЗАТЕЛИ АДАПТАЦИИ СОРТОВ ПОМИДОР, БАКЛАЖАН И ПЕРЦА К МЕСТНЫМ ПРИРОДНЫМ УСЛОВИЯМ ЦЕНТРА

\begin{tabular}{|c|c|c|c|c|c|}
\hline $\begin{array}{c}\text { Наименование } \\
\text { сорта }\end{array}$ & $\begin{array}{l}\text { Площадь, } \\
\text { сотка }\end{array}$ & $\begin{array}{c}\text { Урожайность, } \\
\kappa 己\end{array}$ & $\begin{array}{c}\text { Урожайность } \\
\text { на } 1 \text { га }(\mathrm{m})\end{array}$ & $\begin{array}{c}\text { Чистая } \\
\text { прибыль }\end{array}$ & Рентабельность \\
\hline \multicolumn{6}{|c|}{ Участок 2. Сорта помидор } \\
\hline Хазар & 0.168 & 87 & 51.8 & 28.44 & 87.62 \\
\hline Азербайджан 94 & 0.168 & 105 & 62.5 & 40.49 & 122.70 \\
\hline Перспектив & 0.168 & 82.3 & 48.9 & 25.40 & 78.86 \\
\hline Шекер & 0.168 & 84 & 50.0 & 26.60 & 82.80 \\
\hline Элм & 0.168 & 100 & 59.5 & 36.60 & 109.60 \\
\hline \multicolumn{6}{|c|}{ Участок 5. Сорт «Лейла» по вариантам } \\
\hline Фон & 0.72 & 274 & 38.1 & 104.90 & 120.80 \\
\hline Биогумус 1 га/4т & 0.72 & 401 & 55.7 & 173.80 & 162.60 \\
\hline Биомакс 1 га/2 л & 0.72 & 384 & 53.3 & 170.44 & 173.40 \\
\hline $\begin{array}{l}\text { Гахский компост } \\
1 \text { га/5 т }\end{array}$ & 0.72 & 362 & 50.3 & 153.85 & 154.60 \\
\hline \multicolumn{6}{|c|}{ Участок 7. из расчета биогумус 1 га/5 m } \\
\hline Местный сорт & 1.44 & 830 & 57.6 & 409.17 & 238.10 \\
\hline Лейла & 0.36 & 198 & 55.0 & 94.02 & 210.90 \\
\hline Илкин & 0.36 & 206 & 57.2 & 96.52 & 202.40 \\
\hline Зарраби & 0.36 & 212 & 58.9 & 102.4 & 222.70 \\
\hline Алсу & 0.36 & 181 & 50.3 & 82.97 & 189.70 \\
\hline \multicolumn{6}{|c|}{ Участок 9. из расчета биогумус 1 га/5 m } \\
\hline $\begin{array}{l}\text { Местный } \\
\text { (неизвестный) }\end{array}$ & 1.02 & 531 & 52.1 & 208.74 & 128.10 \\
\hline \multicolumn{6}{|c|}{ Участок 8. из расчета биогумус 1 га/5 m } \\
\hline \multicolumn{6}{|c|}{ Перец } \\
\hline Зумруд & 1.5 & 631 & 42.1 & 147.27 & 73.70 \\
\hline \multicolumn{6}{|c|}{ Баклажаны } \\
\hline Биллур & 0.59 & 328 & 55.6 & 101.48 & 106.50 \\
\hline Захра & 0.73 & 438 & 60.0 & 142.88 & 119.20 \\
\hline
\end{tabular}

Анализируя данные Таблицы 3, можно констатировать:

- по проведенным в условиях «Центра» с 10 сортами помидор наибольшая урожайность с 1 га составила: Азербайджан-94 - 62,5 т; Элм - 59.5 т; Зардаби - 58.9 т; Местный сорт - 57.6 т; Илкин - 57.2 т. Средняя урожайность по сортам томатов: Лейла - 55 т; Местный сорт- 52 т; Хазар - 51.8 т; Алсу - 50.3 т; Шекер - 50.0 т и самая наименьшая у сорта Перспектив 48.9 т.

- за период вегетации растений были проведены соответствующие меры по их защите к заболеваемости. В сорте томата Лейла были выявленыо признаки заболеваемости вирусом и проведены соответствующие меры по их устранению. Урожайность томатов сорта Лейла по вариантам опыта составила: Фон - 38.1 т; Биогумус 1 га/4 т - 55.7 т; Биомакс 1 га/2 л 53.3 т; Компост Гах 1 га/5 т -50.3 т. 
Наибольшая продуктивность приходится по отношению к фону на вариант биогумус 55.7 тонн: в варианте биогумус - $17.6 \mathrm{\text {; }}$ биомакс $-15.2 \mathrm{\text {; }}$ с компостом Гах $-12.2 \mathrm{~T}$ (дополнительный урожай).

Из сортов баклажан получены урожаи: Захра — 60 т/га и Биллур — 55,6 т/га.

На опытном участке с сортом Зумруд по всем фазам развития отклонений не наблюдалось, урожайность составила 42,1 т/га.

\section{Список литературы:}

1. Бабаев А. Г. Экономический и социальный контекст овощеводста в Азербайджане // Материалы международной научно-практической конференции. Ташкент. 2005. С. 9-16.

2. Бабаев В. А. Производство экологических помидоров. Баку. 2016. 29 с.

3. Мамедов Г. М. Применение удобрений под культуру томата на лугово-лесных и серобурых почвах Азербайджана //Агрохимия. 2010. №3. С. 29-33.

4. Алиева К. А. Влияние различных доз азотных удобрений на продукцию томата и агрохимические свойства серо-бурой почвы на Абшеронском полуострове // Почвы и окружающая среда. 2018. №1(3). С. 118-125.

5. Бабаев А. Г. Мониторинг качества почв и экологический контроль. Баку. 2012. 255 с.

6. Бабаев А. Г. Селекция помидоров на основе современных методов в Азербайджане. Баку. 2007. 338 c.

7. Бабаев А. Г. Приоритетные направления селекции и семеноводства овощных и бахчевых культур в современный период и их существующие пробоемы. Баку. 2008. С. 38-41.

8. Бабаев М. П., Оруджева Н. Х., Искендеров С. М. Управление получения высоких урожаев овощных культур в различных почвенно-экологических условиях. Баку. 2007. 240 с.

9. Eyvazova N., Maharramova X. The Necessity of the Organization of Innovative production in the Regions // Economic and Social Development: Book of Proceedings. 2019. P. 26-31.

10. Бабаев А. Г., Бабаев В. А. Основы экологического сельского хозяйства. Баку. 2011. $543 \mathrm{c}$.

\section{References:}

1. Babaev, A. G. (2005). Ekonomicheskii i sotsial'nyi kontekst ovoshchevodsta v Azerbaidzhane. In Materialy mezhdunarodnoi nauchno-prakticheskoi konferentsii. Tashkent. 9-16.

2. Babaev, V. A. (2016). Proizvodstvo ekologicheskikh pomidorov. Baku. 29.

3. Mamedov, G. M. (2010). Primenenie udobrenii pod kul'turu tomata na lugovo-lesnykh i sero-burykh pochvakh Azerbaidzhana. Agrokhimiya, (3). 29-33. (in Russian).

4. Alieva, K. A. (2018). Vliyanie razlichnykh doz azotnykh udobrenii na produktsiyu tomata $i$ agrokhimicheskie svoistva sero-buroi pochvy na Absheronskom poluostrove. Pochvy $i$ okruzhayushchaya sreda, 1(3). 118-125. (in Russian).

5. Babaev, A. G. (2012). Monitoring kachestva pochv i ekologicheskii kontrol'. Baku. 255.

6. Babaev, A. G. (2007). Selektsiya pomidorov na osnove sovremennykh metodov v Azerbaidzhane. Baku. 338.

7. Babaev, A. G. (2008). Prioritetnye napravleniya selektsii i semenovodstva ovoshchnykh i bakhchevykh kul'tur v sovremennyi period i ikh sushchestvuyushchie proboemy. Baku. 38-41.

8. Babaev, M. P., Orudzheva, N. Kh., \& Iskenderov, S. M. (2007). Upravlenie polucheniya vysokikh urozhaev ovoshchnykh kul'tur $\mathrm{v}$ razlichnykh pochvenno-ekologicheskikh usloviyakh. Baku. 240. 
9. Eyvazova, N., \& Maharramova, X. (2019). The Necessity of the Organization of Innovative production in the Regions. Economic and Social Development: Book of Proceedings, 26-31. (in Russian).

10. Babaev, A. G., \& Babaev, V. A. (2011). Osnovy ekologicheskogo sel'skogo khozyaistva. Baku. 543.

Работа поступила

в редакичюю 11.01.2020 г.
Принята к публикащии 18.01.2020 2

Ссылка для циттирования:

Бабаев В. А. Научно-практические аспекты ведения органического производства томатов в Азербайджане // Бюллетень науки и практики. 2020. Т. 6. №2. С. 158-165. https://doi.org/10.33619/2414-2948/51/15

Cite as (APA):

Babaev, V. (2020). Scientific-Practical Aspects of the Organic Tomato Production in Azerbaijan. Bulletin of Science and Practice, 6(2), 158-165. https://doi.org/10.33619/24142948/51/15 (in Russian). 


\title{
ФАКТОРЫ И СУЩНОСТЬ СТРУКТУРНЫХ ИЗМЕНЕНИЙ В АГРАРНОМ СЕКТОРЕ ЮЖНЫХ ОБЛАСТЕЙ УЗБЕКИСТАНА
}

\author{
(СБотирова X. Э., Термезский государственный университет, г. Термез, Узбекистан \\ FACTORS AND ESSENCE OF INDIGENOUS STRUCTURAL CHANGES \\ IN THE AGRARIAN SECTOR OF THE SOUTHERN REGIONS OF UZBEKISTAN
}

\author{
CBotirova H., Termez State University, Termez, Uzbekistan
}

Аннотация. В статье речь идет о материально-техническом состоянии в Узбекистане при осуществлении аграрных реформ, а также приводятся примеры использования опыта развитых мировых стран при проведении реформ в аграрной области. Освещены исторические основы современных методов подготовки специалистов в аграрной отрасли.

Abstract. This article describes the material and technical condition of agrarian reforms in Uzbekistan and the use of the experience of developed countries in the agrarian sector in the reforms as well as the historical basis of modern methods of training specialists in the agricultural sector.

Ключевые слова: экономическая программа, система управления, инфраструктурные объекты, аграрная отрасль, частное предпринимательство, рабочие места, спорт, общественный фонд, международные турниры, здравоохранение, природные ресурсы, экологическая культура.

Keywords: economic program, management system, infrastructure facilities, agricultural industry, private enterprise, jobs, sports, public funds, international tournaments, healthcare, natural resources, environmental culture.

Одной из работ, осуществленных в годы независимости, в области сельского хозяйства, является коренное изменение отношения к собственности, т.е. формирование отношения к частной и личной собственности. Как известно, из опыта развитых зарубежных стран, основным фактором повышения эффективности сельского хозяйства является выполнение работ на основе современных технических средств. Мировая практика показывает непосредственную пропорциональность устойчивости, высокую продуктивность комплексного развития производственных сил, научно-техническое развитие мощностей материально-технической базы производственных отраслей, а также необходимость создания условий для специалистов.

Это можно увидеть на примере фермеров - специалистов, которые нашли свое подтверждение в аграрной отрасли. В США на одного фермера приходится в среднем 150 га. посевной площади. Этот показатель в Канаде равен 190 га, в Великобритании - 70 га, в Франции - 35 га, в Ирландии и Люксембурге - 33 га, в Дании - 32 га, в Албании - 18 га, в Голландии - 17 га, в Италии - 8 га. Но они на практике доказали, что результаты будут высокими только тогда, когда эффективно будут использованы научно-технические достижения. Высокие экономические показатели в сельском хозяйстве зависят от разумного 
использования техники, подготовки высококвалифицированных специалистов в аграрной отрасли, которые во многом связаны и с их качеством [1].

Наряду с достигнутыми успехами в сельском хозяйстве имеется и целый ряд проблем. Во-первых, по действующим правилам земельный налог взимается в два срока: до 1 июля и до 1 декабря. Но финансовое подытоживание сельского хозяйства до конца года формируется один раз. К первому сроку налогообложения сельскохозяйственные предприятия не имеют возможности оплачивать налоги. А налоговые органы за каждый день неоплаченного налога устанавливают надбавочный штраф, и таким образом, основная сумма налога постепенно увеличивается. Поэтому, внося некоторые изменения в налоговое законодательство, необходимо внедрить единый срок оплаты по итогам каждого года.

Во-вторых, расположенные в сельских районных центрах автомобильные, тракторные парки, иногда, по монополистически господствуя, устанавливают очень высокие условия оплаты взамен некачественных услуг. Поэтому путем создания частных альтернативных услуг в агросервисной отрасли необходимо формировать конкретную среду.

В-третьих, по мнению руководителей и специалистов сельского хозяйства, проводимые по строгой банковской системе, взаимные финансовые подсчётные системы стали причиной попустительства бесхозяйственности, ослаблению интереса производителей товаров в получении чистой прибыли [2, с. 43].

В результате отмечается, что и предприятия, получающие прибыль, а также предприятия, несущие убытки не смогли свободно воспользоваться своими средствами. В связи с этим были рассмотрены вопросы устранения препятствий, являющихся помехой для финансово мощных сельских предприятий, а также и были определены границы обеспечения свободного перемещения денежных средств, имеющихся на их счетах.

В-четвёртых, в целях хранения, реализации и переработки продукции сельского хозяйства необходимо организовать пункты доставки товаров и грузов.

В-пятых, необходимо усовершенствование системы оросительных работ в сельском хозяйстве, внедрение передовых технологий, которые соответствуют современным стандартам.

В Узбекистане широко пропагандировались превосходство работ по поливу растений дождеванием, использованию технологий орошения, повысились услуги материальнотехнической базы, усилены ремонтные и сервисные услуги. Организовано производство оросительно-дождевальных аппаратов. Также в Узбекистане, налажено производство сельскохозяйственных машин малого объема, и в ближайшее время планируется все малые и средние фермерские хозяйства в массовом порядке обеспечить удобными машинами [3, с. 31].

В сельском хозяйстве Сурхандарьинской области в 2000-2005 гг был произведен повторный посев сортов хлопка «Юлдуз», «Бухара» и был достигнут сбор урожая с превышением на $28 \%$.

На сегодняшний день, в Узбекистане появилось новое почетное название Сурхандарьи - школа земледельчества. В Джаркурганском, Термезском и Музрабадском районах было построено и пущено в строй объединенное предприятие по совместному выращиванию и производству сахарной свеклы и сахара.

Из вышесказанного можно сделать выводы, что в экономике Сурхандарьинской и Кашкадарьинской областях в переходном периоде в сельском хозяйстве были достигнуты значительные результаты. Несмотря на трудности экономических реформ сельского хозяйства на южных рубежах, благодаря появлению новых возможностей, земледельческое хозяйство значительно развилось. Одним из важных результатов реформ, проведенных в 
сельском хозяйстве было то, что земледельцы стали хозяевами своей земли, у них появилось право свободной продажи своей произведенной продукции.

Одним из негативных явлений стало непринятие во внимание мнений и предложений специалистов, которые считались настоящими землевладельцами, также не по назначению были использованы их опытные работы, в итоге которого в 1999 г в Сурхандарьинской и Кашкадарьинской областях очень большие освоенные площади потеряли свою производственную мощь, тысячи гектаров земли в Кизирикском, Шерабадском, Термезском, Шахрисябзском, Китабском, Муборакском, Косонском, Гузарском, Камашинском, Яккабагском, Нишанском, Чиракском, Дехканабадском, Таллимаржонском районах мелиоративное состояние было полностью разрушено, вследствие которого урожайность снизилась до минимума. В результате пренебрежения знаниями грамотных специалистов Шерабадских, Кизирикских, Музрабадских, Косонских, Муборакских мелиораторов и ирригаторов $2 / 3$ части почвы в этих районах потеряли свою плодородность. Причиной такого горестного состояния является недостаточное внимание проблемам улучшения семеноводства и племенноводства в животноводстве. Нарушаются агротехнические требования в выращивании культур сельского хозяйства. Из-за того, что семеноводство брошено на произвол судьбы резко снизился уровень плодородности хлопка, зерна и других посевов [4, с. 407].

Но в настоящее время, политика Узбекистана по отношению специалистов аграрной отрасли состоит в изучений опытов передовых стран и перенять все лучшее, которое приемлемо для Республики.

На основе узбекской модели исторически в короткое время специалисты аграрной отрасли, опираясь на традиции и национальные особенности повыращиванию сельскохозяйственной продукции достигли больших успехов. Вместе с тем, чем дальше углубляется рыночная реформа не эффективно используются всевозможные методы и средства для успешного развития экономики. Например, одним из важных факторов для обеспечения высокого развития темпов экономики это производительность труда.

Повышение производительности труда несомненно приведёт к расширению объема производства, способствует предотвращению процессов инфляции, снижает расходы, создает реальные возможности увеличению конкурентно-способной продукции, производимой на внутреннем и внешнем рынке, а также повышению уровня заработной платы специалистов в аграрной отрасли. Но, по объективным и субъективным причинам, производительность труда в Узбекистане остается в стороне от внимания большинства. Причиной тому является, что у некоторых категорий руководителей, также некоторых ученных сформировались неправильные точки зрения о путях повышения производительности труда в условиях рыночной экономики. По их мнению, якобы в условиях рыночной экономики производительность труда будет повышаться сама по себе. Поэтому еще раз необходимо подчеркнуть, что нет необходимости макроэкономического влияния на этот процесс со стороны государственных органов и нет нужды в осуществлении специальных научных исследований.

\section{Список литературы:}

1. Народная газета. 2002. 11 апреля.

2. Текущий архив хокимията Сурхандарьинской области (9 протокол). 2003. 43 с.

3. Текущий архив хокимията Сурхандарьинской области (12 протокол). 2005. 31 с.

4. Каримов И. А. По пути безопасности и развития устойчивости. Ташкент. 1998. 407 с.

References: 
1. Narodnaya gazeta (2002). 11 aprelya. (in Uzbek)

2. Tekushchii arkhiv khokimiyata Surkhandar'inskoi oblasti (9 protokol). (2003). 43. (in Uzbek)

3. Tekushchii arkhiv khokimiyata Surkhandar'inskoi oblasti (12 protokol). (2005). 31. (in Uzbek)

4. Karimov I. A. Po puti bezopasnosti i razvitiya ustoichivosti. Tashkent. (1998). 407. (in Uzbek)

Работа поступила

Принята к публикации

в редакииюю 12.01.2020 2.

17.01.2020 2.

Ссылка для цุитирования:

Ботирова Х. Э. Факторы и сущность коренных структурных изменений в аграрном секторе южных областей Узбекистана // Бюллетень науки и практики. 2020. Т. 6. №2. С. 166169. https://doi.org/10.33619/2414-2948/51/16

Cite as (APA):

Botirova, H. (2020). Factors and Essence of Indigenous Structural Changes in the Agrarian Sector of the Southern Regions of Uzbekistan. Bulletin of Science and Practice, 6(2), 166-169. https://doi.org/10.33619/2414-2948/51/16 (in Russian). 


\section{ПИТАНИЕ НА ВОЗДУШНЫХ СУДНАХ: АНАЛИЗ МЕНЮ (ЧАСТЬ 1)}

СБеркетова Л. В., ORCID: 0000-0002-1798-6131, SPIN-код: 4693-8465, канд. техн. наук, Российский экономический университет им. Г.В. Плеханова, 2. Москва, Россия, lidia.berketova@yandex.ru

(Сигинова Р. В., Российский экономический университет им. Г.В. Плеханова, 2. Москва, Россия, r.iginova@gmail.com

\section{NUTRITION ON AIRCRAFTS: A MENU ANALYSIS (PART 1)}

CBerketova L., ORCID: 0000-0002-1798-6131, SPIN-code: 4693-8465, Ph.D., Plekhanov Russian University of Economics, Moscow, Russia, lidia.berketova@yandex.ru CIginova R., Plekhanov Russian University of Economics, Moscow, Russia, riginova@gmail.com

Аннотащия. Организация обслуживания пассажиров воздушного транспорта заключается не только в перевозке пассажиров в пункт назначения, но и в предоставлении различных видов питания, которое может включать в себя горячее питание по меню свободного выбора или скомплектованные рационы на борту самолета, десерты, напитки. Ассортимент блюд зависит от бюджета авиакомпании, сезона, длительности полета, класса обслуживания, времени вылета, принципов здорового питания, национальных особенностей, конкретных вкусов и возраста пассажира. В данной работе рассмотрено меню компании «Аэрофлот - Российские авиалинии». Питание в самолетах «Аэрофлота» делится на два «цикла». В зависимости от направления и продолжительности полета, предоставляется выбор из двух блюд: холодный или горячий завтрак, горячий или холодный обед, закуски и напитки. Меню данной авиакомпании обновляется каждые шесть недель. Меню экономкласса: в зависимости от направления, времени вылета и продолжительности полета содержит завтрак, обед или закуски. Выбор горячих и прохладительных напитков также предоставляется в зависимости от длительности и направления полета. Рейсы продолжительностью до 3-х часов полета предлагают пассажирам завтрак или обед или ужин, прохладительные и горячие напитки. На рейсах продолжительностью от 3-х до 6-ти часов полета в меню входит закуска, основное блюдо, десерт, прохладительные и горячие напитки. Также существует опция заказа специального питания в классе Эконом на рейсах свыше 3-х часов. На рейсах свыше 12 часов полета в Лос-Анджелес, Майами, Гавану пассажирам будет предложен дополнительный рацион - сэндвич и фрукты. Меню класса Комфорт предлагает пассажирам приветственный напиток и предоставляется карта меню. В течение полета в классе Комфорт предусмотрено два обслуживания питанием на рейсах продолжительностью свыше 6-ти часов. Меню данного класса представлено для 14-ти направлений (из Москвы в Бангкок, Пхукет, Пекин, Гонгконг, Дубай, Лос-Анджелес, НьюЙорк, Владивосток, Хабаровск, Петропавловск-Камчатский, Сеул, Шанхай, Тель-Авив, Южно-Сахалинск и обратно). В работе представлены меню с расчетом пищевой ценности и калорийности. 
Abstract. The organization of passenger service for air transport consists not only in the transportation of passengers to their destination, but also in the provision of various types of food, which can include hot meals according to the free choice menu or complete rations on board the aircraft, desserts, drinks. The range of dishes depends on the budget of the airline, season, flight duration, class of service, departure time, principles of healthy eating, national characteristics, specific tastes and age of the passenger. In this paper, the menu of the company Aeroflot - Russian Airlines is considered. Food in Aeroflot airplanes is divided into two cycles. Depending on the direction and duration of the flight, a choice of two dishes is provided: cold or hot breakfast, hot or cold lunch, snacks and drinks. The menu of this airline is updated every six weeks. Economy class menu: depending on the direction, departure time and duration of the flight, it contains breakfast, lunch or snacks. A selection of hot and cold drinks is also provided depending on the duration and direction of the flight. Flights lasting up to 3 hours of flight offer passengers breakfast or lunch or dinner, soft and hot drinks. On flights lasting from 3 to 6 hours of flight, the menu includes appetizer, main course, dessert, soft and hot drinks. There is also the option of ordering special meals in the Economy class on flights over 3 hours. On flights over 12 hours of flight to Los Angeles, Miami, Havana, passengers will be offered an additional diet - a sandwich and fruits. The Comfort class menu offers passengers a welcome drink and a menu card is provided. During the flight in the Comfort class, two meals are provided for flights lasting more than 6 hours. The menu of this class is presented for 14 directions (from Moscow to Bangkok, Phuket, Beijing, Hong Kong, Dubai, Los Angeles, New York, Vladivostok, Khabarovsk, PetropavlovskKamchatsky, Seoul, Shanghai, Tel Aviv, Yuzhno-Sakhalinsk and back). The paper presents a menu with the calculation of nutritional value and calorie content.

Ключевые слова: питание на борту, «Аэрофлот», меню, продолжительность полета, рейс.

Keywords: on-board nutrition, Aeroflot, menu, flight duration, flight.

Одной из форм организации обслуживания пассажиров воздушного транспорта является предоставление горячих видов питания по меню свободного выбора или скомплектованных рационов на борту самолета.

Питание входит в стоимость обычного билета эконом- или бизнес-класса. При наличии особых предпочтений в питании, вызванных религиозными взглядами, рекомендациями врача или собственными убеждениями пассажиров, авиакомпании широко практикуют опцию заказа специального питания, который должен быть сделан заранее (обычно не менее чем за 36 часов до вылета).

Для приготовления бортового питания, которое используется на борту воздушного судна, авиакомпании необходимо заключить договор с определенным предприятием питания, кейтеринговой компанией или создать на своей базе цех бортового питания. Более того, необходимо наличие специального сертификата, который предоставляет право на изготовление продукции для авиапассажиров [1].

Технологический процесс приготовления и обеспечения бортовым питанием состоит из следующих процессов: изготовление кулинарной продукции $\rightarrow$ раскладывание в лотки и противни $\rightarrow$ охлаждение на столах до комнатной температуры $\rightarrow$ охлаждение в холодильных шкафах до $+4-6^{\circ} \mathrm{C} \rightarrow$ комплектация заказа в фасовочном отделении в контейнеры с отдельными боксами вместе с посудой и необходимым инвентарем.

Укомплектованные контейнеры передаются в экспедицию цеха бортового питания и доставляются на борт самолета за 30-45 мин до вылета. Прием бортового питания производит бортпроводник в соответствии с сопроводительной документацией [1]. 
В бизнес-классе уровень обслуживания приравнивается к ресторанному, в связи с чем для его пассажиров необходимо рассчитать количество столовой фарфоровой посуды, металлических приборов и льняных салфеток для сервировки столов исходя из количества порций с учетом однократного их использования, а также запас чистых стаканов и фужеров, обеспечивающий двух- и трехкратный прием воды и напитков всеми пассажирами [2].

Пассажирам эконом класса приносят поднос с набором еды в индивидуальной упаковке и специальной пластиковой посуде: закуска, хлеб, булочка/кекс/пирожное/конфеты, масло, мягкий сыр, соус. В отдельном пакетике - соль, сахар, перец, столовые приборы, салфетки (влажная и сухая).

Ассортимент блюд зависит от бюджета авиакомпании, сезона, длительности полета, класса обслуживания, времени вылета, принципов здорового питания, национальных особенностей, конкретных вкусов и возраста пассажира.

Ассортимент предлагаемых блюд и напитков, возможности по предоставлению специальных видов питания рассмотрим на примере российской авиакомпании: «Аэрофлот Российские авиалинии» [3].

Питание в самолетах «Аэрофлота» делится на два «цикла». В зависимости от направления и продолжительности полета, предоставляется выбор из двух блюд: холодный или горячий завтрак, горячий или холодный обед и закуски. «Аэрофлот» - единственная российская авиакомпания, которая входит в рейтинг авиаперевозчиков с лучшим питанием на борту. Меню обновляется каждые шесть недель [4].

\section{Меню класса «Эконом»}

В зависимости от направления, времени вылета и продолжительности полета предлагается завтрак, обед или закуски. Выбор горячих и прохладительных напитков также предоставляется в зависимости от длительности и направления полета.

Выбор алкогольных напитков (вино и пиво) предоставляется к рациону «Горячий обед». Пиво предоставляется на рейсах продолжительностью свыше 6-ти часов. В Таблицах 1-3 представлено меню для рейсов различной длительностью полета.

В Таблицах Б/Ж/У/ЭЦ означает белки/жиры/углеводы/энергетическая ценность. Пищевая ценность (белки/жиры/углеводы) дана в граммах, энергетическая ценность в килокалориях на 100 г блюда.

Таблица 1.

МЕНЮ ДЛЯ РЕЙСОВ ПРОДОЛЖИТЕЛЬНОСТЬЮ ПОЛЕТА ДО 3 ЧАСОВ

\begin{tabular}{|c|c|c|c|c|}
\hline \multicolumn{5}{|c|}{ Рейсы продолжсительностью до 3-х часов полета } \\
\hline & Из Москвы & В Москву & Б/Ж/У/ЭЦ* & Б/Ж/У/ЭЦ* \\
\hline \multirow{2}{*}{ 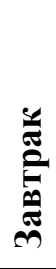 } & $\begin{array}{c}\text { Круассан с сыром, } \\
\text { рулетом из индейки, } \\
\text { икрой из вяленых томатов } \\
\text { и кремчизом с зеленью }\end{array}$ & $\begin{array}{c}\text { Круассан с сыром, } \\
\text { куриным рулетом, } \\
\text { маринованными огурцами } \\
\text { и кремчизом с соусом } \\
\text { Барбекю } \\
\end{array}$ & $10,69 / 24,1 / 19,3 / 340$ & $10,0 / 22,9 / 20,3 / 331$ \\
\hline & \multicolumn{2}{|c|}{ Йогурт натуральный, Шоколад «Аленка» } & \multicolumn{2}{|c|}{$5,0 / 14,9 / 33,8 / 291$} \\
\hline \multirow{2}{*}{$\stackrel{5}{0}$} & $\begin{array}{c}\text { Чиабатта с сыром, } \\
\text { рулетом из индейки, } \\
\text { маринованными огурцами } \\
\text { и кремчизом с соусом } \\
\text { Хойсин } \\
\end{array}$ & $\begin{array}{c}\text { Чиабатта с сыром, } \\
\text { куриным рулетом, перцем } \\
\text { гриль и кремчизом с } \\
\text { сушеными помидорами }\end{array}$ & $11,3 / 14,4 / 19,5 / 257$ & $10,4 / 12,9 / 17,8 / 233$ \\
\hline & \multicolumn{2}{|c|}{ Яблоко, Фруктовый батончик } & \multicolumn{2}{|c|}{$2,6 / 0,5 / 24,2 / 117$} \\
\hline
\end{tabular}


Таблица 2.

МЕНЮ ДЛЯ РЕЙСОВ ПРОДОЛЖИТЕЛЬНОСТЬЮ ОТ 3 ДО 6 ЧАСОВ ПОЛЕТА

\begin{tabular}{|c|c|c|c|c|}
\hline \multicolumn{5}{|c|}{ ЗАВТРАК } \\
\hline & Из Москввы & В Москву & Б/Ж/У/ЭЦ* & Б/Ж/У/ЭЦ* \\
\hline Закуска & $\begin{array}{l}\text { Запеченные баклажаны } \\
\text { с куриной грудкой, } \\
\text { сыром и яйцом }\end{array}$ & $\begin{array}{l}\text { Индейка, говядина, } \\
\text { сыр, помидор Черри }\end{array}$ & $10,1 / 5,6 / 3,5 / 100$ & $18,6 / 10,3 / 0,3 / 169$ \\
\hline $\begin{array}{l}\text { Основное } \\
\text { блюдо }\end{array}$ & Омлет с рататуем & $\begin{array}{l}\text { Фриттата с } \\
\text { картофелем и } \\
\text { сладким перцем, } \\
\text { сливочный соус }\end{array}$ & $7,9 / 12,4 / 2,0 / 151$ & $10,6 / 18,8 / 4,7 / 231$ \\
\hline или & $\begin{array}{l}\text { Геркулесовая каша с } \\
\text { яблоком и корицей }\end{array}$ & $\begin{array}{l}\text { Кукурузная каша с } \\
\text { персиком }\end{array}$ & $9,8 / 5,3 / 65,3 / 338,3$ & $3,2 / 0,5 / 30,3 / 140$ \\
\hline или & Блинчики с вишней & $\begin{array}{l}\text { Блинчики с } \\
\text { шоколадным соусом }\end{array}$ & $5,2 / 10,3 / 23,5 / 202,8$ & $8,1 / 12,4 / 41,7 / 324$ \\
\hline Десерт & Шоколад «Алёнка» & $\begin{array}{l}\text { Фруктовый } \\
\text { батончик }\end{array}$ & $5,7 / 27,9 / 61,4 / 522$ & $9,8 / 0,6 / 72,3 / 352$ \\
\hline & \multicolumn{2}{|c|}{$\begin{array}{l}\text { Йогурт, сливочное масло, джем, круассан, } \\
\text { майонезный соус }\end{array}$} & \multicolumn{2}{|c|}{$6,0 / 24,8 / 28,4 / 361$} \\
\hline \multicolumn{5}{|c|}{ ОБЕД/УЖИН } \\
\hline & Из Москввы & В Москву & Б/Ж/У/ЭЦ* & Б/Ж/У/ЭЦ* \\
\hline Закуска & $\begin{array}{l}\text { Тунец с картофелем, } \\
\text { огурцом, зеленой } \\
\text { фасолью, яйцом }\end{array}$ & $\begin{array}{l}\text { Салат Русский с } \\
\text { куриным рулетом и } \\
\text { помидором Черри }\end{array}$ & $10,3 / 2,28 / 8,03 / 95$ & $8,45 / 17,8 / 3,93 / 213$ \\
\hline $\begin{array}{l}\text { Основное } \\
\text { блюдо }\end{array}$ & $\begin{array}{l}\text { Рыбная котлета с } \\
\text { томатно-сливочным } \\
\text { соусом, рисом и } \\
\text { зеленой фасолью }\end{array}$ & $\begin{array}{l}\text { Курица по- } \\
\text { строгановски с } \\
\text { гречневой кашей и } \\
\text { зеленой фасолью }\end{array}$ & $9,3 / 4,8 / 12,0 / 128$ & $7,4 / 6,6 / 11,2 / 130$ \\
\hline или & $\begin{array}{l}\text { Тушеная говядина с } \\
\text { пастой, зеленой } \\
\text { фасолью и морковью }\end{array}$ & $\begin{array}{l}\text { Баранина с } \\
\text { булгуром и } \\
\text { морковью }\end{array}$ & $10,6 / 7,5 / 28,6 / 227$ & $13,6 / 10,8 / 6,2 / 181$ \\
\hline Десерт & $\begin{array}{l}\text { Тульский пряник с } \\
\text { фруктовой начинкой }\end{array}$ & $\begin{array}{l}\text { Фруктовый } \\
\text { батончик }\end{array}$ & $4,1 / 5,1 / 53,6 / 272$ & $9,8 / 0,6 / 72,3 / 352$ \\
\hline & \multicolumn{2}{|c|}{$\begin{array}{c}\text { Сливочное масло, сливочный сыр, булочка, } \\
\text { ржаной хлеб, майонезный соус }\end{array}$} & \multicolumn{2}{|c|}{$5,8 / 23,1 / 29,8 / 361,1$} \\
\hline
\end{tabular}

Таблица 3.

МЕНЮ ДЛЯ РЕЙСОВ ПРОДОЛЖИТЕЛЬНОСТЬЮ ОТ 6 ЧАСОВ ПОЛЕТА, ВЫЛЕТАЮЩИЕ ИЗ МОСКВЫ

\begin{tabular}{llc}
\hline & \multicolumn{1}{c}{ Первое обслуживание } \\
\hline \multicolumn{1}{c}{ Блюда } & Б/Ж/У/ЭЦ \\
\hline Закуска & Тунец с картофелем, огурцом, фасолью и яйцом & $10,3 / 2,3 / 8,0 / 95$ \\
\hline $\begin{array}{l}\text { Основное } \\
\text { блюдо }\end{array}$ & $\begin{array}{l}\text { Рыбная котлета с томатно-сливочным соусом, рисом и зеленой } \\
\text { фасолью }\end{array}$ & $9,3 / 4,8 / 12,0 / 128$ \\
\hline или & Тушеная говядина с пастой, зеленой фасолью и морковью & $10,6 / 7,5 / 28,6 / 227$ \\
\hline Десерт & $\begin{array}{l}\text { Бисквитное пирожное с шоколадной глазурью и кокосовой } \\
\text { стружкой }\end{array}$ & $5,3 / 23,5 / 44,7 / 402$ \\
\hline & $\begin{array}{l}\text { Сливочное масло, сливочный сыр, булочка, ржаной хлеб, } \\
\text { майонезный соус }\end{array}$ & $5,8 / 23,1 / 29,8 / 361$ \\
\hline
\end{tabular}

Второе обслуживание

(Гонконг, Гуанчжоу, Сеул, Токио, Бангкок, Ханой, Хочимин, Петропавловск-Камчатский, Южно-Сахалинск, Владивосток, Хабаровск)

Закуска Индейка, говядина, сыр, помидор Черри

$18,6 / 10,3 / 0,3 / 169$ 


\begin{tabular}{|c|c|c|}
\hline Основное блюдо & Кукурузная каша с персиком & $3,2 / 0,5 / 30,3 / 140$ \\
\hline или & Блинчики с шоколадным соусом & $8,1 / 12,4 / 41,7 / 324$ \\
\hline \multirow[t]{3}{*}{ Десерт } & Печенье и фруктово-ягодный батончик & $5,8 / 6,1 / 75,9 / 360$ \\
\hline & Сливочное масло, булочка, ржаной хлеб & $5,7 / 19,9 / 35,9 / 357$ \\
\hline & \multicolumn{2}{|l|}{ Вашингтон, Нью-Йорк } \\
\hline Закуска & Индейка, говядина, сыр, помидор Черри & $18,6 / 10,3 / 0,3 / 168$ \\
\hline Основное блюдо & Паста с куриной грудкой и томатно-сливочным соусом & $15,3 / 1,7 / 44,1 / 257$ \\
\hline или & Равиоли со шпинатом и сливочным соусом Песто & $8,4 / 1,4 / 48,6 / 239$ \\
\hline \multirow[t]{2}{*}{ Десерт } & Печенье и фруктово-ягодный батончик & $5,8 / 6,1 / 75,9 / 359$ \\
\hline & Сливочное масло, булочка, ржаной хлеб & $5,7 / 19,9 / 35,9 / 357$ \\
\hline \multicolumn{3}{|c|}{ Гавана, Майами, Лос-Анджелес } \\
\hline Закуска & Салат Русский с куриным рулетом и помидором Черри & $8,5 / 17,8 / 3,9 / 213$ \\
\hline Основное блюдо & $\begin{array}{c}\text { Курица по-строгановски с гречневой кашей и зеленой } \\
\text { фасолью }\end{array}$ & $7,4 / 6,6 / 11,2 / 130$ \\
\hline или & Баранина с булгуром и морковью & $13,6 / 10,8 / 6,1 / 181$ \\
\hline \multirow[t]{2}{*}{ Десерт } & Песочное пирожное & $5,9 / 21,1 / 56,3 / 437$ \\
\hline & $\begin{array}{c}\text { Сливочное масло, сливочный сыр, майонезный соус, } \\
\text { булочка, ржаной хлеб }\end{array}$ & $5,9 / 23,1 / 29,8 / 361$ \\
\hline
\end{tabular}

Также существует опция заказа специального питания в классе Эконом на рейсах свыше 3 часов, дополнительная плата за которое не взимается.

Возможен заказ по 5 разделам: национальная кухня (питание «Русское» - блюда традиционной русской кухни), диетическое питание (без добавленного сахара/с низким содержанием молочного белка/с низким содержанием жиров/ без содержания клейковины/ низкокалорийное питание/питание без добавленной соли), питание, разработанное с учетом религиозных убеждений (постное, мусульманское, халяльное, индуистское невегетарианское, кошерное), вегетарианские блюда (вегетарианское строгое, вегетарианское хинду, фруктовое питание), а также детское питание (детский набор и детское питание для грудных младенцев).

\section{Меню класса «Комфорт»}

Пассажирам класса Комфорт предлагается приветственный напиток и предоставляется карта меню. Питание сервируется в многоразовой пластиковой посуде с металлическими столовыми приборами, горячие блюда подаются в фарфоровой посуде.

В течение полета в классе Комфорт предусмотрено 2 обслуживания питанием на рейсах продолжительностью свыше 6 часов.

Меню данного класса представлено для 14 направлений (из Москвы в Бангкок, Пхукет, Пекин, Гонгконг, Дубай, Лос-Анджелес, Нью-Йорк, Владивосток, Хабаровск, ПетропавловскКамчатский, Сеул, Шанхай, Тель-Авив, Южно-Сахалинск и обратно).

Учитывая разнообразие блюд и широкую географию полетов, рассмотрим лишь часть направлений и сравним предоставляемый рацион: 
Таблица 4.

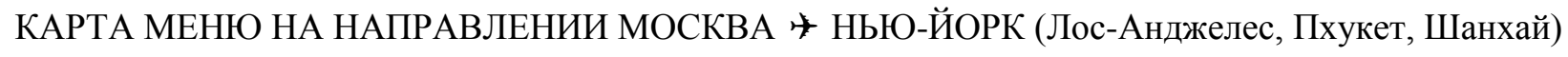

\begin{tabular}{|c|c|c|}
\hline \multicolumn{3}{|c|}{ ОБЕД } \\
\hline Тип блюда & Состав & $Б / Ж / У / Э Ц^{*}$ \\
\hline Закуска & Листья салата, говядина и маринованные опята & $8,3 / 2,8 / 0,2 / 59$ \\
\hline Салат & Салат из свежих овощей & $1,2 / 2,0 / 3,1 / 35$ \\
\hline $\begin{array}{l}\text { Основное } \\
\text { блюдо }\end{array}$ & $\begin{array}{c}\text { Перепёлка, фаршированная овощами, с тыквой и пюре из } \\
\text { брокколи, с соусом Демиглас }\end{array}$ & $19,5 / 30,4 / 19,8 / 431$ \\
\hline или & $\begin{array}{c}\text { Палтус, запечённый в листе Хоба, с рисом и брокколи, } \\
\text { с соусом Мисо }\end{array}$ & $26,3 / 9,0 / 32,1 / 315$ \\
\hline или & Дуэт из цветной капусты & $6,3 / 7,6 / 14,4 / 151$ \\
\hline Десерт & Песочное пирожное & $1,5 / 3,9 / 25,6 / 144$ \\
\hline & $\begin{array}{c}\text { Ржаной хлеб. Булочка Брецель. Сливочное масло. } \\
\text { Оливковое масло }\end{array}$ & $\begin{array}{c}1,4 / 0,2 / 8,8 / 43 \\
2,2 / 0,7 / 14,4 / 73\end{array}$ \\
\hline \multicolumn{3}{|c|}{ УЖИН } \\
\hline Закуска & Салат Столичный с куриной грудкой & $5,6 / 4,5 / 4,4 / 80$ \\
\hline Салат & Листья салата, помидоры Черри, кедровые орешки, крутоны & $2,0 / 3,5 / 5,3 / 61$ \\
\hline $\begin{array}{l}\text { Основное } \\
\text { блюдо }\end{array}$ & $\begin{array}{l}\text { Кролик по-охотничьи с овощами и полентой со шпинатом, } \\
\text { с мясным соусом }\end{array}$ & $36,9 / 21,1 / 12,3 / 388$ \\
\hline или & Запечённый сибас с чечевицей и овощами, с соусом из ревеня & $23,5 / 16,8 / 20,0 / 325$ \\
\hline или & Кукурузные оладьи, с томатным соусом & $9,2 / 16,5 / 28,9 / 301$ \\
\hline Десерт & Пирожное Картошка & $2,5 / 19,7 / 26,6 / 294$ \\
\hline & $\begin{array}{c}\text { Ржаной хлеб. Булочка Брецель. Сливочное масло. } \\
\text { Майонезный соус }\end{array}$ & $\begin{array}{c}1,4 / 0,2 / 8,8 / 43 \\
2,2 / 0,7 / 14,4 / 73 \\
\end{array}$ \\
\hline
\end{tabular}

КАРТА МЕНЮ МОСКВА $~$ БАНГКОК

Таблица 5.

(Шанхай, Пекин, Гонгконг, Петропавловск-Камчатский, Сеул)

\begin{tabular}{|c|c|c|}
\hline & & УЖИН \\
\hline Тип блюда & Состав & Б/Ж/У/ЭЦ* \\
\hline Закуска & Листья салата, говядина и маринованные опята & $8,3 / 2,8 / 0,2 / 59$ \\
\hline Салат & Салат из свежих овощей & $1,2 / 2,0 / 3,1 / 35$ \\
\hline Основное блюдо & $\begin{array}{r}\text { Перепёлка, фаршированная овощами, с тыквой и пюре } \\
\text { из брокколи, с соусом Демиглас }\end{array}$ & $19,5 / 30,4 / 19,8 / 431$ \\
\hline или & $\begin{array}{r}\text { Палтус, запечённый в листе Хоба, с рисом и брокколи, } \\
\text { с соусом Мисо }\end{array}$ & $26,3 / 9,0 / 32,1 / 315$ \\
\hline или & Дуэт из цветной капусты & $6,3 / 7,6 / 14,4 / 151$ \\
\hline \multirow[t]{3}{*}{ Десерт } & Песочное пирожное & $1,5 / 3,9 / 25,6 / 144$ \\
\hline & $\begin{array}{r}\text { Ржаной хлеб. Булочка Брецель. Сливочное масло. } \\
\text { Оливковое масло }\end{array}$ & $\begin{array}{r}1,4 / 0,2 / 8,8 / 43 \\
2,2 / 0,7 / 14,4 / 73\end{array}$ \\
\hline & $3 A B T P A K$ & \\
\hline \multirow[t]{2}{*}{ Закуска } & Салат Русский с говядиной и сыром & $11,4 / 7,7 / 3,9 / 130$ \\
\hline & Фруктовый салат & $0,9 / 0,1 / 12,7 / 55$ \\
\hline Основное блюдо & $\begin{array}{c}\text { Омлет с индейкой, шпинатом, грибами и помидором } \\
\text { Черри }\end{array}$ & $20,8 / 20,5 / 2,3 / 277$ \\
\hline или & Блинчики с малиной & $7,4 / 21,0 / 37,4 / 368$ \\
\hline или & Кукурузная каша с курагой и черносливом & $8,5 / 10,8 / 57,1 / 360$ \\
\hline \multirow[t]{2}{*}{ Десерт } & Песочное кольцо & $2,2 / 9,4 / 20,9 / 178$ \\
\hline & $\begin{array}{c}\text { Джем. Круассан. Йогурт. Сливочное масло. } \\
\text { Майонезный соус }\end{array}$ & $\begin{array}{l}0,0 / 0,0 / 12,6 / 50 \\
2,5 / 9,3 / 15,8 / 157 \\
4,0 / 3,1 / 6,2 / 69\end{array}$ \\
\hline
\end{tabular}


Таблица 6.

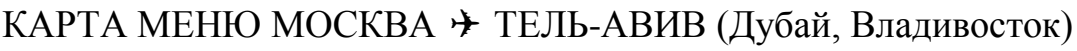

\begin{tabular}{|c|c|c|}
\hline \multicolumn{3}{|c|}{$3 A B T P A K$} \\
\hline Тип блюда & Сосmaв & Б/Ж/У/ЭЦ* \\
\hline \multirow[t]{2}{*}{ Закуска } & Говядина, куриный рулет, сыр Моцарелла и помидор Черри & $7,8 / 5,0 / 1,9 / 84$ \\
\hline & Фруктовый салат & $0,8 / 0 / 10,6 / 46$ \\
\hline Основное блюдо & Омлет с грибами, подается с сырным соусом & $14,1 / 21,0 / 2,8 / 257$ \\
\hline или & Блины с муссом из сливочного сыра и лосося, овощи на гриле & $11,0 / 17,6 / 17,3 / 272$ \\
\hline или & Пшённая каша с тыквой & $1,9 / 10,8 / 28,2 / 230$ \\
\hline \multirow[b]{2}{*}{ Десерт } & Фруктовое пирожное & $1,8 / 5,6 / 15,6 / 120$ \\
\hline & $\begin{array}{l}\text { Джем. Круассан. Йогурт } \\
\text { Сливочное масло }\end{array}$ & $\begin{array}{c}0,0 / 0,0 / 12,6 / 50 \\
2,5 / 9,3 / 15,8 / 157 \\
4,0 / 3,1 / 6,2 / 69\end{array}$ \\
\hline \multicolumn{3}{|c|}{ ОБЕД/УЖИН } \\
\hline \multirow{2}{*}{ Закуска } & Салат Русский с говядиной и сыром & $11,4 / 7,7 / 3,9 / 130$ \\
\hline & Фруктовый салат & $0,9 / 0,1 / 12,7 / 55$ \\
\hline Основное блюдо & Омлет с индейкой, шпинатом, грибами и помидором Черри & $20,8 / 20,5 / 2,3 / 277$ \\
\hline или & Блинчики с малиной & $7,4 / 21,0 / 37,4 / 368$ \\
\hline или & Кукурузная каша с курагой и черносливом & $8,5 / 10,8 / 57,1 / 360$ \\
\hline \multirow[t]{2}{*}{ Десерт } & Песочное кольцо & $2,2 / 9,4 / 20,9 / 178$ \\
\hline & $\begin{array}{c}\text { Джем. Круассан. Йогурт. Сливочное масло. } \\
\text { Майонезный соус }\end{array}$ & $\begin{array}{c}0,0 / 0,0 / 12,6 / 50 \\
2,5 / 9,3 / 15,8 / 157 \\
4,0 / 3,1 / 6,2 / 69\end{array}$ \\
\hline
\end{tabular}

На всех направлениях предоставляется стандартный набор напитков:

Вина: белое вино, красное вино;

Пиво: Жигули барное;

Вода: газированная, негазированная;

Прохладительные напитки: «Пепси кола», «Пепси лайт», «7UP» и другие;

Соки: апельсиновый, яблочный, томатный;

Горячие напитки: чай Greenfield в ассортименте: "Earl Grey Fantasy", "Classic Breakfast", "Japanese Sencha", "Jasmine Dream", "Lemon Spark", "Barberry Garden", "Spring Melody", "Summer Bouquet", "Flying Dragon", "Kenyan Sunrise" и кофе.

Меню класса «Бизнес»

Таблица 7.

МЕНЮ НА РЕЙСАХ КОРОТКОЙ ПРОДОЛЖИТЕЛЬНОСТИ КЛАССА «БИЗНЕС»

\begin{tabular}{|c|c|c|c|c|}
\hline \multicolumn{5}{|c|}{ Меню на рейсах короткой продолжительности } \\
\hline \multicolumn{5}{|c|}{$3 A B T P A K$} \\
\hline & Из Москвы & В Москву & $\overline{E / K /}$ & ЭЦ* \\
\hline Закуска & $\begin{array}{c}\text { Говядина, куриный } \\
\text { рулет, сыр Сулугуни, } \\
\text { консервированное } \\
\text { яблоко, брусничный } \\
\text { джем, свежие фрукты }\end{array}$ & $\begin{array}{c}\text { Говядина, индейка, } \\
\text { сыры Гранд и Грюер, } \\
\text { консервированные } \\
\text { фрукты }\end{array}$ & $18,6 / 9,7 / 2,7 / 172$ & $27,1 / 20,8 / 7,1 / 324$ \\
\hline & \multicolumn{2}{|c|}{ Йогурт } & \multicolumn{2}{|c|}{$4,0 / 3,1 / 6,2 / 69$} \\
\hline & \multicolumn{2}{|c|}{ Джем } & \multicolumn{2}{|c|}{$0,1 / 0,1 / 18,0 / 76$} \\
\hline $\begin{array}{l}\text { Горячие } \\
\text { блюда }\end{array}$ & $\begin{array}{c}\text { Блин с кленовым } \\
\text { сиропом }\end{array}$ & $\begin{array}{c}\text { Омлет с сыром и соусом } \\
\text { Бешамель }\end{array}$ & $3,6 / 10,5 / 26,4 / 214$ & $18,1 / 19,3 / 2,5 / 256$ \\
\hline
\end{tabular}


ОБЕД

\begin{tabular}{|c|c|c|c|c|}
\hline & Из Москвы & В Москву & Б/Ж/ & ЭЦ* \\
\hline Закуски & $\begin{array}{c}\text { Лосось в свекольном } \\
\text { маринаде, свежие } \\
\text { огурцы и крошка из } \\
\text { бородинского хлеба, со } \\
\text { сливочным сыром с } \\
\text { хреном } \\
\end{array}$ & $\begin{array}{c}\text { Сёмга с апельсином, } \\
\text { оливками и } \\
\text { каперсами, с } \\
\text { медовым соусом с } \\
\text { лаймом }\end{array}$ & $12,1 / 15,3 / 8,5 / 220$ & $22,0 / 18,6 / 5,2 / 276$ \\
\hline или & $\begin{array}{c}\text { Говядина Пастрами с } \\
\text { грушей и каперсами, с } \\
\text { желе из белого вина }\end{array}$ & $\begin{array}{c}\text { Говядина с сыром } \\
\text { Пармезан, вялеными } \\
\text { помидорами, } \\
\text { оливками и } \\
\text { каперсами, с соусом } \\
\text { из тунца }\end{array}$ & $8,2 / 3,1 / 21,2 / 145$ & $16,4 / 32,2 / 2,1 / 364$ \\
\hline $\begin{array}{l}\text { Горячие } \\
\text { блюда }\end{array}$ & $\begin{array}{c}\text { Запечённый сибас с } \\
\text { чёрным рисом и } \\
\text { овощами, с томатным } \\
\text { соусом с базиликом }\end{array}$ & $\begin{array}{c}\text { Запечённый лосось с } \\
\text { капустой, вялеными } \\
\text { помидорами и } \\
\text { брокколи, с соусом } \\
\text { Хойсин } \\
\end{array}$ & $21,5 / 11,2 / 21,3 / 272$ & $26,7 / 18,2 / 15,7 / 333$ \\
\hline \multirow[t]{2}{*}{ или } & $\begin{array}{c}\text { Медальоны из говядины } \\
\text { с овощами и } \\
\text { устричными грибами, с } \\
\text { грибным соусом }\end{array}$ & $\begin{array}{c}\text { Куриное бедро, } \\
\text { запечённое в йогурте, } \\
\text { с чёрным рисом и } \\
\text { капустой пак-чой, с } \\
\text { манговым соусом }\end{array}$ & $29,4 / 11,5 / 6,1 / 245$ & $25,7 / 21,8 / 21,8 / 386$ \\
\hline & $\begin{array}{c}\text { Паста с овощами и } \\
\text { сливочно-томатным } \\
\text { соусом }\end{array}$ & $\begin{array}{l}\text { Пилав с овощами, } \\
\text { кешью и миндалём }\end{array}$ & $6,9 / 20,5 / 35,6 / 355$ & $7,0 / 33,0 / 19,2 / 402$ \\
\hline Десерты & $\begin{array}{l}\text { Ванильное мороженое с } \\
\text { миндальными хлопьями }\end{array}$ & $\begin{array}{c}\text { Панна котта с } \\
\text { вишневым вареньем }\end{array}$ & $4 / 14,8 / 13,2 / 202$ & $2,1 / 18,0 / 21,8 / 258$ \\
\hline
\end{tabular}

МЕНЮ НА РЕЙСАХ СРЕДНЕЙ ПРОДОЛЖИТЕЛЬНОСТИ КЛАССА «БИЗНЕС»

Таблица 8.

\begin{tabular}{|c|c|c|c|c|}
\hline \multicolumn{5}{|c|}{ Меню на рейсах средней продолжительности } \\
\hline \multicolumn{5}{|c|}{$3 A B T P A K$} \\
\hline \multirow{3}{*}{ Закуска } & Из Москвы & В Москву & Б/Ж/ & /ЭЦ* \\
\hline & $\begin{array}{c}\text { Говядина, куриный } \\
\text { рулет, сыр Сулугуни, } \\
\text { консервированное } \\
\text { яблоко, брусничный } \\
\text { джем, свежие фрукты }\end{array}$ & $\begin{array}{c}\text { Говядина, индейка, } \\
\text { сыры Гранд и Грюер, } \\
\text { консервированные } \\
\text { фрукты }\end{array}$ & $18,6 / 9,7 / 2,7 / 172$ & $27,1 / 20,8 / 7,1 / 324$ \\
\hline & \multicolumn{2}{|c|}{$\begin{array}{l}\text { Йогурт } \\
\text { Джем }\end{array}$} & \multicolumn{2}{|c|}{$\begin{array}{c}4,0 / 3,1 / 6,2 / 69 \\
0,1 / 0,1 / 18,0 / 76\end{array}$} \\
\hline \multirow{3}{*}{$\begin{array}{l}\text { Горячие } \\
\text { блюда }\end{array}$} & $\begin{array}{c}\text { Фриттата с сыром и } \\
\text { овощами }\end{array}$ & $\begin{array}{l}\text { Омлет с сыром и } \\
\text { соусом Бешамель }\end{array}$ & $12,9 / 15,0 / 4,0 / 203$ & $18,1 / 19,3 / 2,5 / 256$ \\
\hline & $\begin{array}{l}\text { Блины с соусом из } \\
\text { чёрной смородины }\end{array}$ & $\begin{array}{c}\text { Блинчики со } \\
\text { сливочным сыром и } \\
\text { яблоком }\end{array}$ & $7,3 / 21,0 / 38,8 / 373$ & $4,6 / 13,0 / 24,8 / 235$ \\
\hline & Каша овсяная с яблоком & $\begin{array}{c}\text { Рисовая каша с тыквой } \\
\text { и лаймом }\end{array}$ & $4,0 / 3,4 / 29,3 / 164$ & $4,2 / 0,9 / 50,0 / 225$ \\
\hline
\end{tabular}




\begin{tabular}{|c|c|c|c|c|}
\hline \multicolumn{5}{|c|}{ ОБЕД } \\
\hline & Из Москвы & В Москву & \multicolumn{2}{|c|}{ Б/Ж/У/ЭЦ } \\
\hline Закуска & $\begin{array}{c}\text { Лосось в свекольном } \\
\text { маринаде, свежие } \\
\text { огурцы и крошка из } \\
\text { бородинского хлеба, } \\
\text { со сливочным сыром с } \\
\text { хреном }\end{array}$ & $\begin{array}{c}\text { Сёмга с апельсином, } \\
\text { оливками и каперсами, с } \\
\text { медовым соусом с } \\
\text { лаймом }\end{array}$ & $12,1 / 15,3 / 8,5 / 220$ & $22,0 / 18,6 / 5,2 / 276$ \\
\hline или & $\begin{array}{c}\text { Говядина Пастрами с } \\
\text { грушей и каперсами, с } \\
\text { желе из белого вина }\end{array}$ & $\begin{array}{c}\text { Говядина с сыром } \\
\text { Пармезан, вялеными } \\
\text { помидорами, оливками } \\
\text { и каперсами, с соусом } \\
\text { из тунца }\end{array}$ & $8,2 / 3,1 / 21,2 / 145$ & $16,4 / 32,2 / 2,1 / 364$ \\
\hline $\begin{array}{l}\text { Горячие } \\
\text { блюда }\end{array}$ & $\begin{array}{c}\text { Запечённый сибас с } \\
\text { чёрным рисом и } \\
\text { овощами, с томатным } \\
\text { соусом с базиликом }\end{array}$ & $\begin{array}{c}\text { Запечённый лосось с } \\
\text { капустой, вялеными } \\
\text { помидорами и } \\
\text { брокколи, с соусом } \\
\text { Хойсин } \\
\end{array}$ & $21,5 / 11,2 / 21,3 / 272$ & $26,7 / 18,2 / 15,7 / 333$ \\
\hline или & $\begin{array}{c}\text { Медальоны из } \\
\text { говядины с овощами и } \\
\text { устричными грибами, } \\
\text { с грибным соусом }\end{array}$ & $\begin{array}{c}\text { Куриное бедро, } \\
\text { запечённое в йогурте, с } \\
\text { чёрным рисом и } \\
\text { капустой пак-чой, с } \\
\text { манговым соусом } \\
\end{array}$ & $29,4 / 11,5 / 6,1 / 245$ & $25,7 / 21,8 / 21,8 / 386$ \\
\hline или & $\begin{array}{c}\text { Паста с овощами и } \\
\text { сливочно-томатным } \\
\text { соусом }\end{array}$ & $\begin{array}{l}\text { Пилав с овощами, } \\
\text { кешью и миндалём }\end{array}$ & $6,9 / 20,5 / 35,6 / 355$ & $7,0 / 33,0 / 19,2 / 402$ \\
\hline
\end{tabular}

Таблица 9.

МЕНЮ НА РЕЙСАХ ДЛИТЕЛЬНОЙ ПРОДОЛЖИТЕЛЬНОСТИ КЛАССА «БИЗНЕС»

\begin{tabular}{|c|c|c|}
\hline \multicolumn{3}{|c|}{ Меню на рейсах длительной продолжительности } \\
\hline Тип блюда & Сосmaв & Б/Ж/У/ЭЦ“* \\
\hline Аперетив & $\begin{array}{c}\text { Блинчик с лососем, сливочным сыром с васаби и } \\
\text { красной икрой }\end{array}$ & $5,1 / 5,8 / 2,1 / 81$ \\
\hline Закуска & $\begin{array}{c}\text { Лосось, тартар из цуккини, маринованный патиссон с сыром, со } \\
\text { сливочным сыром с луком Чайвс }\end{array}$ & $11,2 / 23,4 / 4,2 / 272$ \\
\hline Салат & $\begin{array}{c}\text { Листья салата, утиная грудка, вяленые помидоры, манго, } \\
\text { медово-лаймовая заправка }\end{array}$ & $1,2 / 10,2 / 3,8 / 112$ \\
\hline Суп & Борщ с говядиной, черносливом и сметаной & $7,1 / 12,2 / 18,5 / 212$ \\
\hline $\begin{array}{l}\text { Горячие } \\
\text { блюда }\end{array}$ & $\begin{array}{c}\text { Фаршированные куриные крылышки с овощами и пюре из } \\
\text { брокколи, с соусом Барбекю }\end{array}$ & $11,7 / 20,4 / 20,1 / 311$ \\
\hline или & $\begin{array}{c}\text { Чёрная треска с капустой пак-чой, кумкватом и имбирём, } \\
\text { с кокосово-лаймовым соусом }\end{array}$ & $21,3 / 7,1 / 12,6 / 199$ \\
\hline или & Овощной тиан, с томатным соусом со сладким перцем & $2,6 / 16,1 / 12,4 / 205$ \\
\hline \multicolumn{3}{|c|}{ Меню из Москвы на рейсах продолюительностью более 6 часов, вылетающих в вечернее время суток } \\
\hline Закуска & $\begin{array}{c}\text { Ассорти из утки, оленины и говядины, с каштаном, грушей и } \\
\text { соусом из чёрной смородины с горчицей }\end{array}$ & $8,8 / 8,8 / 11,5 / 160$ \\
\hline \multicolumn{3}{|c|}{ Аперетив и горячие блюда аналогичны блюдам на рейсах длительной продолжительности } \\
\hline \multirow{2}{*}{ Десерт } & Ванильное мороженое с хлопьями миндаля & $3,9 / 14,7 / 13,4 / 201$ \\
\hline & Ананасовый торт с ванильно-ореховым кремом & $4,4 / 10,7 / 32,0 / 242$ \\
\hline
\end{tabular}


На рейсах свыше 12 часов полета в Лос-Анджелес, Майами, Гавану пассажирам будет предложен дополнительный рачион - сэндвич и фрукты

\begin{tabular}{|c|c|c|}
\hline & вич с козьим сыром и инжирной мостардой & $5,6 / 4,4 / 8,3 / 95$ \\
\hline & с индейкой и сливочным сыром с томатной сальсой & $7,8 / 4,7 / 13,6 / 128$ \\
\hline & Апельсин & $1,7 / 0,3 / 15,3 / 71$ \\
\hline & Чомпу (розовое яблоко) & $0,6 / 0,6 / 19,0 / 83$ \\
\hline & Виноград & $0,6 / 0,6 / 15,0 / 64$ \\
\hline \multicolumn{3}{|c|}{ Между рачионами предлагается корзина со снэками } \\
\hline \multicolumn{2}{|r|}{ Пастила Белёвская } & $0,3 / 0 / 73,5 / 294$ \\
\hline \multicolumn{2}{|c|}{ Фруктово-ореховый батончик с клюквой, миндалём и семенами льда } & $6,1 / 15,2 / 65,6 / 424$ \\
\hline \multicolumn{2}{|r|}{ Ассорти с орешками и сухофруктами } & $11,2 / 27,9 / 46,6 / 483$ \\
\hline \multicolumn{2}{|r|}{ Колечки с солью } & $5,5 / 30 / 53 / 520$ \\
\hline \multicolumn{3}{|c|}{ Во втором обслуживании пассажирам предлагается } \\
\hline \multirow{3}{*}{ Завтрак } & Ассорти из сыров, курага, чернослив, ананасовый десерт & $13,3 / 16,3 / 18,4 / 273$ \\
\hline & Блин с кленовым сиропом & $3,6 / 10,5 / 26,4 / 214$ \\
\hline & Йогурт натуральный & $4,0 / 3,1 / 6,2 / 69$ \\
\hline \multirow[t]{2}{*}{ Обед } & Ассорти из сыров, курага, чернослив, ананасовый десерт & $13,3 / 16,3 / 18,4 / 273$ \\
\hline & Тушёная говядина с картофельным пюре & $10,5 / 13,0 / 10,1 / 199$ \\
\hline
\end{tabular}

На рейсах в Китай, Вьетнам, Японию, Корею и Таиланд пассажирам предлагаются специально разработанные сеты национальной кухни страны назначения. Виды сетов представлены в Таблице 10 .

Таблица 10.

СЕТЫ НАЦИОНАЛЬНОЙ КУХНИ

\begin{tabular}{|c|c|c|}
\hline Tun cema & Cocmaв & Б/Ж/У/ЭЦ \\
\hline \multirow{5}{*}{$\begin{array}{l}\text { Китайский } \\
\text { сет }\end{array}$} & Салат с говядиной по-азиатски и помидором Черри & $3,5 / 1,8 / 2,1 / 39$ \\
\hline & Баклажаны с помидорами, чесноком и красным острым перцем & $0,9 / 5,0 / 3,6 / 63$ \\
\hline & Суп с креветочным вонтоном & $4,1 / 8,2 / 4,8 / 109$ \\
\hline & Курица в кисло-сладком соусе с запеченным ананасом & $19,1 / 14,4 / 12,8 / 256$ \\
\hline & Рис Жасмин & $2,4 / 0,1 / 25,8 / 114$ \\
\hline \multirow{5}{*}{$\begin{array}{l}\text { Вьетнамский } \\
\text { сет }\end{array}$} & Говядина с красным маринованным луком и острым перцем & $2,3 / 0,5 / 3,4 / 27$ \\
\hline & Овощной салат с арахисом, с вьетнамской рыбной заправкой & $2,7 / 2,5 / 5,4 / 50$ \\
\hline & Куриный суп с рисовой вермишелью и зеленым луком & $8,2 / 11,7 / 6,0 / 162$ \\
\hline & Говядина со сладким перцем, кукуруза и перец гриль & $24,7 / 13,6 / 10,1 / 261$ \\
\hline & Рис с овощами & $2,9 / 7,2 / 15,2 / 137$ \\
\hline \multirow{6}{*}{$\begin{array}{l}\text { Японский } \\
\text { сет }\end{array}$} & Ролл Филадельфия, васаби и имбирь & $10,3 / 9,9 / 19,2 / 207$ \\
\hline & Салат Чука с лимоном & $0,5 / 1,2 / 9,8 / 52$ \\
\hline & Соевый соус & $2,0 / 0,0 / 1,6 / 15$ \\
\hline & Суп Мисо с Тофу и водорослями Вакаме & $1,8 / 0,8 / 10,1 / 55$ \\
\hline & $\begin{array}{c}\text { Говядина тушеная в сладком соевом соусе с жареным сладким } \\
\text { перцем, фасолью и кунжутом }\end{array}$ & $19,9 / 12,3 / 15,3 / 251$ \\
\hline & Рис Жасмин & $2,4 / 0,1 / 25,8 / 114$ \\
\hline \multirow{6}{*}{$\begin{array}{l}\text { Корейский } \\
\text { сет }\end{array}$} & Маринованные огурцы по-корейски & $0,5 / 0,7 / 1,1 / 13$ \\
\hline & Жареные креветки с овощами & $3,4 / 0,5 / 1,4 / 24$ \\
\hline & Соус Чили Гулин & $0,7 / 1,4 / 2,2 / 24$ \\
\hline & Кунжутный суп с ростками сои & $10,6 / 6,6 / 8,4 / 135$ \\
\hline & $\begin{array}{c}\text { Говядина тушеная с овощами Калбипчим и острым перцем, с } \\
\text { соусом Чили Гулин }\end{array}$ & $18,4 / 5,1 / 13,8 / 174$ \\
\hline & Рис Жасмин & $2,4 / 0,1 / 25,8 / 114$ \\
\hline
\end{tabular}




\begin{tabular}{lcc}
\hline & Курица с соусом Сатай, базиликом и кинзой & $7,3 / 8,0 / 4,6 / 120$ \\
Тайский & Креветки на гриле & $8,7 / 1,8 / 0 / 51$ \\
сет & Тайский острый соус чили & $1,5 / 0,5 / 1,8 / 18$ \\
& Суп Том Кха с кинзой & $12,3 / 4,8 / 13,5 / 146$ \\
& Говядина в устричном соусе и овощи по-тайски со свежей кинзой & $24,9 / 13,5 / 8,1 / 253$ \\
& Рис Жасмин & $2,4 / 0,1 / 25,8 / 114$ \\
\hline
\end{tabular}

Пассажирам, совершающим полеты бизнес-классом на рейсах средней и короткой продолжительности, предоставляется возможность попробовать блюда из меню, разработанным Камелем Бенмамаром - бренд-шефом ресторана «Рыбы нет» - успешного проекта Аркадия Новикова.

Еще одна особенность питания на борту авиалайнеров компании «Аэрофлот» является опция «Меню на заказ». Данная опция предлагается в дополнение к стандартному рациону питания. Количество порций, предлагаемых для заказа на одном рейсе, ограничено и составляет 24 порции. Оплата производится как в процессе оформления билета, так и после.

АССОРТИМЕНТ БЛЮД ОПЦИИ «МЕНЮ НА ЗАКАЗ»

Таблица 11.

\begin{tabular}{|c|c|c|}
\hline Блюдо & Cocmaв & Б/Ж/У/ЭЦ“* \\
\hline $\begin{array}{l}\text { Сырная } \\
\text { закуска }\end{array}$ & $\begin{array}{c}\text { ассорти из сыров: дор блю, бри, диабло, сулугуни, грушевая } \\
\text { мостарда, виноград, томатные крекеры, мини-багет, сливочное } \\
\text { масло, джем }\end{array}$ & $23,7 / 36,7 / 26,1 / 530$ \\
\hline $\begin{array}{l}\text { Рыбная } \\
\text { закуска }\end{array}$ & $\begin{array}{c}\text { рыбное ассорти: слабосоленый лосось, осетрина горячего } \\
\text { копчения, муксун холодного копчения; волован с красной икрой, } \\
\text { крем-чиз с хреном, лимон, каперс, мини-багет, черный хлеб, } \\
\text { сливочное масло }\end{array}$ & $31,8 / 16,3 / 3,8 / 349$ \\
\hline $\begin{array}{l}\text { Мясная } \\
\text { закуска }\end{array}$ & $\begin{array}{c}\text { запечённый ростбиф, говяжий язык, индейка и куриная грудка, } \\
\text { запечённая в травах и специях, маринованные огурчики, хрен, } \\
\text { сливочное масло, мини-багет, томатные крекеры, соус Барбекю }\end{array}$ & $37,7 / 20,5 / 3,7 / 350$ \\
\hline $\begin{array}{l}\text { Клубничный } \\
\text { мильфей }\end{array}$ & $\begin{array}{c}\text { пирожное из слоеного теста с ванильным кремом из взбитых } \\
\text { сливок, свежая клубника, свежая мята }\end{array}$ & $5,1 / 16 / 42,3 / 334$ \\
\hline $\begin{array}{l}\text { Шоколадная } \\
\text { тарталетка }\end{array}$ & $\begin{array}{c}\text { тарталетка из песочного теста с кремом из темного шоколада и } \\
\text { кокосовым соусом, свежая мята }\end{array}$ & $7,6 / 47,4 / 42,6 / 627$ \\
\hline $\begin{array}{l}\text { Груша в } \\
\text { красном вине }\end{array}$ & $\begin{array}{c}\text { груша, тушенная в красном вине, песочный бисквит с пралине, } \\
\text { жареным миндаль, соус из красного вина, свежая мята }\end{array}$ & $4,9 / 15,9 / 45,7 / 346$ \\
\hline
\end{tabular}

Как видно из представленных данных, компания «Аэрофлот - Российские авиалинии» предлагает разнообразный рацион питания пассажиров на борту авиалайнера.

\section{Источники:}

(1). Липатова Т. Н. Организация питания пассажиров на борту воздушного судна. Пособие для бортпроводников. Ульяновск: УВАУ ГА. 2012.

(2). Бортовое питание. Режим доступа: https://clck.ru/MCrEL (дата обращения 04.04.2019)

(3). ПАО «Аэрофлот - Российские авиалинии»: Питание на борту. Авиакомпания «Аэрофлот». 2008-2019. Режим доступа: https://clck.ru/MCrEW (дата обращения: 01.04.2019)

(4). Питание на борту: что нужно знать. 2007-2019. Режим доступа: https://clck.ru/MCrEk (дата обращения: 04.04.2019) 


\section{References:}

(1). Lipatova, T. N. (2012). Organizatsiya pitaniya passazhirov na bortu vozdushnogo sudna. Posobie dlya bortprovodnikov. Ul'yanovsk: UVAU GA.

(2). Bortovoe pitanie. Rezhim dostupa: https://clck.ru/MCrEL (data obrashcheniya 04.04.2019)

(3). PAO «Aeroflot - Rossiiskie avialinii»: Pitanie na bortu. Aviakompaniya «Aeroflot». 2008-2019. Rezhim dostupa: https://clck.ru/MCrEW (data obrashcheniya: 01.04.2019)

(4). Pitanie na bortu: chto nuzhno znat'. 2007-2019. Rezhim dostupa: https://clck.ru/MCrEk (data obrashcheniya: 04.04.2019)

Работа поступила

в редакциию 16.01.2020 2.
Принята к публикациии 20.01.2020 z.

Ссылка для циитирования:

Беркетова Л. В., Игинова Р. В. Питание на воздушных суднах: анализ меню (Часть 1) // Бюллетень науки и практики. 2020. Т. 6. №2. С. 170-181. https://doi.org/10.33619/2414$2948 / 51 / 17$

Cite as (APA):

Berketova, L., \& Iginova, R. (2020). Nutrition on Aircrafts: a Menu Analysis (Part 1). Bulletin of Science and Practice, 6(2), 170-181. https://doi.org/10.33619/2414-2948/51/17 (in Russian). 


\section{ИССЛЕДОВАНИЕ СИСТЕМ УПРАВЛЕНИЯ ПРЕДПРИЯТИЕМ: СУЩНОСТЬ, МЕТОДЫ И ПРОБЛЕМЫ}

(CАбдуллаев A. M., ORCID: 0000-0002-7971-8490, SPIN-код: 7860-6146, канд. экон. наук, Ферганский политехнический институт, г. Фергана, Узбекистан, iqtisodiyot_bosh@mail.ru СКурпаяниди К. И., ORCID: 0000-0001-8354-1512, SPIN-код: 2321-7606, ResearcherID: $Q$ 5596-2016, Ph.D., Российская академия естествознания, Ферганский политехнический институт, г. Фергана, Узбекистан, konstantin@ferpi.uz,w7777@mail.ru

(C)Тешабаев A. Э., ORCID: 0000-0001-6298-5018, SPIN-код: 5545-2892, канд. техн. наук, Ферганский политехнический институт, г. Фергана, Узбекистан, ateshabaev1958@gmail.com

ССолиева Д. А., базовый докторант, Андижанский машиностроительный институт, 2. Андижан, Узбекистан, soliyeva_dilnoza@mail.ru

\section{RESEARCH OF ENTERPRISE MANAGEMENT SYSTEMS: ESSENCE, METHODS AND PROBLEMS}

(CAbdullaev A., ORCID: 0000-0002-7971-8490, SPIN-code: 7860-6146, Ph.D., Ferghana Polytechnic Institute, Ferghana, Uzbekistan, iqtisodiyot_bosh@mail.ru

CKurpayanidi K., ORCID: 0000-0001-8354-1512, SPIN-code: 2321-7606, ResearcherID: Q-55962016, Ph.D., Russian Academy of Natural Sciences, Fergana Polytechnic Institute, Fergana,Uzbekistan, konstantin@ferpi.uz

CTeshabaev A., ORCID: 0000-0001-6298-5018, SPIN-code: 5545-2892,

Ph.D., Fergana polytechnic institute, Fergana, Uzbekistan, ateshabaev1958@gmail.com CSolieva D., Ph.D. student, Andizhan machine-building institute, Andizhan,Uzbekistan,soliyeva_dilnoza@mail.ru

Аннотащия. Необходимость соответствия конкурентоспособного предприятия требованиям рыночной экономики обязывает его постоянно совершенствоваться как технологически, так и организационно. Базой организационных инноваций служит изучение систем управления организацией - деятельности, направленной на развитие и совершенствование управления в соответствии с постоянно изменяющимися внешними и внутренними условиями. Совершенствование управления современных динамично развивающихся предприятий, как социотехнических систем, требует исследования их свойств, что связано с решением задачи выполнения исследования на высоком научном и методическом уровне. Статья посвящена сущности, принципам, методам и проблемам проведения этих исследований.

Abstract. The need for a competitive enterprise to meet the requirements of a market economy requires it to constantly improve both technologically and organizationally. The basis of organizational innovation is the study of management systems of organizations - activities aimed at developing and improving management in accordance with constantly changing external and internal conditions. Improving the management of modern dynamically developing enterprises, as socio-technical systems, requires the study of their properties, which is associated with solving the problem of performing research at a high scientific and methodological level. The article is devoted to the essence, principles, methods and problems of conducting these studies. 
Ключевые слова: исследование, организация, менеджмент, наблюдения, опыт, подходы, система управления.

Keywords: research, organization, management, observation, experience, approaches, management system.

\section{Введение}

В условиях динамичности современного производства и общественного устройства, управление находиться в состоянии постоянного развития, которое в настоящее время невозможно осуществить без исследования путей и возможностей этого развития, без выбора альтернативных направлений, без инноваций $[1,2]$.

Исследование управления осуществляется в каждодневной деятельности менеджеров и персонала и в работе специализированных аналитических групп, лабораторий, отделов.

Исследователями и практиками управления предприятиями и опытом экономической жизни последних десятилетий, высокий уровень развития управления предприятиями определено как решающий фактор успеха предприятий.

Успех предприятий определяется большим количеством факторов, и потому, выделение роли и количественное определение значимости управления в успехе предприятий представляет собой большую сложную задачу оценки деятельности предприятия. Исследование различных сфер деятельности современных предприятий - это в первую очередь сбор и анализ данных, определяющих ситуацию и тенденции развития предприятия на современном этапе [2].

\section{Материал и методы исследования}

Для развития методов и совершенствования управления и деятельности компаний наиболее важными являются:

изучение потенциальных возможностей компании в данной сфере хозяйствования;

анализ трендов в этой отрасли экономики;

определение и оценка движущих сил развития;

сравнительная оценка результатов хозяйственной деятельности с учетом перспектив развития.

Опыт проведения исследований показывает, что на качество исследований влияют следующие факторы:

наличие специалистов высокой квалификации и опыта проведения исследований;

глубокое знание особенностей технологии производства продукта;

объективность в проведении исследований;

наличие специальных стандартизованных программ исследования;

востребованность результатов исследования для высшего руководства компаний.

На основе анализа доступной литературы и собственного опыта работы на производстве, в том числе и инновационной деятельности, связанной с внедрением новых методов организации труда и анализом эффективности отдельных управленческих решений, самостоятельного проведения исследований в области управления современными предприятиями (на примере АО «Дженерал Моторс Узбекистан», как наиболее развитом в 
технологическом отношении отечественного промышленного предприятия), можно утверждать, что для того, чтобы исследования были эффективными:

они должны носить систематический характер;

должен соблюдаться научный подход, базирующийся на объективности и точности; сбор, регистрация и анализ данных должны проводиться на самом нижнем уровне управления.

\section{Результаты и обсуждение}

В этих условиях необходимо переходить с обработки уже существующей вторичной информации, т.е. данных, собранных на предприятии для целей, отличных от решаемой в настоящий момент проблемы (кабинетного метода исследований), к полевым исследованиям - сбору и обработке специально собираемых данных для конкретного анализа. В лучшем, идеальном случае, полевое исследование предполагает участие исследователя в получении им первичной информации путем накопления собственноручно полученных строго научными методами данных и на основе собственных наблюдений и опросов участников процесса управления и организации технологических процессов.

Для исследований в области управления предприятием, особенно касающихся проблем развития управленческих инструментов и методов, техники и технологий, и, особенно, персонала, наиболее развитым и широко применяемым способом получения нужной информации становится опрос круга лиц, имеющих непосредственное отношение к исследуемой проблеме, что позволяет выявить сущность процессов через личное отношение каждого.

В настоящее время одним из наиболее важных показателей потенциала развития предприятия является активность персонала в улучшении работы предприятия через совершенствование технологических процессов, повышение производительности труда и качества продукции, снижения ее себестоимости в рамках рационализаторской деятельности и работы «кружков качества».

Как указывали в своих работах исследователи проблем современного менеджмента Masaaki Imai [3], Joseph M. Juran [4], James P. Womack, D.T. Jones [5] и другие, деятельность по совершенствованию работы предприятия является важной особенностью современного производства и составной частью современных систем производства, таких как Quality System Management (Система Управления качеством), TQM (Всеобщее управление качеством), Lean production (Бережливое производство) или Continuous Improvement (Постоянные улучшения), указанные системы внедрены и успешно применяются на предприятиях АК «Узавтосаноат», самой технологически совершенной отрасли современного автомобилестроения [6,7].

Вместе с тем, необходимо дальнейшее совершенствование деятельности отрасли. Согласно Постановлению Президента Республики, Узбекистан ПП №3028 от 1 июня 2017 г «О мерах по дальнейшему совершенствованию управления и ускоренному развитию автомобильной промышленности на 2017-2021 годы» [8], к 2021 г предприятия АО «Узавтосаноат» должны увеличить производство товарной продукции в 3 раза, снизить долю импорта в производстве до 12,5\%, увеличить количество занятых в отрасли до $120 \%$. Постановлением предусматривается освоение 51 нового проекта, в т.ч. 7 новых моделей автомобилей, техническое перевооружение и модернизация 9 предприятий отрасли, -35 проектов локализация сырья (в т.ч. стали для автомобилестроения) и авто компонентов.

По нашему мнению, решение поставленных Постановлением задач требует коренного улучшения организации деятельности предприятий, прежде всего, это касается проблем, 
имеющих отраслевое значение, как развития инфраструктуры, совершенствования управления и, прежде всего, системы менеджмента качества, подготовки квалифицированных кадров и др.

Рассмотрим особенности, сущность, методы и проблемы совершенствования Систем менеджмента качества на современных предприятиях. Значимость систем менеджмента качества по ISO 9000 имеет важнейшее, абсолютно подтверждаемое значение для экономики любой страны. По данным международных исследований, за счет внедрения стандартов ISO 9001 и улучшения качества товаров и услуг, повышения доверия к качеству отечественной продукции, удовлетворения ожиданий и требований потребителей достигается рост на $1 \%$ валового внутреннего продукта, т.е. 864 доллара США на потребителя и снижение инфляции на $0,4 \%$.

Сертификация на требования международных стандартов ISO 9000 по новейшей версии, создание интегрированных систем менеджмента качества последнего поколения это большие затраты, которые должны обеспечивать высокую их отдачу через результаты и эффективность систем. Особо значима деятельность по качеству для промышленности Узбекистана, которая проходит этап модернизации и освоения новых видов производств. Крупные предприятия различных отраслей экономики разработали и активно внедряют самые передовые стратегии, в т.ч и методы управления, включая управление качеством по новой версии международного стандарта ISO 9001:2015 на AO “Узбекистан темир йуллари, AO "Navoiyazot” и другие (https://clck.ru/MCrHW; https://clck.ru/MCrHj)

Перечень предприятий, сертифицированных систем управления качеством и внесенных в Государственный реестр сертифицированных систем управления качеством (СМК) Республики Узбекистан составляет на 01.12.2019 г 10694 систем СМК, сертифицированных на 10427 предприятиях и организациях республики на соответствие требованиям международных стандартов. В том числе по ISO 9001-9923, по ISO 14001-99, по OHSAS 18001-143, по ISO 50001-69, по ISO/TS 16949 (обеспечение качества поставляемых частей в автомобилестроении — 43 и по GMP - 22. То есть системы менеджмента качества отечественных предприятий в основном строятся на базе Международных стандартов ISO 9000, хотя существуют и другие модели систем менеджмента качества [9].

Однако, несмотря на большие затраты, внимание и поддержку государственных органов управления, и руководство самих компаний системы менеджмента качества зачастую не оправдывают возлагаемых на них надежд. В первую очередь это относится к достижению главной, системообразующей цели стандартизации - обеспечение высокого, надлежащего качества продукции и услуг и развитию предприятия и системы управления.

По мнению подавляющего большинства, опрошенных (до 80\%) - специалистов и руководителей производства, специалистов по качеству и специалистов по системам качества на предприятиях автомобильной промышленности АК «Узавтосаноат», результативность систем менеджмента качества не соответствует ожиданиям, как и эффективность всего управления качеством, результаты деятельности отделов и групп систем менеджмента качества слабо коррелируются с показателями качества.

Причиной этого множество, основными из которых являются:

организащионные - создание отдельных от структурных подразделений качества структурных подразделений систем менеджмента качества (СМК), облегчает процессы создания и сертификации, развития систем менеджмента качества, но эффективность в обеспечении качества становится слабой, ввиду создания СМК как самодостаточной цели;

административные - слабая увязка показателей эффективности СМК с другими общезаводскими при планировании и контроле, 
слабой подготовке работников подразделений СМК в части - администрирования процессами производства и нехваткой полномочий, которые являются ответной стороной ответственности за качество конечной продукции производства;

недостаточный уровень развития менеджмента предприятия, определяемый, например, по числу приглашенных экспертов для решения узкоспециальных проблем, в т.ч. проблем обеспечения качества продукции и процессов.

Большинство указанных проблем носит формализованный характер, т.е. понятно природа проблемы, ее причины и драйверы, тенденции развития и решения. Ввиду сложности указанных проблем, их решение требует проведения комплексных исследований на высоком научном и методическом уровне.

Важнейшей задачей управления качеством и частью современного менеджмента предприятий является организация и мотивация творческой работы персонала по улучшению качества и совершенствованию продукции и процессов.

В работах по японскому менеджменту указывалось, что своими успехами в обеспечении качества продукции японские компании во многом обязаны творческому отношению к работе своих сотрудников. Например, на японских автомобильных компаниях каждым работником в год подается в среднем 61,6 предложений по улучшению процессов, в то время как этот показатель для их европейских коллег равнялся 0,4 [10].

Поэтому изучение, освоение, адаптация и развитие методов вовлечения работников в управление качеством продукции и общего развития компании, формирование творческого отношения работников к своей работе стало одной из первоочередных целей и задач европейских и американских исследователей и практиков менеджмента качества.

На изучение сущности, методов и инструментов менеджмента качества японских предприятий были направлены значительные ресурсы, и закономерно, были достигнуты большие успехи, например, показатели подачи предложений по улучшениям «кайзен» составили для 4,2 для США и 1,9 — для европейских автозаводов [11, 12].

Вовлеченность работников в улучшение качества продукции и процессов, расширение их технического творчества признается весьма важной и на предприятиях АК «Узавтосаноат», в первую очередь на АO "UzAuto Motors", OOO "SamAvto" и "JV MAN Auto - Uzbekistan".

Так на AO "UzAuto Motors" по образцу зарубежных партнеров еще с 2000 года была развернута система предложений по улучшению производства, во многом схожая с рационализаторством. За этот период подача рационализаторских предложений увеличилась с 402 в 2000 г до 12183 в 2012 г, подача рацпредложений на 1 работника выросла с 0,12 до 2,11 . Коэффициент внедрения (соотношение внедренных и поданных рацпредложений) за эти годы вырос с $35,1 \%$ до $66 \%$ и участие работников в рационализаторстве (коэффициент вовлеченности) увеличилось с $3 \%$ до $82,7 \%$.

По показателям подачи рацпредложений на 1 работника и их внедрения AO “UzAuto Motors" достиг показателей европейских автомобильных компаний, а вовлеченность работников в рационализаторской деятельности оказалось выше среднеевропейских показателей на 18\%. Экономия от внедрения рацпредложений уже 2011 г составила 678 млн. сум, а для предложений поданных в 2012 г экономический эффект превысил более 1 млрд. сум, что ясно показывает успехи в рационализаторстве.

Однако, дальнейшая история рационализаторского движения и, в общем, инновационной деятельности в компании характеризуется стагнацией, что выражается как показателями подачи рационализаторских предложений на рабочих участках и местах, так и свертыванием некоторых программ инновационной деятельности. Детальный анализ 
инновационной деятельности позволяет говорить о проблемах в развитии рационализаторства - формализм и администрирование, большое количество мелких, ради галочки, предложений, низкая ценность большинства предложений.

Для оценки состояния и определения путей улучшения рационализаторства были проведены опросы участников рационализаторского движения на предмет выявления реальных проблем в развитии рационализаторства работников всех категорий. Изучались следующие факторы рационализаторской деятельности:

мотивы участия (стремления улучшить условия труда и вознаграждения);

движущих сил (инициативности, инновационности и требования руководства);

системных факторов (производственная и управленческая культура, производственный климат, поддержка и препятствующие факторы).

Для опроса использовался опросный бланк - анкета из 25 вопросов, по которым опрашиваемым оценивались 10 факторов мотивов, движущих сил, поддержки или препятствий рационализаторской деятельности.

Каждый вопрос оценивался в баллах — от 1 до 5. Было опрошено 154 работника организаторы рационализаторского движения и лучшие рационализаторы в ранге от рабочего (13 чел.), квалифицированного рабочего (27 чел.), бригадира (16 чел.), мастер (48 чел.), инженер (14 чел.), ассистент менеджера (25 чел.), менеджера (13 чел.) и ассистента генерального менеджера (12 чел.).

Основной целью проведения опроса было установить связь между следующими факторами:

уровнем развития работников и их активностью;

развитием системы предложений и результативностью работников;

мотивацией материальной и моральной;

административным воздействием;

качеством предложений.

По итогам опроса, собственных наблюдений и экспертной оценки установлено следующее:

наличие прямой связи числа подаваемых рацпредложений и административного воздействия в подразделения (выполнение плана подачи рационализаторских предложений);

наличие обратной связи между плотностью регистрации предложений за календарный период и показателями классности подаваемых рационализаторских предложений;

наличия прямой связи между квалификацией автора предложения и экономическим эффектом подаваемого предложения;

отсутствие устойчивых корреляционных связей между 10 группами показателей, что объясняется как несовершенством самого метода опроса и анкетирования, так и неадекватной оценкой групп показателей партисипантами опроса.

Для выявления движителей рационализаторства и мотивов технического творчества на современном промышленном предприятии необходимо продолжить исследования в направлении:

увеличения выборки путем расширения круга опрашиваемых лиц и включения работников, не участвующих в рационализаторстве;

совершенствования анкеты; 
проведения панельных опросов, т.е. опросов специально подобранных и квалифицированных лиц, через определенные интервалы для отслеживания динамики процессов.

В целом, можно сделать вывод, что практическая подготовка и осуществление опросов на предприятиях должны иметь строго научный подход к решению исследуемой проблемы и должную методическую базу.

Стратегия развития предприятия, основанная на высвобождении личной инициативы, предполагает усиление роли передового, инновационного менеджмента в обеспечении благоприятных условий хозяйствования:

Необходимо решить главный вопрос управления работниками: кому, как, за что и сколько платить. Если платить по труду, то надо учитывать:

труд прошлый (заслуги прошлого периода);

нынешний (результаты, эффективность настоящего периода);

будущий (наращивание потенциала развития работника на будущее);

что на современном предприятии в основном почасовая оплата труда, что труд - это процесс совместной деятельности (мера труда не имеет отдельной стоимости, его нельзя взвесить или измерить в отдельности от труда других работников).

Любые различные измерители этого процесса, в частности, нормативы - условны и абстрактны, оплата должна зависеть от созданной совместным трудом бригады и отделов добавленной стоимости, для чего необходимо вводить KPI - Key Performance Indicators (ключевых показателей эффективности).

Следует указать, что управление персоналом в части развития инициативы и творчества, весьма специфична, поскольку чем больше ограничений имеет такая малоорганизующаяся система, тем больше она требует ресурсов и энергии для поддержания своего существования, следовательно, развивается труднее, медленнее, чем система без лишних ограничений.

Менеджмент - это вид деятельности человека, который имеет общие и специфические черты. Общие черты отражают этапы развития и уровень научно-технического прогресса и отражены в различных научных подходах. Специфические черты отражают национальные особенности - культуру, прежде всего трудовой и производственной, уровень социальноэкономических отношений, что дает понимание существования американской, японской, и, теперь отечественной модели менеджмента [13].

В условиях развития рыночной экономики отечественный менеджмент отличают:

чрезвычайно высокая скорость протекания социально-экономических процессов, определяющих бизнес-среду менеджмента;

комплекс факторов, затрудняющих укрепление научного менеджмента в Узбекистане;

отсутствие объективных оценок деятельности управленцев, ротации менеджеров внутри организаций и школ резерва руководящих кадров;

низкий уровень управленческого учета и анализа эффективности деятельности предприятий и подразделений [14-17].

В самом общем виде, предметом исследований в современном менеджменте является проблемы, как реальные противоречия, требующее своего разрешения - противоречие 
стратегии и тактики управления, условий рынка и возможностей фирмы, квалификации персонала и потребностей в инновациях и пр.

Методологии исследования предполагает цель исследований, как выбора проблем и подходов - исходных позиций и отправных точек, с которых исследование начинается, и которая определяет его направленность относительно цели.

Подходы могут быть аспектный, системный и концептуальный.

Аспектный подход представляет выбор одной грани проблемы по принципу актуальности, или наличия ресурсов, выделенные на исследование. Так, например, проблема развития персонала может иметь экономический аспект, социально-психологический, образовательный и т.д.

Системный подход отражает более высокий уровень методологии исследования. Он требует максимально возможного учета всех аспектов проблемы в их взаимосвязи и целостности, выделения главного и существенного, определения характера связей между аспектами, свойствами и характеристиками.

Концептуальный подход предполагает предварительную разработку концепции исследования, т.е. комплекса ключевых положений, определяющих направленность, архитектонику и преемственность исследования.

Подходы также могут быть эмпирическими, прагматическими и научными. Если в основном опираются на опыт - эмпирические, если на задачи получения ближайшего результата - прагматические. Наиболее эффективным является конечно, научный подход, который характеризуется научной постановкой целей исследования и использованием научного аппарата в его проведении $[18,19]$.

Методология исследования должна включать также определение и формулирование ориентиров и ограничений. Они позволяют проводить исследование более последовательно и целеустремленно. Ориентиры могут быть гибкими и жесткими, а ограничения явными или неявными [20].

Главную роль в методологии играют средства и методы исследования, которые можно разделить на три группы: формально - логические, общенаучные и специфические. Формально-логические - это методы интеллектуальной деятельности человека, составляющей основу исследований управления. Общенаучные методы отражают научный аппарат исследования, определяющий эффективность любого их типа. Специфические - это методы, которые рождаются спецификой систем правления и отражают специфику управленческой деятельности [21, 22].

\section{Заключение}

В заключение, можно сделать вывод, что исследования управления, в том числе и управления качеством, требуют большой, основательной и практической подготовки, выбора надежных и достоверных источников информации, методов их интерпретации и обработки, должны иметь строго научный подход к решению исследуемой проблемы и должную методическую базу.

\section{Список литературь:}

1. Kurpayanidi K. I. Theoretical basis of management of innovative activity of industrial corporation // ISJ Theoretical \& Applied Science, 01(69). 2019. P. 7-14. http://dx.doi.org/10.15863/TAS 
2. Kurpayanidi K., Mamurov D. Features of the Support of the Innovative Activity: Foreign Experience and Practice for Uzbekistan // Бюллетень науки и практики. 2019. Т. 5. №11. С. 255261. https://doi .org/10.33619/2414-2948/48/29

3. Masaaki I. Kaizen: The key to Japan's competitive success // New York, ltd: McGraw-Hill. 1986.

4. Juran J. M. Juran, Quality, and a Century of Improvement. Quality Press, 2005. V. 15.

5. Womack J. P., Jones D. T. Lean solutions: how companies and customers can create value and wealth together. - Simon and Schuster, 2015.

6. Тешабаев А. Э. Совершенствование управления на современных предприятиях. Ташкент. 2017.

7. Тешабаев А. Э. Человеческий фактор в управлении компанией «УзДЭУавто» // Экономическое обозрение. 2001. №4. С. 40-42.

8. О мерах по дальнейшему совершенствованию управления и ускоренному развитию автомобильной промышленности на 2017-2021 годы.Постановление Президента Республики Узбекистан № ПП-3028 от 1 июня 2017 года // Собрание законодательства Республики Узбекистан, 2017 г., №23, ст. 454.

9. Государственный реестр сертифицированных систем качества. Режим доступа: URL: https://www.standart.uz/ru/page/view?id=43

10. Dillon A. P. A study of the Toyota production system: From an Industrial Engineering Viewpoint. Routledge, 2019. https://doi.org/10.4324/9781315136509

11. Carnerud D., Jaca C., Bäckström I. Kaizen and continuous improvement-trends and patterns over 30 years // The TQM Journal. 2018. https://doi.org/10.1108/TQM-03-2018-0037

12. Teece D. J. Tesla and the Reshaping of the Auto Industry // Management and Organization Review. 2018. V. 14. №3. P. 501-512. https://doi.org/10.1017/mor.2018.33

13. Badawy A. M. Technology management simply defined: A tweet plus two characters // Journal of Engineering and Technology Management. 2009. V. 26. №4. P. 219-224. https://doi.org/10.1016/j.jengtecman.2009.11.001

14. Хамидулин М. Б. Основные направления совершенствования корпоративного управления в Республике Узбекистан // Международный академический вестник. 2015. №6. C. 56-57.

15. Margianti E. S., Ikramov M. A., Abdullaev A. M. Entrepreneurship in Uzbekistan: trends, competitiveness, efficiency //Indonesia, Jakarta, Gunadarma Publisher. 2016.

16. Таиров С. Эффективность системы менеджмента качества в акционерных компаниях Узбекистана // Современные технологии в науке и образовании-СТНО-2017. 2017. C. $130-132$.

17. Abdullaev A. M., Kurpyanidi K. I. To the Problem of Classification of Institutional conditions determining enterprise structure in Uzbekistan // Scientific-technical journal. 2018. V. 22. №1. P. 101-106.

18. Vasilev E. M. A. V. L., Bakhvalov S. I., Prikhod'ko A. N., Kazakov A. V. Internal control in the system of innovation management in the modern business environment // International Journal of Economic Research. 2017. V. 14. №15. P. 409.

19. Yoshida K., Takano K. Research on organizational climate factors contribute to improving performance in modern companies // Journal of Japan Industrial Management Association. 2018. V. 69. №1. P. 1-20. https://doi.org/10.11221/jima.69.1

20. Foster G., Swenson D. W. Measuring the success of activity-based cost management and its determinants // Journal of management accounting research. 1997. V. 9. P. 109-142. 
21. Koskela L. J. et al. Management of production in construction: a theoretical view // Proceedings of the 7th Annual Conference of the International Group for Lean Construction. Berkeley, California, USA, 1999. http://usir.salford.ac.uk/id/eprint/9429

22. Teshabaev A. E. The methodological approaches to management improving for modern companies // Scientific-technical journal. 2018. V. 22. №2. P. 108-115.

\section{References:}

1. Kurpayanidi, K. I. (2019). Theoretical basis of management of innovative activity of industrial corporation. ISJ Theoretical \& Applied Science, 01 (69), 7-14. http://dx.doi.org/10.15863/TAS

2. Kurpayanidi, K., \& Mamurov, D. (2019). Features of the Support of the Innovative Activity: Foreign Experience and Practice for Uzbekistan. Bulletin of Science and Practice, 5(11), 255-261. https://doi .org/10.33619/2414-2948/48/29

3. Masaaki, I. (1986). Kaizen: The key to Japan's competitive success. New York, ltd: McGraw-Hill.

4. Juran, J. M. (2005). Juran, Quality, and a Century of Improvement (15). Quality Press.

5. Womack, J. P., \& Jones, D. T. (2015). Lean solutions: how companies and customers can create value and wealth together. Simon and Schuster.

6. Teshabaev, A. E. (2017). Sovershenstvovanie upravleniya na sovremennykh predpriyatiyakh. Tashkent. (In Russian).

7. Teshabaev, A. E. (2001). Chelovecheskii faktor v upravlenii kompaniei "UzDEUavto". Ekonomicheskoe obozrenie, (4). 40-42. (In Russian)

8. O merah po dal'nejshemu sovershenstvovaniju upravlenija i uskorennomu razvitiju avtomobil'noj promyshlennosti na 2017-2021 gody.Postanovlenie Prezidenta Respubliki Uzbekistan № PP-3028 ot 1 ijunja 2017 goda. Sobranie zakonodatel'stva Respubliki Uzbekistan, 2017 g., 23, st. 454. (In Russian)

9. Gosudarstvennyj reestr sertificirovannyh sistem kachestva. Rezhim dostupa: URL: https://www.standart.uz/ru/page/view?id=43 (In Russian)

10. Dillon, A. P. (2019). A study of the Toyota production system: From an Industrial Engineering Viewpoint. Routledge. https://doi.org/10.4324/9781315136509

11. Carnerud, D., Jaca, C., \& Bäckström, I. (2018). Kaizen and continuous improvementtrends and patterns over 30 years. The TQM Journal. https://doi.org/10.1108/TQM-03-2018-0037

12. Teece, D. J. (2018). Tesla and the Reshaping of the Auto Industry. Management and Organization Review, 14(3), 501-512. https://doi.org/10.1017/mor.2018.33

13. Badawy, A. M. (2009). Technology management simply defined: A tweet plus two characters. Journal of Engineering and Technology Management, 26(4), 219-224. https://doi.org/10.1016/j.jengtecman.2009.11.001

14. Khamidulin, M. B. (2015). Osnovnye napravleniya sovershenstvovaniya korporativnogo upravleniya $\mathrm{v}$ Respublike Uzbekistan. Mezhdunarodnyi akademicheskii vestnik, (6). 56-57. (In Russian)

15. Margianti, E. S., Ikramov, M. A., \& Abdullaev, A. M. (2016). Entrepreneurship in Uzbekistan: trends, competitiveness, efficiency. Indonesia, Jakarta, Gunadarma Publisher.

16. Tairov, S. (2016). Effektivnost' sistemy menedzhmenta kachestva v aktsionernykh kompaniyakh Uzbekistana. In Sovremennye tekhnologii v nauke i obrazovanii-STNO-2017 (130132). (In Russian) 
17. Abdullaev, A. M., \& Kurpyanidi, K. I. (2018). To the Problem of Classification of Institutional conditions determining enterprise structure in Uzbekistan. Scientific-technical journal, 22(1), 101-106.

18. Vasilev, E. M. A. V. L., Bakhvalov, S. I., Prikhod'ko, A. N., \& Kazakov, A. V. (2017). Internal control in the system of innovation management in the modern business environment. International Journal of Economic Research, 14(15), 409.

19. Yoshida, K., \& Takano, K. I. (2018). Research on organizational climate factors contribute to improving performance in modern companies. Journal of Japan Industrial Management Association, 69(1), 1-20. https://doi.org/10.11221/jima.69.1

20. Foster, G., \& Swenson, D. W. (1997). Measuring the success of activity-based cost management and its determinants. Journal of management accounting research, 9, 109-142.

21. Koskela, L. J. (1999, July). Management of production in construction: a theoretical view. In Proceedings of the 7th Annual Conference of the International Group for Lean Construction. Berkeley, California, USA. http://usir.salford.ac.uk/id/eprint/9429

22. Teshabaev, A. E. (2018). The methodological approaches to management improving for modern companies. Scientific-technical journal, 22(2), 108-115.

Работа поступила

в редакциюю 14.01.2020 2.
Принята к публикациии

19.01.2020 2.

Ссылка для циитирования:

Абдуллаев А. М., Курпаяниди К. И., Тешабаев А. Э., Солиева Д. А. Исследование систем управления предприятием: сущность, методы и проблемы // Бюллетень науки и практики. 2020. Т. 6. №2. С. 182-192. https://doi.org/10.33619/2414-2948/51/18

Cite as (APA):

Abdullaev, A., Kurpayanidi, K., Teshabaev, A., \& Solieva, D. (2020). Research of Enterprise Management Systems: Essence, Methods and Problems. Bulletin of Science and Practice, 6(2), 182192. https://doi.org/10.33619/2414-2948/51/18 (in Russian). 


\title{
STATISTICAL ANALYSES OF TOURISM IN UZBEKISTAN: AN EMPIRICAL TEST OF TOURISM A-B-C (T-ABC) MODEL
}

\author{
CJumayev A., ORCID: 0000-0001-8935-032X, Tashkent finance institute, \\ Tashkent, Uzbekistan, akbarjumayev@ rambler.ru
}

\section{СТАТИСТИЧЕСКИЙ АНАЛИЗ ТУРИЗМА В УЗБЕКИСТАНЕ: ЭМПИРИЧЕСКИЙ ТЕСТ МОДЕЛИ А-В-С (Т-АВС)}

\author{
()умаев A., ORCID: 0000-0001-8935-032X, Ташкентский финансовой институт, \\ 2. Ташкент, Узбекистан, akbarjuтауеv@ rambler.ru
}

Abstract. We empirically test the relationship between tourism performance and multiple tourism dimensions, namely, tourism Attractions (A), Basics (B), and Context (C). We test the Tourism A-B-C model using data from regions of Uzbekistan. The results serve to state out major trends, which focus on further research on this topic globally, and also they might be useful in diversifying interventions to improve the impacts in the tourism industry advancement.

Аннотация. Мы эмпирически тестируем взаимосвязь между показателями туризма и несколькими аспектами туризма, а именно: достопримечательности (А), основы (В) и контекст (С). Мы тестируем модель туризма А-B-C, используя данные из регионов Узбекистана. Результаты служат для определения основных тенденций, которые направлены на дальнейшие исследования по этой теме в глобальном масштабе, а также они могут быть полезны для диверсификации мероприятий, направленных на развитие туристической индустрии.

Keywords: Uzbekistan tourism, tourism infrastructure, tourism potential tourism performance, regional economic development, tourism A-B-C model.

Ключевые слова: туризм Узбекистана, инфраструктура туризма, туристический потенциал, показатели туризма, экономическое развитие региона, модель туризма А-В-С.

\section{Introduction}

Tourism is distinguished by high investment multiplier. One sum included in the tourism industry will generate 4 sums in other industries. According to the World Tourism Organization, $11 \%$ of the world's gross national product, $10 \%$ of investments, $11 \%$ of world consumption and $5 \%$ of tax revenues account for tourism.

Uzbekistan is a country with the potential for the expanded tourism industry. Many of its Central Asian cities were main points of trade on the Silk Road, linking Eastern and Western civilizations. Today the museums of Uzbekistan store over two million artefacts, evidence of the unique historical, cultural and spiritual life of the Central Asian peoples that have lived in the region. Uzbekistan attracts tourists with its historical, archaeological, architectural and natural treasures.

According to the Statistical Internet Survey, carried out in May 7-August 27, 2018, the largest proportion of those surveyed (39\%) visit the country because of their interest in the architectural and historical sites of Uzbekistan. The next-largest group (24\%) visit Uzbekistan to observe its 
culture, way of life and customs. Cultural Tourism is the only major product Uzbekistan is providing to visitors since its independence. Samarkand, Bukhara and Khiva are hot spots of tourism. Tourist activities in Uzbekistan range from outdoor activities, such as rock-climbing, to the exploration of its rich archaeological and religious history.

Uzbekistan is located on the Great Silk Road and many neighbouring countries (including Kazakhstan, Kyrgyz Republic, Tajikistan and Turkmenistan) promote their countries based on their location along the Great Silk Road. The World Tourism Organization's Silk Road Office was opened in Samarkand. This office was commissioned to coordinate the efforts of international organizations and national tourism offices of countries located on the Silk Road.

At present, the country is gradually implementing complex measures to diversify the national economy, to develop regions, to create new jobs, to increase the incomes and living standards of the population, as one of the strategic sectors of the country's investment attractiveness. Uzbekistan has huge tourism and recreational potential, with a total of 7,400 sites of cultural heritage, of which 209 are four museums - the Ichan Qala in Khiva, the historic centre of Bukhara, the historic centre of Shahrisabz, Samarkand City and is included in the UNESCO world heritage list. Every year the number of foreigners visiting the Republic of Uzbekistan is increasing. In the last 15 years, foreign citizens' visits to Uzbekistan have risen to 15,5 times, from 442,1 thousand in 2002 to 5346,2 thousand in 2018. The number of foreigners visiting Uzbekistan in 2018 was 8594,800, which is 6,5 times more than in 2002.

There are near seven billion people and about 200 countries around the world, we can say that citizen of the country has the right to travel another country of his choice. In the current globalized process, for example, Chile, which is far from Uzbekistan, can establish international tourism relations. The reason a person leaves their habitual environment is to look for tourist amenities such as conditions, historical places, and nature recourses that are not in that usual environment. Destination decisions mean that the selected state is more competitive in tourism than in other countries. The current activities of international tourism organizations aim to study the factors that influence the tourism industry of countries in its innovative development.

In February 2019 WTO hosted an international conference on "Sustainable Development and Factors Affecting Tourism". The conference presented an international index that shows the innovative development of tourism in countries. There are several statistical methods that analyze the factors that meet these indices and affect the innovative development of tourism.

This research paper is divided into four sections. The next section is material and research methods. In this section, the theory behind the T-ABC model is reviewed and we analyze the methodology of T-ABC model. In Section 3 comparative numerical data for the 14 regions of Uzbekistan is tabulated and discussed, and conclusions are drawn about the strengths and weaknesses of the 14 regions based on a variety of statistics. The number of tourists' arrivals in each country is also compared. We advance hypotheses regarding the relationship between tourism attractions, basics, and context on one hand, and tourism performance on the other. Section four offers a discussion of the research results and implications for the regional economic development of Uzbekistan.

\section{Material and research methods}

A number of inbound tourists and international tourism receipts - both deemed as key measures for assessing for our research, we have selected the T-ABC model, one of the most powerful methods for influencing the innovative development of tourism. First, it has a new model, and secondly, it fully meets the requirements of international indices that assess tourism innovation. 
The model was proposed by 2018 by Al Manrai and S. Friedeborn, University of Delaware Universities, one of the world's leading tourism research centres.

To be able to develop the theory behind our study of tourism in the fourteen regions in Uzbekistan, we must first introduce the T-ABC Model. The Model dimensions, namely, attractions, basics or necessities, and context or environment, were first identified by Manrai and Manrai [1] and later introduced as the Tourism ABC (or T-ABC) model in Manrai, Manrai, and Friedeborn [2]. The Model (see Fig. 1) includes critical considerations that tourists take into account in their destination choice.

Applied to the Uzbekistan context, the T-ABC Model dimension A stands for "attractions" (historical places and natural resources of tourism), dimension B stands for "basics" (accommodation, transportation etc.) and dimension C stands for "context" (crime, the safety of the country environment, etc.). Tourism attractions include all that may draw a tourist to a destination; interest is sparked in a destination when there are unique attractions, such as historical and natural resources of tourism opportunities, in the case of this study.

Once a competitive advantage is established, then destination management and sustainability become important factors in maintaining competitiveness [2]. Tourists seeking new experiences do not want to relinquish familiar comforts and, especially, the security of their home environment [3]. Tourism basics support the initial attraction of destinations: while tourism attractions establish a motivation for travel, tourism basics support that motivation [2].

Tourism basics include accessibility and affordability, including the ability to reach the destination, and the infrastructure that must be in place to welcome tourists, including security, and luxuries such as internet and personal banking access.

Tourism context is comprised of factors that could create a favourable impression, making it more likely that tourists would travel to a destination. Alternatively, there are factors that make tourists wary of travelling to destinations, such as health risks, pollution, quality of life, medical care, or literacy [2]. Strong, enforced regulations promoting a high quality of life and a sustainable tourism industry that ensures quality services for tourists are essential [2]. Importantly, tourism performance is a critical dimension of the T-ABC model. Tourism performance of destinations is assessed by Fig. 1. The Tourism-ABC model. determining the number of tourists and tourist expenditures. International tourist arrivals, international inbound tourists visiting from abroad, and international tourism receipts, expenditures by inbound international visitors from abroad, are deemed key measures used to assess tourism performance [4], but other dimensions, such as travel and tourism industry's total contribution to GDP and to employment, capture important information as well [2].

\section{Results and discussion}

The administrative-territorial division consists of the Republic of Karakalpakstan, twelve regions and the city of Tashkent. Uzbekistan has a favourable climate, with a certain degree of seasonal and daily fluctuations, a dry and hot summer with summers, a humid climate, and a changeable winter. Average temperature ranges from $+5.3^{\circ}$ to $-6^{\circ}$ in January and $+26^{\circ}$ to $+32^{\circ}$ in July.

The pearl of Central Asia is a mountainous region with the most temperate and fertile soil, capable to fully absorb the sun's rays for almost 320 days a year, with the vast amounts and quantities of all the elements of the Mendeleev periodical system. The unique nature of Uzbekistan, with its arid hot climate, rich historical and archaeological heritage, high spiritual values, traditions, national craftsmanship, and outstanding qualities and qualities of its people. The international 
community is widely recognized by the fact that the bee Republic has sufficient potential to become one of the world's tourist centres.

Uzbekistan has a great historical and cultural heritage - more than 7,300 ancient and architectural and archaeological sites. Most of them are located in Samarkand, Bukhara, Khiva, Shahrisabz, Termez, Kokand and Tashkent. More than 200 historical monuments and sites in our country are included in the UNESCO Cultural Heritage List.

\section{Tourism performance}

International tourists, tourism receipts, hotel nights

\begin{tabular}{|l|}
\multicolumn{1}{|c|}{ T-A } \\
Tourism attractions \\
1. Natural wonders, \\
scenery \\
2. Flora and fauna \\
3. National parks \\
4. World heritage sites \\
5.Museums \\
6.Cuisine \\
7.Cultural and historic \\
districts \\
8. Recreational facilities \\
9. Festivals \\
10. Shopping \\
11. Entertainment \\
12. Others
\end{tabular}

\begin{tabular}{|l|}
\multicolumn{1}{|c|}{ T-B } \\
\multicolumn{1}{|c|}{ Tourism basics } \\
1. Airports \\
2. Miles of roadways \\
3. Miles of railways \\
4. Hotels \\
5. Restaurants \\
6. Tour operators \\
7. Hospitals \\
8. Ease of internet and \\
international calling \\
9. Pulic transportation \\
10. Tourists info centers \\
11. Banks \\
12. Power supply
\end{tabular}

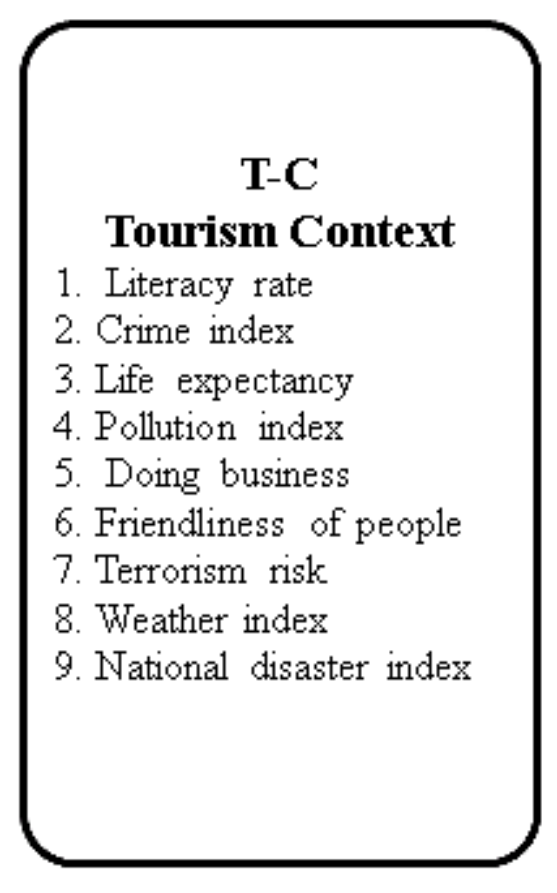

Figure 1. Model structure of T-ABC

In general, one of the main purposes of the visitors of the Republic is to see the rich historical resources of the country.

Table 1 shows the statistical analysis of tourism attractiveness in Uzbekistan. The places included in the UNESCO list are just historical places. Our analysis shows that other countries include tourism resources not only historically, but also natural tourism resources. This, in turn, will increase the attractiveness of tourism in these countries. Only four Bukhara, Samarkand, Khorezm and Kashkadarya regions are included in the World Heritage List.

According to experts, who participated in the statistical assessment of tourism attractiveness in Uzbekistan based on Delphi model, it was found that Jizzakh, Surkhandarya and Tashkent regions have more tourist attraction resources than other regions. In fact, there are natural tourist resources in the Tashkent region that respond to all seasons. 
STATISTICAL ESTIMATION OF TOURISM ATTRACTIVENESS

Table 1. IN UZBEKISTAN BASED ON DELPHI MODEL (FROM 1-7 POINTS)

\begin{tabular}{|c|c|c|c|c|c|c|c|c|c|c|c|c|c|c|}
\hline & 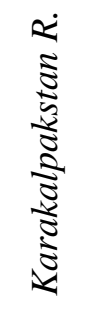 & 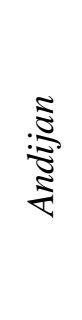 & $\frac{\sqrt{3}}{5}$ & 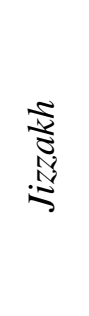 & 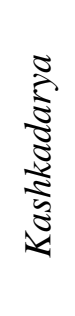 & $\begin{array}{l}\tilde{0} \\
\text { है }\end{array}$ & $\begin{array}{l}\tilde{\Xi} \\
\infty \\
\mathbf{\Xi} \\
\vdots \\
\mathbf{z} \\
z\end{array}$ & 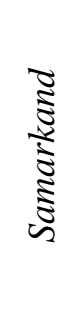 & 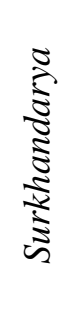 & 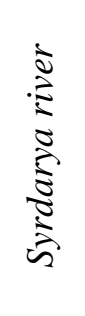 & 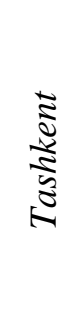 & 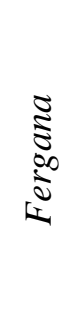 & 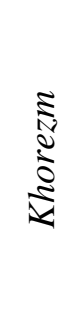 & 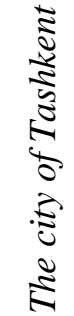 \\
\hline $\begin{array}{l}\text { World Heritage } \\
\text { List }\end{array}$ & & & $\sqrt{ }$ & & $\sqrt{ }$ & & & $\sqrt{ }$ & & & & & $\sqrt{ }$ & \\
\hline $\begin{array}{l}\text { Natural tourist } \\
\text { resources }\end{array}$ & 4,7 & 2,7 & 3,6 & 5,1 & 4,2 & 4,3 & 3,4 & 4,8 & 5,6 & 2,8 & 5,2 & 4,0 & 3,8 & 4,0 \\
\hline $\begin{array}{l}\text { Historical tourist } \\
\text { resources }\end{array}$ & 4,7 & 2,6 & 6,9 & 2,3 & 4,1 & 3,3 & 2,7 & 6,9 & 5,0 & 1,8 & 3,2 & 4,2 & 6,2 & 4,9 \\
\hline
\end{tabular}

Samarkand, Bukhara and Khorezm regions were awarded the highest points in terms of attractiveness of historical resources.

Samarkand has many attractive tourism facilities and is one of the main tourist cities of Uzbekistan. In recent years, a number of documents related to the Samarkand region, such as the Presidential Decree No. PP-3609 “On Additional Measures for the Further Development of Tourism in Samarkand Province for 2018-2019" and the International University of Tourism "Silk Road", 3815 Declared. In addition, the adoption of the Resolution of the Cabinet of Ministers of the Republic of Uzbekistan dated 30 June 2017 "On measures to accelerate the development of tourism potential of Samarkand and Samarkand region in 2017-2019" will allow increasing the flow of tourists and further employment through tourism. which, in turn, will enhance the role of tourism in the economy of the Samarkand region.

We will analyze in B of the ABC model of tourism services. Uzbekistan is one of the two countries in the world that crosses two countries to access the sea. Uzbekistan can only be visited by air, rail or land. The most difficult aspect of tourism in Uzbekistan is air travel. Currently, Uzbekistan Airways operates 30 foreign aircraft. With their help, the national airline operates flights to 20 cities in Europe, America, the Middle East and Asia. In 2018, Uzbekistan Airways increased by $17 \%$ to 3,17 million passengers. This indicator is calculated for all incoming and outgoing visitors.

As of 2018 , there are 816 hotels in the country, with a fund of about 40,000, of which 14,000 are located in Tashkent. Our research shows that there are not enough hotels in the seasonal times, but almost the same as the prices of European hotels and the price is increasing substantially every year. As for the city of Paris, the number of hotels in the city and surrounding areas is 4,260. We have these national levels 5 and a half times lower than that of the country, only 816 hotels worldwide.

According to experts, who participated in the statistical assessment of tourism services in Uzbekistan based on the Delphi model, it is clear that there are problems with tourist safety in Uzbekistan. According to our research, medical services in tourist facilities of the country are in poor condition.

Tourist car rental services are also one of the downsides of the tourism infrastructure, with an average of 2,58 points in Uzbekistan. Tourist car rental services were found to be better only in Tashkent and Samarkand. 


\begin{tabular}{|c|c|c|c|c|c|c|c|c|c|c|c|c|c|c|}
\hline & 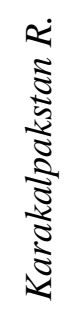 & 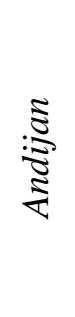 & $\frac{\sqrt{5}}{\frac{5}{5}}$ & 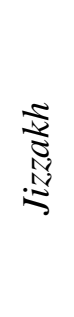 & 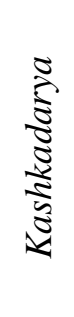 & $\begin{array}{l}\tilde{0} \\
\vec{z}\end{array}$ & 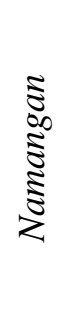 & 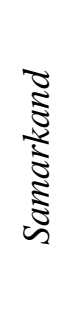 & 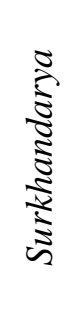 & 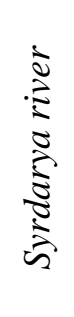 & $\frac{\vec{\Xi}}{\frac{\tilde{J}}{\tilde{J}}}$ & $\begin{array}{c}0 \\
\vdots \\
\vdots \\
0 \\
0 \\
0\end{array}$ & 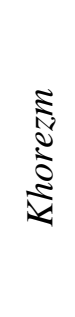 & 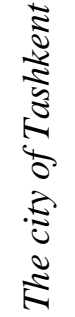 \\
\hline Quality of roadway & 3,6 & 4,3 & 4,9 & 3,2 & 3,9 & 4,0 & 3,9 & 5,4 & 3,2 & 3,4 & 4,9 & 4,3 & 4,8 & 5,9 \\
\hline Quality of hotels & 4,0 & 4,2 & 5,0 & 3,6 & 4,2 & 4,1 & 3,9 & 5,4 & 3,6 & 3,0 & 4,8 & 4,8 & 5,0 & 5,8 \\
\hline Quality of restaurants & 3,4 & 5,1 & 5,4 & 4,2 & 4,6 & 4,1 & 4,2 & 6,0 & 3,9 & 3,2 & 5,4 & 4,8 & 5,3 & 6,3 \\
\hline $\begin{array}{l}\text { Availability and condition of } \\
\text { sanitary and hygiene facilities }\end{array}$ & 2,4 & 3,6 & 4,1 & 2,8 & 2,9 & 3,2 & 3,0 & 4,3 & 2,8 & 2,7 & 3,8 & 3,2 & 3,6 & 4,8 \\
\hline Knowledge of tourism staff & 3,9 & 4,7 & 5,8 & 4,3 & 4,3 & 4,3 & 4,6 & 6,1 & 4,1 & 3,8 & 5,0 & 4,9 & 5,3 & 5,7 \\
\hline Financial and medical services & 2,7 & 3,1 & 3,4 & 2,9 & 2,9 & 3,0 & 3,2 & 3,9 & 2,8 & 2,6 & 3,6 & 3,0 & 3,3 & 4,4 \\
\hline
\end{tabular}

The professional status and availability of guides are 3,37 points due to the lack of guides in the regions during the tourist season who can speak several languages and provide interesting information on history, culture and all matters.

Based on the data in Table 2 we can say that logistics and road infrastructure in almost all regions are on average points out of close to 5, and it should be noted that tourism is not only economic but social. If road conditions and logistics infrastructure are in line with international standards, it will not only promote tourism but also many others, in general, lifestyle.

The availability and condition of hotels are explained by the lack of hotels in tourist centres. Our research has revealed that even the most powerful tourist centres in Samarkand, Bukhara, Khorezm, hotels, their status, knowledge and skills of tourists, and several other tourist infrastructures preclude the development of tourism.

There is a solution to this: firstly, one should bring tourism infrastructure and tourism services to international standards, and then the other, and so on. If we make tourism services competitive in only three regions of Samarkand, Bukhara and Khorezm, tourism will be one of the most localized sectors of the economy.

We analyze the status of the external factors of item $\mathrm{C}$ of the $\mathrm{ABC}$ model. Many citizens of the world do not know enough about Uzbekistan. For example, many Europeans consider Uzbekistan a very dangerous place to travel because it is a country bordering Afghanistan.

The attitude of the local population to the tourists and the culture of communication is one of the strong external factors. According to this indicator, all regions have a level of about 5 points, and the local population in general needs to develop tourism and tourism culture.

In the age of information technology, people cannot imagine themselves without the Internet and communication services, so we have added WI-FI and Internet speeds to look at external factors. Although this figure is 5,2 points better in Tashkent, there is still much to be done in this area compared to developed countries. 
STATISTICAL ASSESSMENT OF EXTERNAL FACTORS

Table 3 IN UZBEKISTAN BASED ON DELPHI MODEL (FROM 1-7 POINTS)

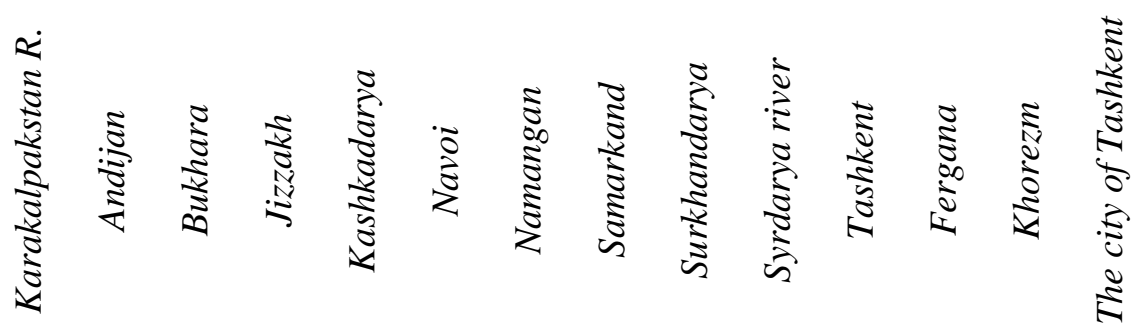

Friendliness of people

$4,9 \quad 6,0 \quad 5,8 \quad 5,2 \quad 5,2 \quad 5,2 \quad 5,8 \quad 6,1 \quad 5,4 \quad 5,1 \quad 5,4 \quad 5,9 \quad 6,0 \quad 6,1$

WI-FI zones and the availability

of Internet speed

\begin{tabular}{llllllllllllll}
3,4 & 4,0 & 4,8 & 3,4 & 3,7 & 3,7 & 3,6 & 4,8 & 3,3 & 3,2 & 4,6 & 4,1 & 3,9 & 5,2 \\
\hline
\end{tabular}

\begin{tabular}{llllllllllllllll} 
The supply of the electric power & 3,4 & 3,7 & 4,2 & 3,2 & 3,6 & 3,6 & 3,4 & 4,3 & 3,2 & 3,1 & 4,1 & 3,8 & 3,4 & 5,9 \\
\hline
\end{tabular}

The sustainability index is included in the International Tourism Competitiveness Index and is therefore included in the list. Against this background, the highest score in Tashkent is 5,9.

Table 4

ABC MODEL AND ITS ANALYSIS

\begin{tabular}{lccc}
\hline & Tourism attractiveness & Tourism & Tourism \\
& $A$ & Basics $B$ & Context C \\
\hline Uzbekistan & 4,2 & 4,1 & 4,4 \\
Samarkand & 5,8 & 5,3 & 5,1 \\
Surkhandarya & 5,3 & 3,6 & 3,8 \\
Bukhara & 5,2 & 4,9 & 4,9 \\
Khorezm & 5,0 & 4,6 & 4,4 \\
The Republic of Karakalpakstan & 4,7 & 3,3 & 3,8 \\
Tashkent & 4,4 & 5,7 & 5,7 \\
Kashkadarya & 4,2 & 3,6 & 4,0 \\
Tashkent & 4,2 & 4,4 & 4,7 \\
Fergana & 4,1 & 4,1 & 4,4 \\
Navoi & 3,8 & 3,4 & 4,1 \\
Jizzakh & 3,7 & 3,3 & 3,8 \\
Namangan & 3,1 & 3,6 & 4,2 \\
Andijan & 2,6 & 4,0 & 4,4 \\
Syrdarya river & 2,3 & 2,9 & 3,7 \\
\hline
\end{tabular}

In this table, the ABC model described, the region of Samarkand is higher than in other regions attractive, the city of Tashkent, the highest tourism services, tourism and external factors that were identified. Increasing tourism attractiveness in Tashkent will result in increased tourist inflow and revenue.

Our analysis shows that the Surkhandarya region also has a strong tourist attraction, which includes more natural resources than historical resources.

In general, several regions of Uzbekistan have both natural and historical resources, sufficient tourism attractiveness, and tourism development in many respects.

In the $\mathrm{ABC}$ model, tourism efficiency is determined by the tourists and tourism revenue. However, the methodology for determining the tourist flow and tourism revenue is not applied in 
Uzbekistan. Therefore, we calculated the correlation chart by referring to the ABC model of foreign tourists staying in the hotels of the provinces, based on the 1st Tourism Report.

Table 5

CORRELATION BETWEEN THE ABC MODEL AND THE TOURISTS STAYING OVERNIGHT IN THE REGIONAL HOTELS

\begin{tabular}{ccccc}
\hline & $Y$ & $A$ & $B$ & $C$ \\
\hline $\mathrm{Y}$ & 1 & & & \\
\hline $\mathrm{A}$ & 0,72 & 1 & 1 & \\
\hline $\mathrm{B}$ & 0,89 & 0,58 & 0,95 & 1 \\
\hline $\mathrm{C}$ & 0,81 & 0,38 & \\
\hline
\end{tabular}

From the table data we can see that there is a strong correlation between tourists and tourism services.

Now, economically analyzing these changes, we will explore the relationship between the ABC model and the tourists staying at regional hotels in 2018.

$Y$ — the tourists staying at regional hotels in 2018.

$X_{1}-\mathrm{A}$, that is, tourism attractiveness.

$\mathrm{X} 2-\mathrm{B}$, tourism services.

$\mathrm{X} 3-\mathrm{C}$, tourism context.

$$
\log _{10} \mathrm{y}=x_{1}+x_{2}+x_{3}
$$

Table 6

RESULTS OF THE REGRESSION EQUATION

\begin{tabular}{lcccc}
\hline \multicolumn{1}{c}{ Variables } & Coefficient & Std. error & $t$-statistics & Probably \\
\hline Const. & $-1,01$ & 1,53 & $-0,66$ & 0,53 \\
$X_{1}$ & 0,33 & 0,17 & 2,01 & 0,07 \\
$X_{2}$ & 0,19 & 0,68 & 0,29 & 0,78 \\
$X_{3}$ & 0,62 & 0,83 & 0,75 & 0,47 \\
$R^{2}$ & 0,86 & & & \\
Adjusted R & 0,82 & & & \\
\hline
\end{tabular}

This table shows variables flow of tourists and tourism attractiveness, tourism services, external factors, the amount of the rights of the relationship between the amount of regression. It also presents standard errors, statistics, and probabilities. $R^{2}$ is, the above factors explain $86 \%$ of the variation in the dependent variable Y.

This statistical sampling regression equation using the $\mathrm{Y}$ importance of the changes in part explain whether or not that is used to verify the hypothesis. We construct zero and one-sided alternative hypotheses as follows:

$$
\begin{gathered}
\text { H } 0: \mathrm{r} 2=0 \\
\text { H } 1: \mathrm{r} 2>0 \\
\mathrm{a}=0,05 \text { significance level for the } \mathrm{F}: \\
\mathrm{F} \mathrm{t}=\mathrm{F} \text { a }(\mathrm{k}-1 ; \mathrm{n}-\mathrm{k})=\mathrm{F} 0.05(3 ; 10)=2,62
\end{gathered}
$$


Table 7

ANALYZE OF VARIANCE

\begin{tabular}{lcccc}
\hline \multicolumn{1}{c}{ dispersion source } & $\begin{array}{c}\text { Degree of freedom } \\
(\text { DF })\end{array}$ & $\begin{array}{c}\text { Squares } \\
\text { Total }(S S)\end{array}$ & MS & F- ratio \\
\hline Regression & 3 & 7,10 & 2,37 & 21,24 \\
Residual squares & 10 & 1,11 & 0,11 & \\
Total & 13 & 8,21 & & \\
\hline
\end{tabular}

F value is $F=\frac{S S R /(k-1)}{S S E /(n-k)}=21,24$

Here, $\mathrm{n}$ - number of observations; $k$ - number of variables; SSR - sum of squares of regression; SSE is the sum of the residual squares.

Rule: $\mathrm{H} 0$ is rejected because $\mathrm{F} \mathrm{j}<\mathrm{F}$.

Consequently, the attractiveness of tourism, tourism services, and external factors are influenced by factors influencing the tourists.

The purpose of the t-test in the model is to test whether the coefficients of the generalized set of linear regression equations differ significantly from zero, that is, they are not random.

Zero and one - sided build hypotheses are as follows:

H 0 : b $1 \leq 0$ H $0:$ b $2 \leq 0$ H $0:$ b $3 \geq 0$ H $0:$ b $4 \geq 0$

$\mathrm{H} 1$ : b $1>0 \mathrm{H} 1$ : b $2>0 \mathrm{H} 1$ : b $3<0 \mathrm{H} 1: \mathrm{b} 4<0$

$\mathrm{a}=0.05$ significance level, the critical value of $\mathrm{T}$, we find:

$$
\mathrm{tt}=\mathrm{t} \mathrm{a}(\mathrm{n}-\mathrm{k})=\mathrm{t} 0.05(10)=1,71
$$

Now, find a sampling of the value of t. In order do this, we first need to clarify some of the statistical values we need.

Standard error of regression coefficients:

$\mathrm{S}$ b1 $=1,53 ; \mathrm{S}$ b2 $=0,17 ; \mathrm{S}$ b3 $=0,68 ; \mathrm{S}$ b4 =0,83;

Rule : $\mathrm{t}<|\mathrm{t} \mathrm{i}|(\mathrm{i}=1,2,3,4,5)$ is the $\mathrm{H} 0$ hypothesis is rejected in all cases. Therefore, setting a regression equation to estimate the positive rates of b2 ,b3 and b4 ratio of negative numbers. The chosen model was successfully passed F- test and t- test

The final regression equation:

$$
\log _{10} y=-1,01+0,33 x_{1}+0,19 x_{2}+0,62 x_{3}
$$

\section{Conclusions}

The regression equation between the $\mathrm{ABC}$ model and the tourists suggests that external factors influence the flow of tourists, the need to strengthen Uzbekistan's position in the international tourism indexes, and to boost external advertising. In conclusion, we can say that tourism is one of the most important sectors of the economy. This is due to the fact that the valueadded in the tourism industry is four times higher than in other areas, and it is possible to make the economy faster due to the diversification of the national economy, the rapid development of the regions, the creation of new jobs, raising the incomes and living standards of the population. 


\section{References:}

1. Manrai, L. A., \& Manrai, A. K. (1993). Positioning European countries as brands in a perceptual map: An empirical study of determinants of consumer perceptions and preferences. Journal of Euromarketing, 2(3), 101-129. https://doi.org/10.1300/J037v02n03_06

2. Manrai, L. A., Manrai, A. K., \& Friedeborn, S. (2018). Environmental determinants of destination competitiveness and its Tourism Attractions-Basics-Context, ABC, indicators. Journal of Economics, Finance and Administrative Science. https://doi.org/10.1108/JEFAS-01-2018-0010

3. Ayikoru, M. (2015). Destination competitiveness challenges: A Ugandan perspective. Tourism Management, 50, 142-158. https://doi.org/10.1016/j.tourman.2015.01.009

4. Assaker, G., Hallak, R., Vinzi, V. E., \& O’Connor, P. (2014). An empirical operationalization of countries' destination competitiveness using partial least squares modeling. Journal of Travel Research, 53(1), 26-43. https://doi.org/10.1177\%2F0047287513481275

\section{Список литературь:}

1. Manrai L. A., Manrai A. K. Positioning European countries as brands in a perceptual map: An empirical study of determinants of consumer perceptions and preferences //Journal of Euromarketing. 1993. V. 2. №3. P. 101-129. https://doi.org/10.1300/J037v02n03_06

2. Manrai L. A., Manrai A. K., Friedeborn S. Environmental determinants of destination competitiveness and its Tourism Attractions-Basics-Context, ABC, indicators // Journal of Economics, Finance and Administrative Science. 2018. https://doi.org/10.1108/JEFAS-01-20180010

3. Ayikoru M. Destination competitiveness challenges: A Ugandan perspective // Tourism Management. 2015. V. 50. P. 142-158. https://doi.org/10.1016/j.tourman.2015.01.009

4. Assaker G. et al. An empirical operationalization of countries' destination competitiveness using partial least squares modeling // Journal of Travel Research. 2014. V. 53. №1. P. 26-43. https://doi.org/10.1177\%2F0047287513481275

Работа поступила

в редакциию 10.01.2020 г.
Принята к публикации 17.01.2020 2.

\section{Ссылка для цичтирования:}

Jumayev A. Statistical Analyses of Tourism in Uzbekistan: an Empirical Test of Tourism A-BC (Т-ABC) Model // Бюллетень науки и практики. 2020. Т. 6. №2. С. 193-202. https://doi.org/10.33619/2414-2948/51/19

Cite as (APA):

Jumayev, A. (2020). Statistical Analyses of Tourism in Uzbekistan: An Empirical Test of Tourism A-B-C (T-ABC) Model. Bulletin of Science and Practice, 6(2), 193-202. https://doi.org/10.33619/2414-2948/51/19 


\title{
ВОПРОСЫ УПРАВЛЕНИЯ, СОХРАНЕНИЯ И МОДЕРНИЗАЦИИ МНОГОКВАРТИРНОГО ЖИЛИЩНОГО ФОНДА
}

\author{
(с)Давлетов И. Х., канд. экон. наук, Ташкентский архитектурно строительный институт, \\ 2. Ташкент, Узбекистан, i.davletov68@gmail.com \\ (СМаманазаров О. Ш., канд. экон. наук, Ташкентский архитектурно строительный \\ институт, г. Ташкент, Узбекистан
}

\section{ISSUES TO MANAGEMENT, PRESERVATION AND MODERNIZATION OF MULTI- APARTMENT HOUSING}

\author{
CDavletov I., Ph.D., Tashkent architecture and civil engineering institute, \\ Tashkent, Uzbekistan, i.davletov68@gmail.com \\ CMamanazarov O., Ph.D., Tashkent architecture and civil engineering institute, \\ Tashkent, Uzbekistan
}

Аннотащия. В статье дается сущность реформирования сферы жилищнокоммунального обслуживания и нормативно-правовых документов в Узбекистане, а также предложения и рекомендации по некоторым вопросам, связанным с управлением, содержанием и модернизацией многоквартирного жилого фонда.

Abstract. The article gives the essence of reforming the sphere of housing and communal services and legal documents in Uzbekistan, as well as suggestions and recommendations on some issues related to the management, maintenance and modernization of multi-apartment housing.

Ключевые слова: жилищное строительство, жилищный фонд, содержание жилищного фонда, управление жилищным фондом, модернизация жилищного фонда, жилищнокоммунальные услуги, коммунальные платежи, текущий ремонт, капитальный ремонт, ремонтно-восстановительные работы, типовые дома, профессиональная управляющая организация, государственно-частные партнерства.

Keywords: housing construction, housing, housing maintenance, housing management, housing modernization, housing and communal services, communal payments, current repair, overhaul, repair and restoration work, typical houses, professional management company, publicprivate partnerships.

\section{Введение}

Основной акцент в научных исследованиях в области управления жилищным фондом в разных странах мира делается на формировании организационных основ управления этой сферой, определении направлений деятельности предприятий в данной сфере и видов предоставляемых ими услуг. В последние годы исследований основное внимание уделяется повышению качества и эффективности этой деятельности, в частности, децентрализации системы управления жилищным фондом и сокращению государственного участия в управлении. Исходя из этого, сегодня применение современных методов в управлении жилищным фондом, использование услуг предприятий частного сектора при осуществлении управленческой деятельности имеет большое значение. 
В соответствии с Постановлением Президента Республики Узбекистан №УП-4947 «О Стратегии действий по дальнейшему развитию Республики Узбекистан» от 7 февраля 2017 г была принята «Стратегия действий по пяти приоритетным направлениям развития Республики Узбекистан в 2017-2021 годах», в соответствии с которой определена задача повышения уровня жизни населения, обеспечения его комфортной жизнью, а также обеспечения населения доступным, комфортным и всесторонне оснащенным жильем, модернизации ведущих отраслей экономики, диверсификации производства, а также «повышения уровня обеспеченности населения коммунально-бытовыми услугами» (www.lex.uz).

Основной целью проводимых в республике реформ в сфере жилищно-коммунального обслуживания является кардинальное улучшение жилищных условий населения и обеспечение высокого уровня коммунальных услуг.

Поэтому в целях повышения качества жилищных условий населения, оказания услуг многоквартирному жилищному фонду и кардинального улучшения взаимодействия организаций сферы в этой связи, а также повышения эффективности деятельности управляющих организаций и предприятий и обеспечения их финансово-экономической устойчивости, были приняты ряд указов и законов, а именно:

Закон Республики Узбекистан «Об управлении многоквартирными домами» [1],

Указ Президента Республики Узбекистан №УП-5017 «О мерах по дальнейшему совершенствованию управления системой жилищно-коммунального обслуживания» от 18 апреля 2017 года [4]

Постановление № ПП-2900 «Об организации деятельности министерства жилищнокоммунального обслуживания Республики Узбекистан» [5],

а также Постановление № ПП-2922 от 22 апреля 2017 года «О мерах по дальнейшему совершенствованию системы содержания и эксплуатации многоквартирного жилищного фонда на период 2017-2021 годы» [6].

Анализ современного состояния жилищного фонда республики, его сохранение и применение инновационных технологий в сфере предоставления коммунальных услуг

Анализ опросов, проведенных на местах, показывает, что полноценный контроль над содержанием многоквартирных жилых домов часто проводится не вовремя и, во многих случаях, допускаются многочисленные нарушения правил по технической эксплуатации жилищного фонда, а также норм и требований для обеспечения безопасного проживания населения. Правила и нормы ремонта зданий и их сроки не соблюдаются, работы по сносу старых домов ведутся на пассивном уровне, а санитарные и гигиенические нормы в соседних многоквартирных домах не соблюдаются в полной мере. Правила и нормы по ремонту, реконструкции и обслуживанию зданий и их сроки выполнения не соблюдаются, снос старых домов проводится пассивным образом, а санитарно-гигиенические нормы в соседних многоквартирных домах не соблюдаются полностью.

В стране на протяжении многих лет существовало только распоряжение государственным имуществом, вопрос об использовании этого имущества решался на основе строго предусмотренных норм. Поэтому использование зданий и сооружений осуществлялось только на основании государственных норм и решений органов местного самоуправления, в результате чего неиспользуемые площади жилых зданий использовались нерационально.

Также в нашей стране был проведен анализ жилищного фонда, согласно которому жилищный фонд составил 507,5 млн. м². (по состоянию на 1 января 2018 г), из которых 
частный жилищный фонд составляет 504,1 млн. м². (99,3\%), а государственный жилищный фонд - состоит из 3,4 млн. м². (0,7\%) (Рисунок 1$)$.

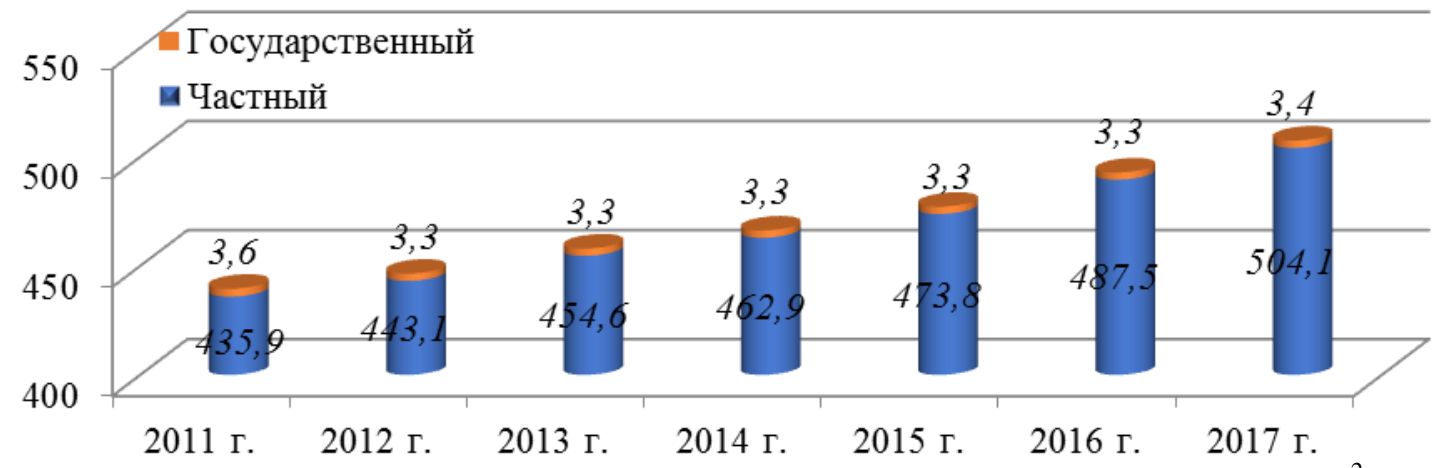

Рисунок 1. Динамика роста жилищного фонда в Узбекистане (млн. м²) (Данные Государственного комитета Республики Узбекистан по статистике. 2018 год)

При анализе средней жилой площади на одного человека в 2011-2017 гг, стало известно,

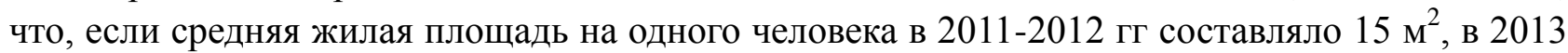

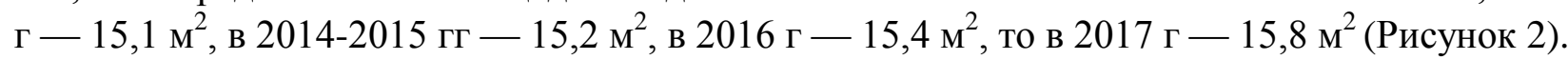

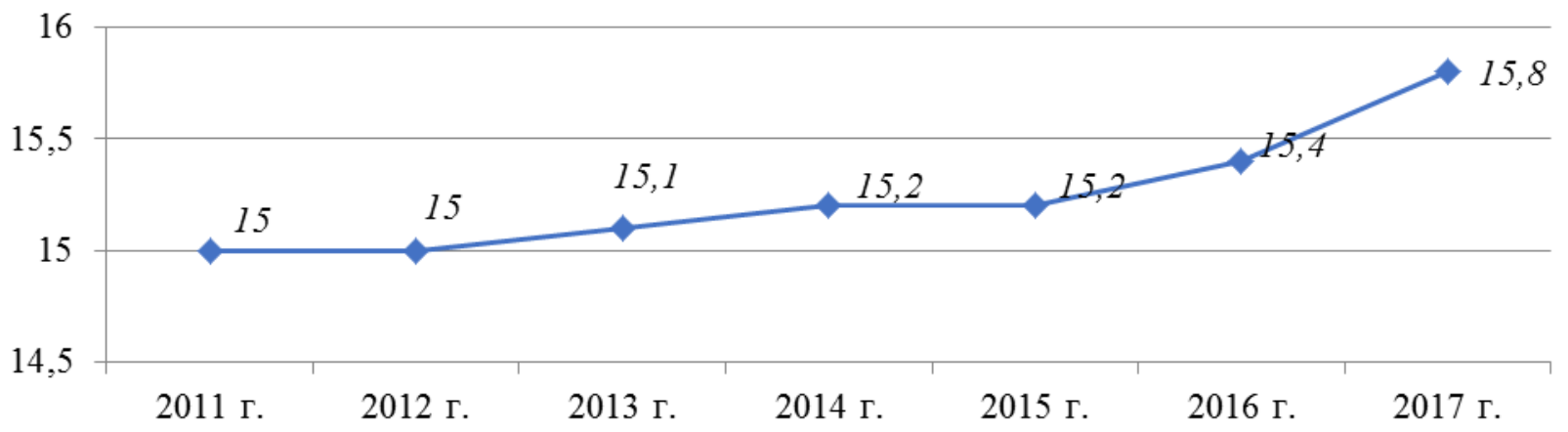

Рисунок 2. Средняя жилая площадь на одного человека $\left(\mathrm{м}^{2}\right)$ (Данные Государственного комитета Республики Узбекистан по статистике. 2018 год)

На Рисунках прослеживается тенденция увеличения жилищного фонда страны, в частности, частного жилищного фонда. Это, в свою очередь, еще больше повысит потребность в эффективной организации и управлении системой частного жилищного фонда.

Следует также отметить, что в результате реализации широкомасштабных реформ в сфере жилищно-коммунального обслуживания, в частности, в ежегодно принимаемых государственных программ, эти проблемы рассматриваются как одно из важных направлений, и в результате развития государственно-частного партнерства в сфере жилищно-коммунального обслуживания, населению качественно оказываются жилищнокоммунальные услуги. Программы, направленные на строительство доступного, уютного и всесторонне комфортного жилья на базе современных проектов в городах и селах, реализуемые в последующие годы, оказывают огромное положительное влияние на уровень жизни и условия жизни населения. Это, в свою очередь, служит повышению уровня обеспеченности социально нуждающихся и малообеспеченных слоев населения качественным жильем.

На сегодняшний день одним из актуальных вопросов является обеспечение жилищнокоммунального обслуживания и социальная целесообразность затрат на использование жилищного фонда. Поэтому возникает необходимость разработки доступных и альтернативных видов предоставления жилищно-коммунальных услуг, а также разработки 
экономически обоснованных критериев установления цен и тарифов на услуги предприятий, рассматриваемых субъектами естественной монополии, в том числе на электроэнергию и теплоэнергию, газоснабжение, услуги питьевого и проточного водоснабжения.

В современных глобальных условиях новые подходы, идеи, а также инновационные технологии все шире используются во всех отраслях и секторах экономики. Например, современные информационно-коммуникационные технологии в деятельности компаний, использование интернет сетей, внедрение систем GPRS и IoB, автоматизация сложных работ и так далее. Применение этих систем создает большие удобства для населения, обеспечивая своевременное и качественное предоставление платежных счетов и отчетов за коммунальные услуги, снижение затрат и своевременное осуществление платежей.

Сегодня необходимо коренное улучшение и более эффективное использование технического состояния многоквартирного жилищного фонда, а также своевременное проведение ремонтно-восстановительных работ в них и др., рассматриваются как один из актуальных вопросов в сфере жилищно-коммунального хозяйства.

\section{Опыт зарубежных стран в управлении многоквартирным жилым фондом и новые нормативно-правовые документы}

В связи с масштабными структурными реформами, проводимыми в нашей стране, необходим также ряд обновлений и изменений в сфере жилищно-коммунального хозяйства для создания совершенно новой системы. В последние годы на основе принятых решений по совершенствованию деятельности предприятий, капитальному и текущему ремонту многоквартирного жилого фонда были реализованы мероприятия, включающие работы по устройству кровли многоквартирных домов, свалки (подвала), фасада, коридора (подъезда), лифтовых и ирригационных сетей, а также по бетонированию тротуаров, озеленению и благоустройству территорий вокруг домов.

Указ Президента Республики Узбекистан «О мерах по дальнейшему совершенствованию системы хранения и использования многоквартирного жилищного фонда в 2017-2021 годах» принят в целях кардинального улучшения технического состояния многоквартирного жилищного фонда и обеспечения необходимых условий для его рационального использования, проведения своевременных ремонтно-восстановительных работ, а также было принято решение о создании необходимых условий для дальнейшего благоустройства территорий, прилегающих к многоквартирным домам.

Следовательно, основной целью изменения системы управления жилищным фондом является возложение на собственников жилья прав, обязанностей и материальной ответственности за содержание их имущества. Стоит отметить, что при изучении опыта некоторых развитых стран мира, в большинстве случаев предоставление коммунальных услуг жилищному фонду, включая их управление, хранение и использование, осуществляется некоммерческими организациями. Например, в США ведут свою деятельность территориальные объединения населения (Planning Unit Developments - PUD), кондоминиумы (Condominium Association), жилищные кооперативы (Housing Cooperatives) в Канаде, синдикаты (Syndicat) во Франции, квартирные акционерные общества в Финляндии, а в России - товарищества собственников жилья (ТСЖ) и жилищно-строительные кооперативы (ЖСК).

Следует также отметить, что в результате реализации реформ в сфере жилищнокоммунального обслуживания, в частности, в ежегодно принимаемых государственных программах, эти вопросы должны быть определены как одно из важных направлений развития государственно-частного партнерства в сфере жилищно-коммунального 
обслуживания, обеспечение дальнейшего повышения качества предоставляемых жилищнокоммунальных услуг и решение ряда актуальных вопросов по другим аналогичным направлениям.

Кроме того, следует отметить, что в целях дальнейшего повышения качества предоставления жилищно-коммунальных услуг и эффективности деятельности предприятий сферы на основе государственно-частного партнерства 4 января 2019 года Кабинетом Министров Республики Узбекистан было принято Постановление №5 “О дополнительных мерах по совершенствованию управления жилищно-коммунальной инфраструктурой города Ташкента". В соответствии с этим постановлением были определены следующие приоритеты дальнейшего развития жилищно-коммунального хозяйства города Ташкента:

- поэтапное внедрение рыночных механизмов (инструментов) в сфере хранения, использования и ремонта многоквартирного жилого фонда, в том числе на условиях государственно-частного партнерства;

- повышение привлекательности рынка жилищно-коммунальных услуг с учетом передового зарубежного опыта, а также переход к конкурентному ценообразованию;

- внедрение энергосберегающих технологий и оборудований в систему жилищнокоммунального обслуживания, а также оснащение объектов жилищно-коммунального хозяйства современными инструментами бухгалтерского учета;

- создание единой биллинговой системы коммунальных услуг и введение унифицированного лицевого счета потребителя;

- совершенствование системы подготовки, переподготовки и повышения квалификации специалистов в сфере жилищно-коммунального хозяйства.

В связи с этим следует отметить, что 7 ноября 2019 г Президент Республики Узбекистан подписал закон № 581 «Об управлении многоквартирными домами» [1].

Целью настоящего Закона является регулирование отношений в сфере многоквартирного управления, его реализация введётся для собственников жилых помещений и нежилых помещений в многоквартирных домах, для организаций и предприятий, управляющих многоквартирным домом, для предприятий собственников жилья, а также для иных лиц, деятельность которых связана с управлением многоквартирными домами.

В частности, как указано в ст. 5 Закона, многоквартирным домом является комплекс из двух и более квартир с самостоятельными выходными коридорами в многоквартирный дом, примыкающий к земельному участку или местам общего пользования в таком доме. Согласно закону, порядок управления многоквартирным домом устанавливается на общем собрании собственников помещений в многоквартирном доме. Также управление многоквартирным домом может осуществляться следующими лицами:

- непосредственно владельцами мест;

- управляющей организацией, являющейся юридическим лицом, или управляющим, являющимся физическим лицом (индивидуальным предпринимателем) на договорной основе;

- некоммерческой организацией (Рисунок 3), представляющей собой общество собственников жилья, объединяющее собственников жилых и нежилых помещений в единый или густонаселенный многоквартирный дом.

Поэтому, согласно закону, общее имущество будет принадлежать собственникам помещений на основании общей долевой собственности. В настоящее время высокий уровень спроса наблюдается на предприятия и организации в сфере жилищно- 
коммунального обслуживания. Это, в свою очередь, требует привлечения квалифицированных управленческих кадров и кадров для этих предприятий и организаций. Опыт зарубежных развитых стран в этом отношении показывает, что специалистов по управлению жилищным фондом готовят в специализированных вузах и специальных колледжах по той же специальности.

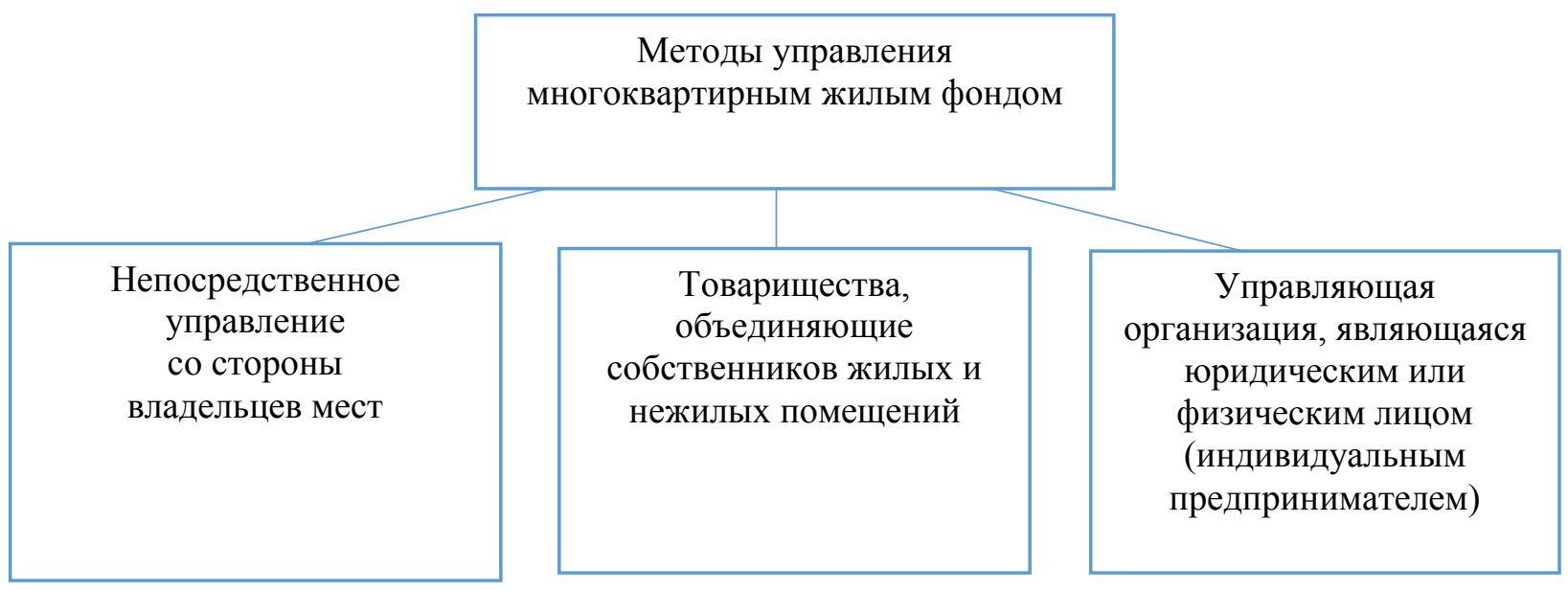

Рисунок 3. Методы управления многоквартирным жилым фондом

А в Венгрии, в соответствии с законом "О товариществах собственников жилья", управляющим кондоминиумом могут стать только лица, прошедшие специальную профессиональную подготовку ${ }^{1}$.

Анализ в сфере показывает, что у существующих частных домовладельцев есть ряд проблем, которые компании ждут своего решения в своей деятельности по содержанию, эксплуатации и ремонту многоквартирного жилого фонда. Сюда входит, прежде всего, обеспечение открытости и прозрачности расходования средств на внедрение и капитальный ремонт общедоступных частей жилых зданий, приобретение стройматериалов и т.д. В то же время, на данный момент указанные работы компании выполняют одновременно, как в качестве заказчика, так и в качестве подрядчика, на основе льготных кредитов коммерческих банков

\section{Вывод и предложения}

В результате проведенного анализа и исходя из вышеизложенного, можно отметить, что ниже приведены некоторые проблемы в управлении и содержании многоквартирного жилищного фонда в республике:

- отсутствие достаточных профессиональных знаний и навыков у председателя и исполнительного директора общества, которые будут избираться из числа собственников квартиры на общем собрании собственников жилья. В большинстве случаев, в компаниях работают те, кто ранее работали в других профессиях, т.е. кто не являются профессионалами;

- отсутствие эффективного контроля над содержанием многоквартирного жилого фонда, в большинстве случаев, технической эксплуатацией жилищного фонда и нарушением установленных процедур и требований по обеспечению безопасных условий проживания населения ;

- низкая численность лиц, поступающих в данную сферу из числа молодежи, окончивших профессиональные колледжи и высшие учебные заведения, обусловленная 
привлекательностью специалистов в сфере жилищно-коммунального хозяйства и низкой заработной платой;

- недостаточное соблюдение порядка и сроков проведения ремонтновосстановительных работ в многоквартирных домах.

Для устранения вышеперечисленных проблем считаем целесообразным выполнение следующих задач и мероприятий:

- создание реального механизма сотрудничества между Министерством жилищнокоммунального хозяйства - Профессиональной управляющей организацией(компанией) Товариществами собственников жилья;

- разработка и утверждение методики определения минимального размера обязательных взносов;

- разработка и внедрение «Единых стандартов» по управлению, хранению и эксплуатации многоквартирного жилого фонда;;

- создание интернет-порталов с персональным кабинетом каждого потребителя, а также создание "Internet of Buildings" - состояние конструкций зданий, учет потребления коммунальных услуг и ресурсов, а также система мониторинга их регулирования;

- развитие и совершенствование материально-технической базы государственного унитарного предприятия "Ремонтно-восстановительная служба" для проведения качественных текущих и капитальных ремонтных работ в многоквартирных домах, а также для благоустройства территории дома со всеми элементами (строительство детских и оздоровительных зон, ремонт дорог, тротуаров и луж, и др.), и обеспечение их квалифицированными специалистами;

- обеспечить своевременный качественный ремонт помещений общего назначения многоквартирных домов и инженерных коммуникаций в квартире и др.

В заключение стоит отметить, что кардинальные изменения и обновления в данной сфере, в частности, развитие предприятий и организаций в системе жилищно-коммунального хозяйства, укрепление их материально-технической базы, привлечение квалифицированных специалистов и другие подобные важные задачи, в конечном итоге обеспечат повышение качества предоставления коммунальных услуг, а также дальнейшее улучшение уровня жизни и условия проживания населения.

\section{Список литературы:}

1. Закон Республики Узбекистан «Об управлении многоквартирными домами». 7 ноября 2019 г, №3РУ-581 // Национальная база законодательных данных, 08.11.2019 г., 03/19/581/4004.

2. Закон Республики Узбекистан «О товариществах частных собственников жилья». Статья третья. 12 апреля 2006 г, №3РУ-32.

3. «Жилищный кодекс» Республики Узбекистан. Утверждена Законом Республики Узбекистан, №713-І от 24 декабря 1998 г. Вступил в силу с 1 апреля 1999 г.

4. Указ Президента Республики Узбекистан №УП-5017 «О мерах по дальнейшему совершенствованию управления системой жилищно-коммунального обслуживания» от 18 апреля 2017 г, ст. 267, 16.

5. Постановление Президента Республики Узбекистан №ПП-2900 «Об организации деятельности министерства жилищно-коммунального обслуживания Республики Узбекистан» от 18 апреля 2017 г // Собрание законодательства Республики Узбекистан, 2017 г, 17, ст. 291. 
6. Постановление Президента Республики Узбекистан № ПП-2922 «О мерах по дальнейшему совершенствованию системы хранения и использования многоквартирного жилищного фонда в 2017-2021 годах» от 24 апреля 2017 г // Народное слово от 26 апреля 2017 г, 82 (6776).

7. Постановление кабинета Министров Республики Узбекистан №5 «О дополнительных мерах по совершенствованию управления жилищно-коммунальной инфраструктурой города Ташкента» от 4 января 2019 г. http://lex.uz/docs/4138252

8. В Узбекистане назвали главные проблемы ТЧСЖ и способы их решения. https://news.mail.ru/society/33979711/

9. Депутаты разрабатывают законопроект, определяющий порядок проживания в многоквартирных домах. http://parliament.gov.uz/

10. Кирсанов С. А. Зарубежный опыт управления многоквартирными домами // ЖКХ: журнал руководителя и главного бухгалтера. 2011. №10. С. 12-23.

11. Прокофьев К. Ю., Моисеев В. А., Егорова Ю. А. Отечественный и зарубежный опыт управления многоквартирными домами // Жилищные стратегии. 2015. №2(4), С.311315.

12. Хасанов Т. А. Новый подход к управлению системой хранения и использования многоквартирного жилого фонда // Сборник тезисов международной научно-практической конференции. Ташкент. 2018. С. 201-203.

\section{References:}

1. Zakon Respubliki Uzbekistan "Ob upravlenii mnogokvartirnymi domami". 7 noyabrya 2019 g, №ZRU-581. Natsional'naya baza zakonodatel'nykh dannykh, 08.11.2019 g., 03/19/581/4004.

2. Zakon Respubliki Uzbekistan "O tovarishchestvakh chastnykh sobstvennikov zhil'ya". Stat'ya tret'ya. 12 aprelya 2006 g, №ZRU-32.

3. "Zhilishchnyi kodeks" Respubliki Uzbekistan. Utverzhdena Zakonom Respubliki Uzbekistan, №713-I ot 24 dekabrya $1998 \mathrm{~g}$. Vstupil v silu s 1 aprelya $1999 \mathrm{~g}$.

4. Ukaz Prezidenta Respubliki Uzbekistan №UP-5017 "O merakh po dal'neishemu sovershenstvovaniyu upravleniya sistemoi zhilishchno-kommunal'nogo obsluzhivaniya" of 18 aprelya 2017 g, st. 267, 16.

5. Postanovlenie Prezidenta Respubliki Uzbekistan №PP-2900 “Ob organizatsii deyatel'nosti ministerstva zhilishchno-kommunal'nogo obsluzhivaniya Respubliki Uzbekistan” ot 18 aprelya 2017 g // Sobranie zakonodatel'stva Respubliki Uzbekistan, 2017 g, 17, st. 291.

6. Postanovlenie Prezidenta Respubliki Uzbekistan № PP-2922 “O merakh po dal'neishemu sovershenstvovaniyu sistemy khraneniya i ispol'zovaniya mnogokvartirnogo zhilishchnogo fonda $\mathrm{V}$ 2017-2021 godakh" ot 24 aprelya 2017 g. Narodnoe slovo ot 26 aprelya 2017 g, 82 (6776).

7. Postanovlenie kabineta Ministrov Respubliki Uzbekistan №5 “O dopolnitel'nykh merakh po sovershenstvovaniyu upravleniya zhilishchno-kommunal'noi infrastrukturoi goroda Tashkenta" ot 4 yanvarya $2019 \mathrm{~g}$. http://lex.uz/docs/4138252

8. V Uzbekistane nazvali glavnye problemy TChSZh i sposoby ikh resheniya. https://news.mail.ru/society/33979711/

9. Deputaty razrabatyvayut zakonoproekt, opredelyayushchii poryadok prozhivaniya v mnogokvartirnykh domakh. http://parliament.gov.uz/

10. Kirsanov, S. A. (2011). Zarubezhnyi opyt upravleniya mnogokvartirnymi domami. ZhKKh: zhurnal rukovoditelya i glavnogo bukhgaltera, (10). 12-23. (in Russian). 
11. Prokof'ev, K. Yu., Moiseev, V. A., \& Egorova, Yu. A. (2015). Otechestvennyi i zarubezhnyi opyt upravleniya mnogokvartirnymi domami. Zhilishchnye strategii, (2(4)), 311-315. (in Russian).

12. Khasanov, T. A. (2018). Novyi podkhod k upravleniyu sistemoi khraneniya i ispol'zovaniya mnogokvartirnogo zhilogo fonda. In Sbornik tezisov mezhdunarodnoi nauchnoprakticheskoi konferentsii. Tashkent. 201-203. (in Russian).

Ссылка для изитирования:

Давлетов И. Х., Маманазаров О. Ш. Вопросы управления, сохранения и модернизации многоквартирного жилищного фонда // Бюллетень науки и практики. 2020. Т. 6. №2. С. 203211. https://doi.org/10.33619/2414-2948/51/20

Cite as (APA):

Davletov, I., \& Mamanazarov, O. (2020). Issues to Management, Preservation and Modernization of Multi-apartment Housing. Bulletin of Science and Practice, 6(2), 203-211. https://doi.org/10.33619/2414-2948/51/20 (in Russian). 


\section{УПРАВЛЕНИЕ ВЗАИМООТНОШЕНИЯМИ С КЛИЕНТАМИ}

СЕрльгина Е. Г., ОRCID: 0000-0003-2049-3845, SPIN-код: 4984-6546, канд. экон. наук, Владимирский государственный университет им. А.Г. и Н.Г. Столетовых, 2. Владимир, Россия, erlygina@mail.ru

(ФФилимонова В. Д., Владимирский государственный университет им. А.Г. и Н.Г. Столетовых, г. Владимир, Россия, filimonova.viktory@gmail.com

\section{CUSTOMER RELATIONSHIP MANAGEMENT}

CErlygina E., ORCID: 0000-0003-2049-3845, SPIN-code: 4984-6546, Ph.D., Vladimir State University, Vladimir, Russia, erlygina@mail.ru

CFilimonova V., Vladimir State University, Vladimir, Russia, filimonova.viktory@ gmail.com

Аннотащия. Современный рынок характеризуется изменениями отношений между компаниями и клиентами. Сегодня взаимоотношения с клиентами это упорядоченный системный процесс, нуждающийся в контроле и управлении. В условиях сложных продаж на высоко конкурентных рынках применение автоматизированных систем обеспечит организациям повышения конкурентоспособности. Автоматизированное программное CRMобеспечение может стать решением для реализации стратегии персонифицированного маркетинга, что позволит более эффективно управлять бизнес-процессами, протекающими в рамках взаимодействия сотрудников предприятия с клиентами.

Abstract. The modern market is characterized by changes in the relationship between companies and customers. Today, customer relationships are an orderly system process that needs to be monitored and managed. In the context of complex sales in highly competitive markets, the use of automated systems will provide organizations with increased competitiveness. Automated CRM software can become a solution for implementing a personalized marketing strategy, which will allow you to more effectively manage business processes that occur within the framework of interaction between employees and customers.

Ключевые слова: взаимоотношения с клиентами, автоматизированные системы, повышение конкурентоспособности.

Keywords: customer relationships, automated systems, increasing competitiveness.

\section{Введение}

В условиях современной экономики и жесткой конкуренции, современный рынок характеризуется изменениями отношений между компаниями и клиентами. Взаимоотношения с клиентами строятся посредством согласованного набора процедур, используя единую технологию, позволяющею создать общее впечатление о компании и продукте.

Сегодня взаимоотношения с клиентами, это не просто совокупность взаимодействий между продавцом и клиентом на протяжении определенного периода времени, а упорядоченный системный процесс, нуждающийся в контроле и управлении. 


\section{Материал и методы исследования}

Процесс управления взаимодействиями с клиентами можно рассматривать как цикл процессов по управлению маркетингом, продажами и обслуживанием. Этапы данного цикла взаимосвязаны и взаимозависимы. Управляя маркетингом, компания тем самым определяет субъект деятельности в процессе по управлению продажами, а управление обслуживанием клиента позволяет повысить лояльность потребителя и закрепить положительный имидж компании.

Под управлением маркетингом понимают анализ, планирование, проведение различных маркетинговых мероприятий, установление и поддержание контактов с целевыми покупателями и контроль за результатами, что позволит получить дополнительную прибыль, увеличит рост объемов сбыта и долю рынка.

Процесс управления маркетингом включает в себя этапы представленные на Рисунке 1.

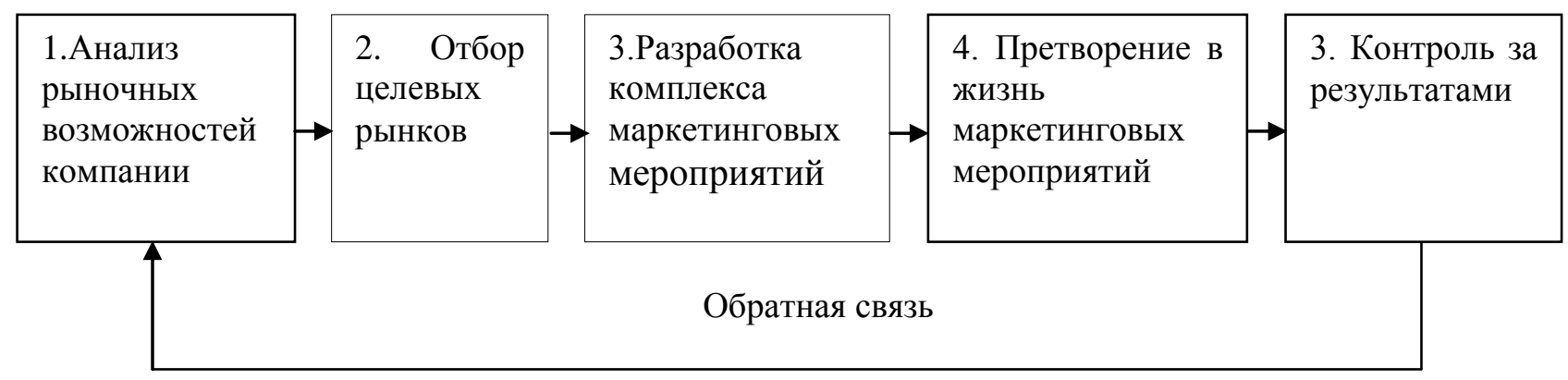

Рисунок 1. Этапы процесса управления маркетингом

На этапе анализа рынка происходит осуществление маркетинговых исследований, изучение рынка потребителей, анализ внешней среды компании. Далее проводится сегментация рынка, анализ существующего спроса и анализ деятельности конкурентов, разработка и осуществление маркетинговой стратегии- плана маркетинговых мероприятий, с помощью которых компания рассчитывает достичь поставленных целей. Заключительным этапом является контроль за результатами. Целью управления маркетингом является обеспечение максимального сбыта продукции, повышение спроса и, как следствие, максимизация прибыли.

Целью процесса управления продажами в широком смысле является оптимизация организации процесса продажи товаров или услуг, а в узком смысле - осуществление последовательности действий, приводящих к заключению сделки.

Процесс принятия решения о покупке не всегда обусловлен упорядоченными процессами и действиями по принятию решений касательно целесообразности покупки товара или услуги. Конечное решение о приобретении какого-либо товара или услуги, как правило, на момент начала построения взаимоотношений продавцом у потребителя еще не сформировано. На исход этих взаимоотношений влияет множество факторов, как внешних, так и внутренних, поэтому при грамотном построении контакта с клиентом возможно не просто склонить его к совершению покупки, но и переубедить в случае если изначально он был настроен к бренду или продукции бренда негативно. Одной из основных проблем для компаний розничной торговли, является проблема отсутствия автоматизированной системы регистрации и сопровождения клиентов. В результате происходит повышение оттока клиентов и как правило снижение их прибыльности. Узким местом в данном процессе является сложность в поисках информации о потребностях клиентов [1]. В условиях сложных продаж на высоко конкурентных рынках применение автоматизированных систем 
может обеспечить организации повышения конкурентоспособности на рынке, а также устойчивого финансово-экономического состояния [2].

\section{Результаты и обсуждение}

Основными этапами управления продажами являются:

1) Стадия осведомленности, или первого вступления в контакт.

На этом этапе происходит установление первого контакта между продавцом и покупателем, и от того, насколько успешно и эффективно продавец наладит контакт зависит дальнейшее построение отношений с клиентом. На этом этапе большую роль для продавца играет информация о том, знаком ли клиент с брендом, имеет ли он представление о том, что производит или продает компания, встречал ли он рекламу компании и, если да, насколько эффективна она была.

Для построения успешного прохождения стадии осведомленности большое значение имеют рекламные и маркетинговые акции, проводимые компанией. Причем на данный момент появляется все больше и больше новых инструментов, позволяющих повышать лояльность потребителей к бренду и привлекать новых клиентов, таких как контентмаркетинг, event-маркетинг, BTL-реклама. Традиционные способы рекламы, конечно же, не теряют своей актуальности, но начинают еще более эффективно воздействовать на потребителя в связке с новыми инструментами продвижения товара, появившимися в эпоху цифровых технологий.

2) Стадия ознакомления, или выявления потребностей.

На стадии ознакомления происходит непосредственный контакт между клиентом и продавцом. На этой стадии клиент уже имеет представление о том, чем занимается компания, у него сформировано отношение к бренду. Продавцу же нет необходимости знакомить покупателя с отраслью, в которой работает компания и ее основными конкурентными преимуществами - можно сразу переходить к этапу конкретизации запроса клиента. Ключевая идея данного этапа процесса взаимоотношения с клиентом для продавца определить потребности, соотнести запросы потребителя с предлагаемыми компанией продуктами или услугами. На этом этапе начинается взаимодействие продавца с клиентом, поэтому от того, насколько профессионально будет работать продавец зависит успех последующих этапов, и, как следствие, результат сделки.

3) Стадия расширения, или презентации.

На данной стадии продавец уже имеет понимание о потребностях клиента, клиент же осознает, что из представленных ранее продавцом товаров может его заинтересовать. Главной задачей продавца на данном этапе является презентация конкретного продукта или услуги клиенту из ранее представленного ассортимента, описание преимуществ и достоинств. На данной стадии продавцом могут использоваться различные способы и методы убеждения, техники продаж. Основное правило убеждения - вызвать у клиента эмоции, воздействовать как на рациональную, так и на эмоциональную составляющую его сознания, тогда покупка будет совершена и клиент останется доволен с большей вероятностью. В процессе продажи важно сформировать определенный акцент на каком-либо свойстве товара либо эффекте от последующего его потребления, однако наиболее действенным методом убеждения является акцент на эмоции, которые получит клиент в процессе пользования продуктом, так как решения о покупке большая часть людей принимает на эмоциональном уровне. 
4) Стадия работы с возражениями.

Возражения - это неотъемлемая и обязательная часть продажи и процесса убеждения в целом. Возражения покупателя могут быть как сознательными, так и бессознательными. Сознательные возражения обусловлены объективными причинами - высокой стоимостью, техническими характеристиками товара, недостаточным уровнем предоставленной информации. Бессознательные же возражения являются естественной реакцией покупателя на вмешательство продавца, чаще всего они обусловлены агрессивной манерой общения и недостаточным уровнем профессионализма продавца. Процесс работы с возражениями, в свою очередь, можно разделить на несколько этапов. Первый из них - формулирование возражения, определение конкретных параметров товара или услуги, которые не устраивают покупателя. Далее наступает сам этап обработки возражения - т.е. в ответ на комментарии покупателя продавец должен предоставить аргументированные ответы, которые смогут нивелировать выявленные клиентом негативные параметры товара и вновь завоевать его внимание.

5) Стадия завершения сделки.

На данной стадии происходит непосредственное завершение сделки, т.е. принятие клиентом решения о покупке. Однако совершение покупки не является окончанием процесса взаимодействия продавца и покупателя. Здесь важную роль играет такое понятие как «послепродажный сервис», т.е. по окончании покупки клиент должен понимать, что в любой момент он может обратиться к представителям компании с вопросами и комментариями, и его мнение будет услышано. Правильное общение с покупателем после завершения сделки чрезвычайно мощное средство для мотивации дальнейших покупок и формирования лояльности.

В процессе управления обслуживанием можно выделить две основных составляющих: технический фактор (выполнение конкретной работы по обслуживанию) и человеческий фактор (уровень общения, т.е. вежливость, доброжелательность, профессионализм). Глобально, процесс управления обслуживанием направлен на повышение лояльности существующих клиентов и привлечение новых. Понятие управления обслуживанием включает такие процессы как управление работой с клиентами, управление работой с заказами, управление базами данных, послепродажное обслуживание, работа с отзывами и претензиями.

Для управления процессом обслуживания клиентов необходима подробная информация о каждом клиенте, его характеристики, история всех сделок, т.е. в основе управления обслуживанием клиентов лежит процесс накопления и анализа информации о них.

Сегодня компании стремятся использовать в управлении процесса взаимоотношения с клиентами единый клиент-ориентированный подход. клиентами:

Основные факторы, влияющие на процесс управления взаимоотношениями с

1) Информация [3].

Компания должна постоянно изучать, накапливать и систематизировать информацию о своих клиентах. Это является основой системы управления взаимоотношениями с клиентами, все дальнейшие процессы взаимодействия строятся на основе информации, полученной и проанализированной ранее. Понимая, к какому сегменту относятся клиенты компании, каковы их основные потребности и ожидания, почему они выбирают определенный бренд или определенный продукт гораздо проще сформировывать бизнесмодель компании, разрабатывать ассортиментную и маркетинговую политики и реализовывать продукцию на определенном рынке. 
Если ранее информация о клиентах накапливалась на бумажных носителях либо вообще никаким образом не документировалась и содержалась только в голове у продавца, то в эпоху цифровых технологий появились решения, позволяющие оптимизировать работу с поступающей информацией и выстраивать новый подход к работе с имеющимися данными по клиентам. Сегодня широкое применение получили CRM-системы (Рисунок 2), позволяющие накапливать и хранить информацию о существующих сделках и клиентах в одном месте. CRM позволяет поддерживать связь с клиентами, что особенно актуально для больших фирм, у которых имеется большой список клиентов [4].

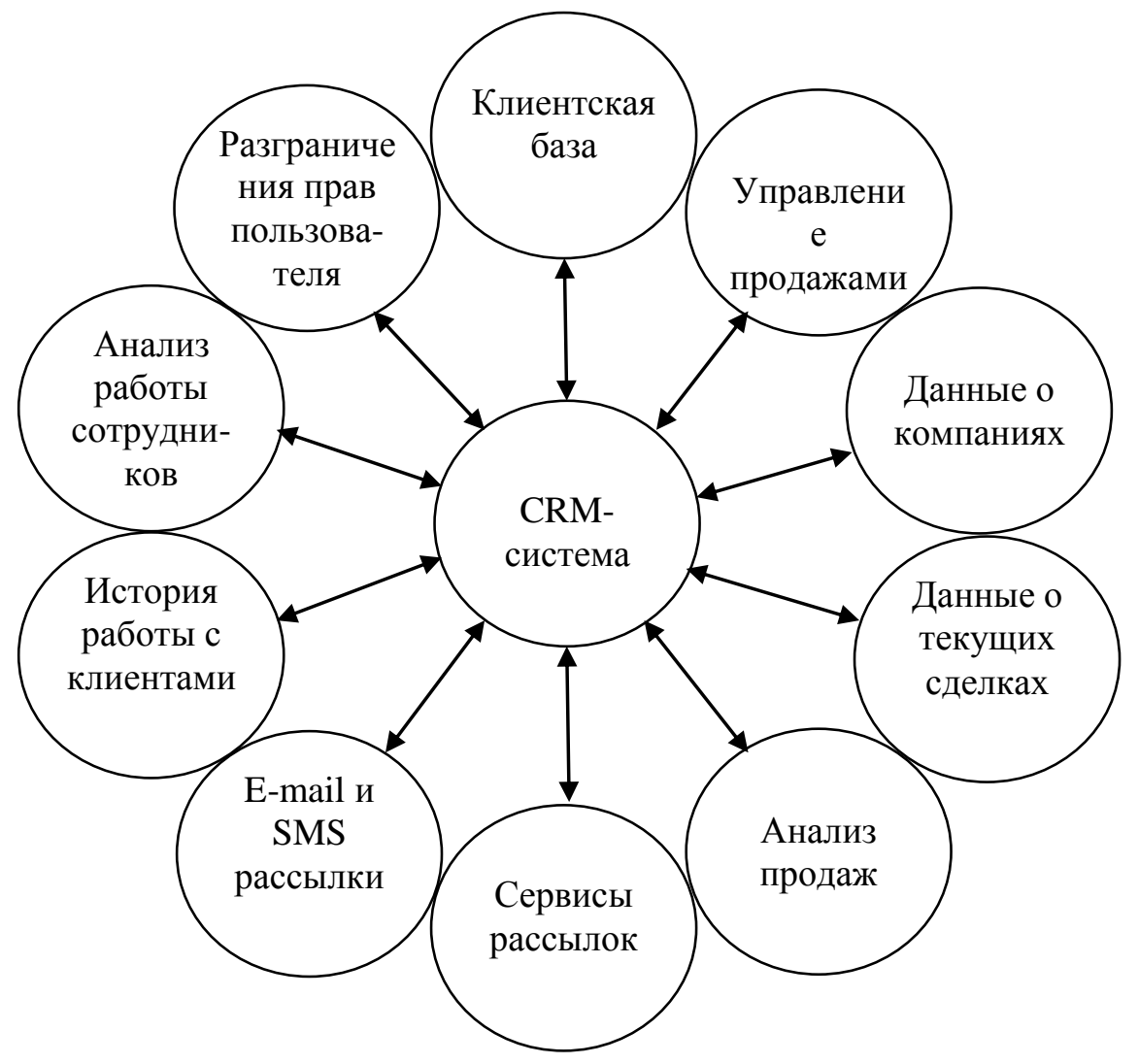

Рисунок 2. CRM-система

Благодаря CRM-системам можно не просто определить статус той иной сделки или посчитать эффективность работы определенного канала продаж, но и определить тенденции развития рынка, проанализировать динамику продаж за долгосрочный период и выявить возможные причины снижения спроса.

2) Индивидуальный подход.

Одним из результатов перехода от продукт-ориентированного к клиенториентированному маркетингу является появление понятия «персонифицированный маркетинг». Такой маркетинг ориентирован в первую очередь на повышение лояльности путем уделения внимания потребностям и целям каждого конкретного клиента.

К основным преимуществам, которые дает компании стратегия персонифицированного маркетинга можно отнести:

- повышение лояльности существующих клиентов компании

- получение компанией конкурентного преимущества

- увеличение спроса на продукцию бренда и рост продаж 
- возможность более точной сегментации клиентов, повышение эффективности направленности маркетинговых мероприятий

3) Уровень профессиональной подготовки и квалификации персонала.

Одним из важнейших ресурсов компании являются ее сотрудники, и от уровня их профессиональной подготовки зависит эффективность внедрения новых методов и технологий в бизнес-процессы организации. От того, насколько сотрудники мотивированы и обеспечены необходимыми теоретическими знаниями и практическими умениями зависит эффективность их работы и, как следствие, эффективность работы организации. В процессе взаимоотношений с клиентами ключевую роль в конечном счете играют не методы, способы и средства взаимодействия с клиентом, а личные навыки и профессионализм представителей компании. Поэтому помимо вложений в средства по хранению и обработке информации важно инвестировать их в навыки людей, которые используют данную информацию в своей работе, обучить применению практических навыков и полученных знаний в работе с клиентами.

\section{Заключение}

Перечисленные факторы эффективно влияют на процесс взаимоотношения с клиентами в том случае, если их воздействие комплексно и последовательно. Действительно, если в компании имеется программное обеспечение, позволяющее накапливать и систематизировать информацию о клиентах, гораздо проще осуществлять стратегию индивидуального подхода. Автоматизированное программное CRM-обеспечение может стать решением для реализации стратегии персонифицированного маркетинга, что позволит более эффективно управлять бизнес-процессами, протекающими в рамках взаимодействия сотрудников предприятия с клиентами [5].

Таким образом, наличие систематизированной и доступной к анализу информации о клиентах компании является основополагающим фактором развития процесса управления взаимоотношениями с клиентами.

\section{Список литературы:}

1. Наприенко Д. В. Модель управления взаимоотношениями с клиентами в сфере ритейла // Молодой ученый. 2018. №20. С. 159-160.

2. Степанова Т. В., Морсина Е. В. О некоторых аспектах применения CRM-систем для управления сложными продажами // Концепт. 2017. Т. 3. С. 174-178.

3. Романова Е. А. Управление взаимоотношениями с клиентами // Вестник Саратовского государственного социально-экономического университета. 2008. №4(23). С. 57-60.

4. Морозов Е. М. CRM-системы как средство автоматизации взаимодействия с клиентами // Современные научные исследования и инновации. 2015. №3. Ч. 3 URL: http://web.snauka.ru/issues/2015/03/49404 (дата обращения: 26.03.2019).

5. Баранова И. В., Мурадов А. А. Формирование стратегии устойчивого развития высокотехнологичного предприятия на основе управления клиентелой // Вопросы инновационной экономики. 2015. Т. 3. №2. С. 20-27.

\section{References:}

1. Naprienko, D. V. (2018). Model' upravleniya vzaimootnosheniyami s klientami v sfere riteila. Molodoi uchenyi, (20). 159-160. (in Russian).

2. Stepanova, T. V., \& Morsina, E. V. (2017). O nekotorykh aspektakh primeneniya CRMsistem dlya upravleniya slozhnymi prodazhami. Kontsept, 3. 174-178. (in Russian). 
3. Romanova, E. A. (2008). Upravlenie vzaimootnosheniyami s klientami. Vestnik Saratovskogo gosudarstvennogo sotsial'no-ekonomicheskogo universiteta, 4(23). 57-60. (in Russian).

4. Morozov, E. M. (2015). CRM-sistemy kak sredstvo avtomatizatsii vzaimodeistviya s klientami. Sovremennye nauchnye issledovaniya $i$ innovatsii, (3)3 URL: http://web.snauka.ru/issues/2015/03/49404 (data obrashcheniya: 26.03.2019). (in Russian).

5. Baranova, I. V., \& Muradov, A. A. (2015). Formirovanie strategii ustoichivogo razvitiya vysokotekhnologichnogo predpriyatiya na osnove upravleniya klienteloi. Voprosy innovatsionnoi ekonomiki, 3(2). 20-27. (in Russian).

Работа поступила

в редакичию 04.01.2020 г.
Принята к публикащчи 09.01.2020 г.

Ссылка для цчитирования:

Ерлыгина Е. Г., Филимонова В. Д. Управление взаимоотношениями с клиентами // Бюллетень науки и практики. 2020. Т. 6. №2. С. 212-218. https://doi.org/10.33619/2414$2948 / 51 / 21$

Cite as (APA):

Erlygina, E., \& Filimonova, V. (2020). Customer Relationship Management. Bulletin of Science and Practice, 6(2), 212-218. https://doi.org/10.33619/2414-2948/51/21 (in Russian). 


\title{
РАЗВИТИЕ ЦИФРОВОЙ ЭКОНОМИКИ В РЕГИОНАХ КЫРГЫЗСТАНА
}

\author{
(C)Аманалиева M. O., ORCID: 0000-0002-8985-7427, SPIN-код: 7807-0248, \\ канд. экон. наук, Киргизский экономический университет им. М. Рыскулбекова, \\ г. Бишкек, Кыргызстан, mahabata@mail.ru
}

\section{DEVELOPMENT OF DIGITAL ECONOMY IN REGIONS OF KYRGYZSTAN}

\author{
CAmanalieva M., ORCID: 0000-0002-8985-7427, SPIN-code: 7807-0248, \\ Ph.D., Kyrgyz Economic University of named Musa Ryskulbekov, \\ Bishkek,Kyrgyzstan,mahabata@mail.ru
}

\begin{abstract}
Аннотация. Рассмотрен процесс экономического развития регионов Кыргызстана с помощью цифровизации. А также анализируется тенденция развития цифровой технологии и ее влияние на национальную стратегию. Нормализация цифровой экономики и ее развитие рассматривается как основной инструмент в Киргизской Республике. Для развития экономики Кыргызстана рассмотрены основные проблемы и пути развития цифровых технологий. В рамках программы Таза Коом принятой в Киргизской Республике 2017 г. для обеспечения национальной безопасности, а также развитие страны рассмотрены технологии, влияющие на них. Для развития цифровой экономики как основной приоритет рассмотрены цифровые технологии и основные рынки. Предложены сегменты для развития сельского хозяйства в Кыргызстане с помощью цифровых технологий. А также (факторы) использование цифровых технологий в сельском хозяйстве, его роль в регионах, цели и преимущества отражены в этой статье. А также в статье рассматривается использование процессов цифровизации экономики на региональном уровне. Проведен анализ мировых тенденций развития цифровых технологий в аграрном секторе и их влияния на стратегии регионального развития. Определены особенности формирования цифровой экономики в регионах Киргизской Республики. Выявлены проблемы и перспективные направления тестирования цифровых технологий в развитии аграрного сектора экономики Киргизской Республики. Рассмотрены возможности трансформации экономики регионов в условиях цифровизации. Проведен анализ существующих подходов к формированию региональных программ цифрового развития и практики их применения. Был выявлен ряд методологических проблем и предложено авторское видение процесса формирования программ цифровой трансформации для региона. Основные направления развития аграрного сектора экономики в регионах сформулированы с учетом цифровизации.
\end{abstract}

Abstract. The process of economic development of the regions of Kyrgyzstan with the help of digitalization is considered. It also analyzes the trend of development of digital technology and its impact on the national strategy. Normalization of the digital economy and its development is considered as the main tool in the Kyrgyz Republic. For the development of the economy of Kyrgyzstan, the main problems and the development of digital technologies are considered. In the framework of the program Taza Koom adopted in the Kyrgyz Republic in 2017, to ensure national security, as well as the development of the country, technologies affecting them were considered. For the development of the digital economy, digital technologies and major markets are considered as the main priority. Segments for the development of agriculture in Kyrgyzstan with the help of digital technologies are proposed. And also (factors) the use of digital technologies in agriculture, 
its role in the regions, goals and advantages are reflected in this article. The paper discusses the use of digitalization processes of the economy at the regional level. The analysis of global trends in the development of digital technologies in the agricultural sector and their impact on regional development strategies is carried out. The features of the formation of the digital economy in the regions of the Kyrgyz Republic are determined. The problems and promising areas of testing digital technologies in the development of the economy of the Kyrgyz Republic are identified. The possibilities of transforming the economy of the regions in the context of digitalization are considered. The analysis of existing approaches to the formation of regional digital development programs and the practice of their application is carried out. A number of methodological problems were identified and the author's vision of the process of formation of digital transformation programs for the region was proposed. The main directions of agricultural development in the regions are formulated taking into account digitalization.

Ключевые слова: цифровая экономика, цифровизация, сельское хозяйство, цифровые технологии, тенденция развития регионов, инновация, регионы.

Keywords: digital economy, digitalization, agriculture, digital technologies, regional development trend, innovation, regions.

\section{Введение}

Принятые в последние годы в Кыргызской Республике документы, определяющие стратегические аспекты развития страны, не оставляют никаких сомнений в том, что цифровая экономика является одним из главных приоритетов государственной политики в ближайшие годы (https://clck.ru/MDJ9S).

В настоящее время интерес к процессу цифровизации связан со структурой экономики, производственными процессами и необходимостью понимать и прогнозировать влияние на развития регионов страны. В контексте увеличения масштаба и качества процедур сбора, систематизации, анализа и использования цифровых данных, возникают объективные предпосылки для изменения приоритетов и целей развития, для обзора традиционных инструментов и инструментов для достижения целей, а также для оптимизации формирования, распределения и использования существующих ресурсов [1]. Все это приводит к появлению новой технологической платформы для качественно более высокой производительности труда и управления рисками в развития сельского хозяйства в регионах страны.

Особая роль уделяется региональному и местному уровню экономики, в котором должны быть реализованы определенные проекты цифровой трансформации, и результаты оцениваются для улучшения качества жизни людей и установления предпосылок для экономического роста.

\section{Материал и методы исследования}

Таза Коом - является основным связующим элементом между государством и населением страны, как отметил президент Кыргызской Республики С. Ш. Жээнбеков [2], осуществление этого проекта, можно сказать доставит гражданам всех регионов множество государственных услуг. Распространение высококачественных технологий помогает в борьбе с коррупцией. А также, улучшение жизненных условий населения, и создание условий для развития регионов. Поставка интернет транзита, обеспечение хранения информации, построение централизованной информационной базы, считается одним из основных целей 
программы Таза Коом - Кыргызстан в центре пути цифровой шелковой дороги [1]. Являясь не только спецификой экономических и информационных коммуникаций становится (преобразуется) общей тенденцией, включающей все сферы сельскохозяйственной деятельности. С каждым днем отмечается как набирает силу цифровая революция — в интернет торговле, в цифровом сельском хозяйстве, в области электронных систем «умный», беспилотный транспорт, персональное медицинское здравоохранение.

Развитие цифровой экономики Кыргызстана в ближайшем будущем будет проводиться в трех приоритетных направлениях. Об этом заявил президент Сооронбай Жээнбеков в г. Ош на первом телекоммуникационном форуме [3].

По словам президента, первое направление - это цифровая трансформация бизнеспроцессов и производственных связей:

-Внедрение инноваций в финансовый и банковский сектор

-Обеспечение компетентными специалистами и повышение эффективности и конкурентоспособности отечественных компаний.

-Развитие цифровой инфраструктуры и цифровых платформ в приоритетных секторах экономики.

Второе направление - это использование стратегий по развитию цифровой экономики стран-партнеров:

-Использование цифровой повестки дня ЕАЭС-2025.

-Восстановление цифрового Великого Шелкового пути через программу «Один пояс один путь» и поддержка других международных инициатив по развитию региональной цифровой инфраструктуры.

Tретье направление - это снижение препятствий на пути развития и разработки цифровых технологий.

Как заявил Жээнбеков, реализация обозначенных направлений позволит расширить рынки сбыта для частного сектора, создать новые виды товаров и услуг, и принять участие в глобальной производственной связи.

Таким образом, в стране появятся новые экономические кластеры. Наши действия будут направлены на создание условий для инвестиций, которые будут стимулировать национальную цифровую инфраструктуру».

В этом положении некоторые компании, регионы, страны соединяя их в сфере цифровой экономики формировании стратегических решений, а также в процессе их реализации и создании технологий, прикладывают свои усилия в долгосрочных планах конкуренции обеспечивая преимущество своих новых видов товаров и услуг на рынке. В это же время в некоторых секторах, регионах и не только, в разных социальных частях населения, во время реализации преимуществ цифровой экономики связанные с оценками их последствий остаются нерешенными ряд принципиально существенных вопросов. Когда неразвитые в технологическом плане секторы экономики снова смогут восстановится и войти в цепочку строения ценообразования, как повлияет процесс цифровизации на обеспечение работой населения близлежащих и отдаленно расположенных регионов, насколько возрастет роль транснациональных корпораций в национальной и региональной экономической работе? На эти все вопросы сегодня не найти удовлетворительных ответов.

\section{Результаты и обсуждение}

Цифровая экономика — не отдельные проекты или направления автоматизации и развития, такие как Интернет или большие данные (Big Data, Smart технологии и другие). Это скорее новая парадигма развития экономики и общества, основанная на сетевых 
коммуникациях, объединении реального и виртуального миров. Это экономика обеспечивающая переход на следующий уровень взаимодействия, возможности и угрозы которого пока лишь смутно осознаются [4]. Как отметил автор, очевидно цифровые технологии меняют модели экономики в целом и одновременно ведут новые проблемы на уровне страны.

Для полного понимания протекающих процессов, возможности ее систематизации и принятие основных решений против ее угроз, требуют глубоких исследований. В целом развитие информационного общества Кыргызской Республики определение ее содержания и строение стратегии, показывает еe согласованность декларациям и принятым взаимоотношениям в мире.

Наше мнение на сегодня цифровой стратегии не хватает следующее:

- развитие цифровой технологии (в целом информационное общество) ее негативные последствия влияния на строение населения и обеспечение работой не определены.

-в части экономического сектора, а также технологическое отставание в социальной среде и ее пути разрешения не разработаны.

- распространение возможностей цифровой экономики, использование ее потенциала, уровень готовности и проблема регионального распределения не исследованы.

Эти важные вопросы для успешной реализации цифровой стратегии вызывают опасения, так как реализация процесса глобализации экономики и ее последствий, а также внутри нее экономической деятельности локальных субъектов и повышение их независимости от транснациональных корпораций. В некоторых регионах с развитием социальной экономики, являясь основой увеличивает разрыв части слоев населения по уровню жизни. Проблемы и пути их решения при реализации и использовании возможностей цифровой экономики в регионах.

Развитие цифровой экономики соответствующей программе «Таза Коом» Принятый 2017 г в Кыргызстане, дополняет и принимает во внимание цели инициативы национальной технологии (https://digital.gov.kg/). Он служит в качестве известной базы для обеспечения национальной безопасности, повышении уровня жизни народа, как порядок развития новых технологий в секторах. Построение и развитие в регионах цифровизации и дополнение работающих программ научно-технологического развития и связанные с ним разработок эффективных решений, а также для продажи отечественных технологий и освоении новых рынков необходимо для реализации работ привлечь широкий круг экспертов, практиков и ученых. Разработка цифровых технологий, должна проводится в каждом секторе, известными экспертами и предпринимателями и государственными учреждениями.

В условиях реализации цифровизации необходимо предварительно помнить о глобальном развитии рынков. Основой разработки цифровой технологии и основой ее развития являются - ее потребители, создание условий для пользования цифровыми технологиями населению [1]. При реализации цифровой технологии основными считаются: существенная информация; искусственный интеллект, реестр системы разделения; квантовые технологии; новые источники портативной энергии; новые производственные технологии; сенсорика, а также компоненты робототехники; беспроводная связь; технология управления качества биологических объектов; нейротехнологии, виртуальный, а также дополнительно реальная технология (http://www.tadvaiser.com). Еще одна особенность развития цифровой экономики- высокая возможность монополизации/олигополизация новых рынков, и концентрация развивающихся и реорганизованных компаний в нескольких государствах (США и западная Европа) [2]. В связи с этим при осуществлении использовании цифровой 
технологии в Кыргызстане необходимо охватить все регионы. Поэтому необходимо выявить на сегодняшний день преимущества при осуществлении цифровизации экономических секторов регионов страны. В условиях цифровизации и задачах развития экономики Республики, указать цели для использования, источников цифровых технологий, для социально-экономического стратегического развития регионов Кыргызской Республики. Используя инфраструктуру регионов, рекомендуется рассмотреть специальные сегменты, для пользования цифровыми технологиями. В развитии цифровой экономики можем посмотреть ниже основные моменты: об уровни развития сельского хозяйства, также особенности регионов и их развития мало отработанной информации об инфраструктуре.

В контексте сегодняшнего времени развитие цифровой экономики в сельском хозяйстве “eagriculture" термин активно распространяется, он понимается как «цифровое (электронное) сельское хозяйство» [2]. Этот термин был внедрен для пользования организацией продовольствия и сельского хозяйства ООН(ФАО) и направлен для улучшения и развития информационно-коммуникационных процессов сельского хозяйства и регионов, и рассматривается как новый сектор в предпринимательстве. Исходя из этого контекста на основе цифрового (электронного) сельского хозяйства, направленный на сельское хозяйство и проектирование инновационных путей сельской местности, развитие оценки и использование, разработка концепций и использование специальных девайсов, секторов, а также лежат в основе сервисы приложений информационно-коммуникационных технологий (ИКТ).

Цели развития стратегии цифрового (электронный) сельского хозяйства определяются следующими факторами:

-производство и использование в регионах сельскохозяйственной продукции, а также роль и значение развития отдельных муниципальных районов;

- развитие сельского хозяйства в данное время и его преимущества в будущем, разработка на рынках регионов продукции и его использование;

-строение региональной агросистемы и ее особенности; региональная стратегия, его цели и преимущества;

-опыт распространения цифрового (электронный) сельского хозяйства.

Основными обязанностями разработки цифрового сельского хозяйства, можно рассматривать следующие ниже:

-повысить эффективность агропроизводства в регионах, и улучшение цепочки ценообразования;

-повысить качество использования ИКТ в агросекторе и других приближённых секторах;

-ускорить достижение цели в эффективной позиции использовании ресурсов, преодоление трудностей и стабильное развитие сельской местности;

- развивать новые виды предпринимательства, а также посредством их обеспечить работой сельскую местность, создавая новые возможности.

Разработка цифрового сельского хозяйства является комплексным направлением и следует принять во внимание следующие компоненты:

- местная инициатива (лидерство) и роль государства;

-стратегия и инвестиционные возможности;

- информационная структура и специализированное развитие ИКТ;

-построение информационно-сервисного контента и его управление;

- регулирование нормативной базы и построение механизма; 
-обеспечение рабочей силой, а также основным финансовым обеспечением.

Сейчас важно развивать цифровую экономику, тенденция глобализации и ее негативные проявление прослеживаются во всей тончайшей среде. В этих условиях, во многих странах разрабатываются и распространяются стратегии и планы для формирования цифровой экономики.

В 2018 г в Кыргызстане были приняты документы, определяющие будущее этого направления, в него входят стратегия развития информационного общества, а также цифровая экономика Кыргызской Республики. Но в этих документах недостаточно уделяется внимания цифровизации экономики.

Учитывая вышесказанное, в производстве продуктов сельского хозяйства в регионах, распространение элементов цифровой экономики т.е. рассмотрение перехода на цифровизацию сельского хозяйства даст большую возможность развития регионов.

\section{Заключение (Bыводы)}

Таким образом, рассматриваемые проблемы о развитии региональной экономики в контексте цифровизации, в настоящее время остается актуальной и недостаточно развитой на государственном уровне. Успех цифровой трансформации аграрного сектора экономики региона во многом будет определять результаты всего национального развития экономики.

Ввиду отсутствия методологической и методологической поддержки регионы вынуждены максимально эффективно использовать свой опыт и знания в области разработки целевых программ и стратегий развития сельского хозяйства в условиях цифровизации. Однако цифровая трансформация как процесс, имеющего системные последствия для сельского хозяйства регионов, требуют использования более объективных подходов, применяемых к программам социально-экономического развития регионов.

Анализ практики создания программ цифровизации показал, что наличие систематических подходов подтверждает необходимость решения ряда методологических проблем.

\section{Список литературь:}

1. E-Agriculture In Action. Food and Agriculture Organization of the United Nations and International Telecommunication Union Bangkok, 2017. C. 118.

2. Алексеев И. В. Цифровая экономика: особенности и тенденции развития электронного взаимодействия // Актуальные направления научных исследований: от теории к практике: материалы X Междунар. науч.-практ. конф. Т. 2. Чебоксары: Интерактив. плюс, 2016. №4(10). С. 42-45.

3. Маркова В. Д. Цифровая экономика. М. 2019. 186 с.

4. Ревенко Н. С. Цифровая экономика США в эпоху информационной глобализации: актуальные тенденции // США и Канада: экономика, политика, культура. 2017. №8. С. 78-100.

\section{References:}

1. E-Agriculture In Action. (2017). Food and Agriculture Organization of the United Nations and International Telecommunication Union Bangkok, 118.

2. Alekseev, I. V. (2016). Tsifrovaya ekonomika: osobennosti i tendentsii razvitiya elektronnogo vzaimodeistviya. In Aktual'nye napravleniya nauchnykh issledovanii: ot teorii $k$ praktike: materialy X Mezhdunar. nauch.-prakt. konf. (2). Cheboksary. Interaktiv. plyus, 4(10). 4245. (in Russian).

3. Markova, V. D. (2019). Tsifrovaya ekonomika. Moscow. 186. (in Russian). 
Revenko, N. S. (2017). U.S. Digital Economy in the Era of Information Globalization: Current Trends. SShA i Kanada: ekonomika, politika, kul'tura, (8), 78-100. (in Russian).

Работа поступила

в редакиию 14.01.2020 2.
Принята к публикащчи 19.01.2020 2.

Ссылка для циитирования:

Аманалиева М. О. Развитие цифровой экономики в регионах Кыргызстана // Бюллетень науки и практики. 2020. Т. 6. №2. С. 219-225. https://doi.org/10.33619/2414-2948/51/22

Cite as (APA):

Amanalieva, M. (2020). Development of Digital Economy in Regions of Kyrgyzstan. Bulletin of Science and Practice, 6(2), 219-225. https://doi.org/10.33619/2414-2948/51/22 (in Russian). 


\title{
РАЗРАБОТКА КОНЦЕПЦИИ ПРОДВИЖЕНИЯ ПРОЕКТА SONY НА ПЛОЩАДКЕ ВАВYВLОG
}

\author{
(СПрокопенкова А. С., Владимирский государственный университет им. А.Г. и Н.Г. \\ Столетовых, г. Владимир, Россия, anya.prokopenkova@yandex.ru \\ (C) мирнов В. Н., ORCID: 0000-0002-4282-6201, канд. экон. наук, Владимирский \\ государственный университет им. А.Г. и Н.Г. Столетовых, \\ 2. Владимир, Россия, vick33ru@mail.ru
}

\section{DEVELOPMENT OF PROMOTION CONCEPT SONY PROJECT ON BABYBLOG SITE}

\author{
CProkopenkova A., Vladimir State University, \\ Vladimir, Russia, anya.prokopenkova@yandex.ru \\ CSmirnov V., ORCID: 0000-0002-4282-6201, Ph.D., Vladimir State University, \\ Vladimir, Russia,vick33ru@mail.ru
}

Аннотащия. В статье рассмотрено понятие интернет-маркетинг и его основные преимущества. Также представлена концепция продвижения проекта Sony на площадке Babyblog и стоимость разработки и реализации данного проекта. На основе стоимости разработанного спецпроекта предложено продавать проекты за не меньшую цену для увеличения выручки компании.

Abstract. The article discusses the concept of Internet marketing and its main advantages. Also presented is the concept of promoting the Sony project on the Babyblog site and the cost of developing and implementing this project. Based on the cost of the developed special project, it was proposed to sell projects for no less than the price to increase the company's revenue.

Ключевые слова: концепция, продвижение проекта, интернет-площадка, Babyblog, проект Sony, интернет-маркетинг.

Keywords: concept, project promotion, online platform, Babyblog, Sony project, Internet marketing.

Сегодня интернет-маркетинг все чаще заменяет традиционный маркетинг. Под интернет-маркетингом понимают действия, направленные на продвижение товаров и услуг в интернете, основной задачей которых является превратить посетителей сайта в покупателей и увеличить прибыль.

Интернет-маркетинг от классического маркетинга отличается тремя важными преимуществами:

- интерактивность (интернет позволяет напрямую контактировать с аудиторией, поддерживать связь и контролировать ситуацию);

- таргетирование (с помощью этого механизма можно определить целевую аудиторию продукта/услуги и показывать рекламу именно ей);

- веб-аналитика (с помощью нее можно определить эффективные рекламные действия, которые привлекли на сайт большее количество посетителей, совершивших покупку) [1]. 
В интернет-маркетинге рост продаж базируется на привлечении посетителей, повышении эффективности сайта (проекта) и возрасте клиентов. Основной задачей любого бизнеса, помимо привлечения клиентов, является их удержание, ведь именно постоянные клиенты приносят бизнесу прибыль. Соответственно, при разработке концепции будущего проекта нужно учитывать все эти моменты [2].

Babyblog - первое и самое крупное родительское сообщество в Рунете. Сайт https://www.babyblog.ru/ pаботает с 2005 г. Сообщество освещает все тематики, интересные женщинам, и дает мамам общаться, обмениваться опытом, находить подруг.

Компания ООО «Бэбиблог-РТ» работает в отрасли диджитал-маркетинга и интернеттехнологий. Основным видом деятельности является предоставление услуг по интернетрекламе компаний на сайте Babyblog.

С 2018-2019 гг. в компании наблюдался прирост числа проектов на 2,4\%, но при этом выручка немного спала на 7,8\%. (Таблица)

Таблица.

ДИНАМИКА ЧИСЛА ПРОЕКТОВ И ВЫРУЧКИ ЗА ПОСЛЕДНИЕ 3 ГОДА

\begin{tabular}{lcccc}
\hline & 2017 г & 2018 г & 2019 г & Bсего \\
\hline Число проектов, шт & 21 & 28 & 38 & 87 \\
\hline Выручка, руб & 58500000 & 87500000 & 124000000 & 270000000 \\
\hline Прирост проектов, \% & - & $33,3 \%$ & $35,7 \%$ & - \\
\hline Прирост выручки, \% & - & $49,5 \%$ & $41,7 \%$ & - \\
\hline
\end{tabular}

В 2019 г в компании Babyblog сменился весь отдел продаж и проектный отдел (кроме руководителя). Так как стоимость одного проекта может варьироваться от 500 тыс. руб до 6 млн. руб, то спад выручки объясняется продажей большим количеством проектов с маленьким бюджетом. Стоимость одного проекта зависит от количества услуг, креативности проекта, его содержания и продолжительности рекламы на сайте Babyblog.

Компания Babyblog предоставляет клиентам много различных услуг по продвижению их брендов. Так для бренда Sony было подготовлено КП (коммерческое предложение) по вводным данным от клиента:

- построить знание о бренде;

- генерировать «живые отзывы»;

- сформировать позиционирование, как модной техники в ритме времени;

- рассказать о преимуществах товаров.

Клиенту было предложено сделать спецпроект с тремя разделами:

Лонгрид на тему: «Подростки и гаджеты: как не нужно бороться с зависимостью» (Рисунок 1). Представлено 5 примеров неправильного использования гаджетов и советы родителям, как правильно распределять время ребенка, чтобы его хватало на игры в гаджеты. При этом акцент сделан на том, чтобы родители понимали, как важен в подростковом возрасте авторитет, стиль и продвинутость.

В лонгрид интегрирована продукция бренда: беспороводные наушники с шумоподавлением для занятия спортом, портативная акустическая система с технологией BLUETOOTH, беспроводные наушники с шумоподавлением и технологией EXTRA BASSTM, портативная акустическая система с технологией BLUETOOTH. 


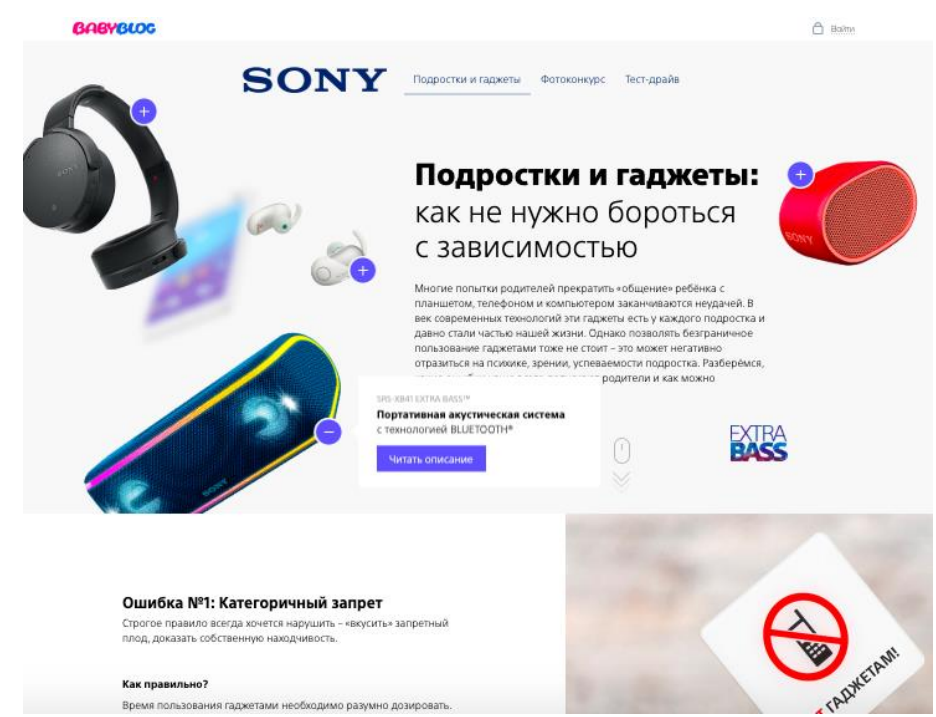

Рисунок 1. Лонгрид Sony на сайте Babyblog

При клике на любой продукт проекта посетителя «перебрасывает» на соответствующую страницу товара на сайте https://www.sony.ru/.

Тест-драйв одной из продукции бренда (тестировали портативную колонку Sony серии EXTRA BASSTM)

Механика тест-драйва (Рисунок 2): пользователи заполняли заявки на участие в соответствующем разделе на сайте babyblog.ru. Из заявок отбирались анкеты претендеток на участие по параметрам: возраст, количество детей, возраст детей и география. Финальный список участниц согласовывался с клиентом (брендом Sony). Участницам, прошедшим отбор, отправили сэмплы (продукция) для тестирования. После тестирования продукта бренда участницы опубликовали отзывы в единой ленте раздела. Отзывы участниц обязательно содержали фото с продуктом.
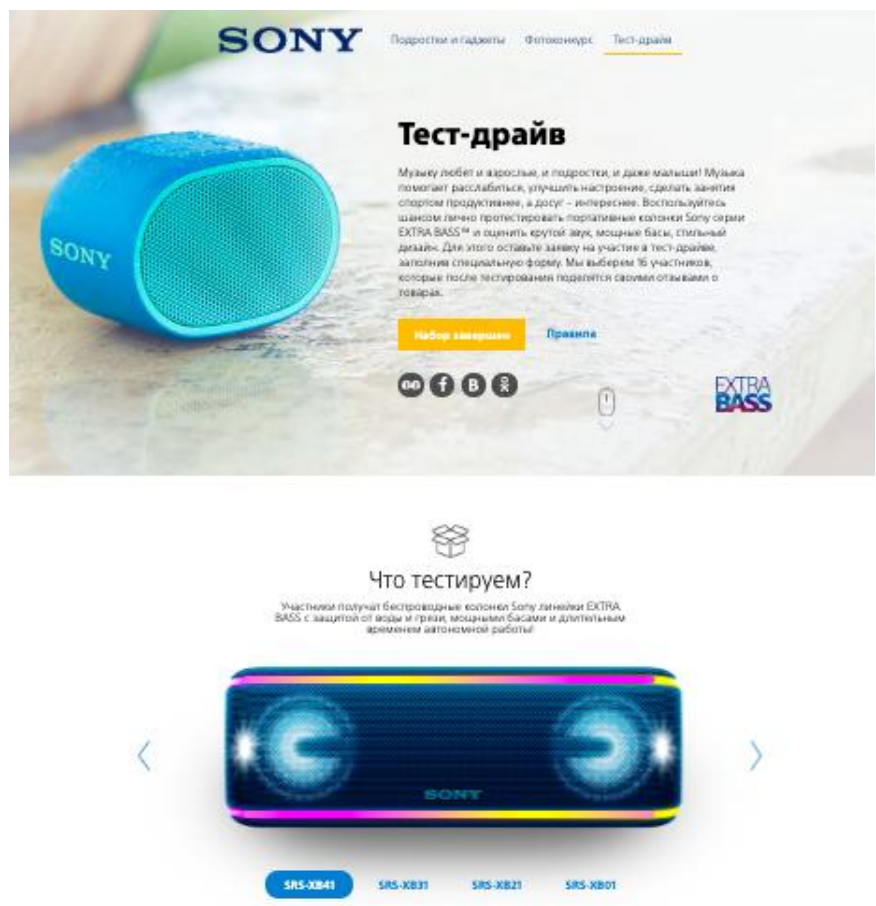

Рисунок 2. Раздел тест-драйва проекта Sony 
На участие в тест-драйве заполнили заявки около 3000 участников. Из них было выбрано для тестирования 16 человек. После завершения тестирования участники отправляли свои отзывы на проверку менеджеру Babyblog, который с свою очередь согласовывал их с клиентом. Далее отзывы публиковались на странице тест-драйва и доступны там даже после завершения проекта.

3. Фотоконкурс Танцы в ритме EXTRA BASS.

Для участия в конкурсе нужно было прислать фото, где мама, ее ребенок или вся семья

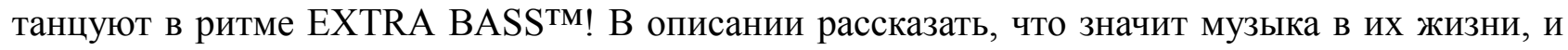
где она сопровождает. Авторам пяти самых интересных работ подарили яркие беспроводные водонепроницаемые колонки с подсветкой Sony SRS-XB21 для живого звука и зажигательных танцев без ограничений!

Около 200 человек отправили заявки на участие. В конкурсе приняли участие 45 мам и только 5 вышли в финал.

Стоимость проекта составила 963516 руб с НДС за 1,5 месяца разработки и реализации. За время реализации проекта был перевыполнен план (41000) по охвату уникальных пользователей спецпроекта на 107\% - 43734 (факт). Охват всех анонсов составил 5-6 млн уникальных пользователей, при этом показы всех анонсов составили 99850 000. Это очень хорошие результаты реализации проекта.

Таким образом, для того, чтобы увеличить выручку в следующем году хотя бы на $1 \%$, нужно больше продавать проектов с бюджетом от 1-2 млн руб и выше. И как можно меньше продавать проектов с бюджетом 500-600 тысяч рублей. Как правило, такие недорогие проекты затем не становится постоянными клиентами, которые в сезон могут обратиться за продвижением продукции.

\section{Список литературы:}

1. Кирьянова А. Из чего состоит интернет-маркетинг // Что такое интернет-маркетинг, стратегии, инструменты и тренды. 2018.

2. Корычева Э. А., Гундарин M. В. Технология PRODUCT PLACEMENT в блогосфере. 2016.

\section{References:}

1. Kiryanova, A. Iz chego sostoit internet-marketing. Chto takoe internet-marketing, strategii, instrumenty $i$ trendy, 2018.

2. Korycheva, E. A., \& Gundarin, M. V. (2016). Tekhnologiya PRODUCT PLACEMENT v blogosfere.

Работа поступила

в редакциию 14.01.2020 2.
Принята к публикаџии 19.01.2020 2.

\section{Ссылка для цчитирования:}

Прокопенкова А. С., Смирнов В. Н. Разработка концепции продвижения проекта Sony на площадке Babyblog // Бюллетень науки и практики. 2020. Т. 6. №2. С. 226-229. https://doi.org/10.33619/2414-2948/51/23

Cite as (APA):

Prokopenkova, A., \& Smirnov, V. (2020). Development of Promotion Concept Sony Project on Babyblog Site. Bulletin of Science and Practice, 6(2), 226-229. https://doi.org/10.33619/24142948/51/23 (in Russian). 


\title{
РАЗРАБОТКА СТРАТЕГИИ ПРОДВИЖЕНИЯ ПРЕДПРИЯТИЯ МАЛОГО БИЗНЕСА В СОЦИАЛЬНЫХ СЕТЯХ НА ПРИМЕРЕ ООО «БЬЮТИ КЛИНИК»
}

(СРотенберг С. В., Владимирский государственньй университет им. А.Г. и Н.Г. Столетовых, г. Владимир, Россия, Sonko2062@yandex.ru (ССмирнов В. Н., ORCID: 0000-0002-4282-6201, канд. экон. наук, Владимирский государственный университет им. А.Г. и Н.Г. Столетовых, 2. Владимир, Россия, vick33ru@mail.ru

\section{DEVELOPMENT OF A STRATEGY FOR PROMOTING A SMALL BUSINESS IN SOCIAL NETWORKS ON THE EXAMPLE OF BEAUTY CLINIC LLC}

\author{
CRotenberg S., Vladimir State University, Vladimir, Russia, Sonko2062@yandex.ru \\ CSmirnov V., ORCID: 0000-0002-4282-6201, Ph.D., Vladimir State University, \\ Vladimir, Russia,vick33ru@mail.ru
}

Аннотащия. В статье рассмотрены теоретические и практические аспекты разработки стратегии развития предприятия малого бизнеса в социальных сетях. На основе анализа разработаны и предложены мероприятия, ориентированные на разработку стратегии продвижения предприятия малого бизнеса в социальных сетях.

Abstract. The article discusses the theoretical and practical aspects of developing a strategy for developing small businesses in social networks. Based on the analysis, measures aimed at developing a strategy for promoting a small business in social networks were developed and proposed.

Ключевые слова: социальные медиа, продвижение в социальных сетях, стратегия, таргетированная реклама

Keywords: social media, social media promotion, strategy, targeted advertising

Социальные сети выступают важной составляющей для современного общества. На сегодняшний момент практически у каждого потенциального клиента существует личная страница в какой-либо социальной сети, с помощью которой можно найти новых друзей, иметь возможность дополнительного приработка, а также узнавать интересующую информацию о компаниях и их услугах. Продвижение предприятия малого бизнеса в социальных сетях является востребованным инструментом по работе с формированием положительного отношения к компании, способным повысить лояльность клиентуры, а также нарастить продажи и прибыль.

Преимуществ продвижения в социальных сетях много, из них были выделены основные:

1. Направленность на целевую аудиторию;

2. Глубокий анализ рекламной кампании;

3. Дешевизна рекламы;

4. Массовость;

5. Повышение степени лояльности к продукту или услуге. 
Для осуществления эффективного продвижения предприятия, необходимо разработать определенную стратегию.

Существует множество теоретических подходов к определению понятия «стратегия». В качестве базисного было выбрано толкование А. Чандлера, который понимает стратегию как «определение основных долгосрочных целей и задач предприятия, и утверждение курса действий, распределение ресурсов, необходимых для достижения этих целей» [1].

Продвижение - это вполне конкретный инструмент маркетинга, направленный на привлечение и удержание внимания как можно большего количества клиентов, с целью воздействия на них и убеждения приобрести товары или услуги предприятия.

Таким образом, под «стратегией продвижения товаров или услуг следует понимать комплекс маркетинговых работ, который включает в себя описание целевого сегмента, позиционирование, структуру бренда, каналы распространения маркетингового обращения и медиаплан» [2].

Процесс разработки стратегии продвижения подчинен определенному алгоритму, предполагающему необходимость прохождения ряда этапов.

В общем виде они представлены на Рисунке.

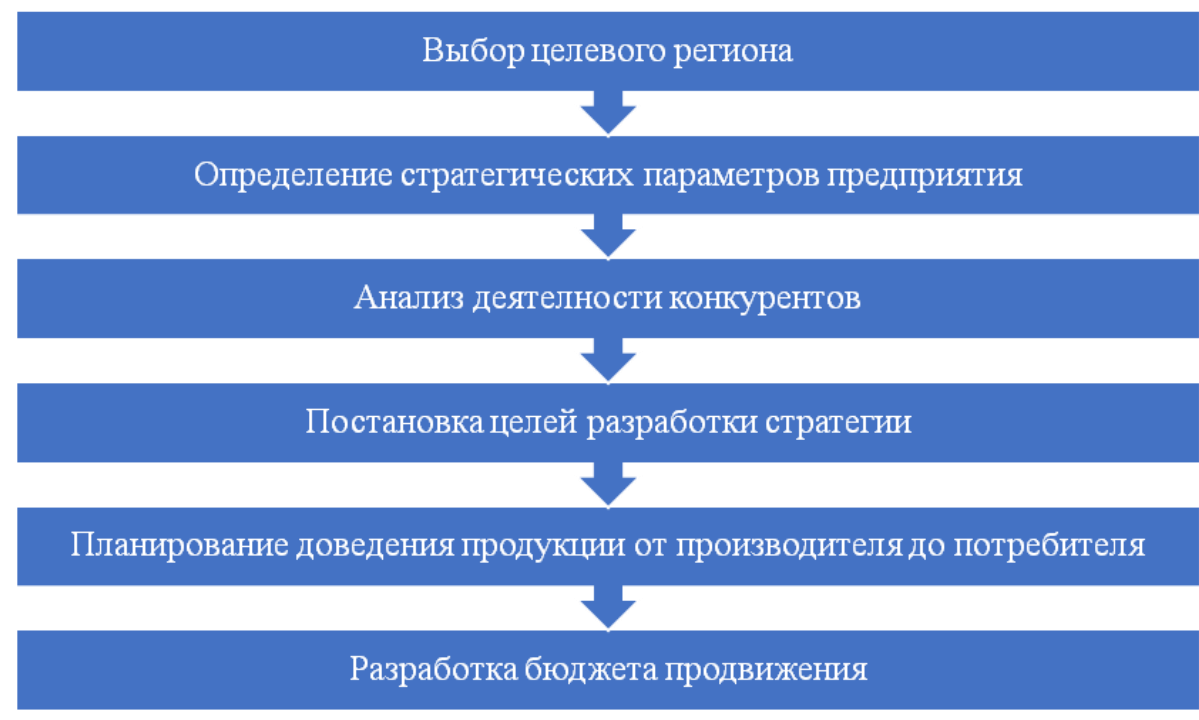

Рисунок. Разработка стратегии продвижения

Объектом анализа для разработки стратегии продвижения предприятия малого бизнеса выступило Общество с ограниченной ответственностью «Бьюти Клиник» (далее ООО «Бьюти Клиник»). Сфера деятельности предприятия — салон красоты. Цель деятельности салона красоты ООО «Бьюти Клиник» ориентирована на жителей города Владимир со средним или высоким достатком. Салон работает непосредственно с небольшим количеством людей, объясняя это тем, что предприятие предоставляет качественные и профессиональные косметические услуги.

Для оказания услуг ООО «Бьюти Клиник» использует продукцию высокого качества, а именно красители класса luxe, приборы для укладки волос, материалы для маникюра или педикюра.

Компания ООО «Бьюти Клиник» работает только с проверенными поставщиками.

Для выявления сильных и слабых сторон предприятия, его потенциальных возможностей и угроз, проведем SWOT - анализ ОOO «Бьюти Клиник» (Таблица 1). 
Таблица 1

АНАЛИЗ ПОЛОЖИТЕЛЬНЫХ И ОТРИЦАТЕЛЬНЫХ ФАКТОРОВ ООО «БЬЮТИ КЛИНИК»

\begin{tabular}{|c|c|}
\hline Сильные стороны: & Слабые сторонь: \\
\hline $\begin{array}{l}\text { выгодное месторасположение фирмы; } \\
\text { широкий спектры предоставляемых услуг; } \\
\text { квалифицированные мастера; } \\
\text { высокая стабильность кадров; } \\
\text { наличие программы лояльности для клиентов, } \\
\text { получающих одновременно комплекс услуг; } \\
\text { высокое качество используемой продукции; } \\
\text { высокая репутация. }\end{array}$ & $\begin{array}{l}\text { низкая конкурентоспособность цен; } \\
\text { отсутствие у ооо «бьюти клиник» отдельных } \\
\text { видов услуг, имеющихся у конкурентов; } \\
\begin{array}{ll}\text { большая } \\
\text { спроса. }\end{array}\end{array}$ \\
\hline Возможности: & Угрозы: \\
\hline $\begin{array}{l}\text { потенциальный рост числа клиентов за счет } \\
\text { демографической ситуации; } \\
\text { открытие косметологического кабинета. На } \\
\text { данном участке района эту услугу никто не } \\
\text { предоставляет; } \\
\text { расширение ассортимента косметической } \\
\text { продукции для клиентов со средними достатком }\end{array}$ & $\begin{array}{l}\text { снижение спроса вызванный спадом в экономике; } \\
\text { быстрое появление новых конкурентов; } \\
\text { изменение потребностей и вкусов потребителей; } \\
\text { использование конкурентами новых } \\
\text { маркетинговых технологий. }\end{array}$ \\
\hline
\end{tabular}

Кроме SWOT - анализа наибольший интерес представляет конкурентный анализ предприятия.

Прежде всего, необходимо выделить критерии, на основе которых проводился конкурентный анализ:

1. Расположение в г. Владимир.

2. Ассортимент предлагаемых услуг.

3. Стоимость предоставляемых услуг.

4. Целевая аудитория.

Несмотря на значительное изменения состояния конкуренции на рынке в последние несколько лет, лидеры остаются неизменными: ООО «Бьюти Клиник», “Сesare Ponti”, "Aurora Solutions".

В последние 2 года появились яркие представители благодаря интернету, такие как «Гримерка», однако данный салон рассчитан на узкую молодежную аудиторию и оказывает ограниченное количество услуг.

Ключевые сравнительные характеристики данных салонов представлены в Таблице 2.

Конкурент, находящийся в шаговой доступности - это салон Гримерка. В целом данный салон предоставляет меньший набор услуг со сравнимыми ценами, что делает наш салон более привлекательным. Существенными недостатками для данной целевой аудитории является то, что специалисты салона работают на основе аренды места, а также отсутствует собственная парковка.

Проведенный анализ показал, что необходимость присутствия в социальных медиа давно стала очевидна для ООО «Бьюти Клиник». 
Таблица 2

СРАВНИТЕЛЬНАЯ ХАРАКТЕРИСТИКА ОСНОВНЫХ УЧАСТНИКОВ РЫНКА САЛОНОВ КРАСОТЫ БИЗНЕС И ПРЕМИУМ КЛАССА В Г. ВЛАДИМИР

\begin{tabular}{|c|c|c|c|c|}
\hline & $\begin{array}{c}\text { OОО «Бьюти } \\
\text { Клиник» }\end{array}$ & Cesare Ponti & Гримерка & Aurora Solution \\
\hline Год создания & 2014 & 2015 & 2016 & 2014 \\
\hline Район расположения & Центральный & Центральный & Центральный & Центральный \\
\hline $\begin{array}{l}\text { Собственная } \\
\text { парковка }\end{array}$ & есть & есть & нет & нет \\
\hline $\begin{array}{l}\text { Количество услуги, } \\
\text { оказываемых } \\
\text { салоном }\end{array}$ & Более 200 & Около 100 услуг & Около 50 услуг & Более 150 услуг \\
\hline $\begin{array}{l}\text { Количество } \\
\text { специалистов }\end{array}$ & 27 & $\begin{array}{c}\text { Около } 40 \\
\text { сотрудников }\end{array}$ & 20 сотрудников & $\begin{array}{c}\text { Более } 35 \\
\text { сотрудников } \\
\end{array}$ \\
\hline Марка косметики & $\begin{array}{c}5 \text { марок: } 1 \text { средняя } \\
\text { ценовая марка и } 4 \\
\text { премиальных } \\
\text { ходовых марки }\end{array}$ & $\begin{array}{c}2 \text { премиальных } \\
\text { марки }\end{array}$ & $\begin{array}{c}3 \text { премиальных } \\
\text { марки }\end{array}$ & $\begin{array}{c}2 \text { премиальных } \\
\text { марки }\end{array}$ \\
\hline Приветственная зона & есть & есть & есть & есть \\
\hline Собственный сайт & есть & есть & нет & есть \\
\hline $\begin{array}{l}\text { Средняя стоимость } \\
\text { стрижки }\end{array}$ & 2500 руб. & 2600 руб. & 2000 руб. & 2000 руб. \\
\hline
\end{tabular}

Таким образом, организация информационного сообщества (группы в ВК и аккаунт в Instagram) поможет преодолеть корпоративные барьеры, объединить потенциальных клиентов для достижения единых целей. Помимо этого, это позволит:

1. Создать площадку для анонсов актуальных акций и скидок;

2. Продвигать услуги предприятиях;

3. Собирать отзывы и обратную связь от потенциальных клиентов.

Вот некоторые задачи, которые можно решить на основе создания аккаунта в Instagram:

1. Реализация новых форм взаимодействия с поставщиками и партнерами;

2. Разработка новых технологий заказа/записи услуг;

3. Анализ и прогнозирование посещаемости салона красоты.

Также салону красоты ООО «Бьюти Клиник» необходимо активно использовать «точечный» маркетинг, применяя таргетированную рекламу в социальных сетях.

\section{Список литературь:}

1. Чандлер А. Стратегия и структура: главы в истории американского промышленного предприятия. Кембридж, Массачусетс: пресса Массачусетского технологического института. 1962. C. 13.

2. Киреев И. В. Содержание отдельных составляющих маркетингового комплекса компаний, работающих в сфере товаров и услуг // Маркетинг в России и за рубежом. 2012. №3. 


\section{References:}

1. Chandler, A. (1962). Strategiya i struktura: glavy v istorii amerikanskogo promyshlennogo predpriyatiya. Kembridzh, Massachusets: pressa Massachusetskogo tekhnologicheskogo instituta. 13. (in Russian).

2. Kireev, I. V. (2012). Soderzhanie otdel'nykh sostavlyayushchikh marketingovogo kompleksa kompanii, rabotayushchikh v sfere tovarov i uslug. Marketing v Rossii i za rubezhom, (3). (in Russian).

Работа поступила

Принята к публикациии

в редакцию 14.01.2020 г. 19.01.2020 2.

Ссылка для циитирования:

Ротенберг С. В., Смирнов В. Н. Разработка стратегии продвижения предприятия малого бизнеса в социальных сетях на примере ООО «Бьюти Клиник» // Бюллетень науки и практики. 2020. Т. 6. №2. С. 230-234. https://doi.org/10.33619/2414-2948/51/24

Cite as (APA):

Rotenberg, S., \& Smirnov, V. (2020). Development of a Strategy for Promoting a Small Business in Social Networks on the Example of Beauty Clinic LLC. Bulletin of Science and Practice, 6(2), 230-234. https://doi.org/10.33619/2414-2948/51/24 (in Russian). 


\section{СRМ-СИСТЕМЫ КАК ИНСТРУМЕНТ ПОВЫШЕНИЯ ЭФФЕКТИВНОСТИ БИЗНЕСА}

(СФилимонова В. Д., Владимирский государственный университет им. А.Г. и Н.Г. Столетовых, г. Владимир, Россия, filimonova.viktory@gmail.com

\section{CRM SYSTEMS AS A TOOL FOR IMPROVING BUSINESS EFFICIENCY}

\section{CFilimonova V., Vladimir State University, Vladimir, Russia, filimonova.viktory@ gmail.com}

Аннотация. В настоящее время для результативного ведения бизнеса, повышения конкурентоспособности компании, необходимо постоянно повышать эффективность управленческой деятельности, отслеживать и анализировать все бизнес-процессы. Применение специализированного программного обеспечения CRM позволит компаниям повысить эффективность управления взаимоотношениями с клиентами, а также оперативно решать текущие задачи.

Abstract. Currently, in order to effectively conduct business and improve the company's competitiveness, it is necessary to constantly improve the efficiency of management activities, monitor and analyze all stages of business. The use of specialized CRM software will allow companies to improve the efficiency of customer relationship management and quickly solve current problems.

Ключевые слова: CRM-системы, клиент-ориентированный подход, повышение конкурентоспособности.

Keywords: CRM systems, client-oriented approach, increasing competitiveness.

\section{Введение}

На сегодняшний день, для максимально эффективного управления деятельностью компании, повышения конкурентоспособности и достижения целей и максимальных результатов, необходимо постоянно повышать коэффициент полезного действия ведения управленческой деятельности, отслеживать и анализировать все этапы ведения бизнеса. В настоящее время требуются взвешенные подходы к формированию маркетинга и системы продаж производственного предприятия со сбалансированным набором эффективных инструментов [1]. Применение специализированного программного обеспечения, автоматизация коммерческих процессов, позволит компаниям оперативно находить решение для текущих задач.

\section{Материал и методы исследования}

На данный момент для работы с клиентской базой многие компании используют специализированные программы - CRM, которые позволяют формировать информационную базу о клиентах, поставщиках, подрядчиках и других контрагентах [2].

Целью внедрения и использования CRM-систем является оптимизация и усовершенствование управления взаимоотношениями с клиентами, и, как следствие, рост прибыли, увеличение числа новых клиентов, увеличение степени их удовлетворённости [3]. 
Процесс управления взаимодействиями с клиентами можно рассматривать как цикл процессов по управлению маркетингом, продажами и обслуживанием. Этапы данного цикла взаимосвязаны и взаимозависимы: управляя маркетингом, компания тем самым определяет субъект деятельности в процессе по управлению продажами, а управление обслуживанием клиента позволяет повысить лояльность потребителя и закрепить положительный имидж компании.

Bсе процессы, составляющие систему взаимоотношения с клиентами можно структурировать в группы, образующие этапы цикла взаимодействия с клиентом маркетинг, продажи, обслуживание, следовательно, управлять процессом взаимодействия с клиентами значит управлять данными элементами посредством реализации единого клиенториентированного подхода к управлению в организации.

Клиент-ориентированный подход направлен на выявление, вовлечение, привлечение клиентов и удержание наиболее прибыльных из них за счет повышения качества обслуживания клиентов и удовлетворения их потребностей.

B основе CRM-системы лежит идея автоматизации информационных данных о клиентах, поставщиках, партнерах, внутренних и внешних процессах, протекающих в компании.

CRM (Customer Relationship Management - управление взаимоотношениями с клиентами) программный продукт или технология направленная на построение устойчивого бизнеса [4].

Входной информацией для системы CRM являются как данные, характеризующие клиента (история контактов, его профиль, история покупок) так и данные об организации (структура продаж, параметры текущего состояния бизнеса и т. д.). Выходной информацией являются агрегированные данные и показатели, выводы, которые используются для оптимизации работы компании в целом и её отдельных работников.

В основном, эта система находит качественное применение в крупных компаниях с большим потоком клиентов, являясь общеорганизационной концепцией. Она дает возможность интегрировать в единый комплекс маркетинговую стратегию, продажи и сервис, технически оснащая возможностью задействовать все каналы связи и базы данных.

Основными элементами, определяющими действие CRM-системы, являются:

1. Программное обеспечение, позволяющее в той или иной степени автоматизировать процесс взаимоотношения с клиентами

2. Совокупность профессиональных компетенций, позволяющих сотрудникам организации работать с CRM-обеспечением и ключевые принципы их взаимодействия с программным продуктом: общедоступность информации, единство центра управления каналами взаимодействия с клиентом, системность анализа входящего информационного потока

3. Основные положения клиент-ориентированной концепции управления, объединяющей и регламентирующей деятельность по управлению взаимоотношениями с клиентами в организации

Перед сегодняшними организациями стоит сложнейшая задача - развитие сильной технологической инфраструктуры в кратчайшие сроки и с минимальными ресурсными затратами. Исходя из этого, сотрудники выступают одной из ключевых фигур в выстраивании прочных взаимоотношений. Клиент-ориентированность оказывает положительное влияние на успешную реализацию маркетинговых мероприятий. Многие исследования показывают, что ключом к высокой ценности и незаменимости на рынке, является наиболее точное понимание желаний клиента. 
Таким образом, к задачам CRM-системы относят:

-создание и ведение клиентской базы благодаря техническому модулю CRM-системы;

-повышение эффективности продаж благодаря увеличению эффективности анализа и сегментации существующей клиентской базы;

- повышение качества обслуживания клиентов путем более детального анализа информации о них, а также работа как с положительной, так и с негативной обратной связью;

-аналитика, т. е. формулирование на основе полученной информации маркетинговых стратегий и управленческих решений.

Получаемая, по каналам связи, менеджером информация, сразу преобразуется в управленческую и имеет необходимость в быстром распространении по задействованный подразделениям без потери актуальности и новизны. Любая важная и срочная информация, необходимая для правильного функционирования организации может быть передана через действующую SRM-систему. Всевозможные стратегии организации, направленные на ориентирование на желания клиента, в 21 веке не могут быть на 100\% эффективны без использования информационных технологий.

Таким образом, в условиях глобализации, использование автоматизированной системы управления информацией позволит добиться снижения численности управленческого персонала, повышения качества функционирования организации, улучшения финансовых показателей деятельности и снижения издержек.

Основные принципы работы CRM-системы определяют порядок взаимодействия работников компании с программным продуктом (Таблица).

ОСНОВНЫЕ ПРИНЦИПЫ РАБОТЫ СRМ-СИСТЕМЫ

Таблица

\begin{tabular}{ll}
\hline \multicolumn{1}{c}{ Принципь } & \multicolumn{1}{c}{ Описание } \\
\hline $\begin{array}{l}\text { Общедоступность } \\
\text { информации }\end{array}$ & $\begin{array}{l}\text { наличие единого хранилища информации, где будут собраны сведения о } \\
\text { взаимодействии с клиентами (различные факты и контактные данные, } \\
\text { способные оптимизировать работу с с клиентами) }\end{array}$ \\
\hline Единство центра & повышает эффективность использования рабочего времени \\
управления каналами & специалистов, позволяет формулировать более точные и объективные \\
взаимодействия с & выводы по эффективности работы того или иного канала взаимодействия \\
клиентом & с клиентом и целесообразности его использования в дальнейшем \\
\hline Системность анализа & проведение систематического анализа имеющейся информации о \\
входящего & клиентах, и подготовка данных для принятия соответствующих решений \\
информационного потока & \\
\hline
\end{tabular}

Важнейшим условием функционирования CRM-системы является наличие общего доступа к имеющейся в системе информации всеми сотрудниками компании. Во-первых, это позволяет высшему менеджменту компании контролировать эффективность работы сотрудников, определять статус всех текущих сделок и составлять рабочие планы и прогнозы. Во-вторых, наличие единой регистрируемой общедоступной базы информации позволяет избежать риска ситуации, когда с увольнением одного сотрудника теряется вся история его взаимодействия с клиентами и эффективность работы резко снижается.

Этапы процесса управления CRM-системой представлены на Рисунке. 


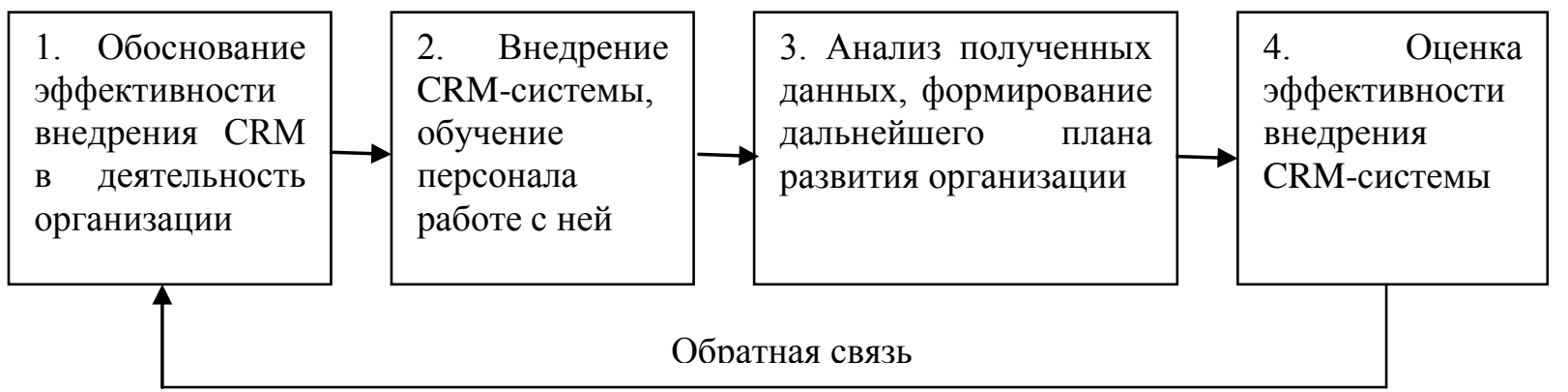

Рисунок. Процесс управления CRM-системой

Основная задача CRM - повышение у потребителя лояльности к бренду в процессе взаимодействия с сотрудниками. Система позволяет упростить и систематизировать базы данных о сделках, заявках, предпочтениях клиента, дает возможность установить напоминание о звонке клиенту, отправить смс-уведомление об актуальных и интересных персональных акциях и предложениях.

В функции операционных систем входит:

- регистрировать входящий трафик (звонки, письма, заявки на сайт);

- хранить в базе данные о клиентах, заявках, сделках, задачах и т.

- автоматизировать документооборот внутри компании;

- фиксировать продвижение сделок по воронке продаж;

- напоминать о запланированных звонках, письмах, встречах;

- ставить задачи и контролировать работу сотрудников

В отличие от операционных систем, аналитические не только фиксируют историю взаимодействия с клиентом, но и помогают проследить закономерности в продажах: клиенты из каких источников покупают чаще всего, на каком этапе срывается большинство сделок, как распределены клиенты по воронке продаж - и все эти данные обновляются в онлайнрежиме, в разрезе любого параметра.

\section{Результаты и обсуждение}

Если рассматривать выбор и внедрение CRM-системы как отдельный проект, осуществляемый в рамках одной конкретной организации, то важным этапом является определение сроков, имеющихся ресурсов и содержания проекта.

Первым шагом является обозначение целей и ожидаемых эффектов от внедрения CRMсистемы. Важной особенностью внедрения данной концепции в бизнес является то, что измерить прямой экономический эффект или получить конкретные показатели эффективности использования системы в деятельности организации крайне сложно. Судить об эффективности внедрения CRM как проекта можно по косвенным показателям, таким как увеличение процентного количества лояльных клиентов из числа общей клиентской базы, увеличение процента успешно закрытых сделок, повышение доходности от среднестатистических клиентов, снижение затрат на обслуживание клиентской базы, оптимизация состава менеджеров на основе их продуктивности. После того, как будет сформулирована цель внедрения CRM можно переходить к анализу рынка программного обеспечения, имеющихся финансовых ресурсов компании и материальной базы. Для успешной с экономической точки зрения реализации проекта по внедрению CRM важно соотносить цели внедрения программы, ожидаемые эффекты и ресурсы, которые планируется использовать в процессе осуществления проекта. 
Проекты по внедрению и развитию СRM-систем остаются одними из наиболее востребованных в практике современных компаний [5].

После того, как будут определены ожидаемые эффекты от использования CRM-системы необходимо определить поставщика программного обеспечения и тип CRM-системы. При выборе конкретного продукта важно обращать внимание на масштабы бизнеса, специфику отрасли и соблюдение баланса расходов на установку и обслуживание программы с ожидаемым в результате ее использования экономическим эффектом.

Когда выбранная CRM-программа будет внедрена в работу сотрудников, наступает следующий этап управления CRM-системой, включающий в себя использование полученных в результате функционирования системы данных для повышения эффективности деятельности организации в целом. CRM-система как концепция призвана повышать значимость клиента посредством оптимизации процесса сбора и управления информацией о них, в то время как традиционные формы действия организации предполагают концентрацию внимания организации на предоставляемом продукте и его совершенствовании.

\section{Заключение}

С растущей популярностью инструментов для сбора данных в социальных сетях, на сегодняшний день, CRM является движущей силой в бизнесе, позволяющей оценить и иметь возможность управлять лояльностью к бренду.

CRM позволяет добиться уникальности ведения бизнеса и является не только программным продуктом, позволяющим автоматизировать бизнес-процессы по управлению маркетингом, продажами и обслуживанием, CRM - это единая концепция управления бизнесом. Высокий уровень лояльности клиентов помогает снизить расходы на маркетинг и увеличить в целом доход организации.

Таким образом CRM-системы позволяют сфокусироваться на компетентности фирмы в получении и интеграции информации, а также вовлечении потребителей в процесс управления стратегией компании, что положительно сказывается на ее показателях.

\section{Список литературы:}

1. Горевая Е. С., Пашко Д. В. ЛИН-технологии при построении системы продаж промышленного предприятия // Российское предпринимательство. 2017. Т. 18. №11. С. 18371850.

2. Ускенбаева Р. К., Булегенов Д. А. CRM система как необходимый компонент успешного бизнеса // Молодой ученый. 2016. №10. С. 101-105.

3. Морозов Е. М. CRM-системы как средство автоматизации взаимодействия с клиентами // Современные научные исследования и инновации. 2015. №3. Ч. 3.

4. Городецкая О. Ю., Гобарева Я. Л. СRM - система как стратегия управления бизнесом компании // Транспортное дело России. 2014. №4. С. 169-173.

5. Манин А. В., Ветрова Т. В. Практики разработки стратегий CRM в российских компаниях // Российский журнал менеджмента. 2017. Т. 15. №4. С. 491-510. https://doi.org/10.21638/11701/spbu18.2017.405

6. Степанова Т. В., Морсина Е. В. О некоторых аспектах применения CRM-систем для управления сложными продажами // Научно-методический электронный журнал «Концепт». 2017. T. 3. C. $174-178$. 


\section{References:}

1. Gorevaya, E. S., \& Pashko, D. V. (2017). LIN-tekhnologii pri postroenii sistemy prodazh promyshlennogo predpriyatiya. Rossiiskoe predprinimatel'stvo, 18(11). 1837-1850. (in Russian).

2. Uskenbaeva, R. K., \& Bulegenov, D. A. (2016). CRM sistema kak neobkhodimyi komponent uspeshnogo biznesa. Molodoi uchenyi, (10). 101-105. (in Russian).

3. Morozov, E. M. (2015). CRM-sistemy kak sredstvo avtomatizatsii vzaimodeistviya s klientami. Sovremennye nauchnye issledovaniya i innovatsii, 3(3). (in Russian).

4. Gorodetskaya, O. Yu., \& Gobareva, Ya. L. (2014). CRM - sistema kak strategiya upravleniya biznesom kompanii. Transportnoe delo Rossii, (4). 169-173. (in Russian).

5. Manin, A. V., \& Vetrova, T. V. (2017). Praktiki razrabotki strategii CRM v rossiiskikh kompaniyakh. Rossiiskii zhurnal menedzhmenta, $15(4) . \quad$ 491-510. https://doi.org/10.21638/11701/spbu18.2017.405 (in Russian).

6. Stepanova, T. V., \& Morsina, E. V. (2017). O nekotorykh aspektakh primeneniya CRMsistem dlya upravleniya slozhnymi prodazhami. Nauchno-metodicheskii elektronnyi zhurnal "Kontsept”, 3. 174-178. (in Russian).

Работа поступила

в редакиию 18.01.2020 г.
Принята к публикащии 24.01.2020 2.

Ссылка для циитирования:

Филимонова В. Д. СRM-системы как инструмент повышения эффективности бизнеса // Бюллетень науки и практики. 2020. Т. 6. №2. С. 235-240. https://doi.org/10.33619/2414$2948 / 51 / 25$

Cite as (APA):

Filimonova, V. (2020). CRM Systems as a Tool for Improving Business Efficiency. Bulletin of Science and Practice, 6(2), 235-240. https://doi.org/10.33619/2414-2948/51/25 (in Russian). 


\section{АКТУАЛЬНЫЕ ПРОБЛЕМЫ В ИЗБИРАТЕЛЬНОЙ СИСТЕМЕ КИРГИЗСКОЙ РЕСПУБЛИКИ}

(САманалиев У. О., ORCID: 0000-0002-7438-8752, SPIN-код: 9833-2091, д-р юрид. наук, Киргизский государственный юридический университет, г. Бишкек, Кыргызстан, aurmato@mail.ru

\section{ACTUAL PROBLEMS IN THE ELECTION SYSTEM OF THE KYRGYZ REPUBLIC}

CAmanaliev U., ORCID: 0000-0002-7438-8752, SPIN-code: 9833-2091, Dr. habil., Kyrgyz State Law University, Bishkek, Kyrgyzstan, aurmato@mail.ru

Аннотащия. Автор, в данной статье дает понятие избирательной системы и рассматривает конституционные основы избирательной системы Киргизской Республики. Рассматривал вопросы выбора депутатов Жогорку Кенеша. Также, для решения проблемных вопросов автором проведен сравнительный анализ избирательной системы ближних и дальних зарубежных государств. Автор в данной статье отметил, что действующая избирательная система способствует безответственности народных представителей. Вопервых, депутат был включен в список с условием согласия с избирательной программой политической партии. Во-вторых, исключение из партии своего представителя, обладающего мандатом, и оставление его в парламенте равносильно неоправданию доверия избирателей. В этом случае партия или народный представитель, исключенный из партии, но все еще работающий в парламенте, прежде всего остаются защищать собственные интересы, а не народа. В результате чего можно утверждать, что у народного представителя, обладающего депутатским мандатом, в парламенте нет ответственности перед избирателями. Предлагаемая автором система будет способствовать развитию передовой юридической мысли в достижении принципов равенства, справедливости и поисках эффективной власти. Данная система сочетает в себе преимущества пропорциональной и мажоритарной системы, устраняет, насколько это возможно, их отдельные недостатки. При преференциальных выборах граждане получают возможность голосовать как на мажоритарных выборах, но голоса проигравших и выигравших будут учитываться, и складываться в общую партийную копилку. Если будет проведена реформа по предлагаемой избирательной системе, то открывается дорога в парламент известным и честным людям, которые имеют заслуги перед народом и страной, хорошую репутацию, деловую подготовку и имеют свою гражданскую позицию.

Abstract. The author, in this article, gives the concept of the electoral system and examines the electoral system of the Kyrgyz Republic. He considered the issues of choosing deputies of the Supreme Council (Zhogorku Kenesh). Also, to solve problematic issues, the author conducted a comparative analysis of the electoral system of neighboring and distant foreign countries. Also, the author in this article noted the irresponsibility of the people's representatives. Firstly, the deputy was included in the list subject to agreement with the election program of a political party. Secondly, the exclusion of a representative with a mandate from the party and leaving him in 
parliament is tantamount to unjustified voters' confidence. In this case, the party or people's representative, expelled from the party, but still working in parliament, first of all remains to protect their own interests, not the people. As a result, it can be argued that the people's representative, who has a deputy mandate, has no responsibility to voters in parliament. The proposed system, the author will develop advanced legal thought in achieving the principles of equality, justice and the search for effective power. This system combines the advantages of a proportional and majority system, eliminates, as far as possible, their individual disadvantages. In preferential elections, citizens are given the opportunity to vote as in a majoritarian election, but the votes of the losers and winners will be counted and put into a common party piggy bank. If we carry out the reform of the proposed electoral system, then the road opens to the parliament for well-known and honest people who have merit to the people and the country, a good reputation, business training and have their own citizenship.

Ключевые слова: выбор, избирательная система, преференция, кумулятивный вотум, демократия, коалиция, политическая партия, пропорциональная система, мажоритарная система.

Keywords: choice, electoral system, preference, cumulative vote, democracy, coalition, political party, proportional system, majority system.

Со дня обретения независимости в Кыргызской Республике прошли несколько раз выборы. Наряду с выборами, Кыргызская Республика прошла через исторически сложные периоды. За этот период было высказано много идей и предложений о выборах и избирательной системе, в данном направлении принято множество законодательных актов и в целях совершенствования избирательной системы внесены изменения и дополнения в Конституцию - наш основной закон государства.

Как говорится «дьявольская игра» выборов, каждый раз при проведении выборов, обществом или государственными органами предпринимались попытки изменить избирательную систему с внедрением новых механизмов эскалации.

На сегодняшний день данный вопрос также находится в центре внимания общественности. Будет правильным сказать, что основной его причиной являются парламентские выборы 2020 года. Первоочередной основой для их подготовки являются нормативные правовые акты. В соответствии со статьей 4 Закона Кыргызской Республики «О нормативных правовых актах Кыргызской Республики» от 20 июля 2009 № 241 Конституция - нормативный правовой акт, имеющий высшую юридическую силу и закрепляющий основополагающие принципы и нормы правового регулирования важнейших общественных отношений, создающий правовую основу для принятия законов и других нормативных правовых актов является Кыргызской Республики [1, с. 124].

Конституция Кыргызской Республики, принятая 27 июня 2010 г, в полной мере отражает избирательную систему страны. В частности, в соответствии с п. 2 ст. 70 Конституции, парламент будет избираться по пропорциональной системе [2].

Что означает анализ системы выборов, определяемый в Конституции, и избирательная система? Какая избирательная система нужна для Кыргызстана в будущем? Рассмотрим эти вопросы, с научной точки зрения.

В правовой науке избирательная система рассматривается в широком и узком смысле. 
В широком смысле избирательная система понимается как совокупность общественных отношений, складывающихся по поводу формирования органов государственной власти и местного самоуправления посредством реализации избирательных прав граждан. Эти процессы происходят в период с назначения даты выборов до опубликования итогов голосования.

Узкое понимание избирательной системь - это метод распределения мандатов среди кандидатов на основании результатов голосования [3, с. 243].

В соответствии с порядком распределения голосов мандаты дать кандидату или партии избирательные системы делятся на следующие виды:

- мажоритарная избирательная система;

- пропорциональная избирательная система;

- смешанная избирательная система.

Согласно мажоритарной избирательной системе (далее - МИС), кандидат для участия в выборах по своему избирательному округу или в общем по стране должен набрать большинство голосов избирателей.

МИС активно используется в таких странах как Англия, Франция, США, Япония, Индия и т.д.

Принципы МИС в союзное время применялись в избирательной кампании от уровня сельских депутатов до общесоюзного уровня. К примеру, по таким принципам были проведены выборы депутатов СССР в 1937-1938 годах и первый съезд народных депутатов СССР в 1989 году и депутаты легендарного парламента - Верховного Совета 12 созыва Кыргызской ССР. В последующем, в период обретения независимости депутаты 1 и 3 созывов Жогорку Кенеша были избраны [4, с. 24].

Депутаты Жогорку Кенеша указанных созывов Отунбаева Р. И., Жээнбеков С. Ш., Текебаев О. Ч.,. Матибраимов А. М, Атамбаев А. Ш., Мадумаров А. К., Сариев Т. А., Жапаров С. и другие известные политики согласно принципам МИС были избраны непосредственно народом и заручившись их поддержкой, показали, что были сильнейшими на политической арене.

В мировой практике есть два вида МИС:

- абсолютное большинство;

- относительное большинство.

По абсолютному большинству — 50\% от общего количества голосов и необходимо иметь плюс 1 голос.

По относительному большинству из числа кандидатов считается избранным тот кандидат, который набрал большинство голосов. В этом если случае кандидат набрал один голос выборы считаются состоявшимися.

Преимуществами МИС можно рассматривать следующие аспекты:

- МИС является универсальной. Таким образом могут проводиться выборы индивидуального лица или корпоративной структуры органов государственной власти;

- в МИС указывается конкретный кандидат, а конкуренция состоит между кандидатами. Избиратели имеют возможность голосовать за кандидатов по критическим взглядам. Другими словами, при выборе кандидатов, имеется возможность определить выбор вне зависимости от какой-либо партийной принадлежности; 
- в МИС граждане, который не является членом партии, имеет возможность участвовать в выборах, также создаются реальные условия, в которых он может выиграть выборы;

- мандат, предоставленный избирателями кандидату, повышает независимость однопартийной системы. Это является источником власти народа (избирателей), но установлено, что это не партийная структура.

Следующая форма избирательной системы - это пропорциональная избирательная система (далее - ПИС).

ПИС представительных органов государственной власти и местного самоуправления, образуемых по партийным спискам.

В девятнадцатом веке был сформирован ПИС наряду с формированием политических партий и их развитием.

Сегодня, особенно в странах, которые имеют парламентскую форму правления, ПИС активно развивается. Распределение депутатских мандатов в ПИС осуществляется в результате участия политических партий в выборах. В этом случае политические партии участвуют в выборах через партийный список кандидатов. Партийный список может принимать форму закрытого или открытого партийного списка.

По списку, составленном в закрытом виде, избиратели голосуют не за конкретного кандидата, а за партийный список, составленный политической партией. Каждая партия, преодолевшая порог процентного показателя, согласно набранным голосам, получает возможность иметь пропорциональное количество мандатов. В качестве примера можно привести статью 64 конституционного Закона Кыргызской Республики «О выборах Президента Кыргызской Республики и депутатов Жогорку Кенеша Кыргызской Республики» от 2 июля 2011 г №68 [4, с. 97].

В списке открытого типа публикуются имена всех кандидатов, включенных в список политической партии. В этом случае, в зависимости от способа голосования, избиратели голосуют за партию или кандидата.

В соответствии с п. 2 ст. 70 Конституции Кыргызской Республики Жогорку Кенеш Кыргызской Республики избирается по пропорциональной системе [1, с. 34]. Это означает, что список кандидатов в депутаты Жогорку Кенеша по пропорциональной системе, как уже упоминалось выше, определяется через партийные списки кандидатов и политические партии. Также, в соответствии с п. 2 ст. 60 конституционного Закона Кыргызской Республики «О выборах Президента Кыргызской Республики и депутатов Жогорку Кенеша Кыргызской Республики» от 2 июля 2011 г №68 право выдвигать списки кандидатов в депутаты Жогорку Кенеша имеют политические партии, прошедшие в установленном порядке государственную регистрацию и перерегистрацию [5, с. 14].

ПИС в Кыргызстане по общереспубликанскому избирательному округу начала применяться с ноября 2007 г.

В Кыргызской Республике депутаты IV, V, VI созывов завладели депутатскими мандатами на основе партийных списков общереспубликанского избирательного округа.

Бытует мнение, что депутаты Жогорку Кенеша, избранные по партийным спискам, работают не в интересах народа, а ради интересов какой-либо политической партии. Депутаты парламента также согласны с этим мнением. Так, например, в программе радио «Марал» из цикла «Избирательные законы и рекомендации президентской группы» вицеспикер Кыргызской Республики Касымалиева А., подтвердила такие высказывания. Касмалиева А., по этому поводу говорит: «У нас наблюдается раскол всякий раз при 
формировании коалиционного правительства. Я войду, я выйду, моя квота, вице-премьера буду я назначать. В случае недовольства сразу оправляем в отставку Правительство...» [6].

Таким образом, на основе анализа можно прийти к следующему выводу.

Во-первых, согласно в Конституции Кыргызской Республики, народные представители, имеющие депутатские мандаты по партийным спискам, формально, с юридической точки зрения считаются народными представителями, фактически они на основании закона по партийным спискам обладают депутатским мандатом в качестве партийного представителя.

Во-вторых, если опираться на политико-правовой мандат депутата Жогорку Кенеша, то на основании анализа нормативных правовых актов выявляется, что они не имеют никакой ответственности перед избирателями. Поскольку депутат Жогорку Кенеша имеющий депутатский мандат, был включен в партийный список с полным одобрением предвыборной программы политической партии, то и голоса избирателей были не за конкретного кандидата, а в целом за партию по списку.

В соответствии с п. 1 ч. 4 ст. 65 конституционного Закона Кыргызской Республики «О выборах Президента Кыргызской Республики и депутатов Жогорку Кенеша Кыргызской Республики» от 2 июля 2011 г №68 депутат исключается из фракции, и его полномочия досрочно прекращаются [5, с. 16]. Возможно депутат, исключенный из фракции не согласен с мнением партии? Это может быть связано с тем, что депутат говорил горькую правду, не так ли? В любом случае политическая партия, принявшая такое решение, и депутат, имеющий мандат в качестве представителя этой политической партии, не могут оправдать доверие избирателей.

Во-первых, депутат был включен в список с условием согласия с избирательной программой политической партии.

Во-вторых, исключение из партии своего представителя, обладающего мандатом, и оставление его в парламенте равносильно неоправданию доверия избирателей.

В этом случае партия или народный представитель, исключенный из партии, но все еще работающий в парламенте, прежде всего остаются защищать собственные интересы, а не народа. В результате чего можно утверждать, что у народного представителя, обладающего депутатским мандатом, в парламенте нет ответственности перед избирателями. Следовательно, нет механизма, определяющего ответственность депутатов, избранных народом, Жогорку Кенеша перед собственным народом. Поскольку в соответствии со ст. 7 Закона Кыргызской Республики «О статусе депутатов Жогорку Кенеша Кыргызской Республики», принятого в 2008 году, депутаты Жогорку Кенеша Кыргызской Республики поддерживают связь с избирателями и рассматривают жалобы избирателей [7, с. 3]. Здесь отношения, выстраиваемые между избирателями и депутатами парламента, всего лишь выражают связь между ними. В Законе не предусмотрены механизмы отчетности депутатов перед народом.

B-третьих, на основании вышеупомянутых законов, отсутствует прямая связь между депутатами и местными жителями. По этой причине, наиболее проблемные вопросы регионов остаются без рассмотрения, а если и рассматриваются, то благодаря освещению в средствах массовой информации или через неправительственные организации.

Принимая во внимание вышеуказанные мнения, ожидается необходимость внесения изменений и дополнений в Конституцию Кыргызской Республики.

Во-первых, мы должны перейти от пропорциональной избирательной системы к смешанной избирательной системе. Поскольку мы являемся демократическим государством, нам нужно сохранить основные принципы политического плюрализма. Однако в демократическом государстве власть принадлежит народу, не так ли?! Но пропорциональная 
избирательная система не позволяет народу в полной мере пользоваться своей властью. Не дает возможности непосредственно и в полной мере реализовать свои права, закрепленные в Конституции. Наше предложение: сохранить пропорциональную избирательную систему и укрепить путь развития политических партий, и в то же время, необходимо обратить внимание на предоставление возможности народу в качестве источника власти избирать конкретного кандидата.

Поэтому наше предложение: введение смешанной избирательной системы. С введением смешанной избирательной системы, иными словами, с использованием мажоритарной избирательной системы, мы сможем сохранить сущность и значение слова «демократия». Демократия - это «народная власть». Тогда как народная власть - непосредственно избираемый народом конкретный кандидат, должен взять на себя бремя общих интересов народа, а не соблюдать интересы политической партии. Народные представители несут ответственность за создание условий для развития государства. Кроме того, с введением смешанной избирательной системы, избирательная система будет создавать возможность дополнять недостатки одного кандидата другим. По смешанной избирательной системе проводятся парламентские выборы Немецкого парламента Бундестаг, парламента Российской Федерации - Государственной Думы и в других странах.

Следующее предложение, Жогорку Кенеш состоит из двух палат, с общим количеством депутатов 65. Из них 25 депутатов избираются в Законодательную палату, в то время как 40 депутатов - в Палату народных представителей.

Депутат Законодательной палаты ПИС на основе партийных списков, обладает мандатом депутата. Тем временем основными функциями Законодательной палаты является принятие законов. Таким образом, качество принимаемых законов могло бы быть лучше, их работа могла бы иметь значительные выгоды для населения.

Вместе с тем обеспечивается открытое формирование партийных списков и избиратели имеют возможность получения широкой информации о том, кого они избирают. В этом случае имеется возможность выбора конкретного кандидата или политической партии. Другими словами, обеспечивается кумулятивное голосование в выборах или ввод преференциальной системы.

Кумулятивное голосование редко встречается в системе многомандатных выборов. В этом случае избиратели имеют право отдать количество голосов, соответствующее количеству кандидатов. Также они могут отдать все свои голоса за одного кандидата или распределить их среди других кандидатов. При преференциальной системе (приоритет, высокая оценка) избиратель может выразить предпочтение одному из кандидатов, включенных в бюллетень, и отдать свой выбор, указав фамилию кандидата.

Во второй структуре парламента депутаты предлагаемой Палаты народных представителей избираются по мажоритарной избирательной системе. Во время организации таких выборов, должна быть принято во внимание численность населения в регионе. На данный момент статистическая информация о численности населения, проживающего в районах, по отношению к распределению депутатских мандатов Палаты народных представителей Жогорку Кенеша по одномандатным округам рассчитывается следующим образом (приблизительно): 


\begin{tabular}{lcc}
\hline \multicolumn{1}{c}{ Названия регионов } & Численность населения & Депутатские мандаты \\
\hline Баткенская область & 525,1 & 4 \\
\hline Джалал-Абадская область & 1214,4 & 6 \\
\hline Иссык-Кульская область & 489,8 & 4 \\
\hline Нарынская область & 287,0 & 3 \\
\hline Ошская область & 1341,9 & 6 \\
\hline Таласская область & 263,5 & 3 \\
\hline Чүйская область & 941,1 & 6 \\
\hline г. Бишкек & 1027,2 & 3 \\
\hline г. Ош & 299,5 & \\
\hline
\end{tabular}

С введение Палаты народных представителей проблемные вопросы регионов будут рассматриваться и решаться в приоритетном порядке. Многие вопросы решались бы на местах. Сегодня проблемы регионов не решаются своевременно, на данное обстоятельство обратила свое внимание вице-спикер парламента Касымалиева А., при рассмотрении в парламенте вопроса по урану.

Следует отметить, что Палата народных представителей могла бы работать на общественных началах, с проведением своих заседаний посредством применения Интернет технологий. Такое нововведение в настоящее время является направлением развития новых технологий по всему миру, также считается, что данный фактор будет способствовать развитию регионов и реализации принятых государственных программ в данном направлении. Состав депутатов Палаты народных представителей может состоять из числа депутатов, вышедших из народа, достойных людей, молодежи, истинных представителей народа, умеющих должным образом защищать интересы своего народа.

\section{Список литературы:}

1. Конституция Кыргызской Республики. Б: Типография. 2017. 124 с.

2. Закон Кыргызской Республики от 20 июля 2009 г №241 «О нормативных правовых актах Кыргызской Республики».

3. Сооданбеков С. С., Укушев М. К. Конституционное право Кыргызской Республики: (общая и особенная части). Б. 2001. 243 с.

4. Курманов 3. К. Пособие для политических партий по правовым основам участия в выборах и партийному строительству. Б. 2014. 24 с.

5. Конституционный закон Кыргызской Республики «О выборах Президента Кыргызской Республики и депутатов Жогорку Кенеша Кыргызской Республики» от 2 июля 2011 г №68.

6. Радио «Марал», программа «Айлампа». Режим доступа: http://maralfm.kg/

7. Закон Кыргызской Республики от 18 декабря 2008 г №267 «О статусе депутата Жогорку Кенеша Кыргызской Республики».

\section{References:}

1. Konstitutsiya Kyrgyzskoi Respubliki (2017). Bishkek. 124.

2. Zakon Kyrgyzskoi Respubliki ot 20 iyulya 2009 g №241 “O normativnykh pravovykh aktakh Kyrgyzskoi Respubliki”.

3. Soodanbekov, S. S., \& Ukushev, M. K. (2001). Konstitutsionnoe pravo Kyrgyzskoi Respubliki: (obshchaya i osobennaya chasti). Bishkek. 243. 
4. Kurmanov, Z. K. (2014). Posobie dlya politicheskikh partii po pravovym osnovam uchastiya v vyborakh i partiinomu stroitel'stvu. Bishkek. 24.

5. Konstitutsionnyi zakon Kyrgyzskoi Respubliki «O vyborakh Prezidenta Kyrgyzskoi Respubliki i deputatov Zhogorku Kenesha Kyrgyzskoi Respubliki» ot 2 iyulya 2011 g №68.

6. Radio "Maral", programma "Ailampa". Rezhim dostupa: http://maralfm.kg/

7. Zakon Kyrgyzskoi Respubliki ot 18 dekabrya 2008 g №267 “O statuse deputata Zhogorku Kenesha Kyrgyzskoi Respubliki”.

Работа поступила

в редакцию 14.01.2020 г.
Принята к публикации

19.01.2020 2.

Ссылка для циитирования:

Аманалиев У. О. Актуальные проблемы в избирательной системе Киргизской Республики // Бюллетень науки и практики. 2020. Т. 6. №2. С. 241-248. https://doi.org/10.33619/2414-2948/51/26

Cite as (APA):

Amanaliev, U. (2020). Actual Problems in the Election System of the Kyrgyz Republic. Bulletin of Science and Practice, 6(2), 241-248. https://doi.org/10.33619/2414-2948/51/26 (in Russian). 


\title{
ОСОБЕННОСТИ ПРАВОВОГО РЕГУЛИРОВАНИЯ АРЕНДЫ ПРЕДПРИЯТИЙ
}

\author{
СВасиленко A. В., ORCID: 0000-0003-4052-3239, Кубанский государственный аграрный \\ университет им. И.Т. Трубилина, г. Краснодар, Россия, vasilenko2014@icloud.com
}

\section{FEATURES OF LEGAL REGULATION OF ENTERPRISE LEASES}

\author{
CVasilenko A., ORCID: 0000-0003-4052-3239, Kuban State Agrarian University, \\ Krasnodar, Russia, vasilenko2014@icloud.com
}

Аннотация. В статье рассмотрены правовые проблемы, возникающие в связи с арендой предприятия как имущественного комплекса. Также исследуются проблемные аспекты, связанные с защитой прав кредиторов и защитой трудовых прав работников предприятия, которые не регулируются действующим гражданским законодательством Российской Федерации.

Abstract. This article discusses legal issues that arise in connection with the lease of an enterprise as a property complex. Also investigated are the problematic aspects related to the protection of the rights of creditors and the protection of the labor rights of employees of the enterprise, which are not regulated by the current civil legislation of the Russian Federation.

Ключевые слова: аренда, арендодатель, арендатор, предприятие, имущественный комплекс, трудовые отношения.

Keywords: rent, lessor, tenant, enterprise, property complex, labor relations.

В настоящее время аренда предприятий достаточно редкое явление в правовой и экономической практике. Для этого есть несколько причин: неточная формулировка в законе и отсутствие практики применения этих правовых стандартов. Предприниматели часто заменяют договор аренды предприятия соглашением о передаче части имущества во временное владение. Предметом договора аренды предприятия является предприятие, поэтому для такого соглашения предусмотрено специальное регулирование. Предприятие как вид собственности имеет сложный характер, состоящий из вещного и обязательственного элементов. Поэтому договор аренды предприятия является комплексным. Он содержит соглашения, на основании которых передаются права на использование и владение конкретной вещью. Таким образом, одна часть договора будет иметь те особенности, которые имеет договор аренды имущества в виде вещей. Другая часть договора - это условия передачи прав собственности. Долги предприятия также являются собственностью и передаются в соответствии с нормативными правилами, указанными в статьях 391 и 392 Гражданского кодекса Российской Федерации [1]. Для перевода долга требуется согласие кредиторов. Третья часть договора - особый вид прав. Например, право на товарный знак, передача прав собственности, знак обслуживания и т.д.

Сторонами договора аренды предприятия всегда являются предприниматели. Количество копий такого договора, как договора аренды предприятия, не может быть меньше количества сторон договора. Такое соглашение должно подлежать обязательной 
государственной регистрации в качестве сделки с недвижимостью, которой является предприятие. Договор заключается только после этой регистрации [5].

Для передачи предприятия требуется инвентаризация ценностей, согласие кредиторов на перевод долгов. Поскольку имущество должно быть передано в исправном состоянии, арендодатель должен произвести необходимый ремонт или заменить неисправное оборудование, освободить помещение от имущества, которое не сдано в аренду. Также арендодатель должен составить бухгалтерский баланс, отражающий активы и обязательства предприятия. Завершающим этапом является подготовка и подписание акта передачи. Передаточный акт - это документ, удостоверяющий состав имущества, передаваемого арендатору в соответствии с договором аренды предприятия. Подготовка предприятия к передаче является обязанностью арендодателя в случае, если договором не предусмотрены другие условия. Аренда предприятия предоставляет арендатору возможность экономической эксплуатации арендованного имущества, а именно максимально возможную свободу юридических и фактических действий с этим имуществом [4].

Арендатор обязан поддерживать имущественный комплекс хозяйствующего субъекта в хорошем состоянии, включая выполнение текущего и капитального ремонта. Поскольку деятельность предприятия осуществляется арендатором, расходы также несет он. Следует отметить, что это обязательство возлагается на арендатора, если иное не указано в договоре. Согласно п. 1 ст. 656 Гражданского кодекса Российской Федерации, по договору аренды все земельные участки, здания, сооружения, оборудование и другие средства передаются арендатору во временное пользование [2]. Однако такие средства, как запасы сырья, топлива, также передаются арендатору, но условия их передачи указаны в договоре.

Арендодатель передает права требования и долги предприятия, то есть дебиторскую и кредиторскую задолженность предприятия. Передача кредиторской задолженности осуществляется с письменного согласия кредиторов. Арендодатель обязан перед передачей предприятия в аренду письменно уведомить кредиторов о предстоящей аренде предприятия (п. 1 ст. 657 Гражданского кодекса Российской Федерации), уведомить кредиторов о том, что задолженность перед ними будет передана другому лицу как минимум за три месяца до передачи предприятия арендатору. Этот период определяется как период, в течение которого кредиторы, которые не согласны с такой передачей долга, могут требовать от должника прекращения или досрочного исполнения обязательств, а также компенсации убытков (пункт 2 статьи 657 Гражданского кодекса Российская Федерация).

Если арендодатель передает компанию вместе с кредиторской задолженностью арендатору и не предупреждает об этом кредиторов, они имеют право подать иск для удовлетворения требований. Для этого кредиторы будут иметь в своем распоряжении целый год с момента, когда им станет известно об аренде предприятия-должника (п. 3 ст. 657 Гражданского кодекса Российской Федерации) [7]. Отвечать перед кредиторами должен не только арендодатель, но и арендатор. Оба они признаны виновными в нарушении требований гражданского законодательства, поскольку они несут солидарную ответственность по долгам, которые без согласия кредиторов были переданы третьей стороне при сдаче предприятия в аренду. На это указывает п. 4 ст. 657 Гражданского кодекса.

Отдельно следует сказать о дебиторской и кредиторской задолженности перед бюджетом и внебюджетными фондами. Данная задолженность не может быть передан арендатору. Гражданское право не распространяется на налоговые отношения (ст. 2 Гражданского кодекса Российской Федерации). Налоговое законодательство также не предусматривает возможности передачи налогоплательщиком своих долгов другому лицу. Арендатор получает вместе с предприятием свои активы и пассивы. Единственное, что 
арендодатель не имеет права передавать арендатору, - это право осуществлять определенные виды деятельности, которые получены на основании соответствующей лицензии (ст. 656 Гражданского кодекса Российской Федерации). Арендатор предприятия не соответствует требованиям кредиторов, если он не может выполнить обязательства перед ними на основании соответствующей лицензии, которой у него нет. Прежде чем сдать предприятие в аренду как имущественный комплекс, арендодатель обязан оплатить своим кредиторам обязательства, на выполнение которых требуется лицензия [8].

Что происходит с людьми, работающими на арендованном предприятии? Рабочие заключили трудовые договоры с арендодателем. Однако, когда компания сдана в аренду, она переходит в собственность другого юридического лица, но рабочие не могут быть переданы компании. Работники могут быть наняты другой организацией, но только с их письменного согласия.

Трудовой кодекс не определяет механизм взаимодействия между работниками и арендодателем, поэтому арендодатель и арендатор должны самостоятельно разработать систему взаимоотношений между ними и работниками, и в случае возникновения каких-либо споров их придется решать в суде [3]. Арендодатель обязан уведомить работников об аренде предприятия не позднее, чем за два месяца до момента передачи предприятия в аренду. Это предупреждение должно быть в письменной форме. Работники имеют право отказаться от такой передачи, но в любом случае письменное заявление должно быть получено от работников. Те сотрудники, которые согласились на перевод, уходят и заключают новый трудовой договор с арендатором.

Таким образом, в заключении хотелось бы отметить, что несмотря на наличие определения предприятия в Гражданском кодексе Российской Федерации, все еще сложно признать совершенной практику законодательного регулирования оборота предприятий. Правовая концепция предприятия должна быть дополнена указанием всех недостающих признаков. Отсутствие в законодательстве четких признаков предприятия как объекта гражданских прав, которые бы отличали предприятие от других аналогичных объектов, рассматривается как основной недостаток действующего российского законодательства. Имущественные комплексы (в том числе предприятия) являются особыми объектами гражданских прав, они не могут быть недвижимыми вещами, подобно тому, как распространение на них режима недвижимости, несовместимое с сущностью комплексов, полностью исключает их из числа объектов оборота. На законодательном уровне необходимо придать имущественному комплексу особый статус недвижимого имущества, поскольку имущество, включенное в имущественный комплекс, отдельно или в составе сложной вещи, следует своей собственной судьбе в рамках независимых правовых отношений. В условиях развития рыночных отношений государство должно уделять больше внимания отношениям, связанным с недвижимостью; требуется привести нормативные акты в соответствие с реалиями и устранить их несоответствие.

\section{Список литературы:}

1. Гражданский кодекс Российской Федерации (часть первая) от 30.11.1994 N 51-ФЗ (ред. от 16.12.2019) // Собрание законодательства РФ. 1994. №32. Ст. 3301; 2014. №7. Ст. 209.

2. Гражданский кодекс Российской Федерации (часть вторая) от 26.01.1996 № 14-Ф3 (ред. от 18.03.2019) // Собрание законодательства РФ, 29.01.1996, №5, ст. 410; 2014. №6. Ст. 491.

3. Трудовой кодекс Российской Федерации от 30.12.2001 N 197-Ф3 (ред. от 16.12.2019) // Собрание законодательства РФ. 
4. Елизаров Д. В. Гражданско-правовые проблемы аренды недвижимого имущества: автореф. дис. ... канд. юрид. наук. Владивосток, 2016. 22 с.

5. Жилинский С. Э. Предпринимательское право (правовая основа предпринимательской деятельности). М.: Норма, 2018. С. 65.

6. Кобылинская С. В. Право человека на достойную жизнь как основная ценность социального государства // Научное обеспечение агропромышленного комплекса: сборник статей по материалам 71-й научно-практической конференции преподавателей по итогам НИР за 2015 год. 2016. С. 386-388.

7. Толстых Г. К. Гражданское право и гражданское законодательство // Правоведение. 2018. №12. С. 78.

8. Хохлов Н. А. Концептуальная основа части второй Гражданского кодекса // Гражданский кодекс Российской Федерации. Ч. 2. М.: ИНФРА-М, 2018. 890 с.

\section{References:}

1. Grazhdanskii kodeks Rossiiskoi Federatsii (chast' pervaya) ot 30.11.1994 N 51-FZ (red. ot 16.12.2019). Sobranie zakonodatel'stva RF. 1994. №32. St. 3301; 2014. №7. St. 209. (in Russian).

2. Grazhdanskii kodeks Rossiiskoi Federatsii (chast' vtoraya) ot 26.01.1996 № 14-FZ (red. ot 18.03.2019). Sobranie zakonodatel'stva RF, 29.01.1996, №5, st. 410; 2014. №6. St. 491. (in Russian).

3. Trudovoi kodeks Rossiiskoi Federatsii ot 30.12.2001 N 197-FZ (red. ot 16.12.2019). Sobranie zakonodatel'stva RF. (in Russian).

4. Elizarov, D. V. (2016). Grazhdansko-pravovye problemy arendy nedvizhimogo imushchestva: avtoref. dis. ... kand. yurid. nauk. Vladivostok, 22. (in Russian).

5. Zhilinskii, S. E. (2018). Predprinimatel'skoe pravo (pravovaya osnova predprinimatel'skoi deyatel'nosti). Moscow, 65. (in Russian).

6. Kobylinskaya, S. V. (2016). Pravo cheloveka na dostoinuyu zhizn' kak osnovnaya tsennost' sotsial'nogo gosudarstva. In Nauchnoe obespechenie agropromyshlennogo kompleksa: sbornik statei po materialam 71-i nauchno-prakticheskoi konferentsii prepodavatelei po itogam NIR za 2015 god. 386-388. (in Russian).

7. Tolstykh, G. K. (2018). Grazhdanskoe pravo i grazhdanskoe zakonodatel'stvo. Pravovedenie, (12). 78. (in Russian).

8. Khokhlov, N. A. (2018). Kontseptual'naya osnova chasti vtoroi Grazhdanskogo kodeksa // Grazhdanskii kodeks Rossiiskoi Federatsii. 2. Moscow, 890. (in Russian).

Работа поступила

в редакичию 16.01.2020 2.
Принята к публикащии 20.01.2020 z.

Ссылка для циитирования:

Василенко А. В. Особенности правового регулирования аренды предприятий // Бюллетень науки и практики. 2020. Т. 6. №2. С. 249-252. https://doi.org/10.33619/2414$2948 / 51 / 27$

Cite as (APA):

Vasilenko, A. (2020). Features of Legal Regulation of Enterprise Leases. Bulletin of Science and Practice, 6(2), 249-252. https://doi.org/10.33619/2414-2948/51/27 (in Russian). 


\title{
ИДЕОЛОГИЧЕСКАЯ ФУНКЦИЯ ПРАВА В ТЕОРИИ ГОСУДАРСТВА И ПРАВА
}

(СТанская В. В., Томский государственный университет, г. Новосибирск, Россия

ССавватеева В. В., Томский государственный университет, г. Новосибирск, Россия iii.sss.2012@mail.ru

\section{THE IDEOLOGICAL FUNCTION OF LAW IN THE THEORY OF STATE AND LAW}

\author{
CTanskaya V., Tomsk State University, Novosibirsk, Russia \\ CSavvateeva V., Tomsk State University, Novosibirsk, Russia, iii.sss.2012@mail.ru
}

Аннотащия. Статья посвящена проблемам идеологического воздействия права на социальные процессы. Право должно оказывать воспитательное воздействие на общество, это должно стать приоритетом развития законодательства.

Abstract. The article is devoted to the problems of the ideological impact of law on social processes. The law should have an educational impact on society, this should be a priority for the development of legislation.

Ключевые слова: идеологическая функция, социальные проблемы, глобализация, социальная эффективность права, социальная ценность права, общество, нормы права, социальные ценности.

Keywords: ideological function, social problems, globalization, social efficiency of law, social value of law, society, legal norms, social values.

К функциям права в общепринятом определении относятся основополагающие направления действия (инструменты) на общественные отношения, преследующие цель урегулированиях данных правоотношений, придания организованности, структурированности и единства структуре правоотношений.

Функции направлены на осуществление важнейших общественных задач, урегулирование острых социальных конфликтов в обществе. Функции права имеют под собой определенную цель в упорядочении общественных отношений и при возникновении, каких-либо неточностей призваны контролировать процессы взаимодействия в социуме; Функции характеризуются длительностью и непрерывностью воздействия, так как невозможно временно прекратить воздействие права на общество, без такового социум просто разрушиться. Поэтому действие права и его функций в частности носит постоянный и непрерывный характер, направленный на стабилизацию общества; Функции в своем действии определяют степень влияния права на форму общественных отношений. Необходимость воздействия на общество характеризуется как потребностью государства в урегулировании и систематизации правоотношений, так и запросами самого социума, нуждающегося в стабильности. В этом случае функции права играют определяющую роль в поддержании стабильности общества; Функции в обществе определяются значением и сущностью самого права. Данная функция обозначает, что само общество в обратном процессе способно оказывать влияние на изменения права, его трансформацию.

Функции права, понятие и классификация которых представлены в статье, имеют ряд характеризующих факторов. Посредством них можно увидеть востребованность и динамику 
развития юридического регулятора в реальности. Таким образом, функции обладают следующими свойствами, а именно:

- перечень функций показывает реальную направленность юридического регулятора и круг правоотношений, который фактически затрагивается;

- как правило, функции постоянны, неизменны;

- функции права показывают направления, которые люди не могут регулировать иными способами, нежели правом;

- содержание каждой функции в отдельности характеризуется динамикой изменения задач, целей и основных направлений, в зависимости от малейших изменений в сфере тех или иных общественно-правовых отношений;

- все без исключения функции входят в единую структуру, что позволяет говорить об их системности.

Следует отметить, что с учетом вышеперечисленных свойств юридические функции права разделены в зависимости от отраслевой принадлежности. То есть одни функции принадлежат одной отрасли, другие - другой. Это значит, что мы можем говорить в отдельности о направлениях действия функции трудового права, административного, гражданского, уголовного и т. п. Помимо этого, системный характер функций и права в целом дает возможность классификации направлений действия регулятора на основе разных факторов [1].

Функции направлены на осуществление важнейших общественных задач, урегулирование острых социальных конфликтов в обществе. Функции права имеют под собой определенную цель в упорядочении общественных отношений и при возникновении, каких-либо неточностей призваны контролировать процессы взаимодействия в социуме; Функции характеризуются длительностью и непрерывностью воздействия, так как невозможно временно прекратить воздействие права на общество, без такового социум просто разрушиться. Поэтому действие права и его функций в частности носит постоянный и непрерывный характер, направленный на стабилизацию общества; Функции в своем действии определяют степень влияния права на форму общественных отношений. Необходимость воздействия на общество характеризуется как потребностью государства в урегулировании и систематизации правоотношений, так и запросами самого социума, нуждающегося в стабильности. В этом случае функции права играют определяющую роль в поддержании стабильности общества; Функции в обществе определяются значением и сущностью самого права. Данная функция обозначает, что само общество в обратном процессе способно оказывать влияние на изменения права, его трансформацию.

В юриспруденции выделятся несколько основных функций права, к которым принято относить: Регулятивная функции права [2]. Исходя из названия и назначения данная функция выступает в форме регулятора, то есть воздействует на правоотношения, приводя их к желаемому результату, приводит к определенным рамкам, способствует динамичному развитию правоотношений. Данная функция включает в себя несколько подфункций и выполняет колоссальную роль в регулировании законодательства [3]. К подфункциям относятся: Динамическая подфункция выражена в направлении общества в определенном векторе развитии законодательных общественных отношений. Чаще используется в экономических отношениях (пример: налоговой законодательство регулирует вопросы налогообложения преимущественно с помощью императивных норм, изменяясь в динамике тем самым обеспечивая реализацию динамической подфункции, то есть изменения общественных правоотношений в определенном направлении развития (ужесточение сборов, снижение налоговых ставок) выгодном государству и условно обществу в целом); 
Статистическая подфункция также играет немаловажную роль в рамках большой функции права. Ее задача заключается в воздействии на правоотношения посредством закрепления отношений в отдельных нормативных актах (пример: с появлением и развитием нового определенного правоотношения, со временем государство начинает вводит в качестве мер контроля законодательное закрепления правил поведения, то есть выполнение статистической функции права. Охранительная функция права. Важнейшая функция выполняющая роль регулятора в охране правоотношений в частности и общества в целом от негативного воздействия различного рода факторов извне. Данная функция предполагает в случае нарушения каких-либо норм методы воздействия в отношении субъекта нарушившего право и сам механизм воздействия, зачастую в виде наложения санкций. Данная функция также подразделяется на ряд подфункций: Карательная подфункция характеризуется методом воздействия правового характера в результате совершения правонарушающего акта. Правом во многом урегулирован процесс введения санкций и исполнения карательной подфункции права. Законодательство в данной области представлено уголовным, административным, гражданским и иными отраслями права, содержащими карательные нормы в отношении как физических лиц, так и организаций и предприятий .

Правовосстановительная функция направлена на устранение негативных последствий в результате нарушения общественного порядка. Нормы данной функции также нашли свое отражением во многих отраслях законодательства как основополагающие постулаты стабильности развития социума и неотвратимости наказания для нарушителей порядка и режима законности.

В литературе высказано мнение о том, что различные ценности лежат в основе права и задают различные типы правопонимания в условиях различных правовых культур. Собственно говоря, применяя ценностный подход к праву, мы выходим за строгие очертания самого права, оцениваем его с помощью неправовых критериев, ценностей самого общества. Следует добавить, что мы выходим и на целый ряд острых идеологических и аксиологических проблем, для разрешения которых необходимо взаимодействие различных наук.

Естественно, нельзя недооценивать влияние, которое оказывают на людей правовые идеи, принципы, правовое сознание, правовая культура. Они непосредственно не регулируют (не нормируют) общественные отношения, но определяют характер правового регулирования, его эффективность, практическое воплощение в жизнь всех элементов механизма правового регулирования . Все это следует учитывать при совершенствовании идеологической функции права, ее реализации в современной России.

Несмотря на то, что во второй половине 20 века великие идеологии превращаются в технократическое сознание (в идеологии «второго плана», по терминологии Ю. Хабермаса), то есть наука превращается в идеологию, их роль сегодня, в условиях массового общества, не снижается, а может быть, даже увеличивается [4]. Социальная жизнь невозможна без традиций, представляющих собой основания всех социальных институтов - систематически повторяющихся общественных отношений. Последние основаны на легитимации (признании широкими слоями народных масс). Легитимация, оправдание существующего положения дел - это основная функция любой идеологии. При этом идеология объявляет естественность соответствующего социального института (традиции), его «разумность», соответствие «природе вещей», «всеобщему благу» или другим мифологемам более высокого (трансцедентного) уровня.

В литературе отмечается, что на сегодняшнем этапе временные ценностные ориентации обусловлены напряженными ритмами, динамизмом быстро сменяющих друг друга событий, 
уплотнением и сокращением временных интервалов. Темп современной жизни «давит» на человека, и это давление отражается в общественных отношениях и в юридических нормах, их регулирующих. Происходит внутренняя темпоральная рассогласованность, которая проявляется в том, что назревшие изменения в общественных отношениях сдерживаются, блокируются уже изжившими себя консервативными юридическими нормами.

Важным вопросом, связанным с совершенствованием идеологического и ценностного воздействия права, является следующий: каковы должны быть критерии отбора тех или иных ценностей, защищаемых правом, в условиях социальной дифференциации, противоречивости социальных интересов? В этом плане интерес представляет точка зрения А. Н. Бабенко, который указывал, что обоснование ценностей связано с осознанием принципа общезначимости. Общезначимо то, что признано взаимодействующими субъектами, способствует стабильности их отношений и образа жизни, взаимоприемлемому развитию. Общезначимое - это общепринятое в определенном сообществе, имеющее социокультурные основания объективности, а также распространяемое на неопределенный круг субъектов на добровольных началах. По мнению А. Н. Бабенко, в качестве одного из критериев установления первичных общезначимых ценностей может быть предложен следующий: в условиях неизбежности разногласий между субъектами об ориентирах жизни, следует выделять такие общие ценности, осуществление которых необходимо для реальной возможности всем субъектам жить в соответствии со своими ориентациями [5].

По мнению ряда авторов, в современном мире происходит смещение акцентов от материальных ценностей, связанных с выживанием, к ценностям, связанным с самовыражением и качеством жизни. Человека, разделяющего ценности самореализации, можно представить как «ищущего себя», заинтересованного в постоянном саморазвитии и психологическом комфорте, стремящегося к неформальному общению. Все эти моменты должны учитываться в ходе осуществления идеологической функции права.

Как известно, в переходные периоды возникает несоответствие правовой идеологии и правовой психологии подавляющего большинства людей изменившейся реальности. При этом правовая идеология может «забежать» далеко вперед в сравнении с развитием социальноэкономической ситуации, а правовая психология - заметно отстать от них. Это приводит к неадекватному поведению субъектов права, усугубляющему социальнопсихологическую дезадаптацию общества в переходный период.

В цивилизациях западного типа, где абсолютизируется ценность личной свободы, упор делается на динамичное развитие. В обществах переходного периода динамика изменений колоссальна, поэтому им более подходят ценности системо-центристской правовой культуры, базирующиеся на солидарности, ответственности, обязанностях по отношению к общине, природе. Только ценности системоцентризма позволяют обеспечивать в этот период устойчивость государственно-правового развития, гражданский мир и согласие. Персоноцентристский тип правовой культуры возможен в обществе, обладающем высокой степенью стабильности и высоким уровнем общей культуры, а также при более или менее справедливой системе распределения материальных благ. В обществе переходного периода персоноцентризм обычно оборачивается диктатурой олигархического меньшинства в условиях глубокой социальной дифференциации.

Приметной чертой идеологических поисков в современной России стали оправдание неравенства, популяризация идей элитизма и создания «правящего слоя» из «активных» групп населения. Плодородной почвой для этих идей послужил резкий рост социального неравенства. Думается, что пропаганда данных идей не будет способствовать социальному развитию, развитию и действенности права как социального регулятора. 
Итак, идеологическая функция права должна не только быть признана в качестве одной из основополагающих функций права, но и нуждается в самом серьезном научном осмыслении и практической реализации, особенно в современных социальных условиях.

Список литературы:

1. Спиридонов Л. И. Теория государства и права. М.: Проспект. 2012. 441 с.

2. Алексеев С. С. Общая теория права. М. 2015. 324 с.

3. Алексеев С. С. Юридические конструкции - ключевое звено права // Цивилистические записки: межвузовский сборник научных трудов. М. 2016. 387 с.

4. Венгеров А. Б. Теория государства и права. Теория права. Т. II. М. 2015. 365 с.

5. Бабенко А. Н. Проблемы обоснования ценностных критериев в праве // Государство и право. 2002. №12. С. 93-105.

6. Комаров С. А., Малько А. В. Теория государства и права. М. 2011. 298 с.

7. Лукьянова Е. Г. Теория процессуального права. М. 2013. 369 с.

8. Нерсесянц В. С. Общая теория права и государства. М. 2012. 368 с.

9. Лазарев В. В., Афанасьев В. С. Общая теория права и государства. М. 2011. 278 с.

\section{References:}

1. Spiridonov, L. I. (2012). Teoriya gosudarstva i prava. Moscow. 441. (in Russian).

2. Alekseev, S. S. (2015). Obshchaya teoriya prava. Moscow. 324. (in Russian).

3. Alekseev, S. S. (2016). Yuridicheskie konstruktsii - klyuchevoe zveno prava. Tsivilisticheskie zapiski: mezhvuzovskii sbornik nauchnykh trudov, Moscow. 387. (in Russian). Russian).

4. Vengerov, A. B. (2015). Teoriya gosudarstva i prava. Teoriya prava, 2. Moscow. 365. (in

5. Babenko, A. N. (2002). Problemy obosnovaniya tsennostnykh kriteriev v prave. Gosudarstvo i parvo, (12). 93-105. (in Russian).

6. Komarov, S. A., Mal'ko A. V. 2011. Teoriya gosudarstva i prava. Moscow. 298. (in Russian).

7. Luk'yanova, E. G. 2013. Teoriya protsessual'nogo prava. Moscow. 369. (in Russian).

8. Nersesyants, V. S. (2012). Obshchaya teoriya prava i gosudarstva. Moscow. 368. (in Russian).

9. Lazarev, V. V., \& Afanas'ev, V. S. (2011). Obshchaya teoriya prava i gosudarstva. Moscow. 278. (in Russian).

Работа поступила

в редакичию 14.01.2020 г.
Принята к публикации 19.01.2020 2.

Ссылка для циитирования:

Танская В. В., Савватеева В. В. Идеологическая функция права в теории государства и права // Бюллетень науки и практики. 2020. Т. 6. №2. С. 253-257. https://doi.org/10.33619/2414$2948 / 51 / 28$

Cite as (APA):

Tanskaya, V., \& Savvateeva, V. (2020). The Ideological Function of Law in the Theory of State and Law. Bulletin of Science and Practice, 6(2), 253-257. https://doi.org/10.33619/24142948/51/28 (in Russian). 


\title{
ДУХОВНАЯ СВОБОДА И ЗАВИСИМОСТЬ В СОВРЕМЕННОМ МИРЕ
}

ССавватеева В. В., Томский государственный университет, г. Новосибирск, Россия, iii.sss.2012@mail.ru

\section{SPIRITUAL FREEDOM AND DEPENDENCE IN THE CONTEMPORARY WORLD}

\author{
CSavvateeva V., Tomsk State University, Novosibirsk, Russia, iii.sss.2012@ mail.ru
}

Аннотащия. В статье рассматриваются различные точки зрения на духовную свободу, а также анализируются причины кризиса духовной свободы человека в современности. Отмечается роль духовной свободы для человека, также предложены способы обретения духовной свободы.

Abstract. The article examines various points of view on spiritual freedom, as well as analyzes the causes of the crisis of human spiritual freedom in modern times. The role of spiritual freedom for a person is noted, as well as ways of gaining spiritual freedom.

Ключевые слова: духовная свобода, зависимость, общество, потребления, гедонизм, одномерный человек.

Keywords: spiritual freedom, dependence, consumer society, hedonism, one-dimensional person.

Феномен духовной свободы находится в центре внимания многих философов: экзистенциалистов, феноменологов, постмодернистов и представителей множества других направлений. Особую актуальность эта тема приобрела в двадцатом веке с его многообразными проблемами дегуманизации, деиндивидуализации, конфликта ценностей и идеологий. Личность оказывается в это время как бы придавленной внешними силами, теряется нравственное достоинство человека, и потому пути обретения внутренней независимости снова оказываются предметом философского анализа. В данной работе под духовной свободой понимается власть человека над своими страстями и греховными чувствами. Свобода духа ассоциируется с чистотой, добротой и непринуждённостью. Духовная свобода - это не только свобода субъективной реальности (сознания человека), но и процесс её реализации во внешней, объективной реальности, в культуре. Духовная свобода неразрывно связана с такими явлениями, как свобода мысли и слова, допустимость инакомыслия и возможность публично выражать свои идеи.

В этом отношении совершенно прав британский философ И. Берлин, утверждая, что «пределы свобод человека или народа выбирать жизнь одну в соответствии со своими устремлениями нужно соизмерять со многими другими ценностями, среди которых, возможно самыми очевидными, будут равенство, справедливость, счастье, безопасность, общественный порядок. По этим соображениям, свобода не может быть безграничной, свободу физически или экономически сильных нужно сдерживать» [2, с. 182].

И. Берлин выделяет негативную и позитивную свободу. Негативная свобода означает лишь одно: невмешательство других в дела субъекта. И. Бёрлин подчеркивает, что «в данном 
контексте свобода не взаимосвязана с демократией и самоуправлением, по крайней мере логически». Негативная свобода - это, прежде всего, индивидуальная свобода, возможность распоряжаться собственной личностью. Это - свобода «от»: от ограничений, накладываемых другими людьми или целым обществом, от вмешательства в частную жизнь. Позитивная же свобода - это, напротив, свобода «для»: свобода вести какой-то определенный образ жизни (быть сторонником какой-либо партии, придерживаться определенных взглядов и т. д.). «Позитивное значение слова «свобода», — пишет И. Бёрлин, - проистекает из желания индивида быть хозяином своей собственной жизни» [2, с. 194]. Но именно здесь, в позитивной свободе, скрывается опасность подмены понятий и раздвоения индивида: опасность замены собственного эмпирического Я на Я идеальное и последующее навязывание индивиду действий в соответствии с «идеальным» Я.

Важность кризиса духовной свободы человека заключается в переосмыслении человеком своих ценностей и взглядов на смысл жизни и жизнь в целом, отношения к смерти и болезням. Изменения, происходящие в период духовного кризиса, затрагивают человека полностью, изменяют деятельность личности и взгляды на жизнь. В период духового кризиса, как и кризиса духовной свободы человека, у человека проявляется воля к жизни, происходит проверка ценностей на прочность [6, с. 33]. Одним из признаков духовной зависимости является духовное отчуждение [8, с. 117].

Что же является главными причинами кризиса духовной свободы человека, а также духовного отчуждения? По всей видимости, основными причинами следует назвать общество потребления и массовый гедонизм, усиление государственной власти и патернализм, господство техники и технологий. Всё это - явления современности. Попытаемся рассмотреть их поподробнее. Казалось бы, гедонизм - идея, отжившая ещё в античном мире. Однако он оказался широко востребованным и в ушедшем двадцатом веке, и в наступившем двадцать первом веке.

Британский социолог 3. Бауман отметил, что рост гедонистических и эгоистических настроений является признаком нашего времени [1]. Американский учёный П. Дж. Бьюкенен выделяет гедонистическую мораль как важнейшую причину демографического кризиса, проблемности развития института семьи и брака. Следование императиву «живи для себя и наслаждайся жизнью», стремление к максимальному комфорту, приоритет карьеры в ущерб семье, эмансипация женщин, эгоизм и культ удовольствий — всё это приводит к разрушению первичных институтов общества [3, с. 75].

Эгоистический гедонизм в случае масштабного распространения может привести к разрушению социальной системы. Американский политолог 3. Бжезинский признаёт, что появление в США общества потребления привело к беспрерывно нарастающему гедонизму. Это напоминает период краха Римской империи, которой, в свою очередь, был вызван, тремя основными факторами: политическим разделением, культурным гедонизмом и финансовой инфляцией [3].

Множество факторов влияют на развитие гедонистических зависимостей у человека. К ним можно отнести нереализованные мечты, страхи, переживания, надежды, негативные мысли и эмоции, которые в будущем могут перерасти в физическую или духовную зависимость. Зависимость - это намеренное ограничение или игнорирование своих собственных возможностей. Также зависимость можно понимать как некое отсутствие человека в собственной жизни из-за его привязанности к низменным потребностям, ведь он начинает делать то, что поможет ему их удовлетворить. Такие действия не всегда могут оказаться положительными.

Нежелание человека избавляться от своих внутренних переживаний может привести к 
возникновению различных форм зависимости. На сегодняшний день для общества характерны следующие формы:

1. Непрерывная работа как вид экономической зависимости. Среднестатистический человек, получающий заработную плату, должен совершать обязательные платежи (коммунальные услуги, налоги и др.). В свою очередь, средств на личные потребности ему нередко не хватает, поэтому человек вынужден всегда работать, при этом постоянно себе в чём-то отказывать.

2. Рекламная зависимость как вид подсознательного внушения. Если, идя по улице, человек оглянётся вокруг, то заметит, что его окружает различная реклама, которая привлекает его внимание на подсознательном уровне: подбором цвета, элементов, призывающих лозунгов, незамысловатых мотивов, которые сразу запоминаются. Реклама действует на психику человека, тем самым «заставляя» приобретать совершенно не нужные ему вещи.

3. Кредитное рабство. Данный вид зависимости сочетает в себе первый и второй виды. С помощью рекламы человеку навязывают дорогостоящую покупку. При этом, возможно, где-то существуют более дешёвые аналоги, но человек их не замечает, так как они менее разрекламированы. Ради покупки человек берёт кредит. Получив его, человек должен постоянно работать, чтобы выплачивать деньги. Таким образом, навязанная покупка «втягивает» человека в долговую зависимость.

4. Привязанность к одному месту. Человек вынужден не менять своё место работы или жительства из-за множества причин. Например, отсутствие денежных средств на переезд или вакансий по его специальности. Также человека может «держать» на одном месте семья, либо он сам не хочет что-то менять в своей жизни. Условия работы или жильё могут быть неприемлемыми, но человек, живущий надеждами о светлом будущем, остается «рабом» данного места.

Физическая зависимость: пищевая, наркотическая, алкогольная, никотиновая и сексуальная. Данный вид зависимости разрушает не только внутреннее состояние человека, но и его физическое здоровье. Люди, имеющие физическую зависимость, испытывают апатию, стресс, депрессию. Их умственная деятельность замедляется, и они постепенно начинают привязываться к объекту своей зависимости.

Духовная зависимость - это один из сильнейших факторов в выборе модели поведения человека, она зачастую оказывается негативным феноменом, мешающим человеку реализовать поставленные перед ним цели и задачи. Современное гедонистическое общество характеризуется процессом деформации личности, который обусловлен сужением горизонта ее бытия, а также разрушением ценностной вертикали, господством «внешнего человека» над «внутренним» [5, с. 222].

Большое влияние на формирование духовных зависимостей оказывает политика усиления государственной власти и патернализма. С одной стороны, патернализм позволяет преодолеть социальный кризис, с другой, он лишает людей самостоятельности. Уверенность в необходимости покровительственной системы отношений, опеки и контроля младших старшими, граждан государством имеет глубокие исторические корни не только в России. Цивилизационное значение и важную роль государственного патернализма не отвергают в странах с развитой рыночной экономикой, но его стараются максимально ограничить. Усиление государственного влияния в большинстве сфер жизнеустройства общества, как правило, репродуцирует патерналистский характер власти.

Что на самом деле привело человечество к духовному кризису, сказать сложно, здесь требуются дополнительные исследования, в целом, выходящие за рамки данной работы, но 
сами по себе здесь не виноваты ни прогресс техники и технологии, ни изменение социальных отношений, ни преобладание научной рациональности. В этом смысле вряд ли можно согласиться с X. Ортега-и- Гассетом, настаивавшем на отказе от достижений научнотехнического прогресса ради гуманизации общества. Уничтожение природы нерационально, поэтому подлинная научная рациональность как раз и должна заключаться в обратном ориентировании на то, что способствует выживанию и подлинному, а не мнимому прогрессу человечества.

При анализе причины кризиса духовной свободы человека интересным представляется исследование идеологии развитого индустриального общества» - книга фрейдомарксистского теоретика Герберта Маркузе «Одномерный человек», отобразившая результат его длительного исследования современного ему общества. По его мнению, в современном обществе все люди, по сути, одинаковы, так как подчиняются одним и тем же желаниям. Общество называется свободным, в то время как на самом деле в обществе царит завуалированный неототалитаризм. Общество массового потребления создало свои ценности, повлияло на культуру и контролирует каждого индивида. Потребности современного человека ложны и навязаны ему извне, что делает его рабом собственных потребностей. Для позитивного изменения общества человек должен совершить «Великий Отказ»: изменить направление своих потребностей от эксплуатации природы в сторону гармонии с ней, обратив свои желания и чувства к высокой духовности [7].

Настоящая духовная свобода выражается в том, что человек становится выше этого мира, выше материальных желаний. Когда человек живёт не ради своего эгоизма и значимости, а ради других людей. Римский Папа Франциск I сказал, что если атеист помогает людям - он хороший человек. Стоит полагать, что без духовной свободы человеческая жизнь не имеет ни смысла, ни достоинства, и это самое главное.

На основании вышеуказанных предположений и заключений к способам обретения духовной свободы мы можем добавить следующие.

Во-первых, одним из путей обретения духовной свободы является глубокое погружение в религию, т. к. вера и молитва способствуют проявлению доброй воли. Отсюда вытекает свобода вероисповедания.

Во-вторых, обретению духовной свободы способствует любовь, так как любить можно только самому, искренно, по доброй воле, из глубины. Здесь проявляется свобода духовной любви и убеждений.

В-третьих, обретение духовной свободы проявляется в творчестве, так как творчество возможно только по вдохновению, из глубин сознания, свободно. Нельзя творить по приказу и не творить по запрету.

Таким образом, можно констатировать, что духовная свобода не сводится к отрицанию чужой опытности и мудрости, но состоит в том, чтобы внутренне освободить себя для духовной жизни без внешнего насилия, принуждения и запугивания.

\section{Список литературь:}

1. Бауман 3. Индивидуализированное общество. М.: Логос. 2005. 390 с.

2. Берлин И. Философия свободы. Европа. М.: Новое литературное обозрение, 2001. $448 \mathrm{c}$.

3. Бжезинский 3. Великая шахматная доска. М.: Международные отношения. 1998. 256 c.

4. Бьюкенен П. Дж. Смерть Запада. М.: АСТ, 2004. 444 с.

5. Гусакова Т. Ф. Современный социум: искушение гедонизмом // Вестник Тюменского 
государственного университета. Социально-экономические и правовые исследования. 2009. №5. C. 221-224.

6. Земцов Ю. Н. Духовный кризис: причины, динамика, последствия // Современные аспекты гуманитарного знания: Материалы II Международной научно-практической конференции. Воронеж. 2017. С. 32-36.

7. Маркузе Г. Одномерный человек. М.: REFL-book. 1994. 368 с.

8. Хохлова А. В. Сущность духовного отчуждения как социального феномена и его особенности в современном мире и России // Вестник Московского государственного областного университета. 2011. №1. С. 116-122.

\section{References:}

1. Bauman, Z. (2005). Individualizirovannoe obshchestvo. Moscow, 390. (in Russian).

2. Berlin, I. (2001). Filosofiya svobody. Evropa. Moscow, 448. (in Russian).

3. Bzhezinskii, Z. (1998). Velikaya shakhmatnaya doska. Moscow, 256. (in Russian).

4. B'yukenen, P. Dzh. (2004). Smert' Zapada. Moscow, 444. (in Russian).

5. Gusakova T. F. 2009. Sovremennyi sotsium: iskushenie gedonizmom. Vestnik Tyumenskogo gosudarstvennogo universiteta. Sotsial'no-ekonomicheskie i pravovye issledovaniya, (5). 221-224. (in Russian).

6. Zemtsov, Yu. N. (2017). Dukhovnyi krizis: prichiny, dinamika, posledstviya. In Sovremennye aspekty gumanitarnogo znaniya: Materialy II Mezhdunarodnoi nauchnoprakticheskoi konferentsii. Voronezh. 32-36. (in Russian).

7. Markuze, G. (1994). Odnomernyi chelovek. Moscow. 368. (in Russian).

8. Khokhlova, A. V. (2011). Sushchnost' dukhovnogo otchuzhdeniya kak sotsial'nogo fenomena i ego osobennosti v sovremennom mire i Rossii. Vestnik Moskovskogo gosudarstvennogo oblastnogo universiteta, (1). 116-122. (in Russian).

Работа поступила

в редакияию 11.01.2020 2.
Принята к публикации 16.01.2020 2.

Ссылка для ичитирования:

Савватеева В. В. Духовная свобода и зависимость в современном мире // Бюллетень науки и практики. 2020. Т. 6. №2. С. 258-262. https://doi.org/10.33619/2414-2948/51/29

Cite as (APA):

Savvateeva, V (2020). Spiritual Freedom and Dependence in the Contemporary World. Bulletin of Science and Practice, 6(2), 258-262. https://doi.org/10.33619/2414-2948/51/29 (in Russian). 


\title{
СООТНОШЕНИЕ КОНСТИТУЦИОННО-ПРАВОВОГО И АДМИНИСТРАТИВНО- ПРАВОВОГО РЕГУЛИРОВАНИЯ СТАТУСА МИГРАНТОВ
}

\author{
(ППопова С. А., Кубанский государственный аграрный университет им. И.Т. Трубилина, \\ Краснодар, Россия, soncha99@mail.ru \\ (СЧернов Ю. И., канд. юрид. наук, Кубанский государственный аграрный университет им. \\ И.Т. Трубилина, Краснодар, Россия, Admfinkubsaи@уа.ru
}

\section{CONSTITUTIONAL-LEGAL AND ADMINISTRATIVE-LEGAL BASES OF THE STATUS OF MIGRANTS}

\author{
(CPopova S., Kuban State Agrarian University, Krasnodar, Russia, soncha99@mail.ru \\ CChernov Yu., J.D., Kuban State Agrarian University, Krasnodar, Russia, Admfinkubsau@ya.ru
}

Аннотация. Изучение конституционно-правовых основ статуса мигрантов позволит определить и обобщить права и обязанности данных лиц, которые в значительной степени влияют на формирование правового общественного порядка. В данной статье рассматриваются конституционно-правовые и административно-правовые основы статуса мигрантов, регулируемые законодательством Российской Федерации. Рассматривая вопрос современного состояния миграционного законодательства РФ, выделяется теоретический аспект миграции как мобилизации людей, с целью смены постоянного места жительства. Определяются причины возникновения данного явления и классификация категорий мигрантов. Разграничиваются определения внешних и внутренних мигрантов, на основе чего далее проводится изучение конституционных норм иностранных лиц, въехавших на территорию Российской Федерации. Согласно Федеральным законам выделяются основные права и обязанности иммигрантов, въехавших в Российскую Федерацию по разным определениям причин и обстоятельств. Рассматриваются административно-правовые основы статуса мигрантов в контексте нарушения правопорядка по нормам Кодекса об административных нарушениях. Выделяется институт гражданства, как статус, который непосредственно влияет на объем прав и свобод личности, что позволяет выделить его в качестве специального статуса мигранта. В заключение подводится итог вышеизложенной теме.

Abstract. The study of the constitutional and legal basis of the status of migrants will allow to determine and summarize the rights and obligations of these persons, which significantly affect the formation of legal social order. This article discusses the constitutional, legal and administrative basis of the status of migrants, regulated by the legislation of the Russian Federation. Considering the issue of the current state of the migration legislation of the Russian Federation, the theoretical aspect of migration as the mobilization of people to change their permanent residence is highlighted. The causes of this phenomenon and the classification of categories of migrants are determined. The definitions of external and internal migrants are differentiated, on the basis of which the constitutional norms of foreign persons who entered the territory of the Russian Federation are further studied. According to Federal laws, the basic rights and obligations of immigrants who entered the Russian Federation for different definitions of reasons and circumstances are distinguished. The article considers the administrative and legal basis of the status of migrants in the context of violation of the rule of law according to the norms of the 
Code of administrative violations. The Institute of citizenship is singled out as a status that directly affects the scope of individual rights and freedoms, which allows it to be singled out as a special status of a migrant. In conclusion, the above topic is summarized.

Ключевые слова: мигрант, конституционно-правовое регулирование, гражданство, административное правонарушение, правовой статус.

Keywords: migrant, constitutional and legal regulation, citizenship, administrative offense, legal status.

Изучение миграции имеет жизненно важное значение, поскольку рождаемость, смертность и миграция определяют размер населения, темпы его роста и, следовательно, структуру населения. Кроме того, миграция играет важную роль в определении распределения населения и предложения рабочей силы в стране. Изучение конституционноправовых основ статуса мигрантов позволит определить и обобщить права и обязанности данных лиц, которые в значительной степени влияют на формирование правового общественного порядка [6].

Миграционное право активно взаимодействует с конституционным и административным правом и данная тенденция обусловлена тем, что миграционно-правовое регулирование в Российской Федерации представляет еще формирующуюся и неполную отрасль законодательства. Его базой служат многие основополагающие акты конституционного, гражданского, административного и другого права [7].

Рассматривая вопрос современного состояния миграционного законодательства РФ, необходимо отметить, что под определением миграции понимается мобилизация, перемещение людей с целью смены постоянного места жительства. Причины возникновения данного гетерогенного явления могут быть, как и политические, экономические, экологические, религиозные, так и этнические и демографические. Рассмотрим более подробно категории и состав миграции на Рисунке.

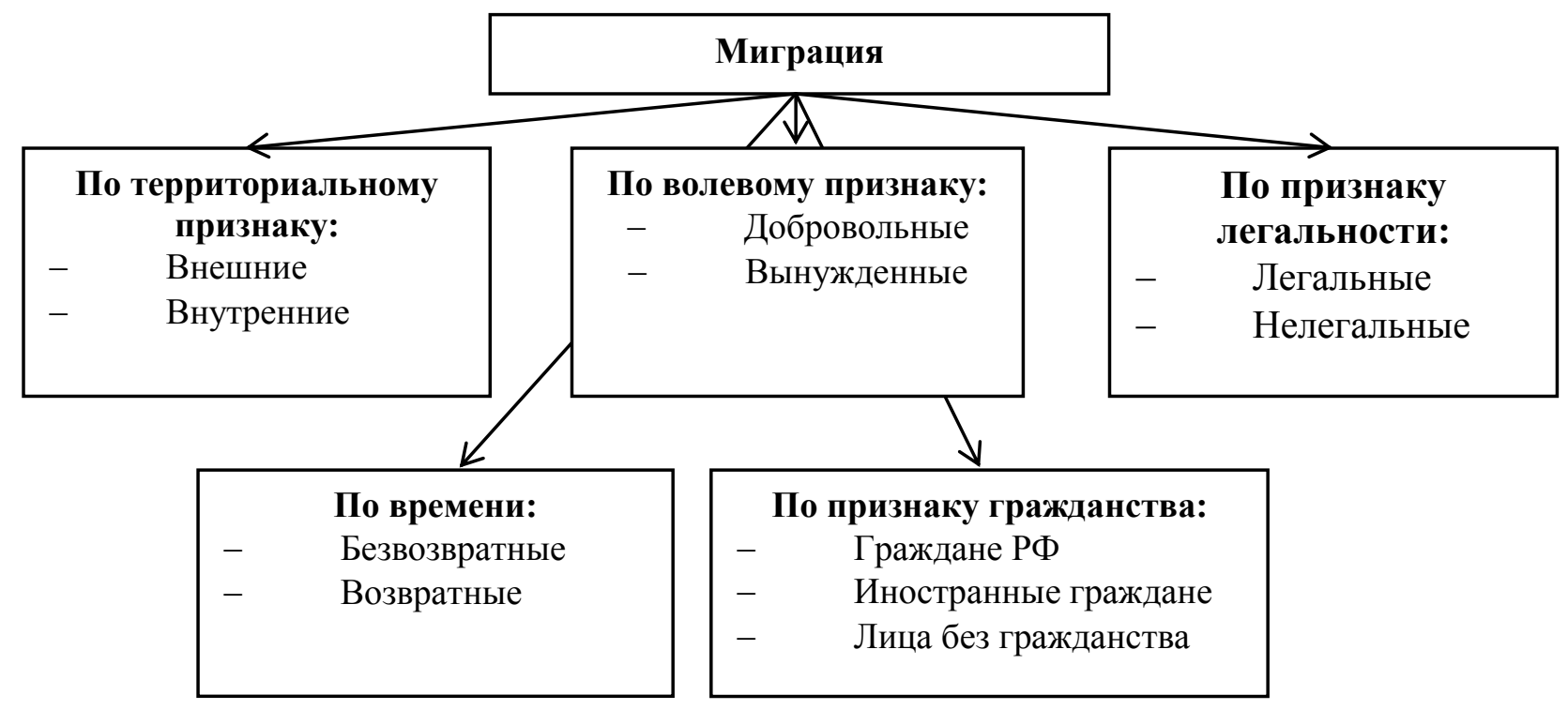

Рисунок. Классификация видов миграции 
В России мигранты наделены специальным правовым статусом, который является сложной, собирательной категорией. Каждому виду мигрантов определен собственный правовой статус, поэтому в правовой литературе можно встретить такие термины, как «правовой статус беженца», «трудовой мигрант», «экологический мигрант» и так далее.

При изучении общего статуса мигрантов необходимо разделить две важные категории данных лиц: внешние и внутренние. Это связано с наделением их разного по содержанию объема прав и обязанностей. Так, например, внутренние мигранты, передвигаясь непосредственно внутри страны, обладают всеми правами граждан РФ, а внешние мигранты делятся на эмигрантов (выехавшие из страны) и иммигрантов (въехавшие в страну).

Наиболее актуален вопрос, связанный с правовым статусом лиц, иммигрировавших в Российскую Федерацию, в контексте чего и будут рассмотрены права и обязанности данных лиц.

Правовой статус иммигрантов регулируется ст. 4 Федерального закона от 25.07.2002 №115-Ф3 «О правовом положении иностранных граждан в Российской Федерации» [3], согласно которому иностранные граждане, прибывшие на территорию страны, обладают теми же правами и обязанностями, что и граждане РФ, кроме ряда некоторых ограничений, где иностранные граждане:

-Вправе территориально изменять положение, при наличии оформленных документов согласно данному закону (ст. 11 №115-ФЗ)

-Не вправе избирать и быть избранными в органы государственной власти (ст. 12 №115-Ф3);

-Не вправе участвовать в референдумах (ст. 12 №115-Ф3);

-Вправе работать, только при наличии специального разрешения (ст. 13№115-Ф3).

Говоря о такой категории иммигрантов, как беженцы, необходимо отметить, что данные иностранные лица в Российской Федерации наделяются дополнительными правами, которые гарантируются и обеспечиваются государством. Данные положения регулирует ст. 6 Федерального закона от 19.02.1993 № 4528-1 «О беженцах» [4], согласно которой беженец:

-Вправе бесплатно получить услуги переводчика;

-Вправе получить обеспечение проезда за государственный счет к месту пребывания;

-Вправе получить единовременное денежное пособие на каждого члена семьи;

-Вправе получить обеспечение места временного проживания;

-Вправе получить обеспечение питанием, коммунальными услугами и медицинской помощи.

Также большим объемом дополнительных прав обеспечена такая категория иностранных граждан, как «экологические беженцы», то есть лица, которые были вынуждены покинуть место жительства по причине экологической катастрофы, которые строго определены российским законодательством. Данные правовые гарантии заключаются непосредственно в социальной защите данных лиц [5].

Существование прав и свобод человека неразрывно связано с определением конкретного объема обязанностей, изучение которых немаловажно для обеспечения регламентированного правового общественного порядка. К обязанностям иностранного лица, въехавшего в РФ, относится:

-Становление на миграционный учет по месту пребывания (Закон №109-Ф3);

-Получения разрешения или патента для получения возможности работать на территории РФ (Закон №115-ФЗ);

-При условии признания лица беженцем прохождение обязательного медицинского осмотра (Закон №4528-1); 
-При условии признания лица беженцем прохождение процедуры идентификации личности и государственной дактилоскопической регистрации (Закон №4528-1).

Рассматривая административно правовые основы статуса мигрантов, необходимо выделить то, что к мигрантам может быть применен такой вид ответственности, как административное выдворение из страны. Данное положение регулирует глава 18 Кодекса РФ об административных правонарушениях, которая содержит отдельные виды административных правонарушений по указанному наказанию [2]. Например, нарушение режима государственной границы (ст. 18.1 КоАП РФ), нарушение режима в пунктах пропуска через границу (ст. 18.4 КоАП РФ), нарушение правил въезда и проживания (ст.18.8 КоАП РФ), незаконное осуществление трудовой деятельности (ст.18.10 КоАП РФ) и так далее.

Гражданство непосредственно влияет на объем прав и свобод личности, что позволяет выделить его в качестве специального статуса мигранта. Конституция РФ закрепляет основные права гражданина России, и распространяет их действие на всех, в том числе и на мигрантов [1]. Однако большинство ограничений прав мигрантов связано с наличием или отсутствием у них гражданства Российской Федерации. Этот фактор отражается на прохождении воинской службы, разрешенный только гражданам РФ, также связано с ограничением вышеуказанного трудоустройства на территории страны и свободным передвижением по территории РФ. Так иностранные лица и лица без гражданства имеют и другие ограничения в своем правовом статусе.

Таким образом, можно сделать вывод, что мигранты являются лицам, обладающими специальным правовым статусом, регулируемым как и конституционными нормами, так и административными, и наделение определенного объема прав и обязанностей происходит исходя из рассматриваемой категории мигрантов.

\section{Список литературы:}

1. Конституция Российской Федерации» (принята всенародным голосованием 12.12.1993) (с учетом поправок, внесенных Законами РФ о поправках к Конституции РФ от 30.12.2008 N 6-ФК3, от 30.12.2008 N 7-ФК3, от 05.02.2014 N 2-ФК3 ) // Собрание законодательства РФ, 14.04.2014, N 15, ст. 1691.

2. Кодекс Российской Федерации об административных правонарушениях от 30.12.2001 N 195-Ф3 (ред. от 04.11.2019). Режим доступа: www.consultant.ru/

3. О правовом положении иностранных граждан в Российской Федерации: Федеральный закон от 25.07.2002 №115-Ф3. Режим доступа: www.consultant.ru/

4. О беженцах: Федеральный закон от 19.02.1993 №4528-1. Режим доступа: www.consultant.ru/

5. Сенченко В. В., Соболь О. М. Административно-правовое регулирование миграционных процессов в РФ. Соотношение международно-правового и административноправового регулирования миграционных отношений в РФ // APRIORI. Серия: Гуманитарные науки. 2016. №3. С. 34-42.

6. Самойлов В. Д., Панов А. И. Миграция как социально-экономическое явление // Экономические и социально-гуманитарные исследования. 2018. №3(19).

7. Чернов Ю. И. Миграционное право. Краснодар, 2019. 87 с.

\section{References:}

1. Konstitutsiya Rossiiskoi Federatsii» (prinyata vsenarodnym golosovaniem 12.12.1993) (s uchetom popravok, vnesennykh Zakonami RF o popravkakh k Konstitutsii RF ot 30.12.2008 N 6- 
FKZ, ot 30.12.2008 N 7-FKZ, ot 05.02.2014 N 2-FKZ ). Sobranie zakonodatel'stva RF, 14.04.2014, N 15, st. 1691.

2. Kodeks Rossiiskoi Federatsii ob administrativnykh pravonarusheniyakh ot 30.12.2001 N 195-FZ (red. ot 04.11.2019). www.consultant.ru/

3. O pravovom polozhenii inostrannykh grazhdan v Rossiiskoi Federatsii: Federal'nyi zakon ot 25.07.2002 №115-FZ. www.consultant.ru/

4. O bezhentsakh: Federal'nyi zakon ot 19.02.1993 №4528-1. www.consultant.ru/

5. Senchenko, V. V., \& Sobol', O. M. (2016). Administrativno-pravovoe regulirovanie migratsionnykh protsessov v RF. Sootnoshenie mezhdunarodno-pravovogo $i$ administrativnopravovogo regulirovaniya migratsionnykh otnoshenii v RF. APRIORI. Seriya: Gumanitarnye nauki, (3). 34-42. (in Russian).

6. Samoilov, V. D., \& Panov, A. I. (2018). Migratsiya kak sotsial'no-ekonomicheskoe yavlenie. Ekonomicheskie i sotsial'no-gumanitarnye issledovaniya, 3(19). (in Russian).

7. Chernov, Yu. I. (2019). Migratsionnoe pravo. Krasnodar, 87. (in Russian).

Работа поступила

в редакциию 10.01.2020 г.
Принята к публикаџии

16.01.2020 2.

Ссылка для ичитирования:

Попова С. А., Чернов Ю. И. Соотношение конституционно-правового и административно-правового регулирования статуса мигрантов // Бюллетень науки и практики. 2020. Т. 6. №2. С. 263-267. https://doi.org/10.33619/2414-2948/51/30

Cite as (APA):

Popova, S., \& Chernov, Yu. (2020). Constitutional-Legal and Administrative-Legal Bases of the Status of Migrants. Bulletin of Science and Practice, 6(2), 263-267. https://doi.org/10.33619/2414-2948/51/30 (in Russian). 


\title{
ПРИНЦИП НАИБОЛЕЕ ТЕСНОЙ СВЯЗИ В МЕЖДУНАРОДНОМ ЧАСТНОМ ПРАВЕ
}

(СЛомакина Е. Н., Кубанский государственный аграрный университет им. И.Т. Трубилина, 2. Краснодар, Россия, lomakinae436@gmail.com

(СПетров А. Д., Кубанский государственный аграрный университет им. И.Т. Трубилина, 2. Краснодар, Россия, adpetrov@те.com

СГлинщикова T. В., SPIN-код: 2152-5300, канд. юрид. наук, Кубанский государственный аграрный университет им. И.Т. Трубилина, 2. Краснодар, Россия, glinshikowa@yandex.ru

\section{PRINCIPLE OF THE CLOSEST RELATIONSHIP IN PRIVATE INTERNATIONAL LAW}

\author{
CLomakina E., Kuban State Agrarian University, Krasnodar, Russia, lomakinae436@gmail.com \\ CPetrov A., Kuban State Agrarian University, Krasnodar, Russia, adpetrov@me.com \\ CGlinshchikova T., SPIN-code: 2152-5300, J.D., Kuban State Agrarian University, \\ Krasnodar, Russia, glinshikowa@yandex.ru
}

Аннотация. Отечественные ученые придают большое значение одному из основополагающих принципов международного частного права - принципу наиболее тесной связи. Концепция наиболее тесной связи была разработана в Англии на основе прецедентного права, нормы которого создавались судьями в судебных решениях по конкретным делам. Законодатель включил принцип тесной связи в ГК РФ, однако, в свете изменений, внесенных в него в результате реформ 2013 г., принципу тесной связи была отведена второстепенная роль по отношению к принципу характерного исполнения. Главное назначение принципа наиболее тесной связи заключается в поиске правопорядка, способного наиболее эффективно регулировать трансграничные отношения. Суду предстоит установить волю сторон договорного правоотношения, направленную на выбор права. Поэтому тесная связь устанавливается на основе предположения суда о том, какое бы право выбрали стороны, если бы рассмотрели этот вопрос. Принцип наиболее тесной связи, в связи с таким подходом, нередко теряет свое самостоятельное значение. Статья 1187 ГК РФ не содержит указания на условия ее применения, а также на сферу ее действия. По этой причине категория наиболее тесной связи носит универсальный характер и применяется независимо от характера трансграничного гражданско-правового отношения. В российском законодательстве отсутствуют четкие критерии определения наиболее тесной связи, что может привести к принятию субъективного решения судом. В этой связи изучение проблем, связанных с применением принципа наиболее тесной связи в судебной практике имеет несомненную актуальность.

Abstract. Russian scientists attach great importance to one of the fundamental principles of private international law - the principle of the closest connection. The concept of the closest connection was developed in England on the basis of case law, the rules of which were created by judges in court decisions on specific cases. The legislator has included the principle of closest connection to the civil code, however, in light of the changes it made in the reforms of 2013, the closest connection principle was assigned a secondary role in relation to the principle of characteristic performance. The main purpose of the principle of the closest connection is to find 
the law and order that can most effectively regulate cross-border relations. The court will have to determine the will of the parties to the contractual relationship, aimed at choosing the right. Therefore, a close relationship is established based on the court's assumption of what right the parties would have chosen if they had considered this issue. The principle of the closest connection, in connection with this approach, often loses its independent significance. Article 1187 of the civil code of the Russian Federation does not specify the conditions of its application, as well as the scope of its action. For this reason, the category of closest relationship is universal and applies regardless of the nature of the cross-border civil relationship. Russian legislation does not have clear criteria for determining the closest relationship, which may lead to a subjective decision by the court. In this regard, the study of problems related to the application of the principle of the closest connection in judicial practice is undoubtedly relevant.

Ключевые слова: тесная связь, международный договор, иностранный элемент, коллизия, коллизионная норма.

Keywords: close relationship, international law, foreign element, conflict, conflict-of-laws rule.

Предмет международного частного права представляет собой совокупность гражданских, трудовых и семейных правоотношений, осложненных иностранным элементом. Присутствие иностранного элемента практически всегда влечет за собой коллизию между отдельными правовыми системами. В тоже время, одной из актуальных проблем современного международного частного права является наличие различий в нормах национальных правовых систем, нередко осложняющих международное сотрудничество. Данная проблема может быть решена с помощью коллизионных норм, составляющих историческую основу международного частного права [1]. В частности, применения коллизионного принципа наиболее тесной связи. В настоящее время, большинство государств признает эффективность и перспективность данного подхода. Зарубежные государства закрепляют данный принцип в национальном законодательстве. При этом, в Болгарии или Швейцарии принцип «тесной связи» закреплен как основное коллизионное начало, когда как в других государствах он играет роль дополнительной (вспомогательной) коллизионной нормы. В России используется смешанная система закрепления изучаемого принципа. Так, раздел VI Гражданского кодекса РФ, посвященный международному частному праву, фиксирует в ст. 1211 его субсидиарное применение. В ст. 1187 ГК РФ этот же принцип используется уже как основное коллизионное начало.

В научной литературе многие правоведы сходятся во мнении о том, что изучаемый принцип носит коллизионный характер. Так, например, И. П. Звеков считает, что принцип «тесной связи» имеет коллизионный статус [2]. С точки зрения Н. Ю. Ерпылевой, в сравнении с автономией воли, рассматриваемый принцип может расцениваться только как дополнительная коллизионная привязка. Однако, мнения правоведов могут разниться, к примеру Е. В. Кабатова предполагает, что схожие черты между коллизионной нормой и принципом «тесной связи» не являются основанием полагать, что это идентичные понятия, наоборот наличие и использование такого принципа может способствовать поэтапному отказу от коллизионного подхода при определении применяемого права [4].

Изначально принцип «тесной связи» был закреплен в XX веке в Англии, в результате неспособности классической коллизионной нормы удовлетворить потребности иностранных 
хозяйствующих субъектов. Это объясняется достаточно жестким (императивным) характером некоторых коллизионных норм.

Первым нормативно-правовым актом, закрепившим принцип наиболее тесной связи, стала Римская конвенция о праве, применимом к договорным обязательствам 1980 г., которая наиболее показательно разъяснила все характерные черты принципа тесной связи [3]. Под его содержанием понимается тесная связь какого-либо договора со страной, в которой сторона договора, исполняющая те или иные требования, имеет основное коммерческое предприятие в этой стране, либо на момент заключения договора проживает в ней. Из этого вытекает, что международные частноправовые отношения, осложненные иностранным элементом регламентируются национальным законодательством того государства, с которым они наиболее тесно связаны. А данная связь зависит от того, в какой стране находится административный центр корпоративной организации, являющейся стороной договора. При этом, если в договоре предусматривается его исполнение в ином месте, отличном от места нахождения основного «центра» корпоративной организации, тогда договор считается тесно связанным со страной местонахождения иного места.

Однако, многие ученые отмечают, что подобное толкование принципа «тесной связи» является не совсем верной. Привязка к месту расположения главного органа организации не может быть единственным основанием для применения изучаемого принципа. Более того, подобное толкование этого принципа носит достаточно субъективный характер, его можно применить в единичных случаях, но универсальным его считать нельзя.

Что касается Российской Федерации, то национальное законодательство, в вопросе регулирования принципа «тесной связи» преуспело, по сравнению с теми же странами СНГ, которые до сих пор равняются на Римскую конвенцию, утратившей в настоящее время силу. После закрепления в Римской конвенцией положений, касающихся принципа наиболее тесной связи, отечественный законодатель сформулировал несколько специальных статей в ныне не действующих Основах гражданского законодательства Союза ССР и республик 1991 г. Однако нормы, содержащиеся в этом акте, являлись чересчур жесткими и односторонними. Например, в соответствии с п. 6 ст. 166 Основ гражданского законодательства Союза ССР и республик в отношении приемки исполнения по договору принимается во внимание право места проведения такой приемки. Подобное толкование также нельзя считать объективным, поскольку содержание принципа «тесной связи» не может регламентироваться заранее установленными положениями и презумпциями. Международное частное право сочетает в себе многообразие правопорядков и находится в постоянной динамике, поэтому установки, закрепленные в Основах гражданского законодательства, не отличались гибкостью.

Поэтому в действующем ГК РФ помимо принципа автономии появился и принцип наиболее тесной связи [5]. Так, согласно ст. 1186 ГК РФ, если международный договор, федеральный закон и признаваемые в РФ обычаи не в состоянии определить применимое право, тогда применяется право государства, с которым гражданско-правовые отношения наиболее тесно связаны [6]. В рамках договорных отношений, данный принцип проявляется как право, тесно связанное с договором. В соответствии с п. 9 ст. 1211 ГК РФ, если из закона, условий или существа договора либо совокупности обстоятельств дела явно вытекает, что договор более тесно связан с правом иной страны, чем та, которая указана в пунктах 1 - 8 настоящей статьи, подлежит применению право страны, с которой договор более тесно связан. При определении наиболее тесной связи суд должен учесть степень интенсивности территориальных контактов и их значение для конкретного правоотношения. 
Таким образом, следует утверждать, что принцип наиболее тесной связи, ввиду усиления международной социально-экономической интеграции, способен эффективно регулировать отношения между субъектами различных государств. Однако в российских реалиях его корректное исполнение достаточно трудно представить, поскольку принцип наиболее тесной связи ориентирован на широкое судейское рассмотрение, а это в свою очередь, может привести к субъективизму суда и превышению им своих полномочий.

\section{Список литературы:}

1. Глинщикова Т. В. Проблемы определения применимого права к договору международного факторинга // Гуманитарные, социально-экономические и общественные науки. 2015. №4. С. 135-137.

2. Звеков В. П. Международное частное право. М.: Инфра-М, Норма, 1999. С. 124.

3. Ерпылева Н. Ю. Международное частное право. М.: NOTA BENE, 1999. C. 87.

4. Кабатова Е. В. Международное частное право: современные проблемы. М. 1994. С. 390-391.

5. Шмидт-Тренц Ю. Плате, Пашке М. Основы германского и международного экономического права. СПб.: СПбГУ, 2007. С. 50-54.

6. Асосков А. В. Основы коллизионного права. М.: Инфотропик Медиа, 2012. С. 12-15.

7. Ахрименко М. А. Концепция гибкого подхода к определению права, подлежащего применению к договорам, в современном коллизионном праве государств Западной Европы и США : дис. ... канд. юрид. наук. М. 2006.

8. Байрамкулов А. К. Толкование договора в российском и иностранном гражданском праве : дис. ... канд. юрид. наук. М. 2014.

9. Гетьман-Павлова И. В., Филимонов К. В. Модификация принципа наиболее тесной связи в Концепции развития гражданского законодательства РФ и в Регламенте ЕС «Рим І». М.: НИУ ВШЭ. 2012. С. 35.

10. Дмитриева Г. К. История науки международного частного права // Вестник Университета имени О. Е. Кутафина (МГЮА). 2015. №2. С. 31-33.

11. Кётц X., Лорман Ф. Проблемы гражданского и предпринимательского права Германии. М.: Бек, 2001. С. 42-44.

12. Лунц Л. А. Курс международного частного права. М.: Спарк, 2002. С. 19.

13. Ходыкин Р. М. Принципы и факторы формирования содержания коллизионных норм в международном частном праве: дис. ... канд. юрид. наук. М. 2005. С. 23-26.

\section{References:}

1. Glinshchikova, T. V. 2015. Problemy opredeleniya primenimogo prava $\mathrm{k}$ dogovoru mezhdunarodnogo faktoringa. Gumanitarnye, sotsial'no-ekonomicheskie i obshchestvennye nauki, (4). 135-137.

2. Zvekov, V. P. (1999). Mezhdunarodnoe chastnoe pravo. Moscow, 124.

3. Erpyleva, N. Yu. (1999). Mezhdunarodnoe chastnoe pravo. Moscow, 87.

4. Kabatova, E. V. (1994). Mezhdunarodnoe chastnoe pravo: sovremennye problemy. Moscow. 390-391.

5. Shmidt-Trents, Yu. Plate, \& Pashke, M. (2007). Osnovy germanskogo i mezhdunarodnogo ekonomicheskogo prava. SPb.: SPbGU, 50-54.

6. Asoskov, A. V. (2012). Osnovy kollizionnogo prava. Moscow, 12-15. 
7. Akhrimenko, M. A. (2006). Kontseptsiya gibkogo podkhoda k opredeleniyu prava, podlezhashchego primeneniyu $\mathrm{k}$ dogovoram, $\mathrm{v}$ sovremennom kollizionnom prave gosudarstv Zapadnoi Evropy i SShA : dis. ... kand. yurid. nauk. Moscow.

8. Bairamkulov, A. K. (2014). Tolkovanie dogovora v rossiiskom i inostrannom grazhdanskom prave : dis. ... kand. yurid. nauk. Moscow.

9. Get'man-Pavlova, I. V., \& Filimonov, K. V. (2012). Modifikatsiya printsipa naibolee tesnoi svyazi v Kontseptsii razvitiya grazhdanskogo zakonodatel'stva RF i v Reglamente ES Rim I. Moscow. 35.

10. Dmitrieva, G. K. (2015). Istoriya nauki mezhdunarodnogo chastnogo prava. Vestnik Universiteta imeni O. E. Kutafina (MGYuA), (2). 31-33.

11. Ketts, Kh., \& Lorman, F. (2001). Problemy grazhdanskogo i predprinimatel'skogo prava Germanii. Moscow. 42-44.

12. Lunts, L. A. (2002). Kurs mezhdunarodnogo chastnogo prava. Moscow. 19.

13. Khodykin, R. M. (2005). Printsipy i faktory formirovaniya soderzhaniya kollizionnykh norm v mezhdunarodnom chastnom prave: dis. ... kand. yurid. nauk. Moscow. 23-26.

Работа поступила

в редакциию 14.01.2020 2.
Принята к публикаџии

19.01.2020 2.

Ссылка для цุитирования:

Ломакина Е. Н., Петров А. Д., Глинщикова Т. В. Принцип наиболее тесной связи в международном частном праве // Бюллетень науки и практики. 2020. Т. 6. №2. С. 268-272. https://doi.org/10.33619/2414-2948/51/31

Cite as (APA):

Lomakina, E., Petrov, A., \& Glinshchikova, T. (2020). Principle of the Closest Relationship in Private International Law. Bulletin of Science and Practice, 6(2), 268-272. https://doi.org/10.33619/2414-2948/51/31 (in Russian). 


\title{
РОЛЬ СРЕДСТВ МАССОВОЙ КОММУНИКАЦИИ В СОЦИАЛЬНОМ КОНСТРУИРОВАНИИ ГРАЖДАНСКОЙ ИДЕНТИЧНОСТИ РОССИЯН (НА ПРИМЕРЕ ПОЛИЭТНИЧНОГО РЕГИОНА)
}

CКоровкина H. B., ORCID: 0000-0003-1716-109X, SPIN-код: 2663-5336, Башкирский государственный университет, г. Уфа, Pоссия, korovkina-natalya@ list.ru (CAдигамова О. Ф., ORCID: 0000-0001-6127-7554, SPIN-код: 1800-7341, Башкирский государственный университет, г. Уфа, Россия

\section{THE ROLE OF MEDIA IN SOCIAL CONSTRUCTION OF CIVIL IDENTITY OF THE RUSSIANS (ON THE EXAMPLE OF A MULTIETHNIC REGION)}

\author{
CKorovkina N., ORCID: 0000-0003-1716-109X, SPIN-code: 2663-5336, \\ Bashkir State University, Ufa, Russia, korovkina-natalya@list.ru \\ (C)Adigamova O., ORCID: 0000-0001-6127-7554, SPIN-code: 1800-7341, \\ Bashkir State University, Ufa, Russia,
}

Аннотащия. В статье рассматривается роль средств массовой коммуникации в социальном конструировании гражданской идентичности россиян на примере полиэтничного региона. Приводятся сравнительные данные стандартизированных интервью местного населения Республики Башкортостан, проведенных в 2012-2013 гг. и 2019 г. в рамках реализации грантов. Результаты приводятся в зависимости от возраста респондентов. Обосновывается особая значимость интернета, который является основным источником информации у более молодых респондентов.

Abstract. The article considers the role of mass media in the social construction of the civil identity of Russians on the example of a multiethnic region. Comparative data of standardized interviews of the local population of the Republic of Bashkortostan in 2012-2013 and 2019 are presented. The results are given depending on the age of the respondents. The special importance of the Internet, which is the main source of information for younger respondents, is substantiated.

Ключевые слова: средства массовой коммуникации, социальное конструирование, гражданская идентичность, полиэтничный регион, российская нация, доверие.

Keywords: mass media, social construction, civil identity, multiethnic region, Russian nation, trust.

\section{Введение}

Формирование гражданской идентичности может быть рассмотрено как целенаправленный процесс, осуществляемый политической и интеллектуальной элитами. Важная роль в этом процессе принадлежит средствам массовой коммуникации (СМК), которые являются основным каналом передачи сообщений, с одной стороны, и выступают площадкой для участия в обсуждении - с другой. 
Большой вклад в развитие концепции социального конструирования гражданской идентичности в отечественной науке внес В. А. Тишков. Он отмечает, что значение гражданской, государственной идентичности усиливается с ростом числа образованных людей, способных осознавать не только локальную и религиозную идентичность. В нашей стране на протяжении длительного времени существовала практика использования понятия «нация» как этнической общности. Значительно позднее возникает мнение о том, что термины «народ» и «нация» можно рассматривать как «территориальное сообщество» (население страны, государства), а также этническая общность (этнос, национальность) [1, с. 19-21].

В. А. Тишков определяет национальную идентичность как общеразделяемое представление граждан о своей стране, ее народе и чувстве принадлежности к ним [1, с. 45]. Общество, в первую очередь интеллектуальная элита и власть, формирует представление о народе [1, с. 49].

В. А. Тишков формулирует идею о том, что национальная идентичность не задана естественным образом, а вырабатывается целенаправленными усилиями интеллектуалов, политиков и общественных активистов. Усиление гражданской идентичности происходит посредством системы норм, официальных документов (национальный паспорт) [1, с. 136137].

Именно коммуникация сделала возможной нашу идентификацию с такими сообществами, как нация, государство, человечество. В процессе коммуникации осуществляется социализация и формирование ряда коллективных идентичностей, к которым относятся как национальная, этническая, гражданская, политическая и др. [2, с. 129].

\section{Материал и методы исследования}

Статья основана на результатах исследований авторского коллектива 2012-2013 гг. и 2019 г. В 2012-2013 гг. в рамках реализации гранта было проведен опрос местного населения Республики Башкортостан методом стандартизированного интервью на тему «Межнациональное общение и социальные проблемы в Республике Башкортостан». Объем выборки составил 1000 человек, выборка многоступенчатая.

В 2019 г. в рамках реализации гранта Российского фонда фундаментальных исследований на тему «Коммуникативные аспекты социального конструирования гражданской идентичности россиян» авторским коллективом был проведен опрос местного населения Республики Башкортостан методом стандартизированного интервью. Объем выборки составил 751 человек. Выборка - квотная, районированная.

Согласно данным исследования 2012 г., наиболее высоким потенциалом с точки зрения охвата аудитории обладали интернет и телевидение. Далее расположились радио и пресса, при этом региональные средства массовой коммуникации вызывали меньший интерес у аудитории, чем федеральные средства массовой информации (СМИ). В свою очередь, местная пресса (город/село) уступала республиканской [3, с. 280-283].

В 2019 г., отвечая на вопрос об источниках получения информации, 72,4\% назвали интернет, 62,5\% - телевидение, в то время как газеты и радио значительно уступили им (18,2\% и 14,8\% соответственно), что очень ярко отражает тенденцию усиления роли сети интернет как средства массовой коммуникации (CMК,) а также демонстрирует довольно устойчивую позицию телевидения. Примерно каждый третий назвал семью и родственников, а каждый четвертый - друзей и знакомых - в качестве источника информации.

Выбор источника информации зависит от возраста респондента (Таблица 1). До 40 лет безусловным лидером в этом отношении является интернет, что особенно ярко проявляется у 
респондентов в категории 21-30 лет (98,1\%). В возрастной группе среди опрошенных от 41 до 50 лет на первое место выходит телевидение $(81,3 \%)$, в то время как интернет ему несколько уступает (75,3\%). Это еще более заметно в группе от 51 до 60 лет, где интернет обозначил лишь каждый второй опрошенный $(54,2 \%)$.

ИСТОЧНИКИ ИНФОРМАЦИИ

Таблица 1.

В ЗАВИСИМОСТИ ОТ ВОЗРАСТА РЕСПОНДЕНТА, в \%

\begin{tabular}{lcccccc}
\hline \multirow{2}{*}{ Источники информачии } & \multicolumn{5}{c}{ Возрастные группы респондентов } \\
\cline { 2 - 7 } & до 20 & $21-30$ & $31-40$ & $41-50$ & $51-60$ & 61 и старие \\
\hline Газеты & 0 & 1,3 & 13,7 & 21,1 & 25,8 & 48,0 \\
\hline Радио & 6,7 & 3,9 & 11,6 & 14,5 & 19,2 & 38,8 \\
\hline Телевидение & 16,7 & 32,9 & 53,4 & 81,3 & 90,8 & 85,7 \\
\hline Интернет & 96,7 & 98,1 & 89,7 & 75,3 & 54,2 & 7,1 \\
\hline Семья, родственники & 26,7 & 25,2 & 28,1 & 38,0 & 31,7 & 21,4 \\
\hline Друзья, знакомые & 26,7 & 28,4 & 26,0 & 22,3 & 21,7 & 17,3 \\
\hline Коллеги, сокурсники & $13, \%$ & 16,1 & 19,2 & 13,9 & 11,7 & 2,0 \\
\hline Другое & 3,3 & 0,6 & 1,4 & 0,6 & 0,8 & 5,1 \\
\hline
\end{tabular}

Прослеживается четкая тенденция обращения к газетам как источникам информации в более старших возрастных группах. Респонденты в возрасте до 30 (и даже 40) лет практически игнорируют этот ресурс, в то время как в старшей возрастной группе почти каждый второй назвал газеты. Телевидение так же не очень популярно среди молодежи, но свою верность ему сохраняют респонденты от 41 года, а в группе от 31 до 40 лет его назвал примерно каждый второй. Опрошенные старше 61 года реже других обращаются за информацией к ближайшему окружению (друзьям, коллегам и т.д.), что, вероятно, может быть связано с сокращением у значительной части ее представителей социальных контактов и активности в целом.

Если говорить о предпочтениях в каналах получения информации новостного характера, то лидером в силу своей оперативности становится интернет $(44,1 \%)$, однако телевидение практически не уступает ему $(43,7 \%)$. Это может быть связано и с тем, что в сети интернет информация появляется быстро, но не всегда она оказывается достоверной.

Оценивая достоверность различных СМК, треть респондентов $(30,1 \%)$ заявили, что степень доверия зависит от ситуации, еще 18,3\% сказали, что не доверяют ни одному источнику, 19,6\% доверяют телевидению, а 18,4\% — интернету.

Молодые люди до 30 лет наиболее склонны проявлять к средствам массовой коммуникации ситуативное доверие - так ответили около $40 \%$. Реже всего такой ответ давали опрошенные старше 61 года $(19,4 \%)$. Более всего респонденты до 40 лет склонны доверять интернету, представители других возрастных групп - телевидению (Таблица 2).

Несколько чаще респонденты отдают предпочтение интернету $(33,6 \%)$ как источнику информации при получении противоречивых сообщений, чем телевидению $(32,4 \%)$. Это можно объяснить предположением о наличии у населения убежденности в допустимости циркуляции в интернете большего количества точек зрения, чем в других СМК. Стоит отметить, что для значительной части населения $(27,2 \%)$ это очень неоднозначный вопрос, на который они не смогли дать ответа. 
УРОВЕНЬ ДОВЕРИЯ К ИНФОРМАЦИИ В СМК

Таблица 2. В ЗАВИСИМОСТИ ОТ ВОЗРАСТА РЕСПОНДЕНТА, в \%

\begin{tabular}{|c|c|c|c|c|c|c|}
\hline \multirow[t]{2}{*}{ Доверие к информации в СМК } & \multicolumn{6}{|c|}{ Возраст респондента } \\
\hline & до 20 & $21-30$ & $31-40$ & $41-50$ & $51-60$ & $\begin{array}{c}61 \text { u } \\
\text { cmapue }\end{array}$ \\
\hline $\begin{array}{l}\text { Наиболее достоверно события освещаются в } \\
\text { газетах }\end{array}$ & 0 & 1,9 & 1,4 & 1,8 & 1,7 & 10,2 \\
\hline $\begin{array}{l}\text { Наиболее достоверно события освещаются } \\
\text { на радио }\end{array}$ & 0 & 0 & 1,4 & 0,6 & 0 & 4,1 \\
\hline $\begin{array}{l}\text { Наиболее достоверно события освещаются } \\
\text { на телевидении }\end{array}$ & 23,3 & 6,5 & 11,6 & 25,1 & 30,8 & 32,7 \\
\hline $\begin{array}{l}\text { Наиболее достоверно события освещаются в } \\
\text { интернете }\end{array}$ & 23,3 & 26,5 & 24,0 & 14,4 & 11,7 & 4,1 \\
\hline $\begin{array}{l}\text { Информация достоверна во всех указанных } \\
\text { средствах массовой коммуникации }\end{array}$ & 0 & 0,6 & 6,8 & 6,6 & 2,5 & 2,0 \\
\hline $\begin{array}{l}\text { Сегодня нельзя доверять ни одному из } \\
\text { указанных средств массовой коммуникации }\end{array}$ & 10,0 & 18,1 & 22,6 & 19,8 & 17,5 & 14,3 \\
\hline $\begin{array}{l}\text { Степень моего доверия к указанным } \\
\text { средствам массовой коммуникации зависит } \\
\text { от конкретной ситуации и освещаемого } \\
\text { события }\end{array}$ & 43,3 & 38,1 & 29,5 & 24,0 & 32,5 & 19,4 \\
\hline Затрудняюсь ответить & 0 & 8,4 & 2,7 & 7,8 & 3,3 & 13,3 \\
\hline
\end{tabular}

Интернет - это сегодня один из важнейших каналов конструирования гражданской идентичности, позволяющий осуществлять как вертикальные, так и горизонтальные коммуникации. Особенно это справедливо по отношению к молодежи.

В 2012 г. практически половина респондентов $(47,1 \%)$ заявила, что ежедневно пользуется интернетом, пятая часть опрошенных - несколько раз в неделю. Не пользовались интернетом, либо пользовались очень редко - около четверти респондентов. В 2019 г. 64,9\% опрошенных сказали, что пользуются интернетом ежедневно, 12,7\% — несколько раз в неделю. Не пользуются или пользуются очень редко около 17\% опрошенных.

Эти данные, с одной стороны, говорят об увеличении доли аудитории интернета, с другой - указывают на рост доверия: респонденты осознают возможность дезинформации в интернете, однако признают и факт наличия множественности взглядов и оценок в глобальной сети.

Наиболее активными пользователями интернета являются молодые люди: в 2012 г. две трети респондентов из категории до 24 лет почти каждый день посещали глобальную сеть. В следующей возрастной группе (25-30 лет) каждый второй респондент пользовался интернетом ежедневно. В 2019 г. эти показатели значительно выросли, достигнув в возрастной группе до 30 лет почти максимального показателя. Закономерно увеличивается (до 22,5\%) количество опрошенных, не пользующихся интернетом, среди опрошенных в возрасте до 60 лет, в следующей возрастной категории достигая 67\% (Таблица 3).

Респонденты используют интернет в самых разнообразных целях: 61,3\% - для общения, $56,4 \%$ - для поиска советов, $51,3 \%$ - смотрят фильмы, слушают музыку, читают книги, $48 \%$ - следят за новостями, $28 \%$ - совершают покупки, $26,2 \%$ - для самообразования и т.д. Наиболее популярными социальными сетями оказались «В Контакте» $(68,4 \%)$, «Одноклассники» $(30,1 \%)$ и “Telegram” (24,7\%). 
ЧАСТОТА ОБРАЩЕНИЯ К ИНТЕРНЕТУ

Таблица 3.

\section{В ЗАВИСИМОСТИ ОТ ВОЗРАСТА РЕСПОНДЕНТА, В \%}

\begin{tabular}{lccccc}
\hline Возраст респондента & \multicolumn{5}{c}{ Вариантыл ответов } \\
\cline { 2 - 6 } & Ежедневно & $\begin{array}{c}\text { Несколько } \\
\text { раз в неделю }\end{array}$ & $\begin{array}{c}\text { Несколько } \\
\text { раз в месяи }\end{array}$ & $\begin{array}{c}\text { Раз в месяи } \\
\text { и реже }\end{array}$ & $\begin{array}{c}\text { Никогда не } \\
\text { пользуюсь }\end{array}$ \\
\hline до 20 & 96,7 & 3,3 & 0 & 0 & 0 \\
\hline $21-30$ & 98,0 & 2,0 & 0 & 0 & 0 \\
\hline $31-40$ & 85,5 & 9,7 & 1,4 & 2,8 & 0,6 \\
\hline $41-50$ & 60,2 & 22,9 & 4,2 & 1,8 & 10,8 \\
\hline $51-60$ & 32,5 & 28,3 & 14,2 & 2,5 & 22,5 \\
\hline 61 и старше & 7,4 & 4,3 & 16,0 & 5,3 & 67,0 \\
\hline
\end{tabular}

Сейчас, оценивая роль СМК, о том, что не обращаются к ним, заявили по отношению к информационным ресурсам сети интернет - 19,9\% опрошенных, социальным сетям и форумам — 23,5\%, центральным телеканалам — 18,2\%, телеканалам Башкортостана $29,1 \%$, центральному радио - 55,4\%, радио Башкортостана - 55,7\%, центральным газетам $51 \%$, газетам республики - 52,8\%, местным газетам - 49,9\%.

В 2012 г. мнение об отрицательной роли республиканских средств массовой информации (СМИ) являлось менее распространенным, чем о соответствующем, дезинтеграционном влиянии центральных каналов массовой коммуникации, однако это можно связать с более высокой популярностью первых. Эта тенденция зафиксирована и в исследовании 2019 г.: чем меньше респондентов обращаются к СМК, тем реже они склонны говорить о негативном влиянии канала, нагнетании напряженности с его стороны. Наиболее часто опрошенные (примерно каждый третий) заявляют о положительном влиянии на обстановку в стране центрального и республиканского телевидения, а также об интернетресурсах.

Более половины респондентов утверждают, что в период предвыборной кампании 2018 г. они не следили за появляющимися в СМИ сообщениями. Еще 18,2\% считают, что СМИ выступали лишь источниками информации, но они почти не влияли на решение, полностью влияние отрицают $10,9 \%, 5 \%$ говорят, что эти сообщения лишь запутали их. Таким образом, влияние СМИ признали лишь 6,4\%. Конечно, респондентам сложно объективно оценить влияние информационным ресурсов, однако эти ответы в некоторой степени отражают установки населения (в первую очередь, эмоционально-оценочный компонент) (Таблица 4).

ВЛИЯНИЕ ОСВЕЩЕНИЯ В СМИ ИЗБИРАТЕЛЬНОЙ КАМПАНИИ

Таблица 4.

И ВЫБОРОВ ПРЕЗИДЕНТА РФ НА ВЫБОР РЕСПОНДЕНТОВ, В \%

\begin{tabular}{lc}
\hline \multicolumn{1}{c}{ Вариант ответа } & Доля \\
& респондентов \\
\hline СМИ служили источником полезной информации, повлиявшей на Ваше решение & 6,4 \\
\hline СМИ служили источником информации, однако почти не повлияли на Ваше решение & 18,2 \\
\hline Информация из СМИ только еще больше запутала Вас & 5,0 \\
\hline Вы обращались к каналам СМИ (смотрели/слушали/читали), но они не оказали & 10,9 \\
\hline никакого влияния на Ваш выбор & 53,5 \\
\hline Вы не интересовались и не следили за ходом избирательной кампанией и выборами & 0,8 \\
\hline Другое & 5,2 \\
\hline Затрудняюсь ответить & \\
\hline
\end{tabular}




\section{Заключение}

Средства массовой коммуникации (пресса, радио, телевидение и интернет) являются важнейшим каналом социального конструирования гражданской идентичности россиян, так как позволяют осуществлять данный процесс как на вертикальном уровне (нисходящие и восходящие коммуникации), так и горизонтальном. СМК в разной степени оказывают влияние на подавляющее число граждан, способствуют формированию гражданской идентичности на трех уровнях: когнитивном, эмоционально-оценочном, деятельностном.

В течение многих последних лет наблюдается устойчивая тенденция увеличения влияния сети интернет. Напротив, телевидение утрачивает свои позиции, сохраняя статус главным образом благодаря старшим категориям граждан. Именно они отдают предпочтение телевидению как наиболее достоверному источнику информации. Значительно ослабело положение радио и прессы. Респонденты склонны более высоко оценивать возможности как позитивного, так и негативного влияния федеральных СМИ в сравнении с региональными. Вероятно, это связано с меньшим охватом аудитории у последних.

Интернет в процессе конструирования российской нации имеет особый статус, так как позволяет более эффективно в сравнении с другими каналами осуществлять вертикальные восходящие и горизонтальные коммуникации. Именно в интернете наиболее ярко прослеживается процесс медиаконвергенции, так как глобальная сеть выполняет целый ряд функций: образовательную, коммуникативную, воспитательную, интеграционную, развлекательную, однако характеризуются также и наличием дисфункций, в числе которых распространение ложной информации, дезинтеграция, информационная перегрузка и др.

Финансирование: статья подготовлена в рамках реализации гранта «Коммуникативные аспекты сочиального конструирования гражданской идентичности россиян» Российского фонда фундаментальных исследований (РФФИ). Договор № 18-311$00199 \backslash 19$

\section{Список литературь:}

1. Тишков В. А. Российский народ: книга для учителя. М.: Просвещение, 2010. 191 с.

2. Труфанова Е. А. Роль коммуникации в построении личностной идентичности // Философия науки и техники. М.: ИФ РАН, 2012. С. 128-142.

3. Коровкина Н. В. Роль СМК в формировании гражданской идентичности // Жизненный потенциал региона: социально-демографические проблемы современного общества: сборник материалов Международной научно-практической конференции. (Аитовские чтения). АЭТЕРНА, Уфа, 2015. С. 280-283.

\section{References:}

1. Tishkov, V. A. (2010). Rossiiskii narod: kniga dlya uchitelya. M.: Prosveshchenie, 191. (in Russian).

2. Trufanova, E. A. (2012). Rol' kommunikatsii v postroenii lichnostnoi identichnosti. Filosofiya nauki i tekhniki. M.: IF RAN, 128-142. (in Russian). 
3. Korovkina, N. (2015). The role of the mass media in the formation of civil identity. The collection of materials of the International scientific-practical conference "The life potential of the region: socio-demographic problems of modern society”. AETERNA, Ufa, 280-283. (in Russian).

Работа поступила

в редакичию 09.018.2020 г.
Принята к публикациии 14.01.2020 2.

Ссылка для циитирования:

Коровкина Н. В., Адигамова О. Ф. Роль средств массовой коммуникации в социальном конструировании гражданской идентичности россиян (на примере полиэтничного региона) // Бюллетень науки и практики. 2020. Т. 6. №2. С. 273-279. https://doi.org/10.33619/2414$2948 / 51 / 32$

Cite as (APA):

Korovkina, N., \& Adigamova, O. (2020). The Role of Media in Social Construction of Civil Identity of the Russians (on the Example of a Multiethnic Region). Bulletin of Science and Practice, 6(2), 273-279. https://doi.org/10.33619/2414-2948/51/32 (in Russian). 


\title{
ФЕНОМЕН БЕССОЗНАТЕЛЬНОГО В ПСИХИКЕ И ДУХОВНОЕ СТАНОВЛЕНИЕ ПОДРОСТКОВ, ЮНОШЕЙ И ДЕВУШЕК
}

\author{
(САдыкулов А. А., канд. психол. наук, докторант, Киргизско-Российский славянский \\ университет, г. Бишкек, Кыргызстан, djambo.aftandil.2014@gmail.com
}

\section{THE PHENOMENON OF UNCONSCIOUS IN THE PSYCHE AND THE SPIRITUAL FORMATION OF AN ADOLESCENT BOYS AND GIRLS}

\author{
(CAdykulov A., Ph.D., doctoral student, Kyrgyz-Russian Slavic University, Bishkek, Kyrgyzstan, \\ djambo.aftandil.2014@gmail.com
}

Аннотация. В статье показаны особенности бессознательной сферы и их значение в формировании духовной сферы личности подросткового и юношеского возраста на основе инстинкта, архетипов и неосознаваемых установок. К проблеме инстинктов необходимо подходить с позиции методологии, понимая ее как психический, бессознательный феномен. Актуальным и важным для подростков и юношей является психологическая сторона. В формировании духовной сферы личности подросткового и юношеского возраста особую роль играют фантазии, образы, желания, побуждения, которые основаны на архетипах и неосознаваемых установках. Половой инстинкт подростков следует рассматривать как феномен бессознательной сферы, имеющий огромный потенциал. Фактором «очеловечивания» инстинктов, в целом, и полового инстинкта в частности, является образование архетипов личности, вбирающих в себя фантазии, образы, желания, побуждения подростков и их связь с архетипом как психологическим детерминантом, основной функцией которого в подростковом и юношеском возрасте является сублимация психической энергии. Психологические детерминанты бессознательной сферы в подростковом и юношеском возрасте могут обусловливать творчество, креативность, определять как субъекта в социальной ситуации развития, идентифицировать себя как личность, содействовать формированию личностных качеств, взаимодействию в группе людей, а также умению достигать поставленных целей. В подростковом и юношеском возрасте проявляются стремление к свободе, попытки найти смысл, творческая активность, стремление к целостности, любовь, ценность, обращение к духовному, высшему божественному миру и единение с ним, проявляющиеся как признаки архетипа «самость».

Abstract. The article shows the peculiarities of the unconscious sphere and their importance in the formation of the spiritual sphere of the personality of adolescent and teenage years on the basis of instinct, archetypes and unconscious attitudes. The problem of instincts must be approached from the perspective of methodology, understanding it as a mental, unconscious phenomenon. The psychological side is currently central and important for youngsters and teenagers. Fantasies, images, desires, inducements, which can be based on archetypes and unconscious mindsets, play a special role in the formation of the spiritual sphere of the personality in adolescent and teenage years. The sexual instinct of teenagers should be treated as an unconscious phenomenon with enormous potential. The factor of 'humanizing' instincts in general and sexual instinct in particular, is the formation of personality archetypes, which include fantasies, 
images, desires, inducements of teenagers and their connection with the archetype, as a psychological determinant being the main function. In adolescence and youth, mental energy sublimates. Psychological determinants of the unconscious sphere at teenage and junior age can cause imagination, creativity, to define it as subject in a social situation of development, identification of the personality, to assist formation of personal qualities, interaction in a group of people and the ability to achieve goals. In prepubescent years and adolescent age there are appear a desire for freedom, an effort to find meaning, creative activity, a desire for integrity, love, value, an appeal to and unity with the spiritual, higher divine world, which are manifested as signs of the archetype 'selfhood'.

Ключевые слова: инстинкты, архетипы, неосознаваемые установки, половой инстинкт, фантазии подростков, духовная сфера.

Keywords: instincts, archetypes, unconscious attitudes, sexual instinct, fantasies of teenagers, spiritual sphere.

В подростковом возрасте начинает доминировать психологический аспект, и духовный мир подростка, юноши и девушки становится актуальным. Насколько и как связаны духовное развитие и культура с этим периодом - сложный вопрос. Чем сложнее общество (индустриальное, постиндустриальное), тем еще более усложняется данная проблема для отдельного индивида, так как семья, дети с малых лет начинают испытывать вторжение в личную жизнь информации с интернет-пространства без ограничения. Какая политика должна проводиться в области воспитания культуры подростков, актуально сегодня не столько для образовательных учреждений, сколько для каждой семьи, для каждого родителя, решившего как-то подготовить своего растущего ребенка к взрослой жизни.

Очень часто в культурах, в семьях господствует табу на какое-либо «просвещение» в половом воспитании детей и подростков. Оправдывается все тем, что это не принято, преждевременно, постыдно и неприемлемо. Эта проблема действительно существует в обществе в связи с тем, что до какого-то времени подготовка к семейной жизни к интимной сфере жизни проводилась в относительно закрытом пространстве с позиции традиций, норм и обычаев народа, предков. Всякие попытки светского общества включить в воспитание и просвещение половой вопрос, встречает сопротивление со стороны определенного слоя общества, чему способствуют стереотипы, негативные установки и предвзятое отношение. В конечном итоге, в результате такого подхода подростки часто оказываются наедине со своими проблемами. Очевидно и то, что у них появляются свои «гуру», случайные взрослые, сомнительные сайты интернет-пространства, т.е. срабатывает принцип «Свято место не бывает пусто». Не секрет, что по статистике на сегодняшний день в обществе остается большое количество «устаревших» традиций: например умыкание невесты - как социально оправданная форма насилия над девушкой, а также изнасилований, количество лиц с сексуальными отклонениями, детей, рожденных вне брака, разводов.

Экскурс в психологическую науку, педагогическую психологию показывает важность данного направления в воспитании личности. Выделяя психологические аспекты полового инстинкта, Л.С. Выготский в свое время отмечал их как ключевые для развития человека и, следовательно, как средство или инструмент воспитания. Он писал, что «психологически половой инстинкт представляет собой могущественнейший источник психических импульсов, страданий, наслаждений, желаний, болей и радостей» [1, с. 106]. 
Здесь важно понимать, какая из психолого-педагогических наук наиболее близко подходит к пониманию психологии подростка. Традиционно считается, что педагогическая психология определяет механизмы, закономерности и условия, обеспечивающие процесс формирования личности в образовательном процессе. Как отмечают ученые, педагогическая психология как отрасль науки, тесно связана с возрастной и дифференциальной психологией, психогенетикой, педагогикой, социальной психологией, философией, культурологией [2, с. $5]$.

Особо следует отметить тесную связь педагогической психологии с возрастной, которая обеспечивает факты и закономерности психологического развития здорового человека в разные периоды его жизни [3].

Было бы весьма удовлетворительно и плодотворно для общества, если бы педагогическая психология показала научные основы обеспечения условий, необходимых для полноценного психического развития учащихся и формирования их личности в подростковый период, особо акцентируя их как период полового созревания. Наряду с этим, необходимо, чтобы она выявила и проектировала социально-педагогические условия, максимально содействующие личностному развитию, самоопределению и саморазвитию подростков как будущих мужчин и женщин; создала методический инструментарий, позволяющий выявить и спрогнозировать особенности личностного развития ребенка в период полового созревания; изучила и показала роли и психологические особенности участников образовательного процесса (родители, учителя, администрация образовательного учреждения) и механизмы их влияния на ребенка, что стало бы основными задачами педагогической психологии духовного формирования личности в этот период.

На сегодня педагогическая психология, в вопросах подросткового периода часто ограничивается выявлением и конструированием эффективных методов работы психолога и педагога с образовательной практикой. Однако без изучения и практического применения достижений возрастной и педагогической психологии в воспитании и обучении методы педагогического воздействия, будучи самоцелью педагогического процесса, без учета специфики полового созревания подростков, становятся малоэффективными и формальными, не задевающими душу ребенка.

Половой инстинкт, как и все инстинкты человека, имеет природную врожденную основу, и заложен в человеческой жизни на генетическом уровне. От того как он реализуется у человека, проявляясь в течение всей жизни, зависит очень многое. В терминах, говорящих, что инстинкт «слепой», «природный», «наследственный», «импульсивный» имеется ссылка, что возникновение, созревание и функционирование этого инстинкта происходит помимо воли и сознания человека. С половым инстинктом связаны такие понятия как половое влечение (либидо), сексуальное, эротическое развитие и так далее, однако насколько связано с ним культурное развитие, остается не достаточно ясным, чтобы мы могли утверждать, что это и есть ключ к воспитанию подростков и юношей с точки зрения педагогической психологии. Тем не менее наиболее важным, если не архиважным, вопрос полового развития, влечения к противоположному полу становится актуальным для мальчиков и девочек, когда они впервые сталкиваются с симптомами данного инстинкта. «Данный инстинкт, - писал У. Джеймс, - мотивируется исключительно самим собой», поэтому важно, как он будет реализован в первый раз, после которого этот инстинкт приобретает форму [4, с. 465].

Созревание инстинкта в психике, как системы внутри, имеет свои характеристики, определяющие его природу. Являясь наследственным, природным половой инстинкт имеет огромный потенциал энергии. 
В работе Л. С. Выготского показано, как Э. Торндайк сравнивал инстинкт с рекой, которую невозможно повернуть вспять и отмечает, что «можно, построив новые каналы, заставить вращать колеса фабрик на служение человеку. Вот здесь дана формула воспитания. И для этого учителю совершенно необходимо конкретно и точно знать, в какие каналы он должен отвести природные стремления ребенка, какие колеса каких фабрик заставить их вращать» [5, с. 194].

Таким образом, правильность и своевременность воспитания, культура воспитания с учетом созревания полового инстинкта, как «мощнейшего инструмента» педагогической психологии, играет важную и первостепенную роль в подростковом и юношеском возрасте.

Методологическое сопровождение вопросов полового инстинкта и воспитания в развитии личности в подростковом и юношеском возрасте может происходить по двум направлениям, когда «при одном методология исследования излагается отдельно от самого исследования, при другом она пронизывает все изложенное» [6, с. 23].

Если при первом подходе методология сравнивается с мягкотелой улиткой, у которой скелет находится отдельно от тела, то второй, которому Л. С. Выготский отдает предпочтение, предполагает наличие «скелета» (остова) внутри исследования.

При изучении инстинкта, здесь есть не только путь в физиологию или в психологию. Критикуя теорию понимающей психологии Э. Шпрангера Л. С. Выготский отмечал «даже эротическое и сексуальное, поскольку они представлены в переживании и составляют предмет психологического рассмотрения, не имеет ничего общего с созреванием половых желез. ... В самостоятельном, замкнутом в себе, идеальном бытии одинаково растворяются и природное, и культурное начало личности» » [6, с. 21].

Другими словами, нельзя рассматривать изолированно только одну сторону, сексуальное либо эротическое, не соскальзывая при этом с психологической плоскости и не скатываясь и не смешивая физиологию развития.

Важность методологии Л. С. Выготский обозначил в работе «Психика, сознание, бессознательное» [5, с. 103], где он ставит сложный вопрос, что включать в психику бессознательное и сознание. Что именно является фактором «очеловечивания» инстинктов, в целом, и «полового инстинкта», в частности, роль инстинктов и их связь с архетипом, как психологическим детерминантом, основной функцией которого является воздействие на поведение субъекта.

Поэтому было важно понимать психику в целом, при этом ставить во главу угла методологию, включая и бессознательное. Как отмечал Л.С. Выготский, «психика, сознание и бессознательное, означают не только три центральных и основных психологических вопроса, но является в гораздо большей степени вопросами методологическими, т. е. вопросами о принципах построения самой психологический науки» [5, с. 132].

Развитие личности в подростковом и юношеском возрасте происходит, как смена стадий, где на каждой из них могут формироваться и развиваться психологические новообразования, присущие этому периоду возраста. Л.С. Выготский писал, что «старая психология отождествляла психику и сознание» [5, с. 142]. Обнаруживается, что возможности развития личности в старшем школьном и юношеском возрасте не ограничены уровнем и возможностями сознания. Сознание имеет очень тесную связь (иногда зависимую) от такого огромного пласта психики, как бессознательная сфера, где скрыты многие возможности психики. Содержания бессознательного в развитии личности могут проявлять себя опосредованно, выступая как «базисный процесс» психического, «независимые переменные». 
Такая исходная позиция, которая включает и сознание и бессознательное в психике, актуализирует вопросы связи между сознанием и бессознательным. В свою очередь, она предполагает дифференциацию их содержаний, так как и сознание, и бессознательное являются содержанием психики, но остаются в этом единстве автономными содержаниями. Когда человек в сознании, он не осознает, не чувствует что происходит в бессознательном, когда же он (в бессознательном) без сознания, например в сновидении, он не осознает психологические детерминанты бессознательного.

Таким образом, инстинкты относятся к бессознательной сфере психики. Половой инстинкт является составной частью целого комплекса инстинктов, следовательно, он также относится и к бессознательной сфере. Исходя из этого, в качестве методологии в изучении природы полового инстинкта можно применить методологические принципы и методы изучения бессознательной сферы психики: неклассический, культурно-исторический, рефлексивно-регулятивный, деятельностный, субъектный подходы, принципы опосредованности, детерминизма, развития, системности, целостности и другие методологические, теоретические подходы и принципы, разработанные классиками зарубежной и российской психологии.

Наряду с вышеизложенным методология исследования бессознательного опирается на частные методологические принципы, которые основаны на работах классиков мировой и российской психологии Л. С. Выготского, С. Л. Рубинштейна, 3. Фрейда, К. Г. Юнга, Д. Н. Узнадзе и психологические детерминанты, их характеристики, выходящие за пределы сознания и имеющие свою динамику развития: единство сознания и бессознательного в психике; автономность сознания и бессознательного; противостояние и сотрудничество сознания и бессознательного; принцип опосредованности в психике; уровни бессознательной сферы (инстинкты, архетипы и образы, психическая энергия в бессознательной сфере, установка и установочная функция бессознательного); трансцендентная функция бессознательного; расширение сознания; развитие личности и индивидуация в бессознательной сфере; бессознательное как источник творчества.

При изучении инстинкта, в русле неклассической психологии в социальноисторическом, культурном контексте наблюдается активное включение, рассмотрение человека, будь это подросток, юноша или девушка, не как вещи среди вещей, а как индивида укорененного в мире культуры, с которым он взаимодействует и строит себя. Неклассический подход позволяет рассматривать личность юноши и девушки как творца активного субъекта, не только формируемого извне или изнутри заранее заложенными программами, сколько как самосозидающего, самодетерминируемого.

Применение неклассического подхода к развитию подростка так же, как и развитию как субъекта культуры, предполагает саморазвитие обучаемого, где во главу угла ставится индивидуальность, инициативность, самобытность развития личности учащегося. Открытие новых возможностей и перспектив в исследовании бессознательных психологических механизмов и детерминантов, взаимосвязи сознания и бессознательного и их проявления в личности юношеского возраста в образовательной среде предполагает формирование психологических основ личности юношей и девушек как активных субъектов, творцов, самосозидающих, самодетерминируемых личностей, что обусловливается не только сознательной частью, но и бессознательными психологическими детерминантами.

Методологические подходы, связанные с активностью, самодетерминацией, саморегуляцией, самосовершенствованием личности раскрывают психическое в разных отношениях; дают целостную картину и понимание субъектного похода; выражают форму познания психического, адекватную ее природе; включают в себя как средства 
теоретического анализа, так и практическое использование, где активность, самодетерминация, саморегуляция, саморазвитие и самосовершенствование субъекта ключевые характеристики личности подросткового и юношеского возраста как субъекта жизни.

Бессознательные психологические детерминанты в духовном воспитании выступают в качестве главной цели, а особенности созревания полового инстинкта (к примеру, огромная психическая энергия) могут выступать как мощнейший инструмент, в виде базовых фундаментальных психических образований (неосознаваемые установки, психические функции, архетипы).

Исследования психологических особенностей взаимодействия сознания и бессознательного дают перспективы и новое понимание возможностей в обучении и воспитании, новые направления для дальнейших исследований проблемы «Я» как в сознании, так и в бессознательном, выявляя закономерности развития личности в старшем школьном и юношеском возрасте. В юношеском возрасте особо стоит вопрос творчества. Сама природа творчества, как показывают исследования, связана не только с сознательной частью психики, но и с бессознательными процессами [5].

Подростки впервые сталкиваются с симптомами бессознательного - инстинктами, неосознаваемыми образами, архетипами и неосознаваемыми и противоречивыми установками, которые ставят их в весьма затруднительное положение. Включение в область «внутреннего мира» сложной области сознания и еще более сложной - бессознательного, приводит к пониманию, насколько трудна и сложна эта задача для самих подростков, юношей и девушек. От того какой путь они изберут, впервые столкнувшись с миром бессознательного, зависит дальнейшее развитие личности. В подростковом и юношеском возрасте происходит поиск своего «Я», встреча и борьба эго с инстинктивными силами - с одной стороны, и требованиями культуры, воспитания, социальной среды - с другой. Все формы идентичности личности с внешними объектами, в качестве которых может выступать коллективное бессознательное, могут отдалять личность от самой себя. В юношеском возрасте осознание своего Я начинает создавать субъекта своего развития. Взаимодействие сознательной и бессознательной части психики в этом возрасте связано с осознанием своего «Я» и формированием значения архетипов личности «эго», «персона», «тень», «анима и анимус», «самость».

Осознание своего «Я», архетипа личности эго, будучи внутри сознания, рассматривается дифференцированно, отдельно от сознания, при этом эго отличается от сознания и выступает как главный архетип сознания личности в юношеском возрасте [6]. Признаки архетипа «эго» проявляются в том, что юноша или девушка начинают представлять себе желаемый, сильный образ себя как настоящего героя, чувствуют силу, прилив энергии; начинают осознавать, что могут достичь желаемого благодаря собственным усилиям, стремятся быть самостоятельными в своих решениях, касающихся их собственных действий и поступков. Однако архетип эго, являясь центром сознания, порой оказывается в зависимом положении от других архетипов личности, которые доминируют в данный период развития.

К примеру, в старшем школьном и юношеском возрасте возникновение, становление и развитие архетипа личности «персона» во внешнем проявлении выступают как «внешний авторитет», как социальная природа, функция, качество, проявляющаяся в межличностных отношениях (маска, лицо), в деятельности, в творчестве, и выражены через объекты, статус, имидж, продукты творчества и т. д. В этом возрасте архетип личности «персона» начинает доминировать над эго. В своей слабости он вынужден обращаться к диктуемым ценностям и нормам коллективного бессознательного, представляемого через архетип «персона» [7]. 
Личность подростка и юноши, проявляя активность, с момента осознания своего «Я» (архетипа «эго») становится субъектом своих внутренних психологических содержаний личности.

Важность систем и их судьбы, о которых Л.С. Выготский, относится и к вопросу связей между сознанием и бессознательным, где «в изменениях связей и бесконечно разнообразных формах движения, возникающих отсюда в том, что возникают на известной стадии новые синтезы, новые узловые функции, новые формы связей между ними, и нас должны интересовать системы и их судьба» [5, с. 131].

В психологии подростка, в переживании подростка, юноши и девушки присутствуют и эротическое, и сексуальное. Однако необходимо уточнить, в каком соотношении и в какой последовательности они находятся между собой, учитывая, что в качестве природного можем рассматривать инстинкт полового влечения. Другими словами, вопросы соотношения эротического и сексуального в работах Л. С. Выготского приводят к проблеме соотношения природного и культурного [6, с. 30, 31].

Когда мы признаем, что половой инстинкт относится к сфере бессознательного так же, как и исследователи относят архетипы, неосознаваемые установки в сферу бессознательного, то в бессознательном мы должны определить связи между половым инстинктом и неосознаваемыми установками, которые могут оказаться «альфой и омегой» исследуемой проблемы.

Противоречие между инстинктивными силами и требованиями культуры, воспитания, среды, в которой находится подросток, юноша или девушка, обусловлено сексуальным развитием, половым созреванием, которое характеризуется и сопровождается новым уровнем психического развития. Здесь происходит встреча со своим бессознательным. Подавленные природные инстинкты усиливают воздействие на личность архетипа «тень», которая является частью бессознательной сферы психики, выступает как материал, подавленный сознанием, недоступна напрямую сознанию, часто проявляет себя как тенденция навязать сознанию то, что является негативным.

Парадокс заключается в том, что в период полового созревания подросток, юноша и девушка, впервые столкнувшись с натиском и бурей эмоций, не в силах управлять ими. К. Г. Юнг обнаружил, что среди инстинктов наличествуют такие, которые следуют специфическому принципу порядка, значения и целеполагания. Психическая жизнь индивида управляется ими.

Когда мы говорим о наследственном факторе, имея ввиду инстинкт, мы должны исходить из того, что половой инстинкт подростка, являясь наследственным, не имеет опыта во внешней культурной среде. Чтобы получить опыт, он должен стать «окультуренным». Являясь глубоко интимной сферой, половой инстинкт при всей могущественной энергии, не может быть реализован так, как хотелось бы бессознательному. Л. С. Выготский пишет, что «половой инстинкт подростка потому и окультуривается, что вызревает поздно и застает к моменту вызревания уже сложившуюся личность со сложной системой функций и аппаратом инстанций и процессов, с которыми вступает в сложное взаимоотношение: с одной стороны, вызывает их перестройку на новой основе, а с другой - сам начинает проявляться не иначе, как сложно преломленный, переработанный и включенный в непростую систему этих отношений» [8, с. 170].

Здесь уместно говорить о подавленных инстинктах, неудовлетворенных желаниях подростка. Л.С. Выготский особое внимание обращает на фантазии подростка, которые впервые обращается в интимную сферу переживаний, скрываемую от других людей: «фантазирует отнюдь не счастливый, а только неудовлетворенный. Неудовлетворенное 
желание - побудительный стимул фантазии. Наша фантазия, - пишет он, - это осуществление желания, корректив к неудовлетворенной действительности» [8, с. 217].

Л. С. Выготский в своем анализе особенностей фантазии подростка соединяет желания, побуждения, чувства и образы в единое: «Наше чувство стремится быть отлитым в известные образы, в которых оно находит свое выражение и свой разряд. И понятно, что те или иные образы являются могущественным средством вызывания, возбуждения того или иного чувства и его разряда» [8, с. 218].

Осуществляя анализ периода созревания полового инстинкта, Л. С. Выготский отметил особенность психологии подростка. «Особенность фантазии подростка: она впервые обращается у него в интимную сферу переживаний, которая скрывается обычно от других людей, которая становится исключительно субъективной формой мышления, мышления исключительно для себя» (8, с. 217).

Далее фантазии и чувства, преобразуясь в образы, наделяются подростком силой определенной формы психологического детерминанта.

Когда на основе фантазии мы строим какие-либо образы, они нам представляются нереальными, несуществующими. Однако чувства заставляют переживать, и как отмечает Л. С. Выготский, чувства, которые вызывают эти фантазии и образы, переживаются как настоящие, «...пролитые им слезы принадлежат действительности. Таким образом, в фантазии подросток изживает свою богатую внутреннюю эмоциональную жизнь, свои порывы... Именно скрытность фантазии указывает на то, что она тесно связывается с внутренними желаниями, побуждениями, влечениями и эмоциями личности и начинает обслуживать всю эту сторону жизни подростка» [8, с. 218].

Следует отметить тесную связь трех компонентов, о которых говорит Л. С. Выготский, - фантазии, образа и чувств, которые в единстве своем заставляют переживать подростка. Как психологические детерминанты, вбирая в себя фантазии, чувства и образы у подростка, основаны на неудовлетворенных желаниях, переживаниях. «Подросток с помощью фантазии, - пишет Л.С. Выготский, - просветляет, уясняет сам себе, воплощает в творческих образах свои эмоции, свои влечения. Неизжитая жизнь находит свое выражение в творческих образах» $[8$, с. 218$]$.

В работах, посвященных психологии подростка, Л. С. Выготский подчеркивает то, что подросток «изживает», «овладевает», «преодолевает» свои собственные чувства. Новые связи обнаруживаются, когда подросток открывает свой новый внутренний творческий, духовный мир эмоций, чувств, которых он раньше не переживал.

«Именно в фантазиях подросток впервые нащупывает свой жизненный план. Его стремления и смутные побуждения отливаются в форму определенных образов. В фантазии он предвосхищает свое будущее, а следовательно, и творчески приближается к его построению и осуществлению» [8, с. 219]. Гениальность Л. С. Выготского заключается в том, что он увидел, как подросток через переживания своих фантазий, образов подходит к образованию и возникновению своего индивидуального опыта в мире эмоций и чувств.

Динамика и структура личности подростка в концепции Л. С. Выготского объясняется:

1) «законом перехода от непосредственных природных, естественных форм и способов поведения к опосредованным, искусственным, возникающим в процессе культурного развития психическим функциям»;

2) законом, когда «отношение между высшими психическими функциями было некогда реальным отношением между людьми; коллективные, социальные формы поведения в процессе становятся способом индивидуального приспособления, формами поведения и мышления личности»; 
3) законом «перехода функций извне вовнутрь» [8, с. 221-224].

С этой точки зрения понятия, принципы опосредованности, учитывающие особенности, связанные непосредственно с половым инстинктом, телесным удовольствием, наслаждением (сексуальность, эротичность), переходят в область опосредованных переживаний, фантазий, образов, архетипов, таких как анима - образ женщины в мужчине, анимус — образ мужчины в женщине и т. д.

Доминирование одного над другим, или «врастание в культуру» (Э. Шпрангер, Л. С. Выготский) при интеграции сексуального и эротического дает два разных тренда в развитии личности. С. В. Мелков отмечает, что сексуализация эротического разрушает идеальную любовь, так как в подростковом возрасте этот идеал нуждается в конкретной красоте телесного образа и еще не способен любить абстрактную личность во всей ее полноте. В свою очередь, полная эротизация сексуального еще не может удаться, поскольку сексуальная сторона еще не совсем созрела в этом возрасте. Врастание в культуру идет через интеграцию эротики и сексуальности, что научает любви и позволяет достичь целостности личности $[9$, с. 79].

Преждевременная сексуализация подростка в ущерб его романтики полового инстинкта формирует грубую личность и может вызвать некоторые отклонения в развитии личности в плане духовного формирования.

Л. С. Выготский писал, что «когда говорят: подросток открывает свой внутренний мир с его возможностями, устанавливая его относительную независимость от внешней деятельности, - то, с точки зрения того, что нам известно о культурном развитии ребенка, это может быть обозначено как овладение внутренним миром [6, с. 327].

Овладение сексуальным поведением становится одной из главных задач в подростковом и юношеском возрасте, которое в дальнейшем может идти в направлении преобразования сексуальных импульсов в романтическое русло любви и переживания единства со значимым другим. Как подросток осваивает свое поведение, свой индивидуальный во многом зависит от его архетипов (личных, коллективных) неосознаваемых установок.

Если инстинкты есть собственно физиологические потребности, воспринимаемые органами чувств, то архетипы более сложное образование. Следующим после инстинкта, но расположенным до сознания, является архетип. К. Г. Юнг исходит из того, что мозг человека функционирует так же, как он функционировал в давние времена. Поэтому благодаря примитивному, основанному на аналогиях способу мышления, специфичному для сновидений, существуют древние образы, которые К.Г. Юнг называет «архетипы». Речь идет, по его мнению, не о врожденных идеях, а об унаследованных структурах мышления. Понятие «архетип» происходит от латинского «типос» (печать, отпечаток, можно еще условно определить его, как модель, схему, паттерн) и означает определенное образование архаического характера, включающее мифологический мотив. Типы поведения, или поведенческие ситуации, диктуемые архетипами, идут из глубокой древности. Эти типы, или «архаические остатки», наиболее ярко прослеживаются в мифах народов.

К. Г. Юнг писал: «Останки древности», «архетипы», «первообразы» - в сущности, они представляют собой заложенные инстинктом устремления, такие же, как у птиц к гнездованию, а у муравьев к устройству упорядоченных поселений. По К.Г. Юнгу, архетип в себе есть некий не представимый наглядно фактор, некая диспозиция, которая в какой-то момент развития человеческого духа приходит в действие, начиная выстраивать материал сознания в определенные фигуры. По определению автора, архетипы суть некие факторы и мотивы, упорядочивающие психические элементы в известные образы (зовущиеся 
архетипическими), но делается это так, что распознать их можно лишь по производимому ими эффекту.

Инстинкт не проявляется в человеческой психике подобно тому, как он обнаруживается у животных. У человека инстинкты проявляются в особой форме, которая опосредованно проходит какие-то этапы. Но инстинкт дает сбой в случае расстройств образной системы. Инстинкт дает «сбой» не только в этом случае, но и тогда, когда искажается стройная система «очеловечивания» в результате придания ей какой-то формы. В определенной степени инстинкт приобретает «человеческую» форму благодаря архетипу. Архетипы не могут присутствовать в мыслях, только элементы архетипов представляют собой образные мысли, объяснение которых нельзя обнаружить в жизни сновидца. Похоже, что они являются первозданными, врожденными и унаследованными от первобытных людей формами разума $[10$, c. 65$]$.

Мы можем отметить, что есть архетипы, которые во внешних поведенческих проявлениях, связаны с основной и жизненной универсальной ситуацией - половым инстинктом, в том числе рождением, браком, материнством, смертью, разводом, важной утратой и т. д.

Архетипы являются фактором «очеловечивания» инстинктов вообще, и полового инстинкта в частности, открывая новые возможности и предоставляя новые инструмент для воспитания ребенка в период полового созревания (божественное дитя, великая матерь, мудрый старец, отец, герой, поклонение предкам, сексуально красивая девушка, анима и анимус и т. д.)

Именно архетип придает инстинктам человека «человеческую» форму. К. Г. Юнг определяет инстинкт как «влечение к определенной деятельности». Кроме того, что архетипы унаследованы, рефлексивны по своему характеру, единообразны, регулярны и бессознательны, они также проявляют себя настоятельно и непреодолимо.

Если обнаруживается особая роль архетипов в «очеловечевании» инстинктов человека, мы твердо можем быть уверенными в том, что есть архетипы, осуществляющие функции «очеловечивания» полового инстинкта, так как между культурой и инстинктами посредником выступают архетипы, символы, мифы, религии, искусство, ритуалы. Архетипы древнее культуры и, выступая как регуляторы поведения личности, проявляются на всех уровнях жизнедеятельности человека.

Во-первых, необходимо отметить, что архетипы относятся к содержанию культуры и форме (мифология, религии, искусство, архитектура, эпосы, ритуалы и обычаи народов). Вовторых, богатство, глубина и разнообразие архетипов находятся в зависимости от культуры, мифологии конкретного народа. Этим содержанием является то, что обнаруживается универсальным, типичным, регулярным, постоянно повторяющимся на протяжении многих веков в традициях и культуре данного народа. Единое сообщество отличают по обычаям, традициям, нормам социального поведения, которые сплачивают и созидают идею о единстве этого сообщества (этноса, народа). Все это находится в коллективном бессознательном.

Архетипы свойственны всем. Они находятся где-то в более глубоких слоях коллективного и личного бессознательного.

Традиции и нормы поведения сохраняются и передаются аналогично педагогической психологии через воспитание, культуру, где идет целенаправленная передача знаний, опыта одного поколения другому на основе коллективного бессознательного. Другая важная сторона состоит в том, как это отражается на психологии отдельной личности как представителя этого сообщества, культуры.

В изучении бессознательной сферы, в части архетипов, обнаруживается очень тесная 
связь архетипов с мифами. Как считают исследователи, архетип имеет свою специфическую энергетику: личные комплексы могут породить лишь пагубное пристрастие к чему-либо. Архетипы дают жизнь мифам, религиям и философским концепциям, воздействуюшим на целые народы и разделяющим исторические эпохи. Мы видим комплексы как компенсацию за однобокость или ошибочность рассудочного восприятия [10, с. 76].

Считают, что своим рождением мифы обязаны обычному рассказчику преданий и его снам, а также людям, действующим и живущим вдохновенно [10, с. 87]. По К. Г. Юнгу, в мифах описывается поведение, как архетипы оказываются драматическими описаниями, исполненными персонифицированным языком психических процессов. Имея особое значение, архетипы отражаются в комплексах личности.

На наш взгляд, в психологии архетипов в легендах и мифах народов можно найти категории для формирования личности подрастающего поколения в современных условиях. Однако педагогическая психология еще недостаточно внимания уделяет этой научной основе передачи знаний, опыта через коллективное бессознательное.

Серьезную трудность представляет то, что «каждое из олицетворений подсознания тень, анима, анимус и самость - имеет как светлую, так и темную стороны. ... Они могут дать стимул жизнеутверждающего и творческого роста или же вызвать застой и физическую смерть» [10, с. 213-214].

Перед юношеским возрастом всегда стоит дилемма: либо успешно адаптироваться к взрослой жизни и научиться решать свои личные проблемы, либо замкнуться в своих фантазиях и остаться ребенком. В этом развитие личности во многом зависит от процессов, происходящих в психике, сознании, бессознательном с точки зрения развития (прогрессирующие, регрессирующие процессы).

О воспитании полового инстинкта Л. С. Выготский писал, что есть два возможных пути - подавление инстинкта или его сублимация: «С психологической точки зрения для воспитания инстинктов существует дилемма - или невроз, или сублимация, то есть или вечное столкновение неудовлетворенных влечений с нашим поведением, или превращение неприемлемых влечений в более высокие и сложные формы деятельности» [1, с. 106].

Таким образом, воспитание полового инстинкта может предполагать направленное опосредованно путь культурного развития. Л. С. Выготский рассматривал сублимацию в творчестве и высоких человеческих отношениях (дружба и любовь) как конструктивный путь воспитания полового инстинкта: «...Расхождением инстинкта со средой является дисгармония между фактическим неиспользованием его и тем громадным напряжением, которое он сообщает; и в этом отношении задача воспитания заключается в том, чтобы направить инстинкт не по линии наименьшего сопротивления, не по кратчайшему и легчайшему пути достижения ближайшего удовлетворения, но по долгому, трудному и прекрасному пути» [1, с. 109].

По мнению Л. С. Выготского, половое просвещение обязательно должно реализовываться совместно с воспитанием полового инстинкта, направленного на его сублимацию через творчество: «Юношеский возраст есть возраст естественного творчества, и педагогу надо только выбрать то направление, в котором должна произойти сублимация» [1, с. 111]. Л. С. Выготский писал, что «вторым источником сублимации, не менее богатым, чем личное творчество, могут служить социальные отношения, которые также являются своего рода естественными каналами, по которым направляется сублимированный половой инстинкт. Дружба и товарищество, глубокие привязанности и душевные связи, которые соединяют юношей в эту пору, не имеют ничего подобного себе ни в каком другом периоде 
человеческой жизни. Такой дружбы, как юношеская, не знает никакой другой человеческий возраст» [1, с. 111].

Таким образом, в качестве основных средств полового воспитания Л.С. Выготский видел создание «такой систематической обстановки работы, которая бы соответствовала жизненным интересам юноши и представляла собой систему хорошо налаженных отводных каналов, могущих вместить в себя и дать правильное направление сублимированной половой энергии. В создании таких каналов и лежит задача полового воспитания, которая должна быть решена таким образом, где-то в стороне от вопросов пола» [1, с. 112].

Л. С. Выготский, подчеркивая значимость социальных условий в рамках воспитания полового инстинкта, считал особо значимым совместное обучение полов, что в его время еще не было распространено в мировом образовательном пространстве. По его мнению, совместное обучение и воспитание полов создает определенные условия для очеловечивания полового инстинкта и вхождения человека в пространство культуры как представителя пола (привычность раздражителя для его культурной сублимации; отношение с личностью, а не с половым объектом; романтизация отношений с уникальной личностью другого; равная этика половой жизни как для мужчин, так и для женщин; богатая среда для самореализации личности в межполовых и социальных отношениях [1, с. 112-117].

\section{Bblводbl}

К проблеме инстинктов необходимо подходить с позиции методологии, так как понимается психическое, бессознательное, сознание. В проблеме инстинктов важна и актуальна для подростков, юношей и девушек её психологическая сторона.

Половой инстинкт подростков следует рассматривать как феномен бессознательной сферы. В формировании духовной сферы личности подросткового и юношеского возраста особую роль играют фантазии, образы, желания, побуждения, которые могут быть основаны на архетипах и неосознаваемых установках.

Фактором «очеловечивания» «полового инстинкта» является образование архетипов личности, вбирающие в себя фантазии, образы, желания, побуждения подростков, как бессознательным психологическим детерминантом, реализуемых в личном творчестве, в социальных отношениях, дружбе и товариществе, глубоких привязанностях и душевных связях.

В юношеском возрасте творчество - это своего рода сублимация психической энергии, которая предполагает необходимость учитывать взаимосвязь и закономерности взаимодействия, возникающие между бессознательной сферой и сознанием. Психологические детерминанты бессознательной сферы в юношеском возрасте могут обусловливать творчество, креативность, определять его как субъекта в социальной ситуации развития, как идентификацию личности, содействовать формированию личностных качеств, взаимодействию в группе людей, умению достигать поставленных целей.

В подростковом и юношеском возрасте проявляются стремление к свободе, усилия найти смысл, творческая активность, стремление к целостности, любовь, ценность, обращение к духовному, высшему божественному миру и единение с ним, проявляющиеся как признаки архетипа «самость».

\section{Список литературь:}

1. Выготский Л. С. Педагогическая психология. М.: Педагогика, 1991. 480 с.

2. Клюева Н. В. Педагогическая психология. М.: Изд-во ВЛАДОС-ПРЕСС, 2003. 400 с. 
3. Палагина Н. Н. Психология развития и возрастная психология. М.: Московский психолого-социальный институт, 2005. 288 с.

4. Джеймс У. Психология. М. 2018. 616 с.

5. Выготский Л. С. Собрание сочинений: в 6 т. Т. 1. М.: Педагогика, 1982. 488 с.

6. Выготский Л. С. Собрание сочинений: в 6 т. Т. 3. М.: Педагогика, 1983. 368 с.

7. Адыкулов А. А. Индивидуальность и архетип личности «самость» в подростковом и юношеском возрасте // Бюллетень науки и практики. 2019. Т. 5. № 12. С. 372-382. https://doi.org/10.33619/2414-2948/49/45

8. Выготский Л. С. Собрание сочинений: в 6 т. Т. 4. М.: Педагогика, 1984. 432 с.

9. Мелков С. В. Прочтение идеи Л.С. Выготского о врастании в культуру в контексте проблем нового времени // Развитие личности. 2017, №1. С. 76 - 93

10. Юнг К. Г., Франц М.-Л. фон, Хендерсон Дж.Л., Якоби Н., Яффе А. Человек и его символы. М.: Серебряные нити, 1997. 368 с.

\section{References:}

1. Vygotskii, L. S. (1991). Pedagogicheskaya psikhologiya. Moscow, 480. (in Russian).

2. Klyueva, N. V. (2003). Pedagogicheskaya psikhologiya. Moscow, 400. (in Russian).

3. Palagina, N. N. (2005). Psikhologiya razvitiya i vozrastnaya psikhologiya. Moscow, 288. (in Russian).

4. Dzheims, U. (2018). Psikhologiya. Moscow. 616. (in Russian).

5. Vygotskii, L. S. (1982). Sobranie sochinenii: 6(1). Moscow, 488. (in Russian).

6. Vygotskii, L. S. (1983). Sobranie sochinenii: (3). Moscow, 368. (in Russian).

7. Adykulov, A. (2019). Individuality and 'Self' Archetype of Personality in Adolescents and Youths. Bulletin of Science and Practice, 5(12), 372-382. https://doi.org/10.33619/2414-2948/49/45 (in Russian). (in Russian).

8. Vygotskii, L. S. (1984). Sobranie sochinenii: (4). Moscow, 432. (in Russian).

9. Melkov, S. V. (2017). Prochtenie idei L.S. Vygotskogo o vrastanii v kul'turu v kontekste problem novogo vremeni. Razvitie lichnosti. (1). 76-93. (in Russian).

10. Yung, K. G., Frants M.-L. fon, Khenderson Dzh.L., Yakobi N., \& Yaffe A. (1997). Chelovek i ego simvoly. Moscow, 368. (in Russian).

Работа поступила

в редакциию 14.01.2020 2.
Принята к публикацุии 19.01.2020 2.

Ссылка для цичтирования:

Адыкулов А. А. Феномен бессознательного в психике и духовное становление подростков, юношей и девушек // Бюллетень науки и практики. 2020. Т. 6. №2. С. 280-292. https://doi.org/10.33619/2414-2948/51/33

Cite as (APA):

Adykulov, A. (2020). The Phenomenon of Unconscious in the Psyche and the Spiritual Formation of an Adolescent Boys and Girls. Bulletin of Science and Practice, 6(2), 280-292. https://doi.org/10.33619/2414-2948/51/33 (in Russian). 


\title{
TEACHING ENGLISH LANGUAGE IN HETEROGENEOUS CLASSROOMS
}

\author{
CWahedi N., ORCID: 0000-0002-3553-290X, Uzbekistan State University of World Languages, \\ Tashkent, Uzbekistan, nargizawahedi@gmail.com
}

\section{ОБУЧЕНИЕ АНГЛИЙСКОМУ ЯЗЫКУ В ГЕТЕРОГЕННЫХ КЛАССАХ}

\author{
СВахеди Н. Г., ORCID: 0000-0002-3553-290Х, Узбекский государственный университет \\ мировых языков, г. Ташкент, Узбекистан, nargizawahedi@gmail.com
}

Abstract. The article aims to provide a thorough insight into the teaching context of heterogeneous classes in line with identifying their most distinctive features, certain elements that form differences that most often EFL teachers note challenging. Based on needs evaluation it is possible to create a successful learning environment where efficient lesson plan assisted by credible techniques will be united around a single concept of a competent teacher ready to espouse the students who need support.

Аннотащия. Целью данной статьи является подробное описание гетерогенных классов в учебном контексте в соответствии с определением их наиболее отличительных черт, и определенных элементов, образующие различия, которые чаще всего отмечают учителя английского языка. На основе оценки потребностей можно создать успешную учебную среду, в которой эффективный план урока с помощью надежных педагогических техник будет объединен вокруг единого понятия профессионального учителя, готового помочь тем ученикам, которые нуждаются в поддержке.

Keywords: heterogeneous class, multi-level class, EFL, receptive skills, productive skills.

Ключевые слова: гетерогенный класс, многоуровневый класс, английский как иностранный, рецептивные навыки, продуктивные навыки.

The English language has been recognized as a lingua franca in recent years that created a growing demand to become competent in it all over the world. Numerous students flooded the EFL classrooms willing to master the global language, which allows them to access various personal and career opportunities. As a result, nowadays, more and more teachers in the EFL context struggle with time-management, maintaining class discipline and attempting to attend to the heterogeneity of learner needs all at once. A heterogeneous class could be defined as "one that has different kinds of learners in it"[1]. Since students of EFL classrooms more than often have various levels of language proficiency, every class can be considered multilevel to some degree [1]. By nature, all classes should be regarded as heterogeneous on the grounds of the assumption that there does not exist any single-level grouping of students. In reality, in any class all learners are unique since language learners move at different rates, some of them are at ease with receptive skills, such as, listening and understanding written material, the others are good at productive skills, e.g., interpersonal communication. 
It is widely acknowledged that every single student is unique and not identical compared to others. Various factors characterize learners. According to P. Ur, several aspects contribute to the formation of a heterogeneous class, namely, "language knowledge, cultural background, attitude to the language, mother tongue, intelligence, world knowledge, learning experiences, knowledge of other languages..."[1]. In line with the aforementioned features, we can also outline the following factors that strongly influence the learner's language performance, these are mentality, surrounding environment, access to resources, and availability to have a free time to learn. For example, the mentality and cultural background of a learner can seriously affect their perception of the teacher's role and the way they conduct a class. If a learner accustomed to a teacher-centred, traditional method of learning and for the first time, he is placed in a classroom with an instructor who uses primarily student-centred methods, the learner may be discouraged assuming unfamiliar ways of conducting the class as something ineffective and strange. Likewise, Julie Mathews-Aydinli and Regina Van Horne presume that the level of literacy and education in the native language, as well as age and social status, make a huge distinction in heterogeneous classes as well [2].

From the perspective of teaching context, the diversity in student backgrounds results in both advantageous and disadvantageous sides of heterogeneous classes. There are many problematic issues when it comes to teaching large and at the same mixed-level classes. First, the domination of proficient and self-confident students who always tend to answer every single question without giving the turn to their peers, interrupting someone who is already speaking but at a slower pace, pressing at someone who needs a moment for recalling a necessary word, speaking without raising their hand or without waiting their turn. Secondly, the passive behavioral patterns of some beginner learners. There are students reluctant to speak as they are afraid to make mistakes or they think that they are not yet ready to express themselves in the target language due to apparent problems e.g., with pronunciation. Thirdly, lack of flexibility in language course books. In other words, the absence of suitable and multilevel course books those teachers can use universally with a set of optional tasks and adjustable activities. In most cases, tasks prepared by course instructors are easy for the majority of students in class or vice versa, they are rather difficult [3]. Consequently, this situation leads to fading away learners' interest, which successively causes boredom and indifference. Lastly, discipline problems arise as in large, heterogeneous classes teachers feel as they lose their authority.

Nonetheless, multi-level classes are hard to teach and instruct, some positive features contribute to effective teaching of the target language. It is known that a teacher can organize class activities within four modes of student division: whole-class interaction, group work, team project, pair work [2]. Therefore, whilst instructors of relatively small classes are limited to organize different activities that involve larger numbers of participants, teachers of heterogeneous classes can vary different modes and group their students following their needs. Besides, heterogeneous classes are "a much richer pool of human resources" [Ur, 305], and the outcome of such varied interaction will be more interesting, abundant in innovative ideas and new insights that could be used efficiently as content-based interaction.

Another idea is the role of a teacher in heterogeneous classes. As the teacher experiences time limitations to control all the students, the students themselves take a responsibility to learn in cooperation. According to M. Rogers, there are three categories of learners: high-level, at-level, and low-level learners. Above-level students attempt to explain the instructions or the grammar rule to a below-level student. Two at-level students can mutually help each other to work out a solution posed by the instructor. Finally, from the position of a teacher, large, heterogeneous classes are demanding to train, require extra time and preparation; however, they foster teacher's creativity, flexibility, tolerance and resistance to stress [4]. 
In the face of many obvious constraints in heterogeneous classes, it is apparent that these classes need to be taught in a different way than homogeneous ones. Some effective strategies could be employed in the teaching practice of heterogeneous classes. To begin with, needs assessment is of paramount importance. Instructors collect valuable insights about what students expect from the course and what they want to learn. One way is to conduct a one-to-one interview with students or organize a class discussion. The initial needs assessment will help a teacher to determine common topics of interest, shared ideas and general background; whilst regular ongoing needs assessment throughout the course will be beneficial for the teacher to navigate through the course and adjust the material accordingly.

Another notable idea is that from the first class, a teacher should indicate an order of transitions from one task to another and incorporate some rules to manage the class, such as turntaking while speaking. Students learn gradually how to follow class procedures; the more they get accustomed to repetitive patterns, the less time teacher needs to re-explain instructions, and that can eliminate the downtime as the course progresses.

Next, concerning material design, it is a good strategy to select a wide range of topics to introduce to the class, teachers can create various activities based on interesting topics, which provoke interest and defeat boredom.

In order to phase out passive participation teachers can use compulsory plus optional instructions offered by P. Ur. A teacher urges students to do a certain number of exercises and the rest is optional; the supplementary material is for the above-level students who wish to work more, in fact, they are encouraged to do the entire set of exercises. One more variation that could be added is leveling the tasks. One exercise is designed to elicit various output, it can be a limited response task with closed-ended questions but also free output in the form of reflection with open-ended questions. In this activity, low-level learners work with closed-ended questions while at-level and high-level learners engage with open-ended variations. Another option to diversify this strategy is to prepare three variations of one worksheet with different levels of difficulty. All three variations are based on the covered material. Students can independently choose easy, medium or advanced variation. This allows the teacher to observe students' self-evaluation concerning their progress as well. Then, the teacher may use different grouping strategies, e.g., he can place similar-ability students together so that they can counsel with each other, find the correct answer and compare it. This strategy fosters cooperation among students and a positive class climate.

Another forceful strategy on how to gain quick insight into students' grasp of explanation or provided input is to use a technique called "Fist to Five". A teacher asks students to evaluate their understanding of the covered input based on a scale from one to five and show it by raising their hands indicating understanding by fingers. If a student shows five fingers that means he completely understands the covered material, but if he shows a fist that means he is completely lost; two, three, and four fingers correspond with average evaluation of self-perception. By doing so, the teacher can assess general class comprehension and students who require extra clarification. "Fist-to-Five" technique is a two-fold utile; teachers can use it additionally as a means to maintain discipline in a class. When students become noisy and distracted, a teacher raises his/her fist and counts to five, within this timeframe, students fix their attention to the teacher and are ready to engage in a new activity. Furthermore, memorizing students' names and addressing them personally is also a helpful technique to control class management.

Overall, as no learner is similar most language classes are heterogeneous that are challenging to teach and properly manage. Although these classes possess certain negative characteristics, there exist many highly efficient techniques to prevent anticipated negative patterns. The success is guaranteed, when thoroughly pre-planned EFL classes are conducted by competent teachers, with a 
positive class atmosphere where students thrive to absorb meaningful input, along with a favorable attitude toward language learning.

\section{References:}

1. Ur, P. A (1996). Course in Language Teaching: Practice to Theory. Cambridge: Cambridge University Press, 375.

2. Hedge, T. (2000). Teaching and Learning in the Language Classroom. Oxford: Oxford University Press, 464.

3. Mathews-Aydinli, J., \& Van Horne, R. (2019). Promoting the success of multilevel ESL classes: What teachers and administrators can do. Washington, DC: Center for Applied Linguistics, Retrieved November 15.

4. Roberts, M. (2019). Teaching in the multilevel classroom. New York: Pearson Education, 2007. Retrieved December 10.

\section{Список литературы:}

1. Ur P. A Course in Language Teaching: Practice to Theory. Cambridge: Cambridge University Press, 1996. 375 p.

2. Hedge, T. Teaching and Learning in the Language Classroom. Oxford: Oxford University Press, 2000. 464 p.

3. Mathews-Aydinli, J., \& Van Horne, R. Promoting the success of multilevel ESL classes: What teachers and administrators can do. Washington, DC: Center for Applied Linguistics, 2006. Retrieved November 15, 2019.

4. Roberts, M. Teaching in the multilevel classroom. New York: Pearson Education, 2007. Retrieved December 10, 2019.

Работа поступила

в редакцию 14.01.2020 2.
Принята к публикащчии

19.01.2020 2.

Ссылка для цүитирования:

Wahedi N. Teaching English Language in Heterogeneous Classrooms // Бюллетень науки и практики. 2020. Т. 6. №2. С. 293-296. https://doi.org/10.33619/2414-2948/51/34

Cite as (APA):

Wahedi, N. (2020). Teaching English Language in Heterogeneous Classrooms. Bulletin of Science and Practice, 6(2), 293-296. https://doi.org/10.33619/2414-2948/51/34 


\title{
PECULIARITIES OF COMMUNICATIVE APPROACH IN FOREIGN LANGUAGE TEACHING
}

\author{
(CWahedi N., ORCID: 0000-0002-3553-290X, Uzbekistan State University of World Languages, \\ Tashkent, Uzbekistan,nargizawahedi@gmail.com

\section{ОСОБЕННОСТИ КОММУНИКАТИВНОГО ПОДХОДА ПРИ ОБУЧЕНИИ ИНОСТРАННОМУ ЯЗЫКУ}

\author{
СВахеди Н. Г., ORCID: 0000-0002-3553-290Х, Узбекский государственный университет \\ мировых языков, г. Ташкент, Узбекистан,nargizawahedi@gmail.com
}

Abstract. This paper looks briefly at the preconditions that gradually formed communicative language teaching (CLT) as a response to the growing demand and needs of non-native learners of English in many different contexts of learning, then draws a parallel between existing conventional methods of language teaching and novel insights presented by CLT. The constituent parts of Communicative competence are introduced. The negotiation of meaning is considered as the most essential function of the target language that learners are capable to master which allows them to maintain flexibility in a deliberate speech despite the gaps in their language proficiency. Besides, the article discusses the current limitations of CLT bound to several factors such as the lack of language proficiency, rigid curricula, and teachers' misconceptions of CLT.

Аннотащия. В этой статье кратко рассматриваются предпосылки, которые постепенно сформировали коммуникативное обучение языку (CLT) как ответ на растущий спрос и потребности учащихся, изучающих английский язык во многих различных контекстах обучения, также проводится параллель между существующими традиционными методами преподавания и новыми идеями основанными на коммуникативном подходе к изучению языка. Представлены составные части коммуникативной компетенции. Коммуникативная компетенция и умение донести смысловую составляющую считается наиболее важной функцией изучения иностранного языка, которую ученики способны освоить, что позволяет им свободно выражать свои мысли, несмотря на некоторые пробелы во владении языком. Кроме того, в статье обсуждаются текущие ограничения коммуникативного подхода, связанные с несколькими факторами, такими как недостаточный уровень знания языка, жесткие учебные планы и заблуждения касающиеся самой природы коммуникативного подхода в представлениях учителей.

Keywords: communicative approach, communicative competence, communicative language teaching.

Ключевые слова: коммуникативный подход, коммуникативная компетентность, коммуникативное преподавание языка.

The prevalence of non-native speakers of the English language over native speakers has created a huge demand in language teaching methodology. When we observe a long path of language teaching development and witness an abundant number of various paradigm changes in it, it is easy to view that every new approach developed in response to some inevitable limitations and constraints of previous language teaching ideologies. When the Classical method, Grammartranslation method or Audio-lingual method fell out of fashion, in the 1970s, new, innovative approach that has come to be known as Communicative language teaching (CLT) or Communicative Approach appeared. 
Most often, we view language teaching and learning as summative knowledge about analysis of grammar structures, sentence formation, translation of textual information, and comprehension of written material. It is a long-standing tradition to include language learning as a compulsory fundamental part of secondary and high education. Within such academic surroundings, in general, students are capable to read, comprehend complicated texts related to their specific fields, translate them into their native language; they possess a stronghold of grammatical input at all levels of language, such as phonology, morphology, and syntax. As for the language, output students could produce carefully structured accurate strings of sentences, translate texts from L1 (native language) into the target language, discuss a limited range of academic topics strictly related to their domains and within which they have a certain amount of practice. Previous foreign language methods have been limited to these features united around a single general notion of grammatical competence. English teachers conducted classes using teacher-centered, Presentation-Practice-Production mode. In the Presentation stage, the teacher introduced a new grammatical structure based on supplementary material such as a short text or a dialogue illustrating covered grammar rule. A brief comprehension check of the explained material followed. In the Practice stage, students did drilling exercises to imitate the newly learned structure. In the last stage, Production, students were encouraged to produce independent chunks attempting to use the pattern without any supplementary material.

A neglected area in the field of grammatical competence was fluency development and pragmatic competence. It was proved the case that when learners found themselves in normal, reallife situational context, they failed to produce meaningful output appropriate to spontaneous situations. This phenomenon has been widely observed in parts of the world where English had a status as EFL (English as a Foreign Language) and not as ESL (English as a Second Language), and learned in an artificial surrounding, which means that the only place for learners to practice the newly acquired language elements was their classroom within assigned lesson time. Consequently, lack or absence of exposure to authentic language environment inside and in some locations outside a class called into question the validity of previous methodologies and created preconditions for CLT.

Globalization around the world resulting in extensive immigration flows turned the direction in English language teaching from academically related analytical knowledge about a language to more practically oriented everyday communication in it. In particular, increase in immigration in such locations as USA, The Great Britain, in some parts of Europe urged English teachers, scholars, textbook writers, policy developers recognize the augmenting need to shift attention away from grammatical competence and sophisticated analysis of language to more practical use of the target language in the contemporary society [1, p. 263]. The primary concern of all non-native speakers of English was to learn how to communicate in a foreign language effectively; to understand and decode the received information and to transfer the message through verbal channel meaningfully ensuring that the interlocutor comprehends fully and in turn, provides a response. In other words, CLT has been developed as a response to a growing need of learners who wanted to be able to use a target language in various social contexts. Thus, knowing the rules employed in sentence formation and constructing accurate sentences on a paper did not prove helpful when there appeared a need to be engaged in meaningful communication. This approach prioritized gaining an insight in language functions. Communicative competence, the term with interdisciplinary status, first used in sociolinguistics became a central tenet of CLT. The communicative competence is the ability of language learners to differentiate social situations following their status, level of formality and use with pragmatic skillfulness chunks of language that are appropriate to the chosen context. The aim is to create an immersive teaching environment where learners through guided input and constant 
practice acquire both native-like accuracy and fluency and can adjust their output in different social settings and attain a communicative intent. The most challenging task for a language learner in CLT is to detect pragmatic nuances in language "which native speakers of language often take for granted" [2, p. 18].

In the 1980s, with further development of CLT, Canadian scholars Canale and Swain based on their observations of French students' language acquisition in line with grammatical competence introduced four additional constituents of communicative competence. [3, p. 5]. First, sociolinguistic competence is the capability of understanding general patterns that govern the society, social norms, implicit subtle nuances in social interaction, speech etiquette, cultural influence on social behavior in which language is used. Second, discourse competence is a recognition of different text types; a thorough comprehension of larger units of language, the proficiency to analyze and to decode implicit socio-cultural information within the inner part of a discourse that is only accessible to native speakers of a certain socio-cultural community. Also, discourse competence is the differentiation of coherence and cohesion that provides unity for a text. Coherence introduces logical connection of ideas presented within deeper implicit layers of a text while cohesion serves to link sentences structurally through cohesive devices essentially bridging words, pronouns, and synonyms.

Third, strategic competence represents the ability of a learner to use different communicative strategies to maintain the conversation despite their limitations in the target language; the strategies that assist learners to fulfill their communicative needs, for example, elaborative probing comprehension questions for ensuring successful message transmission, conversation fillers, paraphrases or skillful use of synonyms. Lastly, grammatical competence is the correct and appropriate usage of grammatical patterns in building meaningful communication units. According to S. Savignon, communicative competence progressive and powerful interpersonal phenomenon as it shaped in the communicative process of people who belong to the same linguistic community [Savignon, 270]. Within the scope of communicative competence, the notion of negotiation of meanings has come to be used to refer to the necessity of constant communicative practice during the entire process of foreign language acquisition for developing communicative abilities. Thus, ensuring further enhancement and productivity in foreign language teaching programs and procedures, "grammar-based methodologies such as the P-P-P have given way to functional and skills-based teaching, and accuracy activities such as drill and grammar practice have been replaced by fluency activities based on interactive small-group work'[4, p. 8].

It is possible to summarize the core principles of CLT as follows:

A learner with communicative competence understands that language is a complex phenomenon with several aims and possesses all necessary skills to transfer a verbal message successfully;

A learner can produce different output following the framework and participants; he comprehends the necessity to react appropriately to different contexts such as formal or informal, oral or written, higher versus lower status;

A learner is proficient in differentiating types of texts, knows their peculiar features and can reproduce them, for example, narratives, reports, interviews; he skillfully employs communication strategies for maintaining message transmission [4, p. 3].

CLT has formulated a fundamentally different view of a lesson format as well as the roles of teachers and learners in it. Earlier perceptions of foreign language learning methodology generally relied on behaviorism ideology that suggested mechanical habit formation through constant drilling patterns and teacher controlled output as the primary way to achieve mastery of a target language. In CLT, the entire format of a lesson has undergone a considerable change. Cooperation and 
interaction among learners became central constituents for conducting a class. CLT shifts attention from a traditional teacher-centered model to a learner-centered approach where students do not view a teacher as a model to imitate; instead, they attempt to create meaningful communicative units by experimenting to express themselves in different contextual situations. Teachers perform roles of facilitators, providing constructive feedback on their performance. Negotiation of meaning is of the utmost importance "as the learner and his or her interlocutor arrive at understanding", [4, p. 4]. Previous activities that used to imply strong teacher-controlled learner output that inevitably led to avoidance of errors were substituted by pair, group and teamwork activities that reinforce learners' cooperation, foster mutual communication among learners and create a positive non-judgmental atmosphere for prolonged learner responses.

Although CLT paradigm has revolutionized the existing teaching context and has gained wide popularity among scholars, to the present day, there are some challenges revealed that need further contemplation. The main limitation of CLT, which is often criticized for, is its inefficiency in applying in locations where the English language is studied as EFL, (where learners' opportunities to utilize a target language constrained by absence of English speaking participants away from the class), and not as ESL (where learners can re-explore learned material in natural English speaking environment). Impossibility to practice a target language outside the classroom hinders learners' progress in language acquisition. Thus, many critics conclude that CLT practices are not pertinent enough to be used in EFL context.

Another problem in the applicability of CLT stems from institutional requirements and reasons. It is known that the majority of educational institutions have their own set of policies along with a rigid curriculum to govern language education with preset learning outcomes. As CLT is a content-dependent approach, it should be related to learners' needs finding its reflection in the course curriculum. Ideally, we should tailor specific solutions to specific problems. However, overall, learners' language progression evaluated regularly and academic performance has paramount importance in terms of learners' future high education prospects. Apparently, in this type of institutions teachers place much more emphasis on curriculum content and prioritize to cover materials present in the language-focused curriculum to ensure students pass grammar-based examinations.

Furthermore, several studies suggested that many EFL and ESL teachers claimed that they conduct classes under CLT approach. It is rather paradoxical however, that their detailed accounts on their teaching do not correspond to core principles of CLT [5, 6]. Lack of confidence, personal beliefs, and misconceptions about the communicative approach, no expertise in developing appropriate CLT materials are the limitations that EFL instructors claim to experience most often. On the one hand, concerning teacher performance in the class, it has been argued that many teachers are not proficient enough in strategic and socio-cultural competence; besides, deficiency in oral skills pose a huge challenge to base all class activities around speaking skills. On the other hand, as reported by Deckert, excessive teacher talk is another major hindrance that constantly violates the principles of CLT. In her observation of ESL classes, she found that overall "instructors were speaking anywhere from two to five times more often than all their students combined" [6, p. 14]. Even so, speaking is an important dimension of language learning, we still regard this skill as the most anxiety-causing stressful experience.

Likewise, the absence of teacher training courses where teachers could deepen their theoretical knowledge about the communicative approach, master teaching strategies, enrich their experience adds to the problematic issues of CLT.

In summary, without regard to some constraints for CLT development in a foreign languageteaching context, it has the potential to involve both EFL teachers and learners in shaping 
personally oriented content that in turn, allows creating many opportunities for meaningful language use. Individual language development is encouraged through the negotiation of meaning and the engagement in communicative activities. Besides, EFL teachers opt for professional growth while they re-design the entire class materials to relate them to learners' communicative experiences.

\section{References:}

1. Savignon, S. J. (1991). Communicative Language Teaching: State of the Art. TESOL Quarterly, 25, (2), 261-277.

2. Duff, P. (2014). Communicative Language Teaching. Teaching English as a Second or Foreign Language. Boston: USA, 15-31

3. Canale, M., \& Swain, M. (1980). Theoretical bases of communicative approaches to second language teaching and testing. Applied Linguistics 1 (1), 1-47.

4. Richards, J. C. (2006). Communicative Language Teaching Today. Cambridge: Cambridge University Press, 52.

5. Li, D. (1998). It's always more difficult than you plan and imagine: Teachers' perceived difficulties in introducing the communicative approach in South Korea. TESOL Quarterly, 32(2), 677.

6. Deckert, G. (2004) The Communicative Approach: Addressing Frequent Failure. English Teaching Forum, 42(1). 12-17.

\section{Список литературы:}

1. Savignon S. J. Communicative Language Teaching: State of the Art // TESOL Quarterly, 1991. V. 25, No.2. P. 261-277.

2. Duff P. Communicative Language Teaching. Teaching English as a Second or Foreign Language. Boston: USA, 2014. P. 15-31.

3. Canale M., Swain M. Theoretical bases of communicative approaches to second language teaching and testing. Applied Linguistics. 1980. 1(1). P. 1-47.

4. Richards J. C. Communicative Language Teaching Today. Cambridge: Cambridge University Press, 2006. 52.

5. Li D. It's always more difficult than you plan and imagine: Teachers' perceived difficulties in introducing the communicative approach in South Korea// TESOL Quarterly, 1998. 32(2). P. 677703.

6. Deckert G. The Communicative Approach: Addressing Frequent Failure // English Teaching Forum. 2004. V. 42. Is. 1. P. 12-17.

Работа поступила

в редакичию 14.01.2020 2.
Принята к публикациии 19.01.2020 2.

Ссылка для циттирования:

Wahedi N. Peculiarities of Communicative Approach in Foreign Language Teaching // Бюллетень науки и практики. 2020. Т. 6. №2. С. 297-301. https://doi.org/10.33619/2414$2948 / 51 / 35$

Cite as (APA):

Wahedi, N. (2020). Peculiarities of Communicative Approach in Foreign Language Teaching. Bulletin of Science and Practice, 6(2), 293-301. https://doi.org/10.33619/2414-2948/51/35 


\section{ВНЕКЛАССНОЕ ИЗУЧЕНИЕ ОБРАЗА УЧИТЕЛЯ В РОМАНЕ ЖУНАЯ МАВЛЯНОВА «ЯСНОЕ НЕБО»}

СМузулманов М. У., Школа-лицей №52, г.Оu, Кыргызстан, tuigun_bm@mail.ru (с)аматова А. А., Ошский государственный университет, г. Ои, Кыргызстан (СРаимбердиев 3. С., канд. пед. наук, Ошский государственный университет, г. Ош, Кыргызстан

\section{EXTRACURRICULAR STUDY OF TEACHER IMAGE IN THE NOVEL 'CLEAR SKY' BY ZHUNAI MAVLYANOV \\ CMuzulmanov M., Lyceum school no. 52, Osh, Kyrgyzstan \\ CMamatova A., Osh State University, Osh, Kyrgyzstan \\ CRaimberdieva Z., Ph.D., Osh State University, Osh, Kyrgyzstan}

Аннотащия. В литературе послевоенных лет писателем, который обратился к образу учителя стал Ж. Мавлянов. Он, изучая образ учителя со всех сторон, сумел описать его многогранную деятельность, его место в человеческом обществе, его борьбу, победы и поражения. Темы войны и образования составляют сюжетно-композиционную линию романа и описываются события, развиваемые вокруг данных тем. В романе «Ясное небо» умело и конкретно раскрыт образ простого сельского учителя Сапара, который, несмотря на тяжелую жизнь в годы войны, трудился во имя процветания жизни народа, боролся за счастливое его будущее, трудился с чистой совестью. Сапар отличался трудолюбием, простотой, добротой, от всей души работал, чтобы вносить свою лепту в образование. В статье проанализированы образ учителя, проблемы воспитания и школьной жизни, предложены методические рекомендации по внеклассному изучению романа «Ясное небо» Ж. Мавлянова в 11 классе с применением новых технологий обучения.

Abstract. In the literature of the postwar years, $\mathrm{Zh}$. Mavlyanov became a writer who turned to the image of a teacher. Studying the image of a teacher from all sides, he managed to describe his many-sided activity, his place in human society, his struggle, victories and defeats. Themes of war and education make up the plot-compositional structure of the novel and describe the events developed around these themes. In the novel 'Clear Sky' skillfully and specifically revealed the image of a simple rural teacher Sapar, who, despite the hard life during the war, worked for the prosperity of the life of the people, fought for a happy future, worked with a clear conscience. Sapar was distinguished by diligence, simplicity, kindness, he worked with all his heart to contribute to education. The article analyzes the image of the teacher, problems of upbringing and school life, offers methodological recommendations for the extracurricular study of the novel 'Clear Sky' by Zh. Mavlyanov in 11th grade using new learning technologies.

Ключевые слова: автобиографические произведения, образ учителя, школа, школьная жизнь, воспитание, рассказ, повесть, роман, технологии обучения, прием «место героя», педагогические технологии.

Keywords: autobiographical works, teacher image, school, school life, upbringing, story, story, novel, learning technologies, 'hero's place' technique, pedagogical technologies. 
Ж. Мавлянов перед началом Великой Отечественной войны учился в Джалал-Абадском педагогическом училище, отсюда уехал на фронт, в 1944 г. вернулся, получив ранение и в 1948 г. окончил Джалал-Абадский учительский институт. После чего он работал учителем в школах «Иринжит», имени Горького, «Кызыл-Дыйкан» Караванского (Джанги-Жольского, ныне Аксыйского) района, с 1955 по 1966 год одиннадцать лет напролет работал директором школы-интерната в райцентре. Значит, он дышал «школьным, классным воздухом», знал школьную жизнь от «А» до «Я», в то же время писал очерки, стихи, статьи на тему школы и учителя, вел дневник.

При чтении произведений Ж. Мавлянова читатель едва замечает, что биографические материалы вместе с «запахом» самого автора срослись с описуемыми событиями. Так, герои повести «Учительница русского языка» Мария Павловна и Нурдин, оставляя учительскую работу, уехали на войну...

Мария Павловна - приехав в село, где нет ни одного русского или русскоязычного человека, начинает работать с таким вдохновением и энтузиазмом, как будто уведёт это село в другую планету. В этой школе было порядка 300 учащихся и четырнадцать учителей. Среди них - Нурдин, который «молчалив, неразговорчив, в свободное от уроков время не болтает бесполезно, как другие, а сядет в угол небольшой учительской комнаты с газетой или книгой...» «...Как начала работать Мария в этой школе, характер Нурдина изменился» [1, с. 330]. Это изменение привело к тёплым отношениям между этими двумя учителями. В описание этих отношений местами включаются эпизоды, как учительская жизнь, экскурсия со школьниками, способы обучения, а с уходом Нурдина на фронт школьная жизнь отводится на задний план, а на передний выходит тема любви. Их любовь была такая же, как свои профессии - питали святое чувство друг к другу, почитали её как нечто сокровенное и священное. Развитие событий повести в мелких деталях и жизненных событиях незаметно подводит к тому, что Мария тоже просилась в армию, наконец уехала, прибыла туда, где воевал Нурдин и они погибли на поле боя.

Как и айтматовский Майсалбек, они не достигли главной жизненной цели - стать учителями. В трагической гибели этих учителей виновата война! Но зато жизнь свою отдали за Родину, за победу. Они - победители. В этой победе читатель увидит патриотизм и чистую совесть учителей, которые старались приблизить победу страны в Великой Отечественной войне.

Но в любом случае почти единственным произведением, более глубоко и разносторонне раскрывшим образ учителя, является роман Джуная Мавлянова «Ясное небо», состоящий из двух книг. Первая книга вышла в свет в 1968 г., а вторая через почти четыре года — в 1971 г.

«Ясное небо» - роман, в котором чётко и убедительно раскрыт яркий образ сельского учителя Сапара через изображение тяжелой жизни народа в дни войны, когда все усиленно работали, чтобы преодолеть все препятствия. Сапар, и простой, и скромный сельский учитель, от всей души, честно и добросовестно трудился во благо Родины на трудном пути просвещения, вкладывая свою лепту своей добротой, трудолюбием.

А также в романе раскрыты образы ряда учителей (Сармат, Джолчубай, Ысман), которые понимали ценность и величие учительской профессии, понимали, что она требует высокой ответственности, тактичности, чистоты, переживаний за все, поиска, созидания нового, и в то же время является самой почетной профессией. Они, несмотря на жизненные трудности, обучали и воспитывали детей, прививая им уважительного чувства к ценнейшим богатствам духовности и культуры народа. 
Привлекает читателя ретроспективное мышление главного героя, заключающееся в том, что он представляет все свое прошлое, и оно проходит перед читателем как кинокадры, состоящие из отдельных событий, которые не исправлены, не разукрашены, а преподнесены в черно-белом изображении, как в самой жизни. Основная особенность литературы — в ее ориентированности на человека. Все чувства автора произведения, приводящие его в восторг, все оттенки его восприятия мира запоминаются в особо художественных образах, в переходе к читателю [6]. Нельзя сказать, что Сапар-учитель иделаен во всем, он также ошибается как обыкновенный человек, но постепенно, увидев перипетии жизни, исправляет свои ошибки и поймёт, что жизнь - это борьба. Произведение, изображающее войну и село под её влиянием, войну и её участника - учителя, предстоит перед нами как художественная ценность, изложенная на эпическом полотне.

Вот что пишет литературовед А. Садыков: «Многие материалы романа автобиографического характера. Это хорошо или плохо? Если писатель не может создать типизированный и индивидуализированный образ, переплетая пережитое самим с художественным вымыслом, то считай, что это произведение ни рыба, ни мясо. А Дж. Мавлянов сумел подняться на высоту обобщения, чего мы хотели от автора. События, происходящие в пределах одного района или одного колхоза, он довел до степени художественной типизации, что не может не повлиять на читателей.

В романе «Ясное небо» есть две сюжетные линии: одна из них - военные события, вторая - жизнь учителей в связи с профессией Сапара. Они согласованы друг с другом, очень умело переплетены. Изображая жизнь в тылу, автор уместно вставляет туда военные эпизоды. Таким образом, читатель получает существенную информацию о фронте, читая роман, написанный в основном на тему тыла» [2, с. 43]. Эти параллельный сюжет и параллельные исторические события, дополняют друг друга, попадая в память писателя, сидящего за столом.

Никто не может отрицать, что учитель - это человек, который дарит неизведанной детской душе первые чувства уважения, чистоты, доброты и любви; это человек, который, обучая и воспитывая, побуждает каждого к правильному шагу в жизни, к формированию как человека. Сапар еще в начальных классах ставил перед собой цель - стать учителем, он всей душой чувствовал и понимал, что учитель имеет особое место в жизни, ибо он воспитывает хозяев будущего, является великим созидателем общества.

К профессии учителя впервые возбудил интерес у Сапара его учитель Джолчубай, который всем сердцем давал детям все, что он знал, как будто от него только зависит все то доброе и хорошее, вселяющее надежду. Он изо всех сил старался, чтобы удачно сложилась судьба каждого учащегося.

Когда Сапар пришел в школу-интернат в райцентре, его желание стать учителем еще усилилось благодаря учителям Сармату и Хакиму Музафаровичу. Есть же хорошие люди везде! «... Мы тоже радуемся вместе с детьми. Это и есть отличие учителей от других. Учитель контролирует своих учащихся всю жизнь, хоть они уже давно стали самостоятельными людьми. Радуется их успехам, печалится, раскаивается, когда они претерпевают неудачу...» [3, с. 313-314], — говорит Сармат-агай, любимый учитель Сапара.

Да, в этом и заключается величие учительской профессии. Учитель - это герой, который еще с детства отличался от других собранностью, чувствительностью, сдержанностью, на самом деле он сеет в чистое сердце детей семена доброты и чистоты, вместе с детьми живёт в мире детей.

В свои 25 лет вернулся с войны на костылях, инвалидом (коленная чашечка раздроблена осколками), и, решая посвятить оставшуюся жизнь школе, с начала нового 
учебного года сменил звание «солдат» на звание «агай» — пришел заведующим учебным отделом и учителем кыргызского языка и литературы семилетней школы «Кызыл-Дыйкан», где до войны проработал один год.

Но он не смог найти общий язык с заведующим райОНО Керимовым и известным чиновником Мадылбековым, мелкие ссоры и конфликты постепенно переросли в большое противостояние. Такие же разногласия по поводу учительской профессии были между Сапаром и легкомысленной учительницей Алтынай. Эти конфликты и другие вводятся писателем с целью показа уровня компетентности педагогического коллектива и их влияния на будущее учащихся. Писатель очень тщательно «проверяет» Сапара и в педагогическом процессе, и в ситуациях внутришкольной жизни. Сапар посещает уроки учителей, в т.ч. уроки Алтынай, анализирует ежедневные план-конспекты, оказывает им методическую помощь. Значит, он не только личность, он и учитель-методист, и мастер. Образ учителя, развиваясь в аналитическом плане и в эволюционном русле, герой-учитель перед нашими глазами перерастает в личность, с которого можно брать пример. Это так мотивируется писателем.

«...Во время урока, объясняя новый материал, Сапар вспомнил поле боя. Представил тех молодых джигитов, чьи жизни проглотила война, представил их жён и детей, которые остались вдовами и сиротами. Когда Сапар объявил в коридоре весть о Победе, поперхнувшись слезами, не знал, что ответить на вопрос удивленной Артыкжан, у которой брови и ресницы словно ощетинились: «Мама говорит, что моего отца убили некие немцы. А что теперь?..». Он не хотел сказать, что её отец больше никогда не вернётся. Когда дети выполняли упражнение из книги, Сапар осторожно подошёл к парте, за которой сидела Артыкжан, погладил её по голове и сказал: «Тот немец сам умер теперь!». Ведь учителя люди милосердные... В этом смысле вспоминаются слова великого педагога, Народного учителя Кыргызстана Мамады Байымбетова: «Учительская профессия - профессия чистоты, взаимоотношений, благодеяния и ежедневного испытания перед ребёнком». Следует отметить, что нельзя рассмотреть врознь биографию писателя и его творчество. Естественно, история написания произведения непосредственно рассматривается в неразрывной связи с биографией писателя. Мы хотим сказать, что главный герой романа Сапар является прототипом самого автора. Основой для этого послужит сама биография Джуная Мавлянова: в 1941 г. был назначен учителем Афлатунской неполной средней школы Караванского района, в 1942-1944 годы был участником Великой Отечественной войны, демобилизовался тяжелораненным, после чего работал в неполной средней школе в своем родном селе - сначала завучем, затем - директором. А также ему было присуждено почетное звание «Заслуженный учитель Киргизской ССР» [4, с. 308-310]. Все это подтверждает высказанную мысль.

Произведение отличается богатством души, высокими человеческими качествами героев и изображением их в глубоком переплетении с реальной жизнью. Образ Сапара призывает современное молодое поколение к патриотизму, любви к своей профессии, простоте, человечности и трудолюбию.

Нашего героя Сапара не очень уместно было бы ставить рядом с учителями сегодняшнего дня и сравнивать. Хотя Сапар не был таким интеллектуальным, разносторонне образованным как сегодняшние просвещенцы, он старался выполнить все, что требовала тогдашняя жизнь с помощью имеющихся у него знаний, самое главное, благодаря своим высоким человеческим качествам он сумел управлять и личной, и школьной жизнью. Поэтому он - великий педагог в полном смысле этого слова. Сельские условия жизни сдавили Сапара. Но он чувствовал, что он не только старше всех, но для многих из них 
годится в брата. Он начал глубоко понимать не только преимущества своей профессии, но и огромную ответственность» [5, с. 430-431]. Читатели без особого труда замечают, что Сапар, несмотря на жизненные невзгоды, сумел проявить заботу об учащихся и с гордостью выполнял свои педагогические обязанности.

Учитель, прежде всего, должен быть образованным, знающим, и обязательно должен сочетать это с высокой человечностью, любовью к детям, милосердием.

Посмотрим эпизод, где описывается жалостная судьба одного из первых учителей Ысмана, вернувшегося с госпиталя в сентябре 1945 года. Он получил ранение на глаза, один глаз - протезный, второй - поврежденный, но, несмотря на это, солдат-учитель спешил в школу, чтобы продолжить своё любимое дело - учить детей, сеять разумное, вечное, доброе... Это разве не подвиг Ысмана?! «...Итак, Ысман взял 1-й класс, так как учебники 1го класса были напечатаны сравнително большими шрифтами - педагогический коллектив семилетней школы «Кызыл-Дыйкан» пополнился еще одним учителем-солдатом. Он, видимо, соскучился по детской душе, обнимая сразу четверых-пятерых, будто курица, огараживающая цыплят; собравшимся вокруг него мальчишкам и девчонкам объяснял чтото очень скурпулёзно...». Посредством нескольких подобных эпизодов на должном уровне раскрыт и образ учителя Ысмана. Он не смог быть равнодушным к своей любимой профессии. Его главной целью было обучение и воспитание детей, подрастающее поколение. Несмотря на инвалидность после войны, он с гордостью продолжил это великое дело.

«В нашей профессии больше муки, чем почета. Это надо терпеть. Воспитать человека человеком - нелёгкое дело. Эту жизнь, если захочет, и очищает сам человек, и оскверняет сам человек. Если захочет, на земле все цветёт, если захочет, обливает кровью... Значит, в его руках - и добро, и зло. Наша обязанность, обязанность воспитателей - воспитать очищающих этот мир. Бороться за это. Иначе говоря, бороться за доброе. В этом, сынок, главный долг знания и воспитания. Педагогика испокон веков ставит перед собой именно эту цель. В этом и величие нашей профессии. В этом ее ценность, ее трудность» [5, 359-360], сказал Сармат-агай. Образ Сапара, который взял на себя всю тяжесть тогдашней школьной жизни, вытерпел все ее трудности, находясь в руководящей должности (зам.директора школы по учебной работе, затем - директор школы), нёс ответственность за её судьбу, может послужить примером для сегодняшних учителей, призывая к трудолюбию, человечности, терпеливости.

«Уметь различать вежливость и культурность от подхалимства и несправедливости - в первую очередь, наша, учительская обязанность», - говорит Сапар [5, 310]. Это подтверждает, что он был учителем, который воспитал в себе эти качества - скромность, культурность и вежливость. В своей педагогической деятельности он привлекал внимание всех именно этими качествами (иногда он не соглашался с мнением чиновников из вышестоящих инстанций - это было для него труднее всего), заслужил авторитет и уважение, успешно руководил коллективом (хотя ввиду тогдашних условий были отдельные недостатки). В произведении так и звучит призыв к человечности, вежливости, уважению к личности. Текст романа от начала до конца сопровождают такие великие идеи, как нравственность, дисциплинированность, милосердие, культура поведения, честность.

«Ясное небо» Дж.Мавлянова есть роман, в котором более глубоко и разносторонне раскрыты школьная жизнь и образ учителя, поэтому в нем встречаются термины, выражающие профессиональные действия героев. Но в литературе, когда тот или иной писатель пишет о людях той или иной профессии, должен учитывать, что его произведение читают представители не только данной профессии, поэтому нельзя описывать все ее подробности, иначе произведение превратится в узкопрофессиональную брошюрку. Ж. 
Мавлянов, избегает именно этого, его учителя служат лишь как профессиональный фон романа, главной целью которого является человек и его жизнь, человек и его взаимоотношения. Но в любом случае по исследуемой нами тематике «Ясное небо» считается романом, которому нет равных и по объёму, и по уровню изложения. В то же время в данном произведении автобиографические изложения подтверждают близость героев и описаний к реальной жизни.

При изучении романа «Ясное небо» для учителей можно предложить следующий ход урока, как один из способов развития творческих способностей учащихся.

Цель урока: характеристика героев литературного произведения.

Обоснование заданий: направленность на определение и анализ портрета автора.

Задание, направленное на пробуждение интереса: учащиеся на ватмане или на доске составят список всех героев произведения.

Задания, направленные на усвоение содержания:

Задание 1. Заполните таблицу.

\begin{tabular}{|c|c|c|c|}
\hline Герой & $\begin{array}{c}\text { Качества героя (по } \\
\text { произведению) }\end{array}$ & Действия & Характеристика \\
\hline & & & \\
\hline & & & \\
\hline
\end{tabular}

Задание 2. Заполните таблицу, посвященную героям.

Имя героя

3 слова, характеризующие героя

Любимый предмет героя

Какие имеются достижения у героя?

Чего боится герой?

Жизненная цель героя

2 события, пережитые героем

\section{Родина героя}

Происхождение героя

Задание 3. Согласно правилам приема «Место героя» из класса выбирается ученик для исполнения роли героя. Герою, сидящему в середине классной комнаты, учащиеся задают вопросы по произведению, которые их волнуют. Перед тем, как приступить к выполнению данного задания, учащимся дается время, чтобы записать в тетрадях свои вопросы. Вопросы, заданные герою, можно развивать по нескольким направлениям:

- По ходу сюжета произведения;

- Относительно поднятых проблем;

- Проблемы, связанные с реальной жизнью;

- Личный взгляд героя.

Конец урока. 
Дескриптор оценивания:

\begin{tabular}{|c|c|}
\hline Знает героя & $\checkmark$ \\
\hline Умеет проанализировать героев & $\checkmark$ \\
\hline Умеет задавать героям существенные вопросы & $\checkmark$ \\
\hline
\end{tabular}

Данное задание можно выполнить в парах, в группах, всем классом.

Задание для закрепления.

Учащиеся с высокой успеваемостью могут проанализировать героев произведения с помощью метода «Дерево решений»:

Класс разделяется на 3 или 4 группы. Каждая группа обсуждает вопрос и впишут в свое дерево (лист ватмана), затем группы меняются местами и впишут свои идеи в дерево соседа.

Задай вопрос.

При самостоятельной работе с текстом учащиеся получат задание «Составьте вопрос». Составляя список героев романа «Ясное небо», по желанию выбирают героя и задают вопросы. Например, задают вопросы, начинающиеся со слов «Кто..?», «Когда...?», «Почему...?», «Где...?». Целесообразно огрнаичить время и количество вопросов.

В любом случае, чтобы правильно, грамотно и кратко сформулировать вопрос, ученик хотя бы поверхностно должен пролистать произведение. Но в этом случае ученик быстрее ознакомится с текстом, чем при получении задания «Прочитайте произведение». Подводя итоги, следует отметить самый лучший вопрос и попросить учащихся ответить на него. Этим мы закрепляем изученную тему.

Чем ответ, вычитанный и выученный наизусть из книги, подобный ответ будет наиболее веским.

\section{Список литературь:}

1. Айтматов Ч. Заметки о себе. Автобиография. Том 4. М., 1972, 4-6.

2. Садыков А. Жетилүү сапарында. Адабий сын макалалар. Ф., 1980, 180 б.

3. Мавлянов Ж. Ачык асман. Ф., 1968.

4. Самаганов Ж. Советтик Кыргызстан жазуучулары. Ф., 1976.

5. Мавлянов Ж. Ачык асман. Эки китептен турган роман. Ф., 1971.

6. Бектуров Т. М. Художественная литература как средство формирования у учащихся эмоционально-ценностного отношения к природе // Современные наукоемкие технологии. 2016. № 2-2. С. 294-297.

\section{References:}

1. Aitmatov, Ch. (1972). Zametki o sebe. Avtobiografiya. (4). M., 4-6.

2. Sadykov, A. (1980). ZhetilyY saparynda. Adabii syn makalalar. F. 180.

3. Mavlyanov, Zh. (1968). Achyk asman. F.

4. Samaganov, Zh. (1976). Sovettik Kyrgyzstan zhazuuchulary. F.

5. Mavlyanov, Zh. (1971). Achyk asman. Eki kitepten turgan roman. F. 
6. Bekturov, T. M. (2016). Khudozhestvennaya literatura kak sredstvo formirovaniya u uchashchikhsya emotsional'no-tsennostnogo otnosheniya k prirode. In Sovremennye naukoemkie tekhnologii, (2-2). 294-297.

Работа поступила

в редакичию 14.01.2020 2.
Принята к публикациии 19.01.2020 2.

Ссылка для циитирования:

Музулманов М. У., Маматова А. А., Раимбердиев 3. С. Внеклассное изучение образа учителя в романе Жуная Мавлянова «Ясное небо» // Бюллетень науки и практики. 2020. Т. 6. №2. C. 302-309. https://doi.org/10.33619/2414-2948/51/36

Cite as (APA):

Muzulmanov, M., Mamatova, A., \& Raimberdieva, Z. (2020). Extracurricular Study of Teacher Image in the Novel 'Clear Sky' by Zhunai Mavlyanov. Bulletin of Science and Practice, 6(2), 302-309. https://doi.org/10.33619/2414-2948/51/36 (in Russian). 


\title{
МЕТОДИЧЕСКИЕ ОСОБЕННОСТИ УПРАЖНЕНИЙ ПО ПЕРЕВОДУ
}

(САбдиев К. Р., канд. пед. наук, Ошский государственный университет, 2. Ou, Kblpгblзстан, tuigun_bm@mail.ru

\section{METHODICAL FEATURES OF EXERCISES ON TRANSLATION}

\author{
CAbdiev K., Ph.D., Osh State University, Osh, Kyrgyzstan
}

Аннотаџия. В статье проанализирован характер речевых упражнений, используемых на занятиях по переводу. Дисциплина «Переводческое дело», включенная в учебный план обучения студентов по направлениям «Филологическое образование», «Лингвистика», имеет сложившуюся традицию и методику обучения. Но методика обучения требует сегодня новых подходов и нового осмысления в плане формирования переводческих навыков и компетенций. Проблема перевода является сегодня актуальной в условиях введения полиязычного обучения, так как те или иные условия применения упражнений по переводу требуют своего обоснования с точки зрения формирования у обучающихся тех или иных компетенций. Каждый язык, отражая национальную форму проявления жизни, предполагает усвоение других элементов лингвокультурологии, включая этнопсихологию и менталитет. Именно эти особенности должны найти отражение в заданиях и упражнениях по переводу. Особое место среди упражнений занимают упражнения, направленные на поиски способов передачи значений фразеологических единиц, пословиц и поговорок, а также лексических единиц, отражающих национальный менталитет. Выполнение подобных упражнений требует от студентов знания семантики фразеологизмов, уместность подбора эквивалентов. Следует отметить, что незнание студентами значения отдельных фразеологизмов приводит их к трудностям, заключающимся в подборе слов для буквального перевода.

Abstract. The article analyzes the nature of speech exercises used in translation classes. The discipline Translation Work, which is included in the curriculum for teaching students in the areas of Philological Education, Linguistics, has an established tradition and teaching methodology. But the teaching methodology today requires new approaches and a new understanding in terms of the formation of translation skills and competencies. The problem of translation is relevant today in the context of the introduction of multilingual education, as certain conditions for the use of translation exercises require their justification in terms of the formation of students with certain competencies. Each language, reflecting the national form of manifestation of life, involves the assimilation of other elements of linguoculturology, including ethnopsychology and mentality. It is these features that should be reflected in assignments and translation exercises. A special place among exercises is occupied by exercises aimed at finding ways to convey the meanings of phraseological units, proverbs and sayings, as well as lexical units that reflect the national mentality. Performing such exercises requires students to know the semantics of phraseological units, and the appropriateness of selecting equivalents. It should be noted that students' ignorance of the meaning of individual phraseological units leads them to difficulties in the selection of words for literal translation. 
Ключевые слова: менталитет народа, обучение второму языку, обратный перевод, перевод, человеческий фактор в языке, этнопсихологический аспект.

Keywords: people's mentality, teaching a second language, reverse translation, translation, human factor in the language, ethnopsychological aspect.

Проблема изучения софункционирования человека, языка и культуры является одной из самых актуальных в современном языкознании. Присутствие человеческого фактора в языке выступает ядром, вокруг которого накоплено все, что связывает человека с языком. Язык это среда существования человека, язык и человек находятся в постоянном взаимодействии, т.к. в центре языковой картины мира стоит человек, который считается началом «отсчета всех категориальных координат языка» [5]. Именно с этой точки зрения человек воспринимается как носитель культуры, обладающий совокупностью своеобразных «фоновых знаний» [1] и поведением, что необходимо в коммуникативном процессе.

Каждый язык в своем контексте содержит «антропологический» аспект, который отражает национальную форму проявления жизни. Поэтому познание и усвоение того или иного языка представителями других национальностей обязательно предполагает усвоение других элементов лингвокультурологии, включая этнопсихологию и менталитет. Следовательно, в задачу преподавателя при обучении иностранному языку входит, в первую очередь, обеспечение правильного понимания и продуцирования обучающимися иноязычного высказывания. И здесь немаловажное значение имеет выяснение вопросов общей теории обучения, психологии познания, психологии речи и мышления.

Хотя обучение русскому языку в кыргызской аудитории накопило богатый опыт, но имеются проблемы «этнопсихолингвистического уровня, рассматривающего язык как отображение социокультурной реальности» [4, с. 245]. Это предполагает необходимость изучения целостной картины мира, которая присутствует в культурной традиции как своего народа, так и народа, язык которого изучается, что «...логически подводит к исследованию ментальности, восходящей к бессознательным глубинам психики» [2, с. 44].

При усвоении второго языка специфика языковых единиц изучаемого языка зачастую трудно воспринимается изучающими. Выражая свои мысли средствами другого языка, необходимо осмыслить «себя», «через себя» «чужое сознание» и их отличие. Этот факт следует учитывать также при переводе текста. Перевод имеет важное значение в процессе изучения второго языка. Межъязыковая речевая деятельность основывается именно на переводе, который выступает как одна из форм диалога культур. Дисциплина «Переводческое дело», включенная в учебный план обучения студентов по направлениям «Филологическое образование», «Лингвистика», имеет сложившуюся традицию и методику обучения. Но методика обучения требует сегодня новых подходов и нового осмысления в плане формирования переводческих навыков и компетенций.

Перевод как один из видов речевых упражнений используется в вузовской методике преподавания довольно успешно. Перевод способствует решению основной задачи обучения, заключающейся в овладении студентами умением читать, понимать и воспроизводить тексты на русском языке. Упражнения по переводу основываются на многократных действиях обучающихся, предполагающих выработку навыков двуязычного речевого поведения. Перевод как упражнение строится с учетом двух учебных ситуаций: в первой ситуации упражнения на перевод выполняют студенты, которые владеют как русским, так и кыргызским языками; во второй ситуации упражнения выполняют студенты, слабо владеющие одним из языков. Следовательно, обе ситуации влияют на отбор материала, 
который предлагается студентам для перевода. И это отражается при разработке упражнений и составлении заданий на перевод.

Практические задания по переводу могут быть следующими:

1. За заданное время перевести письменно текст с русского языка на кыргызский. Здесь может быть предложен текст художественного, газетно-публицистического или научнопопулярного стиля. Время на перевод определяется в зависимости от объёма и сложности текста.

2. Перевести письменно текст художественного или научно-популярного стиля с кыргызского языка на русский. В текстах такого типа отсутствует специальная терминология, выходящая за рамки профиля будущей специальности обучающихся.

3. Перевести диалог в нормальном речевом темпе.

4. Перевести на слух монологическую речь с русского языка на кыргызский и с кыргызского языка на русский с интервалом в 6-7 минут.

5. Перевести устно с русского языка на кыргызский напечатанный текст информационного характера или с социально-политическим содержанием.

6. Перевести текст обратно. Данное упражнение представляет собой обратный перевод. Он предполагает перевод с русского языка на кыргызский, а затем снова на русский язык. Такой перевод применяется как метод обучения неродному языку, как метод его самостоятельного изучения (обычно в письменном виде).

Для выполнения указанных видов упражнений необходимо проводится систематическая работа над данным видом речевой деятельности. На каждом занятии следует применять как минимум один вид перевода, что способствует выработке речевых умений и навыков по применению различных способов трансформации. А также задания следующего характера успешно применяются в целях закрепления сформированных умений и навыков:

1. Объяснение значение слова (узкое и широкое значения).

2. Толкование того или иного слова, словосочетания.

3. Подбор синонимов, объяснение их общности и различия.

4. Подбор антонимов.

5. Добавить или опустить слова по смыслу, опираясь на контекст.

6. Объединение или разделение предложений.

7. Изменение порядка слов;

8. Изменение синтаксической структуры предложений;

9. Замена одной части речи другими, не изменяя смысла и т.д.

Как показывает практика преподавания, отбор материала для заданий и упражнений требует соблюдения последовательности и взаимосвязи заданий и упражнений каждого этапа. Сложность заданий растёт поэтапно, что способствует достижению избирательного усвоения знаний и их творческой переработке.

Основным видом упражнений по переводу являются конструктивные упражнения, так как сам процесс перевода предполагает сконструирование студентами своего текста адекватно тексту, предложенному для перевода.

К переводу предъявляются следующие требования:

a) наиболее существенные элементы текста должны быть воспроизведены наиболее точно и однозначно; 
б) допускается исключение или максимальное сокращение элементов текста, имеющих второстепенное значение и содержащих дополнительную информацию;

в) допускается различные варианты перевода элементов текста различными студентами.

Последний пункт важен тем, что после выполнения задания по переводу предоставляется возможность сопоставления различных вариантов перевода и выявляются неприемлемые варианты с доказательством их неправильности.

Особое место среди упражнений занимают упражнения, направленные на поиски способов передачи значений фразеологических единиц, пословиц и поговорок, а также лексических единиц, отражающих национальный менталитет. Выполнение подобных упражнений требует от студентов знания семантики фразеологизмов, уместность подбора эквивалентов. Следует отметить, что незнание студентами значения отдельных фразеологизмов приводит их к трудностям, заключающимся в подборе слов для буквального перевода.

Немаловажное значение при выполнении упражнений по переводу имеет знание грамматического строя и грамматической системы родного и русского языков. В этом случае проблемы перевода связаны со сходством и различием грамматических систем языков. Например:

а) при переводе на кыргызский язык с русского трудность для студентов представляют категория рода; согласование в роде, числе и падеже; разряды существительных, имеющих форму только одного числа; категория вида глагола; пре,-пост- и интерпозиции придаточных предложений;

б) при переводе с кыргызского на русский язык трудность вызывают: залоговые значения глагола; агглютинирующий способ образования форм слов; порядок слов в предложении; некоторые супплетивные формы слов.

Например, в русском языке при помощи суффиксов -онок/ёнок образуются названия детенышей животных: медведь - медвежонок, утка- утёнок, волк - волчонок и др. В кыргызском языке для выражения данного значения служат супплетивные формообразования: карышкыр (кырг. волк) - бөлтүрүк (волчонок), түлкү (кырг. лиса) бачики (лисёнок), төө (кырг.верблюд) - бото, тайлак (верблюжонок). При переводе подобных слов и выражений необходимо опираться на знания по лексике и фразеологии.

С учетом коммуникативного аспекта обучения русскому языку все упражнения по переводу можно разделить на следующие виды:

1. Предтекстовые упражнения. Эти упражнения включают задания, направленные на работу со словами и выражениями, которые предполагают необходимость исторических, культурологических, психологических, ментальных, географических и т.д. комментариев.

2. Притекстовые упражнения - это задания, проводимые непосредственно в процессе чтения текста. Они связаны с усвоением лексико-грамматических особенностей текста.

3. Послетекстовые упражнения охватывают задания, направленные на понимание глубины восприятия прочитанного текста, усвоения содержащейся в нем информации и создания аналогичного собственного текста.

Таким образом, уточнение характера упражнений по переводу способствует решению ряда вопросов и проблем, связанных с определением и пониманием цели перевода, выявлением особенностей переводческой деятельности в различных сферах общения, в том числе социокультурной. 


\section{Список литературь:}

1. Ахматова О. С. Словарь лингвистических терминов. М.: Советская энциклопедия, 1969. $498 \mathrm{c}$.

2. Гуревич П. С. Ментальность как тип культуры // Культурология. Социологический энциклопедический словарь. М. 1996.

3. Зулпукаров К. Введение в русскую казусологию. Бишкек, 2001.

4. Леонтьев А. А. Язык не должен быть «чужим» // Этнопсихолин-гвистические аспекты преподавания иностранных языков. М., 1999.

5. Катермина В. В. Человеческий фактор в языке // Человек. Культура. Образование. 2015. №2(16).

\section{References:}

1. Akhmatova, O. S. (1969). Slovar' lingvisticheskikh terminov. M.: Sovetskaya entsiklopediya, 498. (in Russian).

2. Gurevich, P. S. (1996). Mental'nost' kak tip kul'tury. Kul'turologiya. Sotsiologicheskii entsiklopedicheskii slovar'. M. (in Russian).

3. Zulpukarov, K. (2001). Vvedenie v russkuyu kazusologiyu. Bishkek. (in Russian).

4. Leont'ev, A. A. (1999). Yazyk ne dolzhen byt' chuzhim. In Etnopsikholin-gvisticheskie aspekty prepodavaniya inostrannykh yazykov. M. (in Russian).

5. Katermina, V. V. (2015). Chelovecheskii faktor v yazyke. Chelovek. Kul'tura. Obrazovanie, 2(16). (in Russian).

Работа поступила

в редакииюю 14.01.2020 г.
Принята к публикации

19.01.2020 2.

Ссылка для цчитирования:

Абдиев К. Р. Методические особенности упражнений по переводу // Бюллетень науки и практики. 2020. Т. 6. №2. С. 310-314. https://doi.org/10.33619/2414-2948/51/37

Cite as (APA):

Abdiev, K. (2020). Methodical Features of Exercises on Translation. Bulletin of Science and Practice, 6(2), 310-314. https://doi.org/10.33619/2414-2948/51/37 (in Russian). 


\title{
ИЗ ИСТОРИИ ТЕРМЕЗСКОЙ ЖЕЛЕЗНОДОРОЖНОЙ МАГИСТРАЛИ
}

\author{
(с)Хидиров Х. Д., Термезский государственный университет, г. Термез, Узбекистан
}

\section{FROM THE HISTORY OF THE TERMEZ RAILWAY}

\author{
CHidirov H., Termez State University, Termez, Uzbekistan
}

Аннотация. В статье на основе исторических источников приводятся сведения о возникновении железнодорожного транспорта в Узбекистане, о строительстве узкоколейки Каган-Термез и экономико-политических интересах в осуществлении строительства дорожного строительства.

Abstract. Based on historical sources, the article provides information on the emergence of railway transport in Uzbekistan, the construction of the Kagan-Termez narrow gauge railway, and economic and political interests in the implementation of road construction.

Ключевые слова: транспортная коммуникация, мировой рынок, народное хозяйство, новые направления, пассажиры, административный центр, техническое снабжение, сельское хозяйство, экономический кризис, государственный план, строительство дорог, искусственные сооружения.

Keywords: transport communication, world market, national economy, new directions, passengers, administrative center, technical supply, agriculture, economic crisis, state plan, road construction, artificial structures.

Железнодорожный транспорт в Сурхандарьинской области занимает свое особое место. Это самое надежное средство перемещения грузов и пассажиров, работающее без перебоев круглый год и вносящее свой неоценимый вклад в социально-экономическое развитие региона. Тем более, что система железнодорожного транспорта Сурхандарьи, сложившаяся к сегодняшнему дню, имеет свою богатую историю, о которой знают не все.

История эта берет начало со времен прихода в эти края войск Российской империи, которое датируется 90-ми годами XIX века. Тогда в соседнем Афганистане уже хозяйничали англичане, и чтобы не допустить их дальнейшего проникновения в Бухарский эмират, 7 августа 1892 года было принято решении об отделении Афганистана. С 15 января 1893 года было принято решение об организации пограничной охраны границы с Афганистаном. 12 декабря 1894 года в кишлак Паттакесар прибыла и разместилась 31 Амударьинская бригада [11, л. 8].

В 1897 году Россия, принимая во внимание важнейшее стратегическое значение города Термеза, принимает решение о постоянной дислокации здесь воинской части. 3 декабря 1885 году было принято решение об организации почтового тракта Самарканд-Термез [10, л. 2425]. В городе, на выкупленных 40 десятинах земли, было начато строительство военных объектов. И не только военных, было положено начало работе по превращению Термеза в 
центр производства тонковолокнистых сортов хлопчатника [8, с. 14]. Как результат, если в 1903 году отсюда было вывезено 17 тысяч пудов хлопка, то уже в 1910-м - 34 тысячи пуда.

Вспоминая те времена, военный инженер А. Г. Ананьев пишет:

1. С военной точки зрения: российские войска, разместившись в Термезе, получат доступ к рабочей силе и достижению жизнеобеспечивающих условий, таких, как самостоятельное производство продовольствия и всего другого, что необходимо для поддержания боеспособности гарнизона.

2. С экономической точки зрения: здесь будет открыт новый рынок по продаже российской продукции, а Россия, в свою очередь, получит возможность закупать по приемлемым ценам более 1 миллиона пудов хлопкового волокна, и перестанет зависеть в этом плане от Америки [11, л. 14].

Именно с перспективой экономического развития региона и оперативного перемещения грузов в оба конца было принято решение о строительстве железной дороги из Бухары в Термез, из Термеза в Гиссар и Куляб. Во-вторых строительство железнодорожной магистрали в Термез было выгодно и эмиру Бухарскому. В Восточной Бухаре, как именовались ранее здешние края, насчитывалось 9 бекств. В них проживало 470 тысяч человек [7, с. 13]. Они занимались в основном земледелием. В год производилось 528 тысяч батманов зерна, 272 тысячи батманов ячменя, 113 тысяч батманов тарика, кукурузы и других культур, а также 152 тысячи батманов риса [2, с. 24]. Край богатый, но отдаленный от крупных рынков, что сдерживало его развитие. Организация транспортного движения открывало новые возможности в деле наращивания и сбыта продукции, завоза нужных материалов и прочего.

С 1887 г в Термезе начала свою работу Амударьинская флотилия. В ее составе было шесть 25-тонных буксиров-пароходов 13 барж, грузоподъемностью от 50 до 150 тонн. Однако, этот транспорт был малоэффективен. К примеру, речной путь из Термеза в Чаржоу составлял 450 км. Летом суда проходили его за семь дней, а зимой - за 11 [6, с. 10]. Каждый пароход расходовал за одни рейс 48 тонн топлива. Его стоимость составляла 2700 рублей, а общий доход за рейс не превышал 2200 рублей [12, с. 24].

Бухарский эмират также имел свою флотилию, состоявшую из более 600 обычных лодок, которые перевозили различные грузы. Передвигались они медленно. К примеру путь из Термеза в Жиликул занимал 12-20 дней летом, а зимой - 15-20 дней. По суше грузы перевозились на верблюдах. Действовало более 7 тысяч караванов, которые доставляли различные грузы по тропам Карши-Гузар, Восточная Бухара - Душанбе. Но уже не отвечало требованиям времени. Строительство железной дороги стало острой необходимостью как для России, так и для Бухарского эмирата [9, с. 113].

В 1902 году царское правительство приняло решение о начале строительства железной дороги Бухара-Термез, Термез-Куляб и Термез-Гиссар. Начало строительства намечалось на 1906 год. Однако, начавшаяся русско-японская война 1905-1906 годов, внесла свои коррективы [1, с. 15].

В 1908 г военное ведомство России приняло решение о начале строительства узкоколейной железной дороги из Бухары до Термеза. Было решено, что с учетом роста английского влияния в Центральной Азии и ее намерениями расширить свои здешние владения, правительство России с согласия бухарского эмира Абдулахадхана, рассчитывало построить дорогу без привлечения средств эмира, а за счет частных российских инвестиций. Это решение было утверждено на заседании правительства России под председательством премьер-министра П. Столыпина 10 апреля 1910 года [4, с. 5]. 
Но Бухарский эмир, учитывая свою заинтересованность в данном проекте распорядился выделить инженеру А. Н. Ковалевскому 600 десятин земли под железнодорожное полотно и дал свое согласие на выделение 25 \% от требуемой на строительство суммы денег. В 1913 году Ковалевский учредил «Акционерное общество строительства Бухарской железной дороги». Его директором был назначен И. М. Слуцкий, главным инженером - Г. С. Кикодзе. Таким образом, было положено начало строительству железной дороги, общей сметной стоимостью 18 миллионов рублей [3, с. 191].

Но и на этот раз строительство было приостановлено в связи с началом первой мировой войны. Начались перебои в поставках рельсов, шпал, механизмов по строительству тоннелей. В связи с нехваткой людей началось использование первых строительных батальонов. К строительным работам были привлечены помимо местного населения - русские, иранцы, татары, итальянцы, чехи, словаки, немцы, грузины, армяне как из числа завербованных, так и из числа военнопленных. Условия для работы были тяжелые, не хватало питьевой воды, провизии, было очень жарко. Назревали бунты и выражения недовольства. Контингент понемногу сокращался, а работы было непочатый край.

В связи с этим, было решено о более широком привлечении к строительным работам местного населения. Организовать трудовую мобилизацию эмир бухарский поручил местных бекам. Так было дано указание Неъматуллобеку о привлечении к строительным работам каратегинцев. На эти цели ему были выделены средства из управления строительства железной дороги. Но он оказался мошенником и привлек людей под предлогом работы на условиях альтернативной воинской службы. Поочередно 2-3 раза людей заставляли бесплатно работать в ужасающих условиях. Начались болезни, некоторые умирали прямо на рабочем месте. Люди написали жалобу губернатору. Но положение не менялось. Вскоре работу бросили и 300 человек, прибывших на стройку из Пензенской губернии. Только в течение 1915 г работы приостанавливались несколько раз. Вместо организации надлежащих условий для труда, руководство легко расставалось с недовольными и набирало новых работников. Были приглашены, например, люди из Баку и из Ирана. Инженер Кикодзе заключил договора с 2000 иранцев. Но 100 из прибывших первых строителей не проработав и месяца, вернулись назад. А остальные и вовсе отказались ехать сюда [5, с. 209].

Однако, кому то работать нужно было. И тут инженеру Кикодзе пришла в голову очередная идея. Он обратился к генерал-губернатору с просьбой дать разрешение на привлечение к работам заключенных местных тюрем. Согласие было дано и вскоре прибыли заключенные. Из Ташкентский тюрьмы - 36 человек, из Ферганы - 60, из Намангана - 10, из Скобелева - 20, из Самарканда - 100, из Каспия - 256 [7, с. 15]. Но толку от этого контингента было мало. Они работали спустя рукава. Поэтому, как и прежде, основная надежда была на местных рабочих, которые несмотря на мошенничество беков с оплатой труда, на лишения и трудности, продолжали работать.

Надо сказать, что строительство железной дороги не могло обходиться без участия специалистов. Особенно это касалось прокладки тоннелей. В этом деле очень помогли итальянские специалисты. В железобетонных работах не было равных австрийцам.

Таким образом, усилиями сотен и тысяч людей различной национальности и вероисповедания, ценой многих человеческих жизней была проложена магистраль, протяженностью 573 версты до Термеза. 14 июля 1916 г состоялась сдача объекта в эксплуатацию [9, с. 217]. Россия получила целый ряд стратегических преимуществ, суливших выход в перспективе к Индийскому океану. А среди текущих приобретений стало техническое, военно-инженерное и социальное обустройство города Термеза с размещением 
здесь воинского гарнизона, открытие новых рынков сбыта для российских товаров, получение надежного и сравнительно дешевого источника сырья для предприятий легкой промышленности в виде хлопкового волокна, возможность развития местной промышленности и сельского хозяйства с перспективой вовлечения всех отраслей в региональную кооперацию.

Однако, далеко не всем этим планам и перспективам суждено было сбыться. Октябрьская революция и последовавшая затем гражданская война внесли свои регрессирующие коррективы. В считанные годы почти вся инфраструктура железной дороги, да и сама дорога, подверглась разрушениям. В частности по приказу Бухарского эмира многое было разрушено и уничтожено на участке дороги от Кагана до станции Самсонова (нынешняя Амударьинская). Политика сделал свое дело.

Но со временем все что было разрушено стали постепенно восстанавливать. Люди поняли, что без железной дороги никакой перспективы и быть не может. К 1923 г основная часть магистрали была частично восстановлена. А в следующем 1924 г и в течение 1925 г на участке Каган-Самсонова-Термез все работы были завершены.

В 1926 г была построена железнодорожная ветка Термез - Жаркурган, протяженностью 33 км. В тот же год была протянута 11-километровая ветка, связавшая станцию Термез с берегом Амударьи, где уже кипела робота по строительству грузового речного порта [5, c. 275].

Одновременно с этим при станции Термез была построена так называемая воинская площадка с прилегающими к ней подъездными путями. Она служила для принятия и разгрузки военных эшелонов созданного к тому времени Туркестанского военного округа. Сюда поступали и отсюда же отправлялись различные грузы. Надо сказать, что строители в те далекие времена работали на совесть. Подъездные пути при воинской площадке прослужили без ремонта до 1994 года.

В 1925 г на станции Термез было четыре ветки. Две для прибывающих и убывающих железнодорожных составов, 1 для стоянки вагонов и четвертая для упомянутой выше воинской площадки. Все подразделения имели модульную телеграфную связь. Поезда имели по 20-25 вагонов с общим весом 450 тонн. Их скорость движения составляла 13 км/час. Дорогу в основном обслуживали российские военные.

В 1925 г Советское государство приняло решение о строительстве железнодорожного пути, протяженностью 248 км до Душанбе. На эти цели было выделено 3 миллиона рублей. Работы велись с 1926 и до 1931 г. Эта дорога позволила связать надежным транспортом многие густонаселенные районы, дала толчок началу качественно новому этапу развития всего региона[5, с. 276].

К 1935 г уже образовалась целая железнодорожная сеть, объединенная в Среднеазиатскую железную дорогу. Она соединила такие города как Ташкент, Ашхабад, Душанбе, Чарджоу, Бухара, Карши, Термез. В большинстве из них были построены вагонные депо, в которых производился текущий ремонт подвижного состава. Свое развитие получила станция Термез, которая превратилась в крупнейший железнодорожный узел. А вскоре и сам регион стал самостоятельной административной единицей - 6 марта 1941 г Советское правительство приняло Постановление об образовании Сурхандарьинской области в составе Республики Узбекистан.

За время, прошедшее со дня обретения независимости, Сурхандарьинский регион значительно преобразился и стал неузнаваем. Претерпело больших изменений и железнодорожное хозяйство. Благодаря взятому курсу на всестороннее реформирование страны и, в частности, развитию транспортных коммуникаций, проложен новый путь через 
горные вершины Ташгузар-Байсун-Кумкурган. Это позволило значительно сократить время и деньги при осуществлении грузопассажирских перевозок, которые ранее осуществлялись через транзитный участок соседнего Туркменистана. Проложен железнодорожный путь и в соседний Афганистан, где никогда доселе не курсировали поезда. Тем самым, положено начало качественно новому этапу торгово-экономического сотрудничества между Узбекистаном и Афганистаном.

По сути Узбекистан стал первым, кто не на словах, а не деле, продемонстрировал всему миру свое стремление к широкой региональной (на первом этапе) интеграции. Впереди - новые задачи в этом важном деле. Недалек тот день, когда железнодорожные пути пересекут весь Афганистан, свяжут воедино все народы Центрально-азиатского региона.

\section{Список литературы:}

1. Аликулов М. К. История развития социалистического города Термеза (1946-1975гг): автореф. дисс. кан. ист. наук. Ташкент, 1979. 15 с.

2. Ахмеджанова 3. К. К истории строительства железных дорог в Средней Азии. Ташкент, 1965. $214 \mathrm{c}$.

3. Маджлисов А. Аграрные отношения в Восточной Бухаре XIX-XX века. ДушанбеАлма-Ата. 1967.337 с.

4. Наше торговое положение в Средней Азии // Московские ведомости. Москва. 1869. №138. C. 5.

5. Турсунов С., Кабулов Э. История Сурхандарьи. Ташкент. 2004. 606 с.

6. Кабулов Э. Место долины Сурхан в торговых сношениях России с восточными странами // Universum: Общественные науки. 2015. С. 10.

7. Kabulov E. History of Termez rail way // Архивариус. 2016. С. 13.

8. Кабулов Э. Развитие хлопководства Сурханской долине // Вопросы науки и образование. 2019. №32. С. 14.

9. Халикова Р. Россия и Бухара: на перекрестке истории. Ташкент. 2005. 240 с.

10. ЦГА РУз,ф. И-2,оп. 1, д. 251, л. 24-25.

11. ЦГА РУз,ф. И-2, оп. 8, д. 277, л. 8; 14.

12. Шмидт Р. Среднеазиатская железная дорога и ее влияние на социальноэкономическую жизнь Туркестанского рая 1880-1914 гг. Ташкент. 1965.

\section{References:}

1. Alikulov, M. K. (1979). Istoriya razvitiya sotsialisticheskogo goroda Termeza (19461975gg). Tashkent. 15. (in Russian).

2. Akhmedzhanova, Z. K. (1965). K istorii stroitel'stva zheleznykh dorog v Srednei Azii. Tashkent. 214. (in Russian).

3. Madzhlisov, A. (1967). Agrarnye otnosheniya v Vostochnoi Bukhare XIX-XX veka. Dushanbe-Alma-Ata. 337. (in Russian).

4. Nashe torgovoe polozhenie v Srednei Azii. Moskovskie vedomosti (1869). Moskva, (138). 5. (in Russian).

5. Tursunov, S., \& Kabulov, E. (2004). Istoriya Surkhandar'i. Tashkent. 606. (in Russian).

6. Kabulov, E. (2015).-Mesto doliny Surkhan v torgovykh snosheniyakh Rossii s vostochnymi stranami. Universum: Obshchestvennye nauki, 10. (in Russian).

7. Kabulov, E. (2016). History of Termez rail way. Arkhivarius, 13. (in Russian).

8. Kabulov, E. (2019). Razvitie khlopkovodstva Surkhanskoi doline. Voprosy nauki $i$ obrazovanie, (32), 14. (in Russian). 
9. Khalikova, R. (2005). Rossiya i Bukhara: na perekrestke istorii. Tashkent. 240. (in Russian).

10. TsGA RUz,f. I-2,op.1, d.251, 1.24-25 .

11. TsGA RUz,f. I-2,op.8, d.277, 1.8; 14.

12. Shmidt, R. (1965). Sredneaziatskaya zheleznaya doroga i ee vliyanie na sotsial'noekonomicheskuyu zhizn' Turkestanskogo raya 1880-1914 gg. Tashkent. (in Russian).

Работа поступила

Принята к публикациии

в редакичию 14.01.2020 г. 19.01.2020 2.

Ссылка для циитирования:

Хидиров Х. Д. Из истории Термезской железнодорожной магистрали // Бюллетень науки и практики. 2020. Т. 6. №2. С. 315-320. https://doi.org/10.33619/2414-2948/51/38

Cite as (APA):

Hidirov, H. (2020). From the History of the Termez Railway. Bulletin of Science and Practice, 6(2), 315-320. https://doi.org/10.33619/2414-2948/51/38 (in Russian). 


\title{
ЭКОНОМИЧЕСКОЕ ПОЛОЖЕНИЕ ЮЖНЫХ ГОРОДОВ УЗБЕКИСТАНА В НАЧАЛЕ ХХ ВЕКА И ПРОЦЕССЫ МИГРАЦИИ
}

\author{
(СТуропова М. T., Термезский государственный университет, г. Термез, Узбекистан
}

\section{THE ECONOMIC SITUATION OF THE SOUTHERN CITIES OF UZBEKISTAN AT THE BEGINNING OF THE TWENTIETH CENTURY AND THE MIGRATION PROCESSES}

\author{
CTuropova M., Termez State University, Termez, Uzbekistan
}

Аннотация. В статье проанализированы демографическое положение на южных территориях Узбекистана в начале XX века, исторические причины возникновения миграционных процессов, факторы природного роста населения, также исследованы территориальное расположение, национальный состав, быт сельского населения.

Abstract. This article analyzes the demographic situation in the southern regions of Uzbekistan in the early XX century, the history of migration processes, the sources and factors of natural population growth. There is also a scientific analysis of the territorial location, national composition, lifestyle of the rural population.

Ключевые слова: демографические процессы, экономическое развитие, этнический состав, исторические этапы, узбеки, список населения, Бухарский эмират, Туркестанский край, национальные интересы, Российское правительство, гражданские права.

Keywords: demographic processes, economic development, ethnic composition, historical stages, Uzbeks, population list, Bukhara emirate, Turkestan region, national interests, Russian government, civil rights.

В начале XX века население Узбекистана множилось двумя путями. Первое, в результате рождаемости, то второе - путём миграции, осуществляющейся за счет переселения населения из других регионов. В Узбекистане рождаемость является основным фактором увеличения населения. Значит для изучения численности населения прежде всего необходимо изучить проблемы рождаемости в начале XX века и факторы, влияющие на них, также подробно надо изучить социально-экономические и историко-географические последствия рождаемости. Статистические данные о всех демографических процессах населения края (рождение, смерть, бракосочетание, расторжение брака и др.) были собраны в начале XX века, а первичные сведения о населении края начались собираться со второй половины XIX века Туркестанским статистическим управлением. На основе собранных сведений Управления в 1872-1879 годы была издана «Статистическая летопись », где были объявлены первые данные о количестве членов каждой семьи [1, с. 37].

Вышеприведенные сведения сами за себя говорят, что «поскольку в тот период имелись ряд факторов увеличения рождаемости, население Узбекистана должно было стремительно увеличиваться и составить значительное количество ». Но статистические данные отражают обратное положение. Если при анализе уровня урбанизации демографических процессов с 1890-1900 годы рождаемость детей на 1000 населения составляла 49,8\%, количество 
умерших (на каждые тысячи человек) было равно 44,8 человек. Естественное увеличение населения Узбекистана составляло 5(49,8-44,8) человек. По иному говоря, рождаемость увеличивалась всего лишь на 5 человек. Этот показатель в России составлял 50, а по Европейской губернии - 14,4 человек. Значит, несмотря на высокую рождаемость, а также из-за увеличения смертности среди населения Узбекистана средняя продолжительность жизни была 32 года, естественное воспроизводство было низкое [2, с. 34].

В процессе исследования были анализированы исторические явления, связанные с миграцией, события были научно сопоставлены и даны разъяснения понятию миграции. Миграция [3, с. 18] (от латинского - migration-переселение) процесс переселения населения с одного места на другое по континентам и странам.

Переселение в Узбекистан осуществлялось поэтапно, в 1903-1917 годы миграционный процесс в определенном смысле усилился. Из-за того, что более 100 тысяч переселенцев во время Столыпинских реформ не были защищены с социально-экономической точки зрения в 1905-1907 гг. были приняты жесткие меры со стороны Российской империи. В результате, в марте месяце 1906 г был разработан специальный Устав по расселению мигрантов, переселившихся в Среднюю Азию. Целью разработки Устава являлась отобрать у коренного населения лишних земель и расселить на эти земли русскоязычное миграционное население. Это привело к тому, что между миграционным и коренным населением в 1910 г усилились конфликты.

В 1912 г из-за голода возросло переселение населения, проживающих вдоль реки Волги в Среднюю Азию. В процессе изучения влияния демографических процессов на уровень урбанизации особо было отмечено, что учитывая ежедневного увеличения потребности в хлопке Советского правительства из соседних областей в Сурханский оазис было переселено большое количество населения. В 1924-1930 годы из Ферганской долины в колхоз «Намуна» Термезского района было переселено 15 узбекских семей, в город Термез 8 русских и 2 семьи еврейской национальности [4].

Из-за тяжелой экономико-политической обстановки к 1918 г в городе Термезе численность населения составляла 1000-1500 человек [5, с. 96].

Начиная с 1920 г в Узбекистане стали строиться заводы и предприятия, города, благодаря которых стали множиться количество населения. В частности, вследствие миграционных процессов быстрыми темпами стали увеличиваться число населения городов Карши, Термез, Денау, Шерабада, Шахрисабза и Гузара, то есть население с 1924 г до 1940 г увеличилось от 258 до 6851 человек.

Отсюда видно население города возросло от 866 до 1,606, а сельское население, от 3392 до 4946 человек [6, с. 36]. Исследования 40-х годов XX века показали увеличение роста населения Узбекистана под влиянием миграционных процессов.

Если в 1928 г городское население в Сурхандарьинской области составляло 64,9 тыс. человек, то к 1930 г их число достигло 244,4 тыс. человек, т. е. за короткий срок оно увеличилось на 179,5 тыс. человек [7, с. 38].

Естественный прирост населения Кашкадарьинской области, то есть историю активного периода миграционного процесса можно разделить на следующие периоды:

Первый период. Строительство железной дороги Бухара-Китаб и Карши-Амударья (1914-1925 гг.)

Второй период. Миграционное положение в Каршинском оазисе в раннем периоде Советского правления (1920-1933 годы).

Третий период. Переселение представителей различных национальностей в годы второй мировой войны. 
Четвёртый период. В целях развития хлопководства в областях переселение десятки тысяч людейиз Сурхандарьинской области в Кашкадарьинскую область в 1925-1940 годы [8, c. 68].

С перераспределением трудовых ресурсов в послевоенные годы из Кашкадарьи в Сурхандарью тоже переселялись семьи. Вчастности , в западные районы Кашкадарьинской области из Каршинского и Камашинского районов было переселено более 5000 тысяч людей [9, с. 11]. Первоначально в 1920-1930 годы в южные области Узбекистана, также в последующие годы после второй мировой войны, особенно в период освоения СурханШерабадской и Каршинской степи и строительства крупныхпромышленных предприятий (Мубараке, Шуртане, Таллимаране) переселялись семьи из Ферганской долины [10, с. 30-31].

Развитие промышленности, освоение новых земель в период господства Советов, стало причиной роста национального состава. В различных архивных документах и источникахтемпы роста населения Кашкадарьи и Сурхандарьи до второй мировой войны в основном характеризовались естественным высоким приростом и влиянием его на национальный состав. Однако в послевоенные годы как по всей территории Республики в этих областях можно наблюдать резкое сокращение темпов роста населения [11, с. 78].

Необходимо отдельно принять во внимание то, что впоследствие политики коллективизации со стороны Советского правительства только из Каршинского, Гузарского, Косонского, Бешкентского и Дехканабадского районов Кашкадарьи жителибыли переселены в южные районы Таджикской ССР, а также в Денауский район Сурхандарьи [12, с. 10].

Кроме того, Кашкадарья считалась областью, которая производила основные сельскохозяйственные продукции народного хозяйства УзССР и к тому же, освоение Каршинской степи, оказало большое влияние на количество населения в области.

Как известно, население Каршинского оазиса проживает в основном в горных и предгорных территориях. Население, расположенное в степной зоне в результате освоения Каршинской степиразмещалось вдоль ирригационных систем. Население области возросло за счет миграциии взаимных связей между республиками Средней Азии, государствами РСФСР, Северного Кавказа и Казахстана [13, с. 35].

Известно, что городское население по отношению сельского считается многонациональным. В 1925-1939 гг большинство узбеков республики проживали в сельской местности. Естественный прирост населения Сурхандарьи привело к увеличению числа населения города. В 1939 г население города составляло 9,3\% из общего числа населения [14, c. 44].

К 40-м годам XX века в результате пробуждения и усиления национальных чувств и других социальных факторов представители различных наций, проживающих в этих областях уехали к себе на родину, после которого наблюдалось постепенное уменьшение в национальном составе южных областей. Заслуживает внимания и то, что в период независимости благодаря внедрения в жизнь демократической национальной политики в Узбекистане особенно в его южных областях, представители различных национальностей проживают в мире, согласии и благополучии.

\section{Список литературы:}

1. Мулляджанов И. Р. Демографическое развитие Узбекской ССР. Т.:1983. С,37.

2. Караханов М. К. Воспроизводство населения и особенности расселения в Уз ССР., Народонаселение и экономика. М:Экономика, 1967. С. 86.

3. Семья и воспитание в условиях независимости. Т: 1994. С.34

4. Мулляджанов И. Р. Население Узбекистана . Т: Узбекистан, 1974. С.18

5. Правда Востока, 1939. 7-июля. 
6. Ж.Мирзо. История Термеза. Т: Шарк, 2001. С. 96

7. Миграция населения // Сб. науч.трудов. Т: ТГУ. 1981. С. 36.

8. Рузиев А. Н. Сурхандарьинская область. Термез: Джайхун. 1996. С. 38.

9. НГА Респ. Уз. 837-ф. 33 список. 5753-дело, 68 с.

10. Янгибоев М. География населения Кашкадарьинской области. Карши. 1980. С. 11.

11. Рахмонов. Перекликающиеся судьбы // Общение. 2004. №4. С. 30-31.

12. Чориев А., Очилов М. Кашкадарьинская область. Т: Узбекистан. 1974. С.78.

13. Янгибоев М. География населения Кашкадарьинской области. Карши:1980, С.10.

14. Хамраев Н., Халиков И. Орошение и освоение Каршинской степи. Т: Узбекистан, 1981. C. 35.

15. Народное хозяйство Сурхандарьинской области в 1980-1989гг. Стат. сборник. Термез: 1989. С. 44.

\section{References:}

1. Mullyadzhanov, I. R. (1983). Demograficheskoe razvitie Uzbekskoi SSR.37.

2. Karakhanov, M. K. (1967). Vosproizvodstvo naseleniya i osobennosti rasseleniya v Uz SSR., Narodonaselenie i ekonomika. Ekonomika, 86.

3. Sem'ya i vospitanie v usloviyakh nezavisimosti (1994). 34.

4. Mullyadzhanov, I. R. (1974). Naselenie Uzbekistana. 18.

5. Pravda Vostoka. (1939). 7 iyulya.

6. Mirzo, Zh. (2001). Istoriya Termeza. 96.

7. Migratsiya naseleniya. Sb. nauch.trudov. (1981). 36.

8. Ruziev, A. N. (1996). Surkhandar'inskaya oblast'. Termez, 38.

9. NGA Resp. Uz..837-f.33-spisok. 5753-delo,68.

10. Yangiboev, M. (1980). Geografiya naseleniya Kashkadar'inskoi oblasti. Karshi. 11.

11. Rakhmonov. (2004). Pereklikayushchiesya sud'by. Obshchenie, (4). 30-31.

12. Choriev, A., \& Ochilov, M. (1974). Kashkadar'inskaya oblast'. Uzbekistan, 78.

13. Yangiboev, M. (1980). Geografiya naseleniya Kashkadar'inskoi oblasti. Karshi. 10.

14. Khamraev, N., \& Khalikov, I. (1981). Oroshenie i osvoenie Karshinskoi stepi. Uzbekistan, 35.

15. Narodnoe khozyaistvo Surkhandar'inskoi oblasti v 1980-1989gg. (1989). Stat. sbornik. Termez. 44.

Работа поступила

в редакциию 14.01.2020 2.
Принята к публикациии

19.01.2020 2.

Ссылка для цุитирования:

Туропова М. Т. Экономическое положение южных городов Узбекистана в начале XX века и процессы миграции // Бюллетень науки и практики. 2020. Т. 6. №2. С. 321-324. https://doi.org/10.33619/2414-2948/51/39

Cite as (APA):

Turopova, M. (2020). The Economic Situation of the Southern Cities of Uzbekistan at the Beginning of the Twentieth Century and the Migration Processes. Bulletin of Science and Practice, 6(2), 321-324. https://doi.org/10.33619/2414-2948/51/39 (in Russian). 


\title{
РЕФОРМЫ СОЦИАЛЬНО-БЫТОВОЙ СФЕРЫ В ГОРОДАХ ЮЖНЫХ ОБЛАСТЕЙ УЗБЕКИСТАНА И ИХ РЕЗУЛЬТАТЫ
}

(СТурсунов А. С., Национальный университет Узбекистана им. Мирзо Улугбека, 2. Термез, Узбекистан

\section{REFORMS OF THE SOCIAL SPHERE IN THE CITIES OF THE SOUTHERN REGIONS OF UZBEKISTAN AND THEIR RESULTS}

\author{
CTursunov A., National University of Uzbekistan named after Mirzo Ulugbek, \\ Termez, Uzbekistan
}

Аннотащия. В статье приводятся сведения об урабанизационных процессах в Узбекистане, эффективности осуществленных реформ, способы решения задач и проблем по оказанию услуг городскому населению, а также анализ исторических основ.

Abstract. The article provides information on the urbanization processes in Uzbekistan, the effectiveness of the reforms, ways to solve problems and problems in providing services to the urban population, as well as an analysis of historical foundations.

Ключевые слова: коммунальная инфраструктура, культурно-нравственный потенциал, программы, спортивные сооружения, фольклорно-этнографический ансамбль, культурные учреждения, книжный фонд, археологические памятники, туристы, урабанизационный процесс, реформы.

Keywords: communal infrastructure, cultural and moral potential, programs, sports facilities, folklore and ethnographic ensemble, cultural institutions, book fund, archaeological sites, tourists, the urbanization process, reforms.

С первых лет независимости и в социальной сфере стали возникать трудности и сложные ситуации. Проблемы в социальных взаимоотношениях становились явными не только в Узбекистане, но и в республиках бывшего Союза. В результате, эти сложные социальные взаимоотношения с первых дней независимости срочно были взяты под контроль, приняты меры по осуществлению соответствующих мероприятий. В прежние времена многие запланированные дела в масштабе бывшего Союза оставались не выполненными. Например, Постановление №275 1990 г Кабинета Министров Республики Узбекистан «Об улучшении обеспечения населения питьевой водой и природным газом» почти не выполнено. Такие примеры в предшествии независимости встречаются много [1, с. 17].

В годы независимости особое внимание было уделено социальной защите населения городов. Ещё с началом реформы в ней были определены основные цели, которые направлены на создание достойных условий для деятельности и жизни человека. С началом перемен заранее были рассмотрены необходимые меры по социальной защите населения. С этой целью широко стали применяться денежные оплаты в виде заработной платы, пенсии, стипендии, компенсации, которые регулярно подвергались изменениям. В 1991 г в городах 
Сурхандарьинской области обеспечение населения природным газом составляло 55,5\%,. Если обеспечение питьевой водой было 50\%, то к 2010 году достигло 75,4\% [2, с. 36].

Обеспечение населения питьевой водой и природным газом, считающаяся проблемой ещё с советского периода была внесена в государственную программу впервые годы независимости. Обеспечение работой трудовых ресурсов, росщие быстрыми темпами в городах Сурхандарьи, Кашкадарьи в 1991-2000 гг, были осуществлены, в основном, за счет открытия новых трудовых мест. Обеспечение работой населения, поддержка малодоходных и многодетных семей, является приоритетной задачей политики государства. В городах Сурхандарьинской и Кашкадарьинской области особое внимание было уделено улучшению благоустройства населения. В этом отношении в годы независимости в городе Карши произошли большие положительные перемены. К февралю 2000 г в городах Карши, Шахрисабз, Гузар, Мубарак, Китаб обеспечение населения питьевой водой составило 60\%, а природным газом $22 \%$ [3, с. 10$]$.

Если исполнение Постановления Кабинета Министров № 275 рассмотреть на примере городов Кашкадарьинской области, то можно заметить, что в течение 1990-1993 годы были проложены и введены в строй более 2000 км газопроводных и 1000176 км водопроводных труб [4, с. 36].

В 1990-1994 гг в строительстве и индустрии города было произведено 1 млн.334 тыс. сборных железобетонных изделий, 4200 млн. штук кирпича, 557 тыс. керамзита. В 1995 г сдан на пользование фонд на 4 млрд.814 млн. сумов, освоены капитальные средства на 7 млрд. 564 млн. сумов, осуществлены строительно-монтажные работы на 4 млрд. 504 млн сумов. В 1995 г построены и сданы на пользование жилые дома на 367 тыс. м² [5, с. 49].

В годы независимости заблаговременно продумав о судьбе подрастающего молодого поколения в городах Кашкадарьи и Сурхандарьи были проделаны большие работы. В 2009 г исходя из потребностей о налаживании службы связи в южных городах, установлении современных средств связи и удовлетворении нужд населения были осуществлены важные практические работы. В 2010 г услуги населению Термеза составили 330,0 млн. сумов, что по отношению 2008 г рост показателя составил 132,9\%. В результате оказания услуг населению 48,8 млн. сумов были использованы для личных нужд, которые по сравнению с 2010 г возросли на 160,5\%. При выполнении видов услуг, которые были осуществлены благодаря “ Сурхандарья Телеком» ДП г. Термеза прибыль составила 241,3 млн. сумов (120,9\%), а прибыль, полученная за оказанную услугу населению составила 40,4 млн. сумов $(169,3 \%)$, а прибыль за оказанную услугу государственным акционерным обществом «Сурхондарёпочтаси» («Сурхандарьинская почта») города Термеза составила 88,7 млн. сумов (182,0\%), а прибыль за услуги населению составила 8,4 млн. сумм $(127,1 \%)[6,34]$.

По сведениям биржи труда города Карши по программе «Бандлик» («Занятость») в 2010 г были созданы новые 35303 рабочих мест, т.е. (100,3\%).

В 2010 г средняя заработная плата рабочих и служащих городов Шахрисабза, Гузара, Мубарака, Китаба составила 15038 сумов, что по сравнению 2008 года рост составляет $128,2 \%$. По отраслям самая высокая средняя зарплата составила в промышленности - 16676 сумов, в финансах, кредитах, страховании и пенсионном обеспечении - 16988 сумов, транспорте - 13964 сумов, геологии и гидрометеорологии - 11729 сумов, в бытовой услуге - 12650 сумов [7, с. 31].

При переходе на рыночную экономику для социальной защиты пенсионеров были, разделены 3 категории и средний размер пенсии стал увеличиваться поэтапно.

Если в Узбекистане в 2003 г средний пенсионный размер составлял 15987 сумов, то к 2006 г приравнивался 37548 сумам [8, с. 142]. 
В канун 2700-летия города Карши воздвигнутый по инициативе Президента в центре стадиона монумент «Эл-юрт таянчи» стал одним из символов заботы о семье. В городах Кашкадарьинской области были разработаны «Территориальная программа по поддержке малообеспеченных семей из источников устойчивых доходов», и программа «Прочность семьи и всесторонняя подготовка молодежи к семейной жизни».

На основе программ 107,8 тыс. малообеспеченным семьям, где детям было до16(18) лет выплачено пособие в размере 18 млрд. 486,5 млн.сумов. 14,9 тыс. малообеспеченным семьям оказана материальная помощь в размере 1 млрд. 154,7 млн. сумов. В целях социальной защиты населения 157 тыс. семьям было израсходовано 31 млрд.884,4 млн. сумов [9, с. 22].

Все это направлено на развитие национальных, духовных ценностей, создание материальной базы.

В 2006 г программой по обеспечению населения, на основе ремесленничества в городах, были определены 28 рабочих мест, благодаря развития этой отрасли в крупных промышленных предприятиях годовой план создания рабочих мест был выполнен на 100\%. В 2006 г были созданы новые 4647 единиц рабочих мест, из которых 3291 мест направлено на создание малого бизнеса и частного предпринимательства, 1228 мест на строительство, реконструкцию новых объектов и расширение деятельности, 128 мест на социальное развитие и расширение рыночной инфраструктуры, новых рабочих мест.

В городе Термезе в течение 2010 г товарооборот в общей розничной цене составил 89149,9 млн. сумов по сравнению 2005 г составил 139,1\%. В том числе по отчету официальных организаций составлял 31223,0 млн. сумов, по сравнению с 2005 г составляет $156,3 \%$ и на душу населения приходится 160,3\%, по действующих ценам населению была оказана торговая услуга на 718,8 тыс. сумов [10, с. 55].

В заключении можно отметить, что в процессе научного анализа процессов урбанизации, благодаря независимости, социально-бытовой облик городов стал меняться коренным образом, что свидетельствует о положительных результатах внедряемой в жизнь новых реформ.

\section{Список литературы:}

1. Государственный архив Сурхандарьинской области. 45 ф., 2 с., 18 док. 17 с.

2. Государственный архив Сурхандарьинской области. 45 фю, 2 сю, 22 док. 36 с.

3. Главное управление статистики Кашкадарьинской области 1991-2005 гг. Карши: 2006. $10 \mathrm{c}$.

4. Текущий архив филиала Кашкадарьинской области архива Президентского аппарата Республики Узбекистан. 829 ф. 4 с. 35 сб. 36 с.

5. Текущий архив филиала Кашкадарьинской области архива Президентского аппарата Республики Узбекистан. 829 ф. 1 с. 88 сб. 49 с.

6. Государственный архив Сурхандарьинской области. 313 сб, 1 с, 19 д, 34 с.

7. Главное управление статистики Кашкадарьинской области 2008-2010 гг. Карши: 2011. $31 \mathrm{c}$.

8. Главное управление статистики Сурхандарьинской области. Термез: 2007. 142 с.

9. Кашкадарьинская область в годы независимости (исходя из брошюры Президента Ислама Каримова «16-летний самостоятельный путь развития Узбекистана» взгляд на экономико-социальное развитие области) / руководитель авторского коллектива А. Эркаев. Т.: Маънавият. 2007. 22 с.

10. Главное управление статистики Сурхандарьинской области. Термез: 2011. 55 с. 
References:

1. Gosudarstvennyi arkhiv Surkhandar'inskoi oblasti. 45-fond, 2-spisok, 18-dokument. 17.

2. Gosudarstvennyi arkhiv Surkhandar'inskoi oblasti. 45-fond, 2-spisok, 22-dokument. 36.

3. Glavnoe upravlenie statistiki Kashkadar'inskoi oblasti 1991-2005gg. Karshi: 2006. 10.

4. Tekushchii arkhiv filiala Kashkadar'inskoi oblasti arkhiva Prezidentskogoapparata Respubliki Uzbekistan829-fond. 4-spisok. 35-sbornik. 36.

5. Tekushchii arkhiv filiala Kashkadar'inskoi oblasti arkhiva Prezidentskogo apparata Respubliki Uzbekistan 829fond. 1-spisok. 88-sbornik. 49.

6. Gosudarstvennyi arkhiv Surkhandar'inskoi oblasti. 313-sbornik, 1-spisok, 19-delo, 34.

7. Glavnoe upravlenie statistiki Kashkadar'inskoi oblasti 2008-2010gg. Karshi: 2011g. 31.

8. Glavnoe upravlenie statistiki Surkhandar'inskoi oblasti. Termez: 2007. 142.

9. Kashkadar'inskaya oblast' v gody nezavisimosti (iskhodya iz broshyury Prezidenta Islama Karimova "16-letnii samostoyatel'nyi put' razvitiya Uzbekistana" vzglyad na ekonomiko-sotsial'noe razvitie oblasti) / rukovoditel' avtorskogo kollektiva A.Erkaev. T.: Ma"naviyat. 2007, 22.

10. Glavnoe upravlenie statistiki Surkhandar'inskoi oblasti. Termez: 2011. 55.

Работа поступила

в редакциию 14.01.2020 г.
Принята к публикацчии

19.01.2020 2.

\section{Ссылка для циитирования:}

Турсунов А. С. Реформы социально-бытовой сферы в городах южных областей Узбекистана и их результаты // Бюллетень науки и практики. 2020. Т. 6. №2. С. 325-328. https://doi.org/10.33619/2414-2948/51/40

Cite as (APA):

Tursunov, A. (2020). Reforms of the Social Sphere in the Cities of the Southern Regions of Uzbekistan and Their Results. Bulletin of Science and Practice, 6(2), 325-328. https://doi.org/10.33619/2414-2948/51/40 (in Russian). 


\title{
ROLE AND PLACE OF TASH-KUMYR SEMICONDUCTOR MATERIALS PLANT IN REGIONAL DEVELOPMENT
}

\author{
CZhumashova G.,Ph.D., Osh State University,Osh, Kyrgyzstan,nilu_56@bk.ru \\ CArstanov S., Ph.D., Osh State University, Osh, Kyrgyzstan
}

\section{РОЛЬ И МЕСТО ТАШ-КУМЫРСКОГО ЗАВОДА ПОЛУПРОВОДНИКОВЫХ МАТЕРИАЛОВ В РЕГИОНАЛЬНОМ РАЗВИТИИ}

\author{
(СЖумашова Г. С., канд. ист. наук., Ошский государственный университет, \\ 2.Ou, Kblpzызстан,nilu_56@bk.ru \\ (САрстанов С. А., канд. ист. наук., Оиский государственный университет, \\ 2. Оu, Кыргызстан
}

Abstract. As for the construction of the Tash-Kumyr semiconductor materials plant, the best mining and metallurgical plant was associated with this plant. Semiconductor materials were used for the development of radio engineering and electrical production, and the construction of this plant in this area was one of the most important priorities of the city's development. In the USSR, the production of semiconductor materials is not very developed. The Soviet government imported a large portion of semiconductor materials from the United States.

Аннотащия. Что касается строительства Таш-Кумырского завода полупроводниковых материалов, то с ним был связан лучший горно-металлургический комбинат. Полупроводниковые материалы использовались для развития радиотехнического и электротехнического производства, и строительство завода в этом районе было одним из важнейших приоритетов развития города. В СССР производство полупроводниковых материалов было не очень развито. Советское правительство импортировало большую часть полупроводниковых материалов из Соединенных Штатов.

Keywords: concept, Kyrgyz Republic, cities, development of small towns, development urban-type settlements, population, territory, economic potential, infrastructure, economics, category.

Ключевые слова: концепция, Кыргызская Республика, города, развитие малых городов, развитие поселков городского типа, население, территория, экономический потенциал, инфраструктура, экономика, категория.

In order to solve this problem, the Politburo of the CPSU Central Committee instructed the Ministry of non-ferrous metallurgy of the USSR to build a powerful plant for the production of semiconductor materials for electrical and radio engineering industries for electric networks. At the same time, as a member of the Politburo of the CPSU Central Committee, Turdaka Usubaliev, after reviewing the minutes of the meeting, after the Minister of non-ferrous metallurgy of the USSR, Pyotr Fadeevich Lomako, made his proposal on the phone, said to Turdak Usubaliev: "no country has asked to build this plant on its territory. We are transferring the development of this event to Kyrgyzstan, and your Republic is responsible for the construction of the plant," he said. After that, 
the Central Committee of the CPSU and the Council Of Ministers of the USSR decided to build a semiconductor materials plant in Tash-Kumyr, Kyrgyz SSR [1, 2].

After reviewing the decision of the Politburo of the CPSU Central Committee on the construction of a semiconductor materials plant in the country, the Minister of non-ferrous metallurgy of the Kyrgyz SSR, L. Kuznetsova, familiarized herself with the decision of the Politburo of the CPSU Central Committee on the construction of a plant for the production of semiconductor materials.Full Name of the Gyz Republic of the proposal and consideration in the Jogorku Kenesh. Lomako's letter, which received a response to this proposal, notes that there are special conditions for launching the plant in Kyrgyzstan [59,315]. As we know, the semiconductor materials plant consumes over 1 million kilowatts / hour of electricity annually. In the Republic, near the city of Tash-Kumyr, on the Naryn river, the Toktogul HPP with a voltage of 1200 thousand kilowatts and three Kurgan HPPs with a voltage of 180 thousand kilowatts operated. Within the Naryn river above these HPPs, with a capacity of 800 thousand kilowatts, the construction of the Kurpsay HPP remains incomplete [3].

In the XI five-year plan, in 1981, the construction of the Tash-Kumyr HPP with a capacity of 450 thousand kilowatts was Started, the total cost of construction is 2.3 million US dollars. the development of the technical and economic foundations of the Kambaratinsk and Shamaldy-Say HPP with a capacity of kilowatts has been started.

The technical project for the construction of the plant was developed and approved in 1982. In 1981, in agreement with the state planning Committee of the USSR, 3 million rubles were provided for the preparatory work for the construction of the plant. For technical and economic construction of the plant in the amount of 342.4 million rubles, for industrial construction-250.4 million US dollars. us $\$ 71$ million has been allocated for the construction of civilian residential buildings. 21 million US dollars for the construction of a production base in the amount of [4] rubles.

In 1981, with the introduction of a semiconductor materials plant, the country allowed the expansion of silicon production at the secondary level with a total capacity of.

The plan XI of the five-year project in 1985 primarily provided for the construction of a semicrystalline silicon plant with a capacity of. The estimated cost of construction in the first place was 183.9 rubles, as well as industrial construction-138 million US dollars. the amount of income tax was 36.3-17 rubles.

In the decision of the main state examination of the state plan of the USSR, expenses included both housing construction objects for developers and the composition of non-production tasks. The plant has a place in the New square and must build in the shortest possible time to put into operation, and in 1981-1985 the estimated cost of construction of houses and the strengthening of social facilities, the total volume cultural buildings amounted to 31 million dollars. funding is provided in the amount of 27.3 rubles.

The Ministry of non-ferrous metallurgy of the USSR and the Central Committee of the Communist party of Kyrgyzstan ask to establish a special order at the semiconductor materials plant in the Kyrgyz SSR, since the plant's products were of special importance in the National economy. When planning and setting of capital were contributed to the Council of Ministers of the USSR of October 20, 1971 No. 2254 [28,17], the distribution of objects of production and non-production purposes, as well as in the destination account total capital loads on building non-production facilities in 1981, attracted 2 million US dollars. sent rubles [5]. 
During this period, the Minister of non-ferrous metallurgy of the SSRF. I. O. Lomako, who, on the basis of order No. 128.3 of February 5, 1981, sent the following directions [3]. The Union center attached great importance to the construction of the plant. The launch and expansion of the plant strengthened the all-Union national economic complex. this production contributed to the socio-economic development of not only the Republic, but also the entire Soviet Union, providing employment and creating thousands of new jobs.

In 1982, with the support of the Ministry of nonferrous metallurgy of the USSR Ministry of construction of the USSR, the State planning Committee of the USSR, Department of state equipment of the USSR on the construction site of the plant were deployed construction work. The Council of Ministers of the USSR and the Central Committee of the CPSU and the Central Committee of the Communist party of Kyrgyzstan sent excerpts from reports and numerous messages during the construction of the plant [1].

The geological conditions for the construction of the Tash-Kumyr semiconductor materials plant were very complex, gravel, sand, and seismological. Under the establishment and during the construction of the plant building, a large area of land is provided for the construction of heavy and defense dams. In 1985 alone, \$ 6 million was raised. 5.9 million cubic meters of bulldozing works were completed and more than 1 million cubic meters were mastered. the volume of production per cubic meter is 10 million US dollars. the soil in tons has been updated.

In 1982-85, 2.5 thousand workers and engineers worked in construction [6]. This year, 25 million US dollars will be raised for the production base. works in rubles at the installation facilities were built annually.

The Ministry of transport of the USSR built railway routes and bridges from the factory to institutions and organizations located in parallel in Kyrgyzstan. Having built not only industrial and production facilities, but also utilities, residential buildings, and cattle farms to provide food for factory workers [3].

A total of $\$ 79.2$ million was raised in 1982-85. capital investments in rubles have been mastered. Chairman of the Council of Ministers of the USSR L. V. Smirnov was the head of defense production issues in the USSR. Leonid Vasilyevich also provided great assistance in solving problems that arose during the construction period [4]. In Tash-Kumyr, with the participation of first Deputy Prime Minister T. Sarpashev, a Requiem rally is held in memory of those killed in the Aksy events of 2002:

"Dear Leonid Vasilevich!!!

As you know, the Ministry of non-ferrous metallurgy of the USSR is building a semiconductor materials plant in the city of Tash-Kumyr of the Kyrgyz SSR, in this connection, a total of 180 thousand rubles of trichloride per year, semi-crystalline silicon, quartz crucibles, singlelayer silicon epitaxial structures will be produced in the object group "100".

According to the national economy plan for 1985, the plant will be put into operation at the 1st place. The company is an energy well, consumes 1.3 billion kilowatt-hours of electricity per year, and also pays attention to creating the technical and economic foundations of the plant. Before putting the plant into operation, it is necessary to start work on the Tash-Kumyrskaya and wind hydroelectric power stations located in the immediate vicinity of the city.

Given the need for a comprehensive solution to the construction of the Tash-Kumyr semiconductor materials plant and the importance of reliable energy supply to the organization, we ask you, the Central Committee of the Communist party of Kyrgyzstan, to approve the list of priority state plans of the USSR and the USSR technical and economic project of the Tash-Kumyr HPP for 1982-83, the list of the wind HPP for 1983 and its renewable construction.”, On July 5, 
1982 (by order no. 65/06), Secretary of the Central Committee of the Kyrgyz Communist party, T. On.Usubaliev sent a letter.

This issue was resolved very quickly, from the position of Deputy Chairman of the state planning Committee of the USSR, Chairman of the Council of Ministers of the USSR N. I. O. dated September 28, 1982, № 26384.

The order of the Council of Ministers of the USSR dated July 15, 1982, No. Vp10932ss and dated August 30, 1982, No. PP-19361 was issued to start construction of electrical equipment and the Tash-Kumyr and Shamaldy-Say hydroelectric power stations of the Tash-Kumyr semiconductor materials plant.

Together with the Ministry of energy of the USSR and the Ministry of non-ferrous metallurgy of the USSR and the state planning Committee of the USSR, in order to provide the Tash-Kumyr plant with semiconductor materials, the construction dates for the Tash-Kumyr and Shamaldy-Say hydroelectric power stations were set [5]. In the first place, the Tash-Kumyr semiconductor materials plant is scheduled to be put into operation in 1985 , and in 1988 , the total capacity will be put into operation.

The plant's electrical equipment must be designed in conjunction with the Central Asian power system and worked out on the balance of the electric load capacity specified at the plant," he wrote. However, this enterprise did not reach its goal until some time after the collapse of the USSR due to the lack of industrial demand. The best experts on the construction of a semiconductor plant metallookandfeel V. V. G. Dubovitskiy, R. S. Deviatiarov and others. I built city structures.Fischer, L. Lamparter, N. Kabashnikov V. Dan'ko, V. Vasiliev, V. V. Doroshenko has made a great contribution.

\section{References:}

1. General provisions of Karimov, D Silicon revival of Tash-Kumyr. In Kyrgyzstan, "silicon valley" has been opened. D.-M.: Eksmo. 07.07.2009. www.24.kg.

2. Sideroff A. M. (1963). Industrial progress of the Kyrgyz. F.: School. 98.

3. Toigonbaev, J. (1982). W the training of qualified personnel of the working class of the Soviet Union: from the history of the formation of the modern working class. Toigonbaev. M .: Nauka, 126.

4. Usubaliev, T. U. (2006).-Kyrgyzstan is my heart T.VI. 2. B.: Sham, 826.

5. Economic basis of local self-government in the Kyrgyz Republic (2009). As amended By the laws of the Kyrgyz REPUBLIC dated February 14, 2008 N 14. Erkin LLP. 213.

6. Central Asia: a private view (2006). Bishkek, 498.

\section{Список литературы:}

1. Каримов Д. Производство поликристаллического кремния в Кыргызстане может получить государственную поддержку со стороны России // ИА «24.kg». 07.07.2009. https://24.kg/archive/ru/cis/52803-2009/07/07/115867.html/

2. Чормонов Б. Ш., Сидоров А. Ф. Промышленный прогресс в Киргизской ССР. Фрунзе: Киргосиздат. 1963.

3. Тойгонбаев Д. Подготовка квалифицированных рабочих кадров в республике. Фрунзе. 1969.

4. Usubaliev T. U. Kyrgyzstan is my heart.. B.: Sham, 2006. 826 c. 
5.Economic basis of local self-government in the Kyrgyz Republic [Text]: as amended By the laws of the Kyrgyz REPUBLIC dated February 14, 2008 N 14. Erkin LLP. 2009. 15 Jul. N213.

6. Central Asia: a private view. Bishkek, 2006. 498 p.

Работа поступила

в редакцию 14.01.2020 г.
Принята к публикациии

19.01.2020 2.

Ссылка для циитирования:

Zhumashova G., Arstanov S. Role and Place of Tash-Kumyr Semiconductor Materials Plant in Regional Development // Бюллетень науки и практики. 2020. Т. 6. №2. С. 329-333. https://doi.org/10.33619/2414-2948/51/41

Cite as (APA):

Zhumashova, G., \& Arstanov, S. (2020). Role and Place of Tash-Kumyr Semiconductor Materials Plant in Regional Development. Bulletin of Science and Practice, 6(2), 329-333. https://doi.org/10.33619/2414-2948/51/41 


\section{МОРФОЛОГИЧЕСКИЕ ДИАЛЕКТИЗМЫ В ПРОИЗВЕДЕНИИ МОЛДО НИЯЗА «САНАТ ДИГАРАСТТАР»}

(САкынбекова А. У., канд. филол. наук, Таласский государственный университет, 2. Талас, Кыргызстан, aimantтu@mail.ru

\section{MORPHOLOGICAL DIALECTISMS IN THE WORK SANAT DIGARASTTAR BY MOLDO NIYAZ}

(CAkynbekova A., Ph.D., Talas State University, Talas, Kyrgyzstan, aimantmu@mail.ru

Аннотация. Молдо Нияз - личность, которая имеет свое неповторимое место в кыргызском языке, литературе, в кыргызской истории и культуре. Он является родоначальником развития формы письменного литературного языка в XIX веке. Его произведение «Санат дигарасттар» имеет огромное значение как один из бесценных документов, который дает возможность размышлять о состоянии языка, почти в предыдущие полтора века и о письменных памятниках кыргызского языка для лингвистической науки в середине XIX века. Художественно-эстетическая ценность, достоинства, вся красота санат песен, оставленных автором, отражена в языковых особенностях. Поэтому для того, чтобы познать письменные приемы древнекыргызского народа, необходимо изучить с разных сторон языковые особенности произведений Молдо Нияза. Опираясь на данное направление, в статье произведен сравнительный анализ грамматической местной языковой особенности языка в произведении акына с современным кыргызским литературным языком. Научные труды исследователей в этом направлении, посвященные диалектам, таких тюркологов как К. К. Юдахин, Б. М. Юнусалиев, И. А. Батманов, Т. К. Ахматов, Ж. Мукамбаев, Г. Бакинова, Э. Абдулдаев, К. Бекназаров, Ш. Жапаров, К. Кырбашев, А. Биялиев, Ж. Жумалиев, Т. Сыдыкова явились научно-теоретической основой нашей работы. Таким образом, изучение, определение таких вопросов как появление кыргызского литературного языка, история, развитие языка - это в наши дни также является одной из основных проблем. При решении данных проблем вопрос исследования произведений акынов, писавших до Октябрьской революции, могут стать основной лингвистической базой. С этой точки зрения сама собой возникает необходимость изучения с разных сторон произведений таких акынов как Молдо Нияз, письменного языка регионального употребления, особенно $\mathrm{XIX}-\mathrm{XX}$ вв. до формирования кыргызского народа как национальности.

Abstract. Moldo Niyaz is a person who has a unique place in the Kyrgyz language, literature, history and culture. He is the ancestor of the development of the form of written literary language in the nineteenth century. His work Sanat Digarasttar is of great importance as one of the priceless documents that makes it possible to reflect on the state of the language, almost in the previous century and a half and on the written monuments of the Kyrgyz language for linguistic science in the middle of the XIX century. Artistic and aesthetic value, dignity, all the beauty of Sanat songs left by the author are reflected in the language features. Therefore, in order to learn the written technologies of the ancient Kyrgyz peoples, it is necessary to study the language features of the works of Moldo Niyaz from different sides. Based on this direction, the article makes a comparative 
analysis of the grammatical local language features of the language in the work of akyn with the modern Kyrgyz literary language. Scientific works of researchers in this direction,devoted to dialects, such turkologists as K. K. Yudakhin, B. M. Yunusaliev, I. A. Batmanov, T. K. Akhmatov, Zh. Mukambaev, G. Bakinova, E. Abduldaev, K. Beknazarov, Sh. Zhaparov, K. Kyrbashev, A. Biyaliev, Zh. Zhumaliev, T. Sydykov were the scientific and theoretical foundations of our work. Thus, the study and definition of such issues as the emergence of the Kyrgyz literary language, history, development of the language-this is today also one of the main problems. When solving these problems, the issue of research of the works of pischuschih akyns before the October revolution can become the main linguistic base. From this point of view, it is necessary to study from different sides the works of akynovkak Moldo Niyaz, the written language of regional use, especially the XIX-XX centuries before the formation of the Kyrgyz people as a nationality.

Ключевые слова: диалект, говор, грамматика, корень, аффикс, падеж, ассимиляция.

Keywords: dialect, dialect, grammar, root, affix, case, assimilation.

В произведении «Санат дигарасттар» акына Молдо Нияза, как родоначальника развития в XIX веке формы письменного литературного языка, корни употребляемых слов мало отличаются от современного кыргызского литературного языка. Но в присоединенных некоторых аффиксах к корням в соответствии с языковыми особенностями говоров ичкилик южно-западного диалекта кыргызского языка наблюдаются нижеследующие грамматические особенности. Например:

1. Характерные говорам ичкилик, присоединенные к словам, оканчивающие на сонорные звуки $[\mathrm{M}],[\mathrm{H}],[\mathrm{H}]$, звук [д] в начале родительного, винительного и творительного падежных аффиксов, уподобляясь переднему носовому гласному, в итоге ассимиляции в некоторых словах звук [д] произносится как звук [н]. Например:

Жан эгемнин бир аты

Жаббар деп Үмүт кылабыз [1 6, с. 26].

Чьчканды көрсө муш деген

Каманны көрсө гуш деген [1 6, с. 37].

Эгиз боюң пас кылар

Этиңди куртка аш кылар.

Желкеннен башын, үзүлсө,

Жер тагинда таш кылар [1 6, с. 26].
Адамнын учар канатьл

Aтты худай жаратты [1 6, с. 28].

Каранугы гөрдө соо кылбайт.

Ар канча кылса арманны $[1$ 6, с. 72].

Давлат кетсе аш кетет,

Ажал жетсе баи кетет.

Азиз таннан жан кетет,

Насибаси үсүлсө [1 6, с. 34].

В данных примерах аффиксы родительного, винительного, творительного падежей своими особыми склонениями отличают говоры ичкилик кыргызского языка от других говоров кыргызского языка. В произведении акына «Санат дигарасттар» названные падежи в литературном языке широко применяются как варианты: катындын, чычканды, санааңдан. Они приравниваясь формам характерным ичкилик говорам кыргызского языка как вышепоказанные подчеркнутые слова каманны, арманны, желкеңнен, таннан, создают двойных морфологических аллофонов вышеуказанных падежных аффиксов. 
2. В произведении акына «Санат дигарасттар» можно встретить явления, где некоторые падежные аффиксы, характерные для юго-западного диалекта кыргызского языка, сокращены или опущены при произношении. Например:

Беш күн өтөр $\underline{\partial и \check{и н} ө \partial \theta(н)}$

Беймаргадавакылсындеп,

Табыпныхудайжараттыл [1 6, с. 27].

Чабандаз(дын) убактын чак кыльли

Үзуп кетсе дак кылыьп,

Канаттуу куштай ойнотуп,

Aтты берип коюптур [1 6, с. 29].

Жилгада тосооржолуцуду,

Жип (ке)байлаарколунуду [1 6, с. 32].
Кыйландыр(н) кыллаар ишиңди

Кьямыгаминдирип [1 6, с. 27].

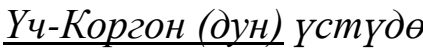

Уйгур менен буйгага

Аустам менен караул

Помду берип коюпдур [1 6, с. 82].

Кант, набат (mbl), бирөөгө

Асалдиберипкоюптур [1 6, с. 28].

В данных примерах в подчеркнутых словах дүйнөдө, кыйлаңуды аффиксы в творительном и родительном падежах переданы в сокращенном виде, а в словах чабандаз(дын), жип(ке) үч-коргон(дун), набат(mы) аффиксы родительного, винительного, творительного падежей опущены при произношении. Б. М. Юнусалиев отмечал, что такие особенности встречаются в речи представителей, подвергающихся под сильным влиянием южного диалекта узбекского языка [2 8, с. 182]. Поэтому такие сокращения или изменения в произношении падежных аффиксов в произведении Молдо Нияза «Санат дигарасттар» можно рассматривать как явление под влиянием узбекского языка. В трудах ученых отмечены, что такие особенности падежных аффиксов характерны и некоторым тюркским языкам. Например, Н. К. Дмитриев отмечал: «В кумыкском и карачаево-балкарском языках в родительном падеже нет отдельных аффиксов. Его функцию выполняет аффикс винительного падежа -ныl. Например, в кумыкском языке: Бу къумукъну тили, бу китапны багасы, китапны окумак» [3 3, с. 55]. По данному факту ученый В. В. Решетов отмечал, что такое явление узбекского языка часто встречается у представителей ферганских и ташкентских говоров, эта особенность распространяется и в других говорах, где в родительном падеже имеется показательный аффикс (-нынг) [4 7, с. 177]. В исследуемом произведении, как уже отмечалось в вышеуказанных примерах, такой языковой факт употребляется в произношении наравне с аффиксами -дан творительного падежа и -нын родительного падежа.

3. В произведении Молдо Нияза «Санат дигарасттар» вместо аффикса -льюк, который указывает принадлежность человека к тому или иному месту, употребляется аффикс $-4 b l$, который обозначает профессию в кыргызском литературном языке. Данный аффикс, постоянно прибавляясь, особенно только географическим названиям как Алай, как и другие прилагательные имеет значение существительного. Например: Өларман жаман алайчbl, Өзудөн башка киши жок [1 6, с. 31]. Бел байлап келип алайчы, Пикир кылды гавирди

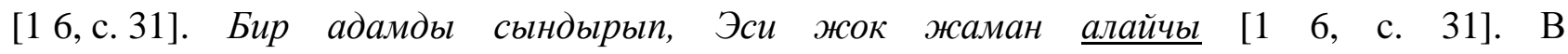
диалектологических трудах ученых отмечено, что особенное употребление аффикса $-4 b l$, который встречается в произведении нельзя рассматривать как факт освоенный с другого языка, потому что применение данного аффикса в вышеуказанной функции не характерно языкам других племен кроме ичкилик. Например, Э. Абдулдаев четко указывал на то, что в тюркских языках (узбекском, уйгурском) аффикс -чьl должен рассматриваться как особенность, развивающаяся во внутреннем процессе языка говора ичкилик, по сравнению с 
употреблением вышеуказанной функции [7 1, с. 77]. Но тем не менее, обозначение свойства принадлежности человека к тому или иному месту при помощи аффикса -чы наблюдается в некоторых говорах северного диалекта кыргызского языка. Точнее говоря, употребление аффикса -чьл в говорах Иссык-Кульских, Нарынских говорах айылчы, сыртчы доказывает расширения географического пространства.

4. Личное местоимение третьего лица ал, как известно, в южных говорах в большинстве случаев применяется как ол. В связи с этим в исследуемом произведении еще одна отмеченная особенность: в современном кыргызском литературном языке как норма принятое личное местоимение третьего лица ал употребляется как в южных говорах ол. Например:

Олуя-Ата, Пишкеги

Орускафиролкетти [1 6, с. 62].

Ононкаттадагыайтсам

ЗорАширдикөргөмүн [1 6, с. 94].

Эгемненонунтилеги,

Эрининмалы аз болсо [1 6, с. 90].

Өлөрудөнзоргобиркылат [1 6, с. 44].
Сыфатыныкиллабыз,

Олкатынмындаөзужок [1 6, с. 90].

Улуту барса угасыц,

Ойтартсаонополордон [1 6, с. 108].

Ондойжаманпалитти

Он күнгөчөтимжүруп

Но такие особенности не последние явления, потому что факт произношения вместо нелабиализованного звука [a] звука [о] известно в древних тюркских письменных памятниках. Например, известный тюрколог Н. Ф. Катанов в труде «Опыт исследования урянхайского языка», где сравнивал 48 языков из тюркских языков, тюркский язык делил на четыре в соответствии с употреблением и звуков «о» или «y» личного местоимения ал, которое выполняло обязанности указательного местоимения и третьего лица:

1) говорящие «о» и «ол»: азербайджанцы, гагаузы, ногайцы, сельджуки, турки, караманы и худабендияры.

2) говорящие «ул»: башкиры, казанские татары, кашкары, яркентцы, мещеряки, сарты, узбеки, тептяры, турины, турфанцы, хамилики, тюменские татары.

3) окающие на «о»- якуты.

4) говорящие «ал» - остальные тюркские языки [5 4, с. 333].

Есть сведения о том, что данный вид личного местоимения раньше и в кыргызском языке употреблялся в виде о // ол, после под влиянием побочных падежей перешел на а // ал [6 5, с. 688]. Таким образом, в названном произведении третье лицо личного местоимения в отличие от кыргызского литературного языка дается в форме о // ол и это доказывает сохранение древних языковых форм кыргызского языка в речи акына.

5. Похожие местные языковые особенности в произведении Молдо Нияза «Санат дигарасттар» наблюдаются и в употреблении указательных местоимений. Например, в кыргызском литературном языке такие местоимения как ошондой, ошондо, ушул, ушу, бул, ошо, ошол жакта, ошолордун в произведении часто встречаются в форме шондой, шондо, шул, шу, бу, шо, шойакта, шолордун. Точнее говоря, такие виды указательных местоимений, характерные для южных говоров (шо // шол; шу //шул; бу) в произведении встречается 41 раз. Из них: шондой 8 раз, шондо 6 раз, шул 6 раз, шу 4 раз, бу 14 раз. Такие виды как шо, шойакта, шолордун встречаются по одному разу. 
Например:

Кара түн менен гам басыл, Карып болдун бу чакта. Абдуллабектен айрыльп, Дүйнөң кетти шо чакта Мунудуу болдун бу чакта Булбулунцнан айрылып Муц̧айгансыц о чакта [1 6, с. 102].
Шондо-иондо деп коём,

Шору курсун шолордун [1 6, с. 91]. Арманың меннен таркабайт, Болбодум шондобашыңда Эгем билет күам шил, Эч көрбөгөн азапты Үмүт кылган дуам щщy [1 6, с. 116].

Безусловно, вышеуказанные формы (шо, шол, шу, шул, шону, шондо, шолордун, шондой) указательных местоимений, имющиеся в названном произведении можно рассматривать как местных языковых особенностей, широко употребляемых в быту, в разговорной речи. В трудах академика Б. М. Юнусалиева отмечены, что в кыргызском литературном языке опущение первого гласного звука указательного местоимения ошо, ошол, ушу, ушул и произношение в виде шо, шол, шу, шул, шону, шондо, шолордун, шондой в большинстве случаев характерны для южных говоров [2 8, с. 201].

6. Одним из важных особенностей, которая отличает говоры ичкилик юго-западного диалекта кыргызского языка от других говоров кыргызского языка наблюдается в местоимениях күдүк. Например, в произведении Молдо Нияза «Санат дигарасттар» встречаются местоимения, которые не были зафиксированы в современном кыргызском литературном языке и северных говорах кыргызского языка: баазги, бир хыл. Они приравниваются к местоимениям в кыргызском литературном языке кээ бир, кай бир. Например:

Бир хыл жерден баш кетти,

Бир нечелер жаш кетти

Бирхылжерден пул кетти

Мусулманжурттунбаарынын

Муунуга зил кетти [1 6, с. 98].
Узун кылыльп худайылм,

Баазилардин колуну [1 6, с. 25].

Э. Абдулдаев, Г. Бакинова, Н. Бейшекеев, исследовавшие местные особенности в языках кыргызов, проживавших в Узбекистане, в своих трудах рассказывали о том, что такие формы күдүк местоимений не могут встречаться в других кыргызских говорах, не связанных с узбеками [8 2, с. 89].

7. Такая же особенность имеется и в обобщенных местоимениях. Например, активно употребляемые в современном кыргызском языке и в северных говорах такие обобщенные местоимения как бүт, бүтүн, бүткүл, баapbl, бардык, жалnы, вместе с ним в том же значении такие местоимения как барча, хамма, касающиеся к говору акына (ичкилик) встречаются в произведении «Санат дигарасттар». Например:

Барчани басып бекиткен,

Кара жердин бооруэкен [1 6, с. 54].

Барча банда тирилип,

Парварузмахшарда [1 6, с. 70].
Баатырлыгың барчага,

Азаматтыгыңааламга [1 6, с. 64].

Көңүлалмаххаммаиштанзыяда,

Аныналдылдамаларпияда [1 6, с. 92]. 
По наблюдениям можно сделать вывод о том, что на основе таких фактов в песнях акына часто употреблялись местные грамматические особенности. Есть полное основание считать, что в произведении «Санат дигарасттар» некоторые из них подчинены в целях сохранения рифм, количества песенных строк (сложение или вычитание в зависимости от условий), некоторые употреблялись в связи с объективными историческими условиями.

Конечно, это тоже может представлять интерес, во-первых, в изучении истории кыргызского языка. Во-вторых, такие факты дают возможность глубокого познания тенденций развития, изменения морфологической структуры языка в хронологическом направлении. Поэтому языковые элементы, характерные для внутреннего говора югозападного диалекта, изучаемого в произведении Молдо Нияза «Санат дигарасттар», полнообразны на научно-теоретической основе, комплексно сочетают тенденции становления, изменения, развития. С этой точки зрения необходимо всестороннее изучение языковых особенностей данного произведения Молдо Нияза.

\section{Список литературы:}

1. Сооронов О. Молдо Нияз «Санат дигарасттар». Бишкек: Учкун, 1993. 175 с.

2. Юнусалиев Б. М. Избранные труды. Фрунзе: Илим, 1985. 201 с.

3. Дмитриев Н. К. Грамматика кумыкского языка. М.; Л.: Изд-во АН СССР, 1940. 205 c.

4. Решетов В. В. Об одном узбекском падеже // Тюркол. сб. М.; Л., 1951. №1. С. 176$177 \mathrm{c}$.

5. Катанов Н. Ф. Опыт исследования урянхайского языка с указанием главнейших родственных отношений его к другим языкам тюркского корня. Казань, 1903. 1539 с.

6. Кудайбергенов С. Местоимения в кыргызском языке. Фрунзе, 1980. 48 с.

7. Абдулдаев Э. Кыргызские говоры: (Общая характеристика). Фрунзе: Илим, 1966. 128 c.

8. Абдулдаев Э., Бакинова Г., Бейшекеев Н. Языковые особенности кыргызов в Узбекистане. Фрунзе: КССР АН, 1962. 152 с.

\section{References:}

1. Sooronov, O. (1993). Moldo Niyaz "Sanat digarasttar”. Bishkek, Uchkun, 175.

2. Yunusaliev, B. M. (1985). Izbrannye trudy. Frunze, Ilim, 201.

3. Dmitriev, N. K. (1940). Grammatika kumykskogo yazyka. Moscow, Leningrad, Izd-vo AN SSSR, 205.

4. Reshetov, V. V. (1951). Ob odnom uzbekskom padezhe. In: Tyurkol. sb. Moscow, Leningrad, (1), 176-177.

5. Katanov, N. F. (1903). Opyt issledovaniya uryankhaiskogo yazyka s ukazaniem glavneishikh rodstvennykh otnoshenii ego k drugim yazykam tyurkskogo kornya. Kazan, 1539.

6. Kudaibergenov, S. (1980). Mestoimeniya v kyrgyzskom yazyke. Frunze, 48.

7. Abduldaev, E. (1966). Kyrgyzskie govory: (Obshchaya kharakteristika). Frunze, Ilim, 128. 
8. Abduldaev, E., Bakinova, G., \& Beishekeev, N. (1962). Yazykovye osobennosti kyrgyzov v Uzbekistane. Frunze, KSSR AN, 152.

Работа поступила

в редакиию 14.08.2019 2.
Принята к публикаџии

19.08.2019 2.

Ссылка для циитирования:

Акынбекова А. У. Морфологические диалектизмы в произведении Молдо Нияза «Санат дигарасттар» // Бюллетень науки и практики. 2020. Т. 6. №2. С. 334-340. https://doi.org/10.33619/2414-2948/51/42

Cite as (APA):

Akynbekova, A. (2020). Morphological Dialectisms in the Work Sanat Digarasttar by Moldo Niyaz. Bulletin of Science and Practice, 6(2), 334-340. https://doi.org/10.33619/2414-2948/51/42 (in Russian). 


\title{
ОБЩНОСТИ СУФФИКСОВ, ОБРАЗУЮЩИХ ОТ ГЛАГОЛОВ ИМЕННЫЕ ЧАСТИ РЕЧИ В КЫРГЫЗСКОМ И ЧАГАТАЙСКОМ ЯЗЫКАХ
}

\author{
(С)Акынбекова А. У., канд. филол. наук, Таласский государственный университет,
} 2. Талас, Кыргызстан, aimantmu@таil.ru

\section{COMMON SUFFIXES THAT FORM NOMINAL PARTS OF SPEECH FROM VERBS IN THE KYRGYZ AND CHAGATAI LANGUAGES}

\author{
(C)Akynbekova A., Ph.D., Talas State University, Talas, Kyrgyzstan, aimantmu@mail.ru
}

Аннотация. В кыргызской лингвистике тексты и переводы письменных памятников были изучены и исследованы языковыми комментариями. Однако, несмотря на то, что в кыргызской лингвистике были высказаны некоторые мнения о языке чагатайской письменности, используемом кыргызами на протяжении XVII-XIX веков и о трудах, написанных в то время, до сих пор исследовательские работы практически отсутствуют. С этой целью в данной статье, опираясь на труды русских и зарубежных ученых, на основе сопоставительно-исторического метода изучены словообразующие суффиксы, производящие от глаголов именные части речи (имя существительное, имя прилагательное, имя числительное и местоимение), чагатайского и современного кыргызского языка. В нем конкретными примерами обозначены единицы их выполняемых функций. В результате, по фактам, приведенным в статье, с течением времени словообразующие суффиксы чагатайского языка были подвержены только фонетическим изменениям, при этом большинство суффиксов до сих пор стабильно сохранены. Это связано с тем, что формы, составляющие систему грамматики по сравнению с лексикой, составляющей словарную систему языка, долгое время остаются неизменными. Поэтому были сделаны выводы о необходимости изучения материалов современного кыргызского языка на основе исторических лингвистических фактов, как специального объекта исследования по вопросам близости, родства с чагатайским языком. Ведь в условиях суверенитета мы должны всесторонне изучить природу нашей письменности, на которую в нашей истории до сих пор не обращали внимания, которая оставалась вне поля нашего зрения и не была изучена в соответствии с требованиями времени. Исследования в этом направлении могут способствовать всестороннему осознанию реальных связей между настоящим и прошлым языка и культуры кыргызского народа, восстановлению его уникальных, неповторимых обычаев и установок.

Abstract. In Kyrgyz linguistics, texts and translations of written monuments have been studied and studied by language commentaries. However, despite the fact that some opinions have been expressed in Kyrgyz linguistics about the Chagatai language used by the Kyrgyz during the XVIIXIX centuries and about the works written at that time, there are still almost no research works. To this end, this article, based on the works of Russian and foreign scientists, on the basis of comparative-historical method, studied word-forming suffixes that produce nominal parts of speech from verbs (noun, adjective, numeral and pronoun), Chagatai and modern Kyrgyz language. In it, specific examples indicate the units of their functions. As a result, according to the facts given in the article, over time, the word-forming suffixes of the Chagatai language were subject only to phonetic 
changes, while most suffixes are still stable. This is due to the fact that the forms that make up the grammar system in comparison with the vocabulary that makes up the dictionary system of the language remain unchanged for a long time. Therefore, conclusions were made about the need to study the materials of the modern Kyrgyz language on the basis of historical linguistic facts, as a special object of research on the issues of proximity, kinship with the Chagatai language. After all, under the conditions of sovereignty, we must thoroughly study the nature of our writing, which in our history has not yet been paid attention to, which has remained out of our field of vision and has not been studied in accordance with the requirements of the time. Research in this direction can contribute to a comprehensive understanding of the real links between the present and the past of the language and culture of the Kyrgyz people, the restoration of its unique, unique customs and attitudes.

Ключевые слова: кыргызские говоры, чагатайский язык, словообразующий суффикс, суффикс образующий от глагола именную часть речи, корень слова.

Keywords: Kyrgyz dialects, Chagatai language, word-forming suffix, suffix forming the nominal part of speech from the verb, the root of the word.

Среди русских и зарубежных ученых-тюркологов всегда большой интерес вызывали вопросы языка и литературы эпохи «Чагатай» (XVIII-XIX вв.). В результате тексты и переводы ряда письменных памятников были изданы с языковыми комментариями. Тем не менее, в кыргызской лингвистике вопрос о чагатайском литературном языке до сих пор не изучен и остается открытым [1-15]. Поэтому в данной статье сравниваются суффиксы, образующие от глаголов именные части речи (имя существительное, имя прилагательное, имя числительное и местоимение), современного кыргызского языка и чагатайского языка, служившего литературным языком в грамотной среде многих тюркоязычных народов, которые на базе своих родных языков до Великой Октябрьской социалистической революции еще не достигли уровня становления литературного языка.

На основании этого на изучаемых объектах были определены следующие обобщения.

Так, суффиксы чагатайского языка -a / -e / -i / -u / -ü, -gupa / -qa / -ge образуют от глаголов существительные и прилагательные: : qoşa «кошо», (вместе), tola «толо, толтура» (полно, полный), yaraşa «жараша, ылайыгына карай» (соответственно), busu «буктурма» (засада), уитrи «жумуру, тоголок» (гладкий, круглый), qisqa «кыска» (коротко), yumurtqa «жумуртка» (яйцо), суффиксы -ğuç / -güç на обоих указанных языках прилагаются к глаголам и образуют существительные, обозначающие орудия труда. Например: на кыргызском языке: аткыч, жазгыч, туткуч, сызгыч, ачкыч, кескич (стрелок, писатель, ручка, линейка, ключ, резак); на чагатайском языке: örgüç «аттын жалын өрүҮ Үчүн колдонулган тарак» (гребень, используемый для плетения конской гривы), sarağuç «чалма, селде » (чалма, тюрбан), suzgüç «чыпка, сүзгүч» (фильтр) diregüс̧ «тирегич» (опора), helpigüç «желпигич» (опахала) и др. [16, c. 275].

А малопроизводный суффикс -ğaq / -qaq, -gek / -kek в кыргызском языке, который образует от глаголов имена существительные, прилагательные соргок (обжора), тайгак (скользко), туткак (ручка), баткак (грязь), сайгак, качкак (беглец) в чагатайском языке образует от глаголов имена существительные. Например: ayğaq / ayğă̆ «көп сүйлөгөн» (много говорящий), batqaq «баткак» (грязь), qaçqaq «качкын» (беженец). Здесь слово ayğaq состоит из двух морфем: $а \check{u}+2 a \kappa$, корень ай в древнетюркском языке нынче обозначает значение слова айm (скажи). К данному слову было присоединено суффикс -гак образовалось 
слово айгак (доносчик, провокатор). Этот суффикс (-гак) в кыргызском языке в таких случаях как, кускак (кто часто сблевывает), туткак (хапуга) означает привычную форму поведения.

Суффиксы -ğun / -qun / -gün / -kün на чагатайском и кыргызском языке образуют существительные, которые были подвержены действию. Например, на кыргызском языке: келгин (перелетныйе птицы), качкын (беженец), туткун (узник), откун (дождь), сүргүн (ссылка); на чагатайском языке: qovğun «куугун / кубалама» (изгнание / гонение)», ötgün «өткүн» (дождь), tutqun «туткун» (пленник), ис̧и «учкун» (искра), yutğun «айлампа, уюлгуган» (водоворот), keskin «кескин» (резко) и др. [16, с. 275].

А в чагатайском языке суффиксы -m, -ým / -im / -um / -üm в словах bilim «билим» (образование), egrim «ийрим» (кружок), ӧlüm «өлүм» (смерть), tutum «көрүнүш, кылыкжорук» (проявление, проступки) прилагаются к глаголам и образуют существительные, обозначающие размер, меру.

Например: tün yarımı «түн жарымы» (полночь), yazım «маңдайга жазган жазуу» (что на роду написано), bir oq atımı «бир ок атымы» (время одной пули), bir süt bışıтıa yavuq «сүттүн бышуу мөөнөтүнө жакын» (время близкое к сроку сварения молока) и т. д. [16, с. 275].

Этот суффикс на кыргызском языке прилагается к глаголам и образует существительные обозначающие абстрактные понятия. Например: Илими балант моллонун, Умараты хат деген [17, с. 119]. ӨзөктүҮ жанга өлүм ак, Жолумду тосуп турар деп, Дува кылам, Афандим [17, с. 135]. Жетимнин мойну бант деген Байларда болот кут деген [17, с. $118]$.

Из нижеследующих примеров можно увидеть, что в кыргызском и чагатайском языках суффиксы -ma / -mе из подобных слов глаголов могут образовывать существительные с абстрактными и конкретными значениями.

Например, на кыргызском языке: баяндама, тапшырма, мүнөздөмө, түймө, сайма (доклад, задание, характеристика, вязание, вышивание) и др., на чагатайском языке: asma «асма, асылып турган» (висячий), basma «басма» (печатный), çekme «чекме» (чеканка), egme «экме» (сеять), qavurma «куурума» (жаркое), suzme «сүзмө» (сюзме), иста «тик жер» (крутое место) и др. [16, с. 275].

В чагатайском языке суффикс -maç / -mес̧, образующий имя существительное от существительного, иногда прилагается к глаголам и встречается в словосочетаниях, обозначающих еду. Например: bulamaç «буламык» (кама), qavurmaç «куурма» (жаркое), tutmaç «майда кесме» (мелкая лапша, используется при изготовлении супа, плова). Данный суффикс существует и в кыргызском языке, но относится к редко встречающимся малопродуктивным видам суффиксов (н: переводчик).

В чагатайском языке суффиксы -nç, -anç, -ýnç / -inç / -unç / -ünç, образующие, слова обозначающие движение можно встретить в таких именах существительных как: ökünç «өкүнүч» (сожаление), qorqunç «коркунуч» (опасность), sevünç «сүйүнүч, кубаныч» (радость), tınç «тынч» (спокойствие), sağýnç «сагыныч» (скука), umanç «үмүт» (надежда), ürkünç «коркунуч, капсалаңдуу, үркүү» (опасность) и т. п. [16, с. 275].

Названные суффиксы в кыргызском языке тоже прилагаются к глаголам и образуют такие же абстрактного значения существительные. Например: кубаныч, жальлььч, коркунуч, сүйүнүч, өтүнүч, сагыныч, сүйөнүч, таяныч (радость, ложь, страх, радость, просьба, уста, радость, опора) и т. д. Такие формы можно увидеть и в некоторых произведениях на кыргызском языке: Кыргыззыьн ханы өлдү деп, Кытайга чапты сүйүнүч. Бутпарас манзгыт аралаш, Бухарга чапты сүйунүч [17, с. 65]. 
А суффиксы -ğur / -qur / -gür / -kür на чагатайском языке обозначают способность определяемого к движению действия и не отличаются образованием имен прилагательных от глаголов на кыргызском языке билгир, алгыр, илгир, өткүр (знающий, хваткий, иепкий, ocmpый). Например: ӧtgür «өткүр» (острый), tınmag்ur «тынбаган, турбаган» (неспокойный), oyğanmağur «оңой ойгонбогон кимдир бирөө» (кто-то, который просыпается с трудом) toymagur «тойбогур» (ненасытный), ylqligur «жыгылган, ураган, кулаган, кыйраган» (упавший, обернувшийся, разрушившийся, сломанный) и т. д. [16, с. 275].

Суффикс -q / -k, -aq / -ek, -uq / -ük встречающиеся на чагатайском языке, используются в следующих формах:

а) в качестве суффикса образующего существительное от глагола: bölük «бөлүк» (часть), buyruq / ğ «буйрук» (приказ), emgek «эмгек» (труд), kesek «кесек,топурак» (глина), qaraq «көз, карек» (глаза, зрачок), tüfürük «түкүрүк» (слюна) и др. [16, с. 275]. Такие языковые факты встречаются в кыргызском языке в таких словах, как тамак, кабак, билек, ичик, бычак (еда, веко, запястье, шуба, нож) прилагаются к корням слов, обозначающих действие и образуют существительные. В существительных с таким значением заметна, что указанная форма сформирована, как неотъемлемая часть слова.

б) в чагатайском языке суффиксы -q/ -k, -aq / - ek, -uq / -ük встречаются в словах прилагательных, обозначающих признак, свойство, признак результата, вызванного действием. Например: açuq «ачык, ачуу» (открытый, горький), artuq «артык» (лишний), с̧ürük «чирик» (гниль), kesük «кесик» (разрез), suzük «сүзүлүү» (растягиваться), ӥzӥk «үзүк, бөлүк»

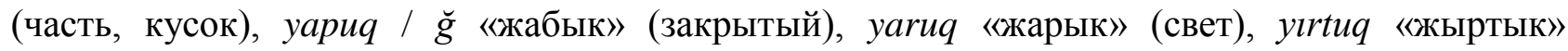
(дырявый), yoluq «түзсүз» (без цвета) и др. [16, с. 275].

Этот суффикс активно используется в кыргызском литературном языке и в его диалектических говорах при образовании существительных от глаголов. Например: күлүк, узак, жумшак, жарык, ашык (скакун, долго, мягко, светло, лишнее) и т. д.

В заключение, можно сказать, что список подобных словообразующих морфем можно продолжать бесконечно, но эти же факты свидетельствуют о том, что подавляющее большинство словообразующих суффиксов на чагатайском языке ничем не отличаются от суффиксов современного кыргызского языка.

В результате, сравнительное исследование материалов кыргызского литературного языка с чагатайским языком показывает, что с течением времени некоторые из словообразующих суффиксов претерпели лишь фонетические изменения и в большинстве своем многие суффиксы до сих пор стабильно сохранены.

Потому что формы, составляющие систему грамматики по сравнению с лексикой, составляющей словесную систему языка, остаются неизменными в течение длительного времени.

\section{Список литературы:}

1. Абдулдаев Э., Бакинова Г., Бейшекеев Н. Языковые особенности кыргызов в Узбекистане. Фрунзе: КССР АН, 1962.

2. Боровков А. К. Али Шер Навои как основоположник узбекского литературного языка. (Ленинград, 1946). М., 1953.

3. Brokelmann C. Osttürkische Grammatik der islamischen Literatursprachen Mittelasiens, Leiden, 1954.

4. Диренкова Н. П. Грамматика ойротского языка. Изд-во Академии наук СССР, 1940.

5. Дмитриева М. Исследования по сравнительной грамматике тюркских языков. II. Морфология. Издательство АН СССР, 1955-1962. 
6. Дыйканов К., Кудайбергенов С., Яншансин Ю. Из истории Кыргызской письменности. Фрунзе, 1958.

7. Canpolat M. Çağatay Dili ve Edebiyat1, Türkler VIII. Ankara: Yeni Türkiye, 2002.

8. Eckmann J. Çağatayca El Kitabı. (Günay Karaağaç, Mut.). Istanbul: Ed. Fak, 1988.

9. Ильминский Н. Материалы для джагатайского спряжения из Бабер-Намэ. Казань, 1865.

10. Кудайбергенов С., Яншансин Ю. Из истории Кыргызской письменности. Фрунзе, 1958.

11. Плоских В. М., Кудайбергенов С. К. Ранние киргизские письменные документы // Известия АН Киргизской ССР, 1968. №4.

12. Самойлович А. Н. Персидский тюрколог XVIII века Мирза Мехди хан, Jaur. / O. Azer. №5. Баку, 1928.

13. Самойлович А. Н. К истории литературного среднеазиатско-турецкого языка // МирАли-Шир, Л., 1928.

14. Щербак А. М. К истории узбекского литературного языка древнего периода. Академику В. А. Гордлевскому к его 75-летию. М., 1953.

15. Юдахин К. К. Киргизско-русский словарь. М., 1940.

16. Юнусалиев Б. М. Избранные труды. Фрунзе: Илим, 1985.

17. Сооронов О. Молдо Нияз «Санат дигарасттар». Бишкек: Учкун, 1993.

\section{References:}

1. Abduldaev, E., Bakinova, G., \& Beishekeev, N. (1962). Yazykovye osobennosti kyrgyzov v Uzbekistane. Frunze, KSSR AN.

2. Borovkov, A. K. (1953). Ali Sher Navoi kak osnovopolozhnik uzbekskogo literaturnogo yazyka. (Leningrad, 1946). Moscow, 1953.

3. Brokelmann, C. (1954). Osttürkische Grammatik der islamischen Literatursprachen Mittelasiens, Leiden.

4. Direnkova, N. P. (1940). Grammatika oirotskogo yazyka. Izd-vo Akademii nauk SSSR.

5. Dmitrieva, M. (1955-1962). Issledovaniya po sravnitel'noi grammatike tyurkskikh yazykov. II. Morfologiya. Izdatel'stvo AN SSSR.

6. Dyikanov, K., Kudaibergenov, S., \& Yanshansin, Yu. (1958). Iz istorii Kyrgyzskoi pis'mennosti. Frunze.

7. Canpolat, M. (2002). Çağatay Dili ve Edebiyat1, Türkler VIII. Ankara, Yeni Türkiye.

8. Eckmann, J. (1988). Çağatayca El Kitabı. (Günay Karaağaç, Mut.). Istanbul, Ed. Fak.

9. Ilminskii, N. (1865). Materialy dlya dzhagataiskogo spryazheniya iz Baber-Name. Kazan.

10. Kudaibergenov, S., \& Yanshansin, Yu. (1958). Iz istorii Kyrgyzskoi pis'mennosti. Frunze.

11. Ploskikh, V. M., \& Kudaibergenov, S. K. (1968). Rannie kirgizskie pis'mennye dokumenty. Izvestiya AN Kirgizskoi SSR, (4).

12. Samoilovich, A. N. (1928). Persidskii turkolog XVIII veka Mirza Mehdi han, Jaur. O. Azer, no. 5, Baku.

13. Samoilovich, A. N. (1928). K istorii literaturnogo sredneaziatsko-turetskogo yazyka. In: Mir-Ali-Shir, Leningrad.

14. Shcherbak, A. M. (1953). K istorii uzbekskogo literaturnogo yazyka drevnego perioda. Akademiku V. A. Gordlevskomu k ego 75-letiyu. Moscow.

15. Yudakhin, K. K. (1940). Kirgizsko-russkii slovar'. Moscow. 
16. Yunusaliev, B. M. (1985). Izbrannye trudy. Frunze, Ilim, 1985.

17. Sooronov, O. (1993). Moldo Niyaz "Sanat digarasttar”. Bishkek, Uchkun.

Работа поступила

в редакциюю 14.01.2020 г.
Принята к публикациии 19.01.2020 2.

Ссылка для цчитирования:

Акынбекова А. У. Общности суффиксов, образующих от глаголов именные части речи в кыргызском и чагатайском языках // Бюллетень науки и практики. 2020. Т. 6. №2. С. 341-346. https://doi.org/10.33619/2414-2948/51/43

Cite as (APA):

Akynbekova, A. (2020). Common Suffixes That Form Nominal Parts of Speech From Verbs in the Kyrgyz and Chagatai Languages. Bulletin of Science and Practice, 6(2), 341-346. https://doi.org/10.33619/2414-2948/51/43 (in Russian). 


\title{
ИСТОРИЧЕСКИЕ ТОПОНИМЫ ВДОЛЬ ТОРГОВОГО ПУТИ ТЕРМЕЗ - «ЖЕЛЕЗНЫЕ ВОРОТА»
}

\author{
СББбоева С. P., Термезский государственный университет, г. Термез, Узбекистан
}

\section{HISTORICAL TOPONYMS ALONG 'TERMEZ - IRON GATE' TRADING WAY}

\author{
CBoboeva S., Termez State University, Termez, Uzbekistan
}

Аннотация. В статье освещены вопросы о месте, значении, содержании и происхождении исторических топонимов, расположенных вдоль торгового пути Термез «Железные ворота», существовавших на территории современной Сурхандарьинской области Республики Узбекистан.

Abstract. It is illuminated the historical toponyms, their origin, location and significance in the Termez and Iron Gate trade routes which is located in the territory of the Surkhandarya region, Republic of Uzbekistan in this article.

Ключевые слова: Железные ворота, Дарбанд, Куфтан, Буг, Хашимгирд, Карна, Ангор, Шерабад.

Keywords: Iron Gate, Darband, Kuftan, Bug, Hashimgird, Karna, Angor, Sherabad.

«Железные ворота» - оборонительное укрепление, длиною в 1,5 км, расположенное в ущелье между горами Сувсизтаг и Саримас на перевале Ак-кутал (Белая гора) между кишлаками Дарбанд и Шураб, на 123-м км Большого узбекского тракта по направлению Термез-Ташкент на территории современной Сурхандарьинской области Республики Узбекистан. Это был комплекс сооружений, защищавших северные границы Кушанского государства, объединяющего в своих владениях также территории Бактрии в I в. н. э. «Железные ворота» - это историческое место, которое было важным звеном в цепи «Великого шелкового пути», связующего Среднюю Азию с Северной Индией во времена Греко-бактрийского (III-II вв. до н. э.) и Кушанского (І в. до н. э. - III в. н. э.) царств [1-2].

Топоним «Железные ворота» в древнетюркском языке называется Темир копуг [3, с. 113], в китайском - теминь гуань, в арабском - баб аль-хадид, в персидских источниках дари оханин [4, с. 34], все последние являются калькой тюркского названия.

Одним из древних письменных источников о «Железных воротах» являются сведения китайского путешественника - буддийского монаха Сюань Цзяна (630 г.). Он пишет, что через эти ворота проходит путь, ограниченный горами с правой и левой сторон. Горы очень высокие. Путь - слишком узкий, с разных сторон висят высокие, черные скалы. Здесь установлены двухстворные ворота, обвитые железом, на которых навешены колокольчики. Эти ворота прикрывали путь в тех местах [4, с. 30-31].

В «Дневниках» испанского посла Руи Гонсалес де Клавихо даются такие сведения о «Железных воротах»: «Следующий день - в понедельник (25 августа 1404 г. - С. Б.) группа послов отдыхали под высокой горы: на вершине этой высокой горы расположено мастерски построенное и украшенное разнообразными орнаментами и украшениями 
крестообразное здание. Гора очень высокая, там имеется дорожка, словно созданная человеческими руками, по этой дорожке можно пересекать ущелье. С разных сторон возвышались плоские и огромные горные вершины. В середине этого пути расположен кишлак, над ним как будто нависли высокие вершины. Данный путь в горах называется «Железными воротами», в этих местах нет другого, кроме этого пути. Эти ворота охраняют Самаркандское царство от Малой Индии. Именно через эти ворота вошли в земли Самарканда, жители Самаркандской империи также приходили в Индию именно по этому пути» [5, с. 33-34].

Из письменных источников известно, что «Железные ворота» на протяжении многих веков сыграли важную роль в существовавших торговых связях Бактрии-Тохаристана не только с Согдом, но и Индии с Согдом и Китаем.

В рабате «Зайн уль-ахбор» («Украшение вестей») Абусаида Гардизи в связи с изложением событий IX в. это место упоминается как Дари оханин [6, с. 181].

Термин Кахалка, названный в «Уложениях Тимура» [7, с. 29] является одним из древних исторических названий «Железных ворот» $[8$, с. 81$]$.

В «Зафар-наме» Шарафиддина Али Язди это место упоминается в двух названиях: Дари оханин и Кахалка [9, с. 180-189]. В «Бабур-наме» Захириддина Мухаммада Бабура данное место упомянуто под названием Кохлуг [10, с. 124].

По результатам последних исторических и археологических исследований известно, что в процессе походов Александра Македонского в области Наутака с Паретакена некоторые из скал Аримаса, Сисимифры, Согда и крепости Кармена были расположены в непосредственной близости с «Железными воротами» и на их территориях.

В середине XVIII в. «Железные ворота» постепенно стали терять свое былое значение. В рабате «Тухват аль-хоний» ( «Подарок хана») Мухаммада Вафо Карманаги, где освещены военные походы Мухаммада Рахимхана в 1757 г., применительно к этому месту использован термин Бузгалахон [11, с. 431].

Через «Железные ворота» проходили торговые пути в Насаф (Карши), Бухару, Самарканд, Чаганиян и другие места от Термезе, который в X в. превратился в крупный город, расположенный на верховьях Джайхуна (Амударьи) [12, с. 20-25].

Одной из стоянок вдоль торгового пути Термез - «Железные ворота» является Буг, относящаяся к IX в.

По В. В. Бартольду, Буг находился после Сармангана между Чаганияном и Дарзанги [13, с. 124]. Ш. С. Камолиддинов отмечает, что в исторических источниках не встречается такие сведения $[14$, с. 40]. Э. В. Ретвеладзе пишет, что кишлак Буг находился на месте безымянной возвышенности, расположенной на берегу канала. Занг на 7 км севера Джаркургана [15, с. 119]. Ш. С. Камолиддинов, основываясь на том, что существование местечка Буг в исторических источниках указывается на расстоянии 6 фарсахов от города Термеза, считает, что этот кишлак был расположен на территории Кафтарханы или на месте Занг-тепы (Кулоглы-тепы) в оазисе Ангор [14, с. 40].

Следует подчеркнуть, что в этом кишлаке родился знаменитый хадисовед исламского мира Мухаммад ибн Иса Савра ибн Муса ибн аз-Заххок Абу Иса ас-Сунамий аз-Зарийр альБугий ат-Термези (209 г. хиджры или 824 г. н. э.) Он умер в 892 г. в кишлаке Буг, поблизости от Термеза и был погребен именно в этом месте [16, с. 6-9].

Топоним Буг имеет два смысла 1) Бог, 2) благоустроенное место на древнем согдийском языке [17, с. 9]. Кроме того, на ягнобском языке Буг означает сад, построенный для житья летом вне города и кишлака, как дача [17, с. 44]. 
Вдоль торгового пути Термез - «Железные ворота» было расположено также поселение Куфтан. Этот топоним несколько раз упоминается в работе ат-Табари в связи с изложением событий в Термезе начала VIII в. В. В. Бартольд читал этот топоним в виде Гуфтан и считал, что он находился в VII-VIII вв. в Шерабадской долине в качестве отдельного владения [13, с. 125].

Э. Т. Ртвеладзе называет это владение в видах Куфтан и Гуфтан и расположил его в центральные и южные части Шерабадской долины [15]. В рабатах Т. Аннаева, Ш. Шайдуллаева [8, с. 50], В. С. Соловьева [18, с. 8-14], Э. В. Ртвеладзе, Г. А. Пугаченковой [1, с. 128] точно также локализовано это владение. В работах этих авторов не говорится об этимологии топонима Куфтан.

Этимология и локализация Куфтана нашли свое решение в исследованиях Ш. С. Камолиддинова. Он отмечает, что в письменных источниках этот топоним записан в формах Куфтан и Куфйан [19, с. 128].

Со второй половина VIII в. Куфтан не упоминается в исторических источниках. По мнению Ш. С. Камолиддинова, это название до XV в. было сохранено виде Кухтан. В «Бабурнаме» написано, что гора, расположенная на севере Термеза и Чаганияна называется Кухтан [10, с. 22-25]. Следует отметить, что топоним Кухитанг этимологически восходит к термину Кухистан. Персидско-таджикское слово Кухистан состоит из морфем Кух (гора) + истон (место). В согдийском языке морфема -истон встречается в формах -стана, -стане, -стан, истон. Топоним Кухитанг состоит из слов кух — гора и танг (тан) — страна и означает горная страна [14, с. 40]. По убедительным данным, приведенным Ш. С. Камолиддиновым, владения Куфтан или Кухтан было непосредственно расположено на Кухитангских горах (его центром был кишлак Куйтин) [19, с. 128]. В древнеперсидском языке слово кух означало гору. Например, гора Кухибобо в Афганистане означает Бабатаг (гора-дед или старшая гора) слово танг (санг) в персидско-таджикском языке означает камень или гора, что соответствует тюркскому значению слово таг.

На однодневном расстоянии от Термеза и на двухдневном расстоянии от «Железных ворот» находилось историческое место Хашимгирд. Хашимгирд был знаменит своим животноводством и шерстяными изделиями. По мнению М. Е. Массона, этот город был расположен на территории Наушахар (нау — новый, шахар - город — новый город) [20, c. 98$]$.

По О. Т. Большакову, Хашимгирд находился в Шерабадской долине [21, с. 179], по Э. В. Ртвеладзе - в Кафтархане, вблизи Ангора [15], по Ш. А. Рахманову - в Занг-тепе (Кулоглы-тепе), в 30 км на северной стороне Термеза [22, с. 40]. Ш. С. Камолиддинов, подробно изучая арабские источники IX-XIII вв. и сравнивая их с археологическими сведениями, сделал следующие выводы: в IX-X вв. Хашимгирд был одним из крупных городов Термезского вилоята. В письменных источниках IX-XII вв. Хашимгирд не упоминается [14, с. 38-39]. В работе ат-Табари в связи с изложением событий конца VII в. первой половины VIII в. упоминается городище Хушвараг (Хашура). Оно было расположено на возвышенности Катта-тепы (Хосият-тепы) в 7 км на южно-западной стороне Шерабада. Общая площадь этого города была 20 га [19, с. 128-129]. В восточном древнеиранском языке слово Хушвараг (Хушвара) состоит из морфем хуш — хороший, добротный, красивый, -вара (-бара) - крепость, хорошая или красивая крепость.

По мнению В. В. Бартольда, название города Хашимгирд непосредственно связано с именем его основателя - властителя Вахша и Холоварда Хашима ибн Бонуджури (умер в 243 г. хиджры или в 857-858 гг. н. э.) [13, с. 128-129]. 
Э. В. Ртвеладзе связывает название Хашимгирда с именем древнеиранского злого бога Хошима [12, с. 37-40].

Этимология названия Хашимгирд (город Хашима, хашимийцев) подробно освещена в работах Ш. С. Камолиддинова. По его мнению, название города Хошимгирд непосредственно связано с именем Хашима - общего предка династии пророка Мухаммада, халифа Али и аббасидов. Это объясняется тем, что во второй половине VIII в. из центральных территорий арабского Халифата переселилось в Туркестанский край, в том числе и в территории Термеза и Чаганияна множество население, относящееся к арабскому этносу, которое основало здесь многие города. На основании этих доводов исследователь делает вывод о том, что связать этимологию города Хашимгирд с именем династии хашимидов является всесторонне обоснованным [23, с. 33-34].

В письменных источниках IX в. упоминаются также рабат Розыка и Карна, существовавшие вдоль торгового пути Термез - «Железные ворота». Следуют отметить, что локализация этих двух поселений и особенно объяснение этимологии термина Карна до сих пор остаются проблематичными. Рабат Розыка упоминается со стороны аль-Истахри, место аль-Карна указано в работе аль-Мукаддаси [19, с. 129-130]. Историки и археологи указывают, что поселение аль-Карна было расположено в районе Мунчак-тепы на территории Сайроба [24-26] или на месте Хисор-тепы [15, с. 29], а рабат Розыка — в Шерабадской долине.

По мнению Ш. С. Камоллидинова, рабат Розыка находился на месте исторического памятника Амиркунды, расположенного на правом побережье низовья Шерабаддарьи на расстоянии в 25 км южнее от Сайроба. До сих пор остаются проблематичными точные места поселений рабата Розыка и аль-Карна и взаимосвязанных с ними памятников.

Этимология названия рабат Розыка толкуется как караван-сарай Розыка. Смысл топонима аль-Карна до сих пор не объяснен историками, топонимистами и лингвистами. Аль-Карну можно толковать как огражденную вокруг стенами крепость (от корня Карна или Карнак, т. е. крепость).

В письменных источниках XIV в. в число мест вдоль торгового пути Термез «Железные ворота» входит также Ангор. Следует отметить, что в работах, посвященных топонимам Сурханской долины, Ангор в качестве поселения не упоминается [17, 27]. Некоторые сведения об Ангоре встречаются в работе «Зафар-наме» Шарафиддина Али Язди. Он, в частности, упоминает о сражениях между войсками Амира Тимура и амира Хизира Ясавури, которые происходили в Ангоре [9, с. 189]. Современный Ангор находится в 30 км северо-западнее Термеза.

По мнению Т. Нафасова, топоним Ангор произошел не от персидского слова ангора, что означает посевная площадь, а от слова анхор, означающее водяной путь, канал [17, с. 1314]. Достоверность этой мысли топонимиста подтверждается тем, что, как свидетельствуют археологические сведения, развитые искусственные ирригационные сооружения в Ангорской долине были созданы еще в I в. до н.э. и в науке наименованы «Зангской системой орошения». Эти оросительные сооружения были отведены от Карасу и Сурхандарьи (в древности Чагонруд) [28, с. 6]. В археологических источниках 50-х годов ХХ в. относительно этой территории применен термин анхор [29, с. 115-137]. Ангор означает длину измерения. В древних арабских и персидских источниках однодневный путь считан одним ангором. Действительно, от Термеза до Ангора проходит однодневный путь.

Одним из исторических топонимов вдоль торгового пути Термез — «Железные ворота», относящихся к позднему средневековью, является Шерабад. 
Следует отметить, что ко временам, когда в исторических источниках стали отмечать топоним Шерабад, «Железные ворота» полностью потеряли свое былое значение. В XIX в. Шерабад стал крупным экономическим, торговым и культурным центром восточной Бухары. Топоним Шерабад связан с именем исторической личности - Шералихана, представителя Убайдуллахана в XVIII в., из кунгиратского рода по происхождению, который основал это место [30, с. 113].

В исторических и лингвистических исследованиях существуют также другие трактовки термина Шерабад. В частности, С. Н. Турсунов трактует этот термин на основе слов шох (большой, основной, главный) и рабат (крепость), как главная стоянка, большой каравансарай [31-32]. Т. Нафасов считает, что Шерабад от морфем шер (шир) + равут означает горное пастбище, верхнее пастбище или шер (шир) + рават - каменная крепость [17, с. $217-$ 218].

На территории Шерабадской долины с древнейших времен была развита городская культура. Здесь начиная с третьего тысячелетия до н. э. был расположен древнейший город Джаркутан. Он был центром Шерабадской долины до второго тысячелетия до н. э. и первого тысячелетия н. э. Начиная с первого тысячелетия до н. э. центр Шерабадской долины сформирован на месте возвышенности Джондавлат в деревне Саййидобод приблизительно в 10 км на северо-восточнее центра современного Шерабада. Несмотря на то, что с 1994 г. ведутся широкомасштабные исследовательские работы на Джондавлат-тепе, до сих пор не найдены эпиграфические сведения относительно древнего названия этого города. Известно, что он с IX-VIII вв. до н. э. и до V в. н. э. продолжал быть центральным городом Шерабадской долины.

В V в. н. э. возник третий центр Шерабадской долины около деревни Куллукшо, на месте Катта-тепы (Хосият-тепы). Относительно названия этого центра в научных работах существуют споры. Однако в ряде письменных источников сохранились отдельные сведения. Так, в «Истории» ат-Табари упоминается город Хушвараг или Хашура.

По мнению Э. В. Ртвеладзе, этот город находился месте Катта-тепы [33, с. 44]. Ш. С. Камоллиддинов пишет, что город Хушвараг в первой половине VIII в. был разрушен арабами и кратчайшие сроки заново был восстановлен и переименован как Хашимгирд (Хашимджирд) [19, с. 129]. В письменных источниках после Х в. топоним Хашимгирд не упоминается.

В средние века в Шерабдской долине и на граничащих к ней горных территориях существовало множество рабатов, т. е. караван-сараев и таможенных пунктов. Сюда относится крепость Товка, расположенная в одном из древнейших кварталов Шерабада вблизи крепости Нондахана в VI-VII вв., которая в основном выполняла функцию таможенного пункта [34, с. 53-55].

Приблизительно до XVIII в. центр Шерабадской долины существовал в основном в деревне Куллукша и в ее окрестностях. Оба берега реки Шерабаддарьи до местечка Нондаханы составляли кишлак, специализированные в основном ремесленничеством. Например, кишлак Чуянчи (дословно означает чугунщики) и др.

В XVIII в. Шералихан основал четвёртый городской центр Шерабадской долины. Этот город был назван непосредственно с его именем Шерабад (Шер - усеченное имя Шералихана, абад или обод - благоустроенный, т. е. благоустроенный Шером или Шералиханом).

Следует отметить, что историки и топономисты, определившие топоним Шерабад как шох бекат (главная стоянка или главный караван-сарай) смешивают и не различают смысл двух терминов: рабат и рабад. Никто из специалистов не сомневается в том, что термин 
рабат означает караван-сарай или постой. Несомненным является также толкование термина рабад как вне города. В составе слова Шерабад фонема рабад (рабод) означает вне города. Что касается рабатов или караван-сараев, существовавших в Шерабадской долине или на приближенных ей территориях, то они имели свои четкие названия, например рабат Розыка, Карна и др.

Все поселения Шерабадской долины, которые упомянуты в исторических, в частности арабо-персидских источниках, основательно освещены Ш. С. Камолиддиновым и как он справедливо указывает, что толкование термина Шерабад как шох бекат (главная остановка или главный караван-сарай) им не замечено в исторических источниках [14, с. 18].

Таким образом, мы рассмотрели основные топонимы, расположенные вдоль торгового пути Термез - «Железные ворота». Научное изучение и освещение вопросов о месте и роли, содержания и происхождения этих топонимов имеют важное значение не только с точки зрения истории, но и современности.

\section{Список литературь}

1. Пугаченкова Г. А, Ртвеладзе Э. В. Северная Бактрия - Тохаристан. Ташкент: Фан, 1990.

2. Пидаев Ш. Р. Тармита-Термиз 1220 йилгача: Шахарнинг келиб чиқиши ва тажридий тараққиёти // Термиз - буюк йиллар чоррахасидаги кўхна ва янги шахар. Ташкент: Шарқ, 2001. Б. 20-25. (на узб. яз.).

3. Камалиддин Ш. С. Древнетюркская топонимия Средней Азии. Ташкент: Шарк, 2006.

4. Аннаев Т., Тиловов Б., Худойбердиев Ш. Бойсун археологик ёдгорликлари. Ташкент: Абдулла Қодирий номидаги халқ мероси нашриёти, 1999. (на узб. яз.).

5. Руи Гонсалес де Клавихо. Дневник путешествия в Самарканд ко двору Темура (14031406). Перевод, предисловие и комментарии И. С. Мироковой. М.: Наука, 1996.

6. Гардизий ва унинг «Зайн ул-ахбор» асари. Форсийдан Ғулом Каримов таржимаси // Чағониён тарихи. Ташкент: Ислом университети, 2002. (на узб. яз.).

7. Темур Тузуклари. Ташкент: Ғофур Ғулом номидаги нашриёт матбаа бирлашмаси. 1991. (на узб. яз.).

8. Аннаев Т., Шайдуллаев Ш. Сурхондарё тарихидан лавхалар. Ташкент: Абдулла Қодирий номидаги халқ мероси нашриёти, 1991. (на узб. яз.).

9. Шарофиддин А. Я. «Зафарнома» Форсийдан О. Бўриев таржимаси // Чағониён тарихи. Ташкент: Тошкент Ислом университети, 2002. Б. 180-189. (на узб. яз.).

10. Захириддин М. Б. Бабур-наме (Записки Бабура). Ташкент: Главная редакция энциклопедии, 1993.

11. Бартольд В. В. Дер-и Ахенин / соч., т. III. М.: Наука, 1965.

12. Ртвеладзе Э. В. Стена Дарбанда Бактрийского // Общественные науки в Узбекистане. 1986. №12.

13. Бартольд В. В. Туркестан в эпоху монгольского нашествия / соч. М.: Наука.

14. Камолиддинов Ш. С. О средневековых городах области Термеза // Ўзбекитонда ижтимоий фанлар. 1993. №2. С. 40.

15. Аршавская 3. А, Ртвеладзе Э. В., Хакимов 3. А. Средневековые памятники Сурхандарьи. Ташкент: Издательство литературы и искусства имени Г. Гуляма, 1982.

16. Уватов У. Икки буюк донишманд. Ташкент: Шарқ, 2005. (на узб. яз.).

17. Нафасов Т. Ўзбекистон топонимларининг изохли луғати. Ташкент: Ўқитувчи, 1988. (на узб. яз). 
18. Соловьев В. С. Северный Тохаристан в раннем средневековье. Елец: Елецкий государственный педагогический университет, 1997.

19. Камолиддинов Ш. С. Историческая география южного Согда и северного Тохаристана по арбоязычным источникам IX-XIII вв. Ташкент: Узбекистон, 1996.

20. Массон М. Е. Городища старого Термеза и их изучение // Труды Узбекистанского филиала Академии Наук СССР. Серия. I. Термезская археологическая комплексная экспедиция. Ташкент, 1941. Вып. 2.

21. Беленицкий А. М., Бентович И. Б., Большаков О. Г. Средневековый город Средней Азии. М.: Наука, 1973.

22. Рахманов Ш. А. Исследования на городище Кулаглы-тепа в Ангорском районе Сурхандарьинской области // История материальной культуры Узбекистана. Вып. 23. Ташкент, 1990.

23. Камолиддинов Ш. С. Хошимжирд шахри номининг келиб чиқиши масаласига доир // Ўзбек тили ва адабиёти. 2004. №6. Б. 30-34. (на узб. яз.).

24. Камолиддинов Ш. С. К вопросу о происхождения топонима Хашимгирд // Moziydan sado. 2004. №2 (22). C. 25-27.

25. Kamoliddin Sh. K. To the question of origin at the Name Hashimgird // Eran and Aneran: studies presented to Boris Ilich Marschak on the Occasion at His 70th birthday, edited by M. Compareti, P. Rafetta, C. Scarcia. Venice: Librerid Editrice cotoscarina, 2006. P. 333-341.

26. Rtveladze E. V. On the Historical Geography of Bactria-Tokharistan // Silk Road Art and Archaeology. 1990. №1. P. 1-33.

27. Турсунов С. Сурхондарё вилояти топонимлари. Ташкент: Алишер Навоий номидаги Ўзбекистон Миллий кутубхонаси нашриёти, 2008. (на узб. яз.).

28. Аннаев Т. Ангор ёдгорликлари. Самарқанд: ЎзРФА археология институти нашри, 1993. Б. 6. (на узб. яз.).

29. Альбаум Л. И. Некоторые данные по изучению анхорской группы археологических памятников (1948-1949 гг.) // Труды института истории и археологии АН Уз ССР. Ташкент, VII, 1955. C. 115-137.

30. Бартольд В. В. Термез / соч., т. V. М.: Наука, 1963.

31. Турсунов С. Н. Шеробод. Фан ва турмуш, 1983. Б. 30.

32. Турсунов С. Н. Шерободликлар. Ташкент: Алишер Навоий номидаги Ўзбекистон миллий кутубхонаси нашри, 2006.

33. Ртвеладзе Э. В. К локализации Хушвары (Хашуры) // Ўзбекистонда ижтимоий фанлар, 1992. №3-4. С. 44.

34. Рахманов Ш. А. Товка. Ташкент: Абдулла Қодирий номидаги халқ мероси нашриёти, 2002.

\section{References:}

1. Pugachenkova, G. A, \& Rtveladze, E. V. (1990). Severnaya Baktriya - Tokharistan. Tashkent, Fan.

2. Pidaev, Sh. R. (2001). Tarmita-Termiz 1220 iilgacha: Shaharning kelib chikishi va tazhridii tarakkieti. In: Termiz - buyuk iillar chorrakhasidagi kuhna va yangi shahar. Tashkent, Shark, 20-25. (in Uzbek).

3. Kamaliddin, Sh. S. (2006). Drevnetyurkskaya toponimiya Srednei Azii. Tashkent, Shark.

4. Annaev, T., Tilovov, B., \& Khudoiberdiev, Sh. (1999). Boisun arkheologik edgorliklari. Tashkent, Abdulla Kodirii nomidagi khalk merosi nashrieti. (in Uzbek). 
5. Rui Gonsales de Klavikho. Dnevnik puteshestviya v Samarkand ko dvoru Temura (14031406). Moscow, Nauka, 1996.

6. Gardizii va uning Zain ul-akhbor asari. Forsiidan Gulom Karimov tarzhimasi. In: Chagonien tarikhi. Tashkent, Islom universiteti, 2002. (in Uzbek).

7. Temur Tuzuklari. Tashkent, Gofur Gulom nomidagi nashriet matbaa birlashmasi. 1991. (in Uzbek).

8. Annaev, T., \& Shaidullaev, Sh. (1991). Surkhondare tarikhidan lavhalar. Tashkent, Abdulla Kodirii nomidagi khalk merosi nashrieti. (in Uzbek).

9. Sharofiddin, A. Ya. (2002). Zafarnoma Forsiidan O. Buriev tarzhimasi. In: Chagonien tarikhi. Tashkent, Toshkent Islom universiteti, 180-189. (in Uzbek).

10. Zakhiriddin, M. B. (1993). Babur-name (Zapiski Babura). Tashkent, Glavnaya redaktsiya entsiklopedii.

11. Bartold, V. V. (1965). Der-i Akhenin, work, v. III, Moscow, Nauka.

12. Rtveladze, E. V. (1986). Stena Darbanda Baktriiskogo. Obshchestvennye nauki v Uzbekistane, (12).

13. Bartold, V. V. Turkestan v epokhu mongol'skogo nashestviya, work. Moscow, Nauka.

14. Kamoliddinov, Sh. S. (1993). O srednevekovykh gorodakh oblasti Termeza. Uzbekitonda izhtimoii fanlar, (2), 40.

15. Arshavskaya, Z. A, Rtveladze, E. V., \& Khakimov, Z. A. (1982). Srednevekovye pamyatniki Surkhandar'i. Tashkent, Izdatel'stvo literatury i iskusstva imeni G. Gulyama.

16. Uvatov, U. (2005). Ikki buyuk donishmand. Tashkent, Shark. (in Uzbek).

17. Nafasov, T. (1988). Uzbekiston toponimlarining izohli lugati. Tashkent, Ukituvchi. (in Uzbek).

18. Solovev, V. S. (1997). Severnyi Tokharistan v rannem srednevekov'e. Elets, Eletskii gosudarstvennyi pedagogicheskii universitet.

19. Kamoliddinov, Sh. S. (1996). Istoricheskaya geografiya yuzhnogo Sogda i severnogo Tokharistana po arboyazychnym istochnikam IX-XIII vv. Tashkent, Uzbekiston.

20. Masson, M. E. (1941). Gorodishcha starogo Termeza i ikh izuchenie. In: Trudy Uzbekistanskogo filiala Akademii Nauk SSSR. Seriya. I. Termezskaya arkheologicheskaya kompleksnaya ekspeditsiya. Tashkent, issue 2.

21. Belenitskii, A. M., Bentovich, I. B., \& Bolshakov, O. G. (1973). Srednevekovyi gorod Srednei Azii. Moscow, Nauka.

22. Rakhmanov, Sh. A. (1990). Issledovaniya na gorodishche Kulagly-tepa v Angorskom raione Surkhandar'inskoi oblasti. In: Istoriya material'noi kul'tury Uzbekistana, issue 23, Tashkent.

23. Kamoliddinov, Sh. S. (2004). Khoshimzhird shahri nomining kelib chikishi masalasiga doir. Uzbek tili va adabieti, (6), 30-34. (in Uzbek).

24. Kamoliddinov, Sh. S. (2004). K voprosu o proiskhozhdeniya toponima Khashimgird. Moziydan sado, (2), 25-27.

25. Kamoliddin, Sh. K. (2006). To the question of origin at the Name Hashimgird. In: Eran and Aneran: studies presented to Boris Ilich Marschak on the Occasion at His 70th birthday. Venice, Librerid Editrice cotoscarina, 333-341.

26. Rtveladze, E. V. (1990). On the Historical Geography of Bactria-Tokharistan. Silk Road Art and Archaeology, (1),1-33.

27. Tursunov, S. (2008). Surkhondare viloyati toponimlari. Tashkent, Alisher Navoii nomidagi Uzbekiston Millii kutubkhonasi nashrieti, 25-26. (in Uzbek).

28. Annaev, T. (1993). Angor edgorliklari. Samarkand, UzRFA arkheologiya instituti nashri, 6. 
29. Albaum, L. I. (1995). Nekotorye dannye po izucheniyu ankhorskoi gruppy arkheologicheskikh pamyatnikov (1948-1949 gg.). In: Trudy instituta istorii $i$ arkheologii AN Uz SSR. Tashkent, VII, 115-137.

30. Bartold, V. V. (1963). Termez, work, v. V., Moscow, Nauka.

31. Tursunov, S. N. (1983). Sherobod. Fan va turmush, 1983, 30. (in Uzbek).

32. Tursunov, S. N. (2006). Sherobodliklar. Tashkent, Alisher Navoii nomidagi Uzbekiston millii kutubkhonasi nashri. (in Uzbek).

33. Rtveladze, E. V. (1992). K lokalizatsii Khushvary (Khashury). Uzbekistonda izhtimoii fanlar, (3-4), 44.

34. Rakhmanov, Sh. A. (2002). Tovka. Tashkent, Abdulla Kodirii nomidagi khalk merosi nashrieti.

Работа поступила

в редакциюю 14.01.2020 г.
Принята к публикаичии 19.01.2020 2.

Ссылка для циитирования:

Бобоева С. Р. Исторические топонимы вдоль торгового пути Термез - «Железные ворота» // Бюллетень науки и практики. 2020. Т. 6. №2. С. 347-355. https://doi.org/10.33619/2414-2948/51/44

Cite as (APA):

Boboeva, S. (2020). Historical Toponyms Along 'Termez - Iron Gate' Trading Way. Bulletin of Science and Practice, 6(2), 347-355. https://doi.org/10.33619/2414-2948/51/44 (in Russian). 
УДК 165

https://doi.org/10.33619/2414-2948/51/45

\section{ФЕНОМЕНОЛОГИЧЕСКАЯ СОЦИАЛЬНАЯ ТЕОРИЯ В КОНТЕКСТЕ ПОСТНЕКЛАССИКИ}

(C)Антипина A. C., ORCID: 0000-0001-6482-2706, SPIN-код: 9574-7979, канд. филос. наук, Московский государственный технический университет им. Н.Э. Баумана, Москва, Россия

\section{PHENOMENOLOGICAL SOCIAL THEORY IN THE CONTEXT OF POST-NON-CLASSICS}

(C)Antipina A., ORCID: 0000-0001-6482-2706, SPIN-code: 9574-7979, Ph.D., Bauman Moscow State Technical University, Moscow, Russia

Аннотация. В статье используется модель классической, неклассической и постнеклассической рациональности. Постнеклассика определяется в перспективе усиления зависимости объекта Науки от ее метода; также в работе анализируется субъектность нового типа в современной теории познании. На основе предпринятого анализа делается вывод об адекватности феноменологической социологии парадигмальности нового типа — как ее общим мировоззренческим принципам, так и трансформациям самой социальной теории. Так, показано, что феноменологическая социология вносит существенный вклад в преодоление крайностей ментализма и бихевиоризма в объяснении человеческих действий социальной теорией; с точки зрения общей мировоззренческой направленности, феноменология намечает новый вектор взаимоотношений естественнонаучного и гуманитарного знания.

Abstract. The article uses the model of classical, non-classical and post-non-classical rationality. Post-non-classics is defined in the perspective of increasing the dependence of the object of Science on its method; the paper also analyzes the subjectivity of a new type in the modern theory of knowledge. On the basis of the undertaken analysis, the conclusion is made about the adequacy of phenomenological sociology of a new type of paradigmality - both its General worldview principles and transformations of the social theory itself. Thus, it is shown that phenomenological sociology makes a significant contribution to overcoming the extremes of mentalism and behaviorism in the explanation of human actions by social theory; from the point of view of the General ideological orientation, phenomenology outlines a new vector of relations between natural science and humanitarian knowledge.

Ключевые слова: классическая, неклассическая, постнеклассическая рациональность, социальная феноменология, теория социального действия.

Keywords: classical, non-classical, post-non-classical rationality, social phenomenology, theory of social action.

\section{Введение}

В рамках нашей работы мы используем модель классической, неклассической и постнеклассической рациональности, а также выдвигаем гипотезу адекватности 
феноменологической социологии постнеклассике - как ее общим мировоззренческим принципам, так и трансформациям самого социологического дискурса.

Постнеклассический идеал рациональности определяется нами, во-первых, как продолжение линии зависимости объекта науки от ее метода. На смену идее «реальности самой по себе» приходит признание принципиальной множественности социокультурных миров. Как следствие - отказ от идеи построения «подлинно научного», а потому единственно верного метода, рассматриваемого в качестве привилегированной формы доступа к истине. Исследовательский интерес все больше смещается в сторону рассмотрения деятельности по получению нового знания и закреплению за ним статуса «научного». Таким образом, проблематизируется сама возможность познания чего-либо вне определенной социальной практики использования тех или иных методов, систем описаний.

С другой стороны, мы отмечаем выдвижение плана Субъекта в рамках общей мировоззренческой ориентации постнеклассики. Однако сама по себе «субъектность» не должна вводить в заблуждение: речь не идет о классическом рацио, вообще не о субъекте (научного) познания как таковом, но о практическом агенте. Новое понимание Субъекта уместно связать с проблематизацией статуса самой Науки - рассмотрением сквозь призму породивших ее социально-культурных реалий. Данная ориентация была заявлена, в частности, Э. Гуссерлем в «Кризисе европейских наук и трансцендентальной феноменологии»: тематизирована укорененность науки в «предданном мире». Эту стратегию наследует А. Шюц. Наука рассматривается в качестве одной из «конечных областей смысла». Ученый теряет монопольное право на истину в рамках пространства социального: отныне его полноценным участником становится рядовой агент социокультурных практик. При этом - подчеркнем еще раз - не столько автономный в своем выборе индивид, сколько «паттерны взаимообмена» (термин К. Джерджена), обусловленность перспективы субъекта ситуационным контекстом «здесь и сейчас».

«Внутренний» ракурс постнеклассики определяется нами как тенденция к сближению «акционизма» и «структурализма» в социальной теории.

Так, феноменологическая социология существенно трансформирует понимание теории социального действия, тем самым перспектива «акционизма», заявленная социологической неклассикой М. Вебера, Г. Зиммеля и др., значительно ослабляется. Действие уже не есть в полной мере мое - спланированное и т. п.; оно в значительной степени предопределено социально разделяемыми типизациями обыденного мышления. «Субъективный смысл» М. Вебера, в интерпретации феноменологов, рождается не в сознании индивида, но в скоординированных формах деятельности - «смысловое» продуцируется социальными отношениями, не индивидом. Многие феноменологии используют в этой связи понятие «социально организованных актов интерпретации»: смысл социального действия не есть мотив (как достояние актора), но социально организованные конвенции как способы приписывания субъектам определенных «побудительных мотивов».

Представляется необходимым в этой связи отметить следующее. Разделяемая А. Шюцем, Г. Гарфинкелем критика «целе-» и «ценностно-рационального» у Вебера зачастую расценивается как уступка бихевиоризму [1, с. 293-304]: если убрать план сознания, то останутся лишь поведенческие реакции. Это не так. Важно не поведение как таковое, но социальный контекст его обнаружения. При этом «индивид» феноменологии не пассивный ретранслятор предустановленных социальных порядков - позитивистское «человек-вобществе-социолога» (термин Г. Гарфинкеля) отвергается. Нормативные правила, согласно феноменологам, устанавливаются посредством их способности рационализировать практики (повседневной жизни), но эта возможность не дана априори. Правила происходят из 
«обстоятельств их применения» - формируются непосредственно по ходу коммуникации, которую они организуют. В этом смысле этнометодологи будут говорить о рациональности как о «текущем результате» организованных действий повседневной жизни.

Тем самым, на наш взгляд, феноменологическая социология вносит свой вклад в преодоление крайностей ментализма и бихевиоризма в объяснении человеческих действий.

Следует также подчеркнуть, что общая перспектива «социального» в феноменологии это типически организованный порядок повседневной жизни, «продукт общей схемы интерпретации, формирующей стандартизированные и стандартизирующие фоновые ожидания» [2, с. 54].

В этой связи отметим, что люди у социальных феноменологов крайне «заинтересованы» в социальном порядке - ничуть не меньше социологов. Но создают этот порядок они своими рутинными повседневными действиями, а не посредством участия («ролевого») в функционировании «государства», «культуры» (в качестве независимых субстанций). Институты суть, в первую очередь, привычные формы деятельности - в этом смысле они «реальны», но реальны именно потому, что мы свои действия организуем в соответствии с этой «реальностью».

Сошлемся в этой связи на классика феноменологической социологии А. Шюца. Для характеристики «социальной реальности» он использовал понятие «обычаев Мы-группы». Это социально признанные в качестве «хороших и правильных» способы обращения с вещами и другими людьми. Мир воспринимается как неоспоримая данность, основания которой не проблематизируются просто в силу того, что все эти институциональные образования до сих пор «выдерживали проверку» [3, с. 621]. А. Шюц и последующая традиция, будут, тем самым, при объяснении социального мира исходить из философских положений, артикулированных еще Э. Гуссерлем: Selbstverständlichkeit (само-собойразумеемость), а также принципы действия как принципы «и так далее» и «я могу сделать это снова».

«Почему это так? - Потому что так заведено»: основанные на здравом смысле действия, рутинно воспроизводимые практики, «рациональность» которых уместнее связывать с тем, что они выдержали проверку временем, нежели с тем, что они служат каким-то априори «разумным» целям. Классическая социология атрибутировала подобные структуры «примитивным», «архаическим» обществам, противопоставляя им общества модернизационного типа, где институты описываются исходя из успешно исполняемых ими функций. Социальные феноменологи (как и ряд других современных социологических теорий) будут описывать нормативный строй общества на уровне повседневных практик, оспаривая функциональное «разделение труда» между институциями. Подобно тому, как медицинские научные центры не только исследуют болезни и врачуют людей, но и ведут документооборот, в рамках которого конструируются сами «болезни», - так и суды присяжных не открывают «объективных» фактов, но создают их самой практикой судебной деятельности (Демонстрация подобных зависимостей феноменологами и этнометодологами никогда не преследовала цели изобличать научную, равно как и любую другую, деятельность.).

Помимо «плана онтологии» (оппозиция «действие-структура» в теории социального действия), мы выделяем гносеологический план. В рамках постнеклассики, с нашей точки зрения, он может быть интерпретирован как новая трансдисциплинарность, пересмотр традиционного разведения «наук о природе» и «наук о культуре». Отныне это не противопоставление «идиографичекого» и «номотетичсекого», но смена вектора перспектива «включенного наблюдения», а не дистанцирование ученого (либо посредством 
презумпции объективности научных фактов, либо рациональной природы человека). В рамках «социологической классики» безоговорочно доминировал идеал количественных методов анализа (апелляция к «фактам», привлечение математического аппарата), «неклассическая социология» привнесет перспективу «идивидуального», но преломляемую в свете «абсолютных ценностей». Позиции «вненаходимости» противостоит «включенное наблюдение» постнеклассической рациональности. Данная стратегия разрабатывается, в том числе, представителями «качественной методологии», стремящимися преодолеть разрыв между не обремененной эмпирическим материалом высокой теорией социального ученого и лишенным всякого теоретизирования коллекционированием фактов. Данная ориентация во многом наследует установку социального феноменолога А. Шюца - его постулат «субъективной адекватности» теории. Зачастую последний трактуется превратно. Мы полагаем, что требование возможности «обратного перевода» категорий социальной науки на язык самого практического деятеля не есть лишь призыв к самоописанию. Альтернатива «внешней» позиции ученого традиционной социологии - не просто «спросить у туземца», как иронично замечает Д. Силвермен. Описание социальной системы будет адекватным в том случае, если удастся усвоить разделяемые в этой системе повседневные практики организации жизни. Все то, что следует знать или во что следует верить, чтобы вести себя приемлемым для членов этой группы образом [4].

Мы также полагаем, что гносеологическая перспектива «постнеклассики» может быть интерпретирована и в более широком контексте: речь не только о методах социальной науки, но, как представляется, и о возможности нового синтеза «естественнонаучного» и «социогуманитарного».

Еще недавно столь популярные рассуждения социологов о том, что «социальное» бесконечно богаче и сложнее «физического», сегодня не оправданы. Реставрация позитивизма, на наш взгляд, невозможна не потому, что гуманитарии доказали неприменимость этого стандарта к «человеческой реальности», но в силу того, что механицизм, к которому он апеллировал, давно «скомпрометирован» самой физикой. «Инонаучность» социогуманитарного сравнительно с «естественным» посему больше не работает; «иными» стали сами «науки о природе». Они уже не остов «объективности» и «беспристрастности» - конвенционализм в порядке вещей среди «естественников».

В этой связи разведение перспектив «вещного» и «субъектного» должно возыметь свой предел. Современное социально-гуманитарное знание уже не может позволить себе недооценку «вещей» - в противовес классической гуманитаристике, самоопределяющейся в перспективе «не-природного», - необходимо увидеть другую природу.

Феноменология, на наш взгляд, дает мощный философский ресурс для переосмысления связи «природного» и «культурного», ибо в повседневной практике, на анализ которой ориентируют науку представители феноменологической социологии, — мир не дан человеку в качестве состоящего из «мертвых вещей» и «высоких смыслов», но предстает как целокупный обжитой мир. Здесь же становится очевидным, что прагматическое будет «утилитарным» и «корыстным», только если будет противостоять не менее надуманной чистой теории.

Нам представляется, что тем самым намечается плодотворная возможность пересмотра непростых отношений «наук о природе» и «наук о культуре». Ведь именно повседневная реальная жизнь - сошлемся на справедливую мысль Б. Латура, «постоянно и неуклонно смиряет» все попытки «научного» разведения «природного» и «культурного», «вещного» и «смыслового», «реального» и «сконструированного» [5]. 


\section{Заключение}

В свете сказанного, однако, особо следует подчеркнуть тот факт, что и сегодня концепт «позитивизма-антипозитивизма» остается во многом главным инструментом при анализе социальных теорий XX века. Так, значительная часть современных исследователей, заслуженно упрекая традицию О. Конта в игнорировании специфики социокультурной реальности, в преднамеренном методологическом редукционизме и объективизме, проявляющемся в забвении социогуманитарными науками их «человекоразмерности», - не видят ему иной альтернативы, кроме как в «субъективизме». Приведем весьма характерную точку зрения: «Классическая социологическая парадигма, или же позитивистски ориентированная социология, противопоставляет свое видение социального мира альтернативной парадигме, связанной с работами феноменологов и этнометодологов. Отличительная черта натуралистического толкования социальной реальности - отрицание или недооценка субъективного фактора в общественной жизни... В противоположность натуралистическому подходу в концепциях субъективизма основное внимание уделяется именно сознанию. При всем многообразии разновидностей субъективизма (от феноменологической социологии до философии лингвистического анализа) всем им присуще игнорирование объективной естественно-исторической обусловленности жизни общества» [6, с. 92].

Подобные прочтения не оставляют выбора: любые стратегии, не укладывающиеся в «позитивистски ориентированную» модель социального познания, с неизбежностью будут причислены к «социологическому субъективизму».

Со своей стороны отметим, что заявленная оппозиция (позитивизм/объективизм антипозитивизм/субъективизм) не является универсальной. Она была оправдана в условиях критики позитивизма формирующейся тогда культурцентристской парадигмой. Однако на современном этапе развития социально-философского знания во многом утратила свою эвристическую ценность.

Так, попытки преодоления схематизма структурно-функционального истолкования человеческого поведения отнюдь не означают апологии «субъективизма» и «идеализма» в социальном познании, и от аксиологии баденской школы неокантианства феноменологическая социология отличается не меньше, чем от «натурализма» теоретических построений Г. Спенсера.

Работа выполнена при финансовой поддержке РФФИ в рамках научного проекта № 18-311-00157 «мол_а» «Разработка постнеклассической методологии соџиального познания».

\section{Список литературь:}

1. Девятко И. Ф. Социологические теории деятельности и практической рациональности. М.: Аванти плюс, 2003. 331 с.

2. Уолш Д. Социология и социальный мир // Новые направления в социологической теории. М.: Прогресс, 1978. С. 47-79.

3. Шюц А. Равенство и смысловая структура социального мира // Избранное. Мир, светящийся смыслом. М.: РОССПЭН, 2004. С. 616-666.

4. Силвермен Д. Предварительные замечания // Новые направления в социологической теории. М.: Прогресс, 1978. С. 29-46.

5. Латур Б. Надежды конструктивизма // Социология вещей: сб. статей. М.: Издательский дом «Территория будущего», 2006. С. 365-389. 
6. Смирнова Р. А. Природа социальной реальности: Бытие и познание. Минск: Наука и техника, 1991. 168 с.

\section{References:}

1. Devyatko, I. F. (2003). Sotsiologicheskiye teorii deyatel'nosti i prakticheskoy ratsional'nosti. Moscow, Avanti plyus, 331. (in Russian)

2. Uolsh, D. (1978). Sotsiologiya i sotsial'nyy mir. In: Novyye napravleniya $v$ sotsiologicheskoy teorii. Moscow, Progress, 47-79. (in Russian).

3. Shyuts, A. (2004). Ravenstvo i smyslovaya struktura sotsial'nogo mira. In: Izbrannoye. Mir, svetyashchiysya smyslom. Mosciw, ROSSPEN, 616-666. (in Russian).

4. Silvermen, D. (1978). Predvaritel'nyye zamechaniya. In: Novyye napravleniya $v$ sotsiologicheskoy teorii. Moscow, Progress, 29-46. (in Russian)

5. Latur, B. (2006). Nadezhdy konstruktivizma. In: Sotsiologiya veshchey. Moscow, Izdatel'skiy dom Territoriya budushchego, 365-389. (in Russian).

6. Smirnova, R.A. (1991). Priroda sotsial'noy real'nosti: bytiye i poznaniye. Minsk, Nauka i tekhnika, 168. (in Russian)

Работа поступила

в редакичию 14.01.2020 2.
Принята к публикациии

19.01.2020 2.

Ссылка для циитирования:

Антипина А. С. Феноменологическая социальная теория в контексте постнеклассики // Бюллетень науки и практики. 2020. Т. 6. №2. С. 356-361. https://doi.org/10.33619/2414$2948 / 51 / 45$

Cite as (APA):

Antipina, A. (2020). Phenomenological Social Theory in the Context of Post-non-classics. Bulletin of Science and Practice, 6(2), 356-361. https://doi.org/10.33619/2414-2948/51/45 (in Russian). 


\title{
ПРИРОДА И ИСТОЧНИКИ ДУХОВНОЙ ОПАСНОСТИ
}

\author{
СШарипова Э. К., д-р филос. наук., Ошский государственный университет, \\ 2. Оu, Кыргызстан \\ (СКедейбаева Ж. А., Ошский технологический университет им. акад. М.М. Адышева, \\ 2. Ош, Кьргызстан \\ СКурбанбаев К. А., Ошский государственный университет, г. Ои, Кыргызстан
}

\section{NATURE AND SOURCES OF SPIRITUAL DANGER}

CSharipova E., Dr. habil., Osh State University, Osh, Kyrgyzstan

CKedeybaeva Zh., Osh Technological University named by M.M. Adyshev, Osh, Kyrgyzstan CKurbanbaev K., Osh State University, Osh, Kyrgyzstan

Аннотащия. В нашем исследования мы хотим подчеркнуть, что каждое конкретное государство и народ в силу множества причин и условий, одним из которых является географическое положение, вынуждено решать свой ряд задач, связанных с обеспечением как национальной, так и духовной безопасности. При этом значительные различия между народами и государствами в их экономической, технологической и военной мощи, в количестве населения с необходимостью приводит к тому, что так или иначе одни народы и государства выступают на исторической арене в качестве силы, способной и стремящийся навязать свою волю, культуру и язык другим народам и государствам, а другие, соответственно, как сторона, которая должна тем или иным образом воспринять влияние и давление, исходящие от сильных и многочисленных государств и народов. Речь в данном случае идет об экономическом и военном давлении. Однако, в не меньшей мере это может относиться к культурному и духовному влиянию, давлению.

Abstract. In our study, we want to emphasize that each particular state and people due to many reasons and conditions, one of which is the geographical location, is forced to solve its own number of tasks related to ensuring both national and spiritual security. Significant differences between peoples and states in their economic, technological and military power in the population leads to the fact that somehow some nations and states in the historical arena as a force able and willing to impose their will, culture and language of other peoples and States, and others, respectively, as a party, which must in one way or another to perceive the influence and pressure coming from the strong and the many States and peoples. In this case, we are talking about economic and military pressure. However, no less it can relate to cultural and spiritual influence, pressure.

Ключевые слова: безопасность, народ, основа, угроза, защита, народ.

Keywords: security, people, basis, threat, protection, people.

Совершенно очевидно, что для того чтобы выработать определенные способы и пути защиты духовной безопасности, необходимо понять откуда и почему возникают эти угрозы. Начнем с того, что вполне понятно, что иначе не может быть, что эти угрозы исходят от 
людей, от народов и государств, из чего следует, в частности то, что причину этих угроз необходимо искать в сущности человека, в его природе.

Практически любое расширение каким-либо социумом территории и собственного влияния с необходимостью наталкивается на сопротивление других социумов, на территории которых посягают либо хотят распространить собственное влияние.

Очевидно, что в основе желания распространить свое влияние, в том числе культурное, духовное лежал и лежит какой-то глубокий, основополагающий, фундаментальный мотив, движущая сила. В принципе мы не ошибемся, если укажем в качестве данного мотива на достаточно простое и очевидное желание человека, конкретных людей распространять свое влияние, силу, господство на тех, кто обладает меньшей силой и влиянием. Надо признать, во всяком случае, исходя из реальной практики, что это желание укоренено в нас самой природой, т. е. оно является существенной частью нашего естества [1-4].

По причине наличия у человека разума и социальной его природы феномен воли к власти воплощается в куда более сложных и разнообразных формах, чем в остальной живой природе, но сам принцип остается при этом незыблемым, сохраняя свою универсальность. Как показывает практика, весь исторический опыт, люди строго и неотступно следовали и следуют данному принципу, стремясь распространить свою власть везде, где это только представляется возможным. Однако вместе с ней они, как показывает опыт, распространяли и распространяют все то, что сопутствует и укрепляет эту власть, чем является в самом общем виде культура. Это вполне очевидно. Так же очевидно, что одним из самых эффективных и одновременно необходимых и, в сущности, неизбежных средств и инструментов распространения собственной силы, влияния и культуры является язык. Поэтому, распространяя и укрепляя собственную власть, влияние, люди распространяют свою культуру и язык. С другой стороны, распространяя свою власть, культуру и власть, люди, а вернее, одни социумы с необходимостью вытесняют культуры и язык других менее успешных и конкурентоспособных - социумов.

С момента возникновения первых государств и цивилизаций культуры уже настолько разнились между собой, что конфликты и войны между государствами приобрели форму конфликтов и войны между культурами и, соответственно, между духовными феноменами, представлявшими эти культуры.

Итак, первый закон гласит, что государства увеличиваются по мере развития культуры народов, образовывающих эти государства. Т. е. развитие культуры, расширяющее возможности социума, в определенной мере тождественно тенденции расширения.

Второй закон утверждает, что территориальный рост, расширение государства ведет к различным проявлениям развития его культуры в производственной, идеологической и прочих сферах, в коммерческой деятельности, в сфере прозелитизма, т. е. обращении чужеродных элементов в собственную веру и в конечном счете культуру.

Таким образом, развитие культуры ведет к расширению государства, которое, расширяясь, начинает распространять на новые территории собственную культуру.

Третий закон говорит о том, что процесс расширения сопровождается процессом абсорбции, т. е. впитыванием и поглощением этнических и политических величин меньшей значимости и величины. Другими словами, расширяющийся социум, оказываясь на чужой территории, стремится к уподоблению и полному поглощению автохтонного населения, и культура в этом случае выступает как наиболее действенный инструмент в стратегии захвата, долгосрочной политике.

И, наконец, четвертый закон гласит, что тенденция к абсорбции, т. е. поглощению менее значимых этнических единиц и групп побуждает, подталкивает в конечном счете к еще 
большему расширению своих территорий [5, с. 35-36], т. е. речь идет о стремлении, тенденции, которая как бы подпитывает саму себя и выражается в простой формуле: чем сильней, тем больше, и чем больше, тем сильней.

Как показывает мировой исторический опыт, многие культуры исчезали в результате того, что их носители по тем или иным причинам вступали в длительный и постоянный контакт с более многочисленным социумом и таким образом погружались с более мощную культурную среду. Данный фактор, тенденция, закономерность не только сохранены, но и значительно усилились в настоящее время. Соответственно, существенно усилилась угроза исчезновения многих культур малых или относительно немногочисленных народов. Еще в последние десятилетия XX века известный итальянский ученый, основатель и первый президент Римского клуба, исследовавший глобальные модели развития человечества, А. Печче и писал в связи глобальной тенденцией, связанной с исчезновением множества культур, следующее: «Защита и сохранение культурных особенностей народов и наций совершенно справедливо объявлены, в особенности в последние годы, ключевым моментом человеческого прогресса и самовыражения.

Само собой разумеется, жизнь во всем ее разнообразии и противоречиях намного богаче, чем любое теоретическое положение, каким бы глубоким и точным не было последнее. В реальной жизни народы, стремящиеся распространить собственное влияние и культуры на другие народы, практически всегда наталкиваются на сопротивление последних. С другой стороны, так или иначе могущественные противники, приблизительно равные по силе, наталкиваются друг на друга, и равенство сил сторон часто приводит к тому, что у народов, испытывающих чужое влияние, появляется некоторый выбор, возможность для маневра и сохранения собственной культуры и языка. Данный вопрос мы рассмотрим более подробным образом в одном из последующих разделов нашего исследования, а сейчас ограничимся тем, что укажем на то, что естественно богатство и разнообразие жизни не отменяет еe основополагающих принципов, что в данном случае означает, что ассимилятивные культурные процессы не только не прекратятся, но, по всей видимости, будут со временем только усиливаться. Данное обстоятельство для малочисленных народов, в том числе кыргызского, означает, что со временем угрозы их духовной безопасности будет только возрастать.

У каждого государства и народа в соответствии с его материальной и духовной мощью и, соответственно, уровнем его материальной и духовной безопасности существует свой набор и иерархия угроз и их причин. Сообразно данной иерархии должна существовать и иерархия мер, которая позволяла бы действенным образом отразить эти угрозы, если они начнут реализовываться.

Для того чтобы сохранить государство и народ, надо непосредственно сохранить его общество, а для этого, естественно, и образующих его личностей, т. е. тех представителей народа, выступающих теперь в виде членов этого определенного общества.

Из сказанного следует, что основным и непосредственным объектом национальной и духовной безопасности выступает не нация, а общество, образуемое ею. Если разрушить у нации ее общество, она превращается просто в конгломерат индивидов, не представляющих единого целого, не объединенных общей духовной жизнью, идеями, понятными им всем и воспринимаемыми, по сути, одинаковым образом. В результате такое разрозненное общество превращается в материал для других обществ и других наций, а может и просто исчезнуть физически, будучи отторгнутым от других обществ и наций.

Хотя субъектом национальной и духовной безопасности в конечном счете является и может являться только нация (народ), но непосредственным субъектом своей национальной 
безопасности она выступать не может. Если в первобытную эпоху каждое племя и было обществом (общиной), а каждое общество образовывалось (к концу этой эпохи) из определенного племени, то в цивилизованном обществе дело уже обстоит совсем иначе. Тут действует отчужденное от индивидов общество. И оно может образовываться как из одной нации, так и из некоторого множества наций, образующих многонациональный народ данного общества [6-8]. А в таком обществе, без гибельного для такого общества шовинизма и национализмов, не может и не должна вестись речь о большей защите одних наций и о меньшей защите других наций.

Если национальную и духовную безопасность рассматривать через призму национальных интересов, когда под национальными интересами следует понимать иерархию жизнеобеспечивающих интересов общества, то главным объектом национальной и духовной безопасности оказывается объективно общество в целом, общество как целое, общество как исторический организм, общество как носитель истории и культуры определенного народа. Национальные интересы страны, оцениваемые через исторические интересы ее народа, имеют долгосрочный характер и определяют основные цели национальной политики безопасности, формируют стратегические и текущие задачи внутренней и внешней политики государства как главного субъекта этой безопасности и реализуются через организацию государственного управления как обществом в целом, так отдельными личностями и общностями, входящими в это общество и образующими это общество.

Национальные интересы, как внутренние, так и внешние, не могут оставаться вечными и неизменными. По мере изменений объективной реальности внутри страны и за ее пределами в мире меняются содержание национальных интересов и стратегия деятельности государства по обеспечению этих интересов. Однако коренные внешние национальные интересы, которые оно обязано осуществлять, такие, как сохранение его народом самого себя, целостности своей жизнеобеспечивающей земли, своего исторически полученного и созданного национального богатства, своей культуры, остаются у национального государства неизменными.

Кроме того, при реализации собственных национальных интересов любое государство обязано учитывать национальные интересы других государств, добиваясь их определенного баланса. Без этого не сохранить сегодня и в будущем оптимальный для своей страны уровень международной безопасности, в условиях которой только можно надежно обеспечить национальные интересы своего народа.

Основные угрозы для нашей молодой республики извне обусловлены в первую очередь ее весьма незначительной экономической и военной мощью, значительным внутренним ослаблением, вызванным разрушением Советского Союза, частью которого был Кыргызстан, отсутствием опыта, радикальным характером проводимых политических и социальноэкономических реформ, относительно слабой стартовой позицией и т. д. Проведенные в течение почти трех десятилетий реформы привели не только к положительным, но и, к сожалению, к отрицательным последствиям, которые породили серьезную угрозу для национальной и духовной безопасности во внутриполитическом плане. В первую очередь это связано с глубоким разделением общества на незначительное количество богатых и существенное количество бедных людей при относительно малом количестве людей со средним достатком.

Конкретные внутренние и внешние угрозы национальной и духовной безопасности предполагают решение соответствующий набор целей и задач и способов их решения. Среди очевидных внутренних предпосылок, обеспечивающих национальную и духовную безопасность нашей страны, следует назвать в первую очередь: 
-объединение народа для решения общенациональных задач духовного и материального порядка, осознание ее представителями собственных интересов и проявление организованной воли их защищать;

-оптимизированные государственные институты, готовые обеспечить защиту общенациональных интересов, гарантировать стабильное и гармоничное развитие общества;

-опережающее духовное, культурное и научное развитие;

-сохранение общей стабильности в государстве, предотвращение вовлеченности нашего государства во внешнюю войну;

-установление отношений делового взаимовыгодного партнерства со всеми государствами мира, но тоже с учетом далекой исторической перспективы;

-обеспечение надежной защиты суверенитета, целостности и безопасности своего государства;

-сохранение окружающей среды как внутри страны, так и в пределах всего Центрально-азиатского региона с объединением усилий всех других стран региона;

-обеспечение действенного подавления организованной преступности, ликвидации криминальных факторов, создание гарантий личной безопасности граждан.

Очевидно, что не все из вышеуказанных предпосылок имеют прямое отношение к обеспечению духовной безопасности, однако без создания этих предпосылок невозможно успешное решение проблем, связанных с обеспечением духовной безопасности.

В соответствии с приведенным определением обеспечение национальной безопасности связано в первую очередь с сохранением и развитием национального самосознания, отражающего традиции жизнеустройства общества, его культуры и истории. Мы разделяем данную точку зрения, считая, что деградация, а затем и исчезновение национального (или этнического) самосознание означает, по сути, духовную смерть народа — носителя данного самосознания. Поэтому логично сделать вывод, что все, что угрожает уничтожению национального самосознания, таит в себе опасность его растворения в самосознании других народов, является угрозой для духовной безопасности народа.

Через язык формируется способ, образ, модель мышления, а с ним, естественно, и поведения у каждого из носителей того или иного языка, из чего следует, что язык приводит всех своих носителей к единому стандарту мышления и поведения. Носители одного и того же языка, используя один и тот же набор слов и понятий, одни и те же грамматические конструкции, систему лексических связей, мыслят в пределах одинаковых стандартных схем. Разные языки, сообразно своим особенностям, задают разные способы мировосприятия, различные модусы мировоззрения и, следовательно, различные картины мира, а это в свою очередь означает, что разные языки задают и формируют различные формы, типы и структуры мышления. Структурно и схематически определяя, программируя и кодируя форму мышления, язык таким образом создает и формирует тип мышления, а вместе с типом мышления — и систему поведения носителя языка.

\section{Bblводbl}

1. Каждое конкретное государство и народ в силу множества причин и условий вынужден решать свой ряд задач, связанных с обеспечение как национальной, так и духовной безопасности. При этом значительные различия между народами и государствами в их экономической, технологической и военной мощи, в количестве населения с необходимостью приводит к тому, что одни народы и государства выступают на исторической арене в качестве силы, способной и стремящийся навязать свою волю, культуру и язык другим народам, а другие - как сторона, которая должна тем или иным образом воспринять влияние и давление. 
Речь идет не только об экономическом и военном давлении, но и культурном и духовном влиянии.

2. Как показывает история и длительная практика, государства и народы, если для этого сушествуют благоприятные условия, стремятся к расширению своих территорий. Расширяя же их, с необходимостью приходится распространять свое влияние, в том числе культурное и духовное. В качестве основополагающего мотива к расширению лежит очевидное желание человека, конкретных людей распространять свое влияние, силу, господство на тех, кто обладает меньшей силой и влиянием. Это желание вкоренено в нас самой природой, т.е. оно является существенной частью человеческого естества, и его можно определить, как воля к власти, к господству, которая в конечном счете является волей к жизни.

3. По причине наличия у человека разума и социальной его природы феномен воли к власти воплощается в куда более сложных и разнообразных формах, чем в остальной живой природе, но сам принцип остается при этом незыблемым, сохраняя свою универсальность. Как показывает весь исторический опыт, люди строго и неотступно и строго следовали и следуют данному принципу, стремясь распространить свою власть везде, где это только представляется возможным. При этом культура выступает одним из необходимых и важных инструментов воздействия и распространения собственной силы и влияния, прочного закрепления на чужих территориях.

4. Процесс конкуренции между народами и государствами практически начался с того момента их возникновения, а вернее, конкуренция между родами и племенами естественным образом трансформировалась в борьбу народов и государств, как только они возникли. С момента возникновения первых государств и цивилизаций культуры уже настолько разнились между собой, что конфликты и войны между государствами приобрели форму конфликтов и войны между культурами и, соответственно, между духовными феноменами, представлявшими эти культуры.

\section{Список литературы:}

1. Белл Д. Грядущее постиндустриальное общество. Опыт социального прогнозирования. М.: Academia, 1999. 956 с.

2. Бердяев Н. А. Истоки и смысл русского коммунизма. М.: Наука, 1990. 224 с.

3. Гегель Г. Философия истории. М.: Мысль, 1990. 474 с.

4. Гегель Г. Философия права / пер. с нем., ред. и сост. Д. А. Керимов и В. С. Нерсесянц. М.: Мысль, 1990. 524 с.

5. Астахова Л. В. Информационная безопасность: герменевтический подход. М.: РАН, 2010. $185 \mathrm{c}$.

6. Бабурин С. Н. и др. Стратегия национальной безопасности России. Теоретикометодологические аспекты. М.: Магистр, 2014. 512 с.

7. Возжеников А. В. и др. Основные концептуальные положения национальной безопасности России в XXI веке. М.: ЭДАСПАК, 2000. 48 с.

8. Возжеников А. В. Парадигма национальной безопасности реформирующейся России / 2 изд. испр. и доп. М.: ЭДАСПАК, 2000. 358 с.

\section{References:}

1. Bell, D. (1999). Gryadushchee postindustrial'noe obshchestvo. Opyt sotsial'nogo prognozirovaniya. Moscow, Academia, 956. (in Russian).

2. Berdyaev, N. A. (1990). Istoki i smysl russkogo kommunizma. Moscow, Nauka, 224. (in Russian). 
3. Gegel, G. (1990). Filosofiya istorii. Moscow, Mysl, 474. (in Russian).

4. Gegel, G. (1990). Filosofiya prava. Moscow, Mysl, 524. (in Russian).

5. Astakhova, L. V. (2010). Informatsionnaya bezopasnost': germenevticheskii podkhod. Moscow, RAN, 185. (in Russian).

6. Baburin, S. N., \& al. (2014). Strategiya natsional'noi bezopasnosti Rossii. Teoretikometodologicheskie aspekty. Moscow, Magistr, 512. (in Russian).

7. Vozzhenikov, A. V., \& al. (2000). Osnovnye kontseptual'nye polozheniya natsional'noi bezopasnosti Rossii v XXI veke. Moscow, EDASPAK, 48. (in Russian).

8. Vozzhenikov, A. V. (2000). Paradigma natsional'noi bezopasnosti reformiruyushcheisya Rossii. 2 ed. Moscow, EDASPAK, 358. (in Russian).

Работа поступила

в редакиию 14.01.2020 г.
Принята к публикации

19.01.2020 2.

Ссылка для циитирования:

Шарипова Э. К., Кедейбаева Ж. А. Курбанбаев К. А. Природа и источники духовной опасности // Бюллетень науки и практики. 2020. Т. 6. №2. С. 362-368. https://doi.org/10.33619/2414-2948/51/46

Cite as (APA):

Sharipova, E., Kedeybaeva, Zh., \& Kurbanbaev, K. (2020). Nature and Sources of Spiritual Danger. Bulletin of Science and Practice, 6(2), 362-368. https://doi.org/10.33619/2414-2948/51/46 (in Russian). 

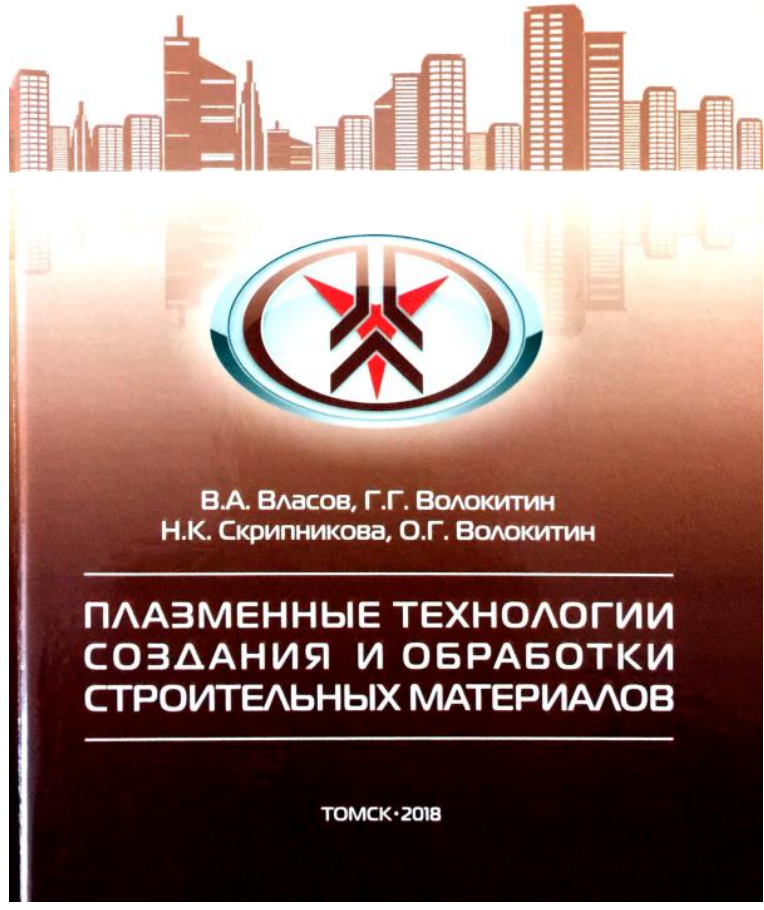

Власов В. А., Волокитин Г. Г., Скрипникова Н. К., Волокитин О. Г. Плазменные технологии создания и обработки строительных материалов: монография. Томск: Изд-во НТЛ, 2018. 512 с.

\section{РЕЦЕНЗИЯ НА МОНОГРАФИЮ}

\section{Плазменные технологии создания и обработки строительных материалов}

Авторы: проф., д-р техн. наук В. А. Власов, проф., д-р техн. наук Г. Г. Волокитин, проф., д-р техн. наук Н. К. Скрипникова, проф., д-р техн. наук О. Г. Волокитин, Томский государственный архитектурно-строительный университет

Данная монография посвящена одному из актуальных направлений в современном строительном производстве - плазменным технологиям создания и обработки строительных материалов.

На сегодня в монографиях, учебных пособиях, учебниках данному направлению и связанным с ним проблемам уделяется недостаточное внимание. Это касается как материаловедения разновидностей строительных композитов, так и условий, режимов, параметров технологии получения и модифицирования их структур методами физических воздействий, в том числе, высокоэнергетических плазменных, способных привести к прорывным эффективным достижениям.

Значение теоретического и прикладного знания о технологии создания и обработки строительных материалов средствами физико-технических воздействий с использованием энергии плазмы трудно переоценить. Развитие и практическое освоение рассматриваемого и 
формируемого в монографии знания по данным вопросам является актуальным и насущно необходимым.

В связи с указанным, появление монографии «Плазменные технологии создания и обработки строительных материалов» следует считать своевременным.

Необходимо специально отметить, что основой подготовки монографии стали в значительной мере оригинальные работы советника Российской академии архитектуры и строительных наук, доктора технических наук, профессора В. А. Власова, доктора технических наук, профессора Г. Г. Волокитина и возглавляемого ими творческого коллектива, из состава которого соавторами рассматриваемого научного труда являются Н. К. Скрипникова, О. Г. Волокитин.

Остановимся на некоторых специфических моментах монографии. И в этом отношении укажем важность первой главы, посвященной физическим основам газового разряда, и второй главы, в которой рассматривается проблема возможного применения ВЧ плазмы для создания и обработки строительных материалов. Содержание этих глав задает определенный уровень основательности, фундаментальности подготовленной к изданию монографии.

В третьей и четвертой главах дается информация о технике и оборудовании для воплощения плазменных технологий. Центральное положение при этом занимает анализ процессов плазменных воздействий и управление ими. Вопросы управления рассматриваются в рамках математического моделирования процессов, численного их моделирования применительно к силикатным расплавам и системам.

В пятой и шестой главах, самых крупных по объему, обобщены (начиная от математической постановки задачи, физической модели получения защитного слоя, процессов силикатно- и стеклообразования и др.) результаты многолетних исследований авторов по плазменной технологии создания защитно-декоративных покрытий на строительных материалах силикатной группы. С учетом этого рассмотрены условия образования защитно-декоративных покрытий на цементном бетоне, на керамических изделиях, на силикатном кирпиче. Интересными и важными являются разработки по технологии минерального волокна во вращающемся плазмохимическом реакторе.

Монография завершается седьмой главой, в которой даются перспективы развития плазменных технологий в области создания и обработки силикатных материалов различного назначения. При этом исключительно актуальным видится плазмохимический синтез цементного клинкера, получение нанопорошка диоксида кремния. Этим открываются возможности формирования основ нанотехнологий этих материалов.

С полной уверенностью можно считать, что монография по ее актуальности, фундаментальности, новизне научного знания, перспективам инженерного приложения разработок отвечает приоритетам развития строительного материаловедения и строительных технологий.

Монография может быть интересна и полезна научным, инженерно-техническим работникам, аспирантам, магистрантам занимающимся вопросами современных строительных технологий, опирающихся на реализацию физических и физико-химических явлений создания и преобразования твердофазных состояний вещества. Выход в свет монографии В. А. Власова, Г. Г. Волокитина, Н. К. Скрипниковой, О. Г. Волокитина «Плазменные технологии создания и обработки строительных материалов» подтверждает высокий уровень научных исследований и разработок специалистов Томского государственно архитектурно-строительного университета. 
Монография может быть рекомендована на соискание золотой медали и диплома Российской академии архитектуры и строительных наук (PAACH) в номинации «за лучший научный труд, монографию в области строительных наук».

Руководитель Центрально-Черноземного представительства ЦТО РААСН, директор ОТАЦ «Архстройнаука» ВГТУ, академик РААСН Е. М. Чернышиов

Работа поступила

в редакиию 14.01.2020 2.
Принята к публикащчи 19.01.2020 2.

Ссылка для циитирования:

Чернышов Е. М. Рецензия на монографию Плазменные технологии создания и обработки строительных материалов // Бюллетень науки и практики. 2020. Т. 6. №2. С. 369371. https://doi.org/10.33619/2414-2948/51/47 
ISSN 2414-2948

Научное сетевое издание

БЮЛЛЕТЕНЬ НАУКИ И ПРАКТИКИ

Сетевое издание https://www.bulletennauki.com

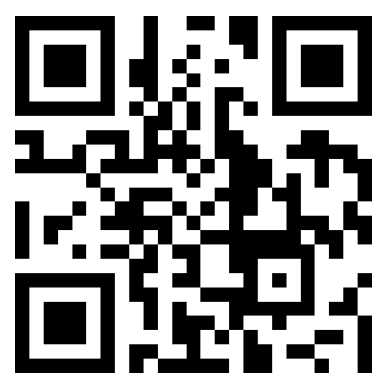

Ответственный редактор - Ф. Ю. Овечкин.

Техническая редакция, корректура, верстка - Ю. А. Митлинова

Выход и размещение на сайте - 15.02.2020 г. 